\title{
THE RACIAL AND ETHNIC COMPOSITION OF LOCAL GOVERNMENT EMPLOYEES IN LARGE METRO AREAS, 1960-2010
}

by

\author{
Todd Gardner \\ Center for Economic Studies \\ U.S. Census Bureau \\ 4600 Silver Hill Rd., \\ Washington, DC 20233 \\ Todd.K.Gardner@census.gov
}

CES 13-38

August, 2013

The research program of the Center for Economic Studies (CES) produces a wide range of economic analyses to improve the statistical programs of the U.S. Census Bureau. Many of these analyses take the form of CES research papers. The papers have not undergone the review accorded Census Bureau publications and no endorsement should be inferred. Any opinions and conclusions expressed herein are those of the author(s) and do not necessarily represent the views of the U.S. Census Bureau. All results have been reviewed to ensure that no confidential information is disclosed. Republication in whole or part must be cleared with the authors.

To obtain information about the series, see www.census.gov/ces or contact Fariha Kamal, Editor, Discussion Papers, U.S. Census Bureau, Center for Economic Studies 2K132B, 4600 Silver Hill Road, Washington, DC 20233, CES.Papers.List@census.gov. 


\begin{abstract}
This study uses census microdata from 1960 to 2010 to look at how the racial and ethnic composition of local government employees has reflected the diversity of the general population in the 100 largest metro areas over the last half century. Historically, one route to upward social mobility has been employment in local government. This study uses microdata that predates key immigration and civil rights legislation of the 1960s through to the present to examine changes in the racial and ethnic composition of local government employees and in the general population. For this study, local government employees have been divided into high- and low-wage occupations. These data indicate that local workforces have grown more diverse over time, though representation across different racial and ethnic groups and geographic areas is uneven. African-Americans were underrepresented in high-wage local government employment and overrepresented in low-wage jobs in the early years of this study, particularly in the South, but have since become proportionally represented in high-wage jobs on a national level. In contrast, the most recent data indicate that Hispanic and other races are underrepresented in this employment group, particularly in the West. Though the numbers of Hispanic and Asian highwage local government employees are increasing, it appears that it will take several years for those groups to achieve proportional representation throughout the United States.
\end{abstract}

Keyword: local government employment, race, ethnicity 


\section{Introduction}

The Immigration and Nationality Act of 1965 abolished the quota system for immigration to the United States based on national origins that had been in place for several decades. Since lifting these restrictions, the population of the United States has become increasingly diverse, particularly with the growth of populations of Asian and Hispanic origin. Historically, one route to upward social mobility has been employment in local government. As the general population has changed, the demographic composition of the local government workforce has changed, as well. Also, the Civil Rights Act of 1964 banned discrimination in employment on the basis race, color, religion, sex and national origin. This study uses census microdata from 1960 to 2010 to look at how the racial and ethnic composition of local government employees has reflected the diversity of the general population in the 100 largest metro areas over the last half century. The earliest dataset used in this study predates the immigration and civil rights legislation of the 1960s. This study then measures the diversity of the workforce and the general population at decennial intervals, including 1960, 1970, 1980, 1990 and 2000, and also uses more recent microdata from the American Community Survey (ACS) covering the period from 2006 to 2010, which averages to 2008. The population is divided into four groups: non-Hispanic whites, non-Hispanic blacks, Hispanics, and other races. The first figure on page 6 shows the growth of these groups in percentage terms nationally from 1960 to 2010 and the first figure on page 7 narrows the focus to the 100 largest metro areas during the same period.

\section{Methodology}

For this study, local government employees have been divided into high- and low-wage occupations using an earnings score based on the median earned income for each occupational title in 1990. Using the variable ERSCOR90 from the Intergrated Public Use Microdata Series (IPUMS), which is described in detail on the IPUMS website at http://usa.ipums.org/usa-action/variables/ERSCOR90\#description_section, the median earned income of each occupational title is expressed as a percentile rank. In this study, high-wage occupations are those ranked 50 and above, and low-wage occupations are those ranked below 50 .

Racial/Ethnic Categories - The resident population and the composition of the local government workforce uses the following categories:

- Hispanic - Hispanic ethnicity (see note below for how this was determined in each year) of any race. In this study Hispanic ethnicity was determined first and treated as a mutually exclusive category with the race groups.

- White Non-Hispanic - White in 1960, 1970, 1980 and 1990, and white alone in 2000 census and in the 2010 ACS data, and not of Hispanic origin.

- Black Non-Hispanic - Black, African American, or Negro in 1960, 1970, 1980 and 1990, and black alone in 2000 census and in the 2010 ACS data, and not of Hispanic origin.

- Other - All other race categories and all mulitirace categories in the 2000 census and in the 2006-2010 ACS data. 
Hispanic Ethnicity - Since 1980 the decennial census has included questions on Hispanic origin. In the 1970 census, the Census Bureau experimented with a few different variables to establish Hispanic ethnicity, notably "Puerto Rican Stock," "Spanish Origin or Descent” and "Spanish Surname”, all of which are used to establish Hispanic ethnicity for 1970 in this study. The "Spanish Surname" variable is included in the 1960 and 1970 data, although it is only coded for residents of California, Texas, Arizona, New Mexico and Colorado. In this study Hispanic ethnicity was established for 1960 by using a combination of birthplace, parental birthplace, language spoken at home, and Spanish surname.

Local Government Employees - Included in the tabulations for local government employees are those whose employment status is "civilian labor force, at work" and whose job status is "local government employee”. No distinction was made in the 1960 data for local, state, or federal employees, so only those employees with an industry code for "local public administration" are included in the figures for 1960. This results in too few cases and no test of occupational bias have been done, so this study only uses racial and ethnic proportions and not tabulated counts for the high- and low-status local government employee groups. Also, in this study the location of local government employees is determined by place of work information rather than place of residence information provided by the respondent. Occupational status was determined by using the IPUMS variable ERSCOR90. All occupational titles with a score of 50 or greater were included in the high-status group, while those with scores below 50 were included in the low-status group.

Shannon's Equitability (E) - Shannon's Diversity Index (H), which measures the overall diversity of a population, is the sum of the proportion of each group $\left(p_{i}\right)$ multiplied by its natural log, and multiplied by -1. Shannon's Equitability is Shannon's Diversity Index divided by the maximum value of that index for a given number of groups. That is, the case where all groups are represented equally and $p_{1}=p_{2}=p_{3}=\ldots=p_{n}$. A value of 1 means all groups are present in equal numbers in the population, lower values indicate less diversity. 
taking the EWPR calculation described above, sorting the groups in ascending order by disproportion $\left(p_{i} / P_{i}\right)$, plotting the cumulative proportions of the groups in local government versus the cumulative proportions of the groups in the working-age population, and calculating the the area under the "ideal line" (with a slope of 1, where all groups in the employment group are represented in proportion to their numbers in the working-age population). This number is then subtracted from 1 so that 0 signifies perfect representation and lower values mean less proportionate representation.

Metropolitan areas and central cities - This study uses the current metropolitan statistical area definitions (as published by the Office of Management and Budget in December, 2009) of the 100 most populous metro areas as of the 2000 census. The December, 2009, definitions use counties as the basic geographic unit, and these county definitions are applied to all years of data used in this study. This study also tabulates figures for "traditional central cities," which are those places that were designated as central cities of metro areas no later than 1960. A few of the 100 largest metro areas did not achieve metropolitan status until 1970 or 1980 . For these areas, this study considers the cities of that were designated when the metro area was first delineated as traditional central cities. These include San Buenaventura (Ventura), CA, Edinburg, TX, McAllen, TX, Boise City, ID, Santa Rosa, CA, and Modesto, CA, which were the original central cities in metro areas initially defined in 1970, and Poughkeepsie, NY, Sarasota, FL, Bradenton, FL, Lakeland, FL, Melbourne, FL, and Titusville, FL, which were the original central cities in metro areas initially defined in 1980.

\section{Results}

The second figure on page 7 shows that those employed in high-wage local government jobs have consistently been disproportionately white over the past 50 years. Where the general population in the 100 largest metro areas was 84.9 percent white in 1960, 92.7 percent of people working in high-wage occupations were white. The most recent ACS data shows that while the general population of the 100 largest metro areas was only 57.8 percent white, high-wage local government employment remained at over two-thirds (69.7 percent) white. Still, high-wage employment has become more diverse over this period as the population has changed. African Americans comprised 10.7 percent of the population of the 100 largest metro areas in 1960, but only 5.2 percent of high-wage local government employees. The passage of civil rights legislation in the 1960s signaled a change in the presence of African Americans in these jobs, however, and by 2008 blacks had become proportionately represented in high-wage government jobs in large metro areas except the Midwest (page 11). Hispanic and other races continue to be underrepresented in high-wage government jobs. In 2008 Hispanics made up 19.4 percent of the population of the 100 largest metro areas but only 10.6 percent of high-wage local government employees. Other races make up 9.0 percent of the general population but only 6.1 percent of local government employees.

Looking at low-wage local government jobs shows an interesting variation on this theme. Blacks have long been disproportionately represented in low-wage local government employment. The degree of disproportion has been slowly declining since 1970 but is still quite high. Hispanics were underrepresented in low-wage local government employment before 1980, but in recent years have become proportionally represented in the 100 largest metro areas. Looking more closely at 
regional differences, however, reveals that Hispanics were underrepresented in local government employment overall, regardless of earnings, in all regions except the West (page 15).

The second tier of figures on page 7 also shows population and employment ratios for the historical urban cores (cities classified as "central cities" by 1960) of the 100 largest metro areas. These figures demonstrate the greater diversity of urban core areas. The high-wage jobs figure also shows the disproportionate representation of whites has been especially pronounced in large cities, though this gap has narrowed somewhat in recent years. Where the percentage of whites in central cities fell from 76.3 percent in 1960 to 41.0 percent in 2008, the percentage of high-wage local government employees who are white went from 90.4 to 55.9 percent.

Page 13 shows that high-wage employees in the South were less diverse and more disproportionately white in 1960 prior to the passage of civil rights legislation. By the turn of the century, however, the diversity among high-wage employees in the South was comparable to the rest of the United States. In recent years, in metro areas in the West, with larger and more rapidly growing Hispanic and Asian populations, high-wage local government employment has had comparatively greater difficulty in mirroring the diversity of the population, as shown on page 15.

Shannon's Equitability is a measure of overall diversity, where a value of 1.0 represents equal representation of all groups and lower values indicate less diversity. This index reveals that high-wage government employees were considerably less diverse than the working-age population in 1960. In that year Shannon's Equitability for the working-age population in the 100 largest metros was 0.39 , while this measure applied to high-wage employees working in these areas was only 0.23. By 2008, Shannon's Equitability for the working-age population stood at 0.81 while the same measure of high-wage employees had climbed to 0.67, a marked improvement yet still behind the working-age population as a whole. Shannon's Equitability for central cities was 0.52 in 1960 and rose steadily to 0.92 by 2008 . The diversity of central city high-wage employees was far below that of the working-age population in these cities in 1960, starting at only 0.28 but rising dramatically to 0.82 by 2008 . The diversity of high-wage employees has paralleled the increasing diversity of the working-age population in all regions, albeit with a lag of several years.

Finally, in an effort to find a single index to measure how well those employed in high-wage local government jobs reflects the diversity of the working-age population, this study uses a modified Gini index. Using this Composite Representation Index (CRI), 1.0 means all groups are represented in proportion to their numbers in the working-age population. The CRI figures on page 7 show that it has been a greater challenge for local governments of central cities to match the diversity of the working-age population in those places. This measure also reinforces the points made above about the South in the early years of this study and the West in the latter years. Among the 100 largest metro areas in 1960, the 15 metro areas with the lowest CRI values were located in the South. By 2008, six of the seven metro areas with the lowest CRI values were located in California, where the Hispanic and Asian populations were proportionally larger in the general population. Though the numbers of Hispanic and Asian high-wage local government employees are increasing, it appears that it will take several years for those groups to achieve proportional representation throughout the United States. 


\section{Conclusion}

Using microdata from historical censuses and the American Community Survey provides a sweeping source for examining the growing diversity of the American population over the past half-century, and how that diversity has been reflected in the composition of the workforce employed by local governments. These data indicate that local workforces have grown more diverse over time, though representation across different racial and ethnic groups and geographic areas is uneven. African-Americans were underrepresented in high-wage local government employment and overrepresented in low-wage jobs in the early years of this study, particularly in the South, but have since become proportionally represented in high-wage jobs on a national level. In contrast, the most recent data indicate that Hispanic and other races are underrepresented in this employment group, particularly in the West. Though the numbers of Hispanic and Asian high-wage local government employees are increasing, it appears that it will take several years for those groups to achieve proportional representation throughout the United States. While high-wage local government employment has become more diverse over time and has generally paralleled the increasing diversity of the population, keeping up with the rapid pace of diversification has been a longstanding challenge for local government employment. 


\section{The United States}

Population and Local Government High-Wage Employees in The United States
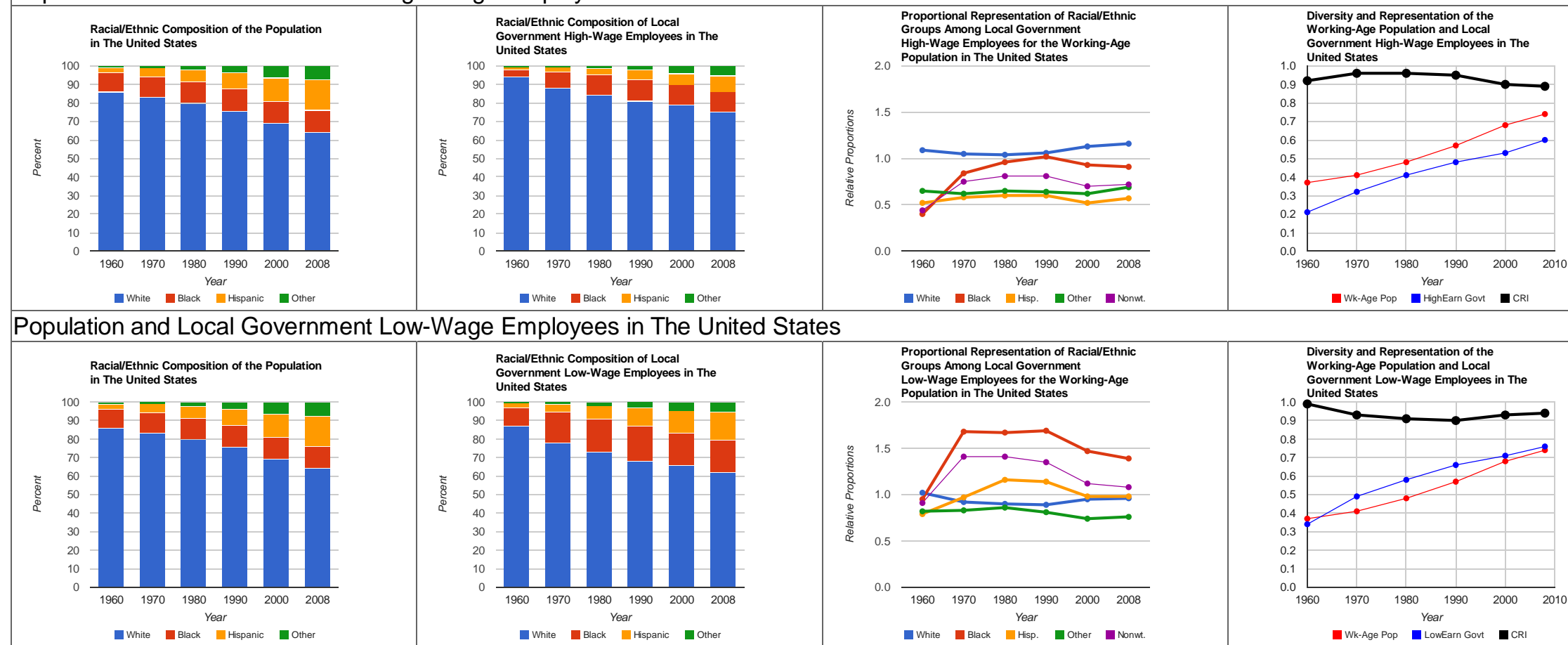

White Black Hispanic not

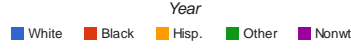

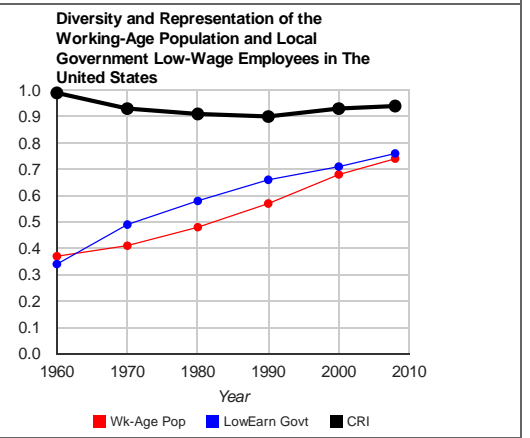


Large Metro Areas in the United States

Population and Local Government High-Wage Employees in Large Metro Areas in the United States
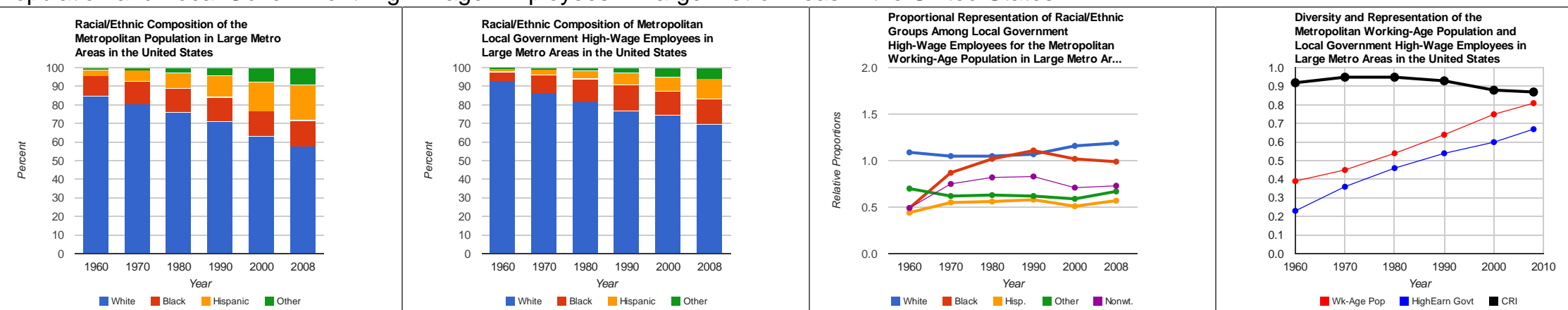

Population and Local Government High-Wage Employees in Central Cities of Large Metro Areas in the United States
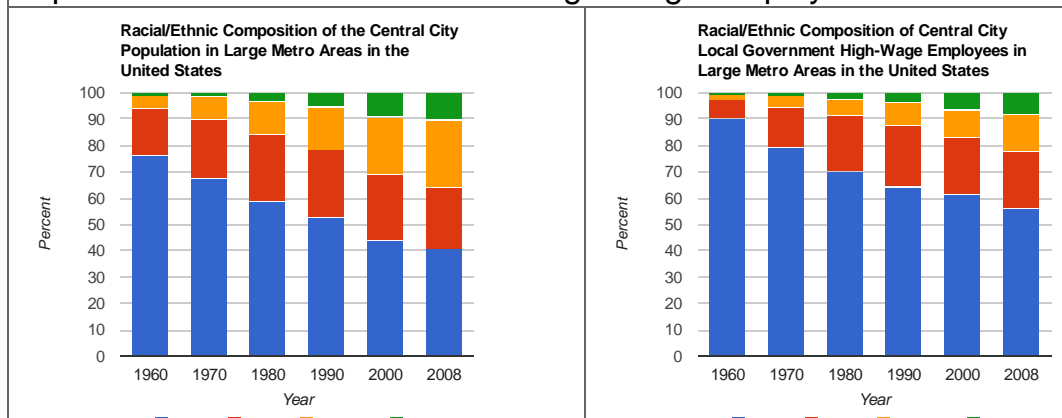

Proportional Representation of Raciallethic

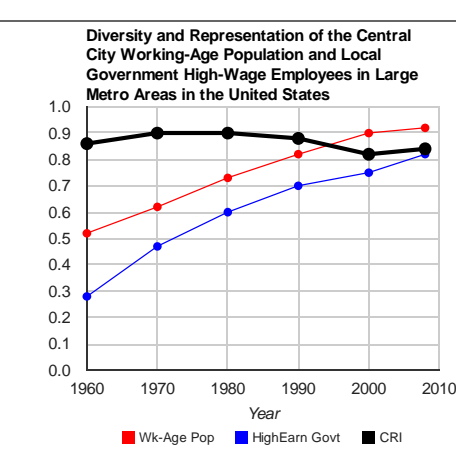


Large Metro Areas in the United States

Population and Local Government Low-Wage Employees in Large Metro Areas in the United States
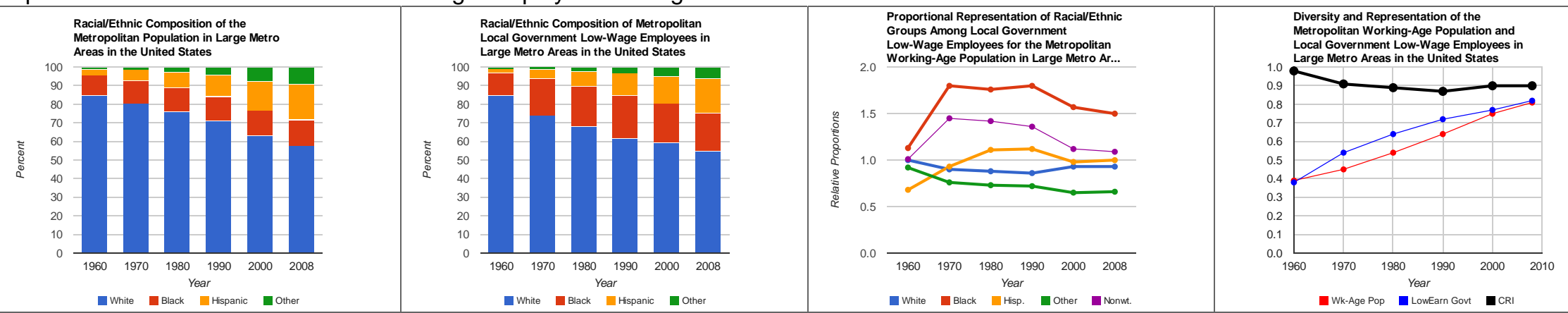

Population and Local Government Low-Wage Employees in Central Cities of Large Metro Areas in the United States
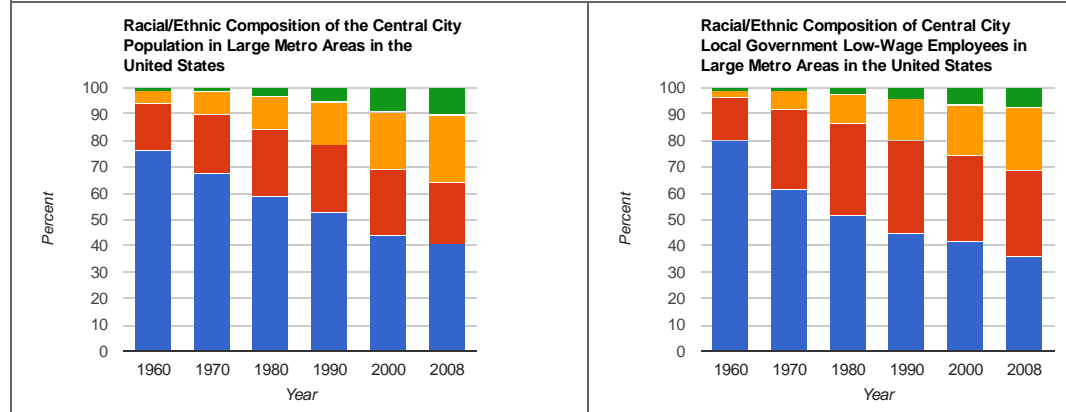

Proportional Representation of Racial/thnic

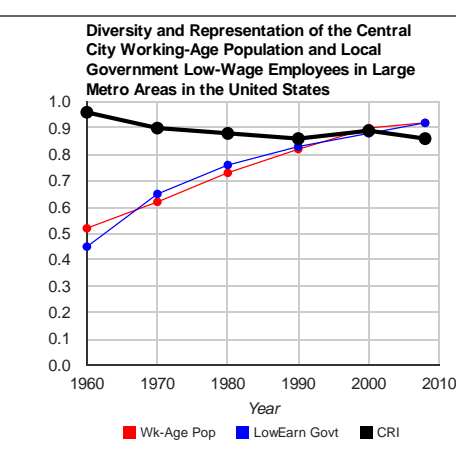


Large Metro Areas in the Northeast

Population and Local Government High-Wage Employees in Large Metro Areas in the Northeast
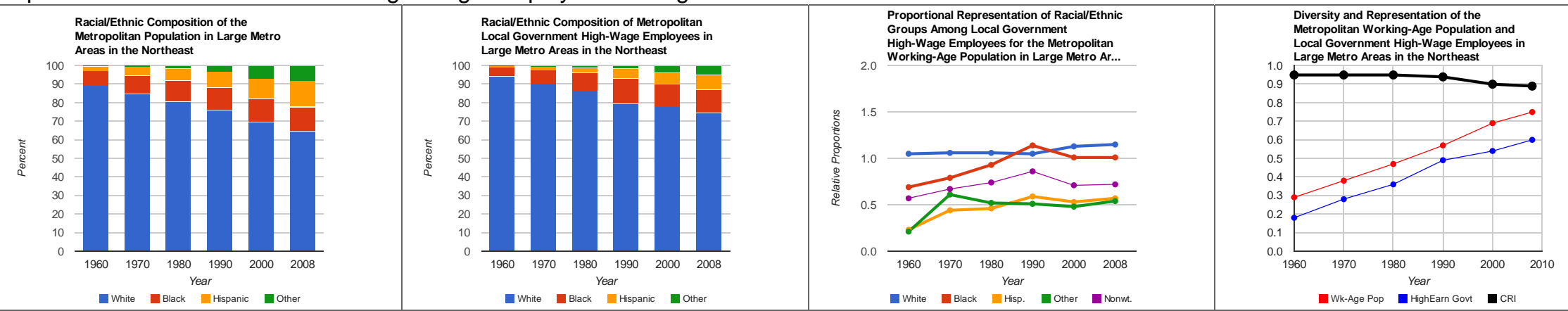

Population and Local Government High-Wage Employees in Central Cities of Large Metro Areas in the Northeast

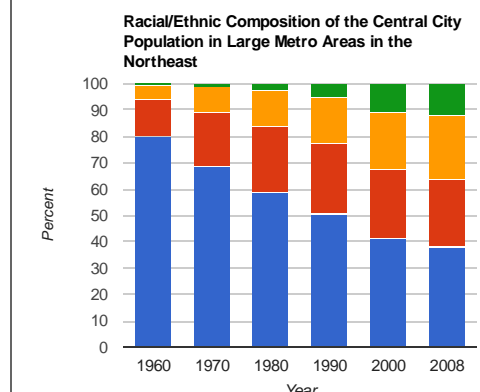

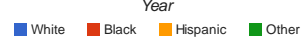

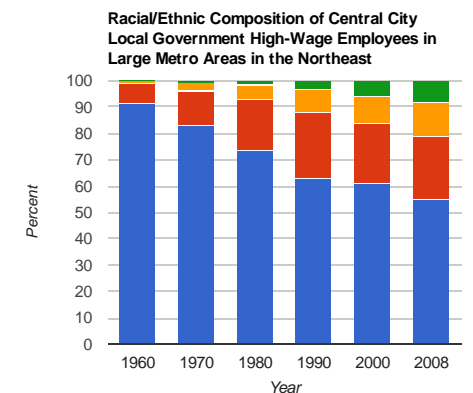

White Black Hispanic Dother
Proportional Representation of Racial/Ethnic

High-Wage Employees for the Central City
Working-Age Population in Large Metro Ar.

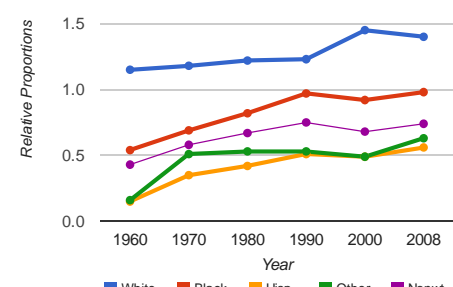

Diversity and Representation of the Central
City Working-Age Population and Local
Government Government High-Wage Employees in Large
Metro Areas in the Northeast

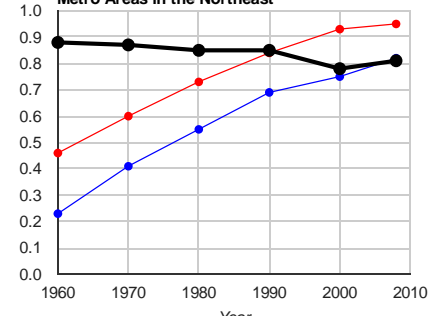

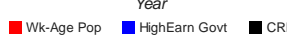


Large Metro Areas in the Northeast

Population and Local Government Low-Wage Employees in Large Metro Areas in the Northeast
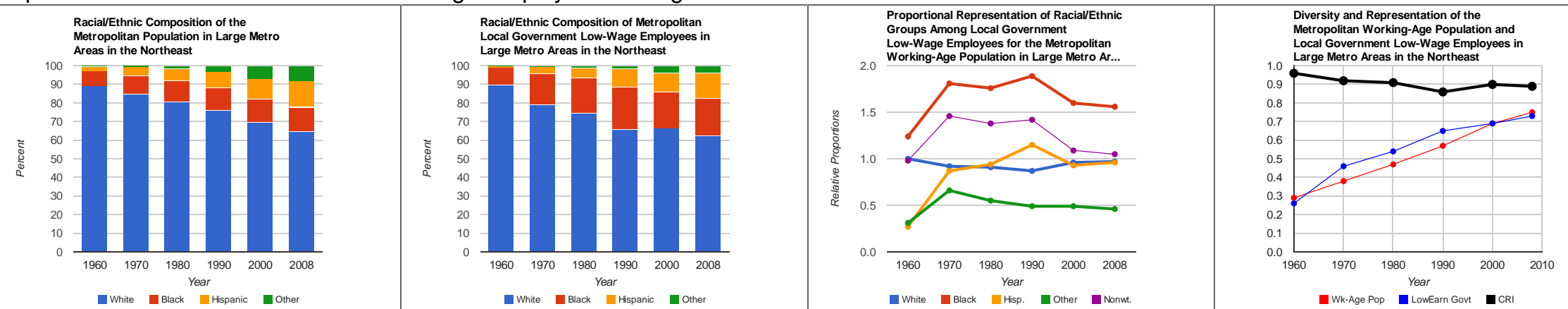

Population and Local Government Low-Wage Employees in Central Cities of Large Metro Areas in the Northeast

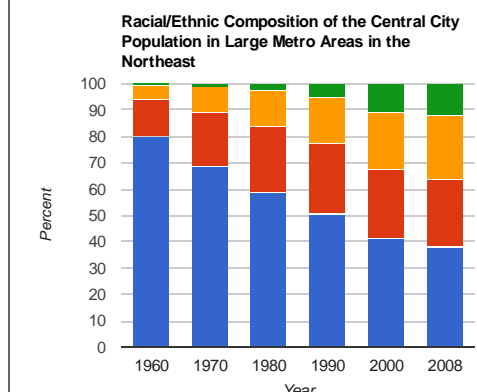

White I Black Mear

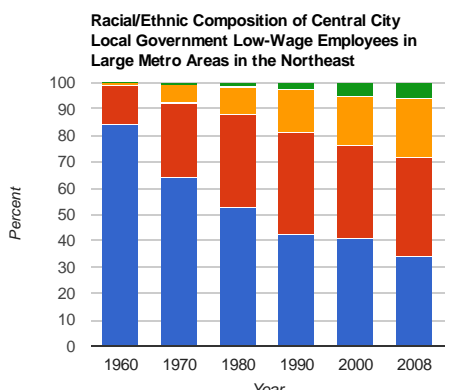

White Black Hear
Groportional Representation of Raciall/thnic

Low-Wage Employees for the Central City
Working-Age Population in Large Metro Ar.

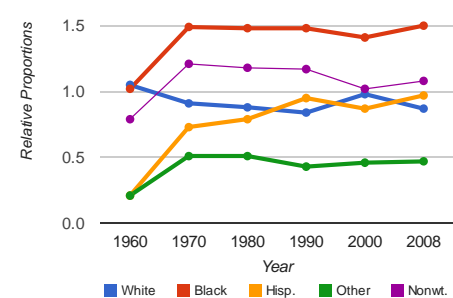
Diversity and Representation of the Central
City Working-Age Population and Local
Government Low-Wage Employees in Large

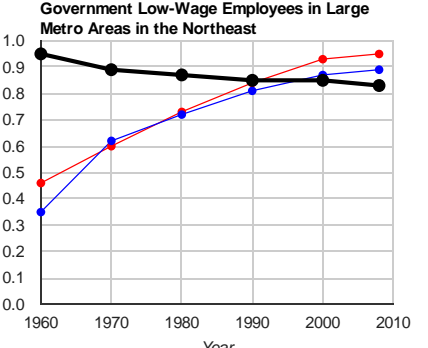

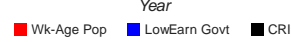


Large Metro Areas in the Midwest

Population and Local Government High-Wage Employees in Large Metro Areas in the Midwest
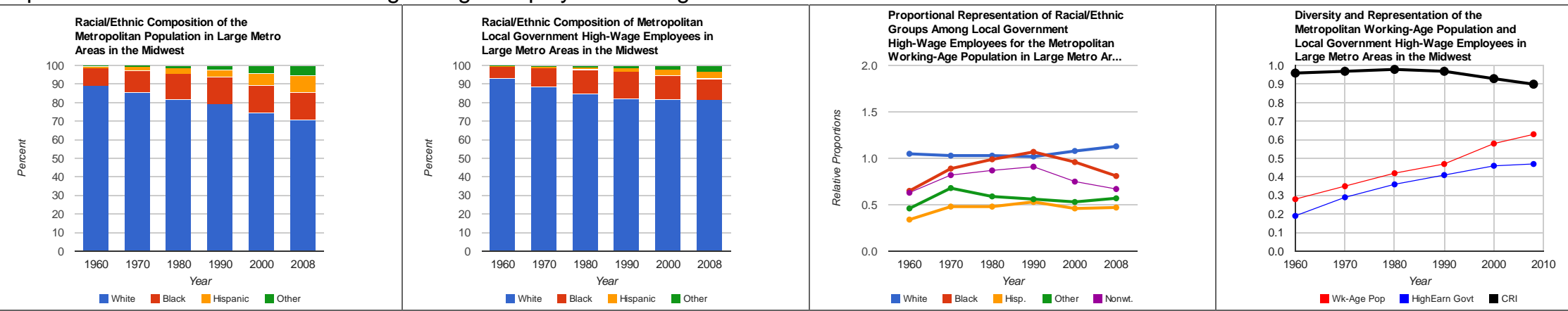

Population and Local Government High-Wage Employees in Central Cities of Large Metro Areas in the Midwest
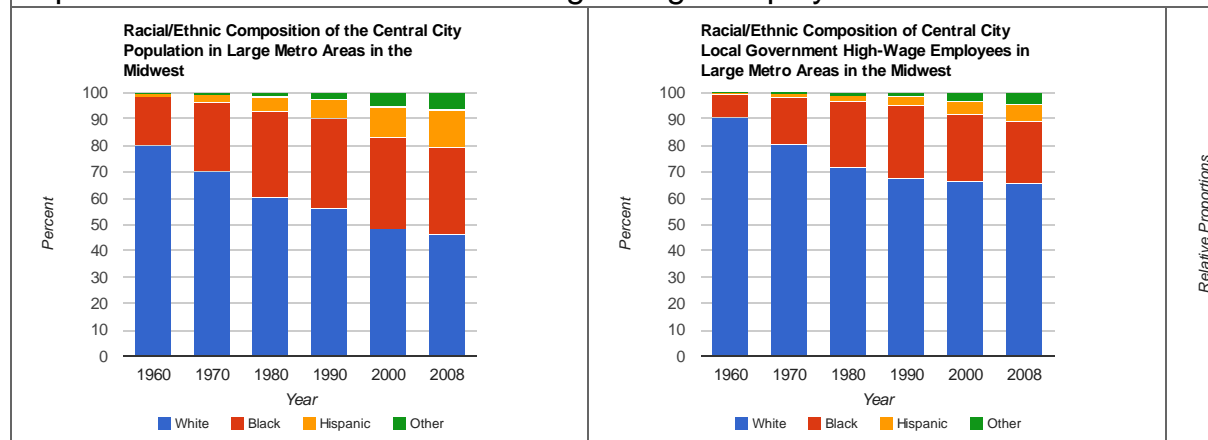

Groups Among Local Government
High-Wage Employees for the Central City
Working-Age Population in Large Metro Ar.

White In Black Yur Hispanic Eother

White 1 Black Year 1 Hispanic $\square$ other
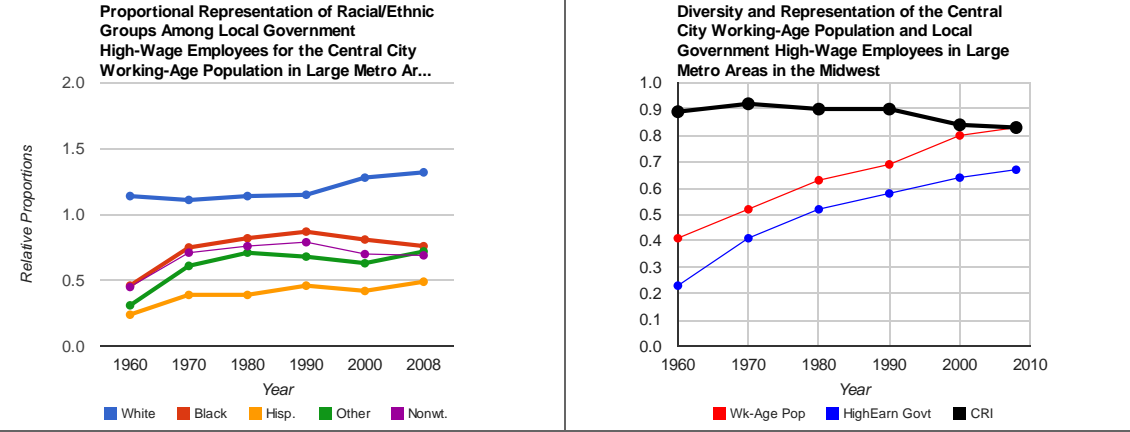
Large Metro Areas in the Midwest

Population and Local Government Low-Wage Employees in Large Metro Areas in the Midwest

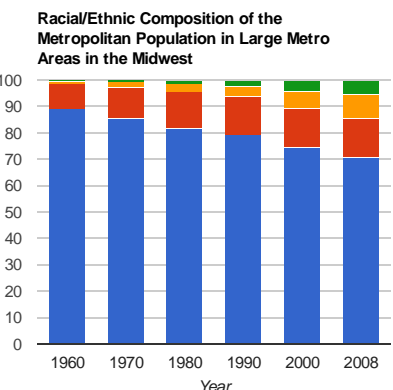

White Elack Year Hispanic other

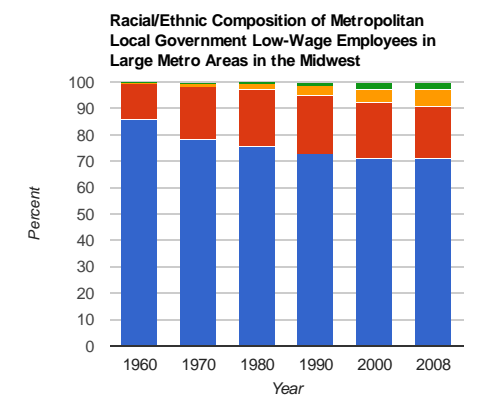

White Black Year
Proportional Representation of Raciall/Ethnic

Low-Wage Employees for the Metropolitan
Working-Age Population in Large Metro Ar.

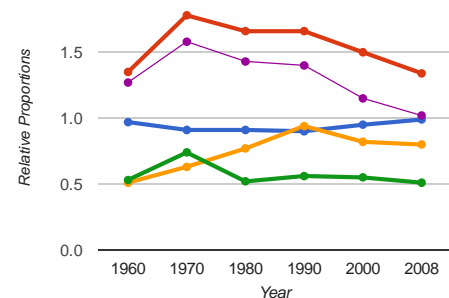

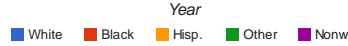

Population and Local Government Low-Wage Employees in Central Cities of Large Metro Areas in the Midwest

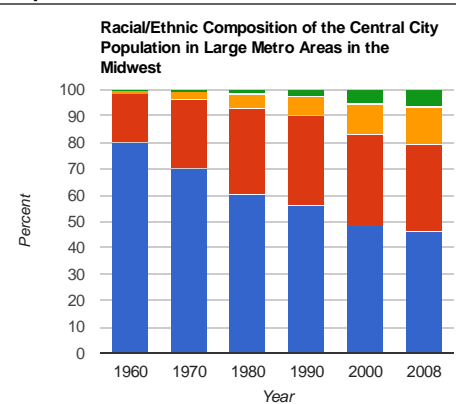

Racial/Ethnic Composition of Central City
Local Government Low-Wage Employees in
Large Metro Areas in the

Large Metro Areas in the Midwest

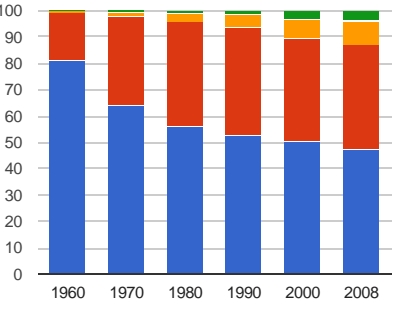

WWite MBlack Hear Hispanic Mother

White IBlack Hear Hispanic Wother

Proportional Representation of Raciallethnic

Low-Wage Employees for the Central City
Working-Age Population in Large Metro Ar.

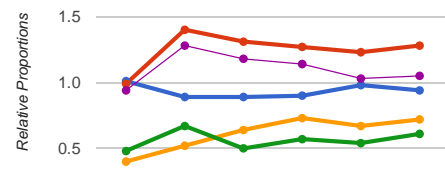

\begin{tabular}{lllllll}
0.0 & \multicolumn{1}{l}{1960} & 1970 & 1980 & 1990 & 2000 & 2008
\end{tabular}

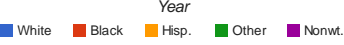

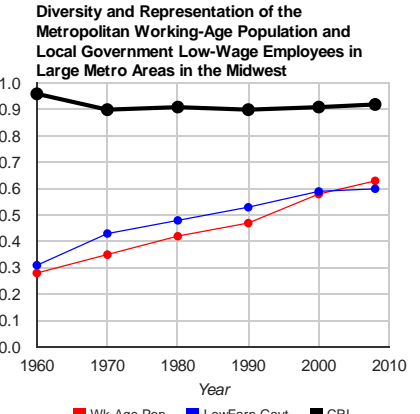

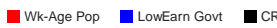

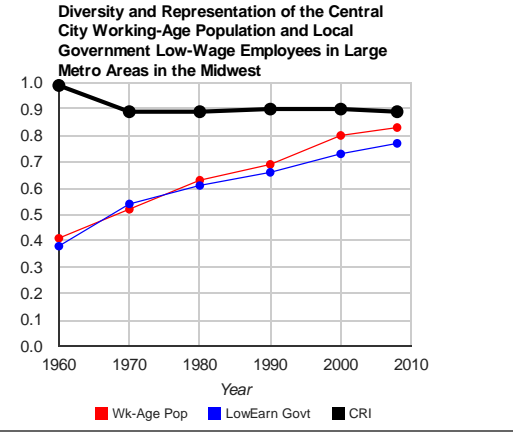


Large Metro Areas in the South

Population and Local Government High-Wage Employees in Large Metro Areas in the South
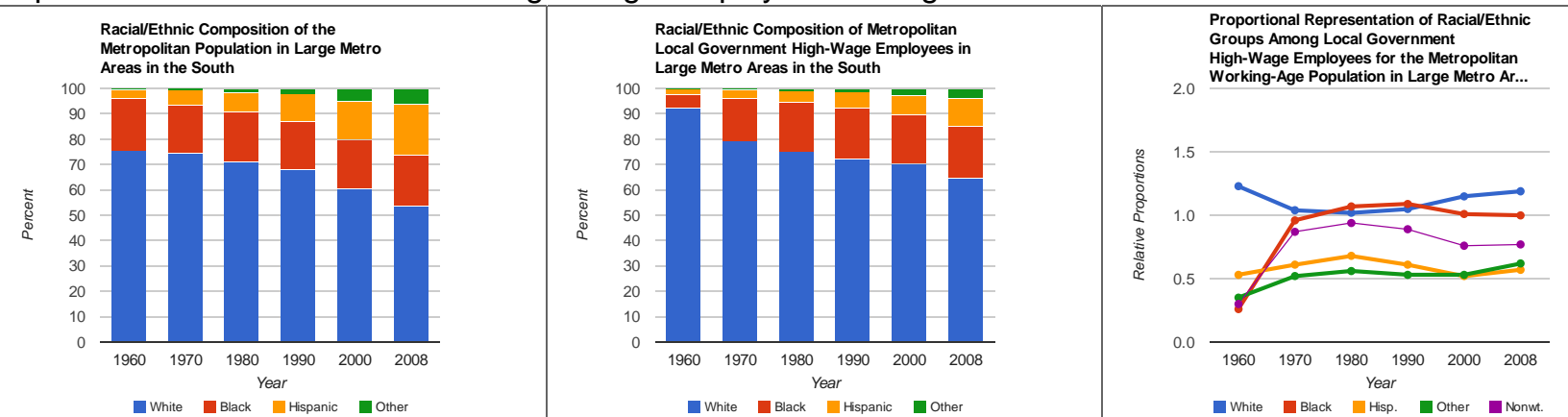

Population and Local Government High-Wage Employees in Central Cities of Large Metro Areas in the South
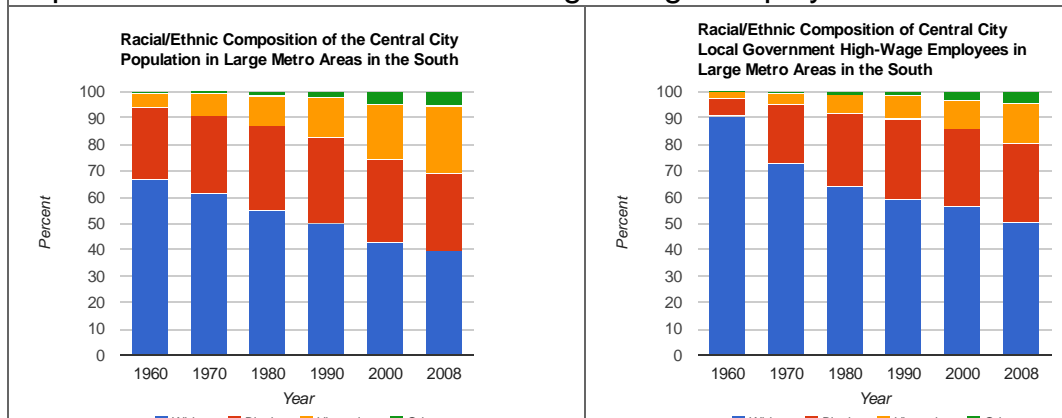

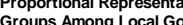

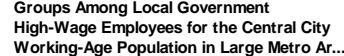

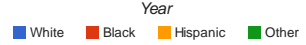

- White Mblack 1 Hear
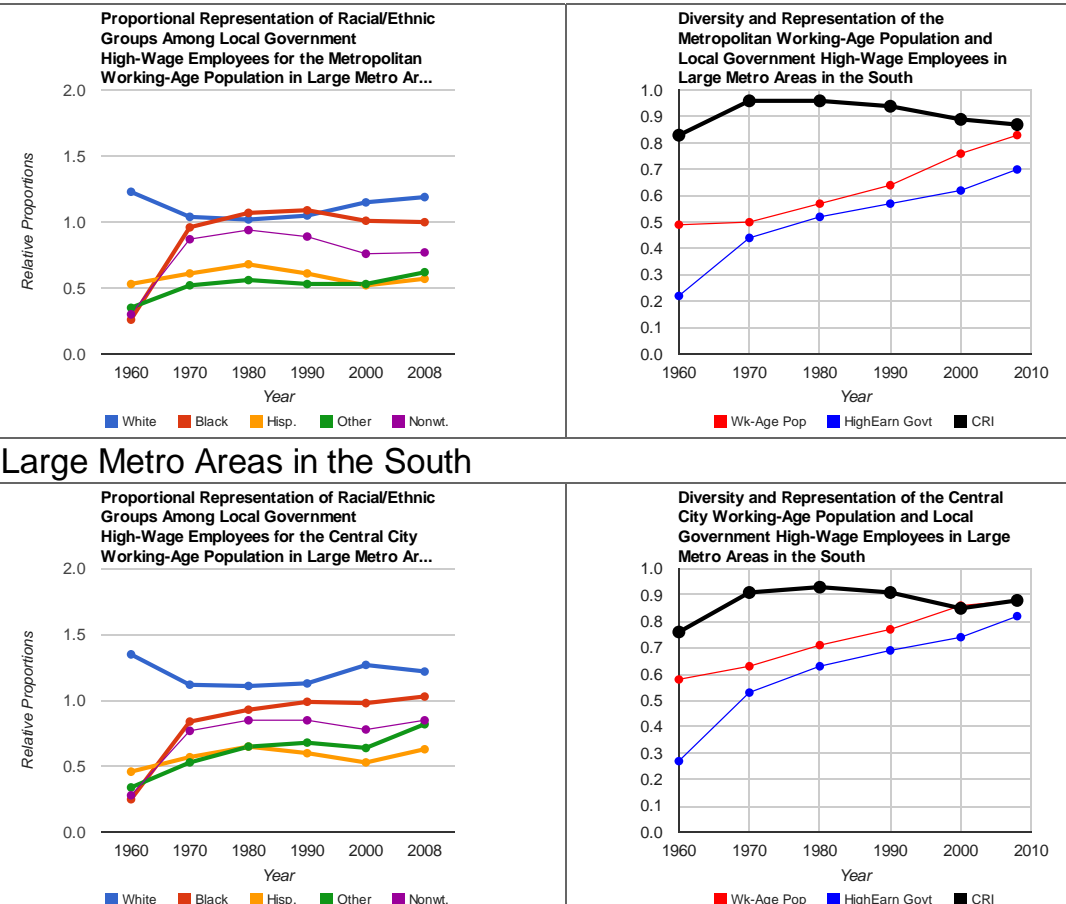

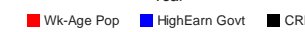

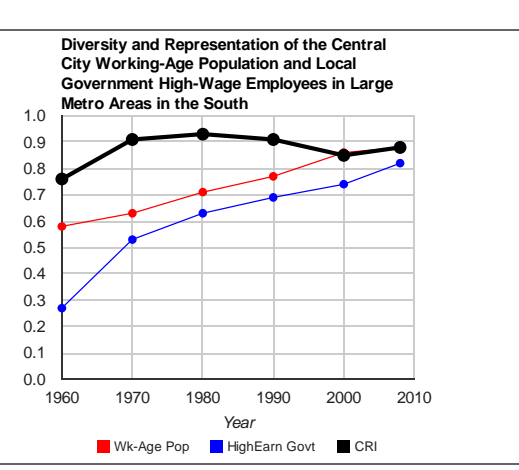


Large Metro Areas in the South

Population and Local Government Low-Wage Employees in Large Metro Areas in the South
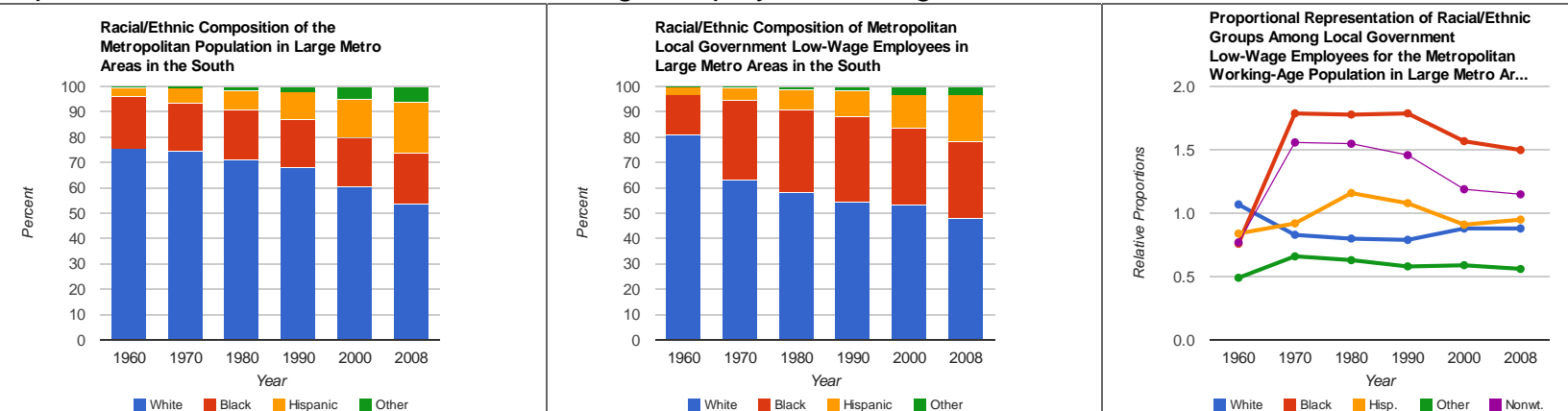

Population and Local Government Low-Wage Employees in Central Cities of Large Metro Areas in the South

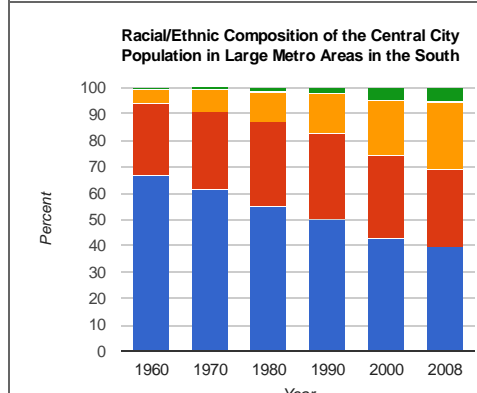

Raciall/Ethnic Composition of Central City
Local Government Low-Wage Employees in

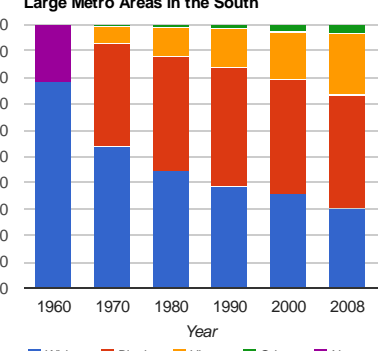

croponstonal Represent in

Groups Among Local Government
Low-Wage Employees for the Central City
Working-Age Population in Large Metro Ar...

White Black Year

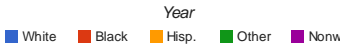
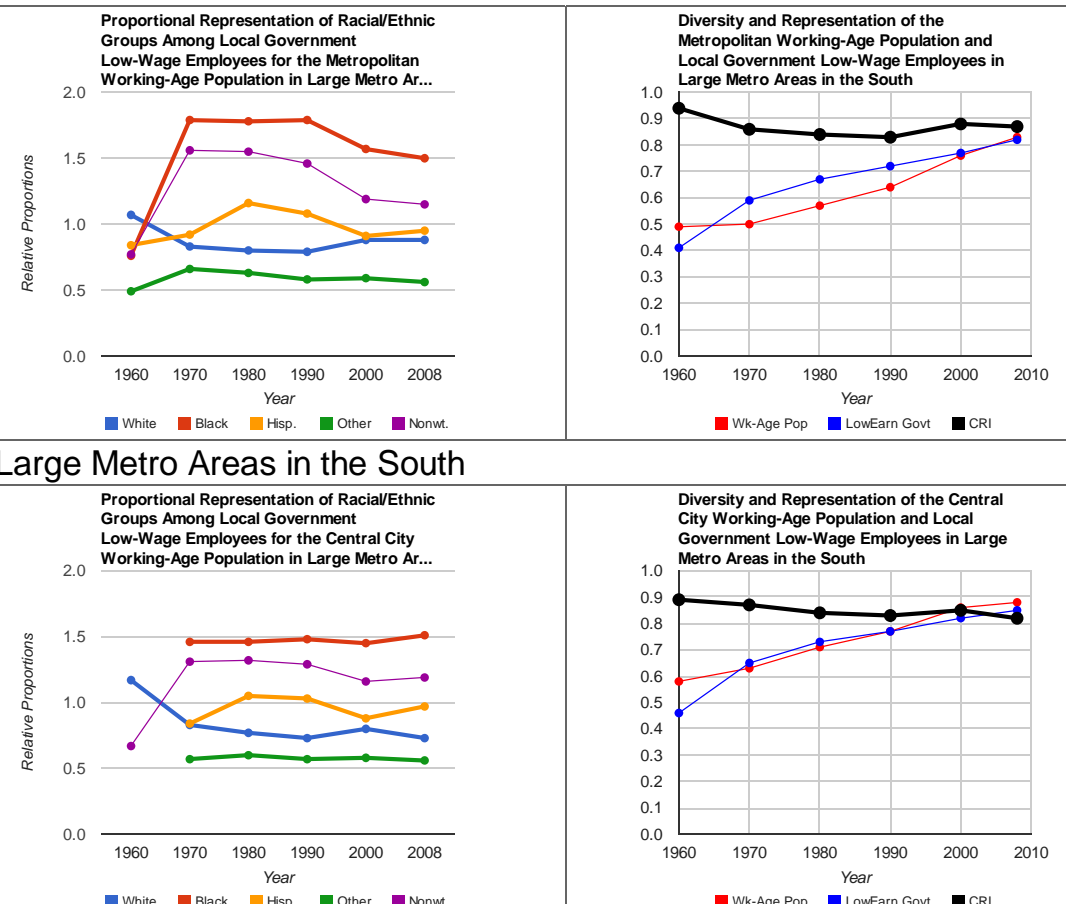

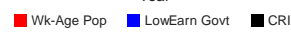

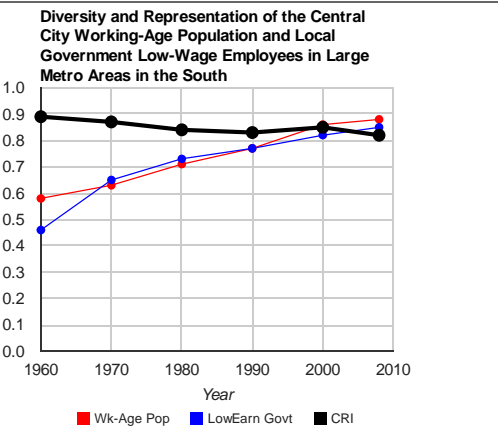


Large Metro Areas in the West

Population and Local Government High-Wage Employees in Large Metro Areas in the West

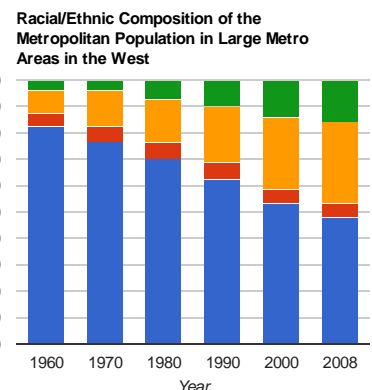

White Elack Year Hispanic nother

Population and Local Government High-Wage Employees in Central Cities of Large Metro Areas in the West

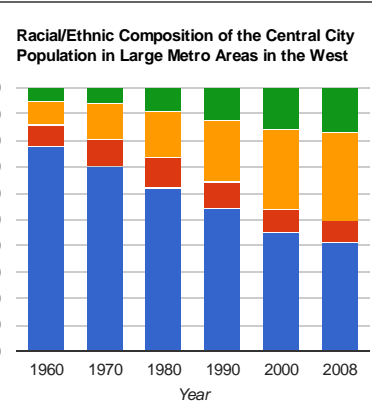

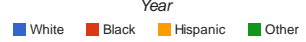

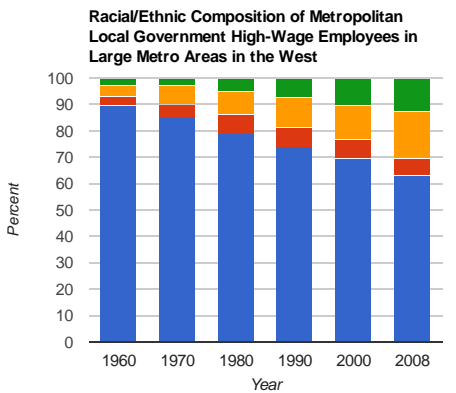

Raciall:Ethnic Composition of Central city

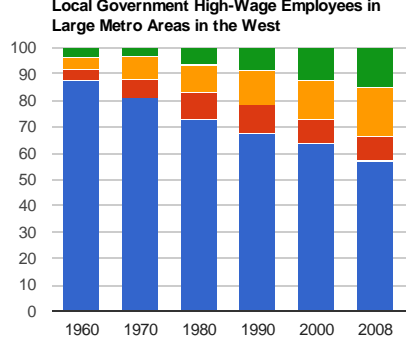

White $\quad$ Black $\quad$ Hispanic $\quad$ Other High-Wage Employees for the Metropolitan
Working-Age Population in Large Metro Ar.

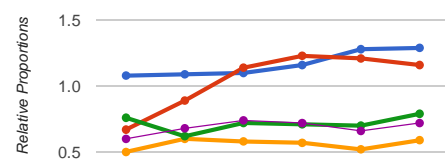

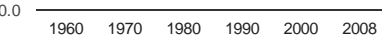
$1960 \quad 19701980 \quad 199020002008$
Year

Proportional Representation of Racial//thr
Groups Among Local Government
High-Wage

High-Wage Employees for the Central City
Working-Age Population in Large Metro Ar.

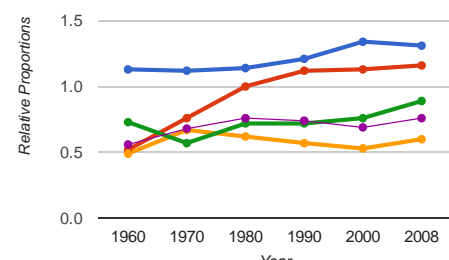

- White Black Year
Proportional Representation of Raciall/thn
Diversity and Representation of the Local Governmentighe Population and

Large Metro Areas in the West

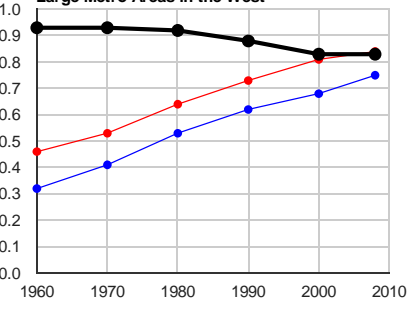

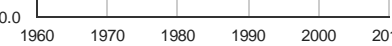

-Wk-Age Pop Highearn Gove

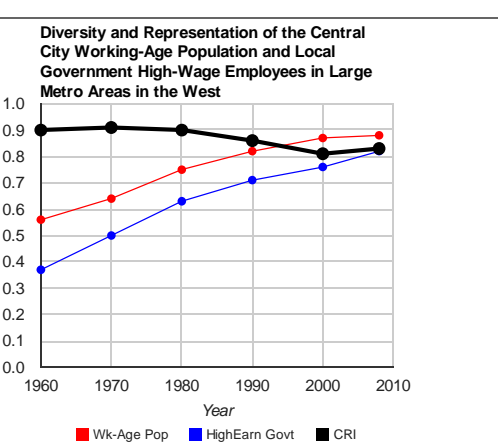


Large Metro Areas in the West

Population and Local Government Low-Wage Employees in Large Metro Areas in the West

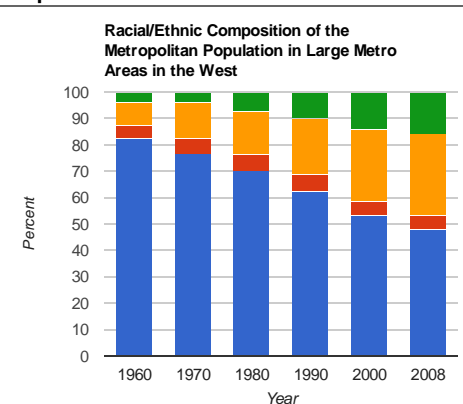

White Elack Year Hispanic other

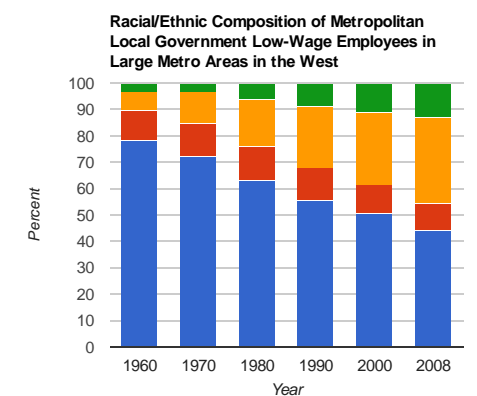

White Elack Year ${ }_{\text {Hspanic }}$ other
Proportional Representation of Raciall/Ethnic Low-Wage Employees for the Metropolitan
Working-Age Population in Large Metro Av.

$$
2.5
$$

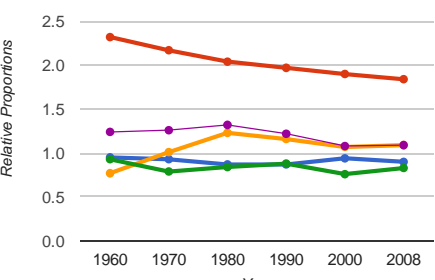

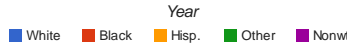

Population and Local Government Low-Wage Employees in Central Cities of Large Metro Areas in the West
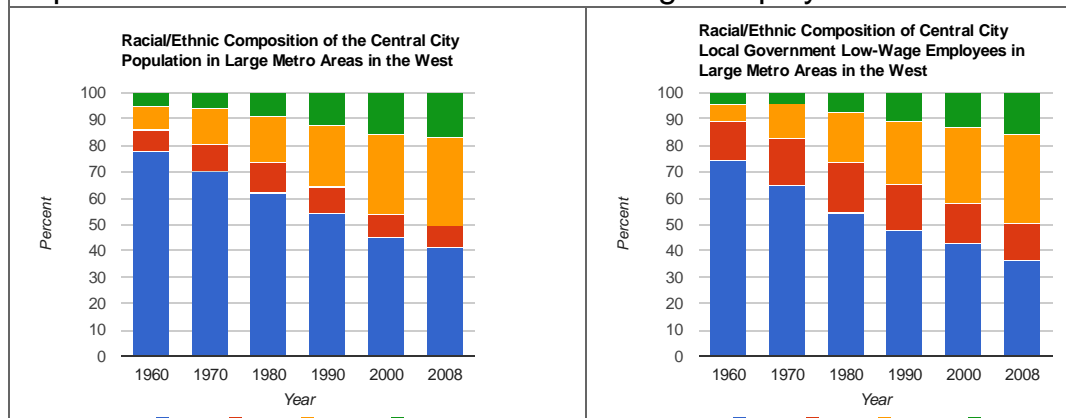

Proportional Representation of Racial/Ethnic

Groups Among Local Government
Low-Wage Employees for the Central City
Working-Age Population in Large Metro Ar.

White In Black Yur Hispanic Eother

White M Black Year
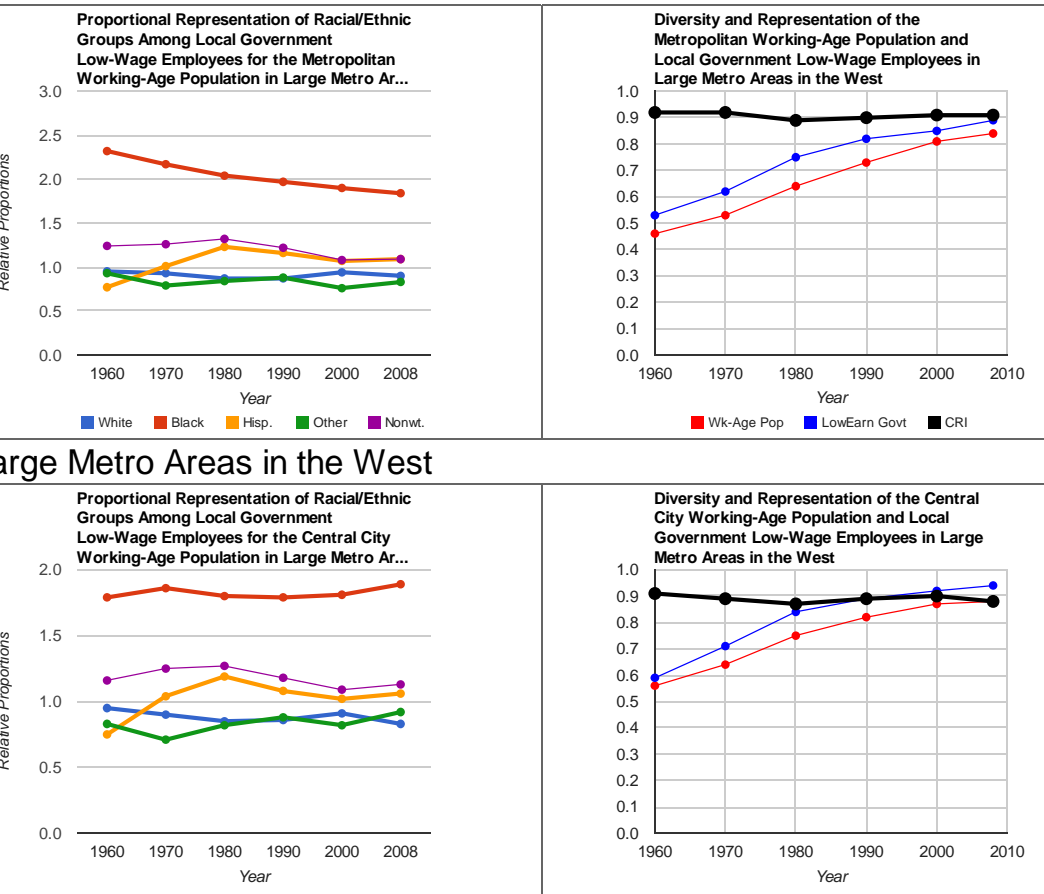

-Wk-Age Pop $\quad$ LowEarn Govt $\quad$ CRI

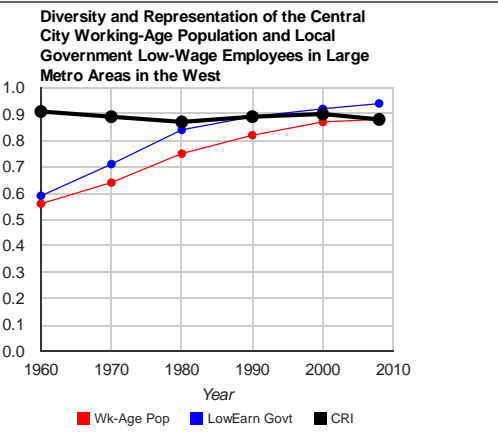




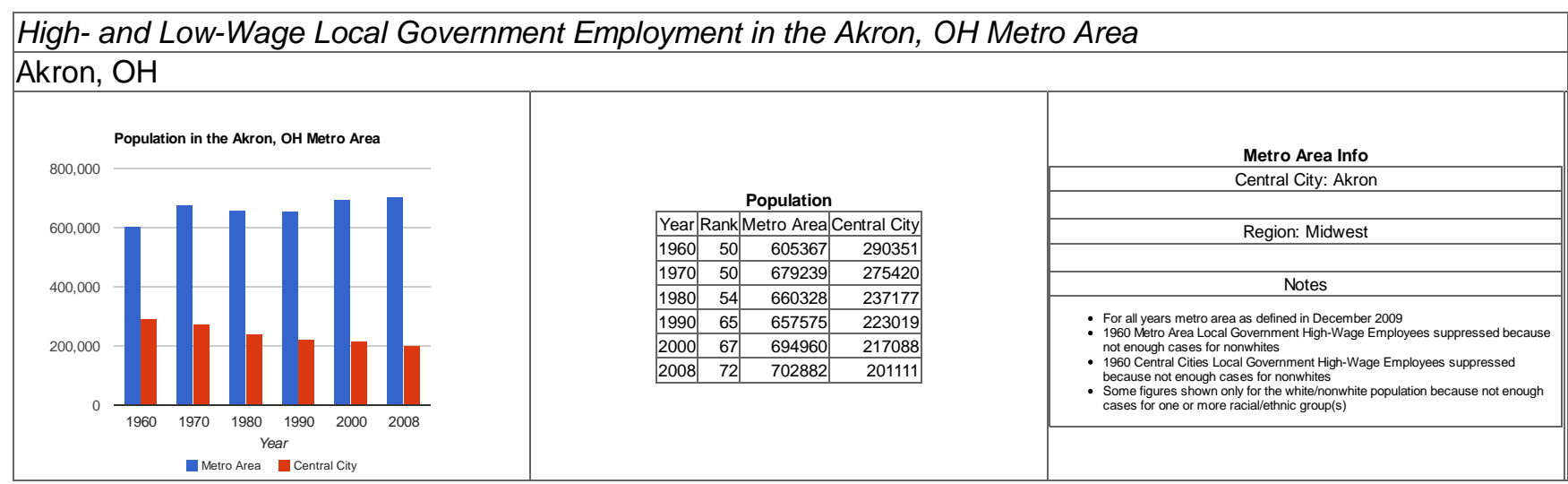


High- and Low-Wage Local Government Employment in the Akron, OH Metro Area

Local Government High-Wage Employees in the Metro Area
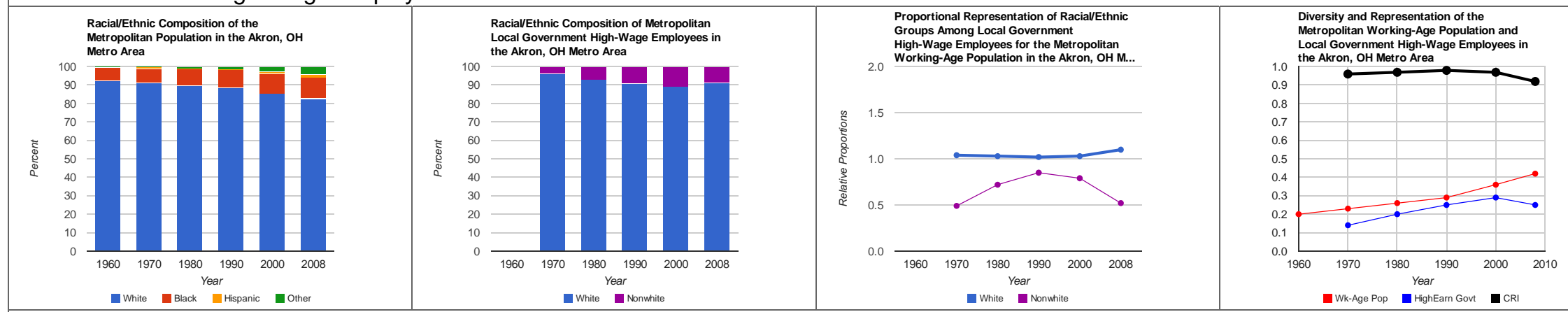

Local Government High-Wage Employees in the Central City
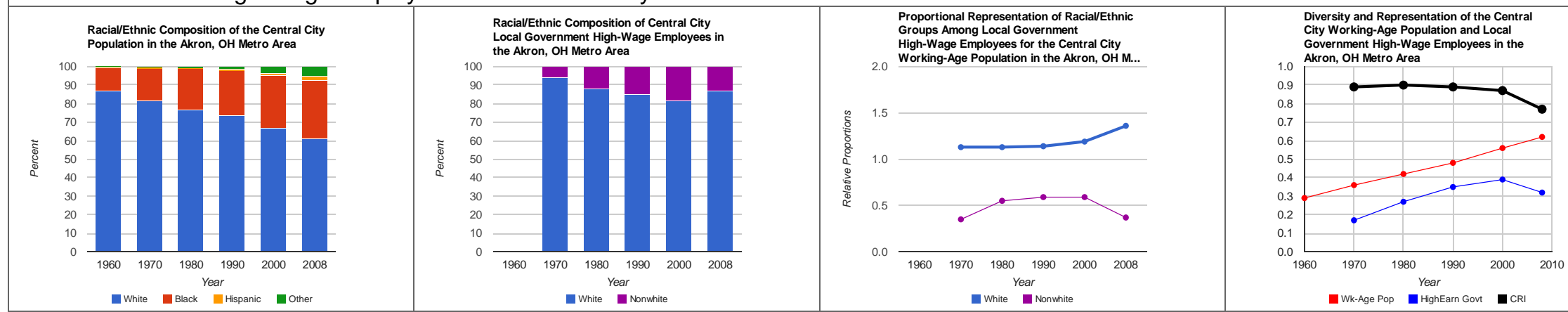
High- and Low-Wage Local Government Employment in the Akron, OH Metro Area

Local Government Low-Wage Employees in the Metro Area
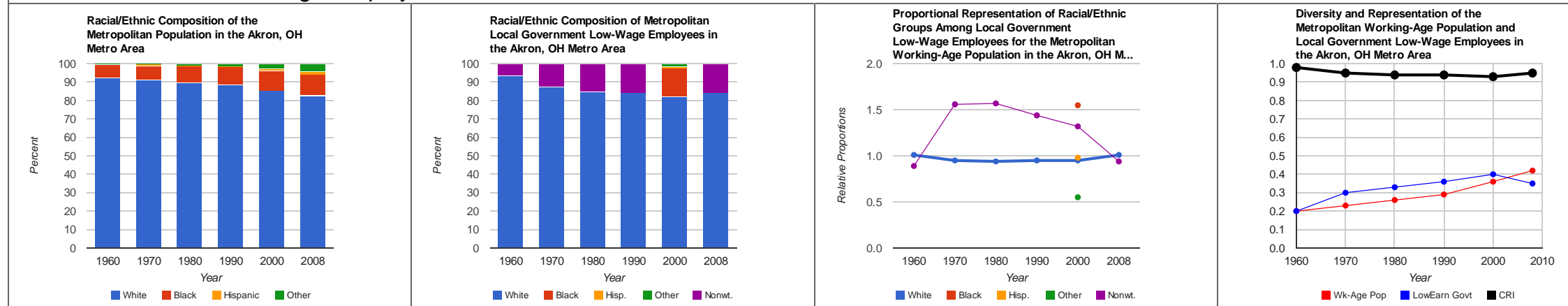

Local Government Low-Wage Employees in the Central City
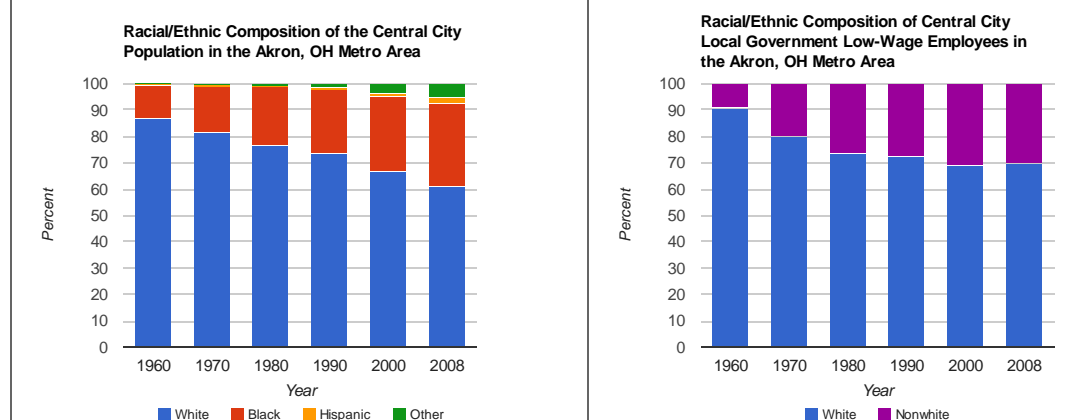

Proportional Representation of Racial/Ethnic Groups Among Local Government 20 Working-Age Population in the Akron, OH M..

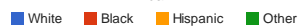
- White $\stackrel{\text { Year }}{\text { Nonwhite }}$
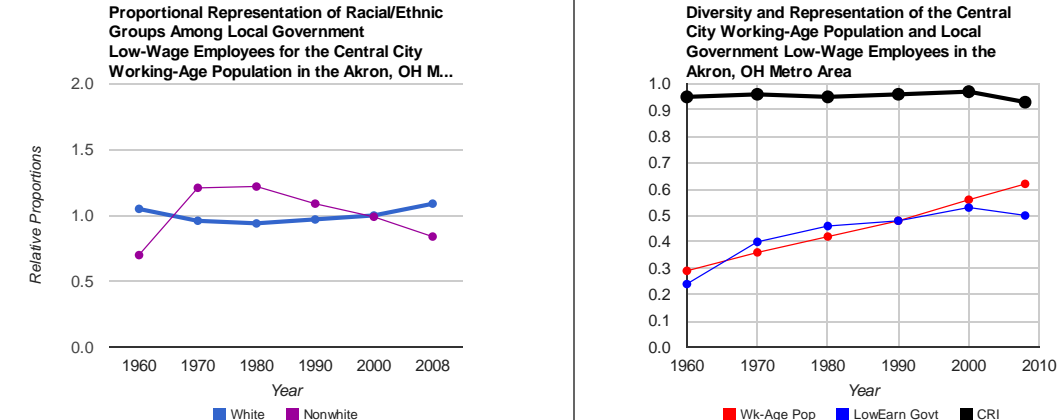

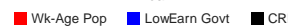




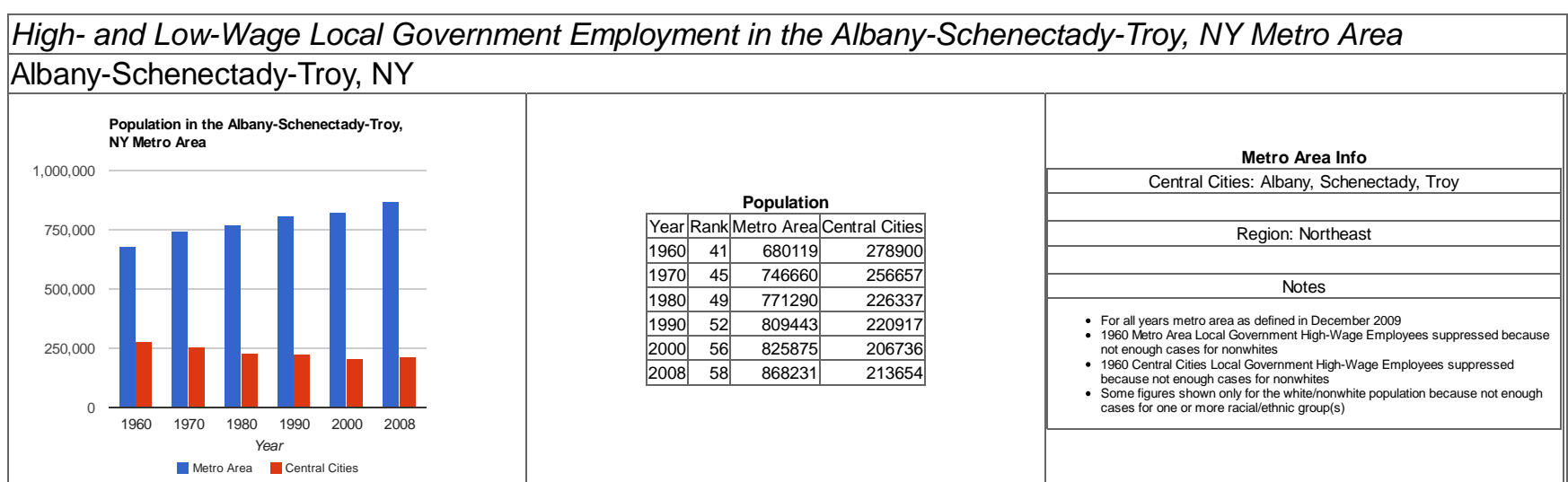


High- and Low-Wage Local Government Employment in the Albany-Schenectady-Troy, NY Metro Area

Local Government High-Wage Employees in the Metro Area
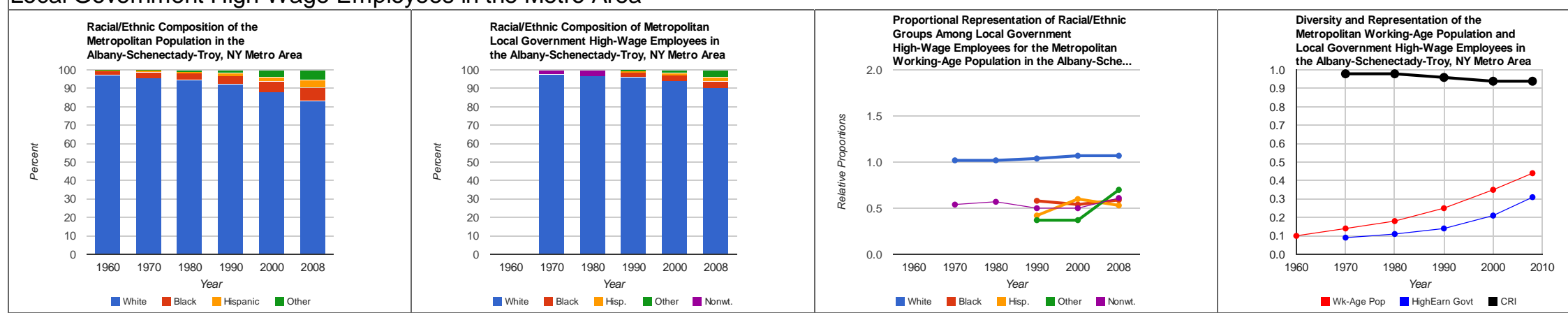

Local Government High-Wage Employees in the Central Cities

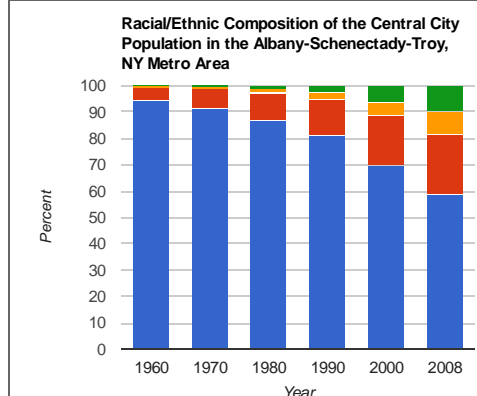

White Inlack Hear Hispanic nother

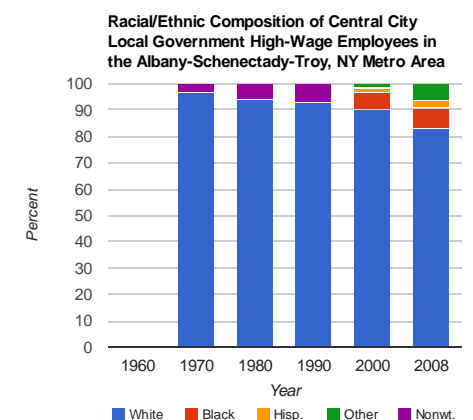

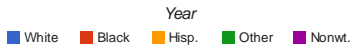

Proportional Representation of Raciall/Ethnic
Groups Among Local Government Groups Among Local Government
High-Wage Employees for the Central City High-Wage Employees for the Central City
2.0 Working-Age Population in the Albany-Sche...

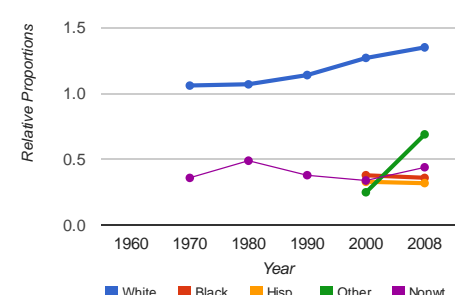

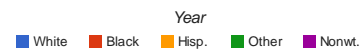

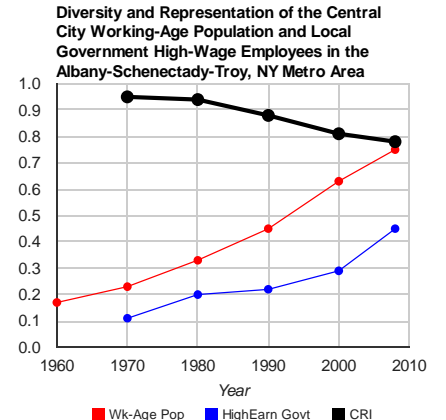

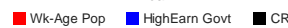


High- and Low-Wage Local Government Employment in the Albany-Schenectady-Troy, NY Metro Area Local Government Low-Wage Employees in the Metro Area
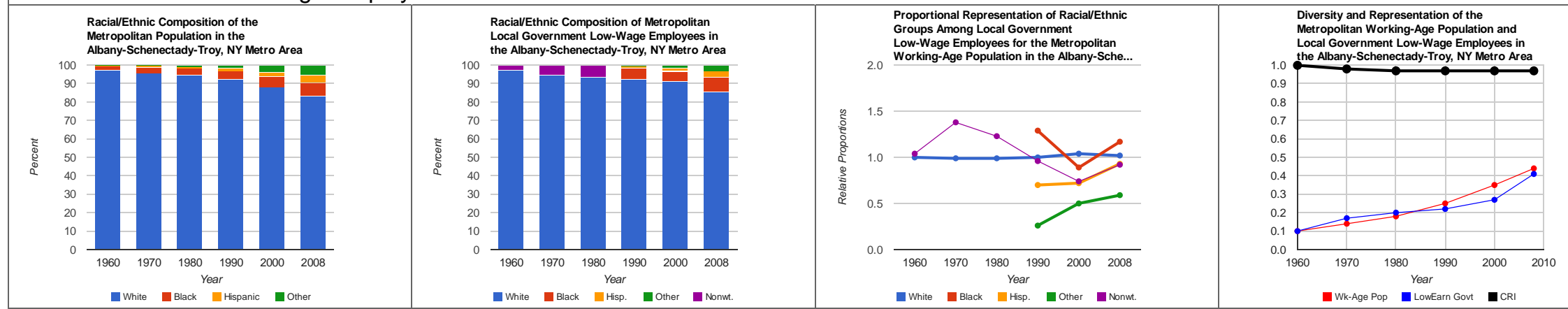

Local Government Low-Wage Employees in the Central Cities
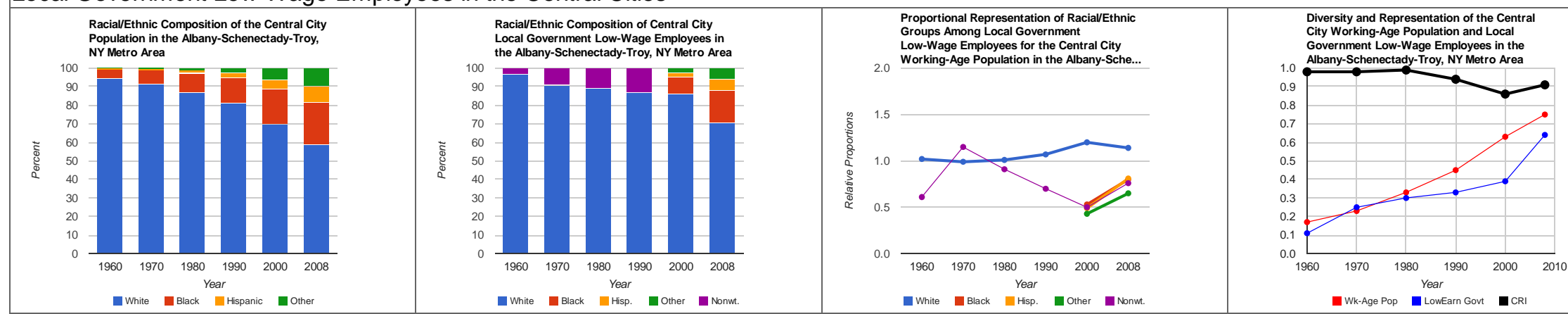


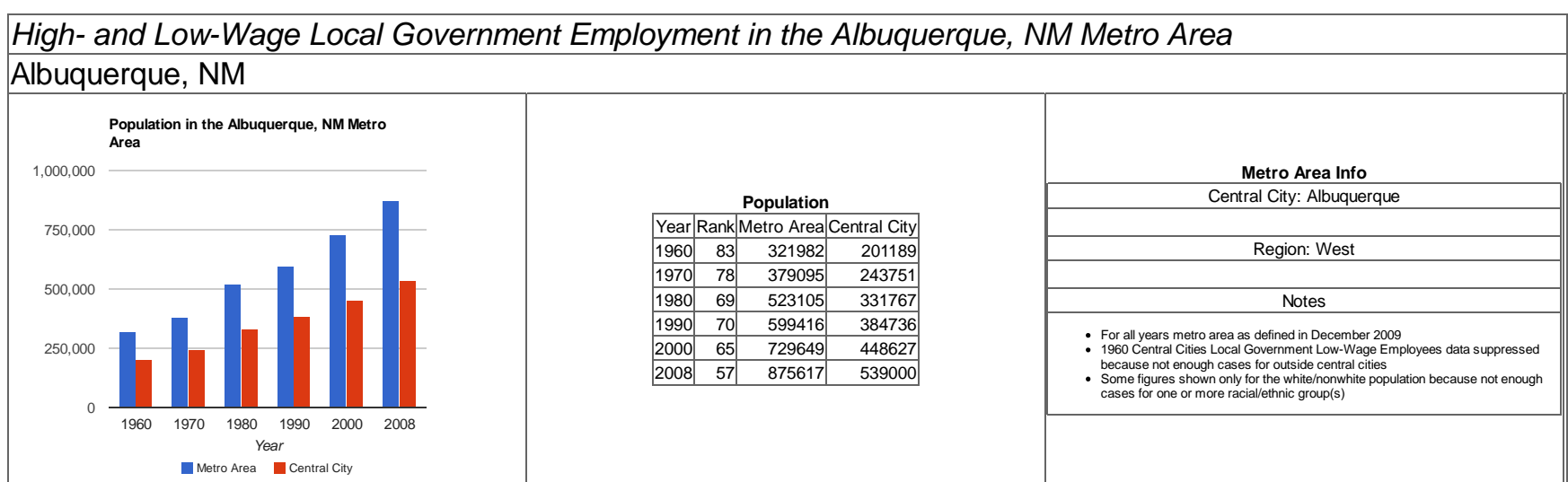


High- and Low-Wage Local Government Employment in the Albuquerque, NM Metro Area

Local Government High-Wage Employees in the Metro Area
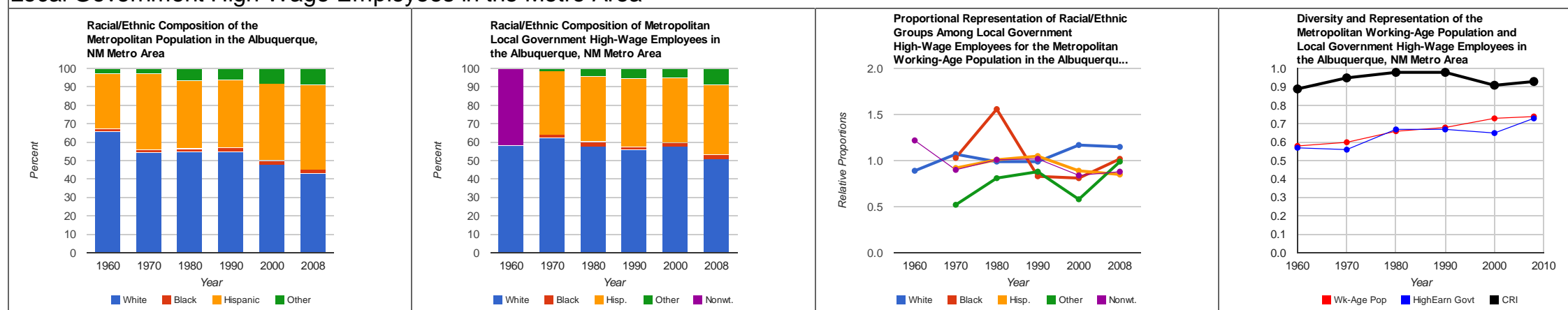

Local Government High-Wage Employees in the Central City
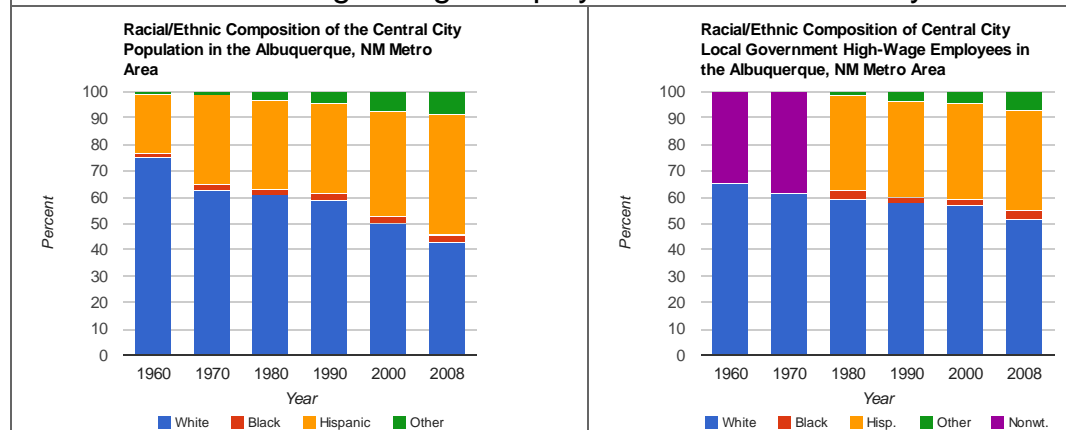
Proportional Representation of Raciall/Ethnic
Groups Among Local Government
High-Wage Employees for the Central City Working-Age Population in the Albuquerqu...

White Elack YHispanic nother

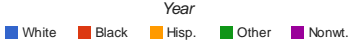
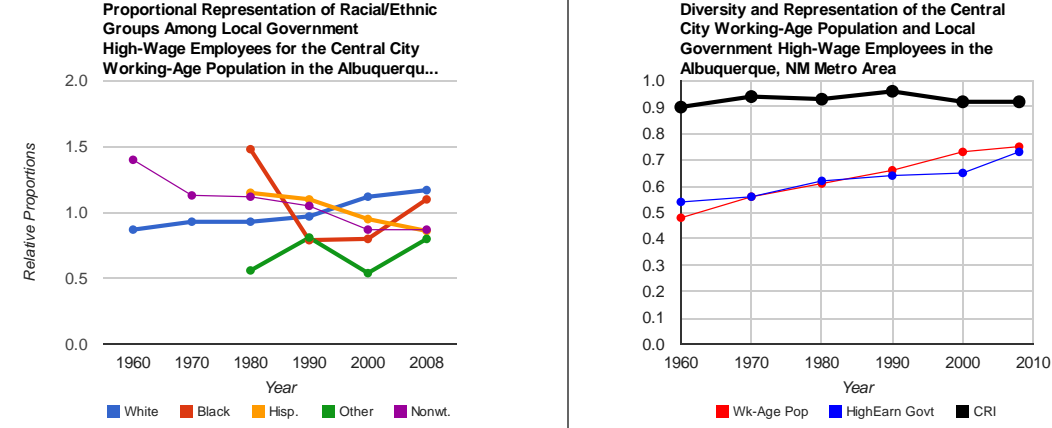
High- and Low-Wage Local Government Employment in the Albuquerque, NM Metro Area

Local Government Low-Wage Employees in the Metro Area
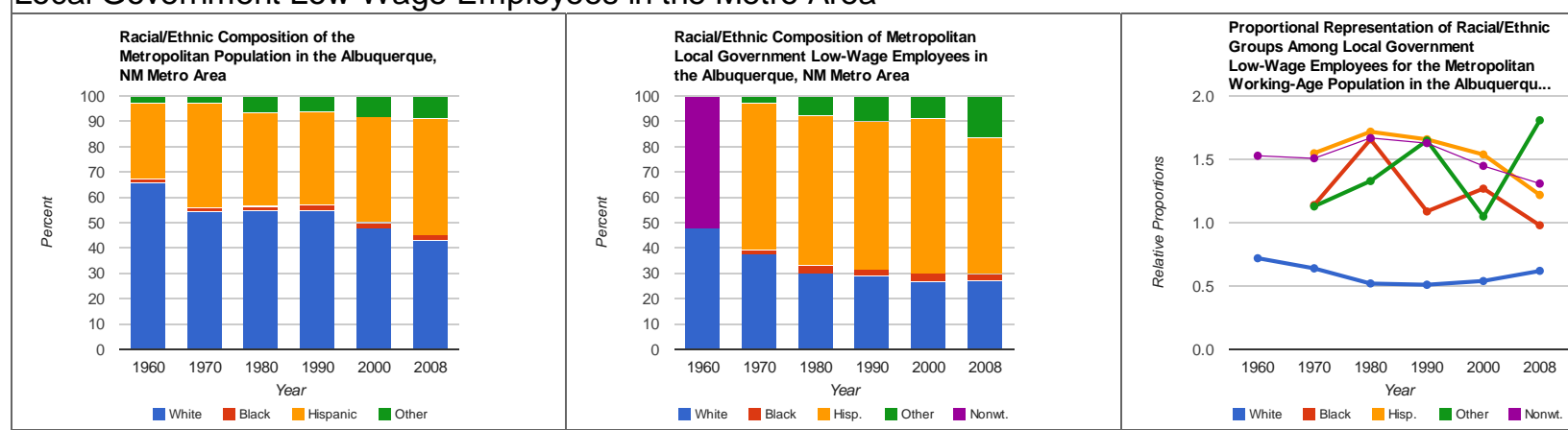

Diversity and Representation of the
Metropolitan Working-Age Popultion Metropolitan Working-Age Population and the Albuquerque, NM Metro Area

White Black Hispanic ather

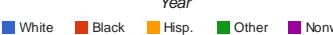

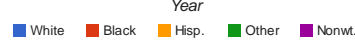

1.0
0.9

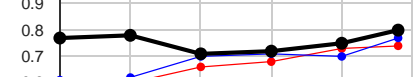

$0.6 \rightleftharpoons$

0.3

0.2

0.1
0.0

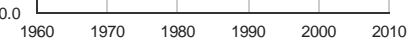

- Wh-Age Pop Lowearn Govt -

Local Government Low-Wage Employees in the Central City

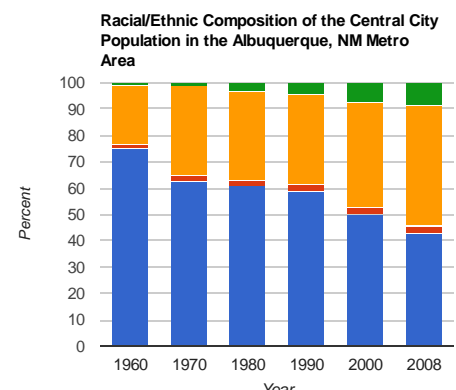

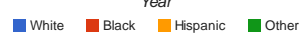

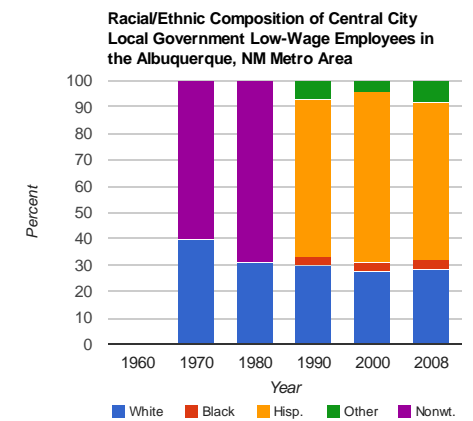

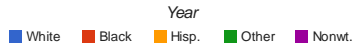

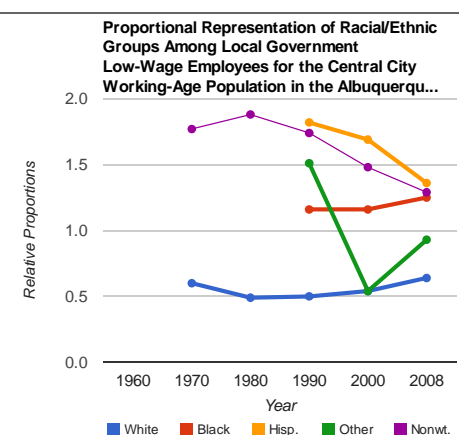

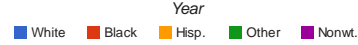

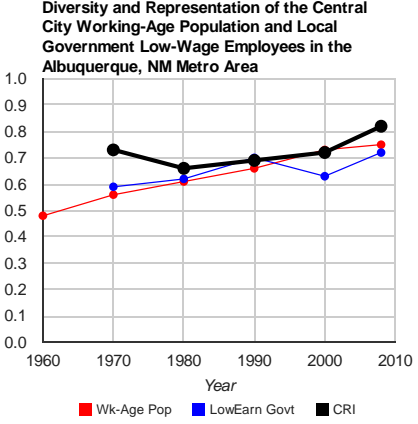




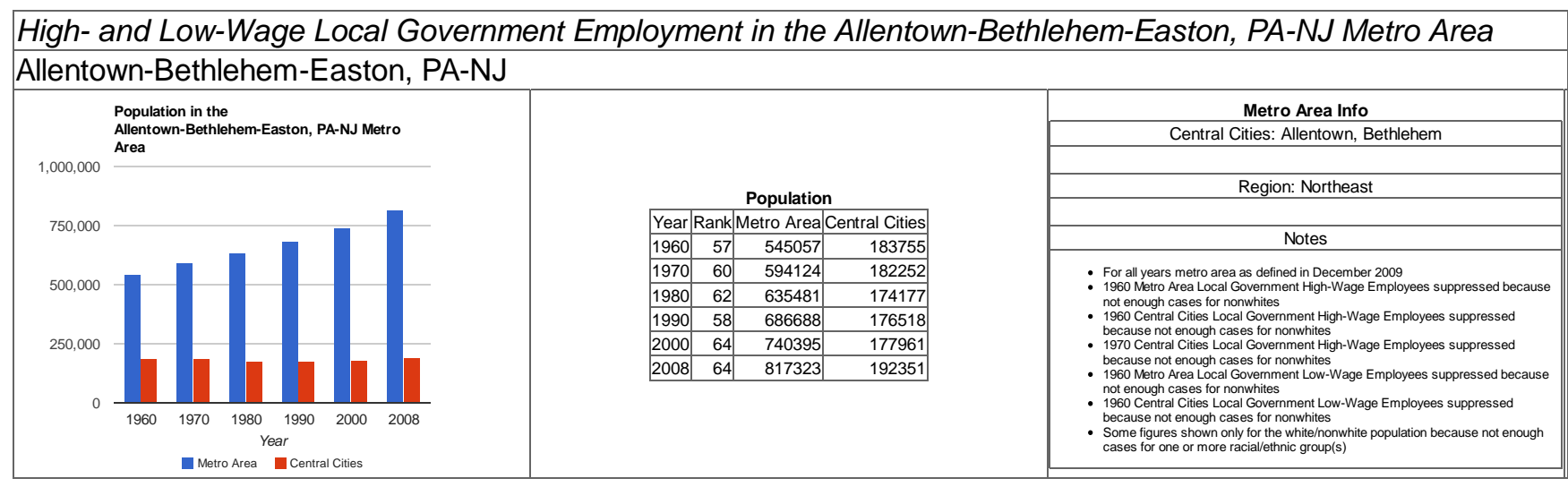


High- and Low-Wage Local Government Employment in the Allentown-Bethlehem-Easton, PA-NJ Metro Area Local Government High-Wage Employees in the Metro Area

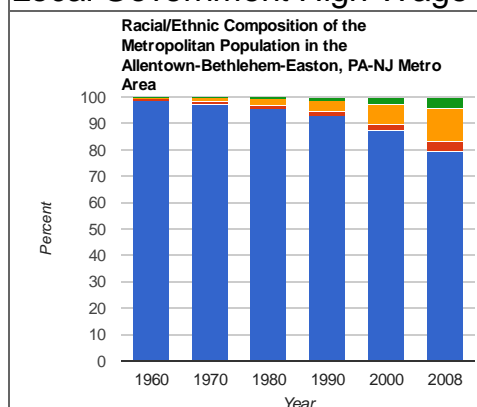

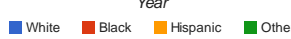

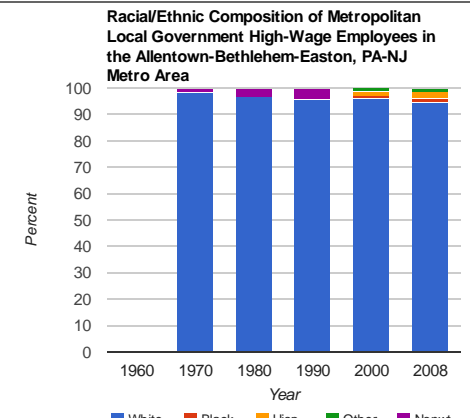

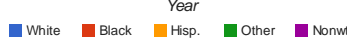

Local Government High-Wage Employees in the Central Cities

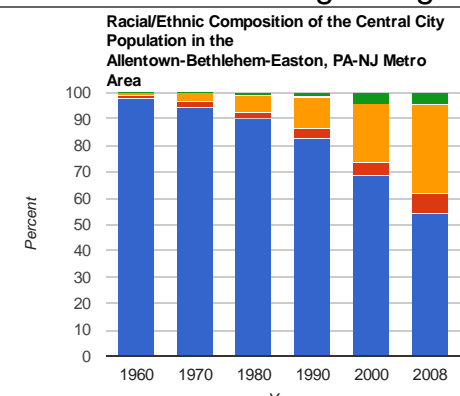

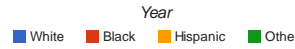

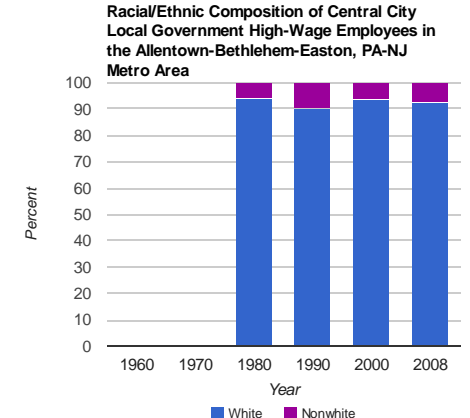

White ${ }_{\text {Nonnwite }}$

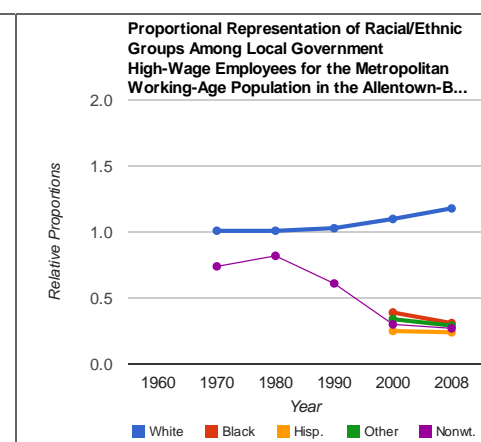

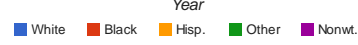

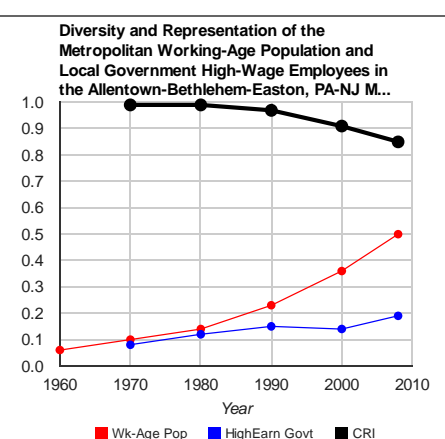

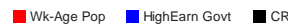

Proportional Representation of RaciallEthnic
Groups Among Local Government Groups Among Local Government
High-Wage Employees for the Central City High-Wage Employees for the Central City
2.0 Working-Age Population in the Allentown-B...

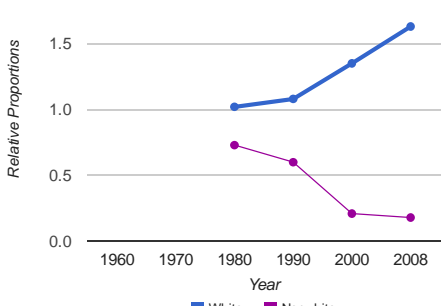

White ${ }_{\text {Nonunhite }}^{\text {Year }}$
Diversity and Representation of the Central
City Working-Age Population and Locat Dity Working-Age Population and Local
Government

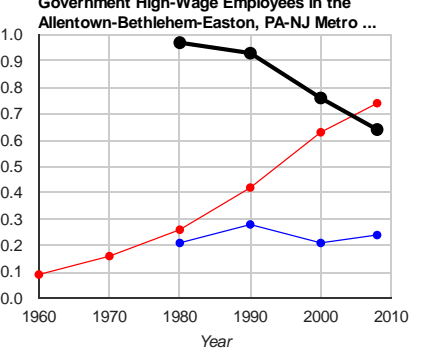

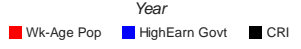


High- and Low-Wage Local Government Employment in the Allentown-Bethlehem-Easton, PA-NJ Metro Area Local Government Low-Wage Employees in the Metro Area

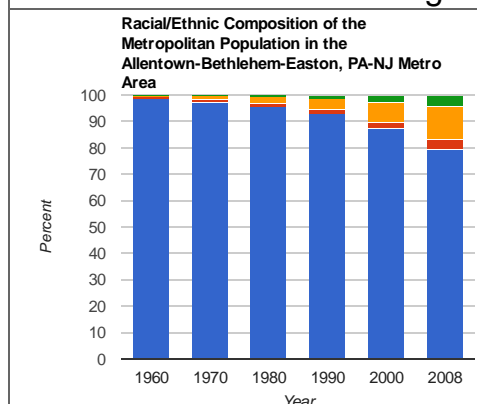

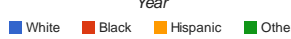

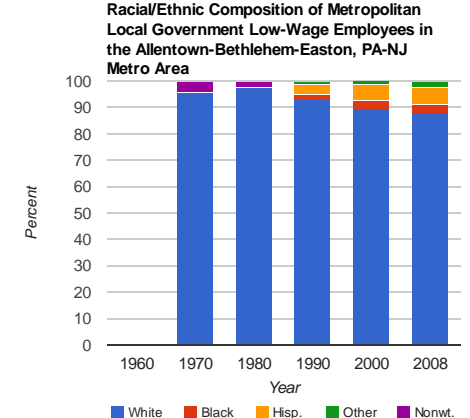

White Black Year

Local Government Low-Wage Employees in the Central Cities

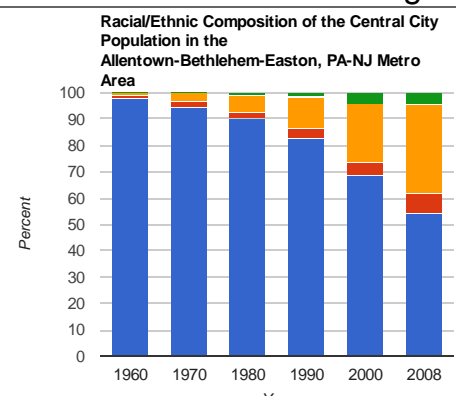

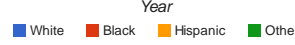

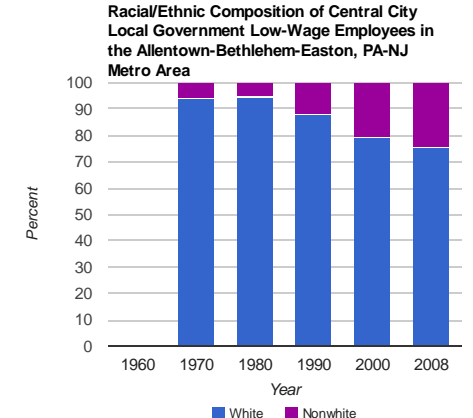

White ${ }_{\text {Nonnwite }}$

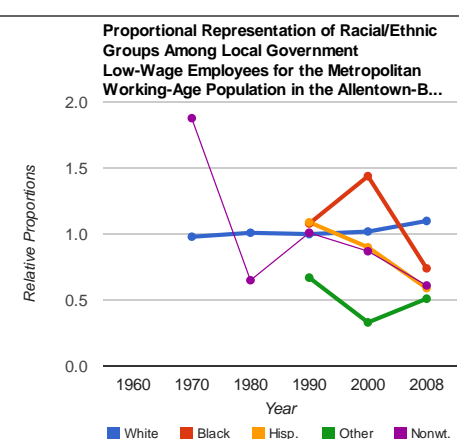

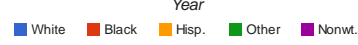

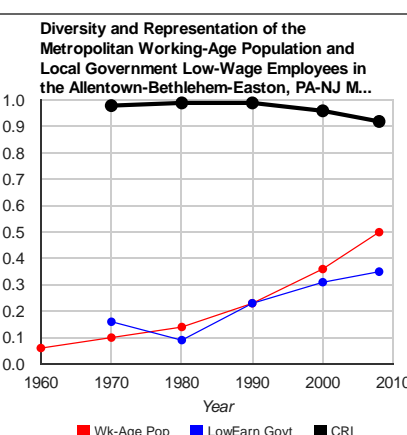

- Wk-Age Pop — LowEarn Govt @
Proportional Representation of RaciallEthnic
Groups Among Local Government Groups Among Local Government
Low-Wage Employes for the Central City Low-Wage Employees for the Central City
2.0 Working-Age Population in the Allentown-B...

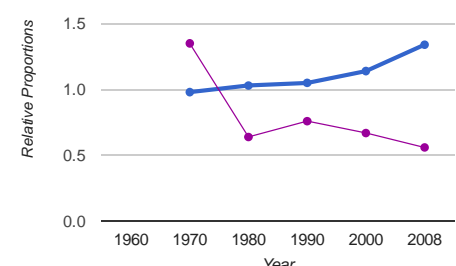
White ${ }_{\text {Nonunite }}$

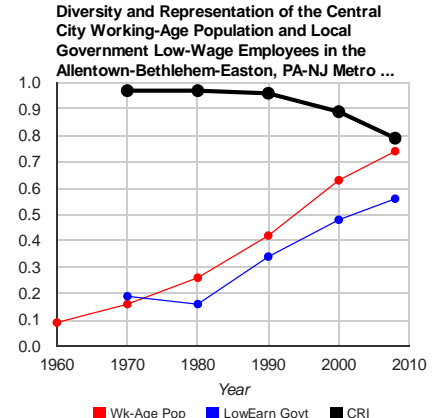

- Wk-Age Pop — LowEarn Govt 


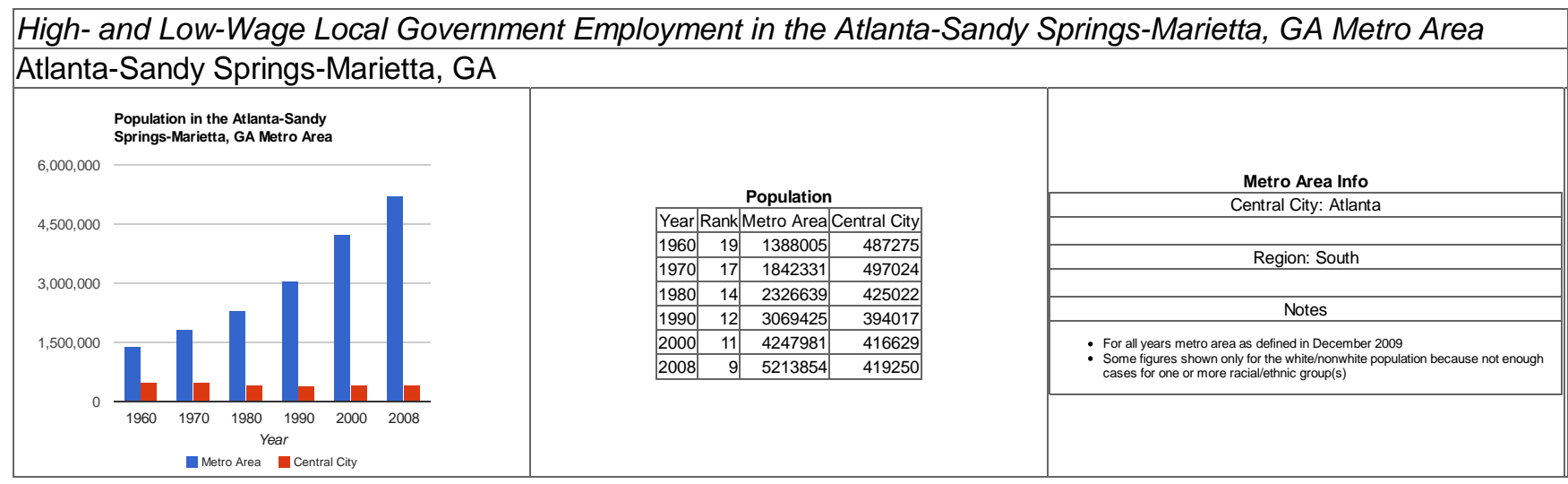


High- and Low-Wage Local Government Employment in the Atlanta-Sandy Springs-Marietta, GA Metro Area Local Government High-Wage Employees in the Metro Area
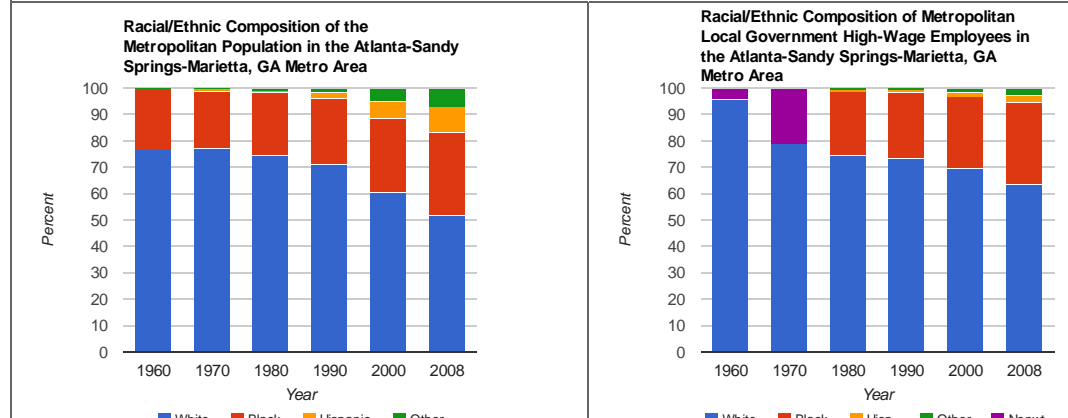

Local Government High-Wage Employees in the Central City
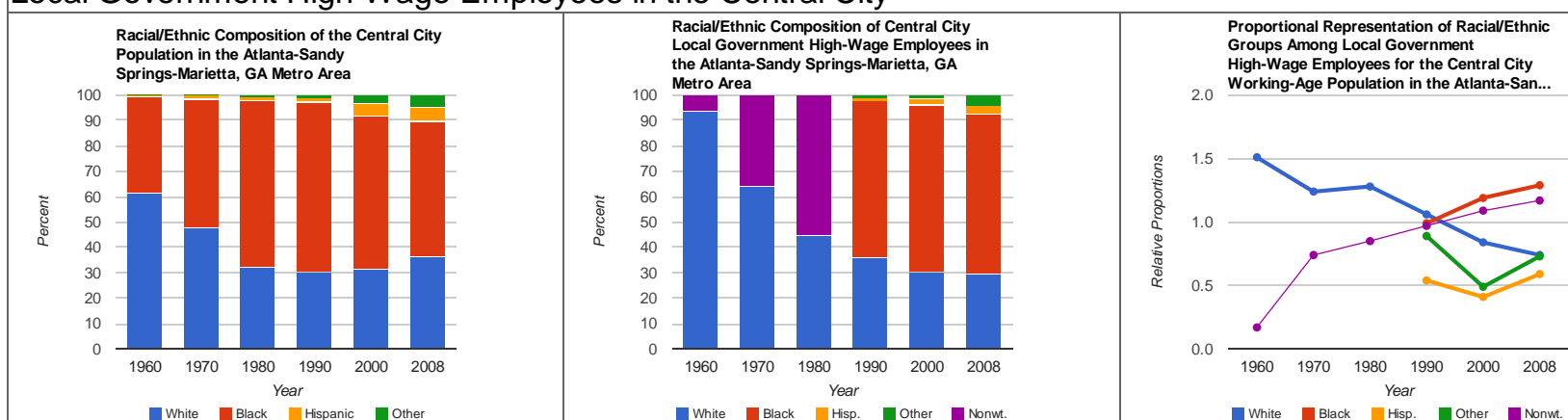
City Working-Age Population and Local Proportional Representation of Racial/Ethnic
Groups Among Local Government

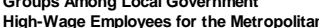
Working-Age Population in the Atlanta-San...

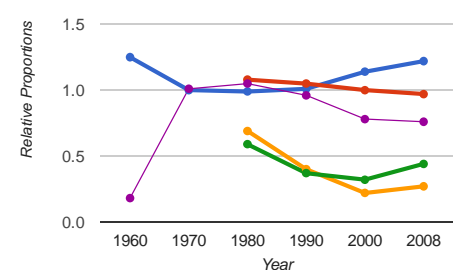
White 1900 Year 190000

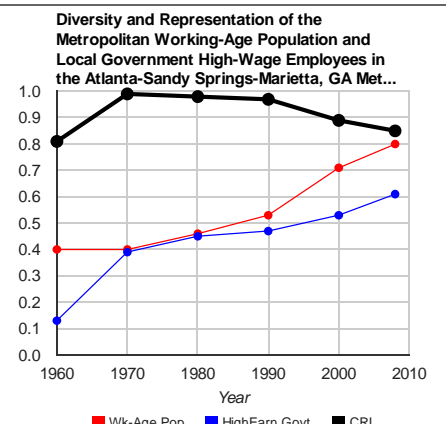

- Wk-Age Pop G HighEarn Govt - CRI

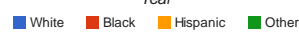

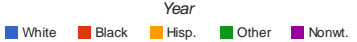

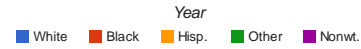

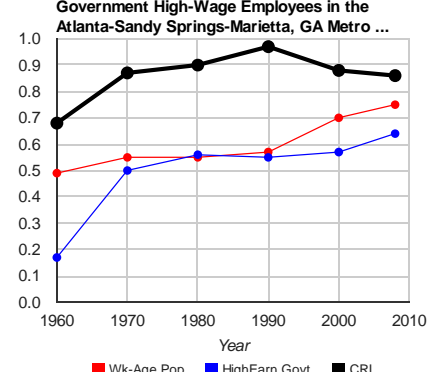

—Wk-Age Pop - HighEarn Govt @ CRI 
High- and Low-Wage Local Government Employment in the Atlanta-Sandy Springs-Marietta, GA Metro Area Local Government Low-Wage Employees in the Metro Area
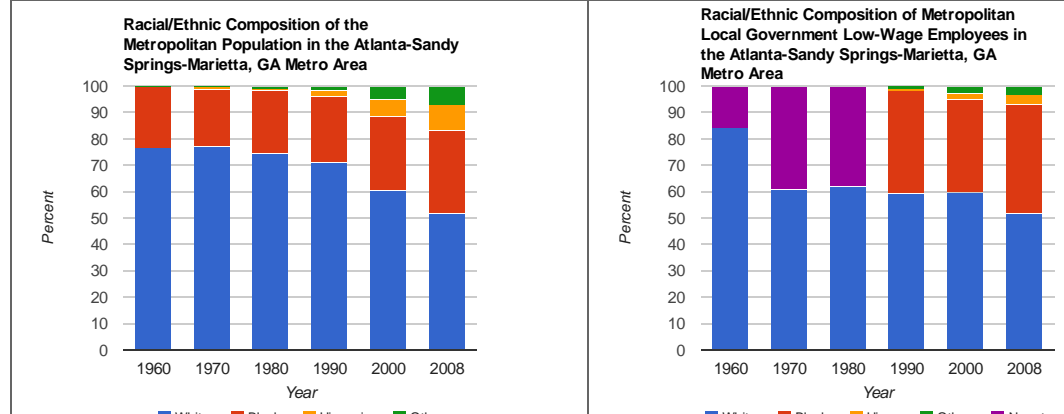

Local Government Low-Wage Employees in the Central City
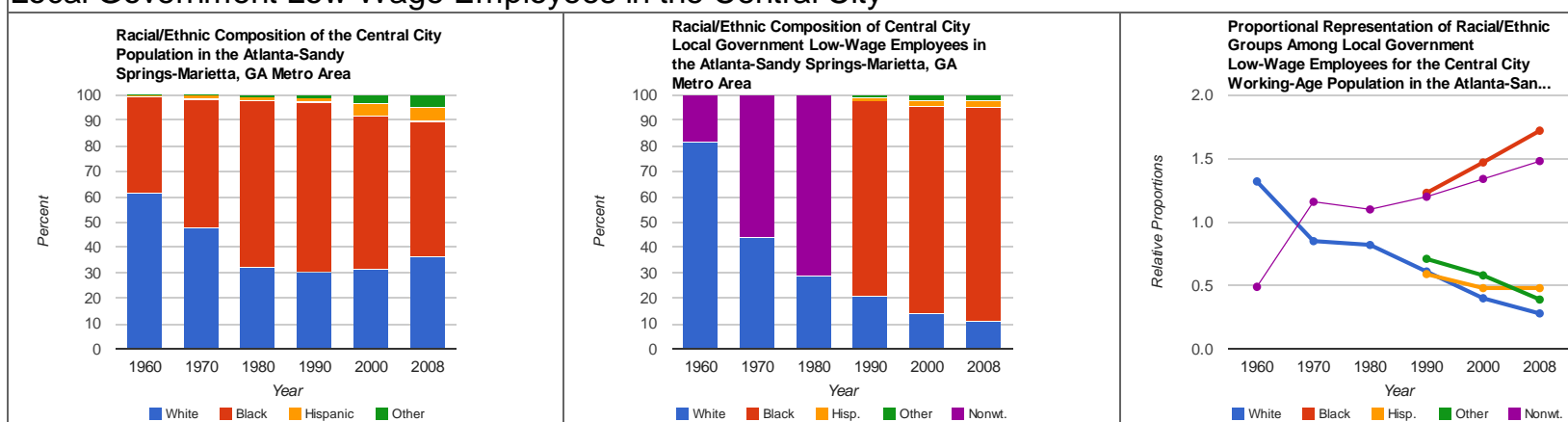
Diversity and Representation of the Central
City Working-Age Population and Local
Government Low-Wage Employees in the Diversity and Representation of the
Metropolitan Working-Age Population and
Local Government Low-Wage Employees in the Atlanta-Sandy Springs-Marietta, GA Met...
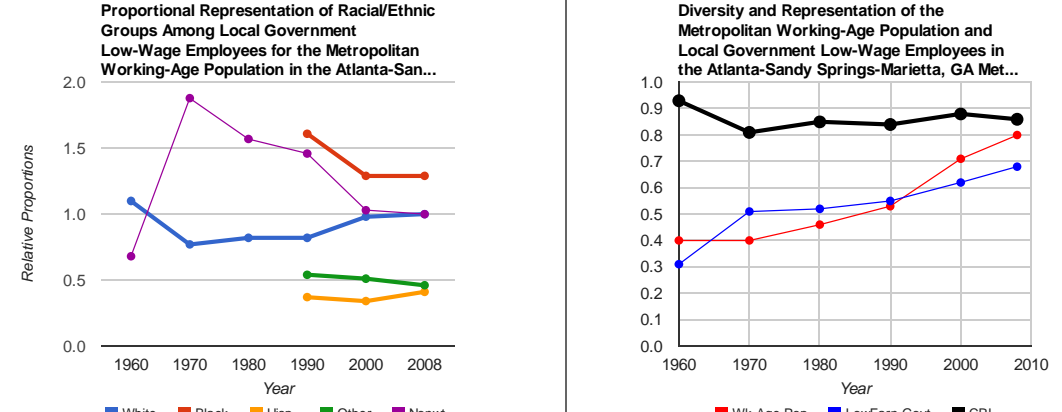

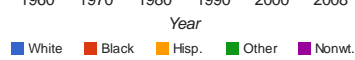
-Wk-Age Pop $\quad$ Lowearn Govt MCR

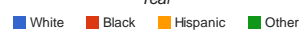

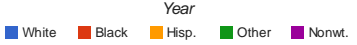

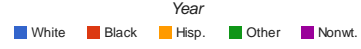

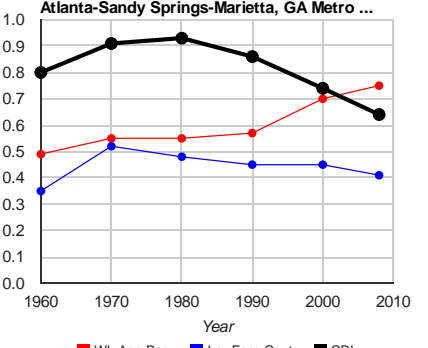

-Wk-Age Pop $\quad$ LowEarn Govt $\quad$ CRI 


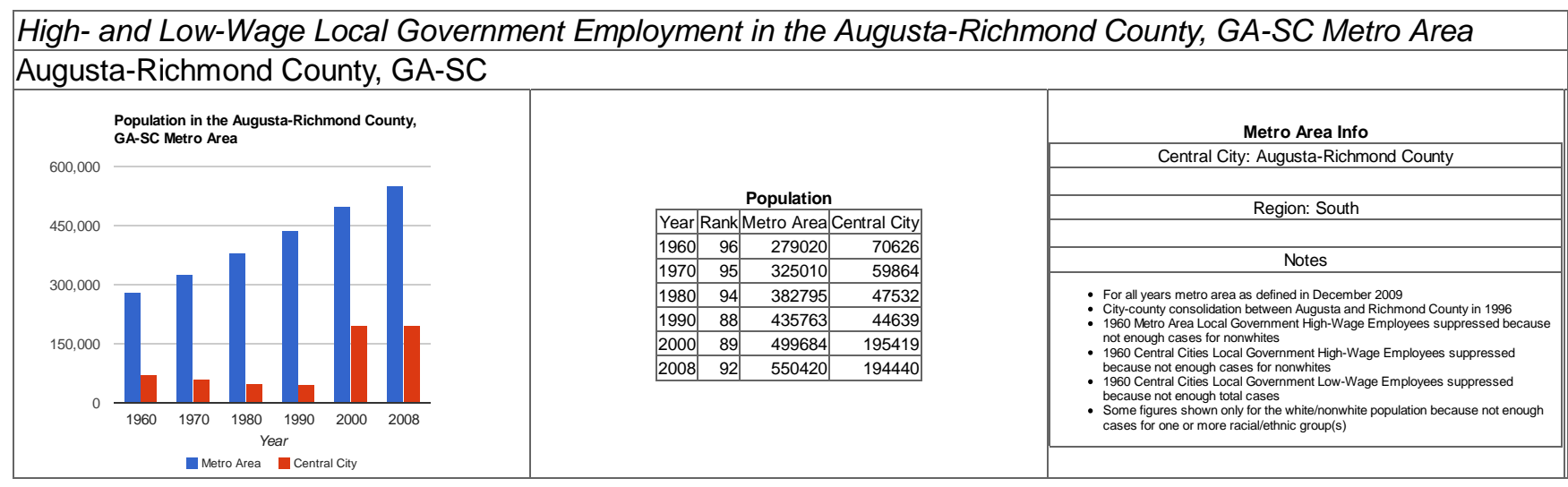


High- and Low-Wage Local Government Employment in the Augusta-Richmond County, GA-SC Metro Area Local Government High-Wage Employees in the Metro Area
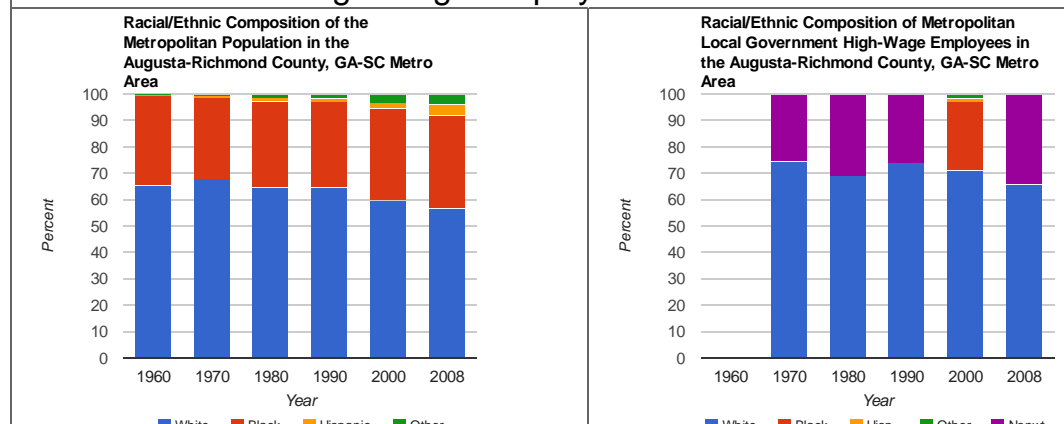

White Black Year

Local Government High-Wage Employees in the Central City

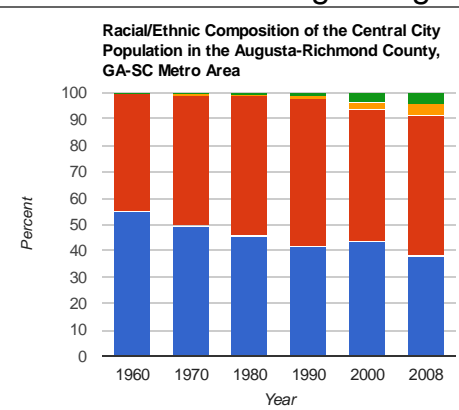

White Inlack Year

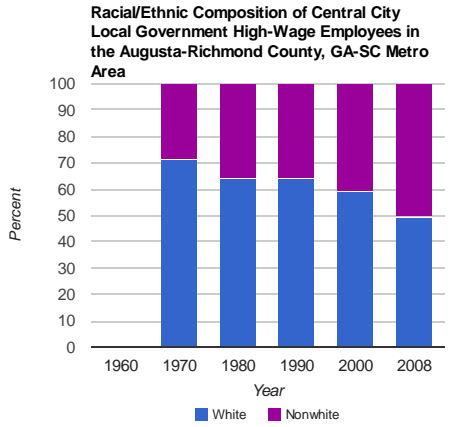

Diversity and Representation of the Central City Working-Age Population and Local
Government High-Wage
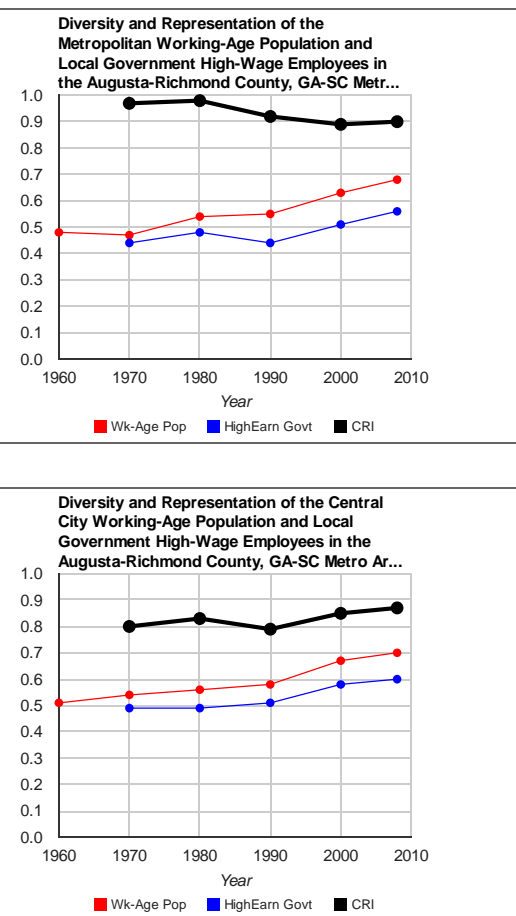

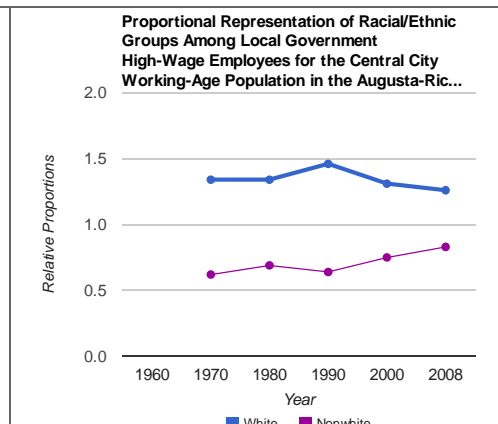

$\begin{array}{llllll}1960 & 1970 & 1980 & 1990 & 2000 & 2008\end{array}$

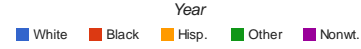

Proportional Representation of Racial/Ethnic
Groups Among Local Government

High-Wage Employees for the Metropolitan
Working-Age Population in the Augusta-Ric...

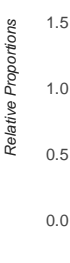

of Raciallethnic Groups Among Local Government
High-Wage Employees for the Central City
Working-Age Population in the Augusta-Ric.

White Nonuhite

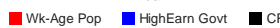


High- and Low-Wage Local Government Employment in the Augusta-Richmond County, GA-SC Metro Area Local Government Low-Wage Employees in the Metro Area
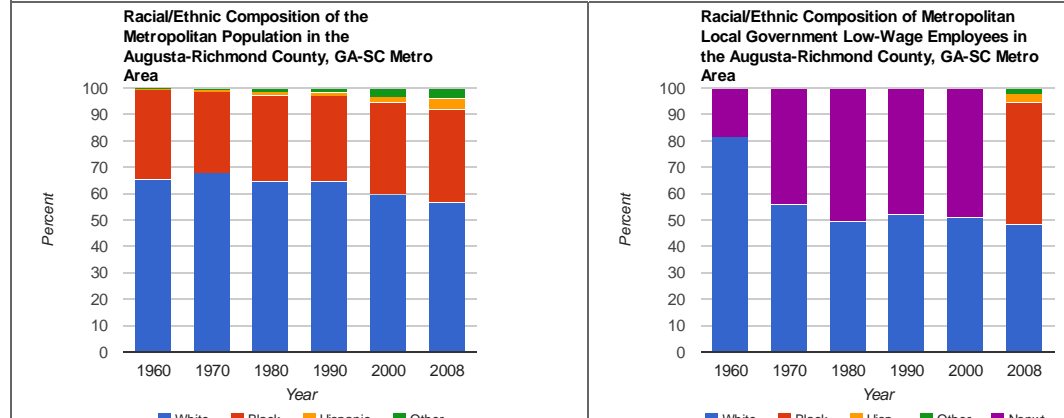

White 1 Black 1 Hisp.

Local Government Low-Wage Employees in the Central City

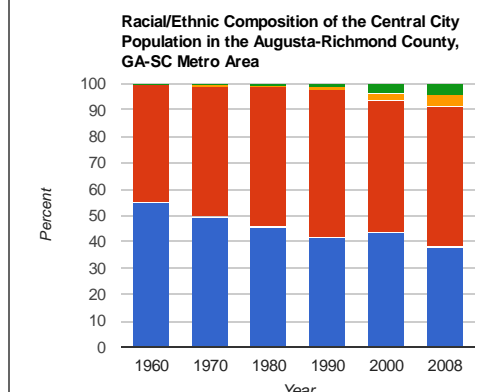

White Black Hear Hispanic

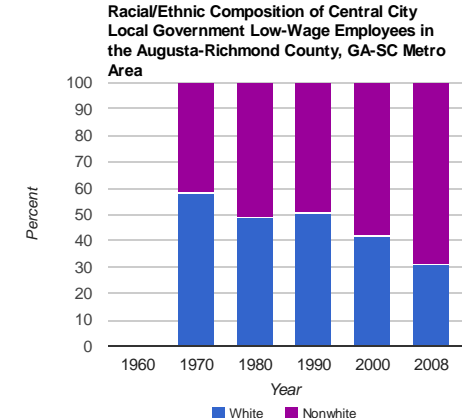

White ${ }_{\text {Nonnwite }}$
Proportional Representation of Raciall/Ethnic Groups Among Local Government

2.0 Working-Age Population in the Augusta-Ric...

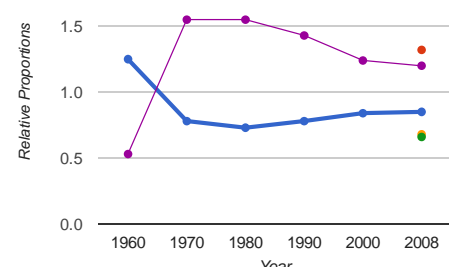

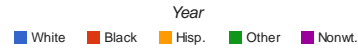

Diversity and Representation of the
Metropolitan Working-Age Population

Metropoitian Working-Age Population and

the Augusta-Richmond County, GA-SC Metr..

1.0

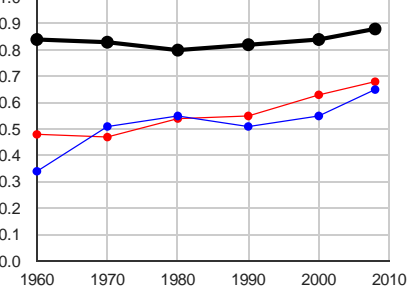

${ }_{1960}^{0.0} \quad 1970 \quad 1980 \quad 1990 \quad 2000 \quad 2010$

- Wk-Age Pop Lowearn Gout ac a

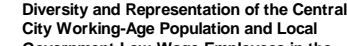
Proportional Representation of Raciall/Ethnic
Groups Among Local Government
Low-Wage Employees for the Central City 20 Working-Age Population in the Augusta-Ric...

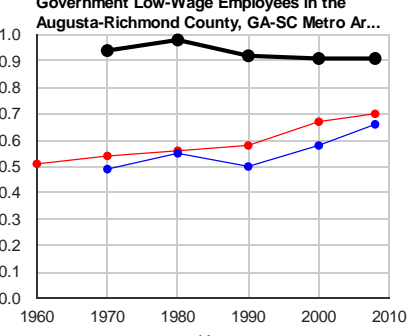

- wk-Age Pop LowEarn Govt @ CR 


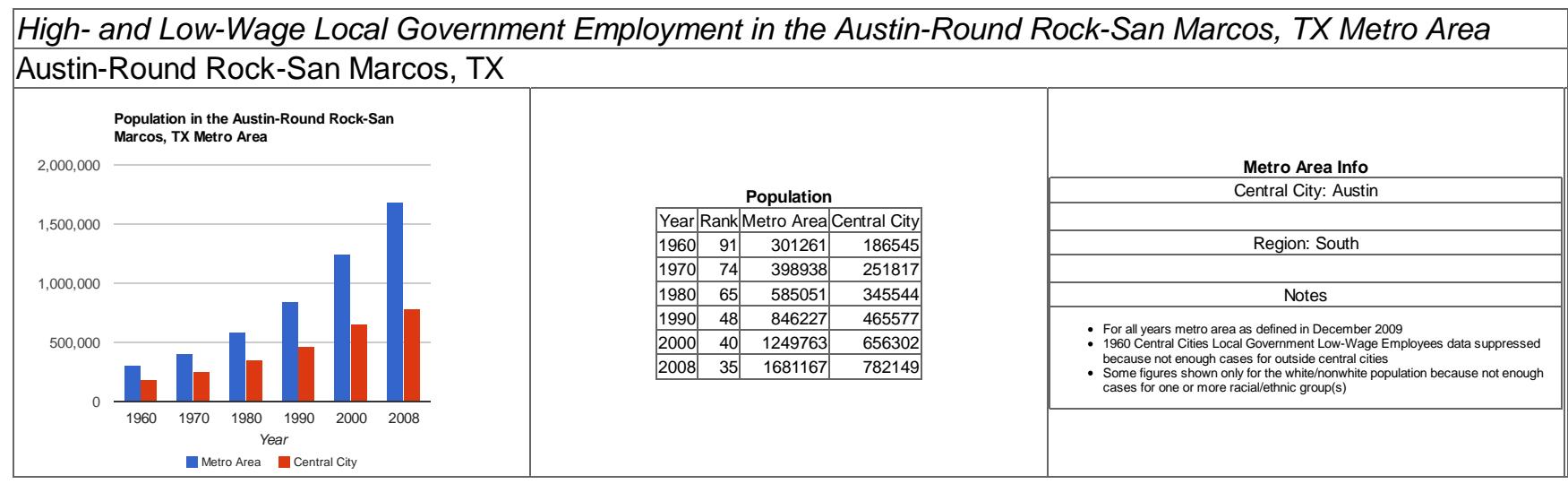


High- and Low-Wage Local Government Employment in the Austin-Round Rock-San Marcos, TX Metro Area Local Government High-Wage Employees in the Metro Area
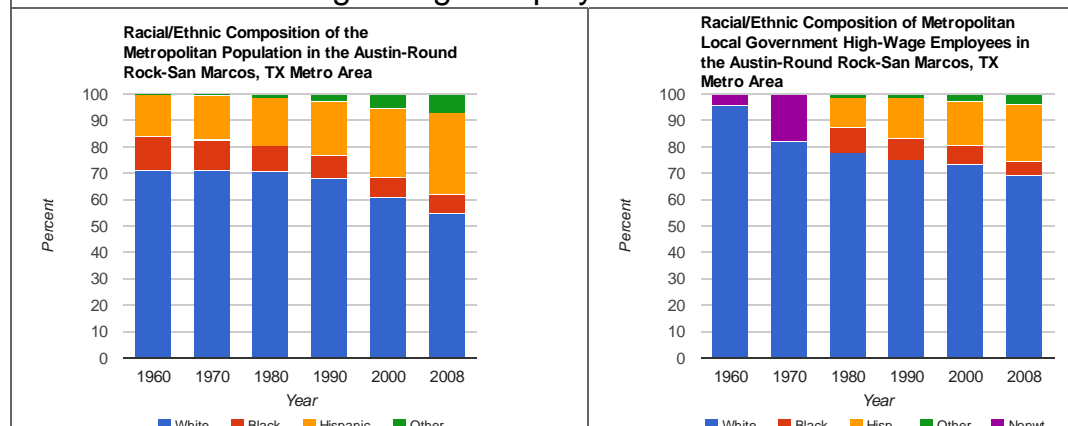

Local Government High-Wage Employees in the Central City
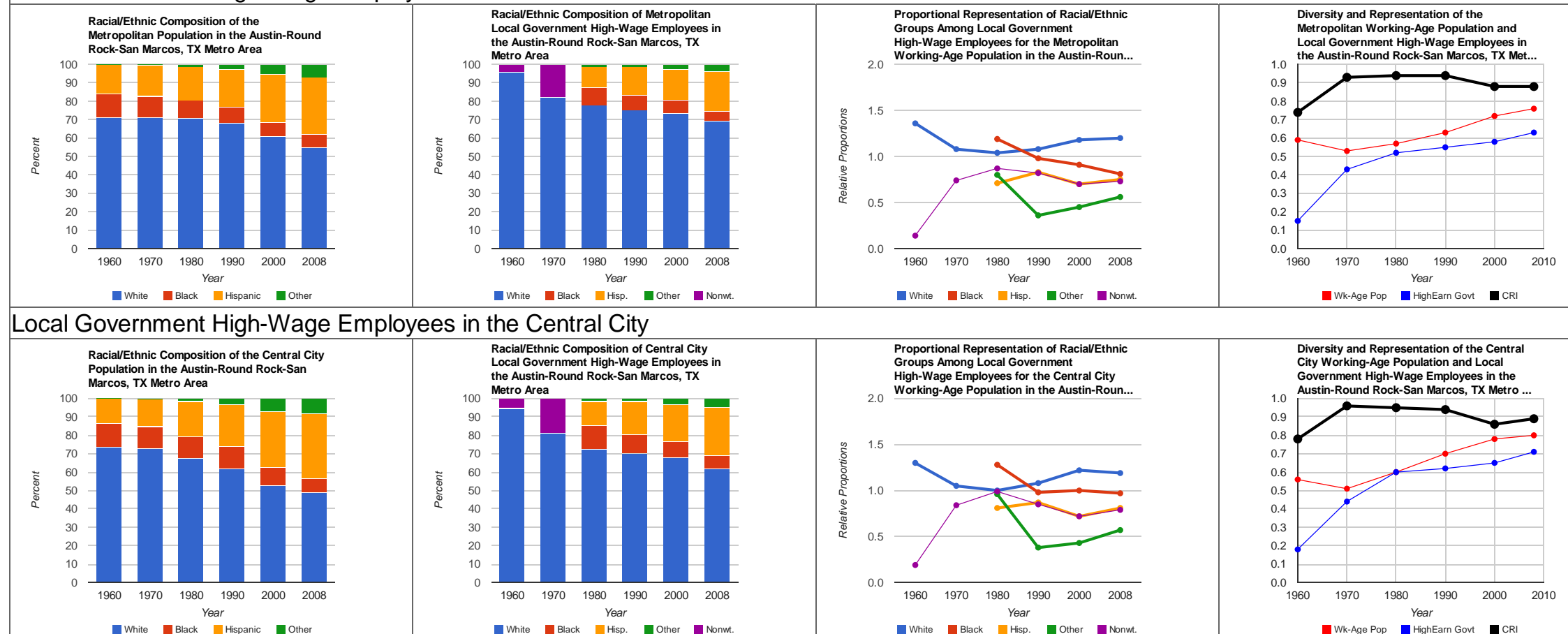

Proportional Representation of Racial//thnic
Groups Among Local Government High-Wage Employees for the Metropolitan
Working-Age Population in the Austin-Roun...

White Black Hispanic nother

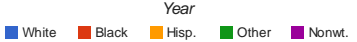

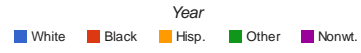

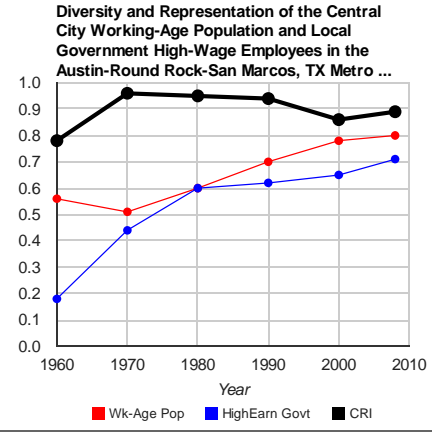


High- and Low-Wage Local Government Employment in the Austin-Round Rock-San Marcos, TX Metro Area Local Government Low-Wage Employees in the Metro Area
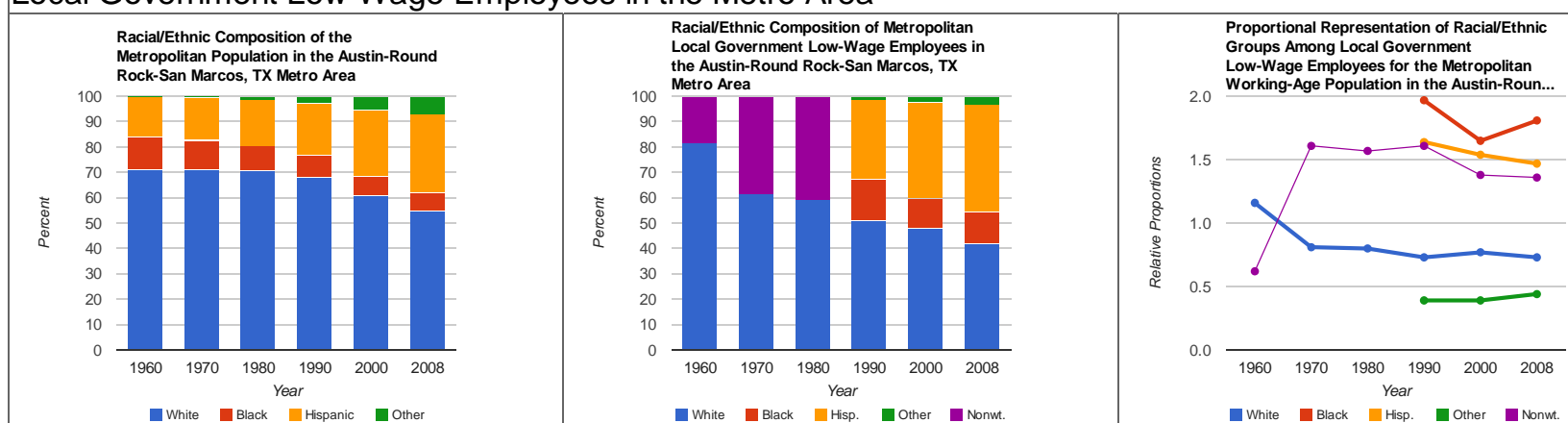

Local Government Low-Wage Employees in the Central City

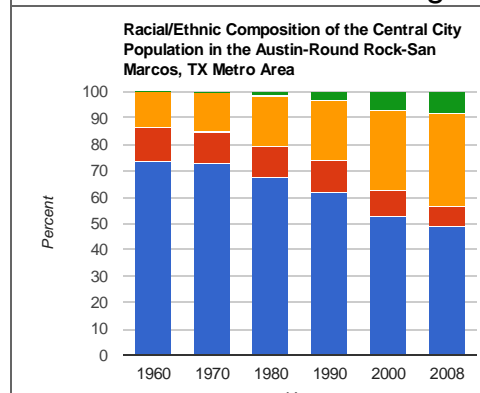

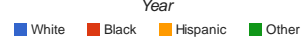
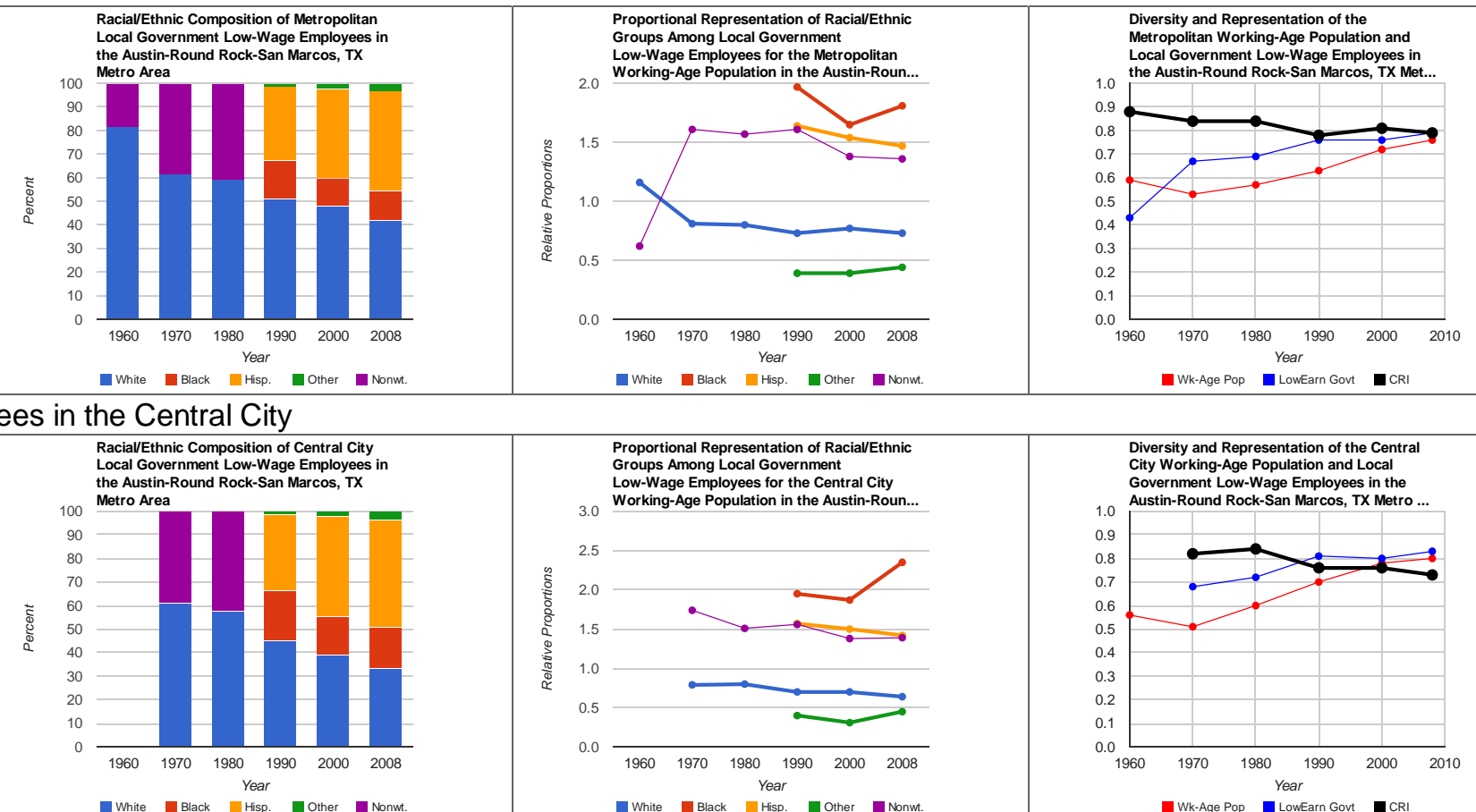

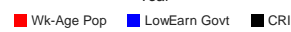

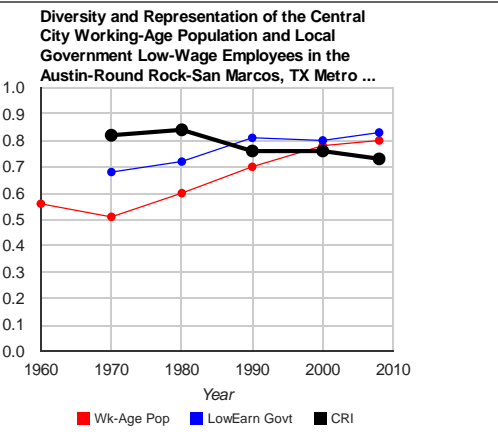




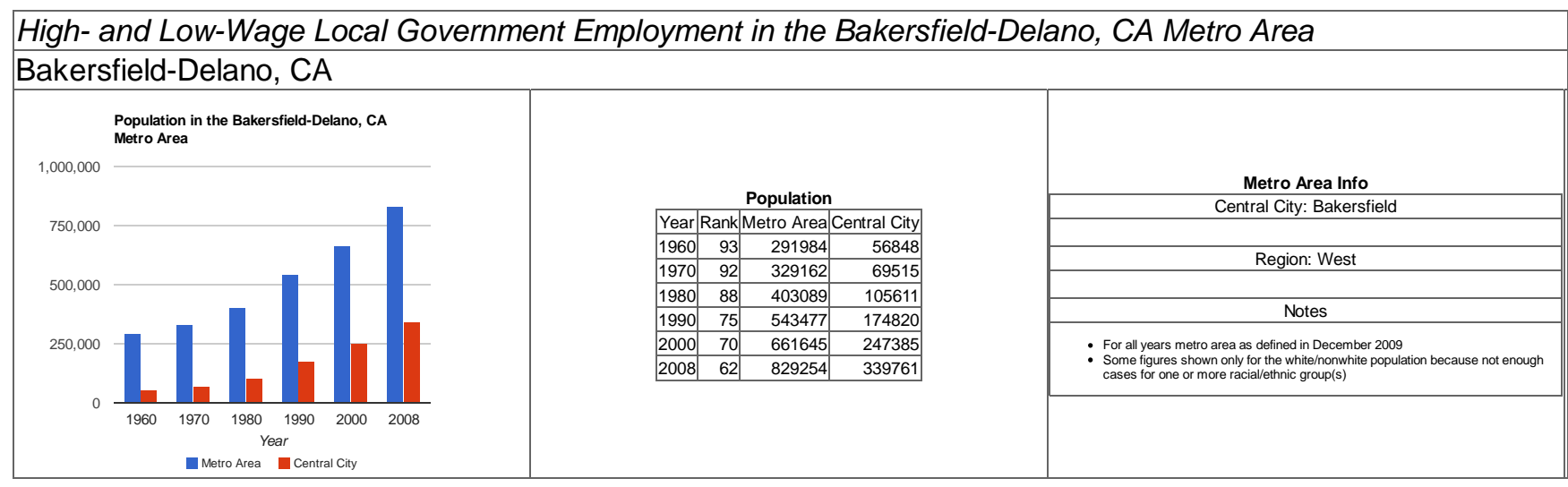


High- and Low-Wage Local Government Employment in the Bakersfield-Delano, CA Metro Area Local Government High-Wage Employees in the Metro Area
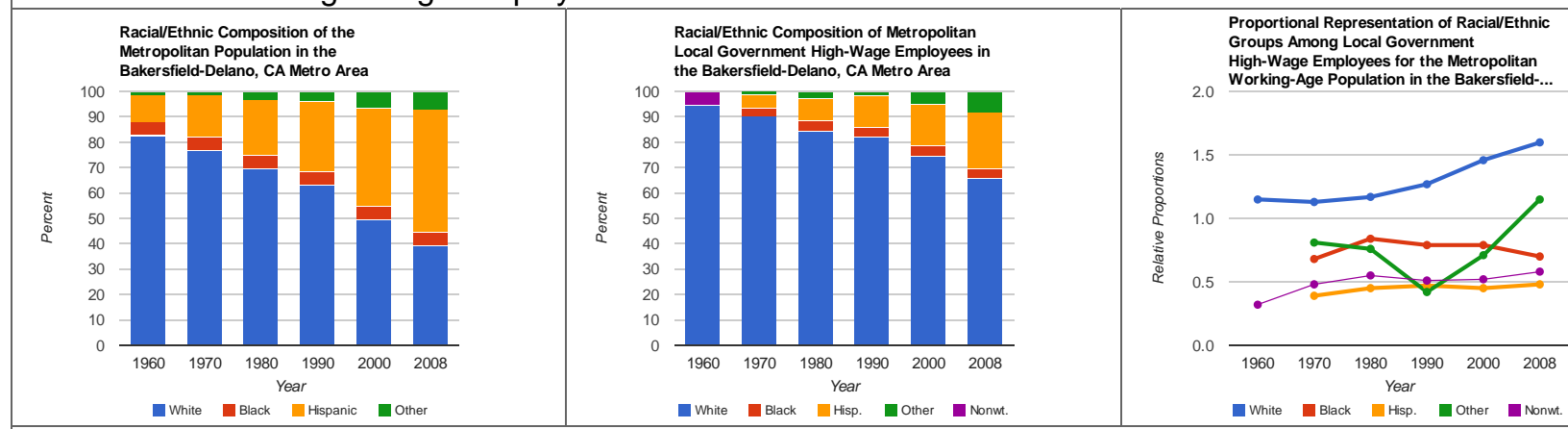
Diversity and Representation of the
Metropolitan Working-Age Population and the Bakersfield-Delano, CA Metro Area

White Black Hispanic moter - White 1 Black 1 Hisp.

Local Government High-Wage Employees in the Central City

RaciallEthnic Composition of the Central City
Population in the Bakersfield-Delano, CA

Metro Area

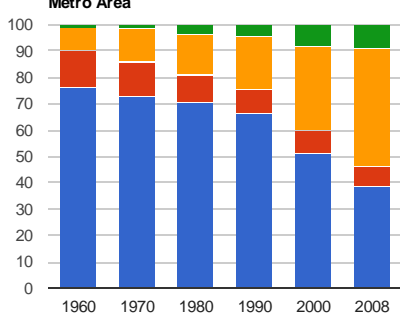

Racial/Ethnic Composition of Central City

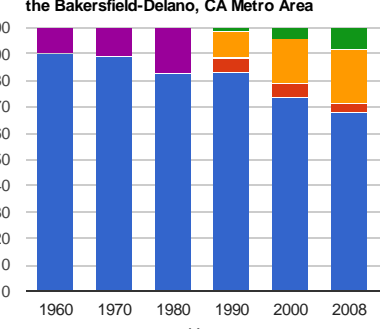

White \#Black

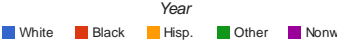

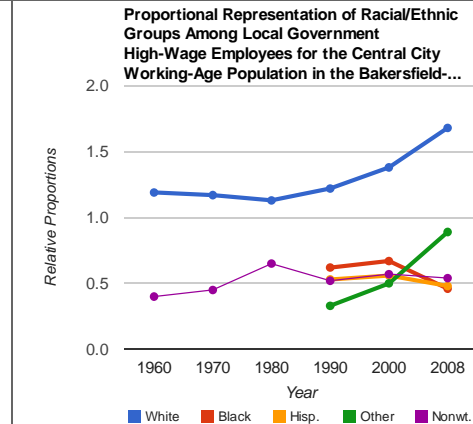
Diversity and Representation of the Central
City Working-Age Population and Local Government High-Wage Employees in the
Bakersfield-Delano, CA Metro Area

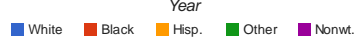

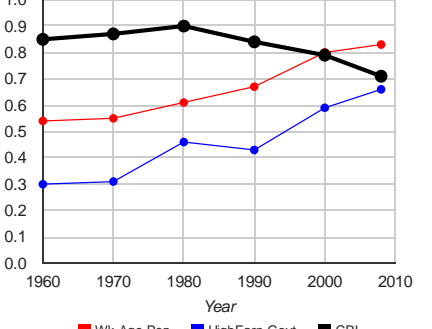

-Wk-Age Pop U Highearn Govt MCRI 
High- and Low-Wage Local Government Employment in the Bakersfield-Delano, CA Metro Area Local Government Low-Wage Employees in the Metro Area
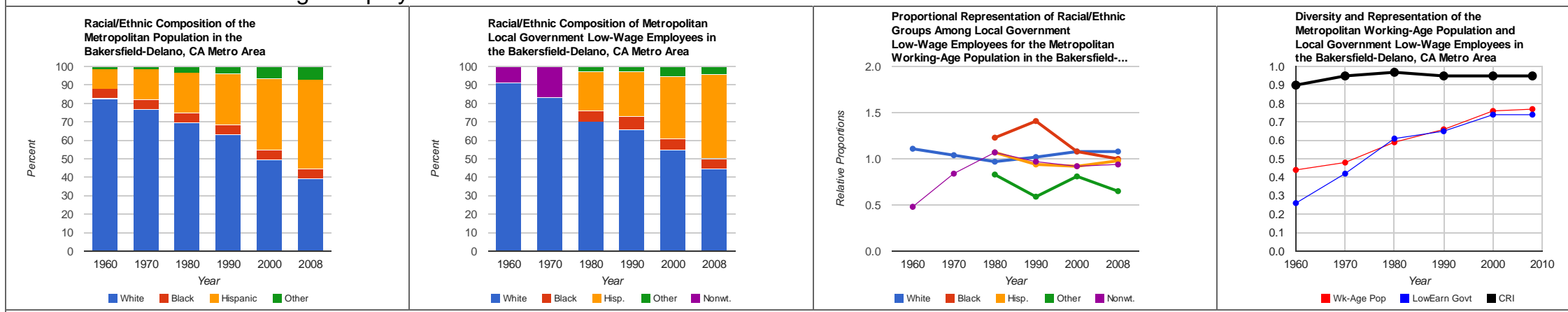

Local Government Low-Wage Employees in the Central City
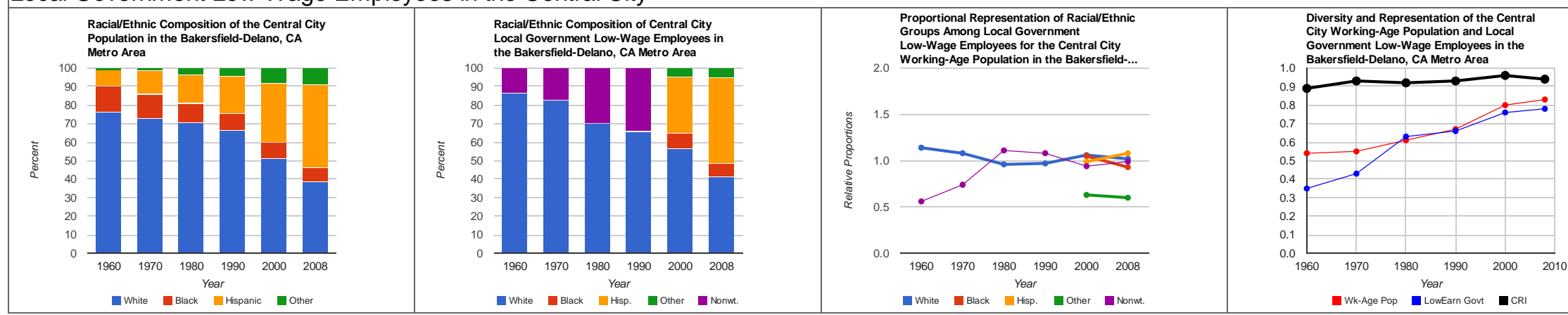


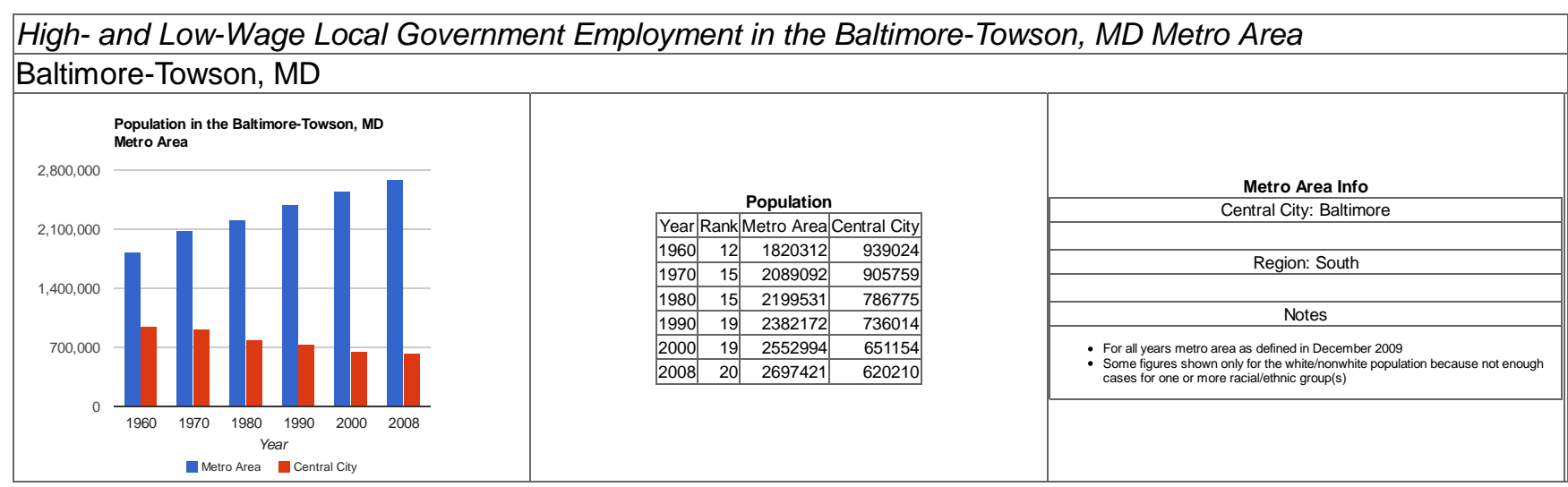


High- and Low-Wage Local Government Employment in the Baltimore-Towson, MD Metro Area

Local Government High-Wage Employees in the Metro Area
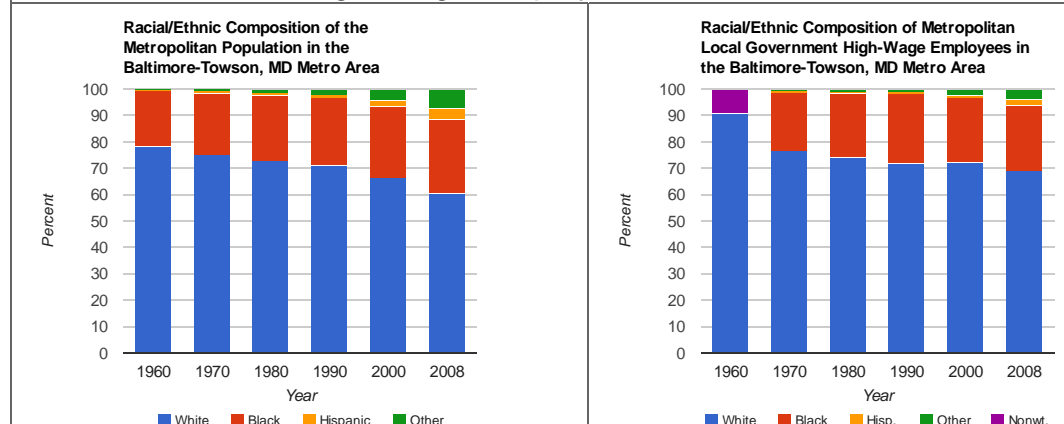

Local Government High-Wage Employees in the Central City
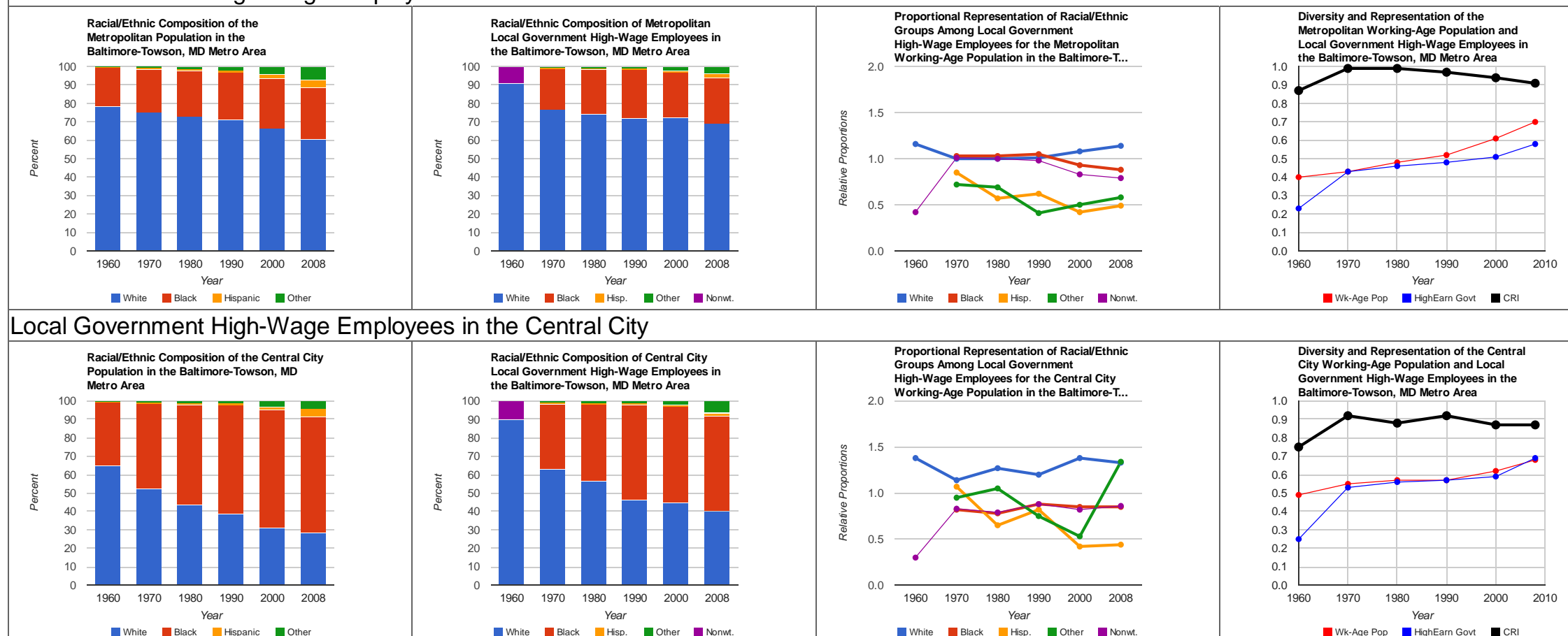

חWk-Age Pop M Highearn Govt -

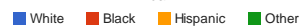

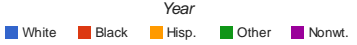

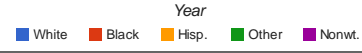

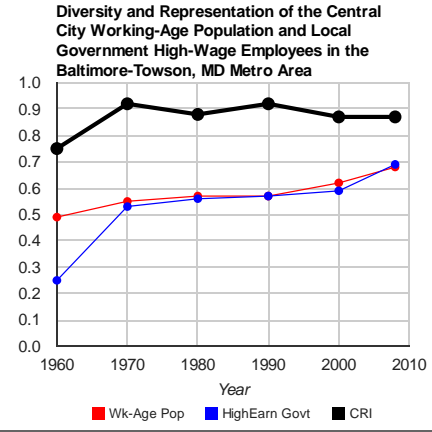


High- and Low-Wage Local Government Employment in the Baltimore-Towson, MD Metro Area

Local Government Low-Wage Employees in the Metro Area
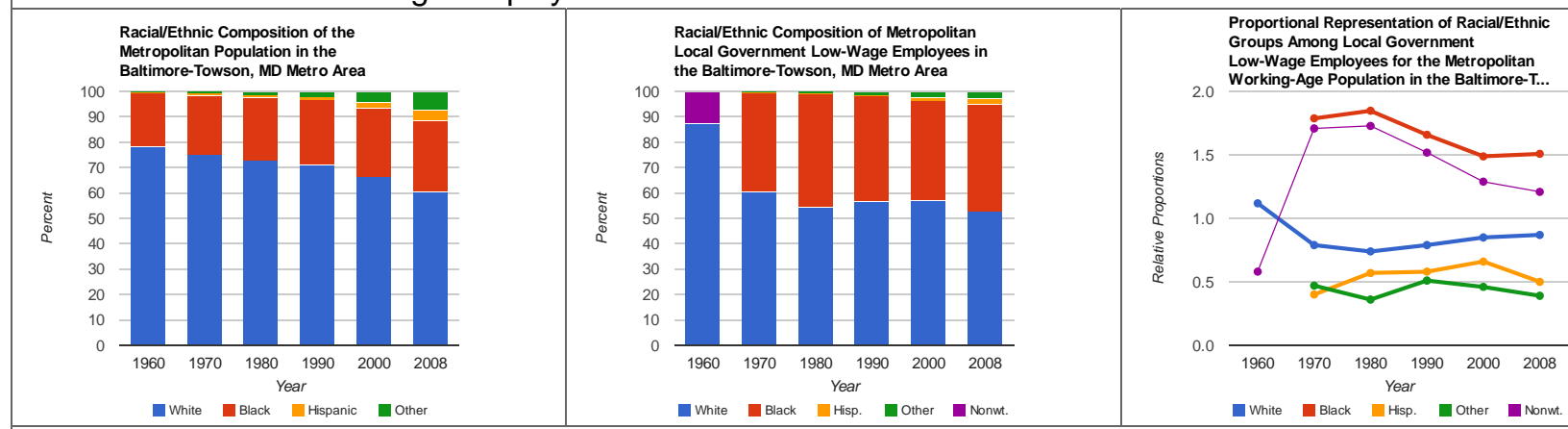

Diversity and Representation of the
Metropolitan Working-Age Population and

the Baltimore-Towson, MD Metro Area

White Black Hispanic Eother

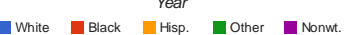

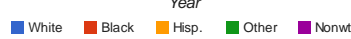

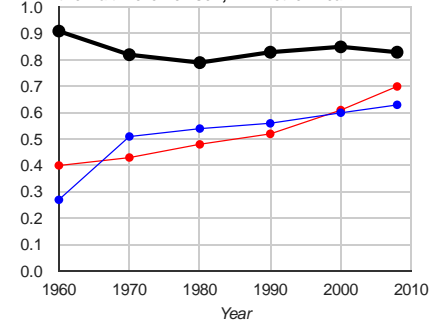

Local Government Low-Wage Employees in the Central City

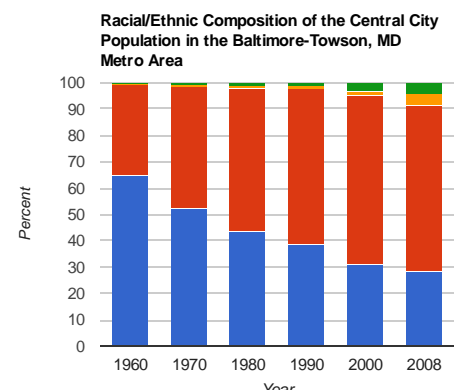

RaciallEthnic Composition of Central City
Local Government Lition

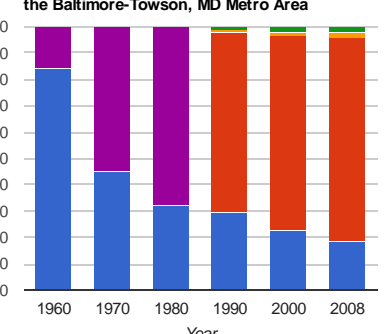
Groups Among Local Government Working-Age Population in the Baltimore-T...

White Ulack Hear Hispanic nother

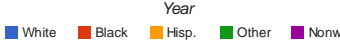
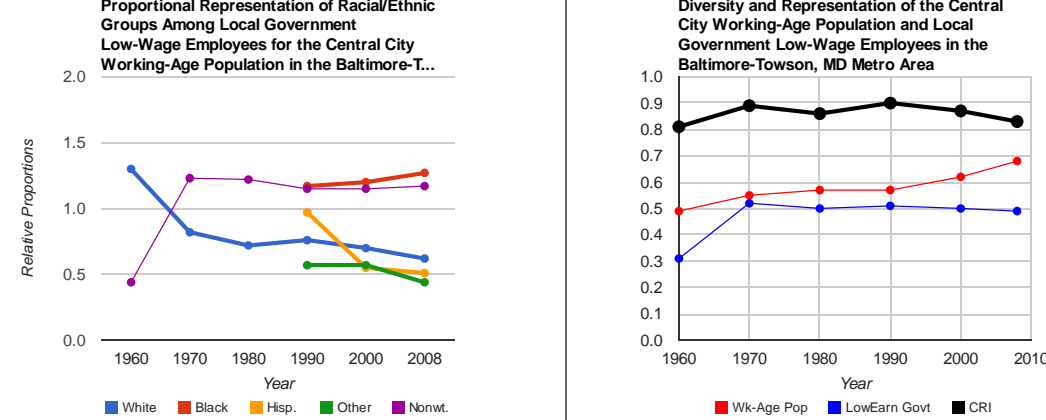
High- and Low-Wage Local Government Employment in the Baton Rouge, LA Metro Area

Baton Rouge, LA

\begin{tabular}{|c|c|c|c|c|c|}
\hline & $\begin{array}{l}\text { Population in the Baton Rouge, LA Metro } \\
\text { Area }\end{array}$ & \multirow{3}{*}{\multicolumn{3}{|c|}{ Population }} & \multirow[b]{2}{*}{ Metro Area Info } \\
\hline \multirow[t]{2}{*}{800,000} & & & & & \\
\hline & & & & & Central City: Baton Rouge \\
\hline \multirow[t]{3}{*}{600,000} & & \multirow{7}{*}{\begin{tabular}{|l|r|} 
Year & Rank N \\
1960 & 67 \\
1970 & 65 \\
1980 & 64 \\
1990 & 68 \\
2000 & 66 \\
2008 & 65 \\
\end{tabular}} & \multirow{2}{*}{\multicolumn{2}{|c|}{ 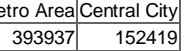 }} & \\
\hline & & & & & Region: South \\
\hline & & & 467346 & 165970 & \\
\hline \multirow{4}{*}{400,000} & & & 591383 & 219419 & Notes \\
\hline & & & 623853 & 219531 & - For all years metro area as defined in December 2009 \\
\hline & & & 705973 & 227920 & 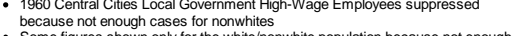 \\
\hline & & & 795254 & 229169 & 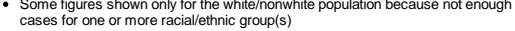 \\
\hline
\end{tabular}


High- and Low-Wage Local Government Employment in the Baton Rouge, LA Metro Area

Local Government High-Wage Employees in the Metro Area
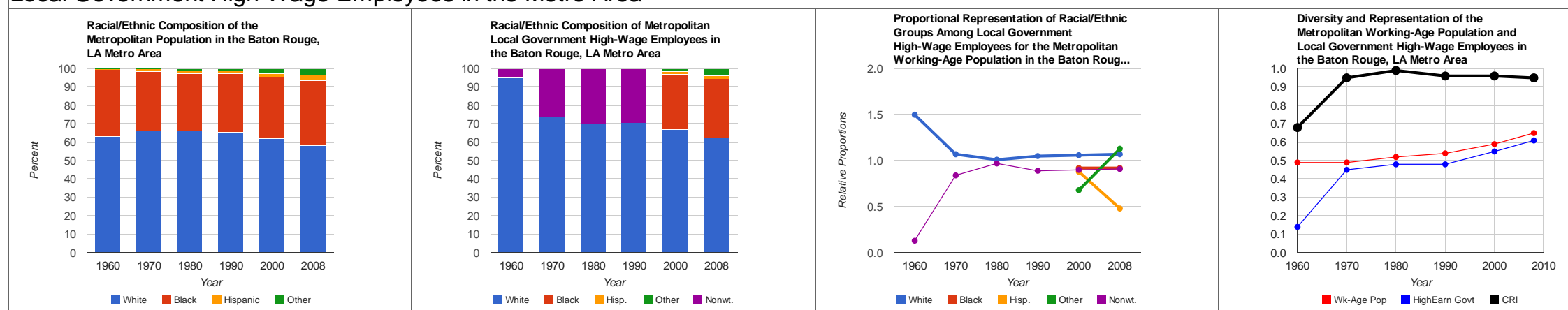

Local Government High-Wage Employees in the Central City
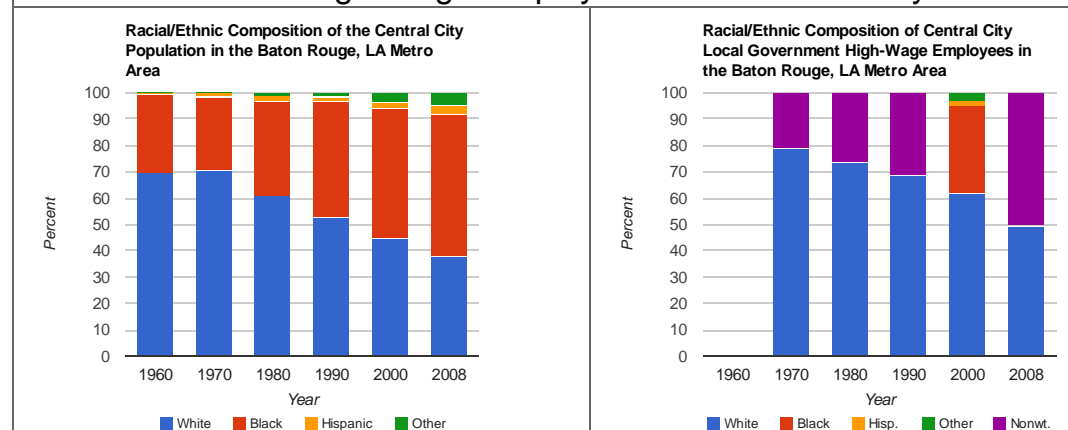
Proportional Representation of Raciall/Ethnic
Groups Among Local Government
High-Wage Employees for the Central City Working-Age Population in the Baton Roug... White Ilack Hear Hispanic nother

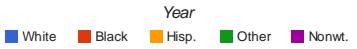
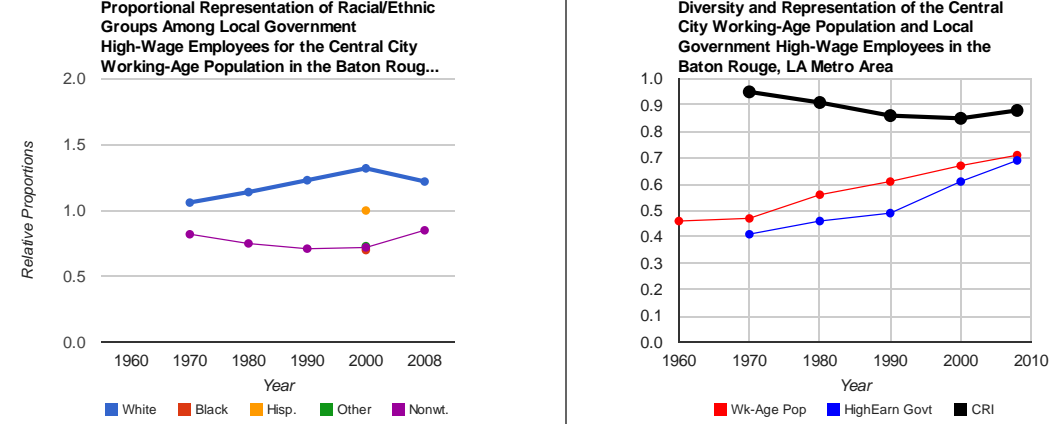
High- and Low-Wage Local Government Employment in the Baton Rouge, LA Metro Area

Local Government Low-Wage Employees in the Metro Area
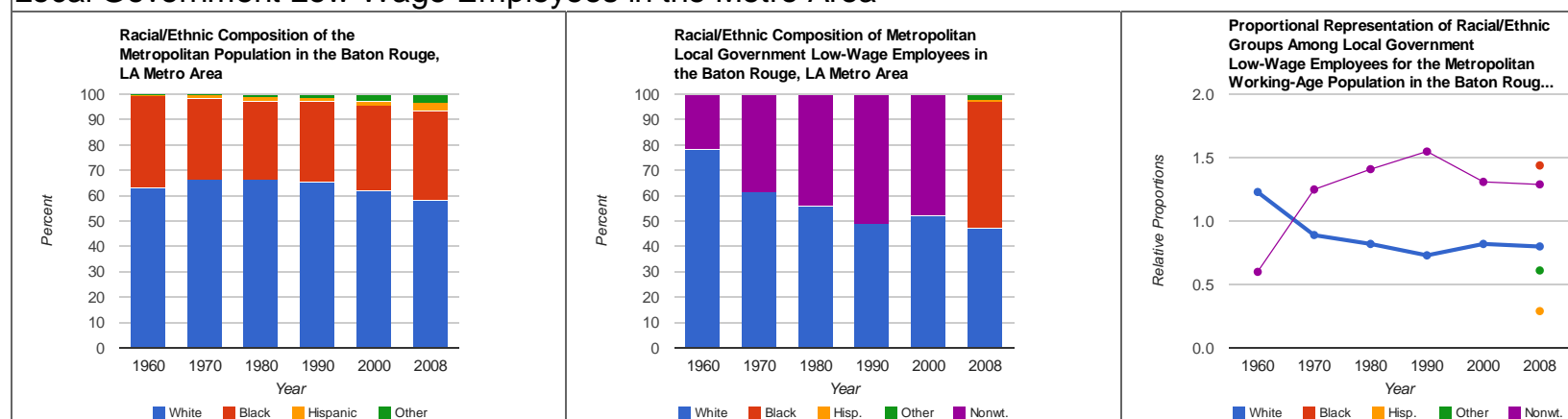
Diversity and Representation of the
Metropolitan Working-Age Population and the Baton Rouge, LA Metro Area

Local Government Low-Wage Employees in the Central City
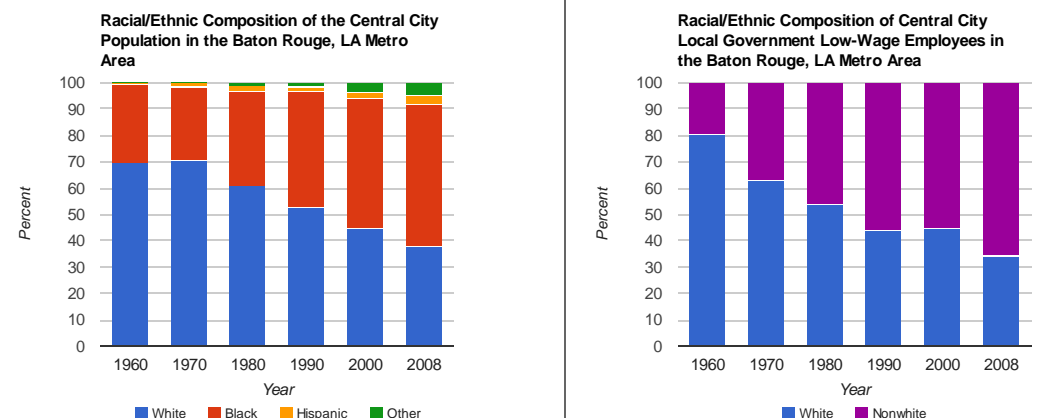

Proportional Representation of Raciall/thn Groups Among Local Government Working-Age Population in the Baton Roug...

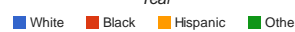
White Nonwhite $^{2}$

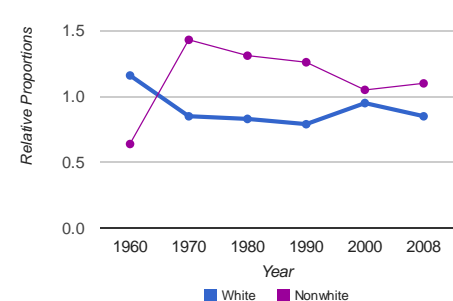

White Nonuthite

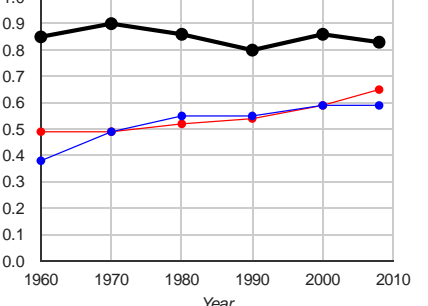

- Wk-Age Pop Lowearn Govt ace

Diversity and Representation of the Central City Working-Age Population and Local
Government Low-Wage Employes in the Government Low-Wage Emplo
Baton Rouge, LA Metro Area

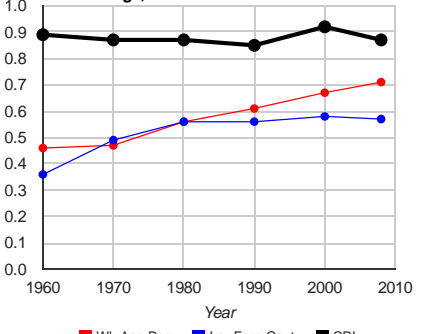

- Wk-Age Pop L LowEarn Govt - CRI 


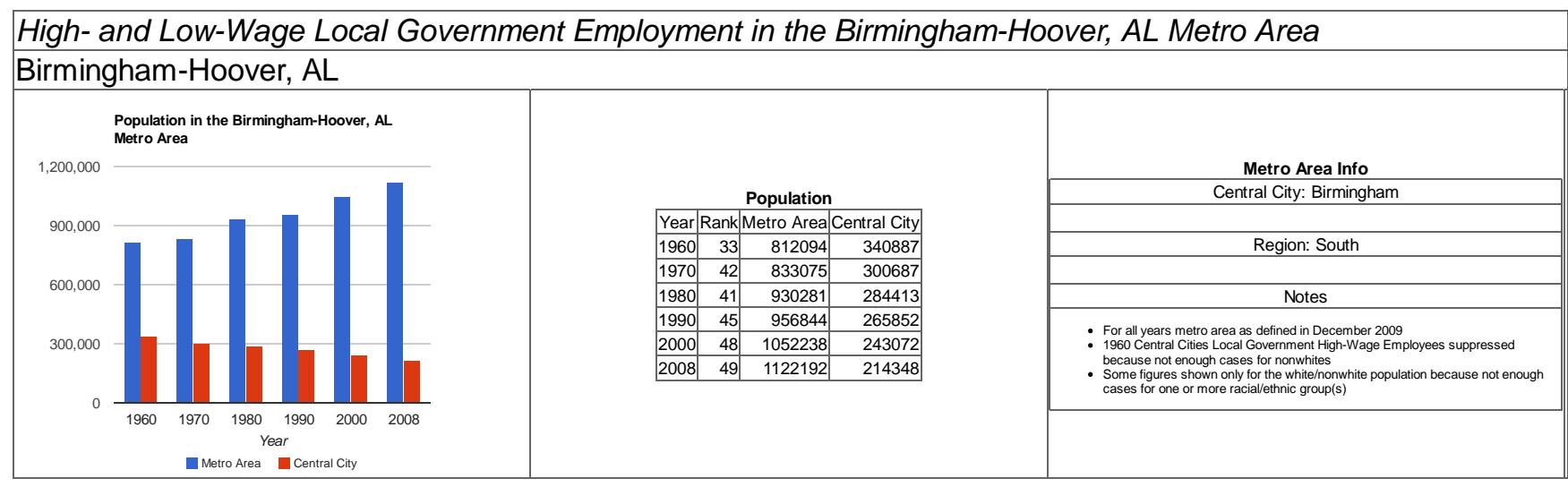


High- and Low-Wage Local Government Employment in the Birmingham-Hoover, AL Metro Area

Local Government High-Wage Employees in the Metro Area
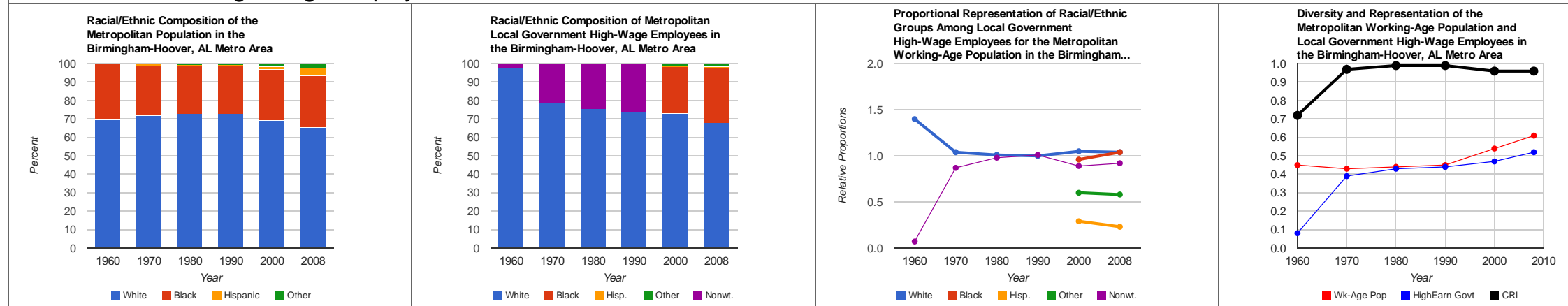

Local Government High-Wage Employees in the Central City
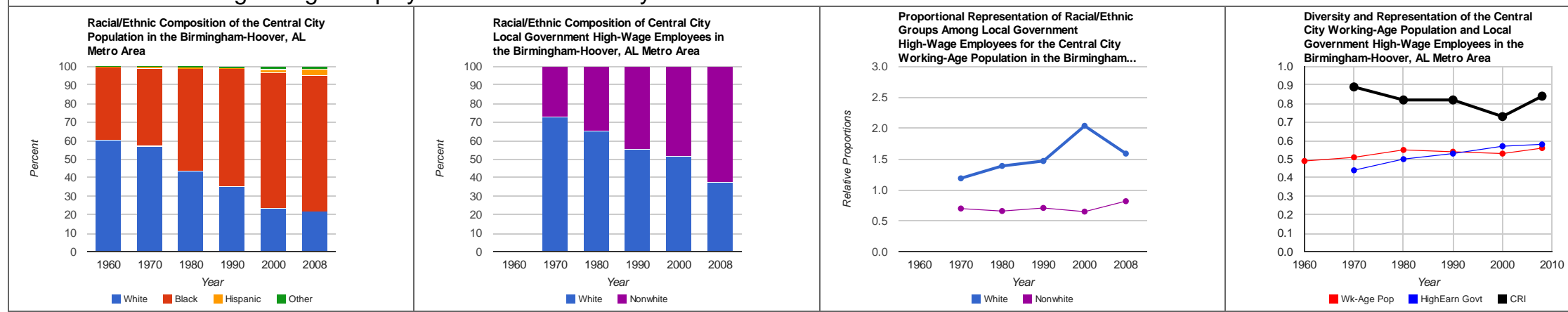
High- and Low-Wage Local Government Employment in the Birmingham-Hoover, AL Metro Area

Local Government Low-Wage Employees in the Metro Area
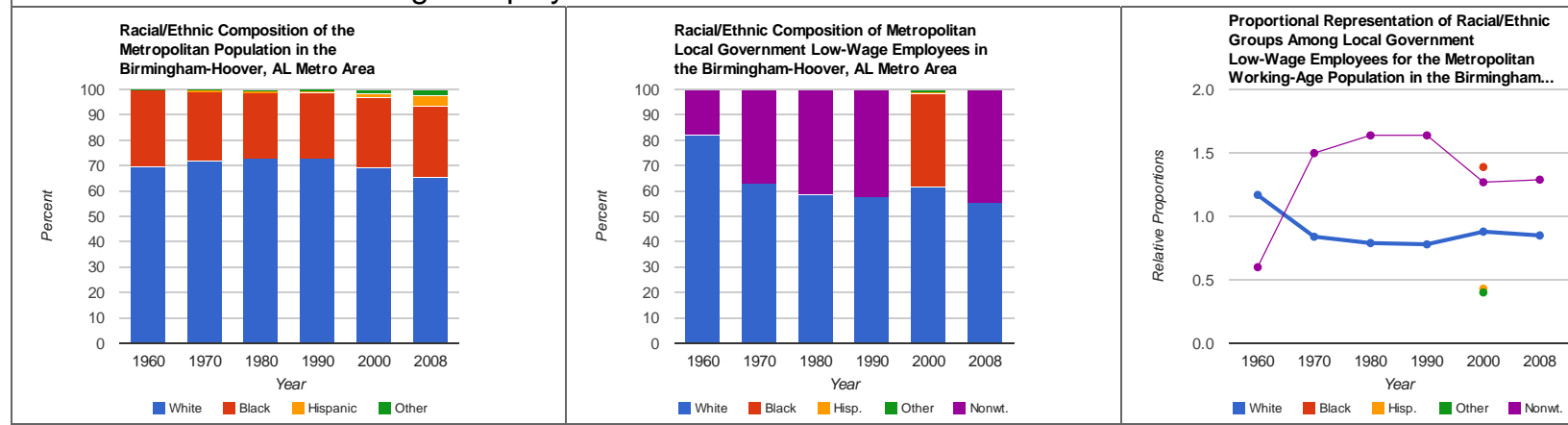

Diversity and Representation of the
Metropolitan Working-Age Population and

the Birmingham-Hoover, AL Metro Area

White Black Hispanic

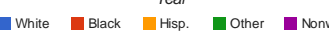

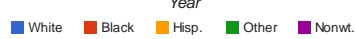

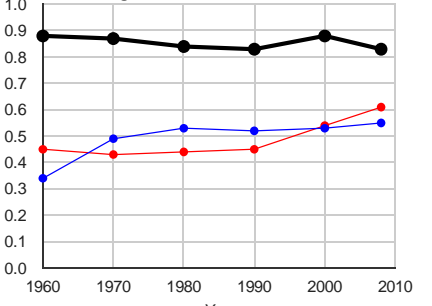

-Wk-Age Pop LowEarn Govt acR

Local Government Low-Wage Employees in the Central City

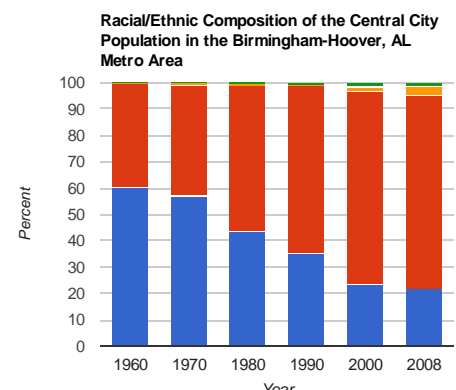

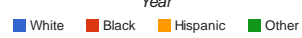

Raciall/Ethnic Composition of Central City

the Birmingham-Hover,

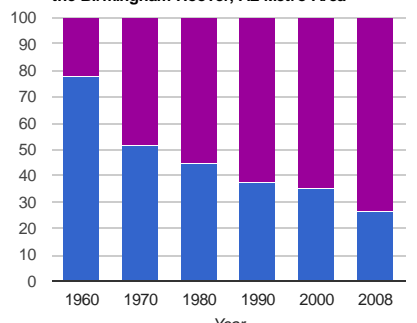

- White ${ }_{\text {Nenwhite }}$ Low-Wage Employees for the Central City
Working-Age Population in the Birmingham

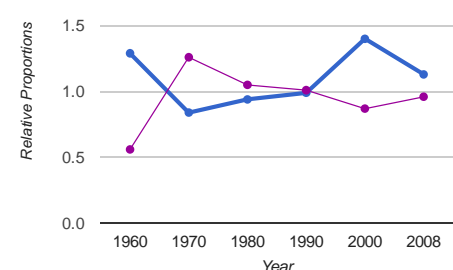

I White $\stackrel{\text { Year }}{\text { Nonwhite }}$
Diversity and Representation of the Central City Working-Age Population and Local
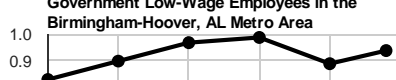

0.8
0.7

0.6
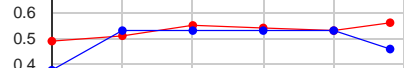

0.2

0.1

$\begin{array}{llllll}0.0 & & & & & \\ 1960 & 1970 & 1980 & 1990 & 2000 & 2010\end{array}$

- Wk-Age Pop Lowearn Govt - 
High- and Low-Wage Local Government Employment in the Boise City-Nampa, ID Metro Area

Boise City-Nampa, ID

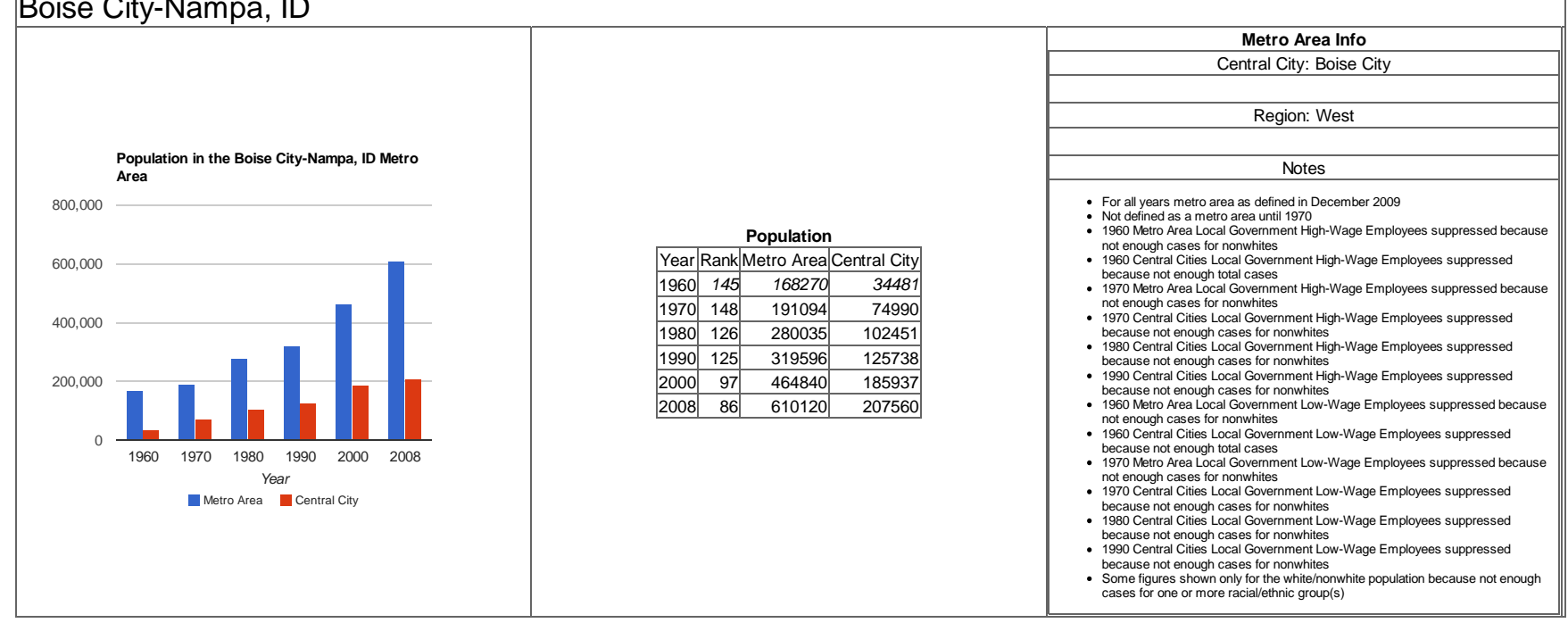


High- and Low-Wage Local Government Employment in the Boise City-Nampa, ID Metro Area

Local Government High-Wage Employees in the Metro Area
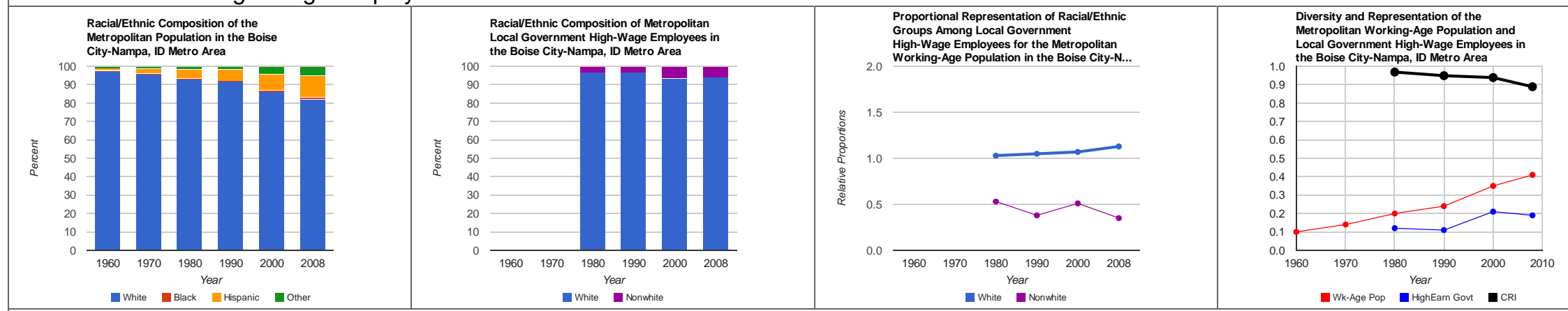

Local Government High-Wage Employees in the Central City
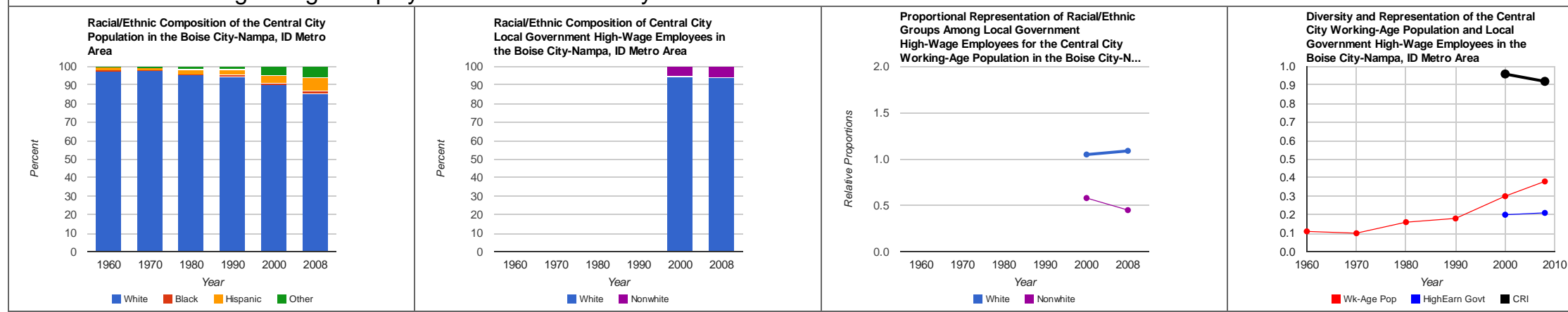
High- and Low-Wage Local Government Employment in the Boise City-Nampa, ID Metro Area

Local Government Low-Wage Employees in the Metro Area
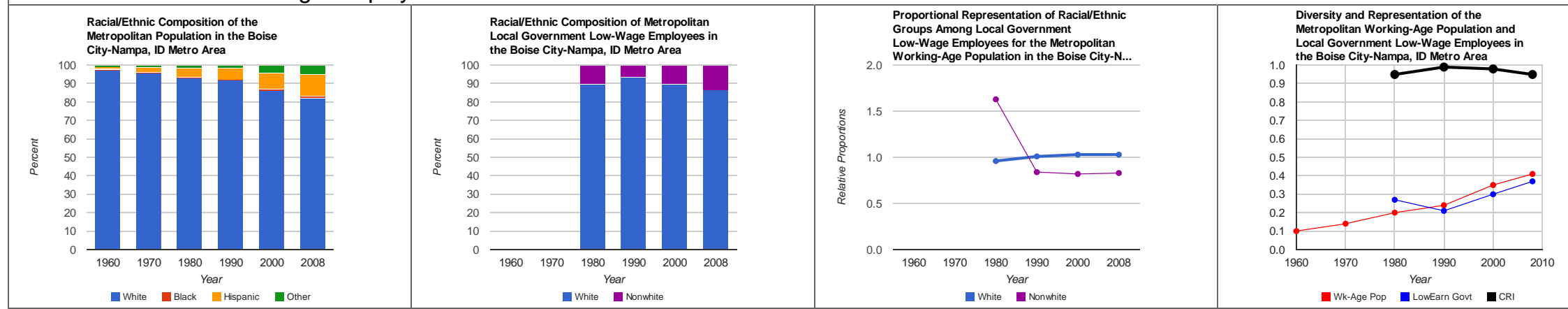

Local Government Low-Wage Employees in the Central City
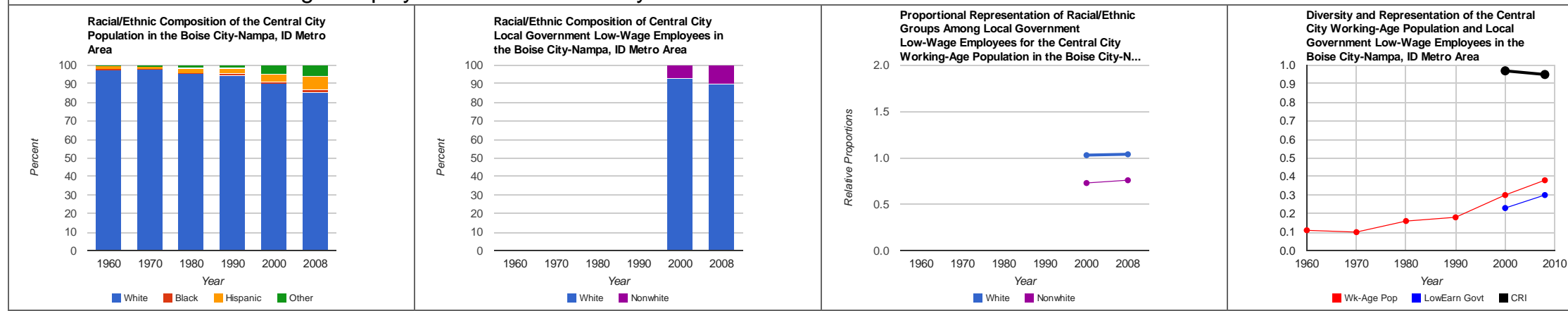
High- and Low-Wage Local Government Employment in the Boston-Cambridge-Quincy, MA-NH Metro Area

Boston-Cambridge-Quincy, MA-NH

\begin{tabular}{|c|c|c|c|c|c|}
\hline \multirow{4}{*}{$\begin{array}{l}6,000,000 \\
4,500,000\end{array}$} & $\begin{array}{l}\text { Population in the Boston-Cambridge-Quincy, } \\
\text { MA-NH Metro Area }\end{array}$ & & & \multirow{3}{*}{ Metro Area Info } \\
\hline & & & & & \\
\hline & & \multicolumn{3}{|c|}{ 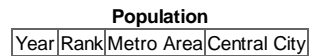 } & \\
\hline & & \begin{tabular}{|l|l|l|l}
1960 & 6 \\
\end{tabular} & 3517174 & 697938 & \\
\hline \multirow{5}{*}{$3,000,000$} & & 1970 & 3918092 & 641053 & Region: Northeast \\
\hline & & \begin{tabular}{l|l}
1980 & 6 \\
\end{tabular} & 3938585 & 562994 & \\
\hline & & \begin{tabular}{l|l}
1990 & 6 \\
\end{tabular} & 4133895 & 574283 & Notes \\
\hline & & 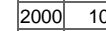 & 4391344 & 589141 & - For all years metro area as defined in December 2009 \\
\hline & & 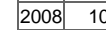 & 4521737 & 609942 & 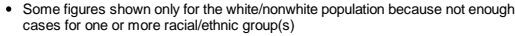 \\
\hline
\end{tabular}


High- and Low-Wage Local Government Employment in the Boston-Cambridge-Quincy, MA-NH Metro Area Local Government High-Wage Employees in the Metro Area
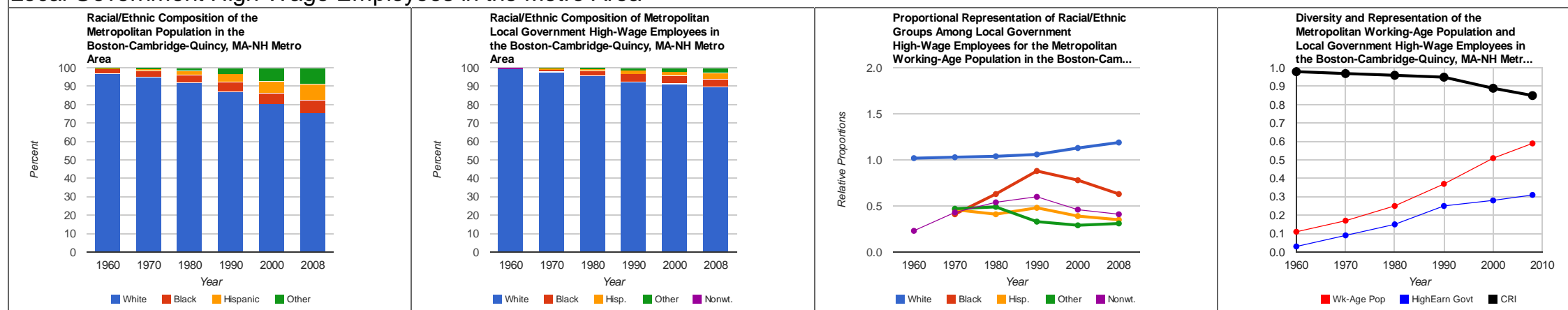

Local Government High-Wage Employees in the Central City
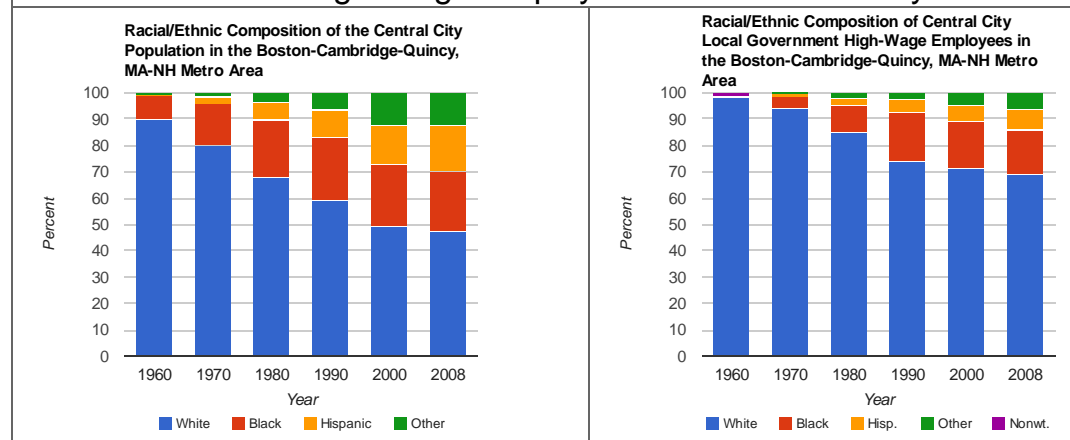
Proportional Representation of Raciall/Ethnic
Groups Among Local Government
High-Wage Employees for the Central City 0 Working-Age Population in the Boston-Cam...

White Elack YHispanic Mother

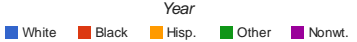

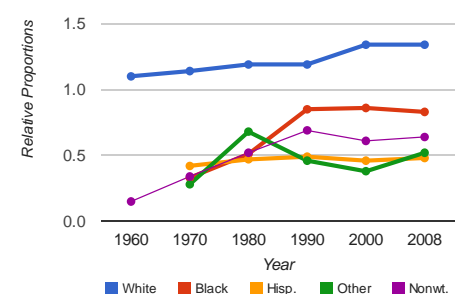
Diversity and Representation of the Central
City Working-Age Population and Local
Government High-Wage Employees in the Government Aigh-Wage Employeses in the
Boston-Cambridge-Quincy, MA-NH Metro Ar.

MA-NH Metro Area

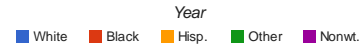

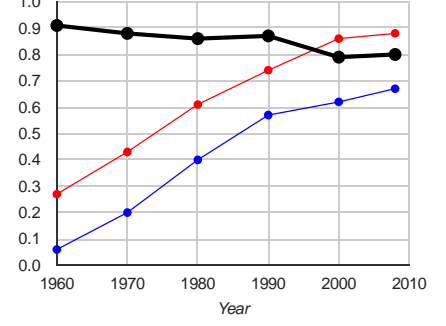

-Wk-Age Pop - HighEarn Govt - CRI 
High- and Low-Wage Local Government Employment in the Boston-Cambridge-Quincy, MA-NH Metro Area Local Government Low-Wage Employees in the Metro Area
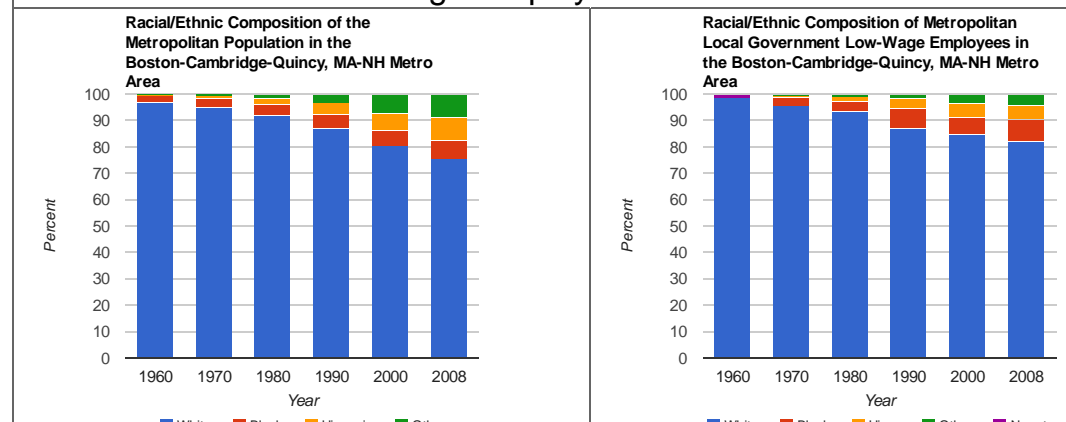

Local Government Low-Wage Employees in the Central City
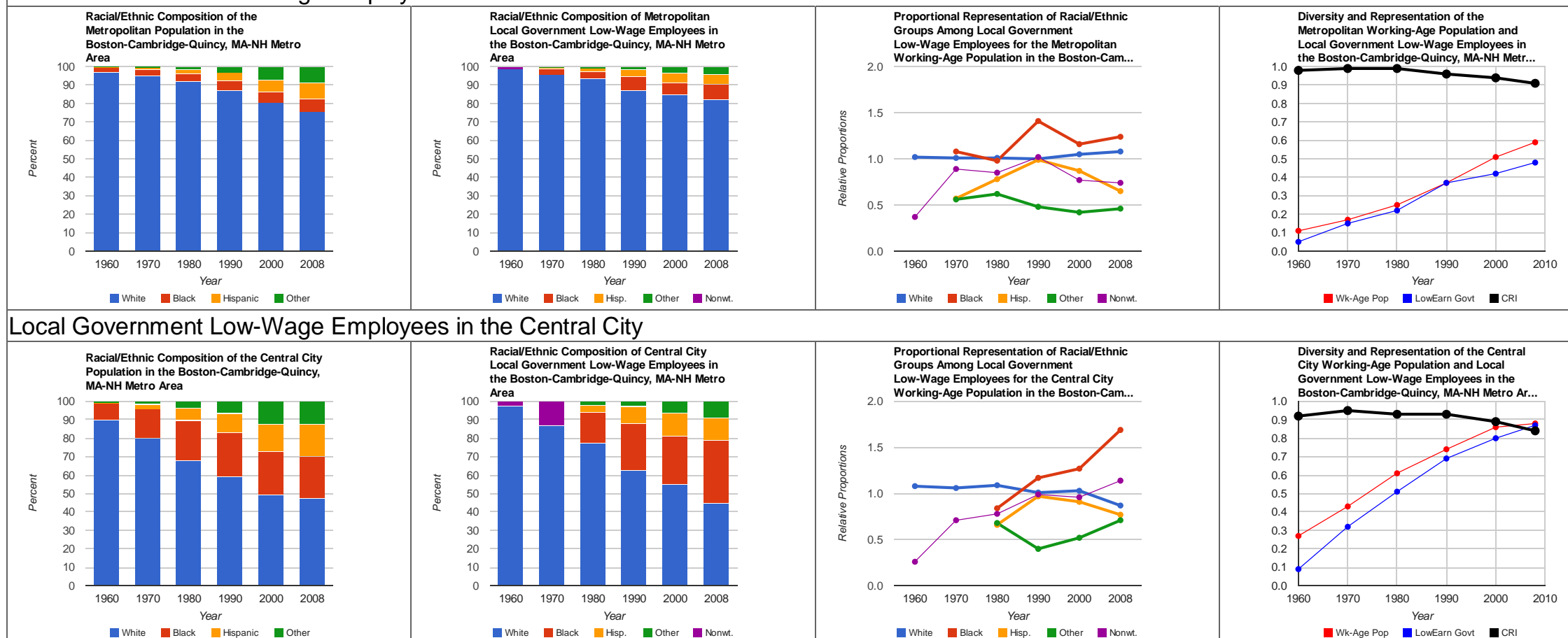

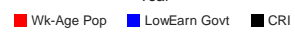

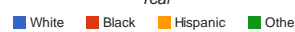

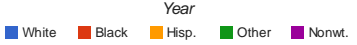

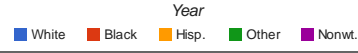

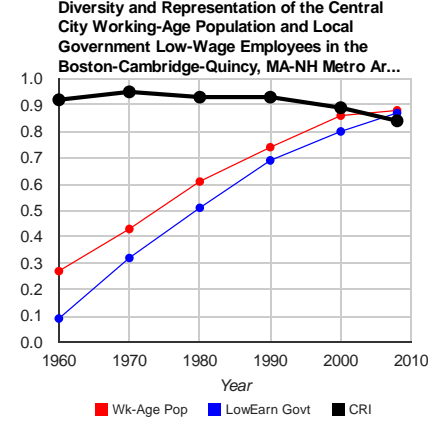




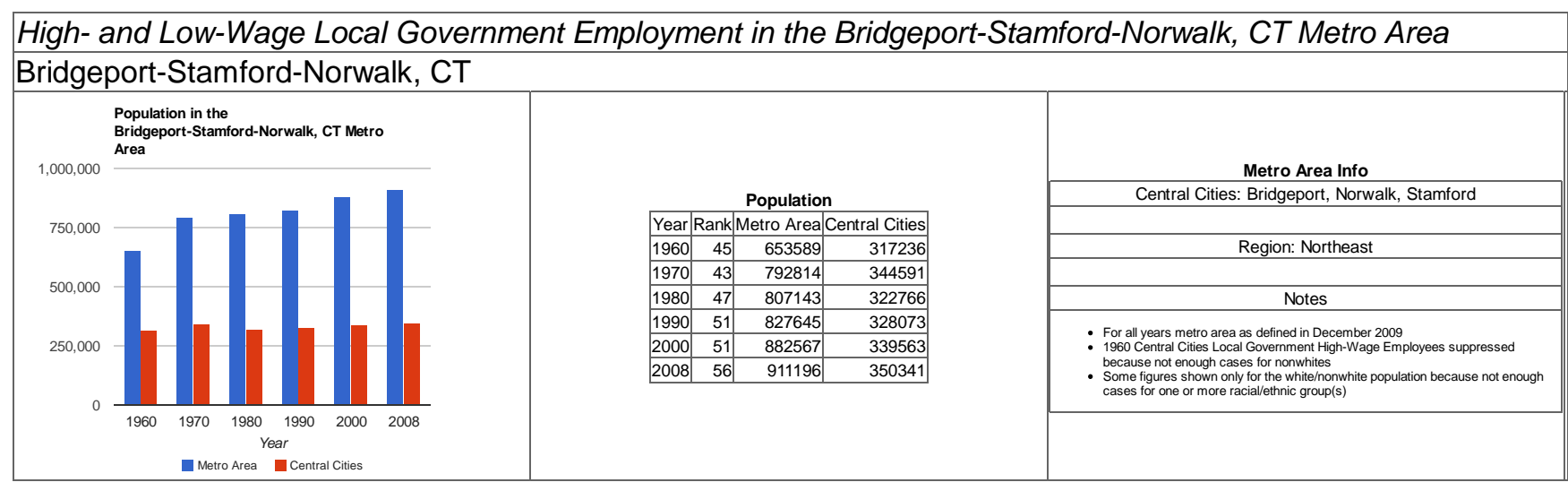


High- and Low-Wage Local Government Employment in the Bridgeport-Stamford-Norwalk, CT Metro Area Local Government High-Wage Employees in the Metro Area
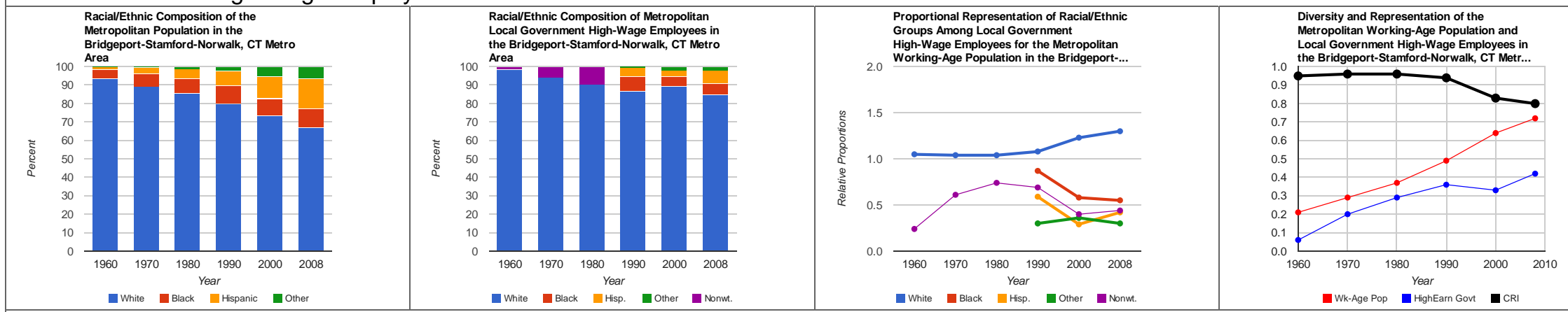

Local Government High-Wage Employees in the Central Cities
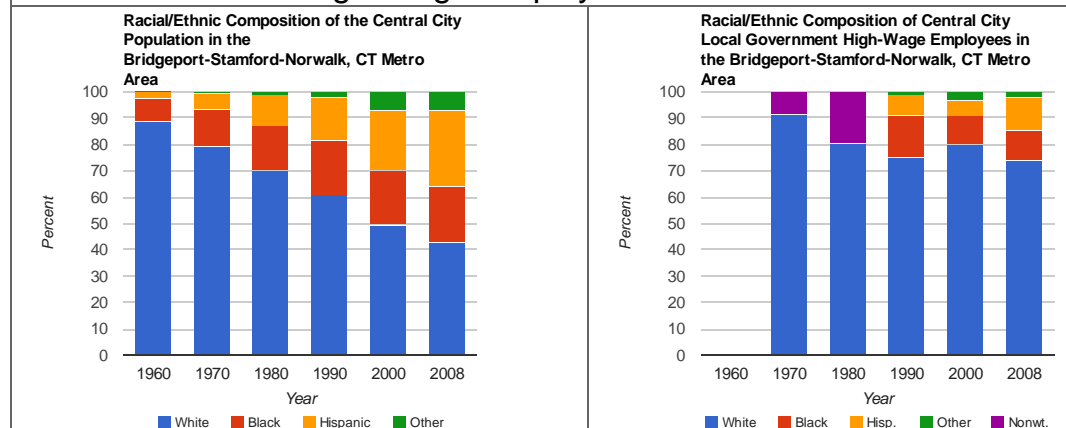
Proportional Representation of Raciall/thnic
Groups Among Local Government
High-Wage Employees for the Central City Groups Among Local Government
Hight-Wage Employees for the Central City
Working-Age Population in the Bridgeport-.

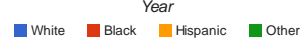

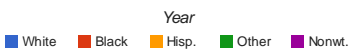

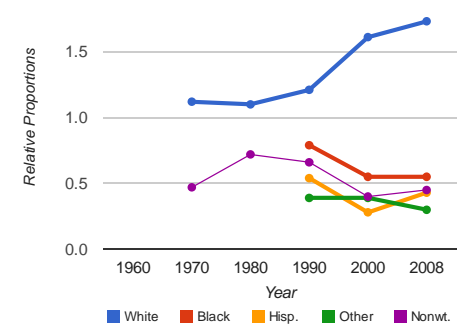
Diversity and Representation of the Central
City Working-Age Population and Local
Government High-Wage Employees in the

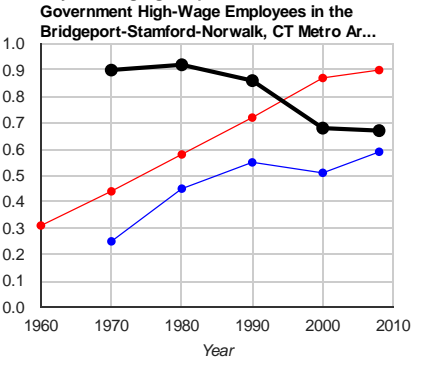

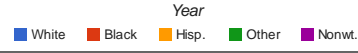

Wk-Age Pop - Mighearn Govt 
High- and Low-Wage Local Government Employment in the Bridgeport-Stamford-Norwalk, CT Metro Area Local Government Low-Wage Employees in the Metro Area
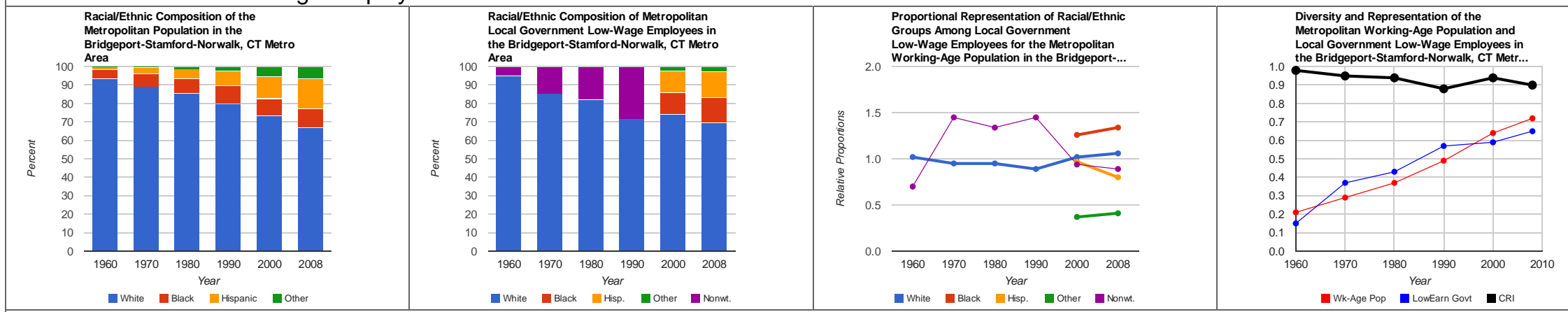

Local Government Low-Wage Employees in the Central Cities
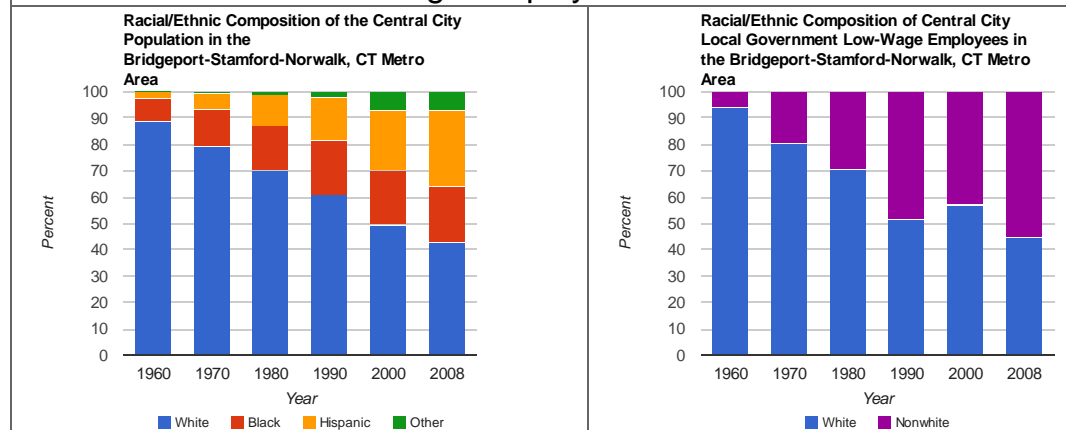

Proportional Representation of Raciall/Ethnic
Groups Among Local Government Working-Age Population in the Bridgeport-...

White Inlack Year Hispanic Eother

white Nonuhite $^{\text {Year }}$
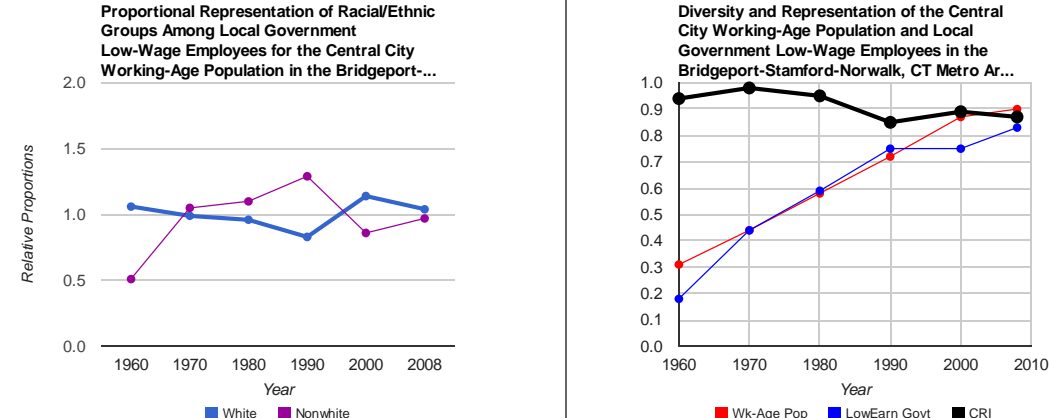

-Wk-Age Pop $\quad$ LowEarn Govt 


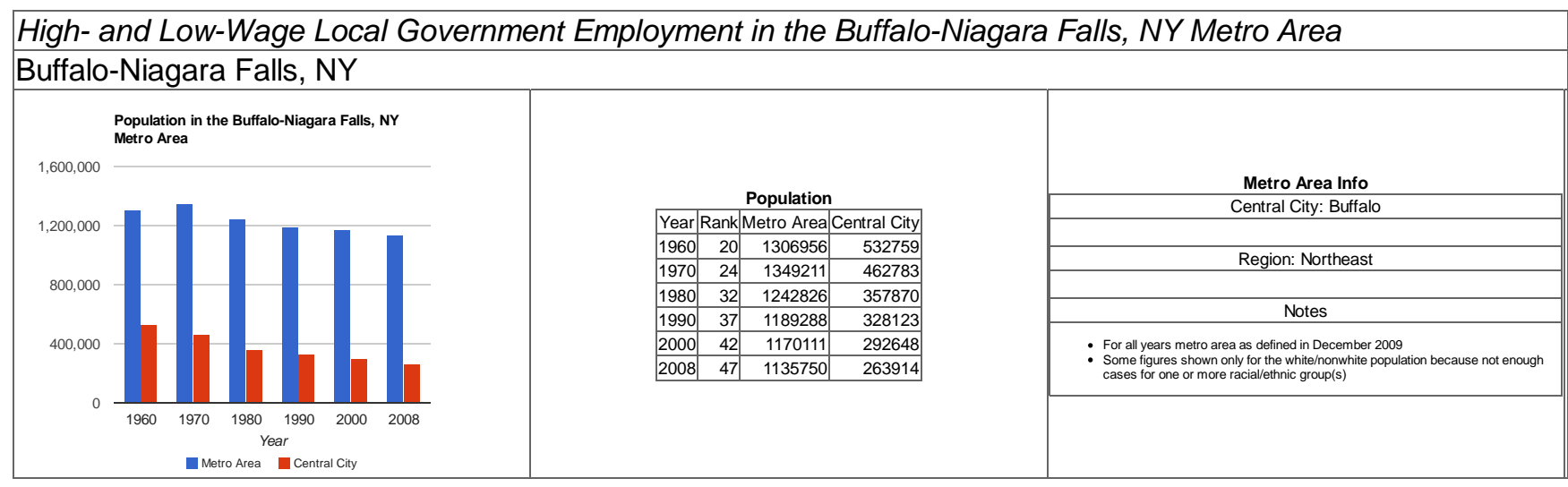


High- and Low-Wage Local Government Employment in the Buffalo-Niagara Falls, NY Metro Area Local Government High-Wage Employees in the Metro Area
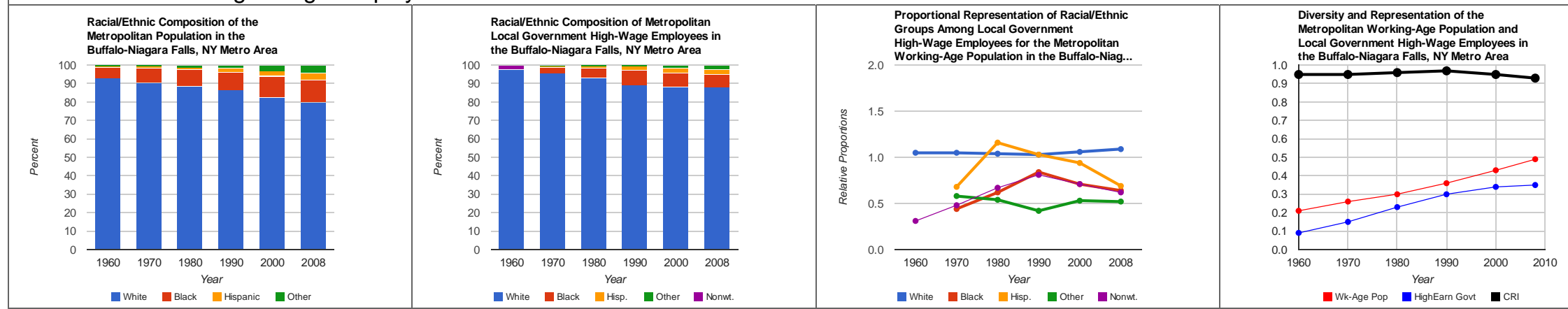

Local Government High-Wage Employees in the Central City
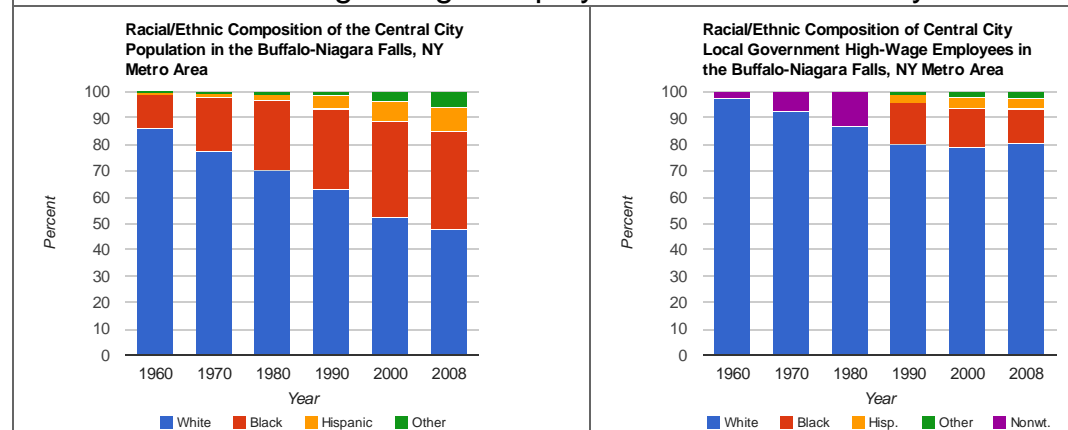

Proportional Representation of Racial//Ethnic Groups Among Local Government
High-Wage Working-Age Population in the Buffalo-Niag... White Elack YHispanic nother

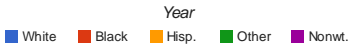

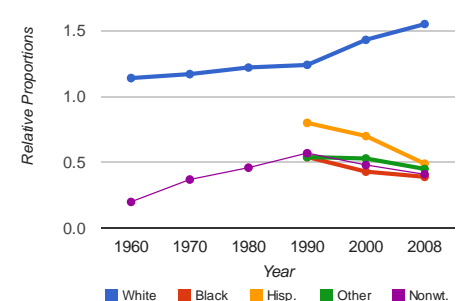
Diversity and Representation of the Central
City Working-Age Population and Local
Government High-Wage Employees in the

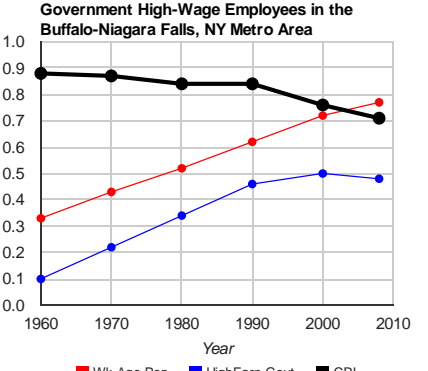

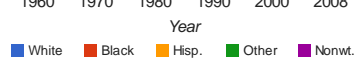

Wk-Age Pop - Highearn Govt 
High- and Low-Wage Local Government Employment in the Buffalo-Niagara Falls, NY Metro Area Local Government Low-Wage Employees in the Metro Area
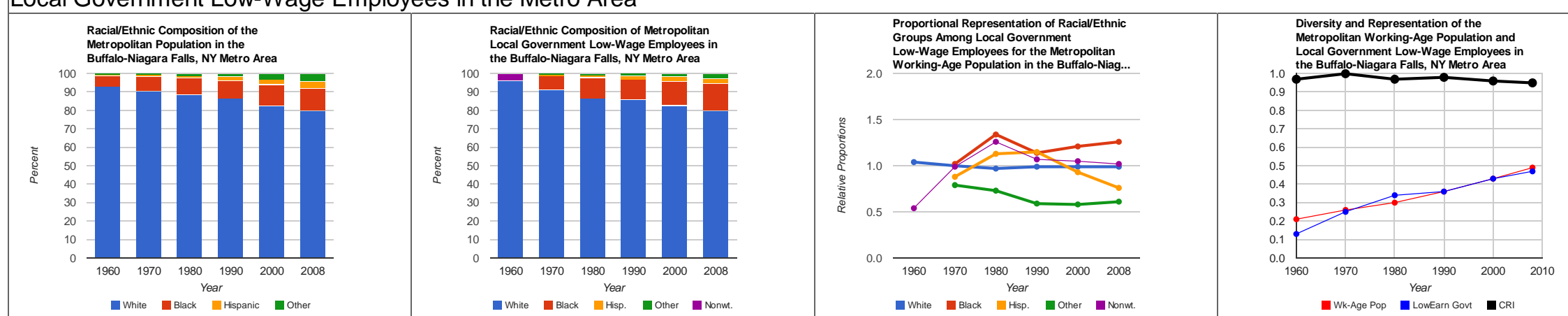

Local Government Low-Wage Employees in the Central City
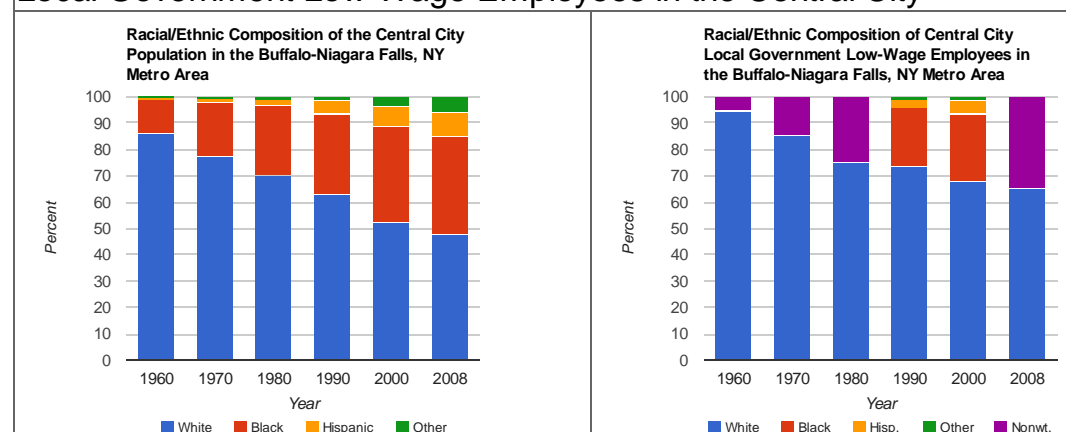
Proportional Representation of Raciall/Ethnic
Groups Among Local Government
Low-Wage Employees for the Central City Working-Age Population in the Buffalo-Niag... White Elack YHispanic Mother

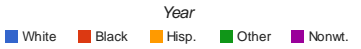
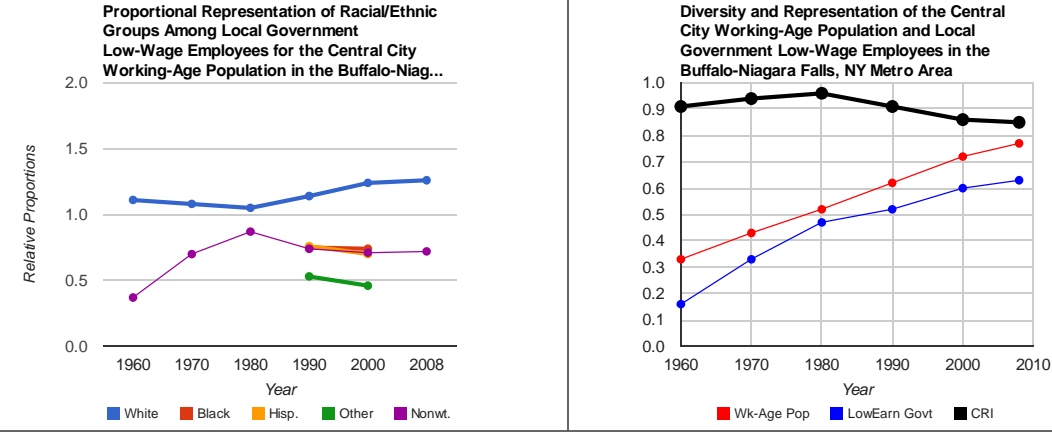


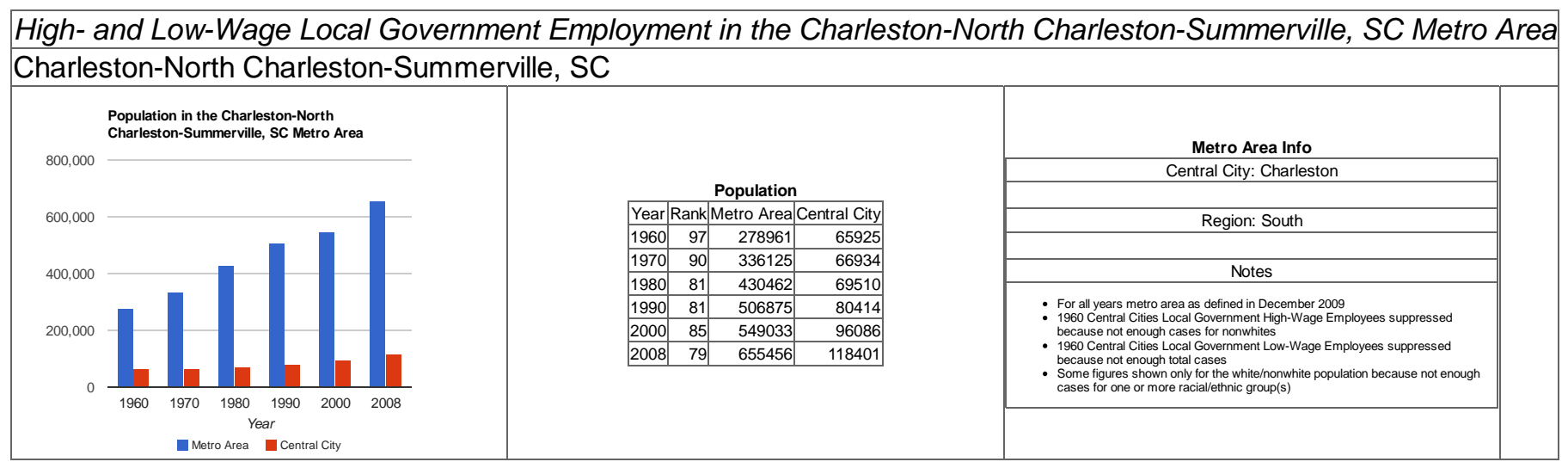


High- and Low-Wage Local Government Employment in the Charleston-North Charleston-Summerville, SC Metro Area Local Government High-Wage Employees in the Metro Area
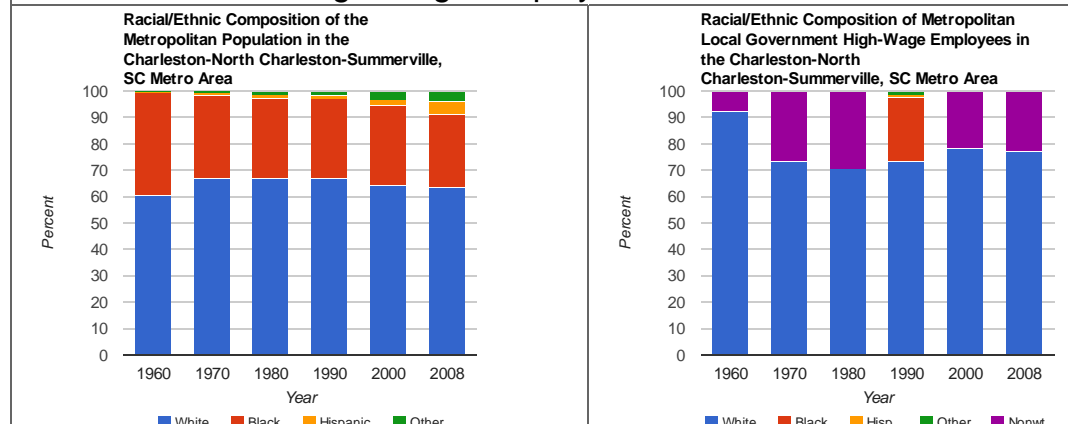

Local Government High-Wage Employees in the Central City
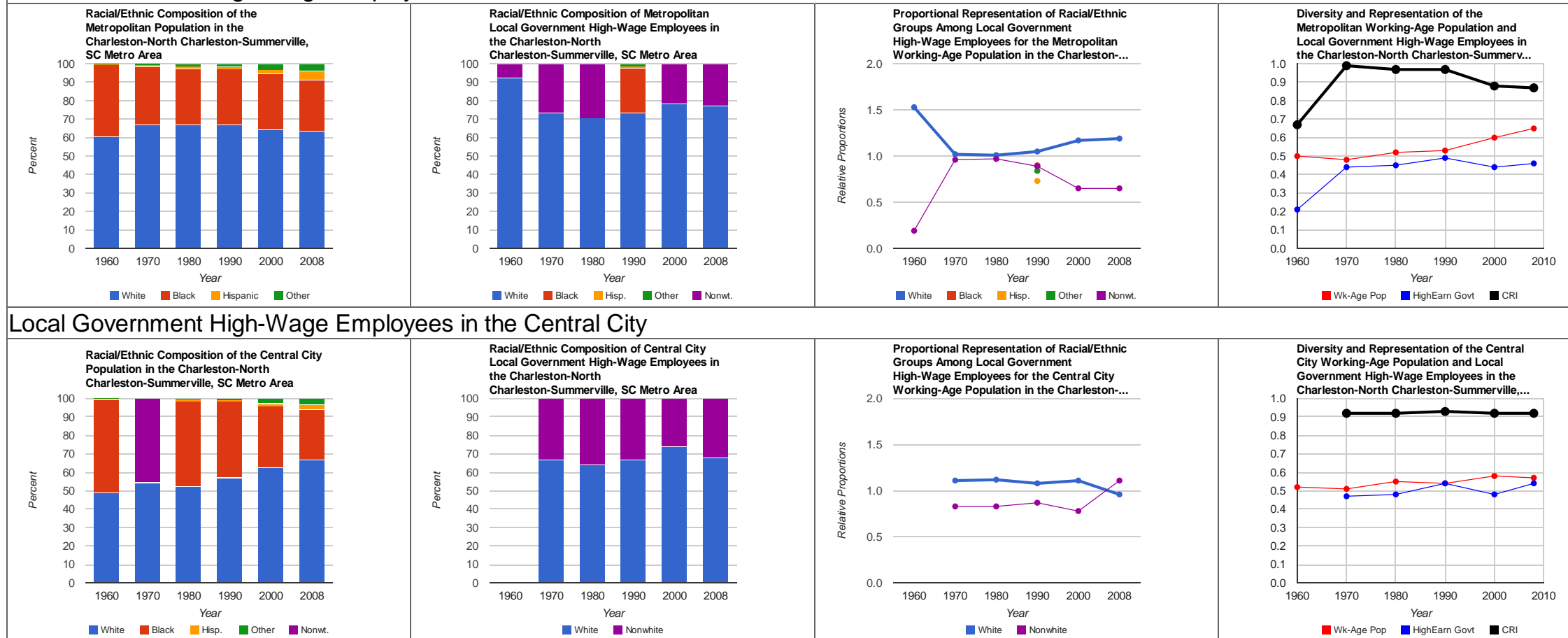

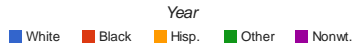

- White $\stackrel{\text { Year }}{\text { Nonwhite }}$

Proportional Representation of Raciall/thnic
Groups Among Local Government
High-Wage Employees for the Central City

High-Wage Employees for the Central city
Working-Age Population in the Charleston-...

Diversity and Representation of the Central City Working-Age Population and Local
Government High-Wage Employees in the

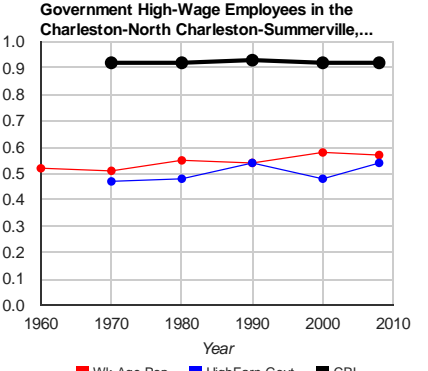

$0 . 0 \longdiv { 1 9 6 0 } \quad 1 9 7 0 \quad 1 9 8 0 \quad 1 9 9 0 \quad 2 0 0 0 \quad 2 0 0 8$ White ${ }_{\text {Nonumite }}^{\text {Year }}$

- Wk-Age Pop - Mighearn Govt 
High- and Low-Wage Local Government Employment in the Charleston-North Charleston-Summerville, SC Metro Area Local Government Low-Wage Employees in the Metro Area
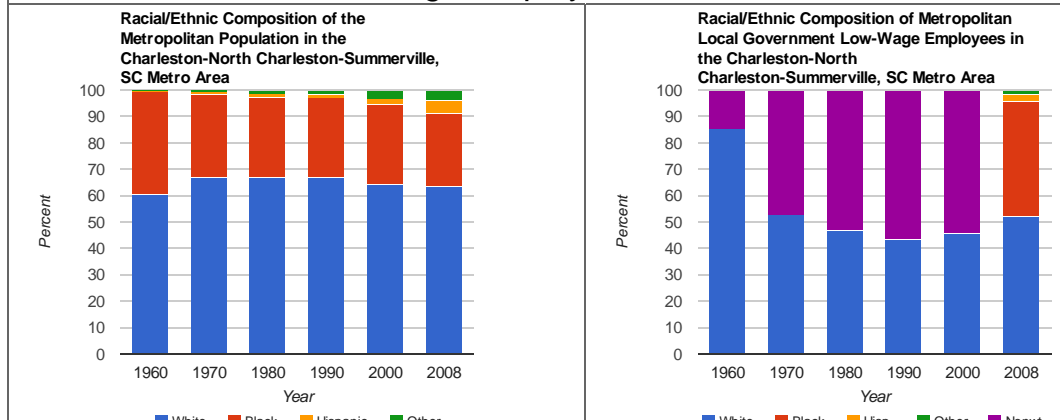

Local Government Low-Wage Employees in the Central City
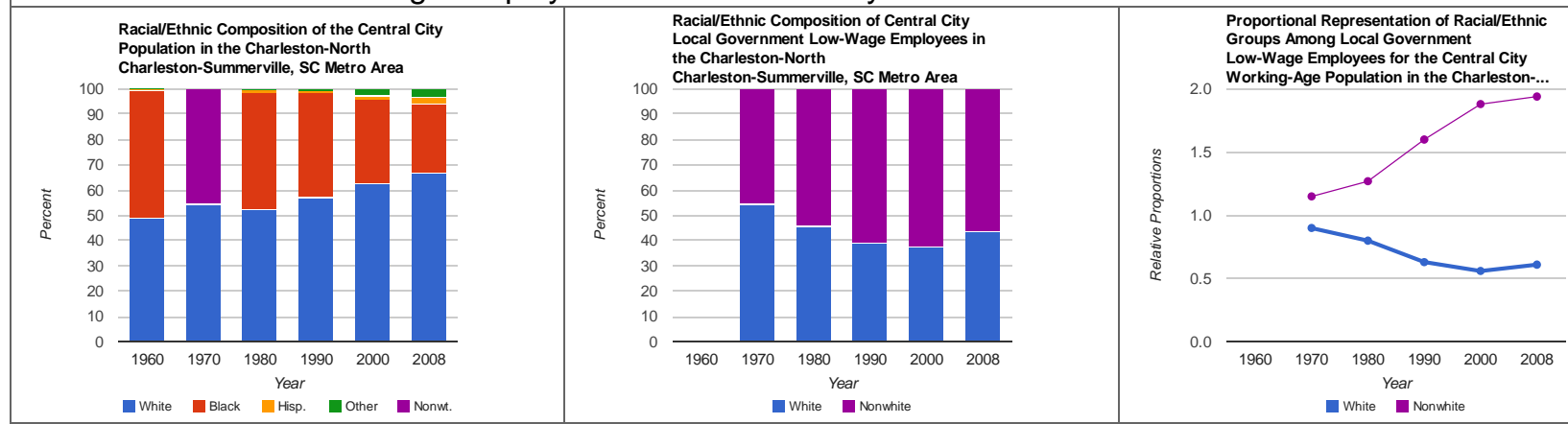

Diversity and Representation of the
MMeropolitan W Working-Agge Population and
Local Government Proportional Representation of RaciallEthnic
Groups Among Local Government Groups Among Local Government
Low-Wage Employees for the Metropolitan
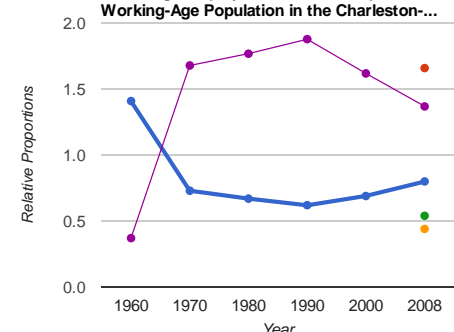

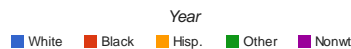

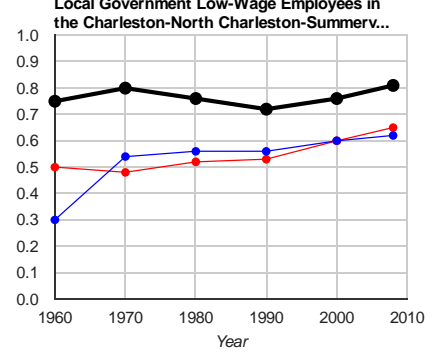

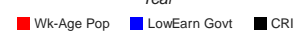

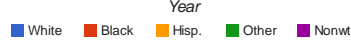
White ${ }_{\text {Nonnwite }}$ White ${ }_{\text {Nonuwhit }}$

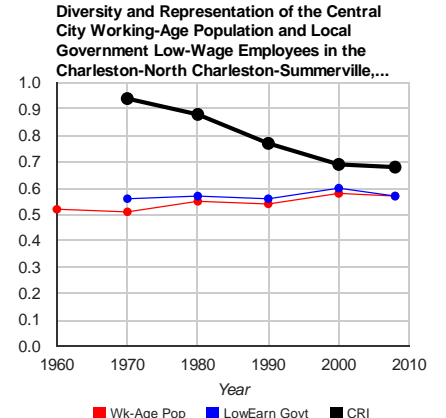

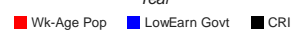




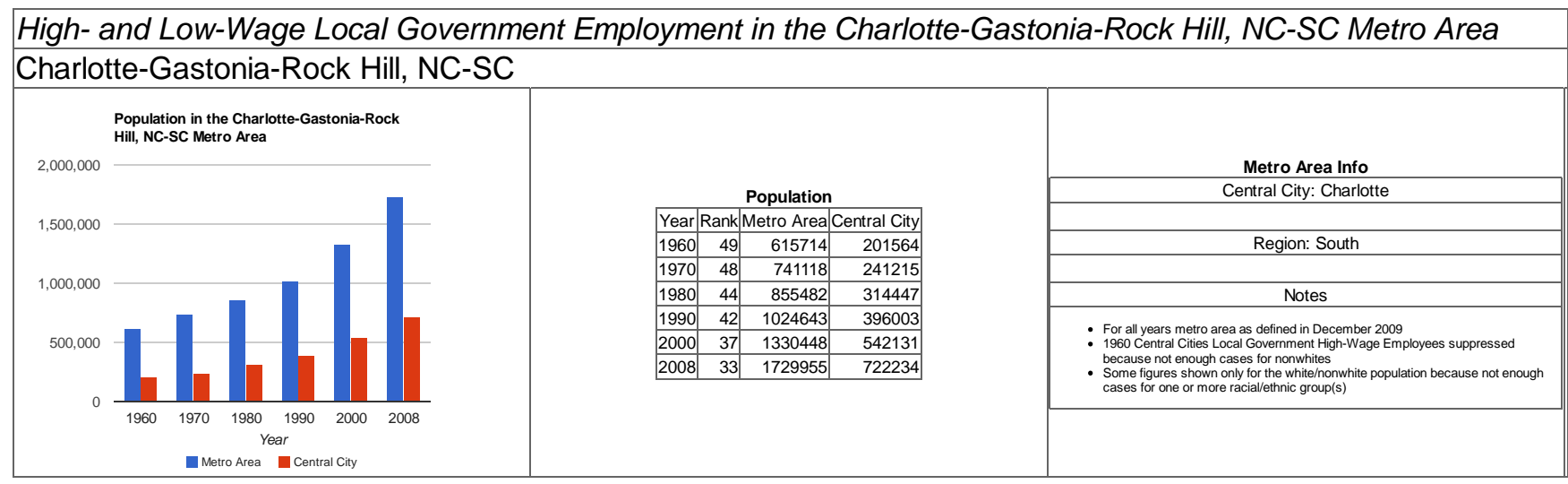


High- and Low-Wage Local Government Employment in the Charlotte-Gastonia-Rock Hill, NC-SC Metro Area Local Government High-Wage Employees in the Metro Area
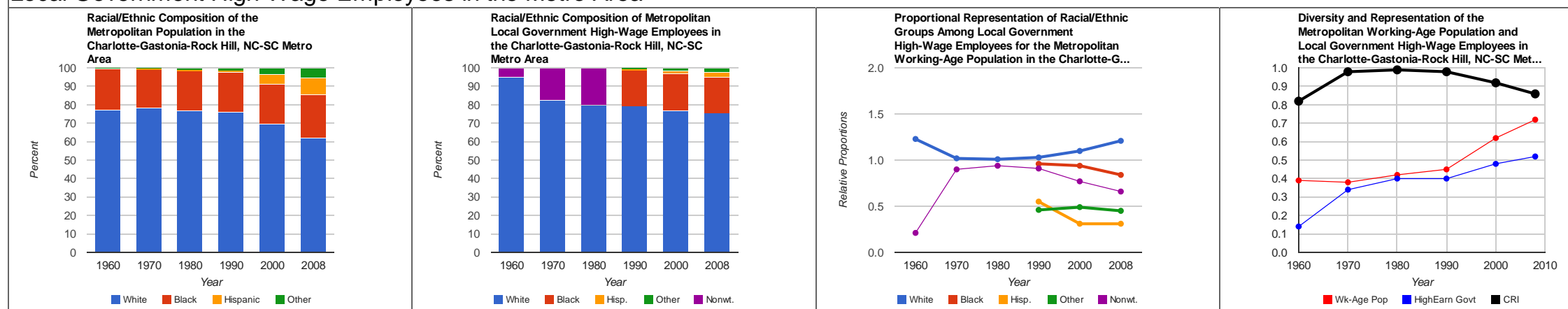

Local Government High-Wage Employees in the Central City
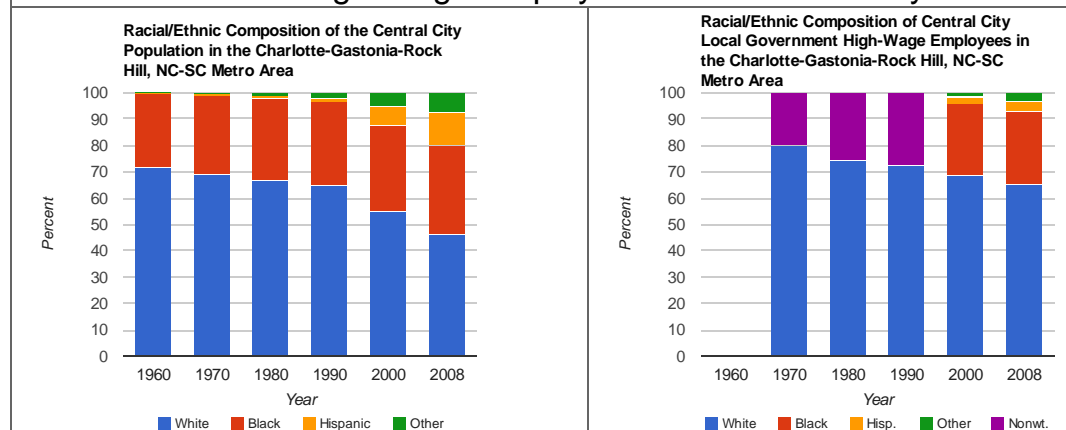
Proportional Representation of Raciall/Ethnic
Groups Among Local Government
High-Wage Employees for the Central City 20 Working-Age Population in the Charlotte-G...

White Elack YHispanic Mother

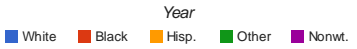

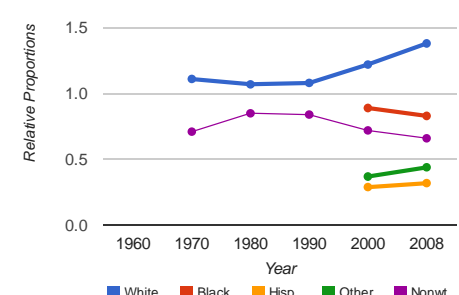
Diversity and Representation of the Central
City Working-Age Population and Local
Government High-Wage Employees in the

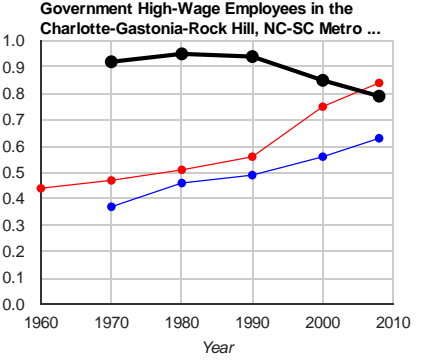

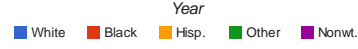

Wk-Age Pop - Mighearn Govt 
High- and Low-Wage Local Government Employment in the Charlotte-Gastonia-Rock Hill, NC-SC Metro Area Local Government Low-Wage Employees in the Metro Area
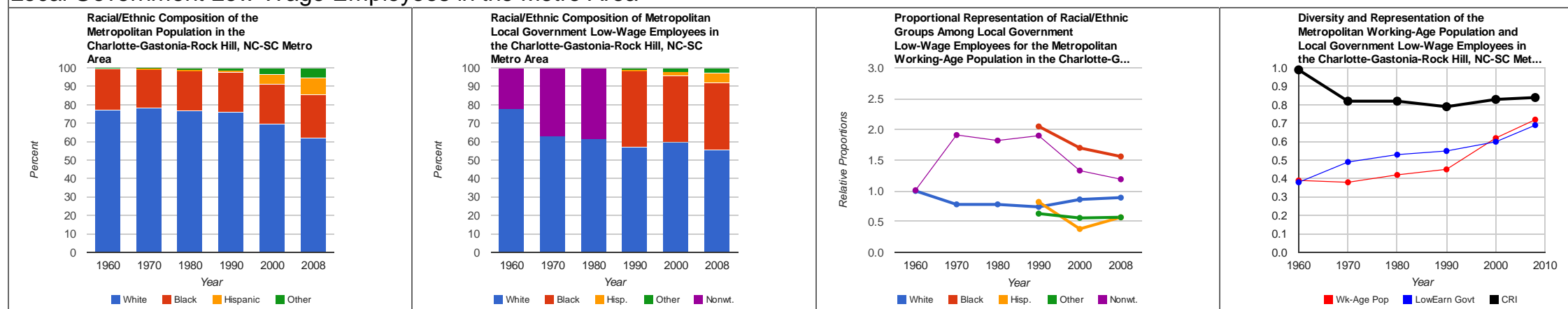

Local Government Low-Wage Employees in the Central City
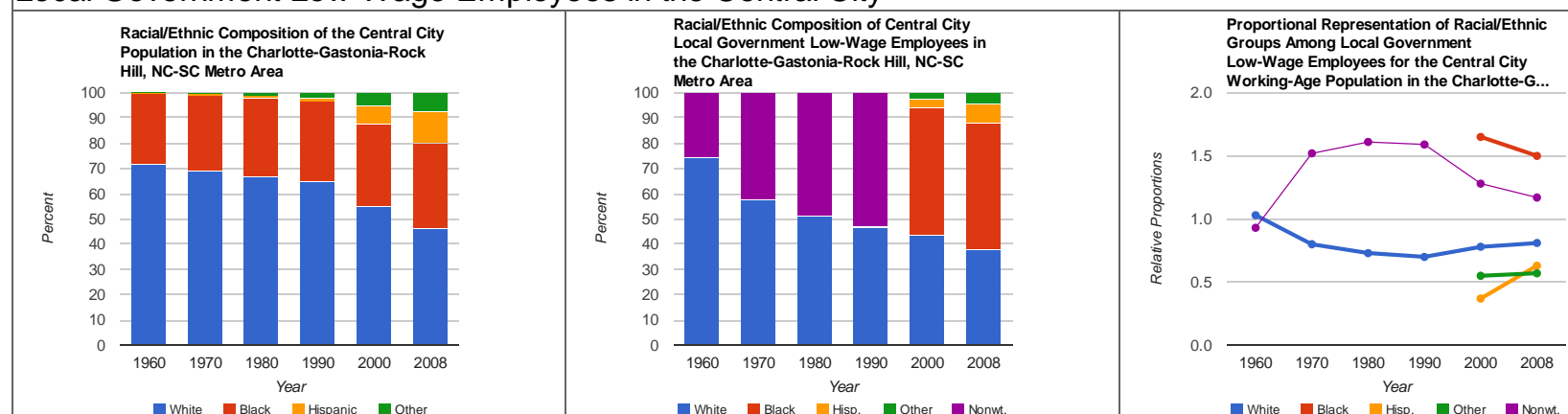

Diversity and Representation of the Central
City Working-Age Population and Local

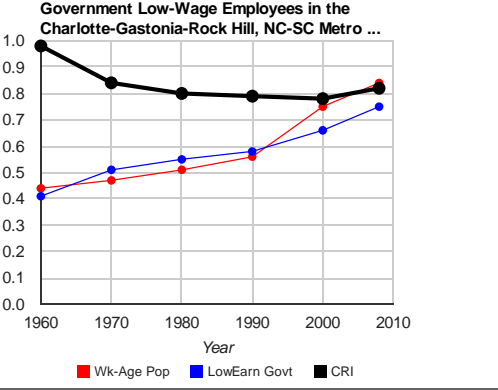

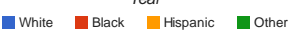

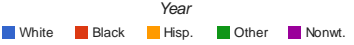

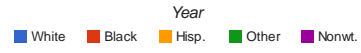

- Wh-Age Pop LowEarn Govt - 
High- and Low-Wage Local Government Employment in the Chattanooga, TN-GA Metro Area

Chattanooga, TN-GA

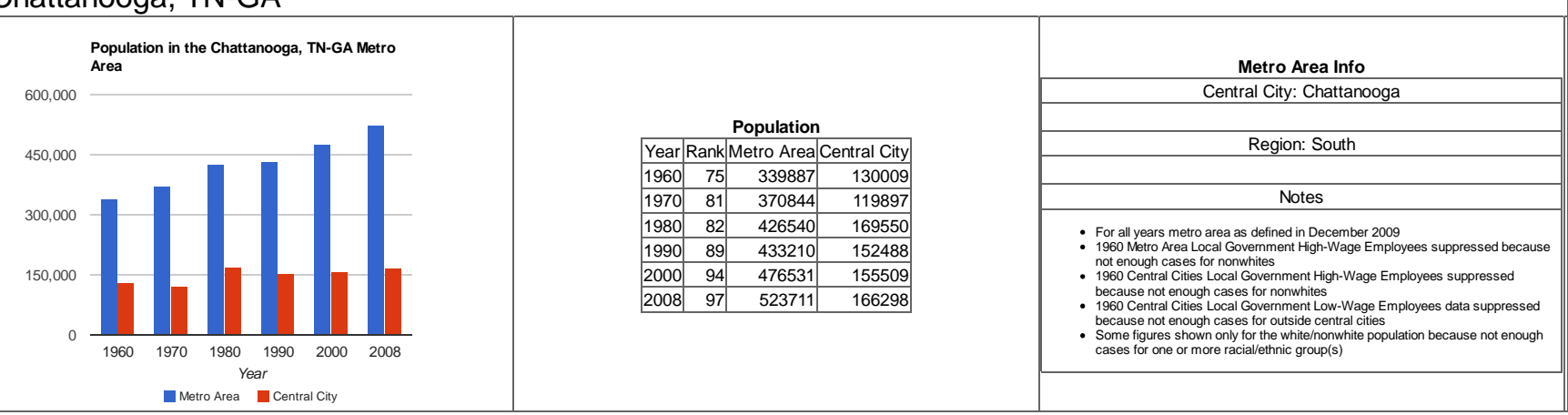


High- and Low-Wage Local Government Employment in the Chattanooga, TN-GA Metro Area

Local Government High-Wage Employees in the Metro Area
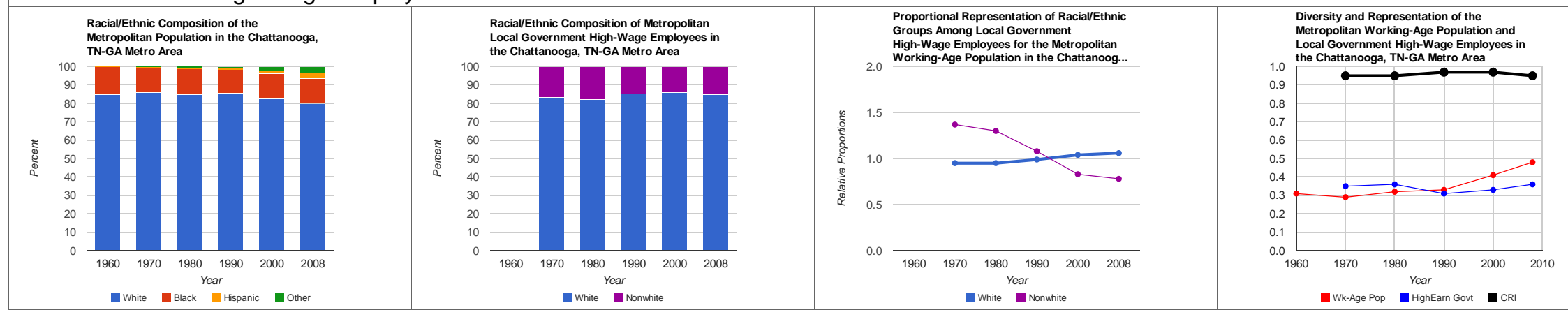

Local Government High-Wage Employees in the Central City
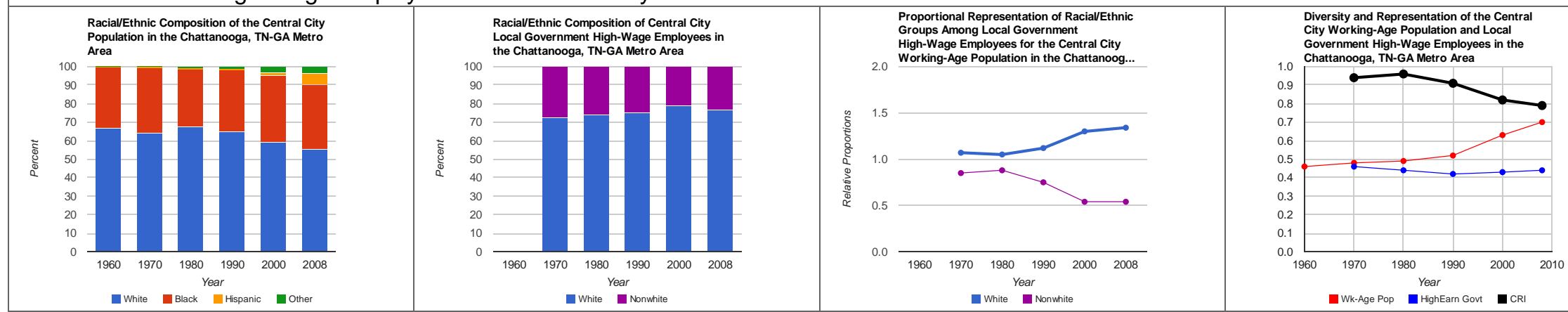
High- and Low-Wage Local Government Employment in the Chattanooga, TN-GA Metro Area

Local Government Low-Wage Employees in the Metro Area
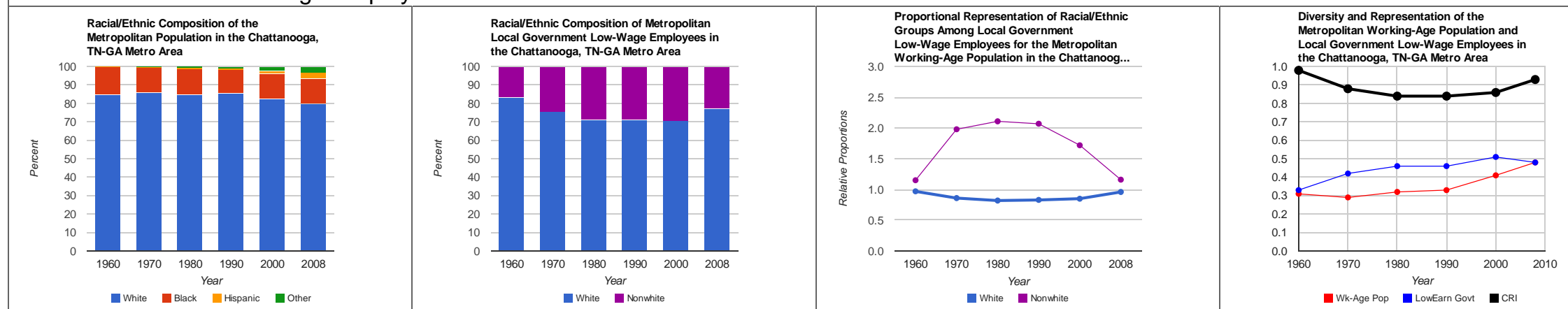

Local Government Low-Wage Employees in the Central City
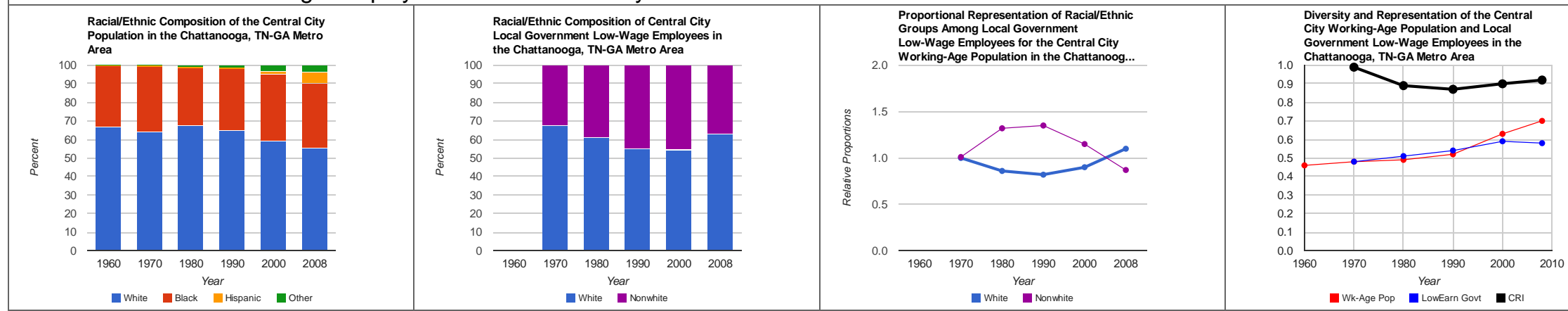


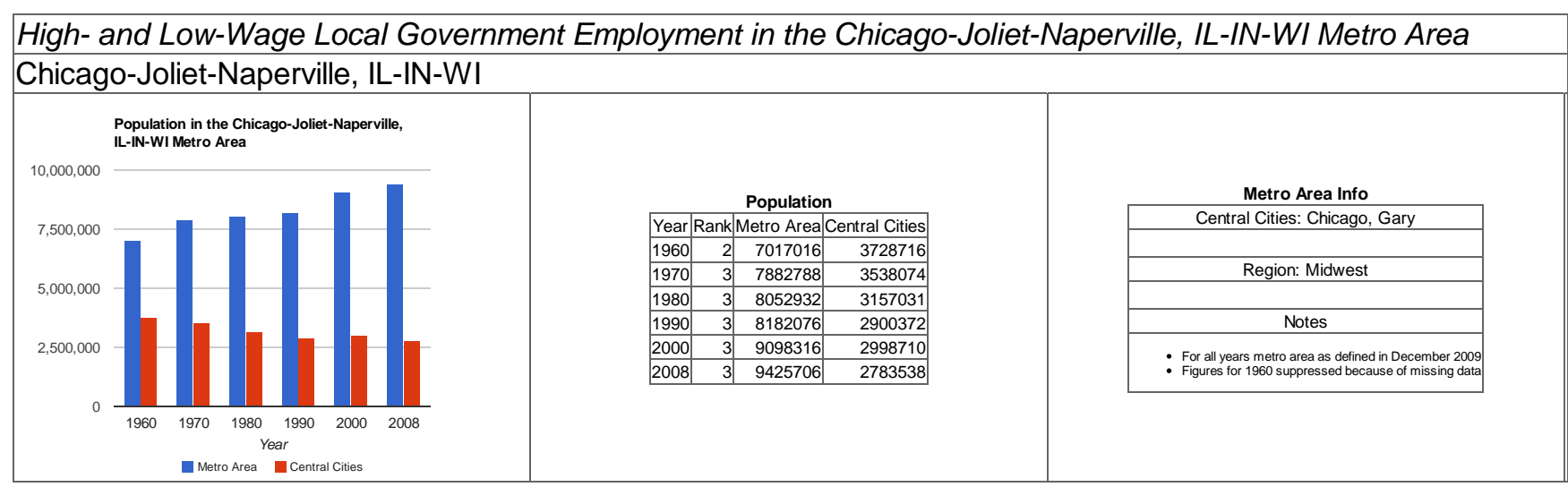


High- and Low-Wage Local Government Employment in the Chicago-Joliet-Naperville, IL-IN-WI Metro Area Local Government High-Wage Employees in the Metro Area
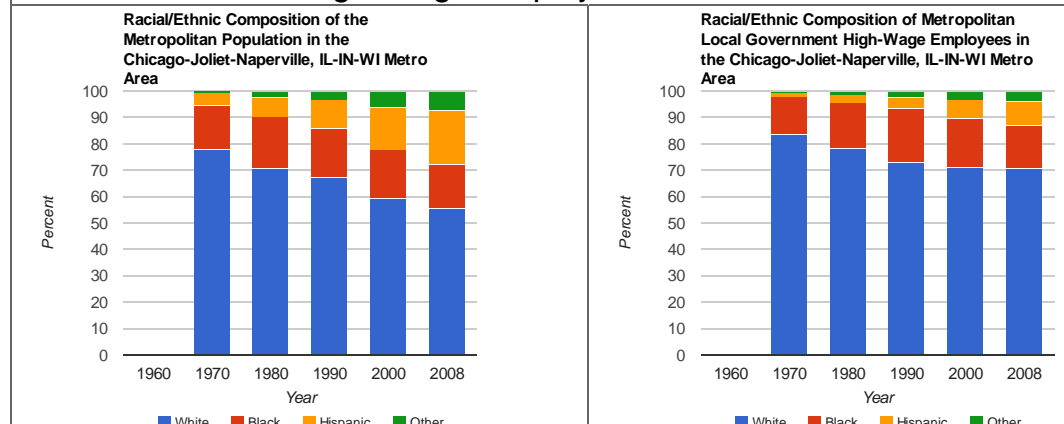

White Beack ${ }_{\text {Hispanic }}^{\text {Yother }}$

Local Government High-Wage Employees in the Central Cities
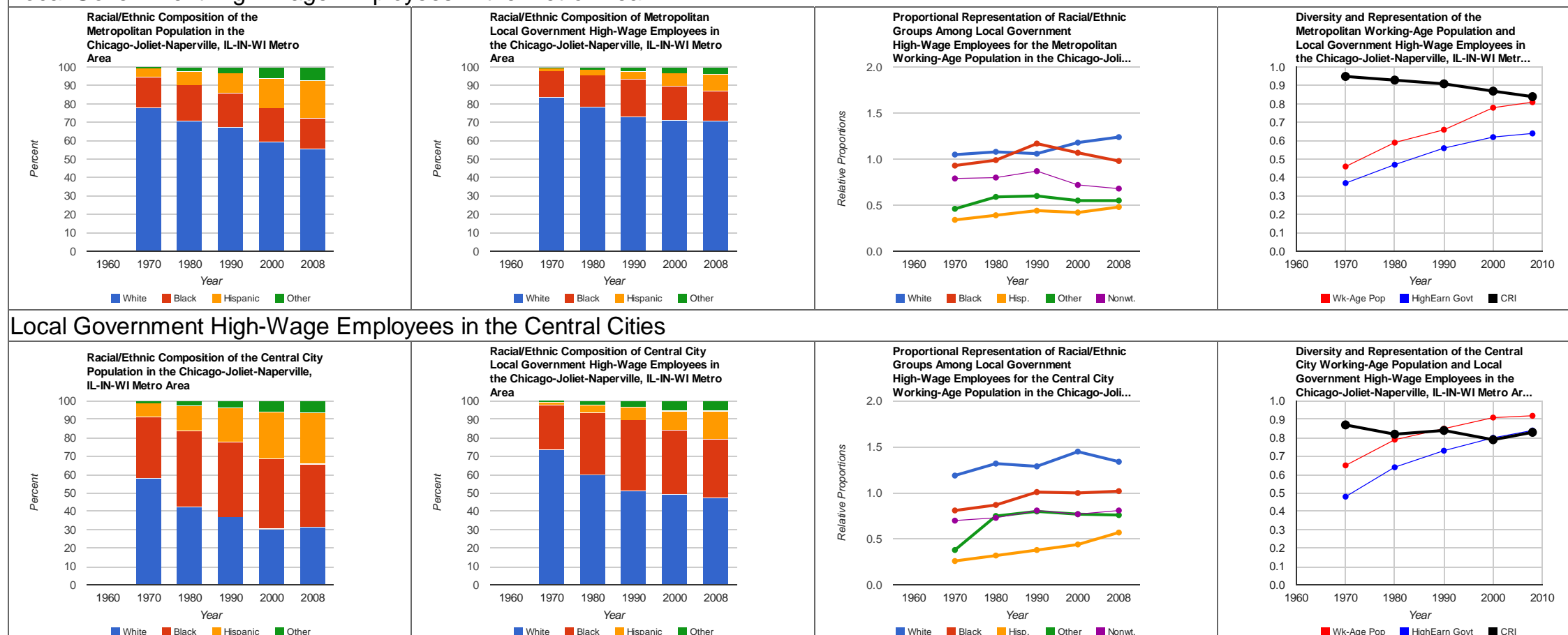

- White Black $\quad$ Hispanic nother

White Mlack Hear Hispanic Mother

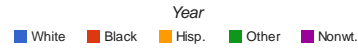

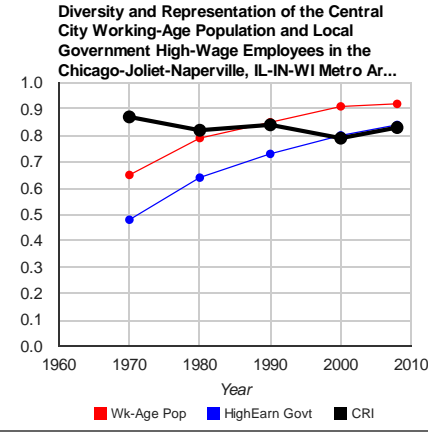


High- and Low-Wage Local Government Employment in the Chicago-Joliet-Naperville, IL-IN-WI Metro Area Local Government Low-Wage Employees in the Metro Area
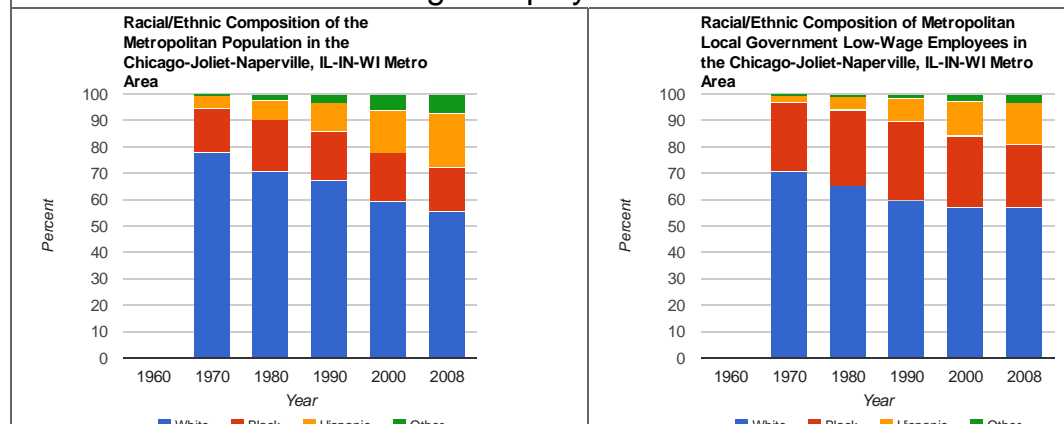

White Elack Year Hispanic Eother

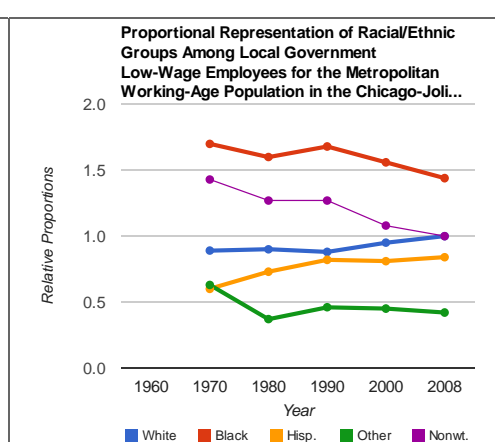

Local Government Low-Wage Employees in the Central Cities
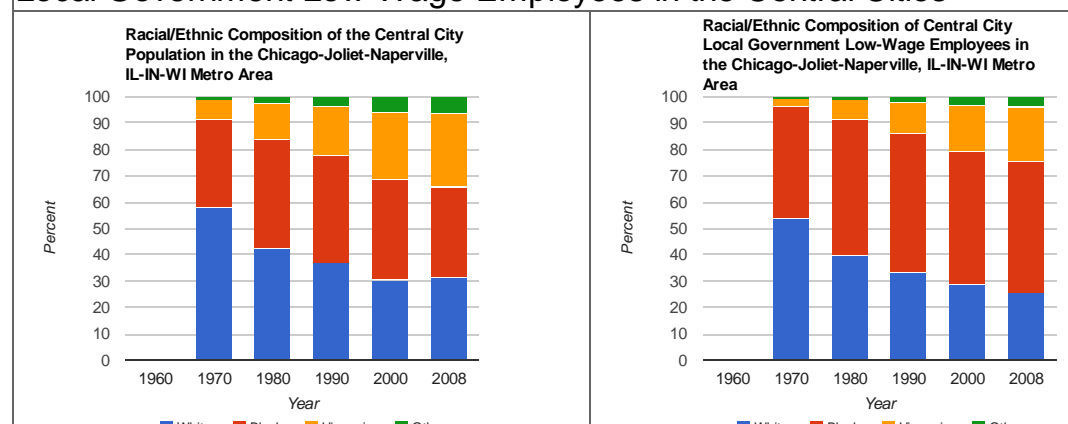
Proportional Representation of RaciallEthnic
Groups Among Local Government
LOw-Wage Employees for the Central City Groups Among Local Government
Low-Wage Employes for the Central City
2.0 Working-Age Population in the Chicago-Joli... White Inlack Yur Hispanic Eother White Elack Year

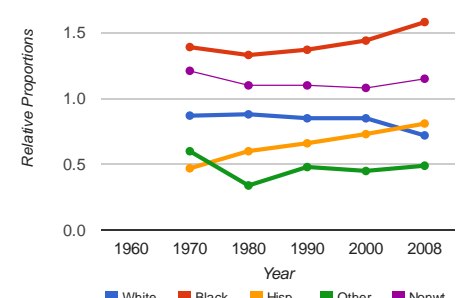
Diversity and Representation of the Central
City Working-Age Population and Local
Government Low-Wage Employees in the

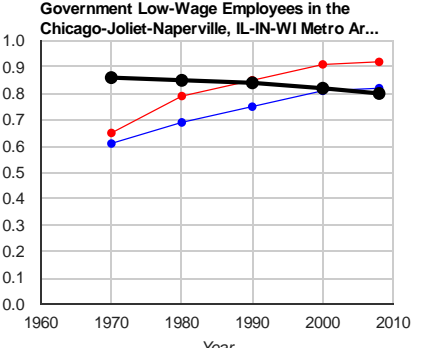

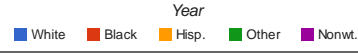




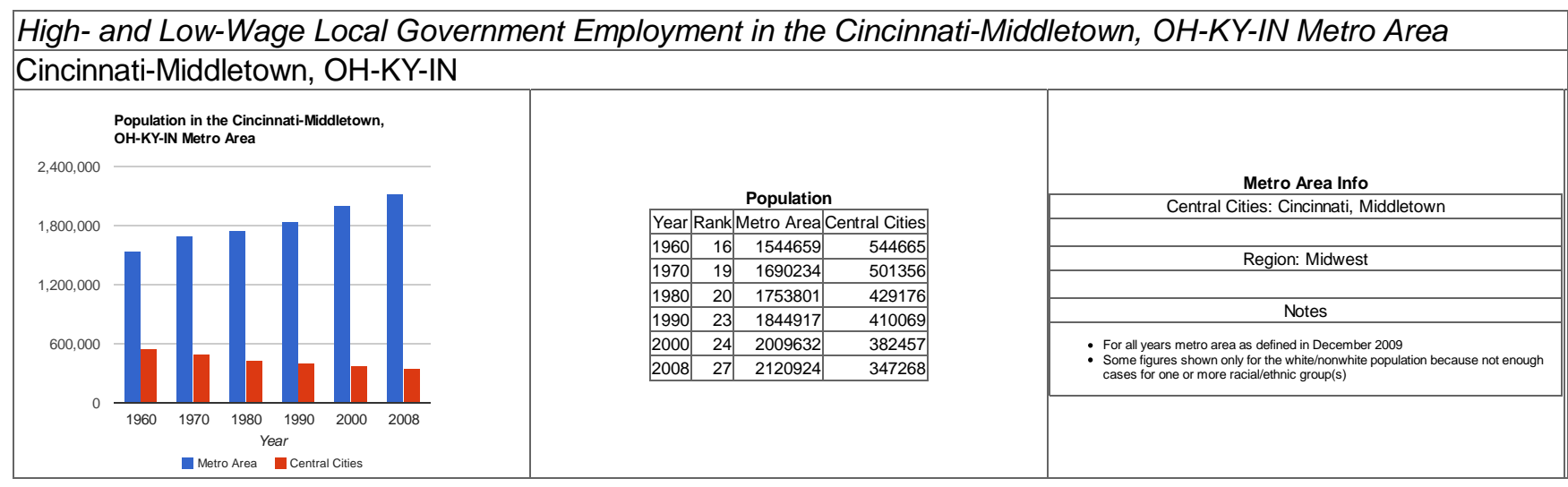


High- and Low-Wage Local Government Employment in the Cincinnati-Middletown, OH-KY-IN Metro Area Local Government High-Wage Employees in the Metro Area
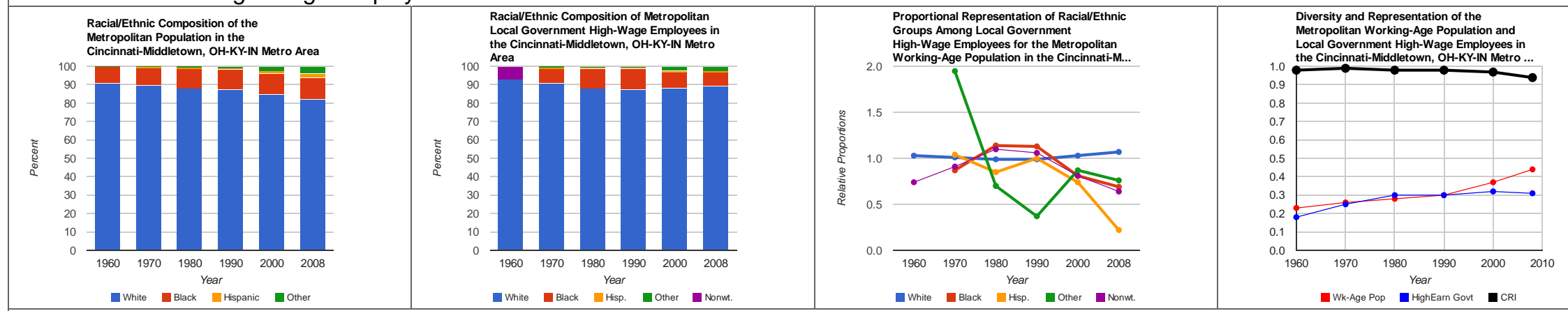

Local Government High-Wage Employees in the Central Cities
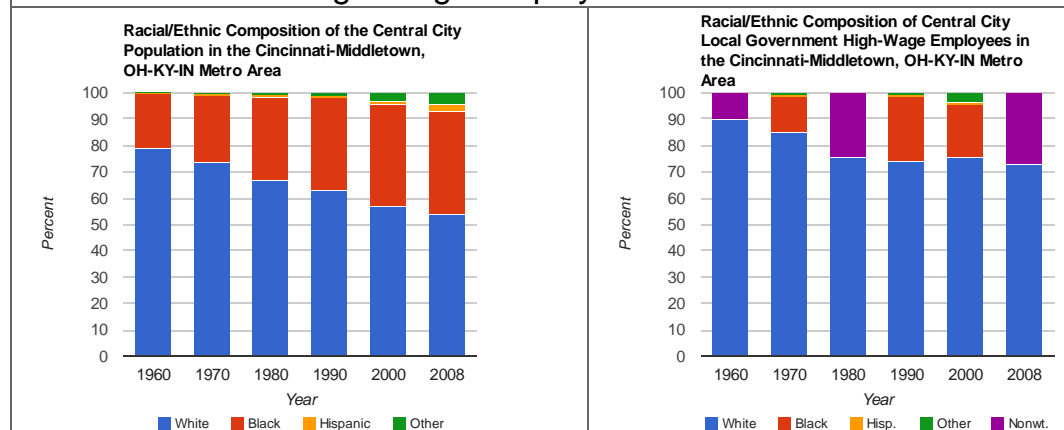
Proportional Representation of Raciall/Ethnic
Groups Among Local Government
High-Wage Employees for the Central City Working-Age Population in the Cincinnati-M... White Elack Mear Hispanic Inother

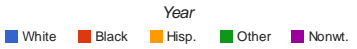

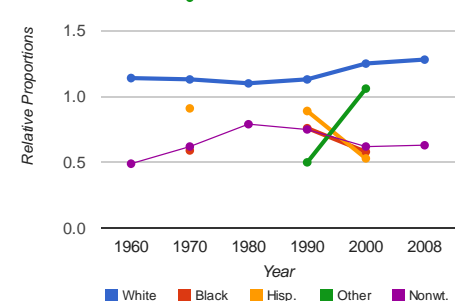
Diversity and Representation of the Central
City Working-Age Population and Local
Government High-Wage Employees in the Government High-Wage Employees in the
Cincinnati-Middletown, OH-KY-IN Metro Area

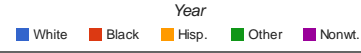

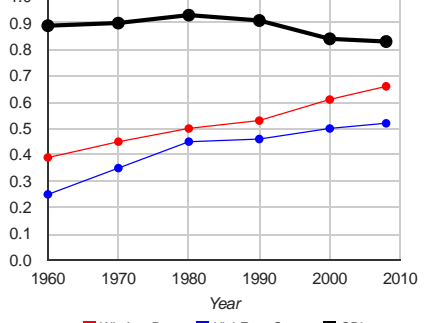

-Wk-Age Pop M HighEarn Govt - CRI 
High- and Low-Wage Local Government Employment in the Cincinnati-Middletown, OH-KY-IN Metro Area Local Government Low-Wage Employees in the Metro Area
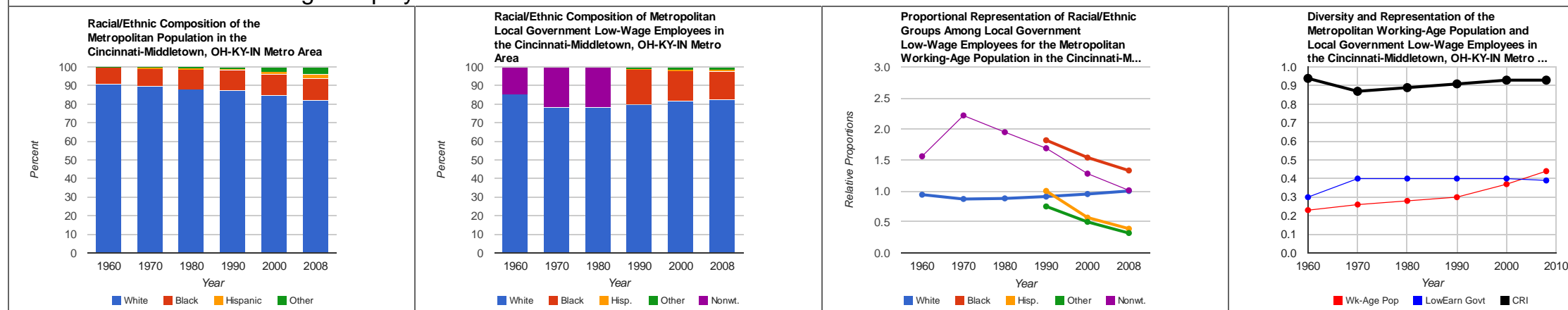

Local Government Low-Wage Employees in the Central Cities
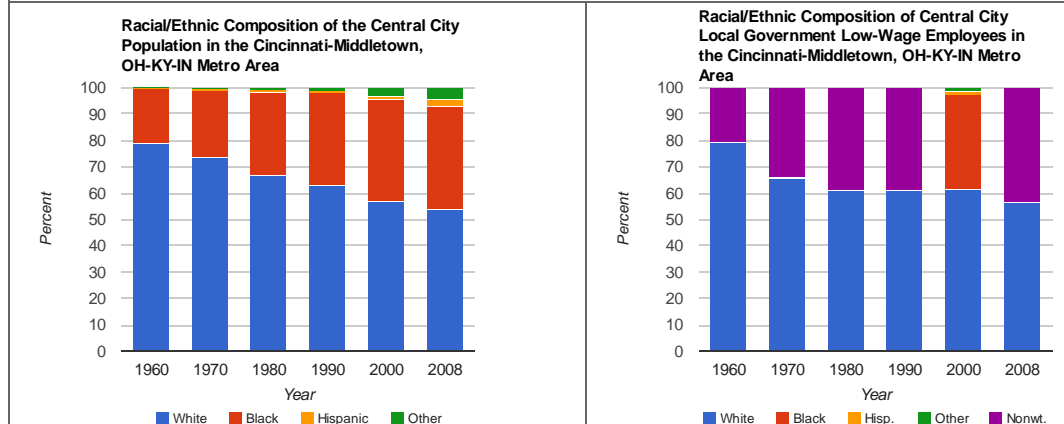
Proportional Representation of Raciall/Ethnic
Groups Among Local Government
Low-Wage Employees for the Central City Working-Age Population in the Cincinnati-M...

White Ulack Hear Hispanic nother

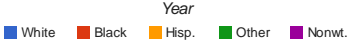
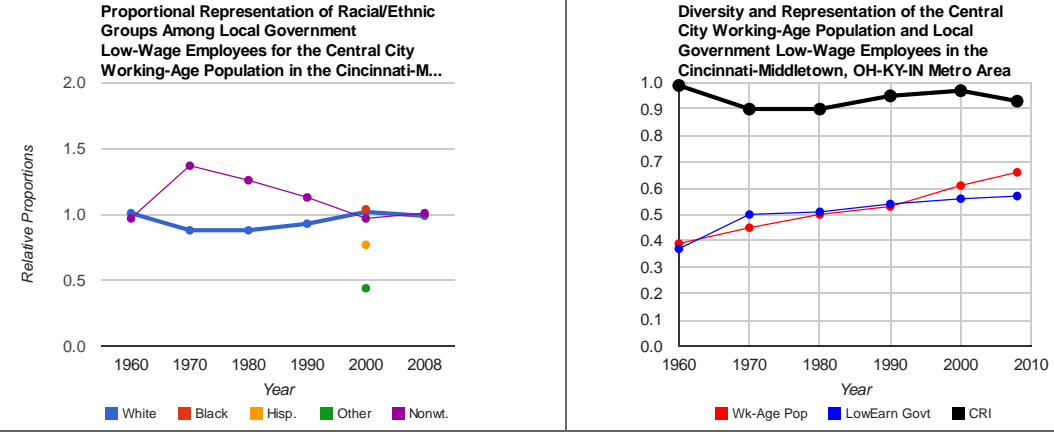


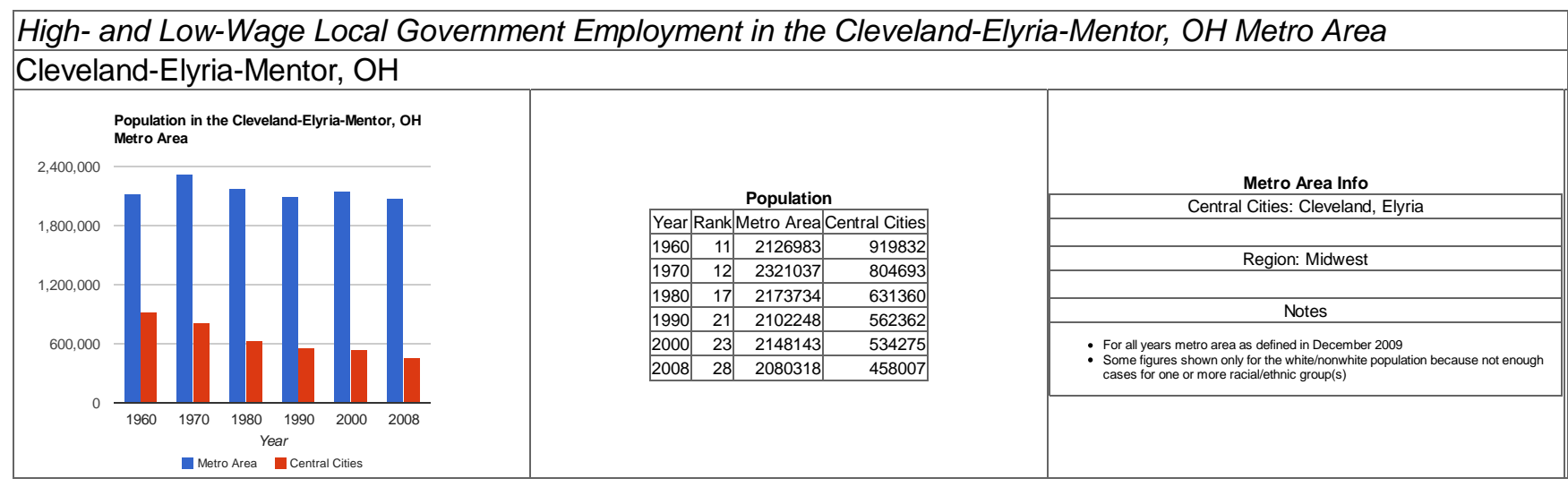


High- and Low-Wage Local Government Employment in the Cleveland-Elyria-Mentor, OH Metro Area Local Government High-Wage Employees in the Metro Area
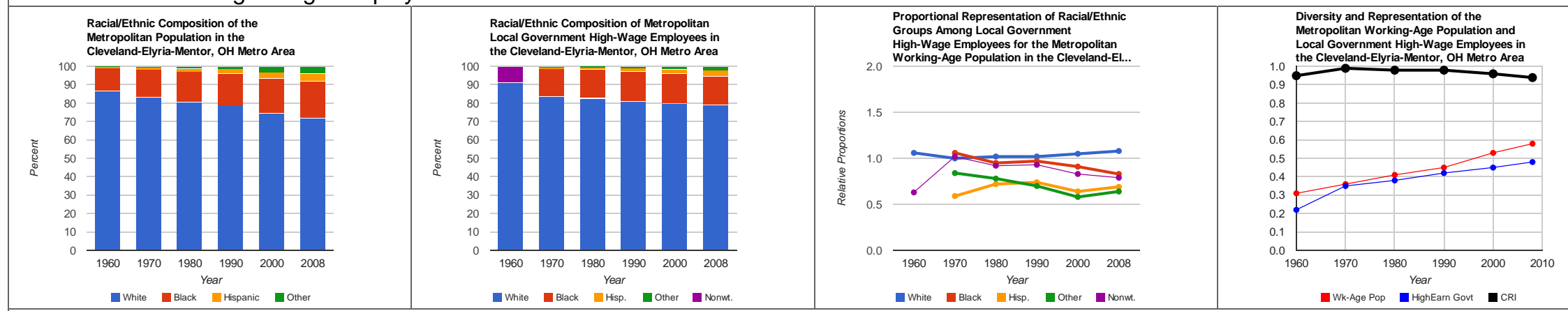

Local Government High-Wage Employees in the Central Cities
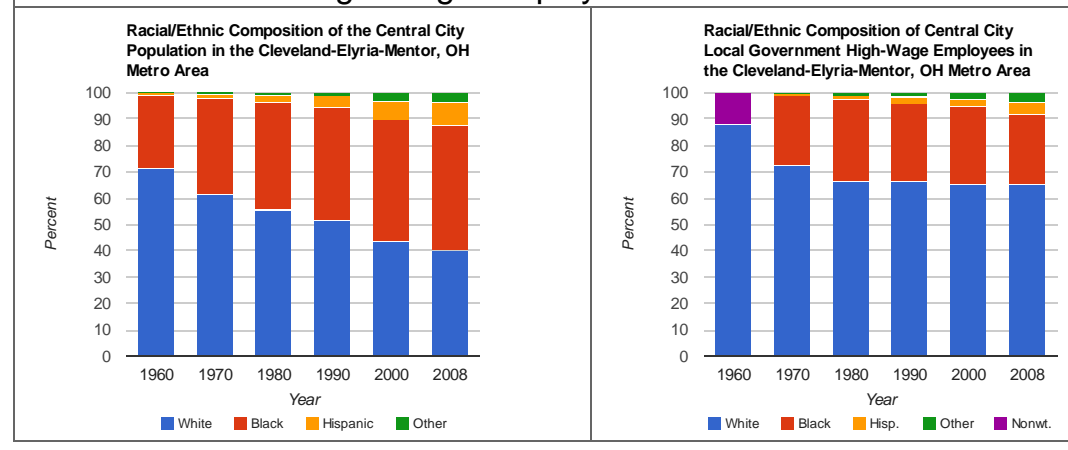
Proportional Representation of Raciall/Ethnic
Groups Among Local Government
High-Wage Employees for the Central City Working-Age Population in the Cleveland-El... White Elack YHispanic Inother

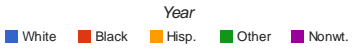

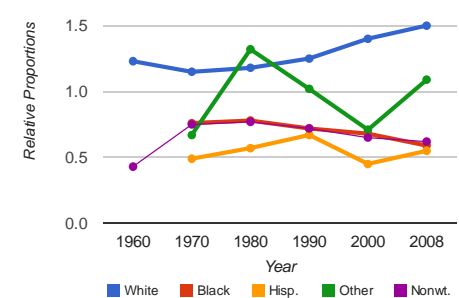

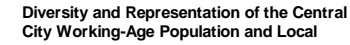
City Working-Age Population and Local Government High-Wage Employees in the
Cleveland-Elyria-Mentor, OH Metro Area

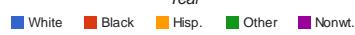

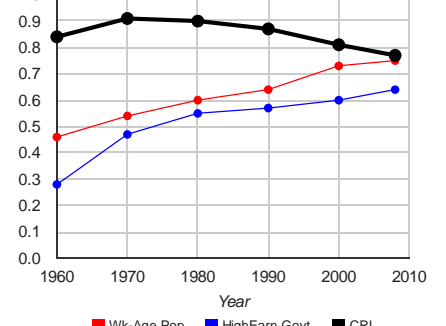

- Wk-Age Pop - MighEarn Govt - CR 
High- and Low-Wage Local Government Employment in the Cleveland-Elyria-Mentor, OH Metro Area Local Government Low-Wage Employees in the Metro Area
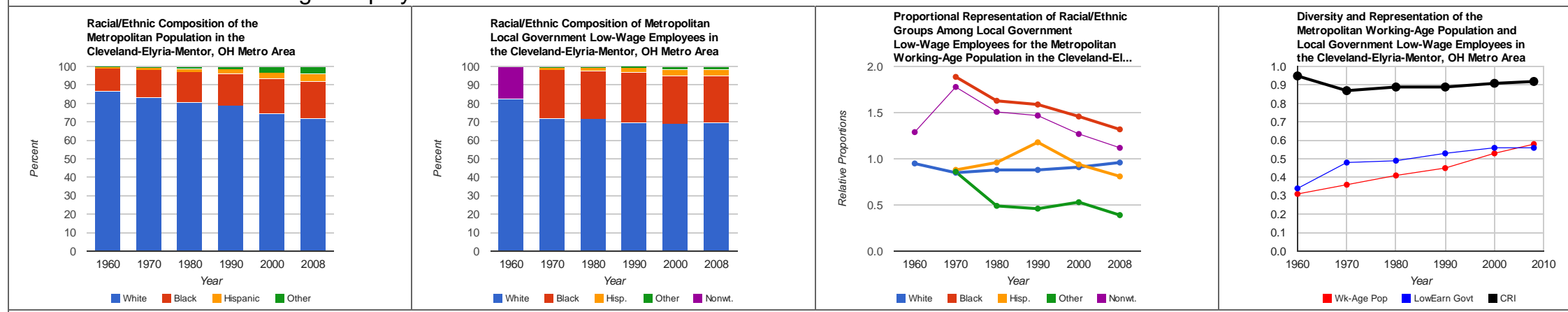

Local Government Low-Wage Employees in the Central Cities
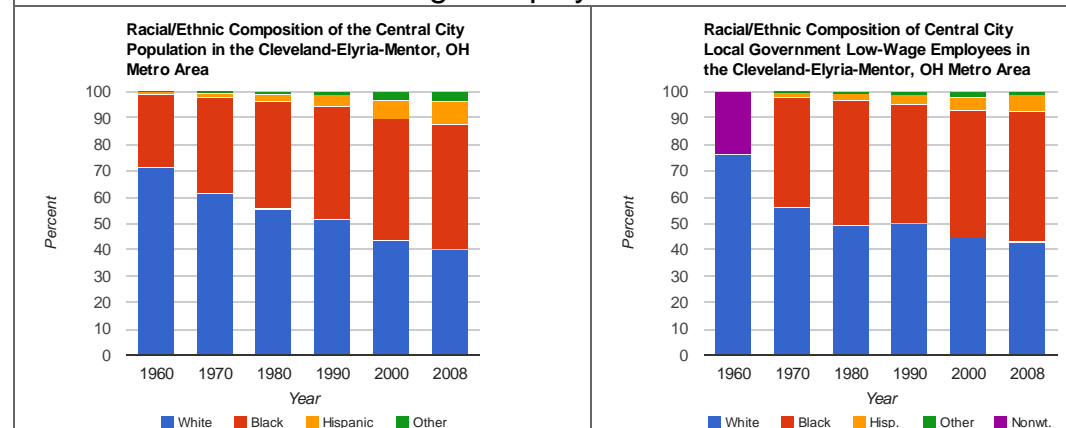
Proportional Representation of Raciall/thnic
Groups Among Local Government
Low-Wage Employees for the Central City 20 Working-Age Population in the Cleveland-El... White Elack Mear Hispanic Inother

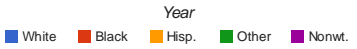
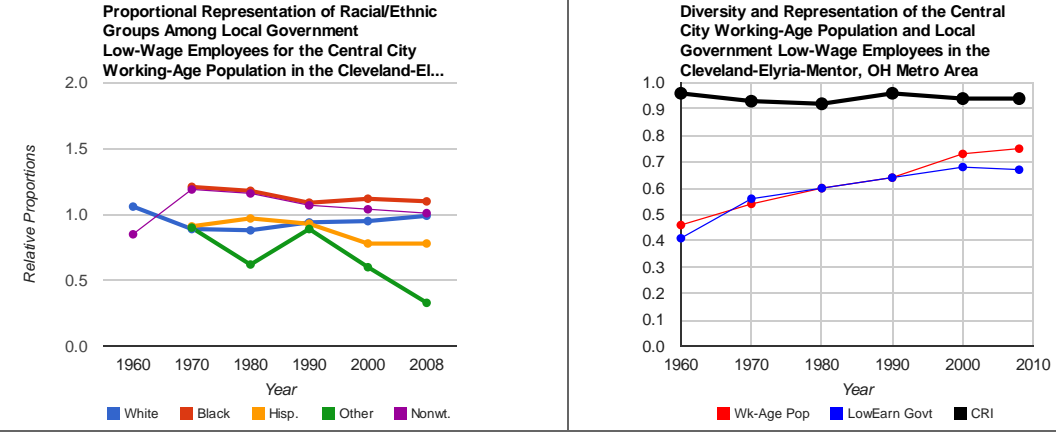


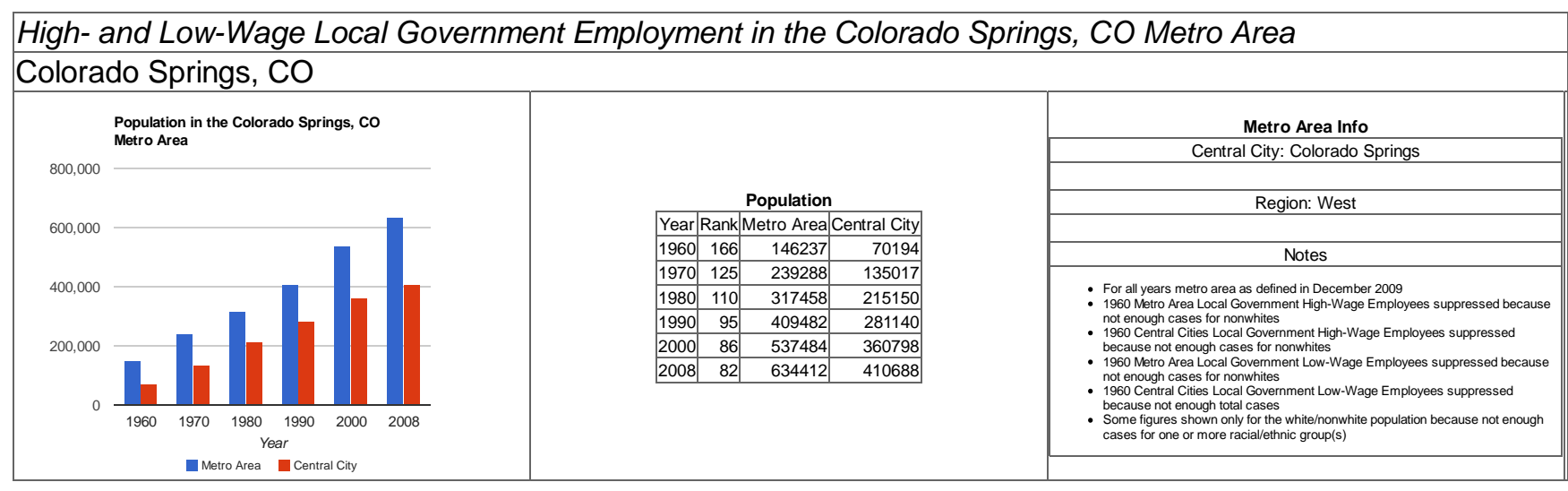


High- and Low-Wage Local Government Employment in the Colorado Springs, CO Metro Area

Local Government High-Wage Employees in the Metro Area
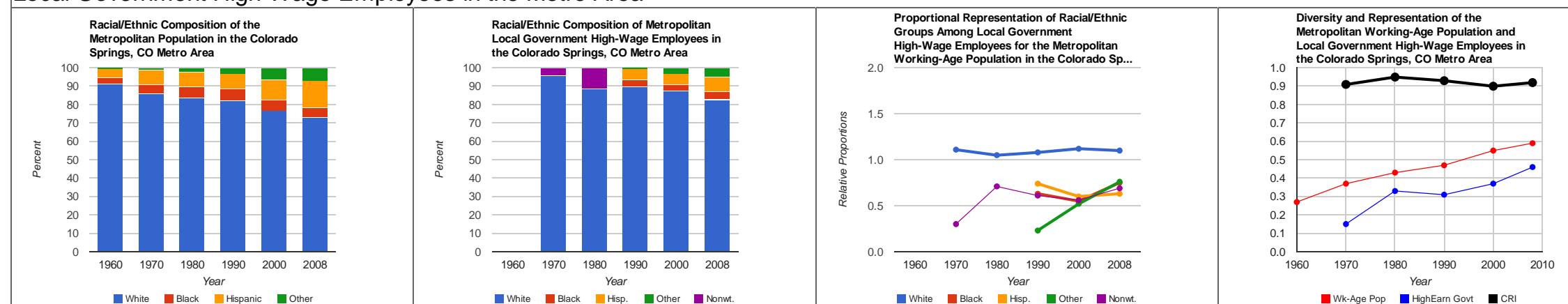

Local Government High-Wage Employees in the Central City
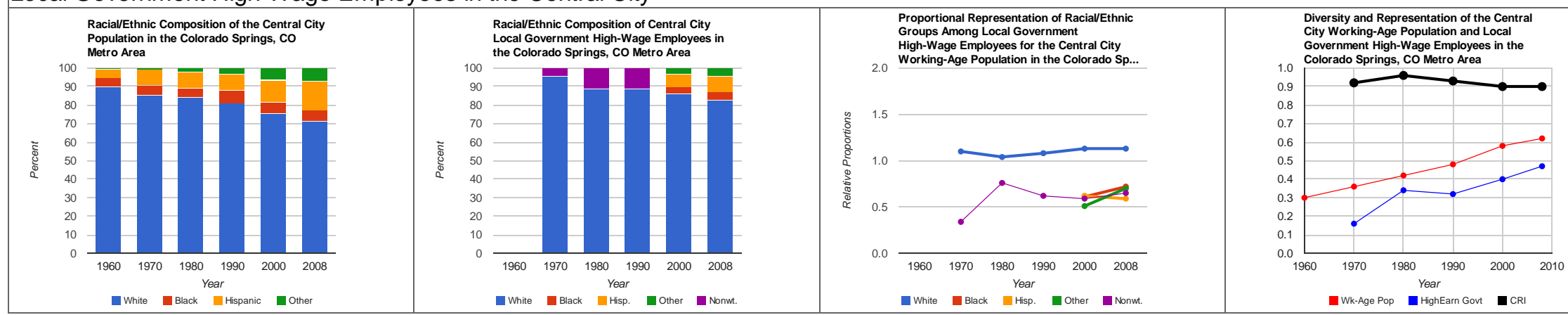
High- and Low-Wage Local Government Employment in the Colorado Springs, CO Metro Area

Local Government Low-Wage Employees in the Metro Area
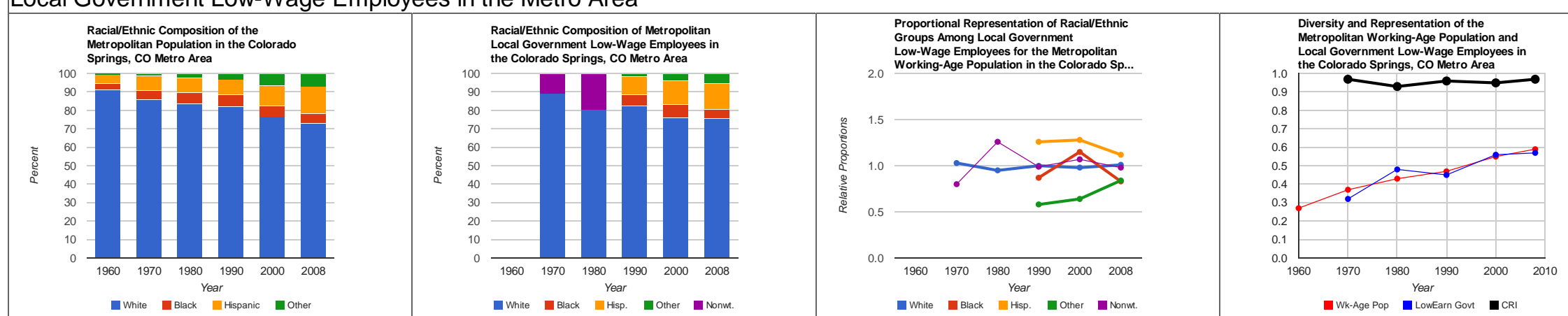

Local Government Low-Wage Employees in the Central City
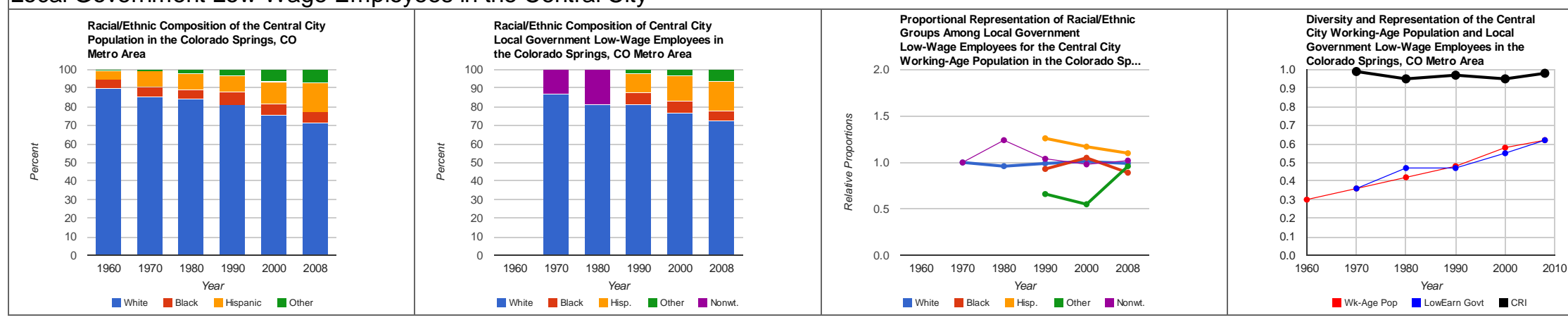


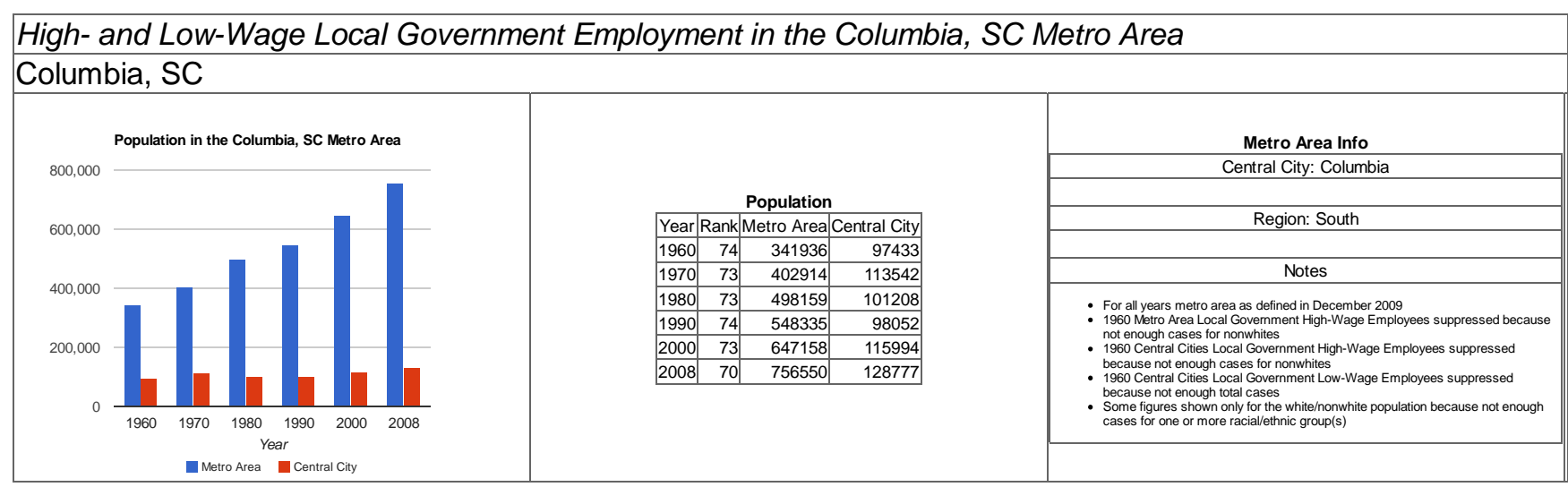


High- and Low-Wage Local Government Employment in the Columbia, SC Metro Area

Local Government High-Wage Employees in the Metro Area
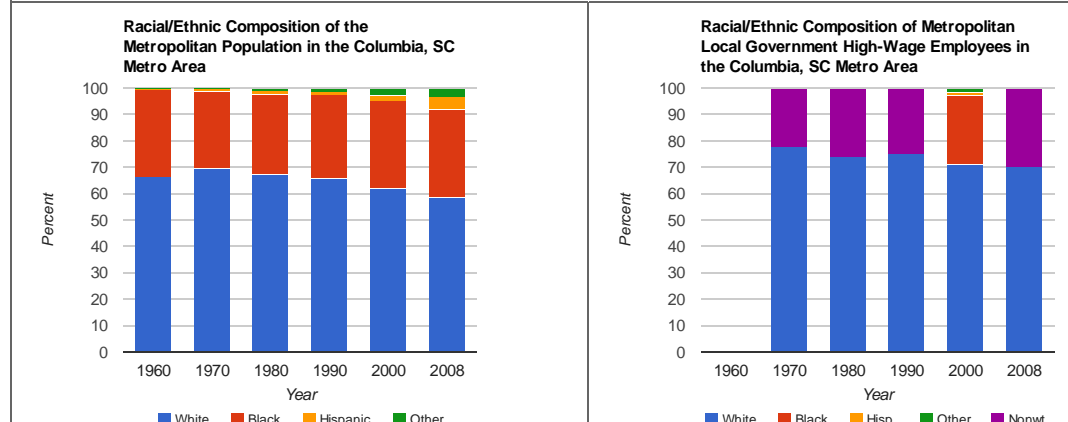

Local Government High-Wage Employees in the Central City

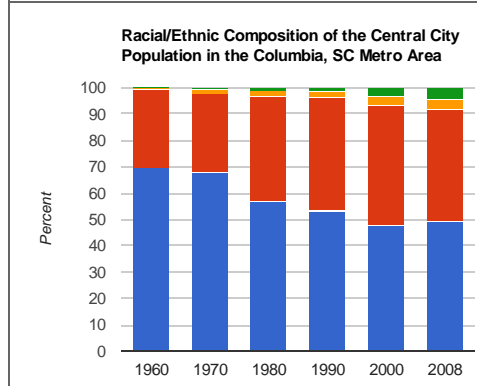

White Black Year
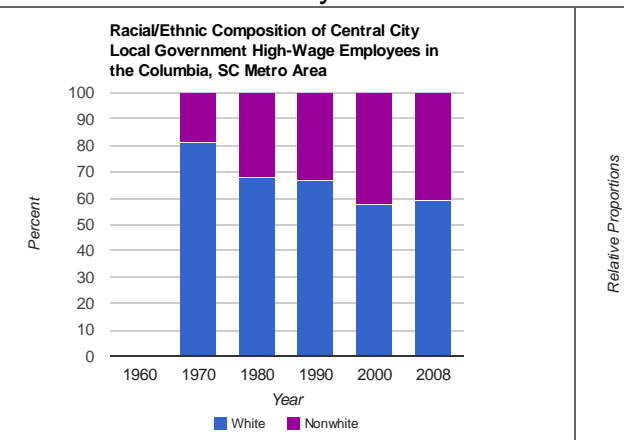

Groups Among Local Government

Proportional Representation of Raciall/Ethnic
Groups Among Local Government Groups Among Local Government
High-Wage Employes for the entropolitan

Working-Age Population in the Columbia, S...

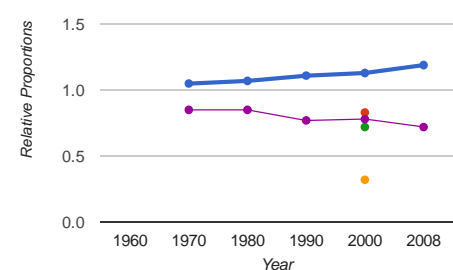

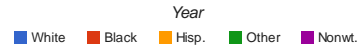

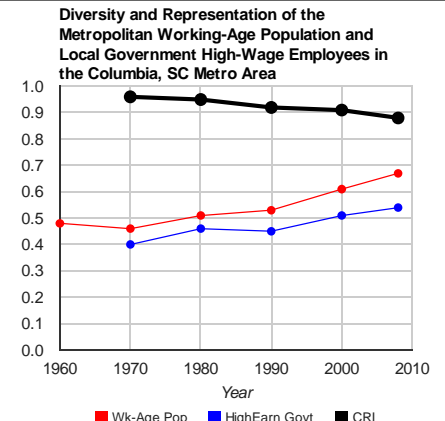

-Wk-Age Pop WighEarn Govt - CR

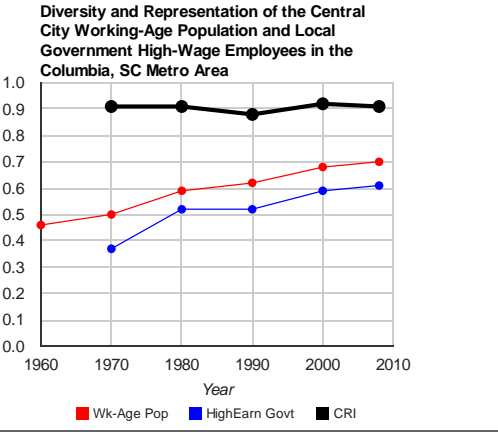


High- and Low-Wage Local Government Employment in the Columbia, SC Metro Area

Local Government Low-Wage Employees in the Metro Area
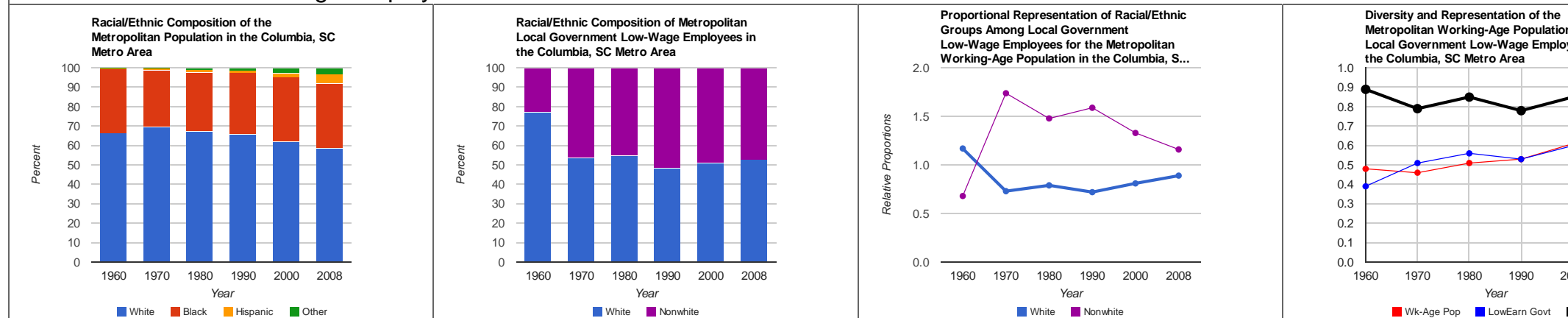

Metropolitan Working-Age Population and

Local Government Low-Wage
the Columbia, SC Metro Area

White Black Hispanic other

- White ${ }_{\text {Nonwh }}$

I. White ${ }^{\text {Year }}$ Nonnhiil

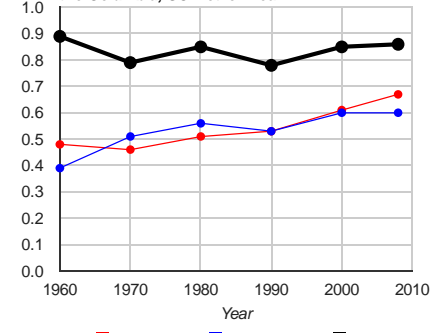

Local Government Low-Wage Employees in the Central City

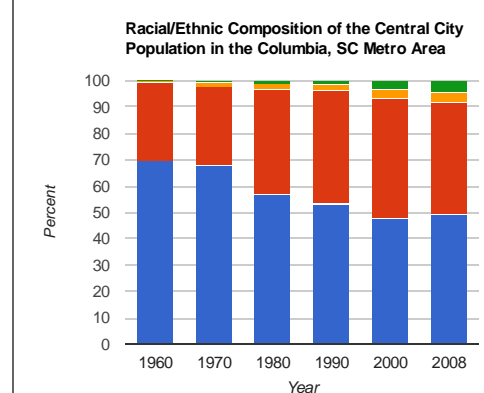

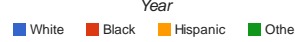

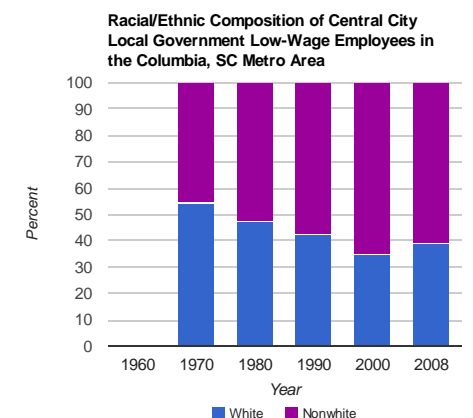

White $\mathbf{m}$ Nonwhite Proportional Representation of Raciall/Ethnic
Groups Among Local Government
Low-Wage Employees for the Central City Low-Wage Employees tor hne Central City
Working-Age Population in the Columbia, s...

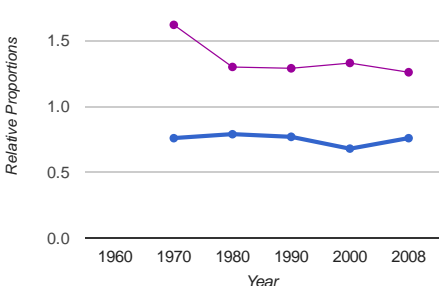

White ${ }_{\text {Nonunhite }}^{\text {Year }}$

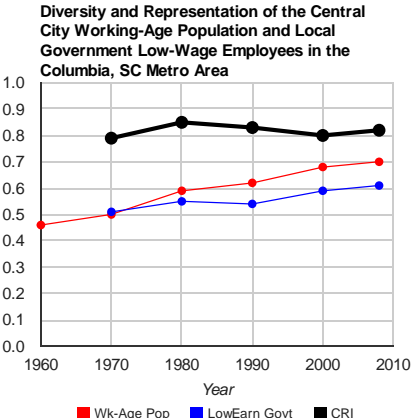

- Wh-Age Pop Lowearn Govt - 


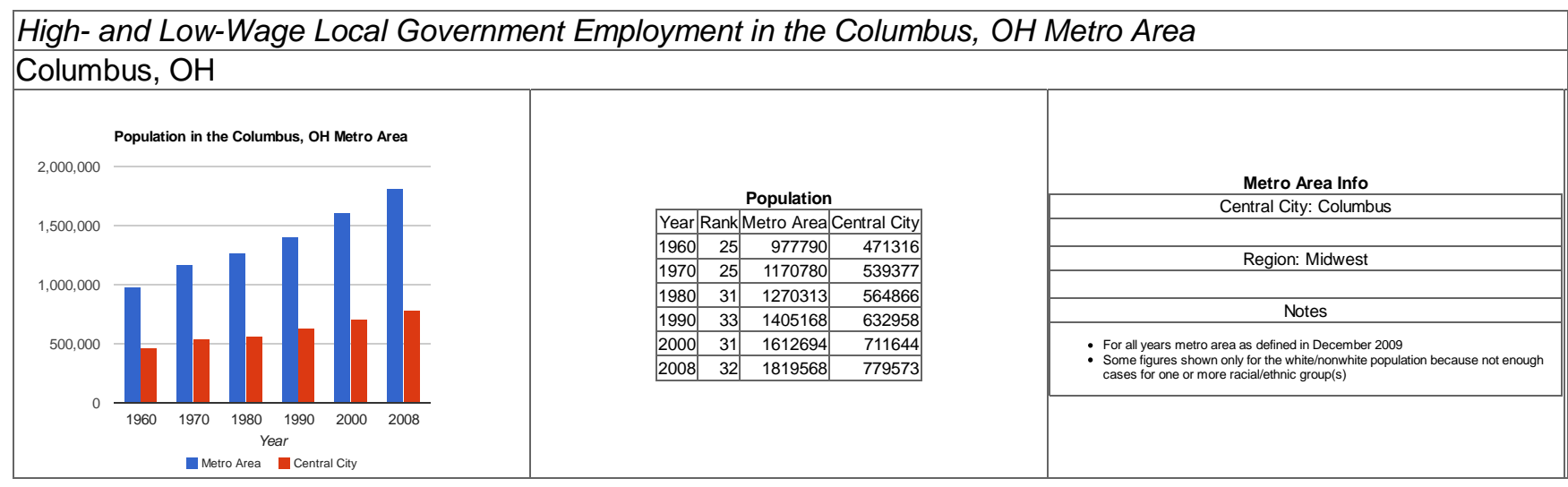


High- and Low-Wage Local Government Employment in the Columbus, OH Metro Area

Local Government High-Wage Employees in the Metro Area
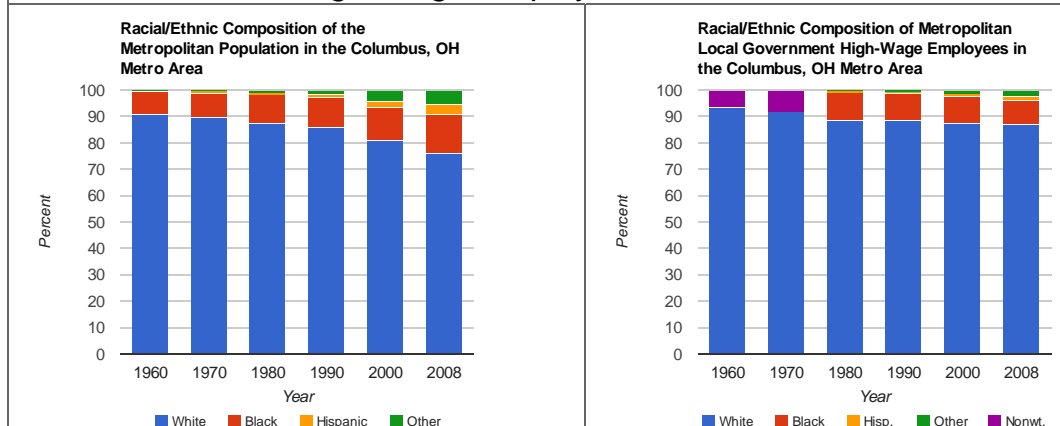

Local Government High-Wage Employees in the Central City
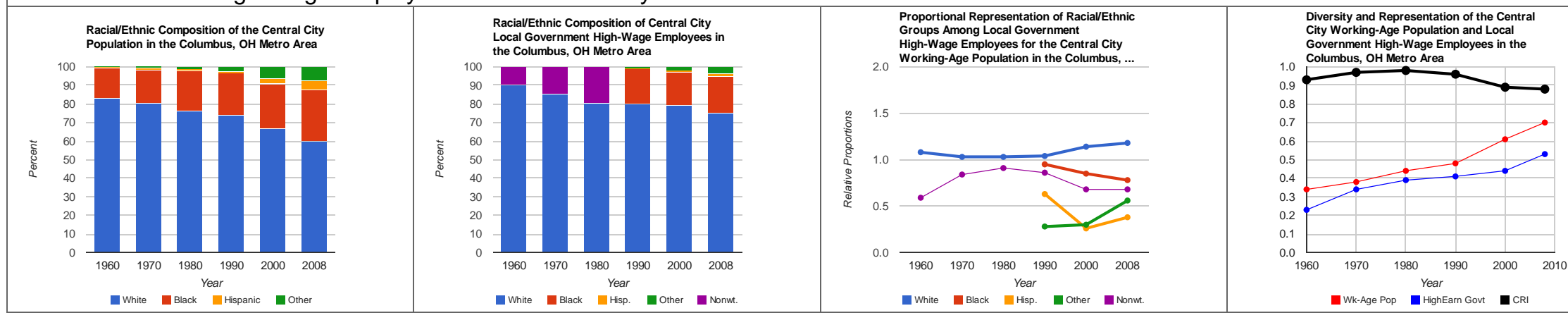
High- and Low-Wage Local Government Employment in the Columbus, OH Metro Area

Local Government Low-Wage Employees in the Metro Area
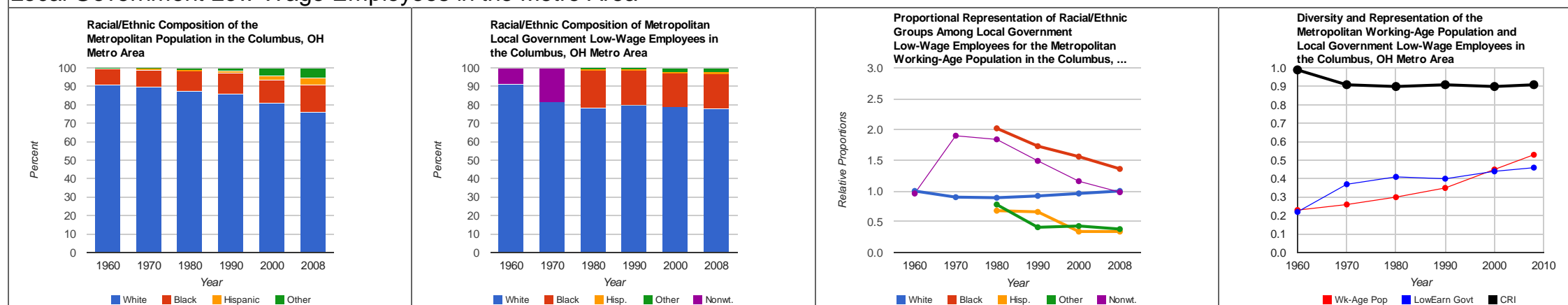

Local Government Low-Wage Employees in the Central City
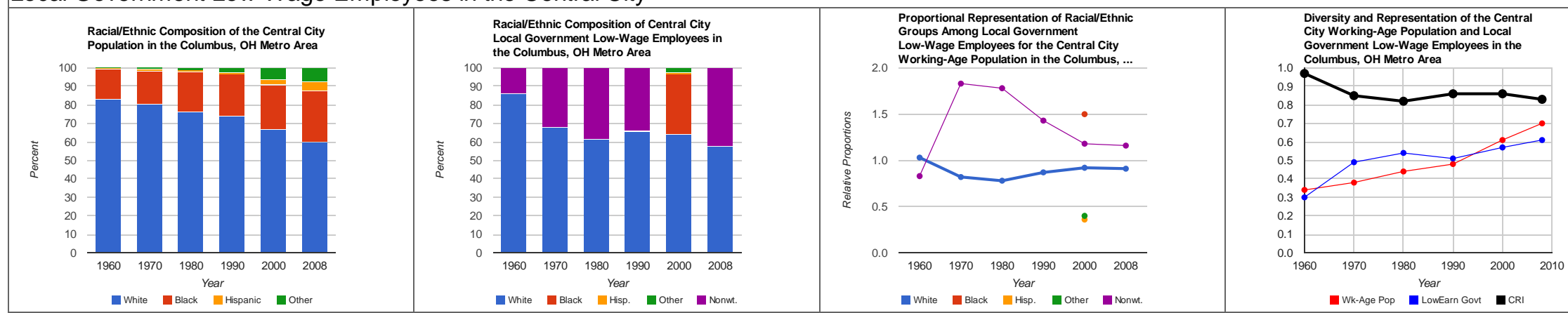


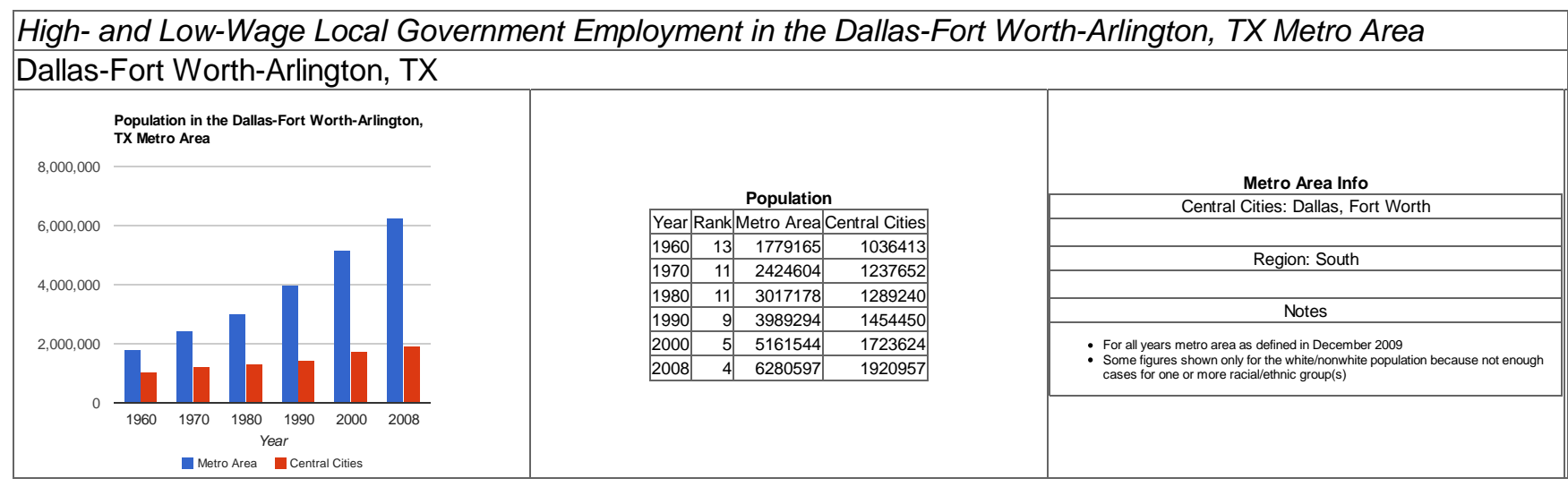


High- and Low-Wage Local Government Employment in the Dallas-Fort Worth-Arlington, TX Metro Area Local Government High-Wage Employees in the Metro Area
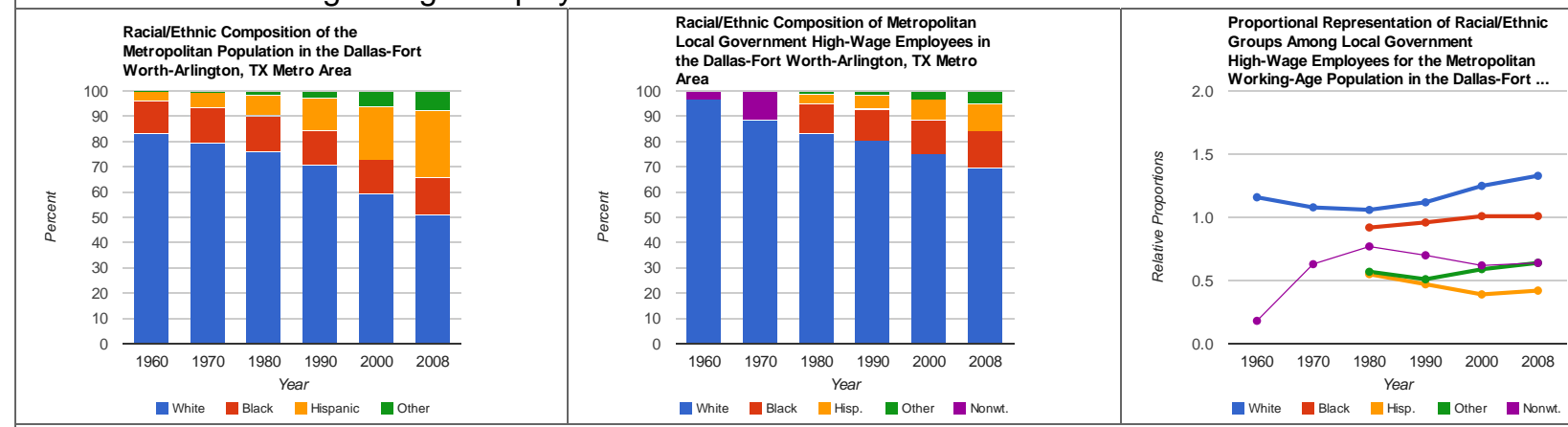
Diversity and Representation of the
Metropolitan Working-Age Population and the Dallas-Fort Worth-Arlington, $\mathrm{TX}$ Metro $\mathrm{A}$.

White Elack HHispanic nother White M Black Year

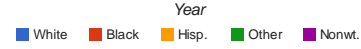

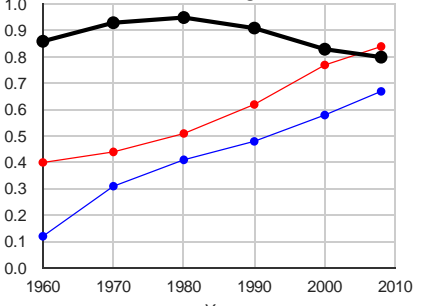
@Wk-Age Pop M Highearn Govt $\quad$ CR Local Government High-Wage Employees in the Central Cities
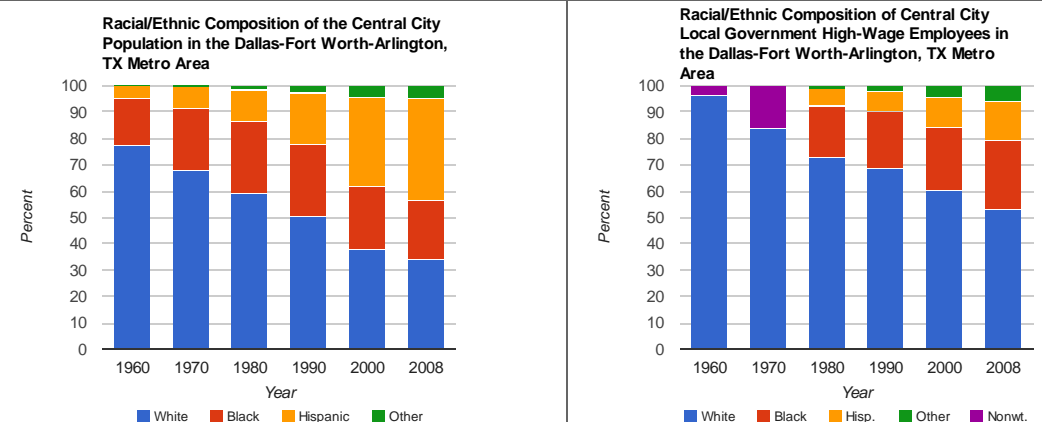
Proportional Representation of Raciall/Ethnic
Groups Among Local Government
High-Wage Employees for the Central City Working-Age Population in the Dallas-Fort ...

White Elack YHispanic Mother

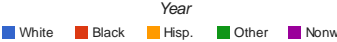

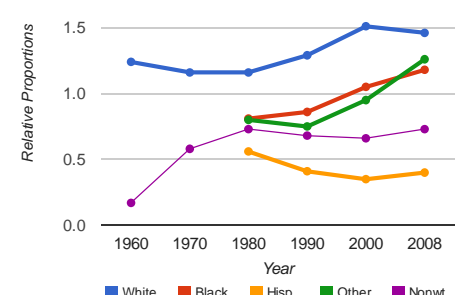
Diversity and Representation of the Central City Working-Age Population and Local
Government High-Wage Employees in the Government High--Wage Employees in the
Dallas-Fort Worth-Arlington, IX Metro Area 0.9

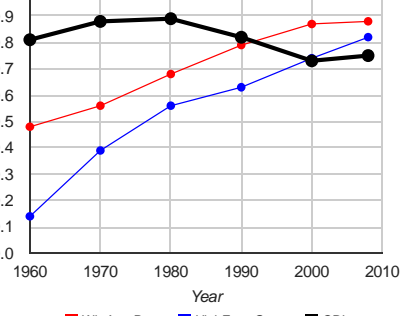
White Black Year

Wk-Age Pop - Highearn Govt 
High- and Low-Wage Local Government Employment in the Dallas-Fort Worth-Arlington, TX Metro Area Local Government Low-Wage Employees in the Metro Area
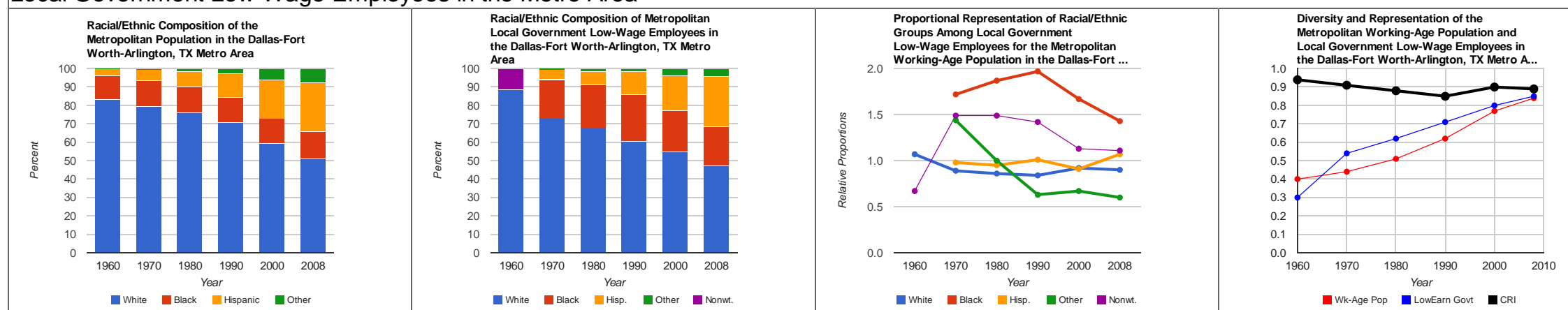

Local Government Low-Wage Employees in the Central Cities
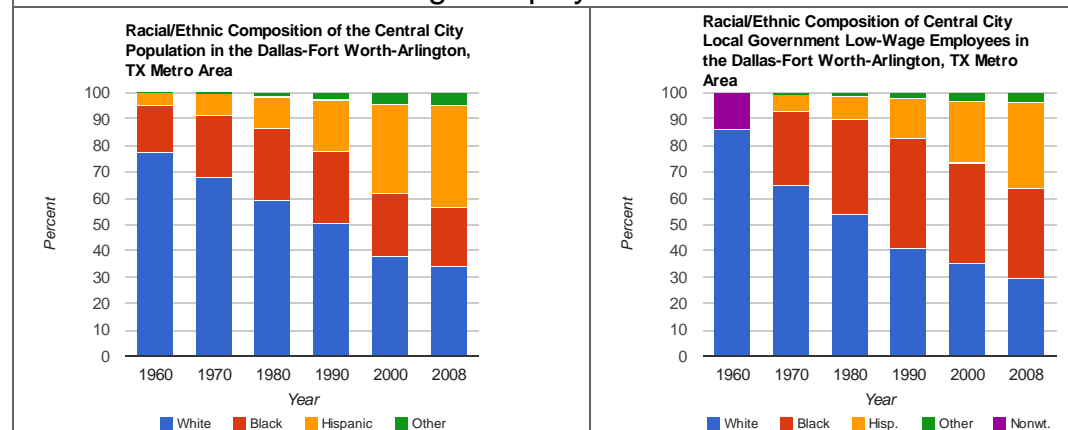
Proportional Representation of Raciall/Ethnic
Groups Among Local Government
Low-Wage Employees for the Central City Groups Among Local Government
Low-Wage Employes for the Central City
2.0 Working-Age Population in the Dallas-Fort ...

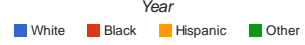

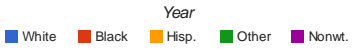

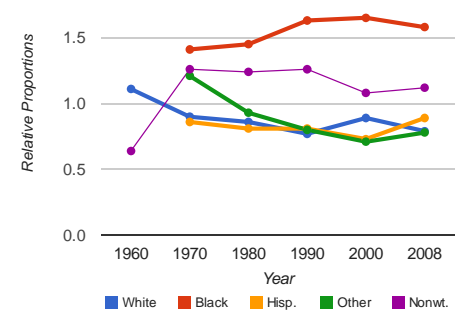
Diversity and Representation of the Central
City Working-Age Population and Local
Government Low-Wage Employees in the Government Low-Wage Employees in the
Dallas-Fort Worth-Arlington, TX Metro Area

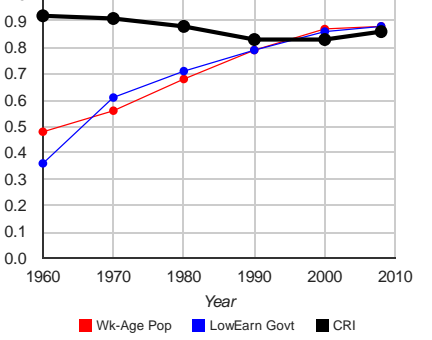

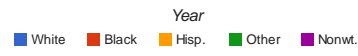

-Wk-Age Pop —Lowearn Govt - 
High- and Low-Wage Local Government Employment in the Dayton, OH Metro Area

Dayton, $\mathrm{OH}$

Population in the Dayton, OH Metro Area

$1,000,000$

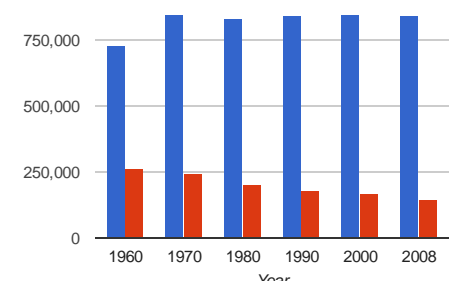

Metro Area 1 Central city
Population

Year Rank Metro Areal Central City

\begin{tabular}{|l|l|l|l|}
\hline 1960 & 39 & 727121 & 262332 \\
\hline 1970 & 40 & 850200 & 223459 \\
\hline
\end{tabular}

\begin{tabular}{|l|l|l|l|}
1970 & 40 & 850266 & 243459 \\
\hline 1980 & 46 & 830070 & 203371 \\
\hline
\end{tabular}

\begin{tabular}{|r|r|r|r|}
1980 & 46 & 830070 & 203371 \\
\hline 1990 & 49 & 843835 & 182044 \\
\hline
\end{tabular}

\begin{tabular}{|l|l|l|l|l|}
\hline 2000 & 54 & 848153 & 1820193 \\
\hline
\end{tabular}

\begin{tabular}{|l|l|l|l|l|}
2000 & 54 & 848153 & 166193 \\
\hline 2008 & 61 & 843230 & 144044 \\
\hline
\end{tabular}
Metro Area Info Central City: Dayton

Region: Midwest

Notes

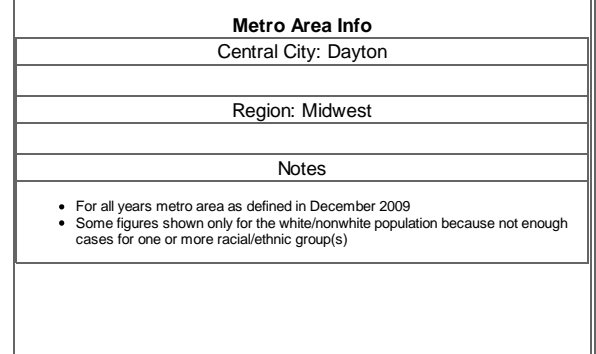


High- and Low-Wage Local Government Employment in the Dayton, OH Metro Area

Local Government High-Wage Employees in the Metro Area
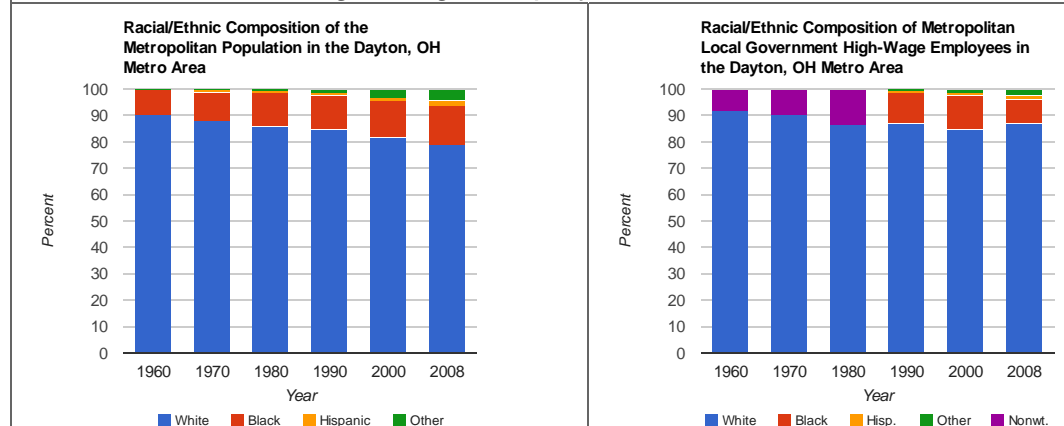

Local Government High-Wage Employees in the Central City
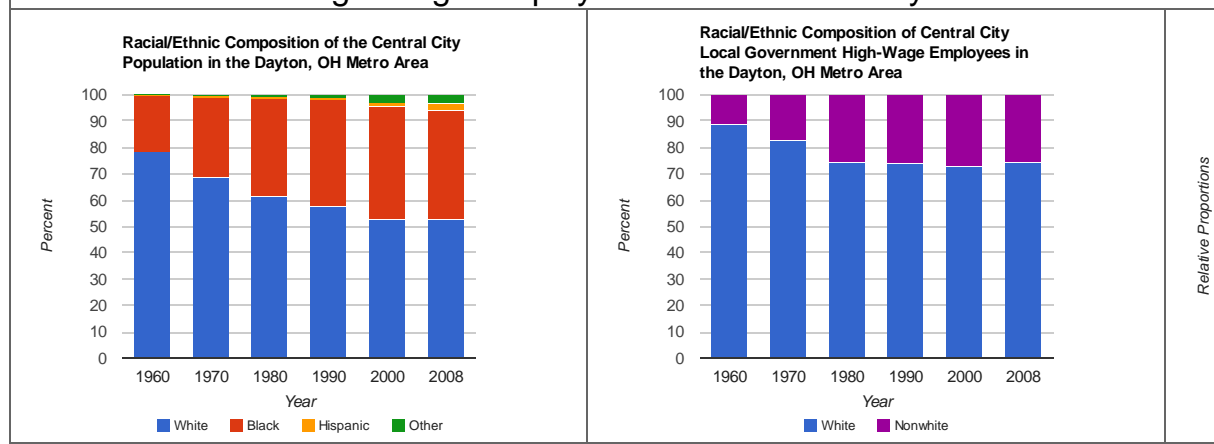
Groups Among Local Government

Proportional Representation of Raciall/Ethnic
Groups Among Local Government High-Wage Employees for the Metropolitan
Working-Age Population in the Dayton, $\mathrm{OH}$

—White 1 Black Year

— White $\stackrel{\text { Year }}{\text { Nonwhite }}$

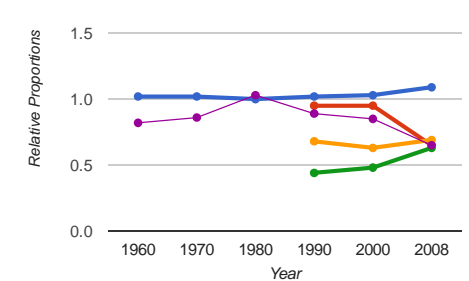

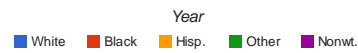

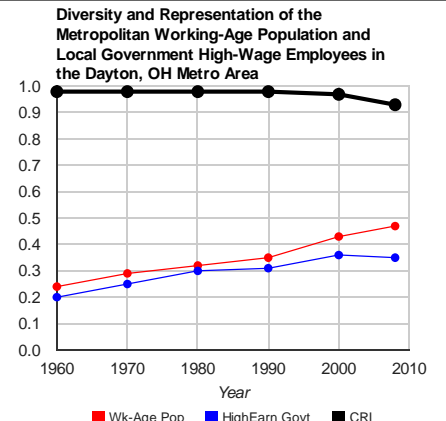

-Wk-Age Pop M Highearn Govt - CR

Working-Age Population in the Dayton, OH...

Diversity and Representation of the Central
City Working-Age PWpution City Working-Age Population and Local
Government High-Wage Employees in

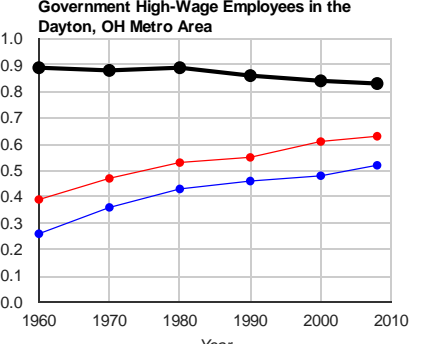

\begin{tabular}{llllll}
\hline 1960 & 1970 & 1980 & 1990 & 2000 & 2008
\end{tabular} White $\quad$ Year

- Wk-Age Pop - MighEarn Govt - CR 
High- and Low-Wage Local Government Employment in the Dayton, OH Metro Area

Local Government Low-Wage Employees in the Metro Area
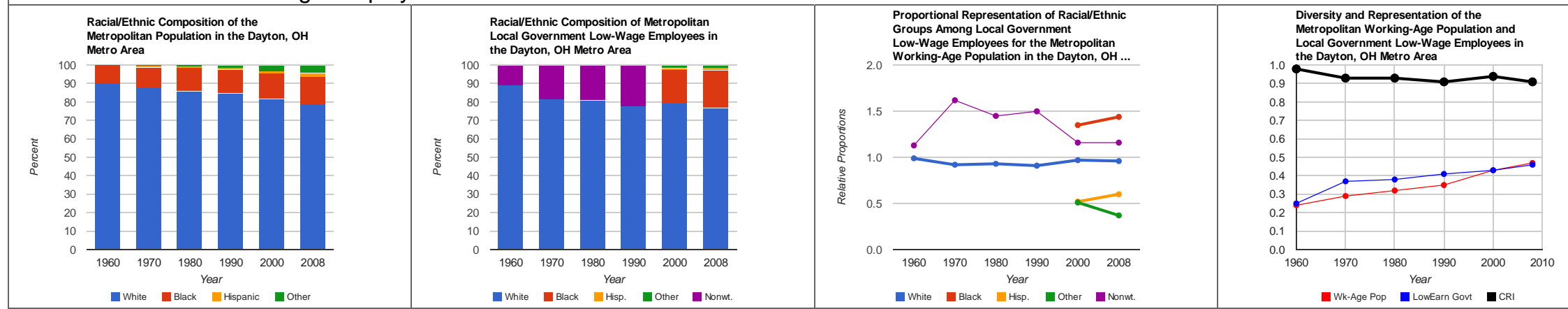

Local Government Low-Wage Employees in the Central City
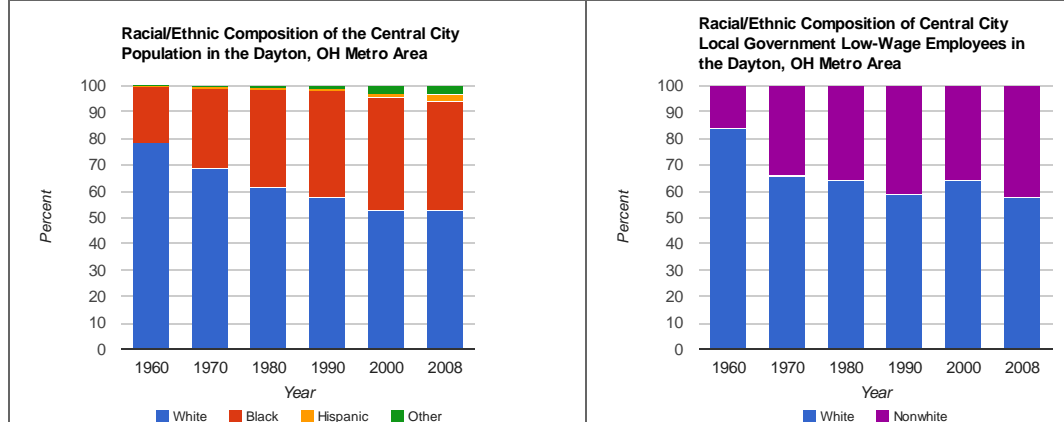
Proportional Representation of RaciallEthnic
Groups Among Local Government
Low-Whage Working-Age Population in the Dayton, $\mathrm{OH}$...

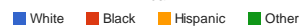
- White $\stackrel{\text { Year }}{\text { Nonwhite }}$
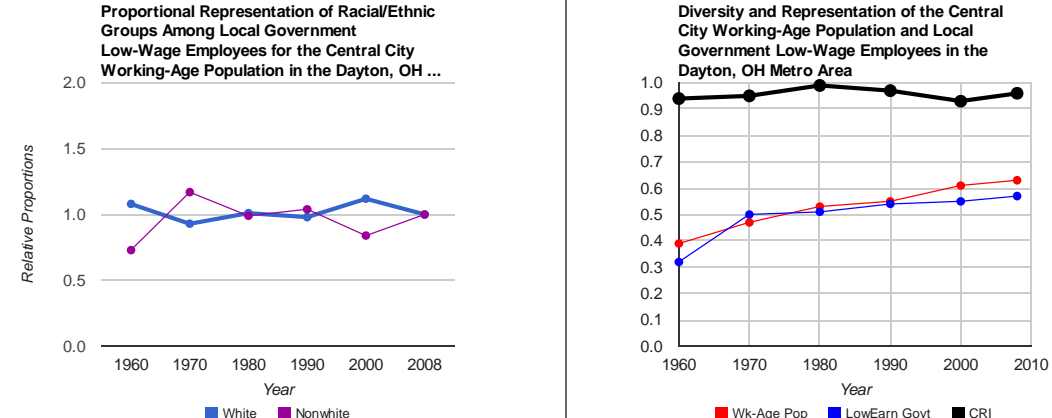

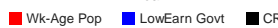




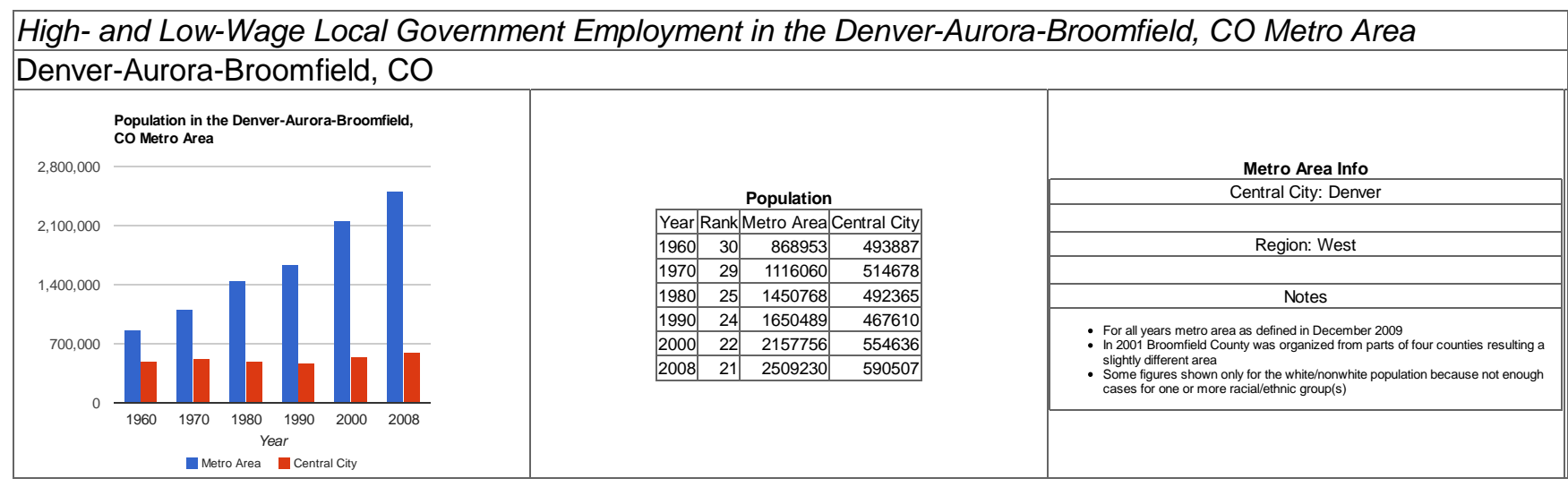


High- and Low-Wage Local Government Employment in the Denver-Aurora-Broomfield, CO Metro Area Local Government High-Wage Employees in the Metro Area
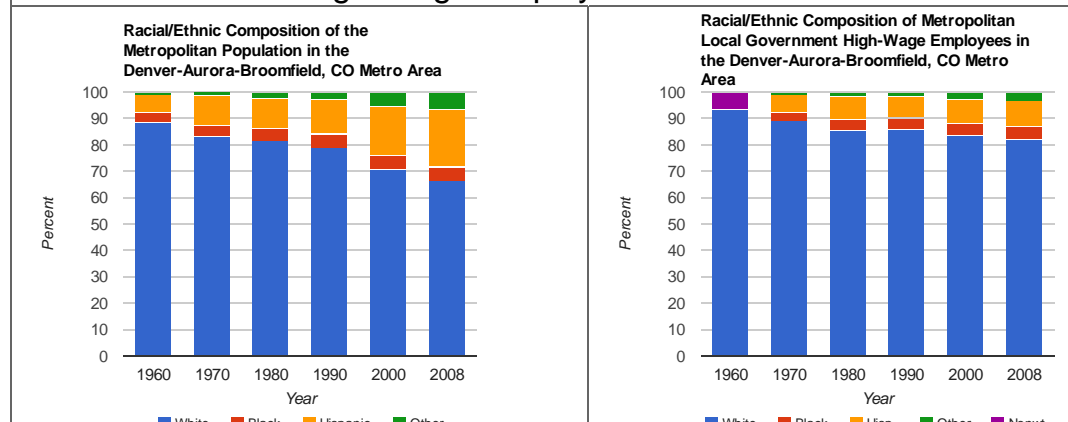

Local Government High-Wage Employees in the Central City
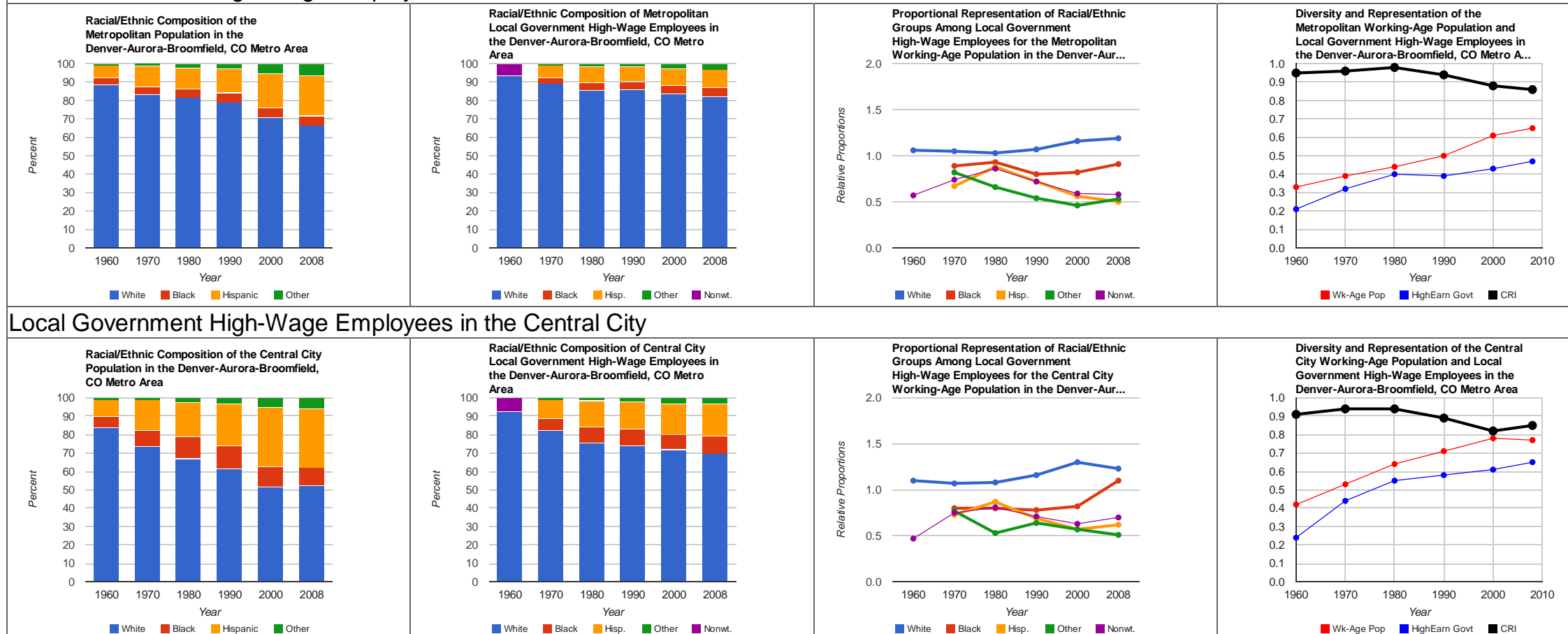

-Wk-Age Pop — HighEarn Govt - $\mathrm{CRI}$

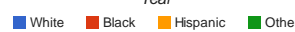

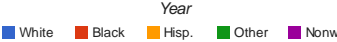

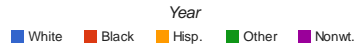

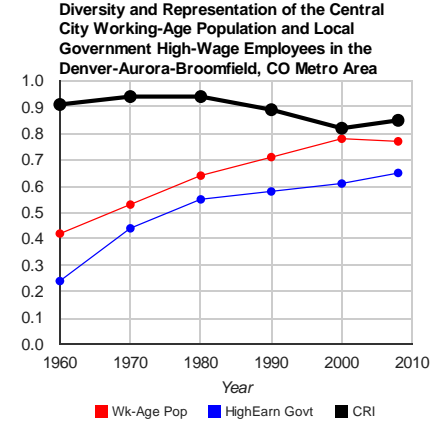


High- and Low-Wage Local Government Employment in the Denver-Aurora-Broomfield, CO Metro Area Local Government Low-Wage Employees in the Metro Area
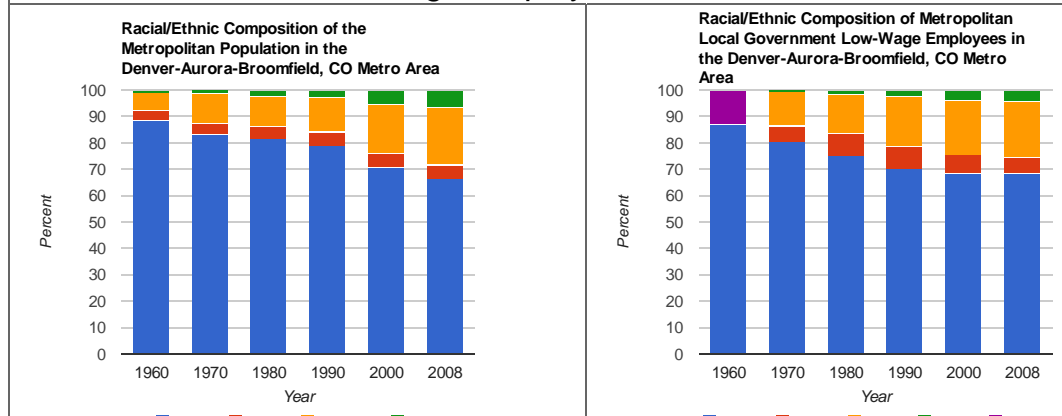

White 1 Black rear

Local Government Low-Wage Employees in the Central City

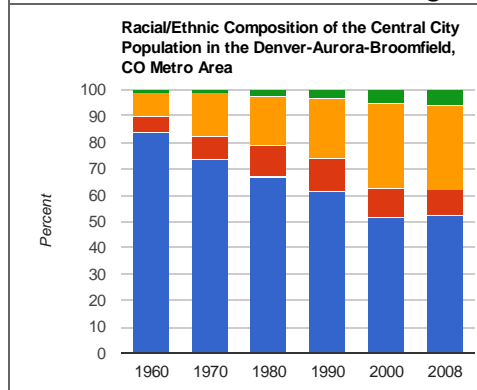

White Ulack Hear Hispanic nother
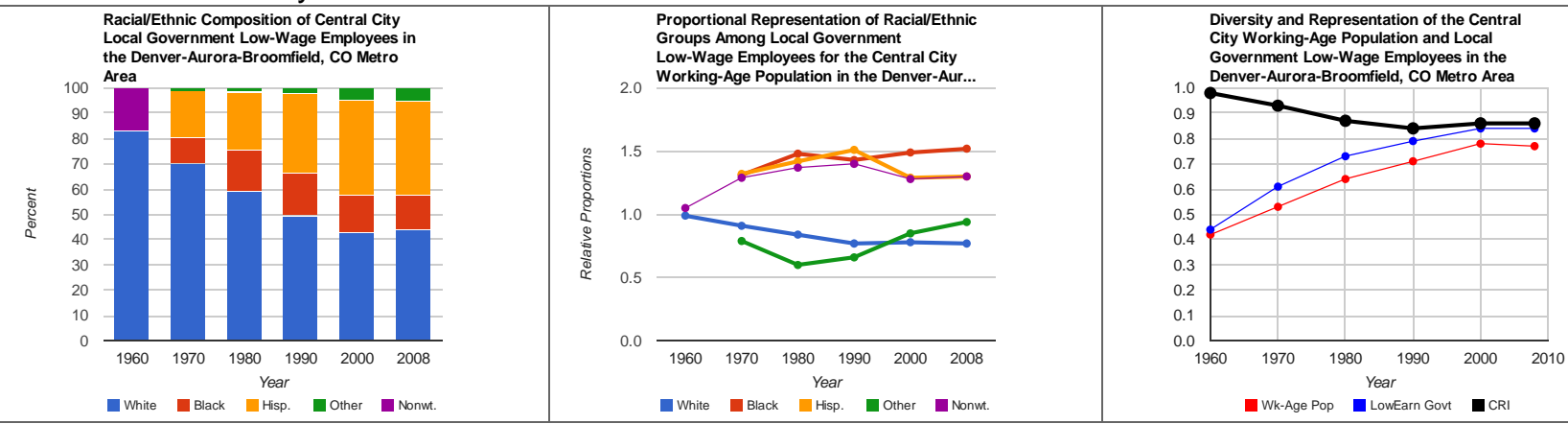
High- and Low-Wage Local Government Employment in the Des Moines-West Des Moines, IA Metro Area Des Moines-West Des Moines, IA

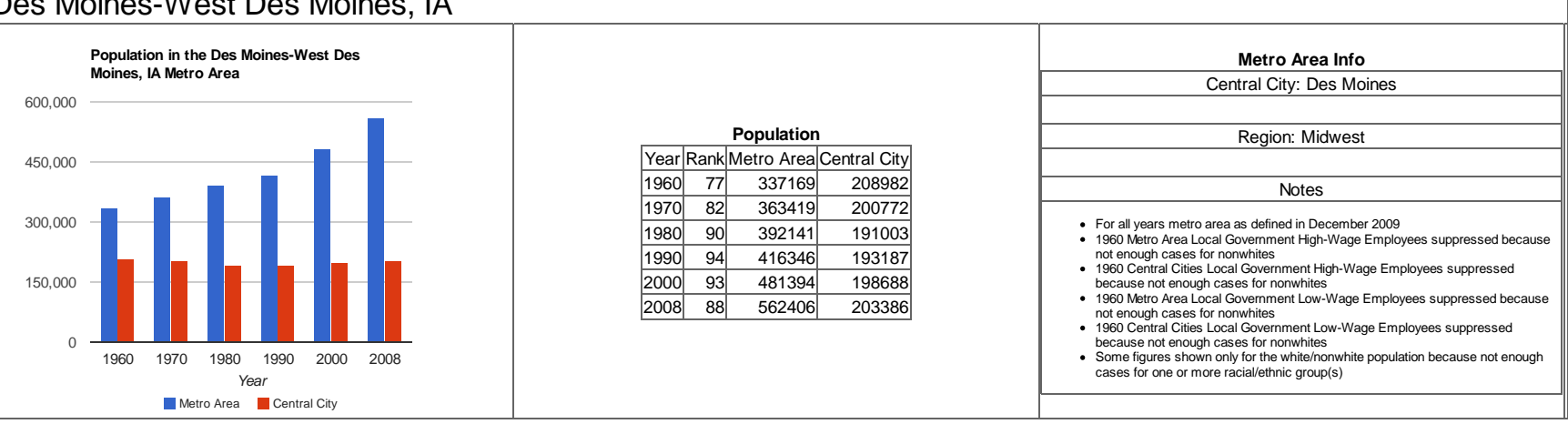


High- and Low-Wage Local Government Employment in the Des Moines-West Des Moines, IA Metro Area Local Government High-Wage Employees in the Metro Area
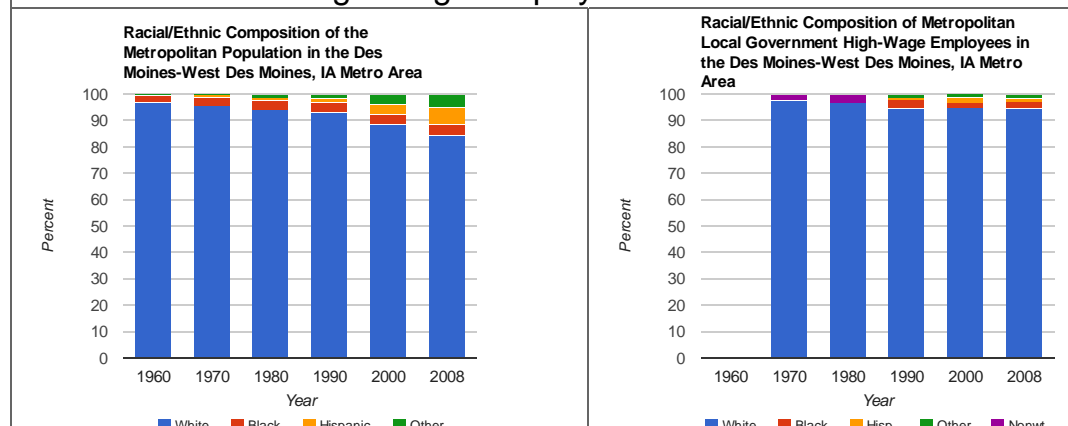

Local Government High-Wage Employees in the Central City

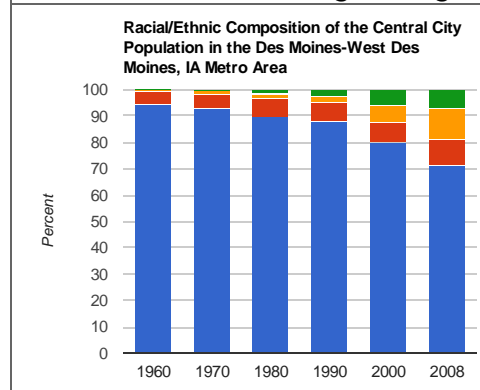

White Inlack Year Hispanic Eother
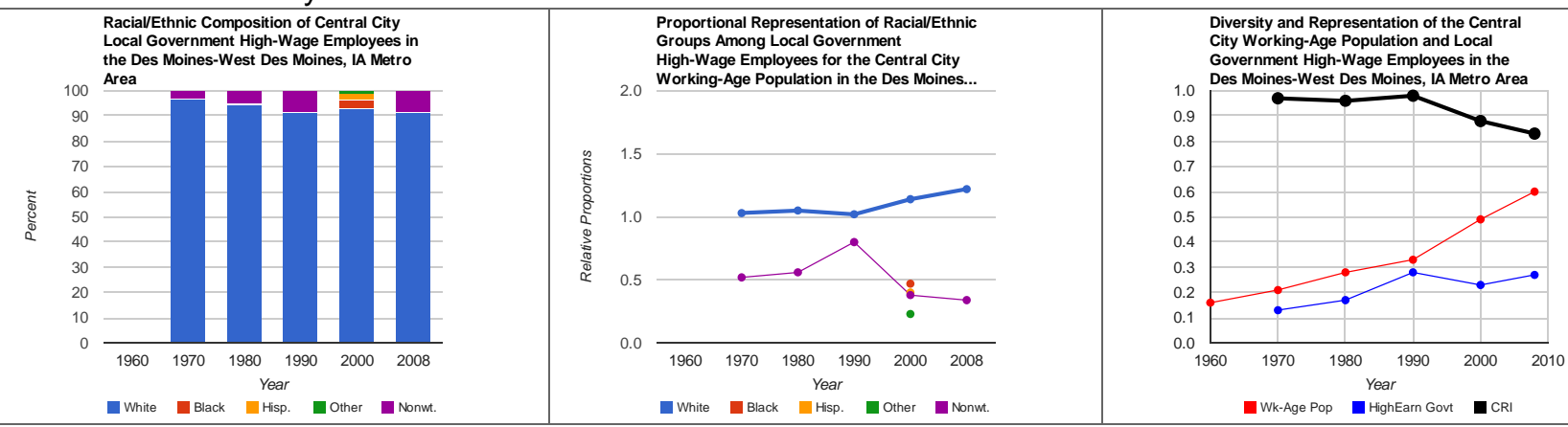
High- and Low-Wage Local Government Employment in the Des Moines-West Des Moines, IA Metro Area Local Government Low-Wage Employees in the Metro Area
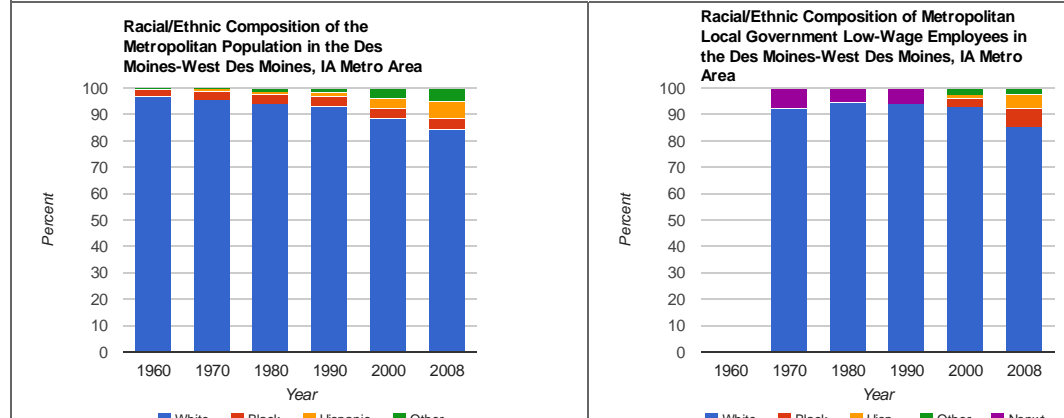

Local Government Low-Wage Employees in the Central City
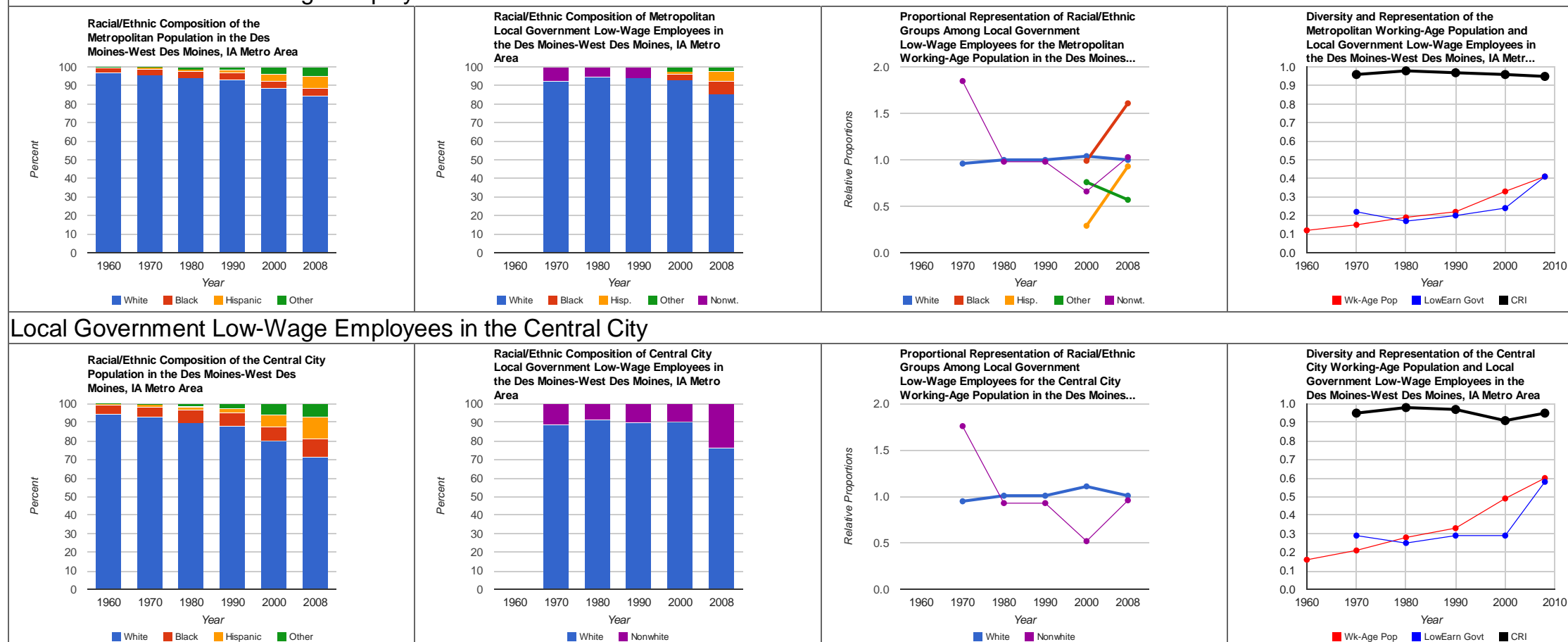

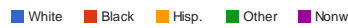

-Wk-Age Pop - Lowearn Govt - Crel

White $\square$ Black Hispanic $\quad$ Other

- White $\stackrel{\text { Year }}{\text { Nonwhite }}$

Low-Wage Employees on the Cont

Working-Age Population in the Des Moines... Diversity and Representation of the Centra
City Working-Age Population and Local
Government Low-Wage Employe col in the
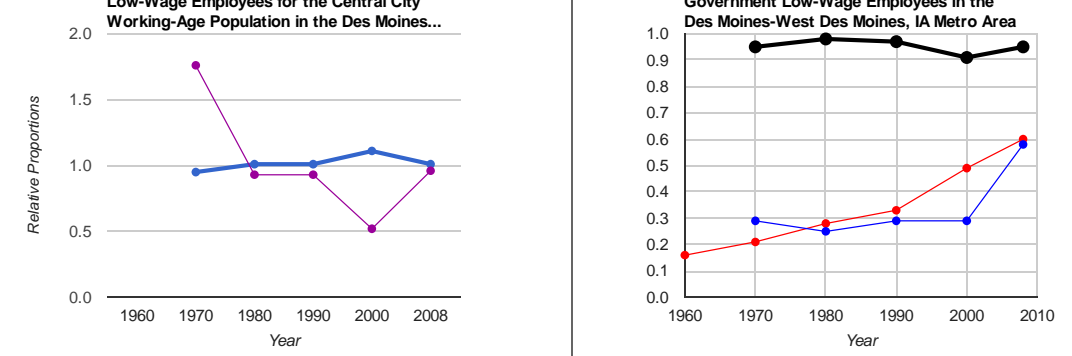

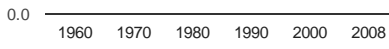
White Nonmhite

- Wk-Age Pop $\quad$ LowEarn Govt 
High- and Low-Wage Local Government Employment in the Detroit-Warren-Livonia, MI Metro Area Detroit-Warren-Livonia, MI

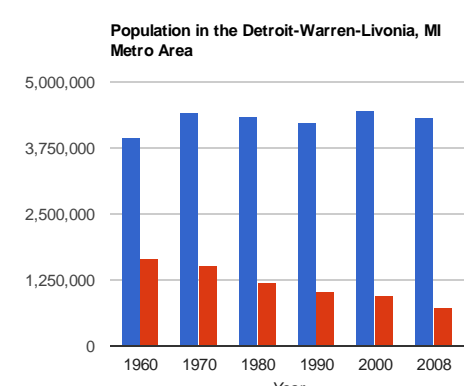

Metro Area Info

Population
Year Rank Metro Area Central City

\begin{tabular}{|l|r|r|r|}
\hline 1960 & 5 & 3951491 & 1670144 \\
\hline 1970 & 5 & 4431390 & 1511336
\end{tabular}

\begin{tabular}{|l|l|l|l|}
1970 & 5 & 4431390 & 1511336 \\
\hline 1980 & 5 & 4353413 & 1203339 \\
\hline
\end{tabular}

\begin{tabular}{l|lll|l|l|l}
1980 & 5 & 4353413 & 1203339 \\
\hline 1990 & 5 & 4248699 & 1027974 \\
\hline
\end{tabular}

$2000 \quad 0 \quad 94452557 \quad 951270$

$2008 \quad 12 \quad 4320082 \quad 738223$
Region: Midwest

Notes

- For all years metro area as defined in December 2009

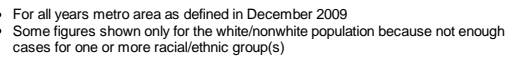


High- and Low-Wage Local Government Employment in the Detroit-Warren-Livonia, MI Metro Area

Local Government High-Wage Employees in the Metro Area
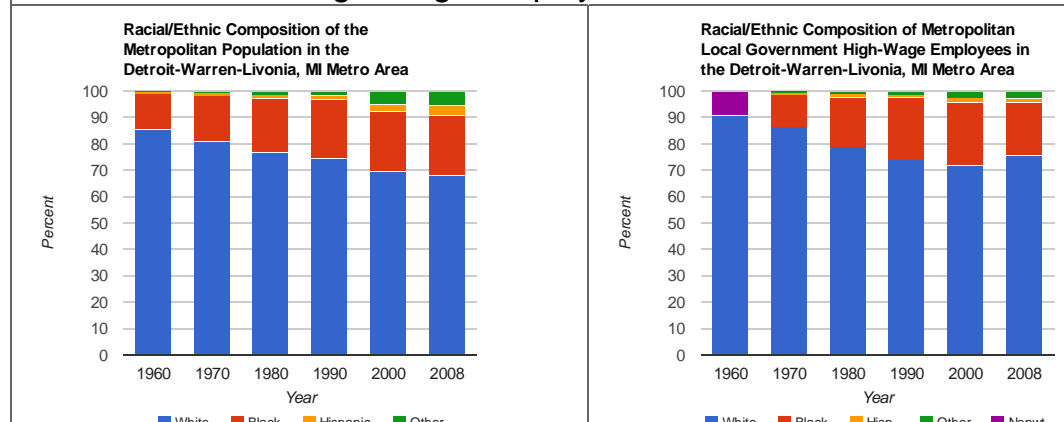

Local Government High-Wage Employees in the Central City
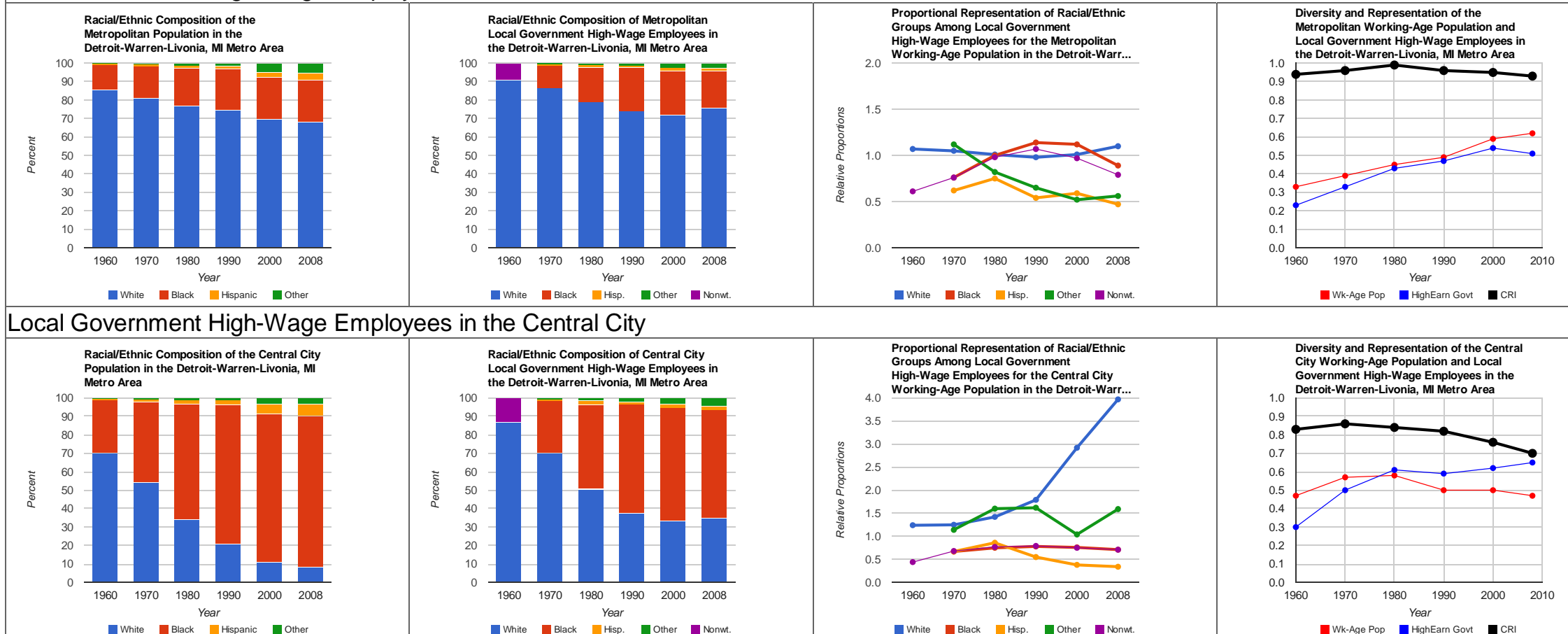

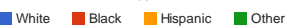

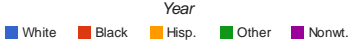

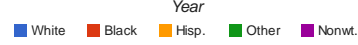

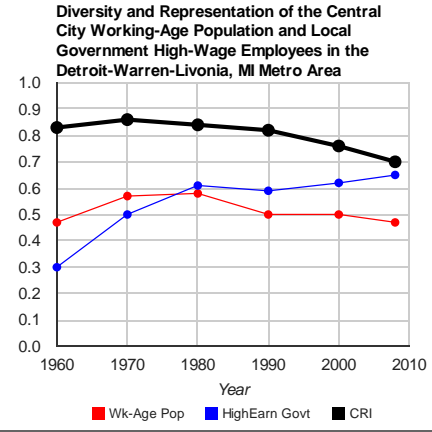


High- and Low-Wage Local Government Employment in the Detroit-Warren-Livonia, MI Metro Area

Local Government Low-Wage Employees in the Metro Area
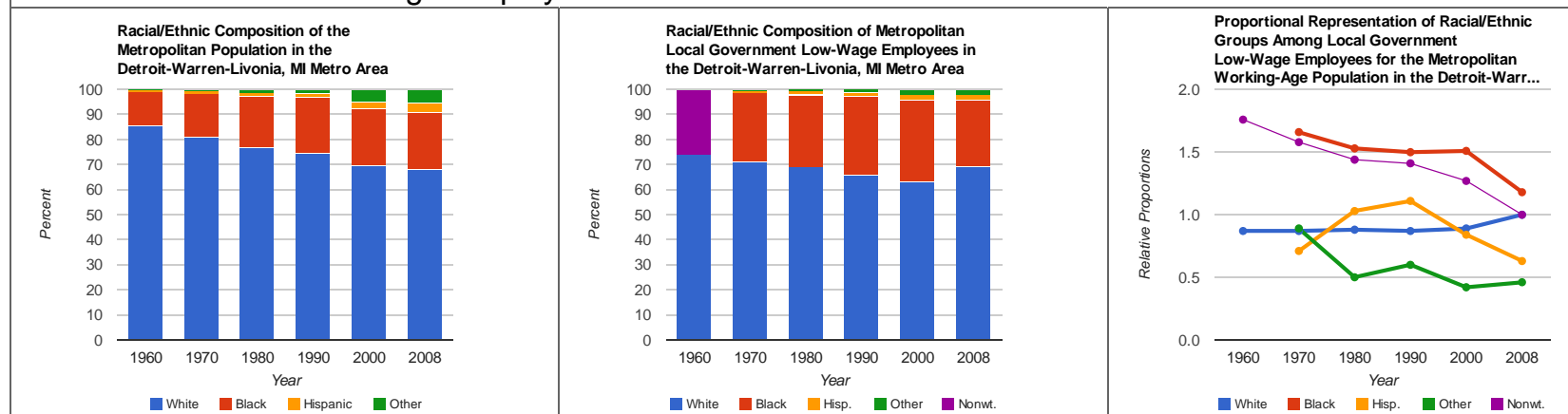

\section{Diversity and Representation of the
Metropolitan Working-Age Population and} Local Government Low-Wage Employees in
the Detroit-Warren-Livonia, MI Metro Area

White Black Hispanic Eother

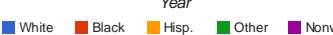

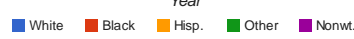

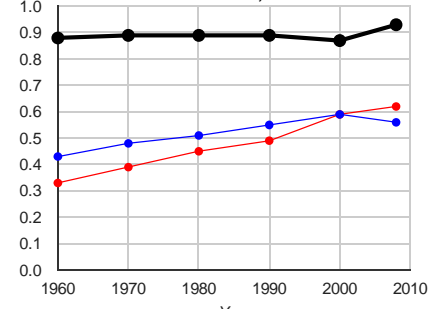

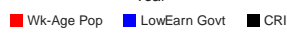

Local Government Low-Wage Employees in the Central City

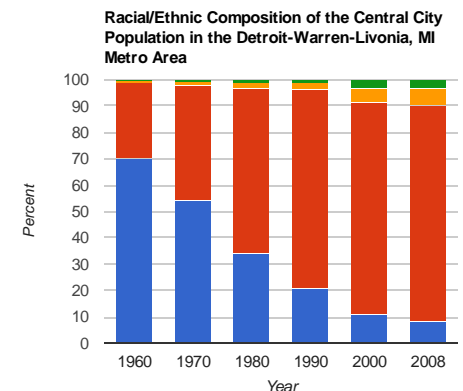

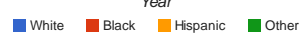

RaciallEthnic Composition of Central City
Local Gover the Detroit-Warren-Livonia, MI Metro Area

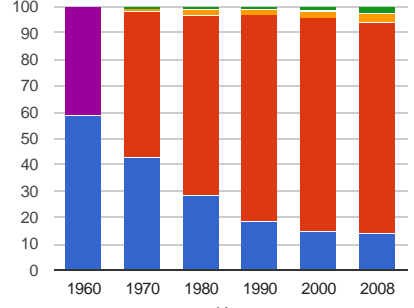

G White
Proportional Representation of Raciall/Ethnic Groups Among Local Government
Low-Wage Employees for the Central 20 Working-Age Population in the Detroit-Warr...

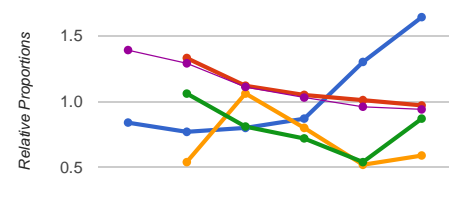

\begin{tabular}{lllllll}
0.0 & \multicolumn{1}{c}{1960} & 1970 & 1980 & 1990 & 2000 & 2008
\end{tabular}

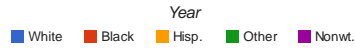

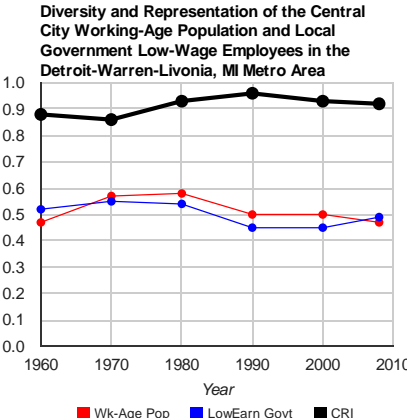

- Wk-Age Pop Lowearn Govt Ca 
High- and Low-Wage Local Government Employment in the El Paso, TX Metro Area

El Paso, TX

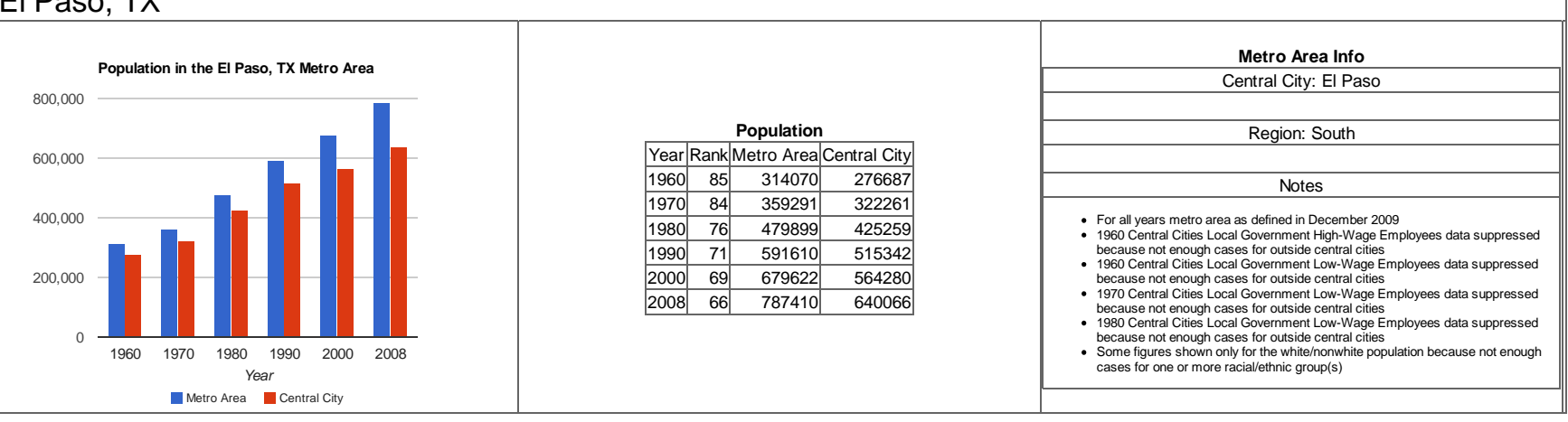


High- and Low-Wage Local Government Employment in the El Paso, TX Metro Area

Local Government High-Wage Employees in the Metro Area
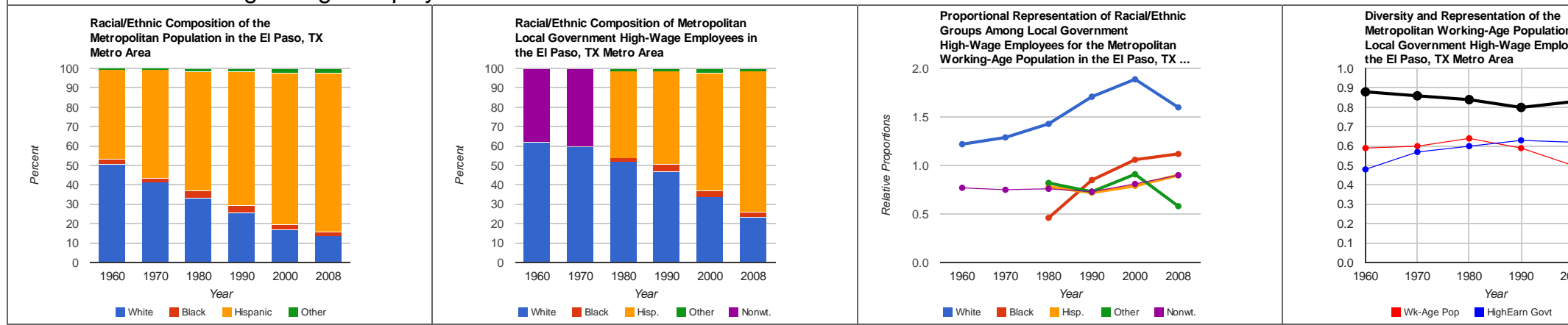

Metropolitan Working-Age Population and

the El Paso, TX Metro Area

White Black Hispanic Wothe

White Black Year Hisp. Wother @ Nonm.

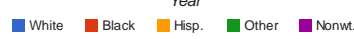

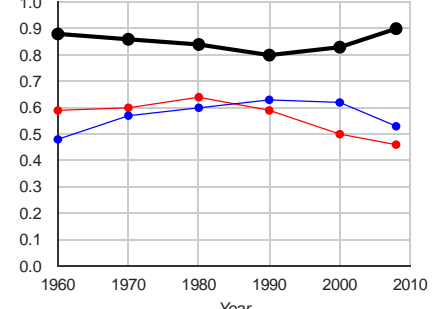

Ww-Age Pop HighEarn Govt $\mathrm{C}$

Local Government High-Wage Employees in the Central City

Raciallethnic Composition of the Central City
Population in the EI Paso, TX Metro Area

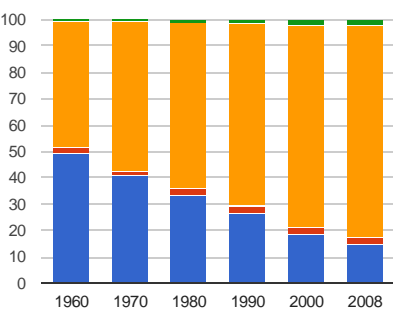

RaciallEthnic Composition of Central City
Local Government High-Wage Employees in

100

作

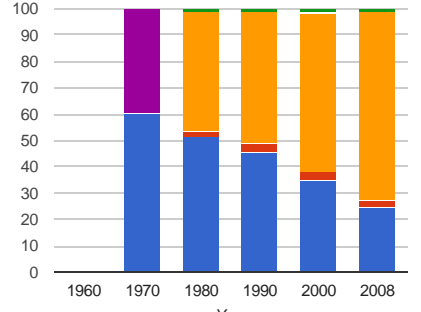

White Elack Year Hispanic Inother

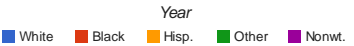

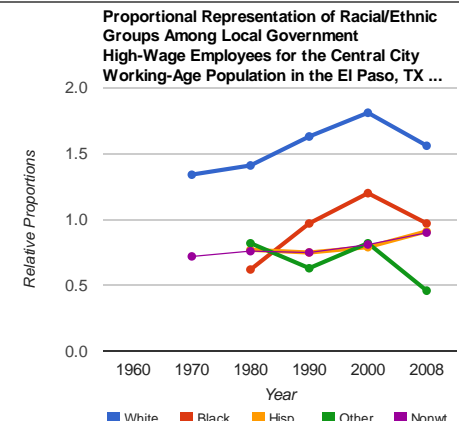

Diversity and Representation of the Central
City Working-Age Population and Local

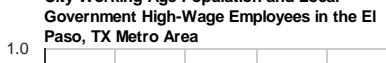

1.0
0.9

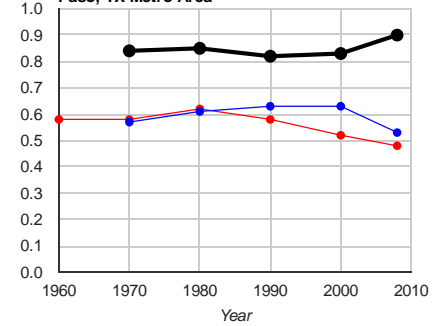

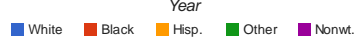

-Wk-Age Pop - HighEarn Govt - 
High- and Low-Wage Local Government Employment in the El Paso, TX Metro Area

Local Government Low-Wage Employees in the Metro Area
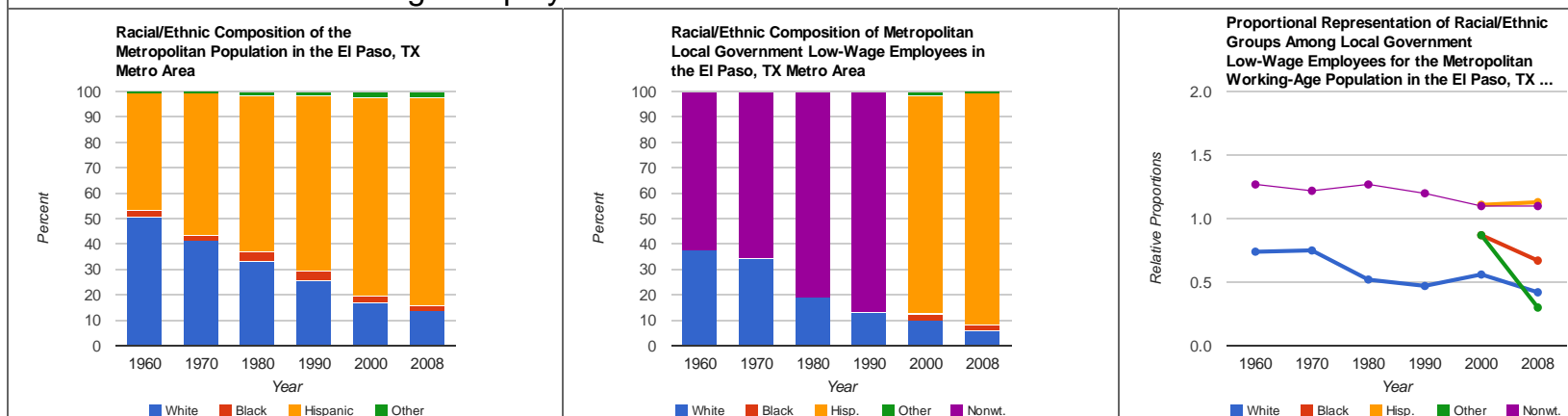
Diversity and Representation of the
Metropolitan Working-Age Population and the El Paso, TX Metro Area
to White Black Hisp. Other Nonm.

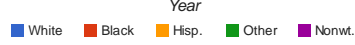

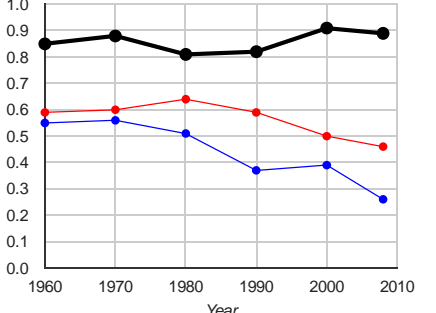

-Wk-Age Pop L LowEarn Govt

Local Government Low-Wage Employees in the Central City

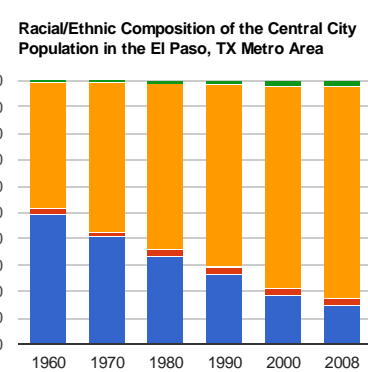

- White Black Year

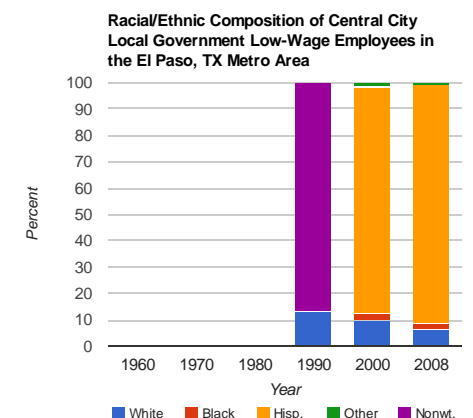

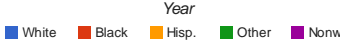

Proportional Representation of Raciall/Ethnic
Groups Among Local Government
Low-Wage Employees for the Central City

20 Working-Age Population in the EI Paso, TX ...

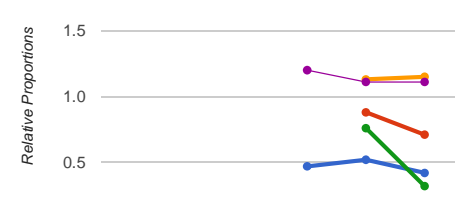

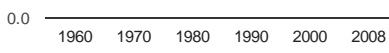
- White Black Year

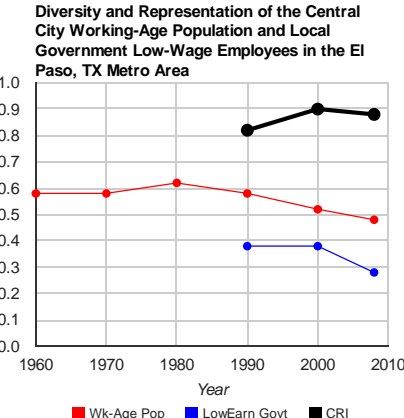

Wk-Age Pop Lowearn Govt 


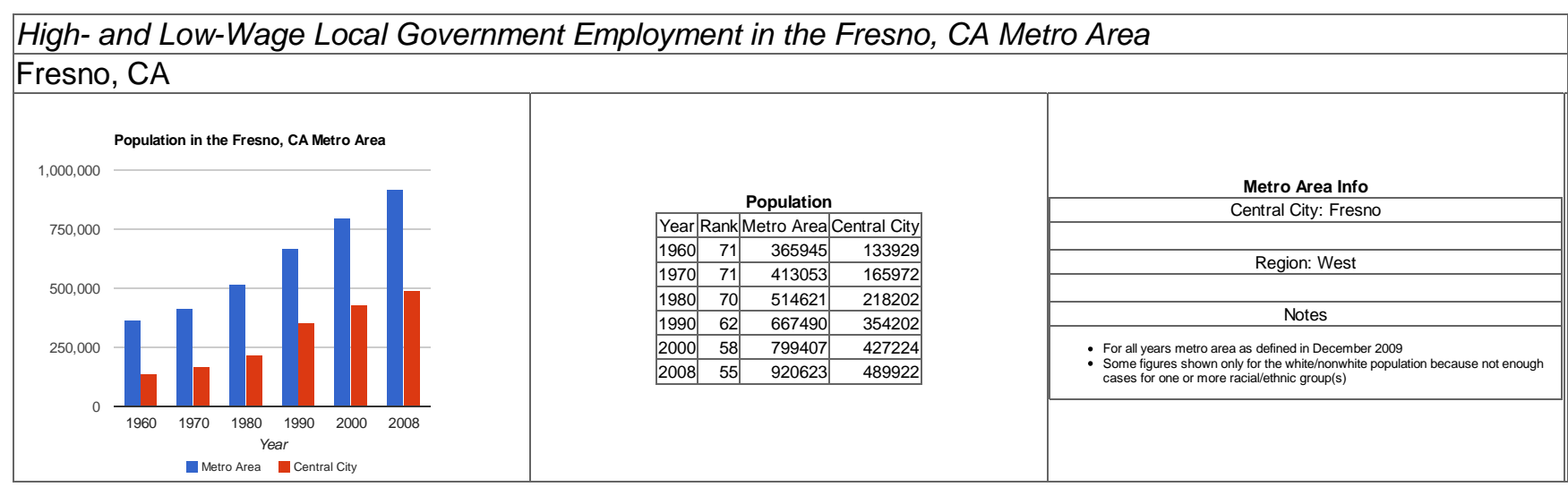


High- and Low-Wage Local Government Employment in the Fresno, CA Metro Area

Local Government High-Wage Employees in the Metro Area
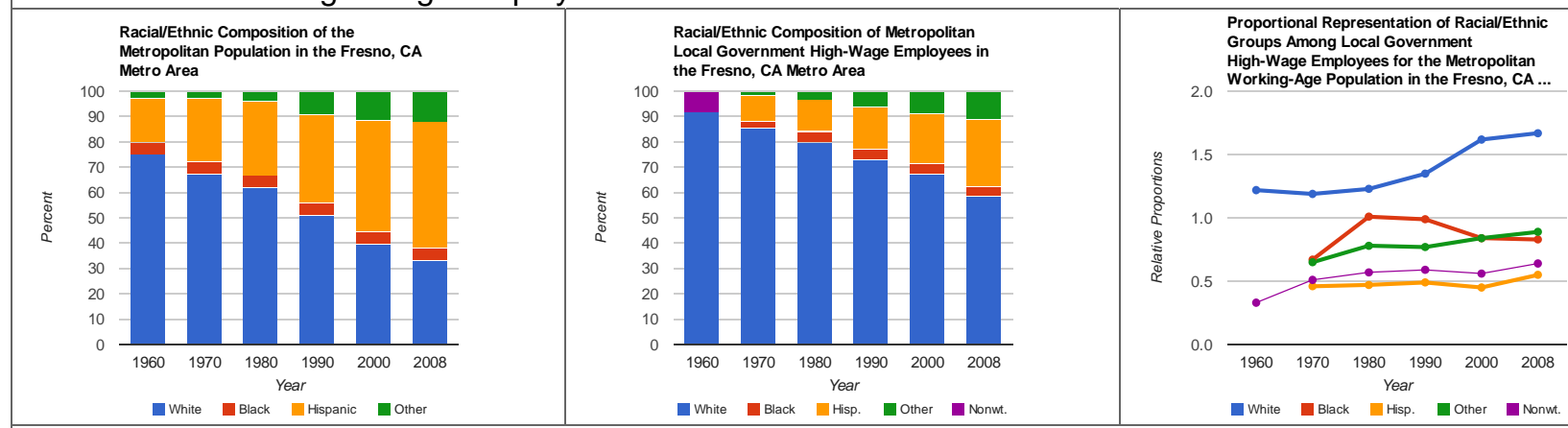
Diversity and Representation of the
Metropolitan Working-Age Population and
Local Government High-Wage Employees in the Fresno, CA Metro Area

White Black Hispanic Eother White $\square$ Black $\square$ Hisp.

Local Government High-Wage Employees in the Central City
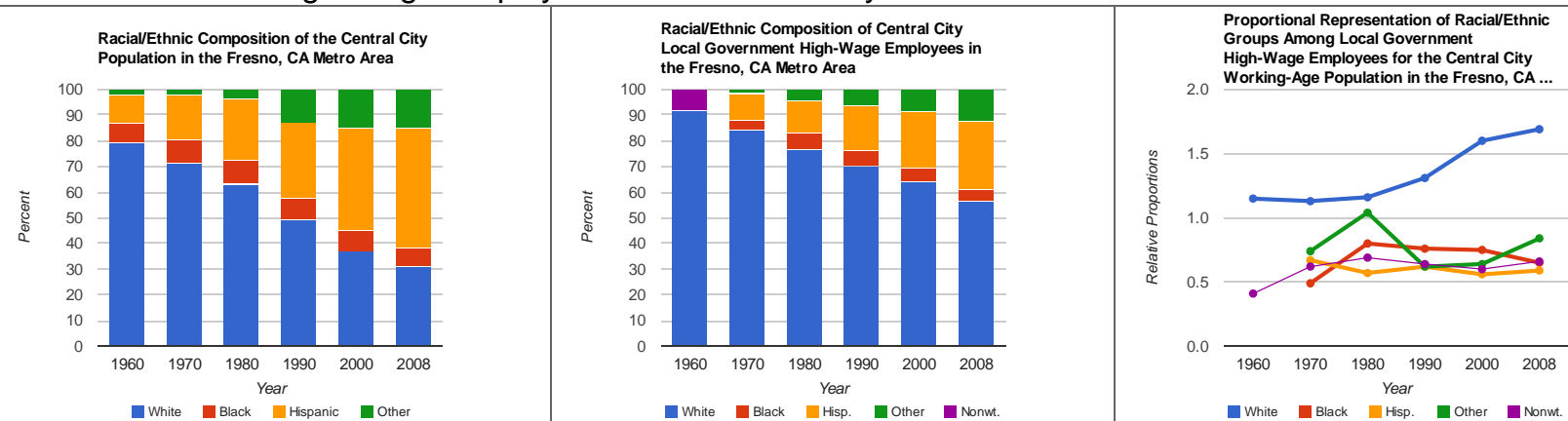

Diversity and Representation of the Central City Working-Age Population and Local Fresno, CA Metro Area

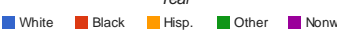

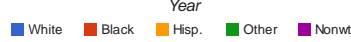

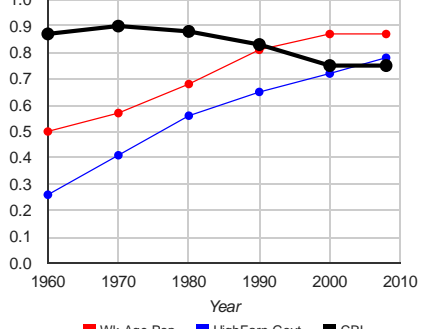

-Wk-Age Pop — HighEarn Govt a CRI 
High- and Low-Wage Local Government Employment in the Fresno, CA Metro Area

Local Government Low-Wage Employees in the Metro Area
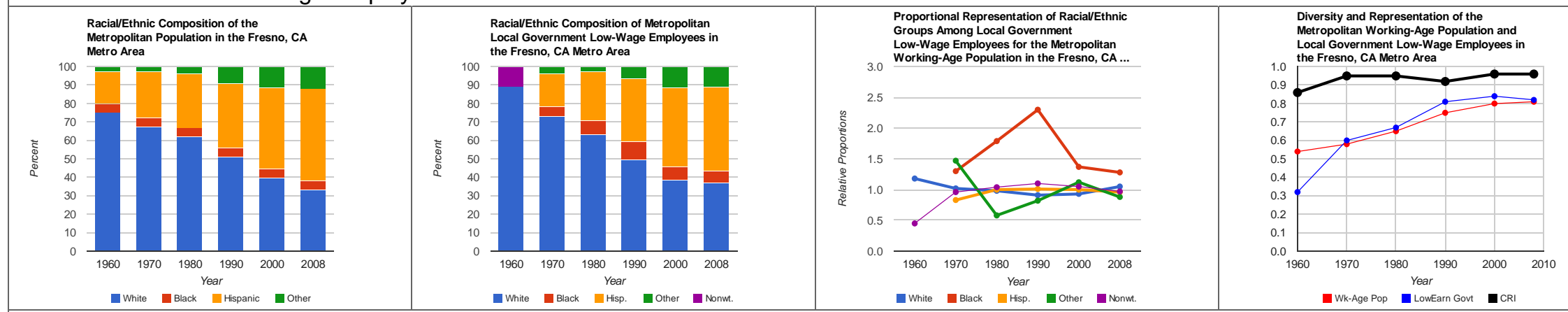

Local Government Low-Wage Employees in the Central City
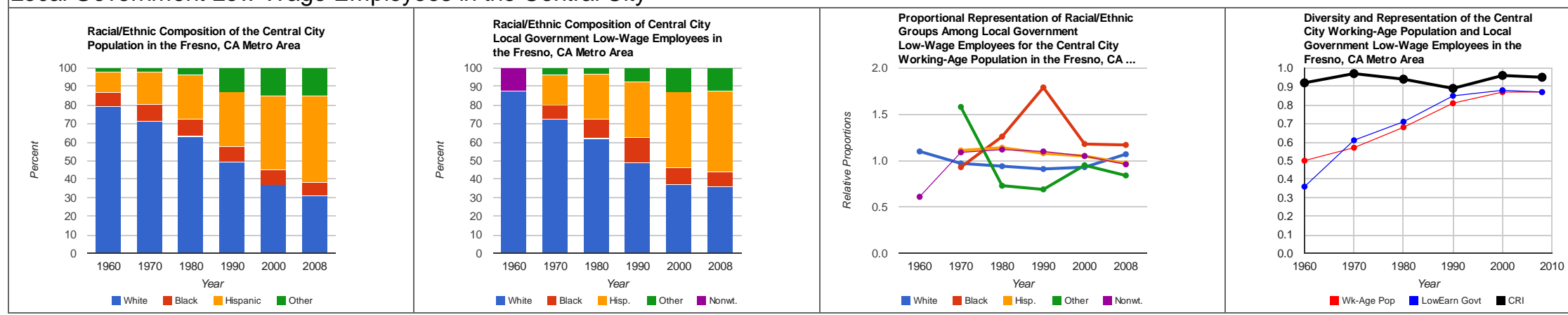


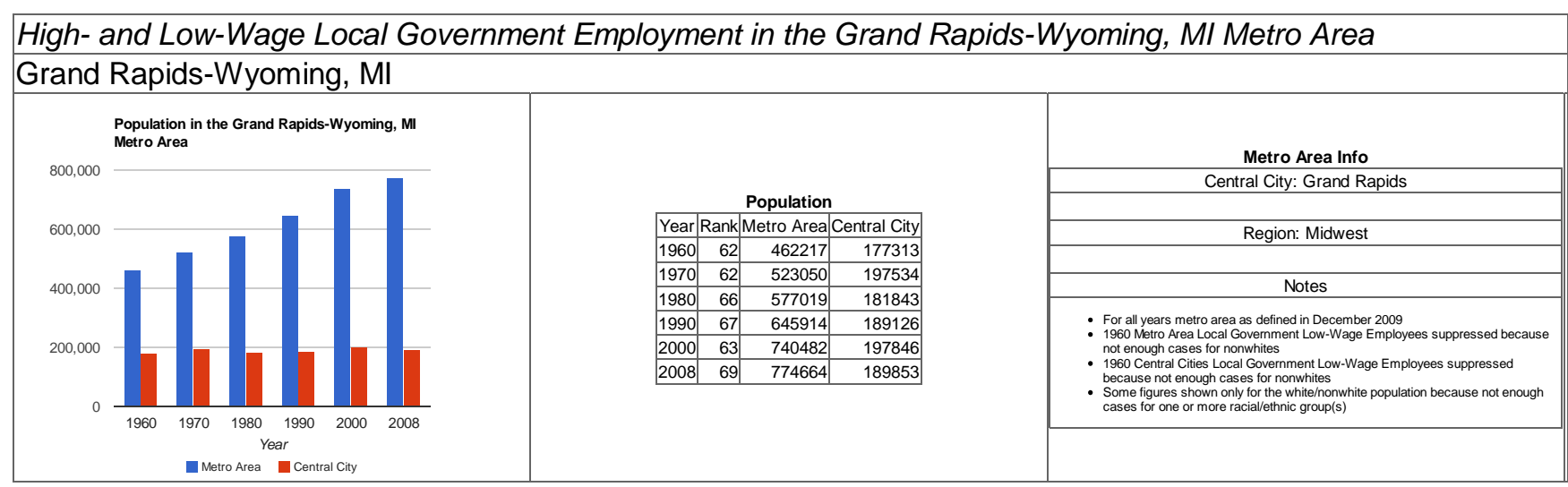


High- and Low-Wage Local Government Employment in the Grand Rapids-Wyoming, MI Metro Area

Local Government High-Wage Employees in the Metro Area
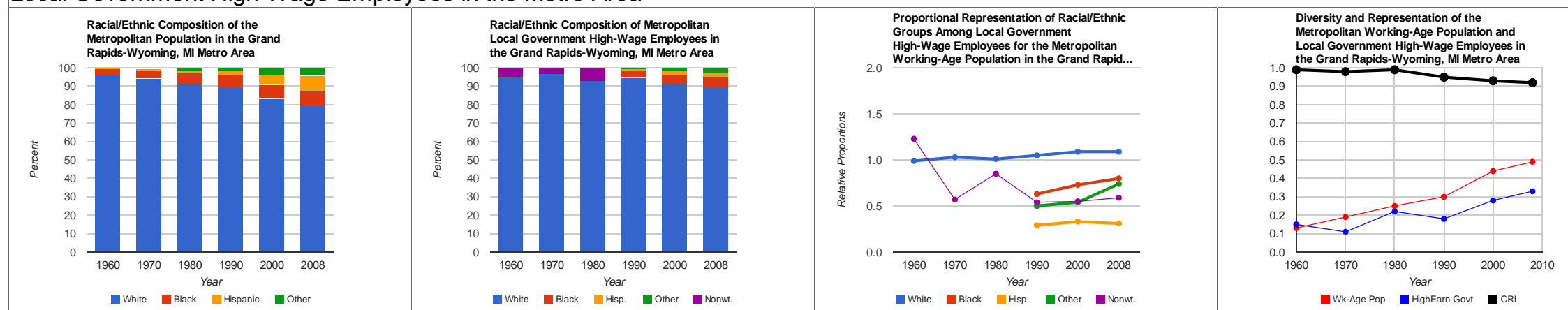

Local Government High-Wage Employees in the Central City
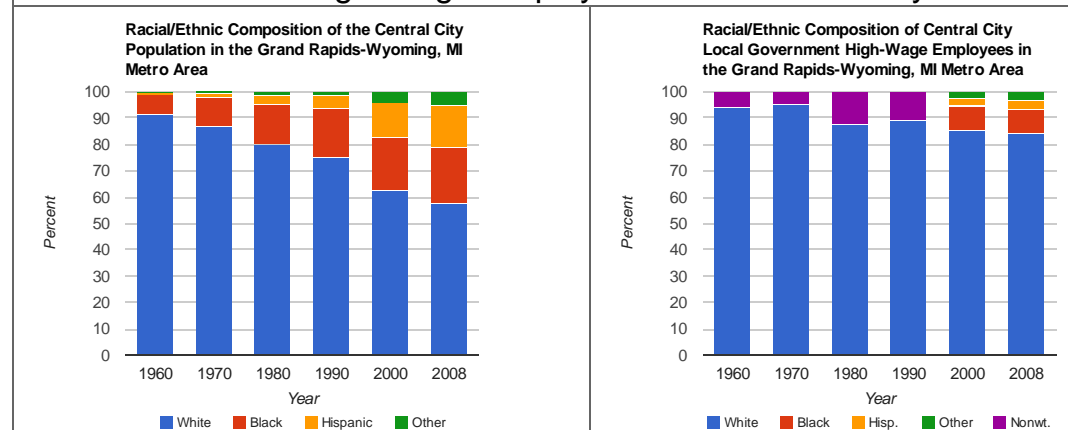
Proportional Representation of Raciall/Ethnic
Groups Among Local Government
High-Wage Employees for the Central City Working-Age Population in the Grand Rapid... White Elack YHispanic Inother

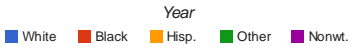
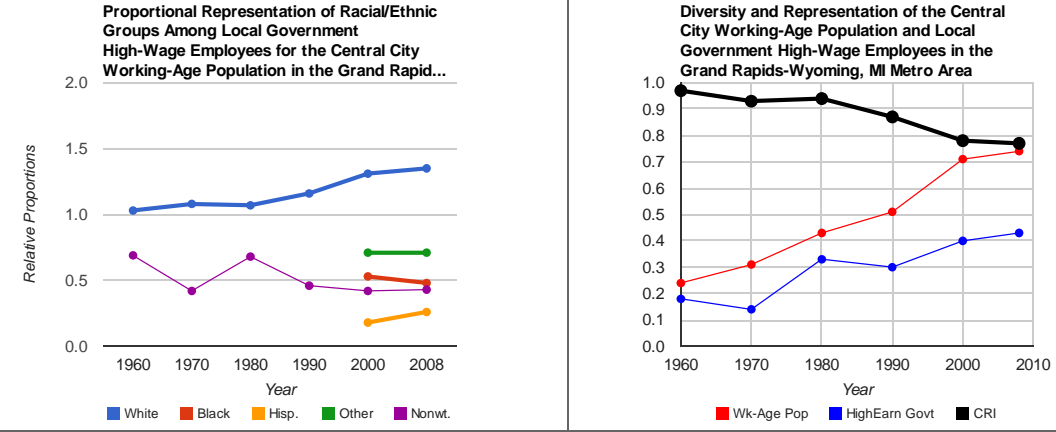
High- and Low-Wage Local Government Employment in the Grand Rapids-Wyoming, MI Metro Area

Local Government Low-Wage Employees in the Metro Area
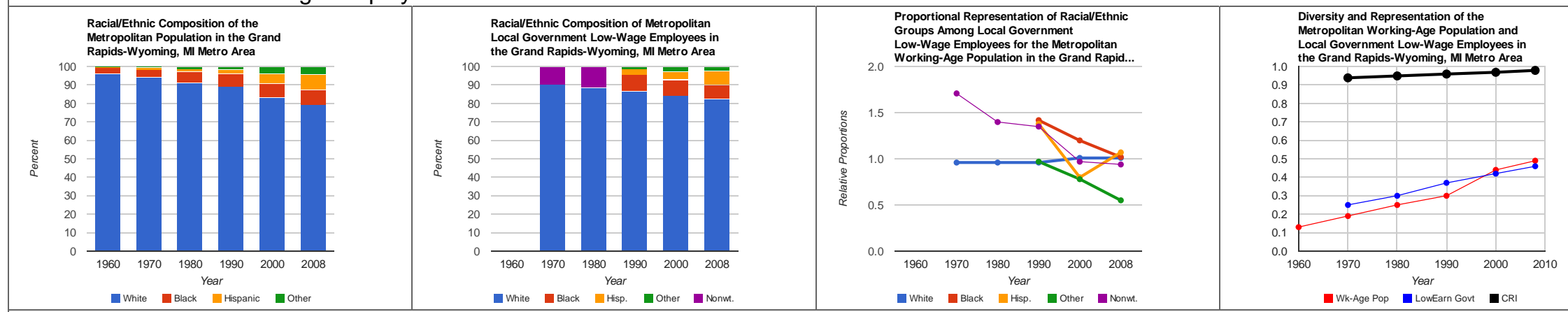

Local Government Low-Wage Employees in the Central City
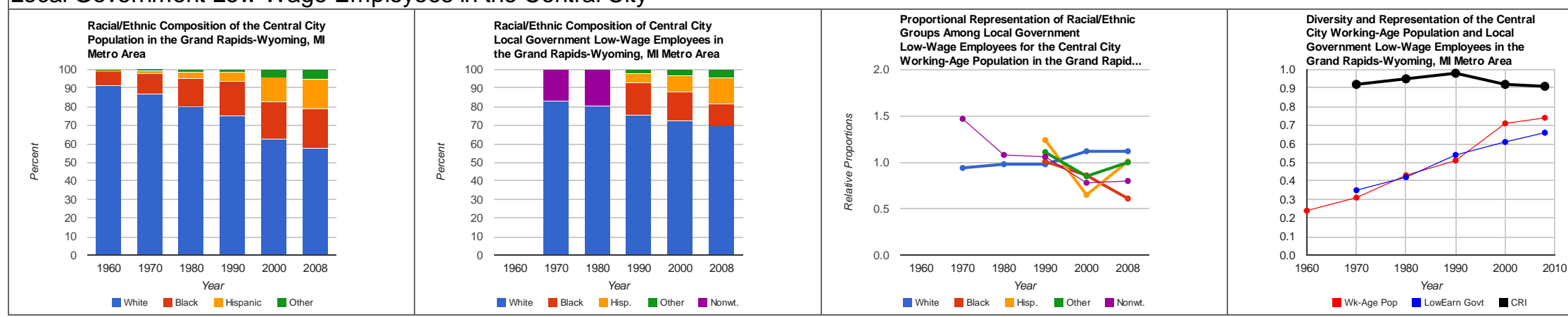


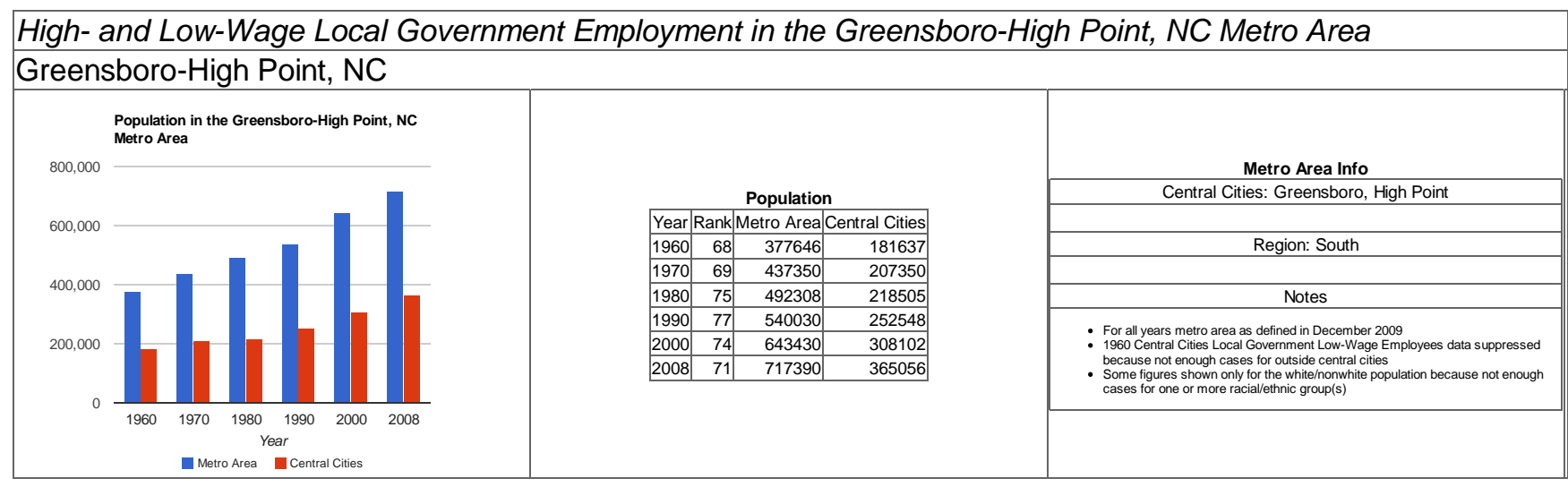


High- and Low-Wage Local Government Employment in the Greensboro-High Point, NC Metro Area Local Government High-Wage Employees in the Metro Area
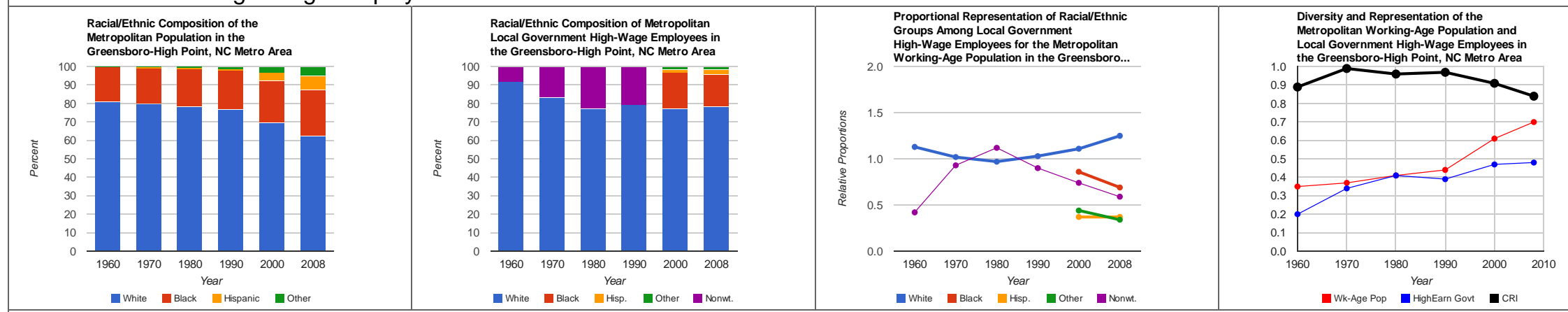

Local Government High-Wage Employees in the Central Cities
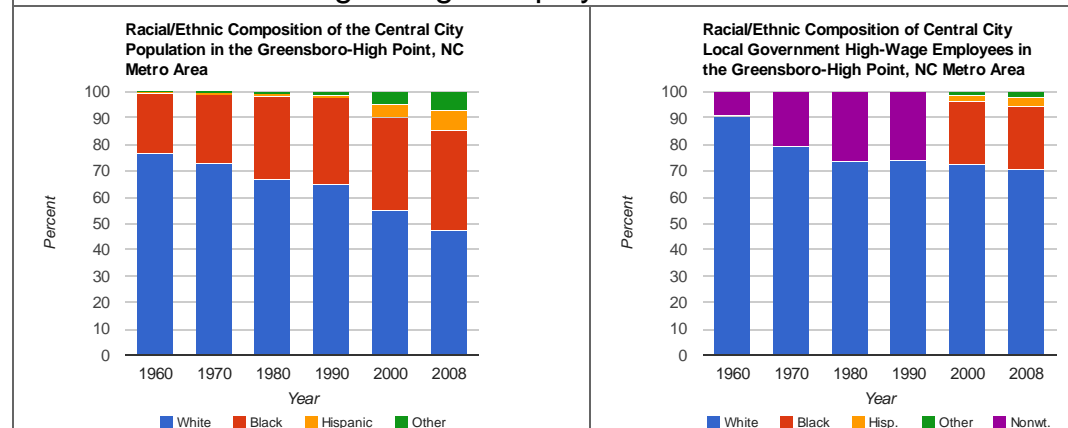
Proportional Representation of Raciall/Ethnic
Groups Among Local Government
High-Wage Employees for the Central City Working-Age Population in the Greensboro... White Elack YHispanic Mother

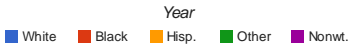

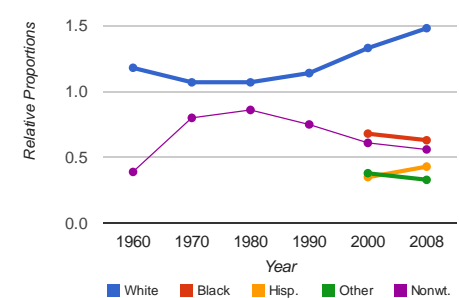
Diversity and Representation of the Central
City Working-Age Population and Local
Government High-Wage Employees in the Government High-Wage Employees in the
Greensboro-High Point, NC Metro Area Metro Area

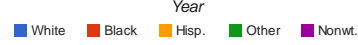

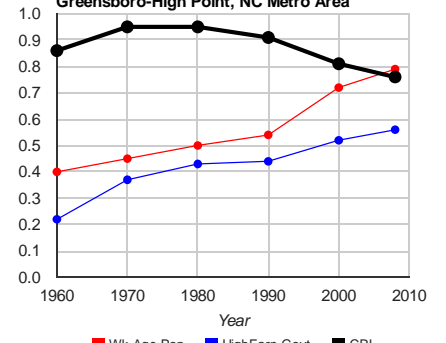

-Wk-Age Pop - Highearn Govt CR 
High- and Low-Wage Local Government Employment in the Greensboro-High Point, NC Metro Area Local Government Low-Wage Employees in the Metro Area
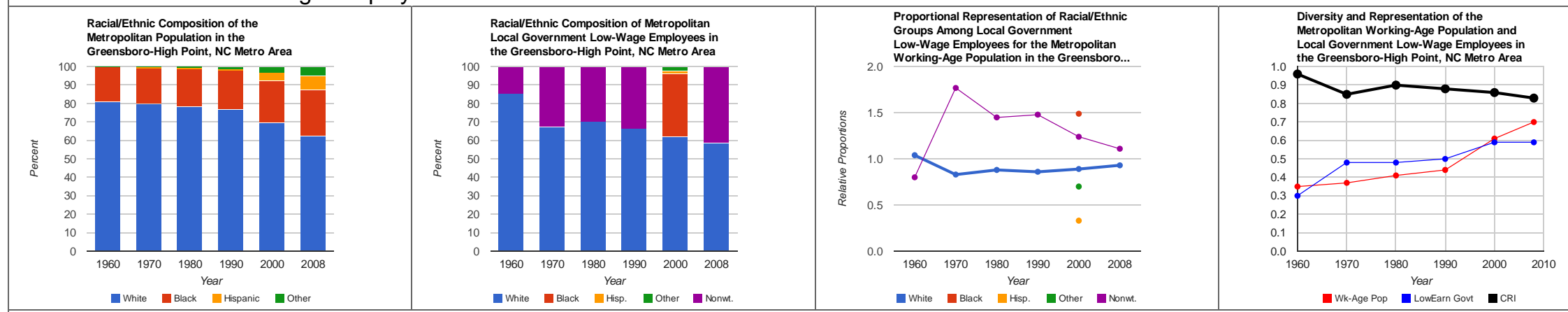

Local Government Low-Wage Employees in the Central Cities
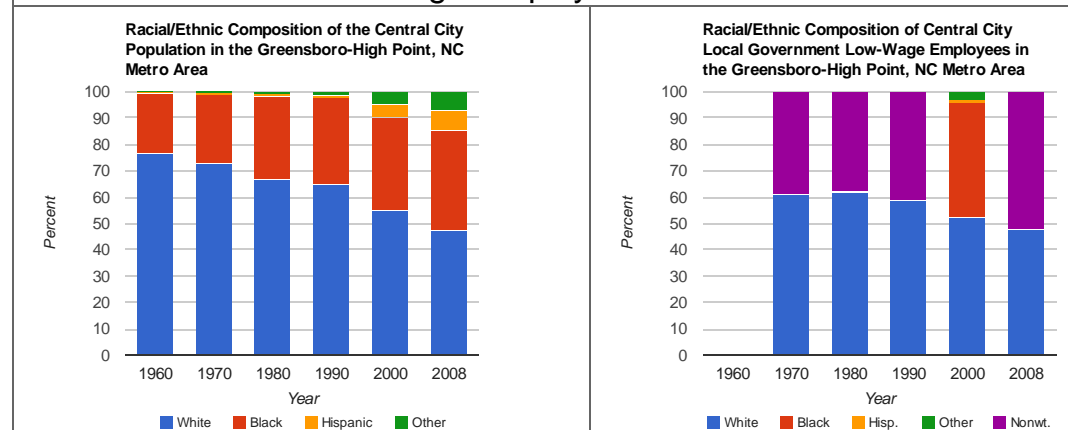
Proportional Representation of Raciall/thnic
Groups Among Local Government
Low-Wage Employees for the Central City Working-Age Population in the Greensboro... White Ulack Mispanic nother

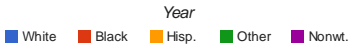

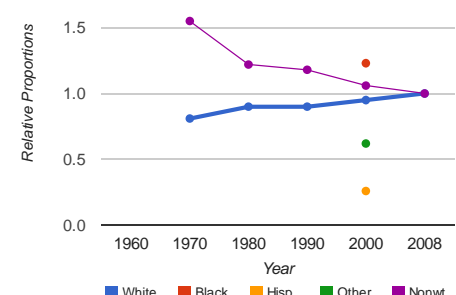
Diversity and Representation of the Central
City Working-Age Population and Local
Government Low-Wage Employees in the Government Low-Wage Employees in the
Greensboro-High Point, NC Metro Area Metro Area

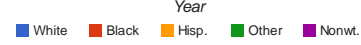

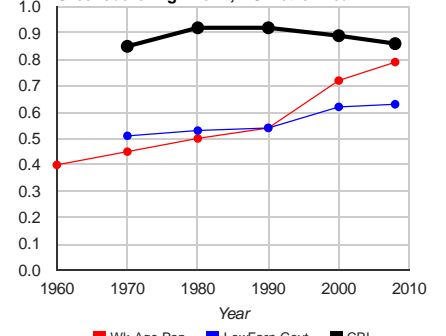

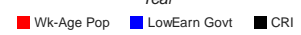




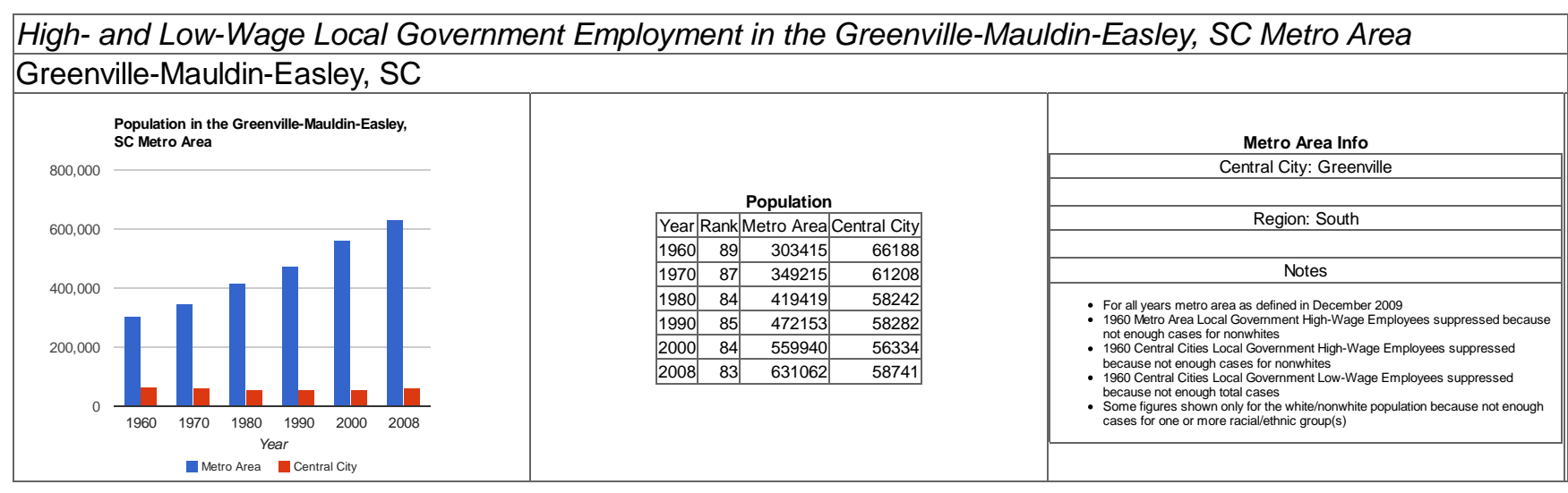


High- and Low-Wage Local Government Employment in the Greenville-Mauldin-Easley, SC Metro Area Local Government High-Wage Employees in the Metro Area
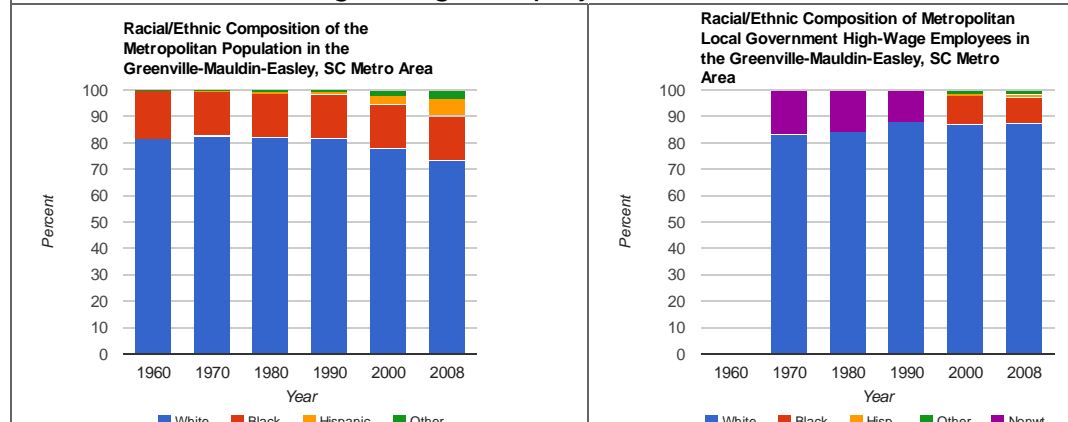

Local Government High-Wage Employees in the Central City
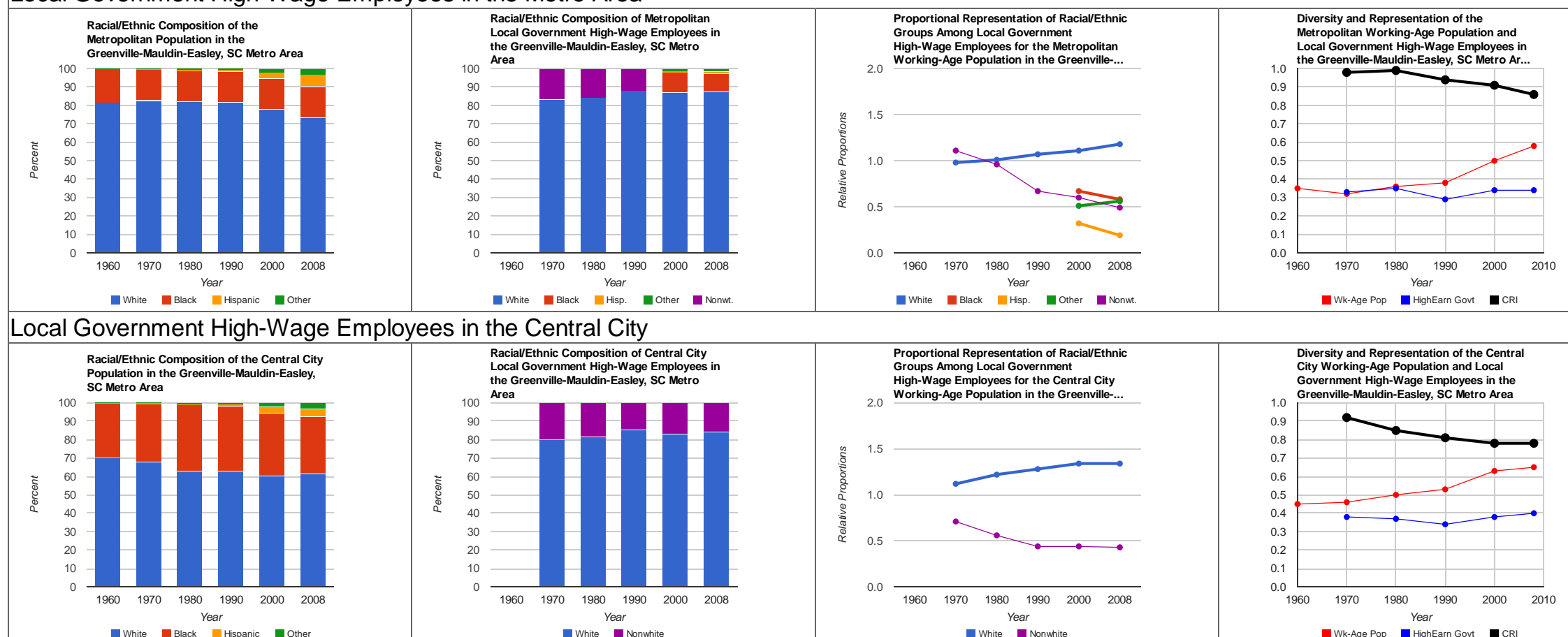

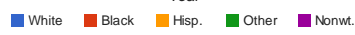

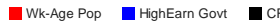

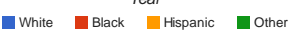

- White ${ }_{\text {Nonuhite }}^{\text {Year }}$

Proportional Representation of Racial/Ethnic
Groups Among Local Gol High-Wage Employees for the Central city
Working-Age Population in the Greenville-.

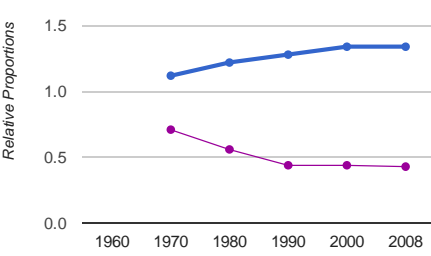

- White $\stackrel{\text { Year }}{\text { Nonmwite }}$

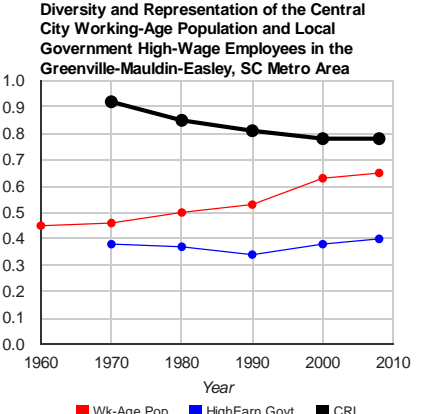

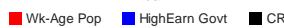


High- and Low-Wage Local Government Employment in the Greenville-Mauldin-Easley, SC Metro Area Local Government Low-Wage Employees in the Metro Area
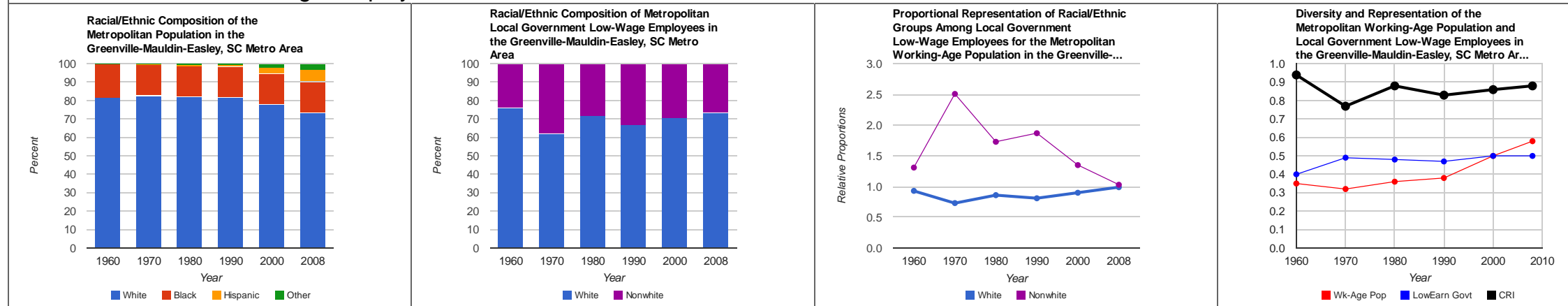

Local Government Low-Wage Employees in the Central City
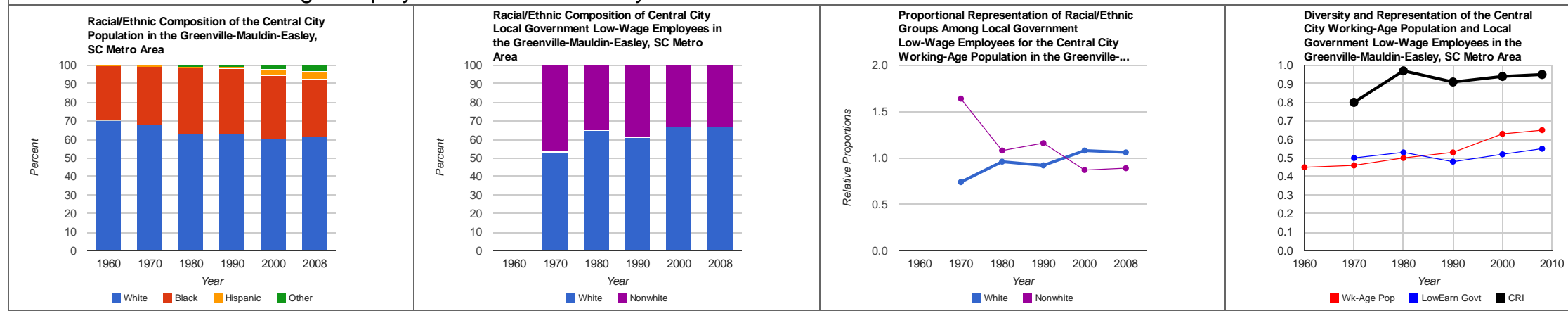


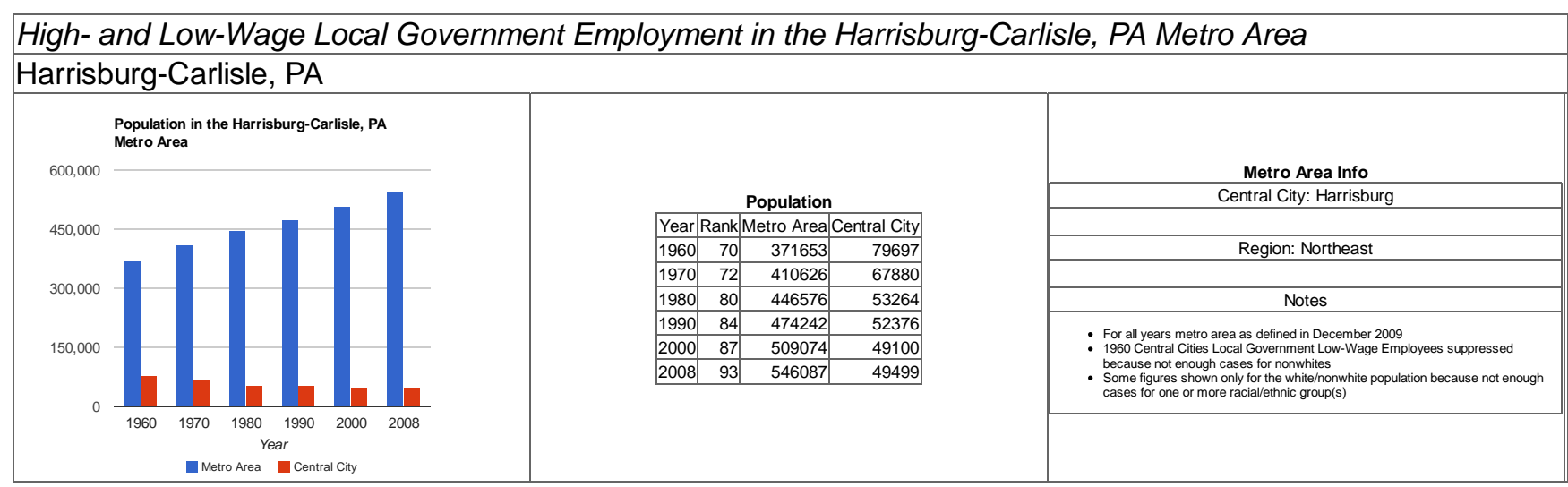


High- and Low-Wage Local Government Employment in the Harrisburg-Carlisle, PA Metro Area

Local Government High-Wage Employees in the Metro Area
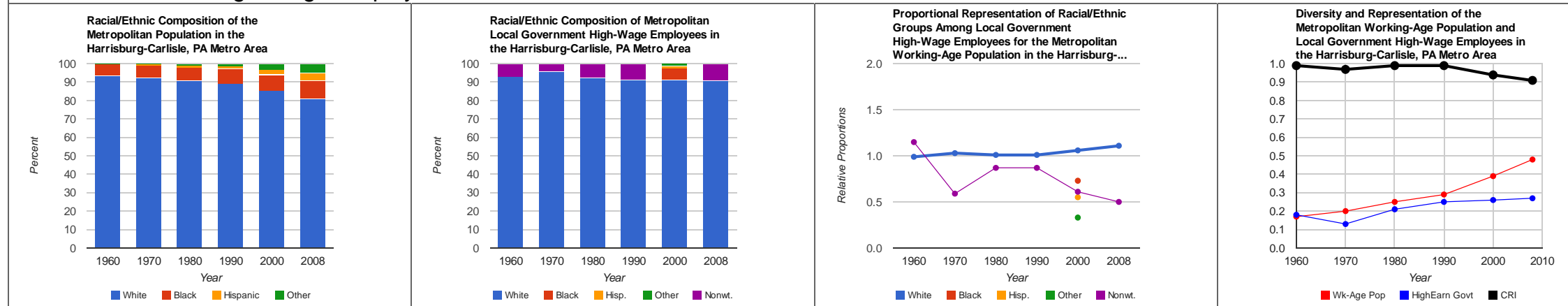

Local Government High-Wage Employees in the Central City
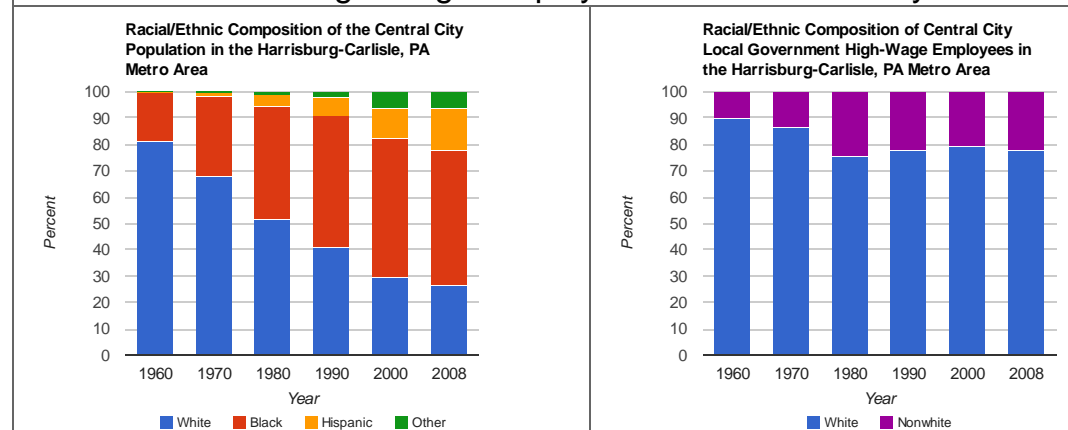
Proportional Representation of Raciall/thnic
Groups Among Local Government
High-Wage Employees for the Central City High-Wage Employees for the Central City
Working-Age Population in the Harrisburg...

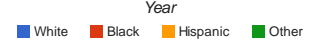
I White $\stackrel{\text { Year }}{\text { Nonwhite }}$

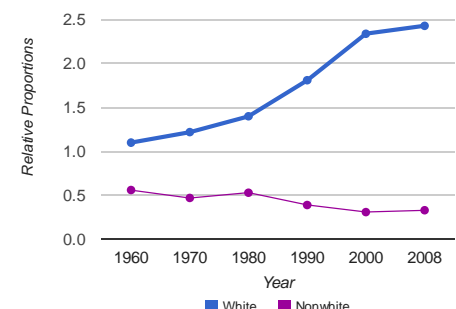
Diversity and Representation of the Central
City Working-Age Population and Local
Government High-Wage Employees in the Government High-Wage Employees in the
Harrisburg-Carlisle, PA Metro Area Metro Are White ${ }_{\text {Nonnwitis }}$

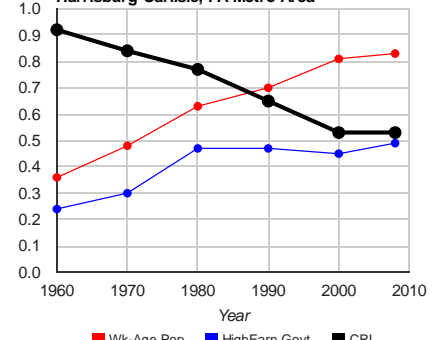

-Wk-Age Pop - Highearn Govt - CRI 
High- and Low-Wage Local Government Employment in the Harrisburg-Carlisle, PA Metro Area

Local Government Low-Wage Employees in the Metro Area
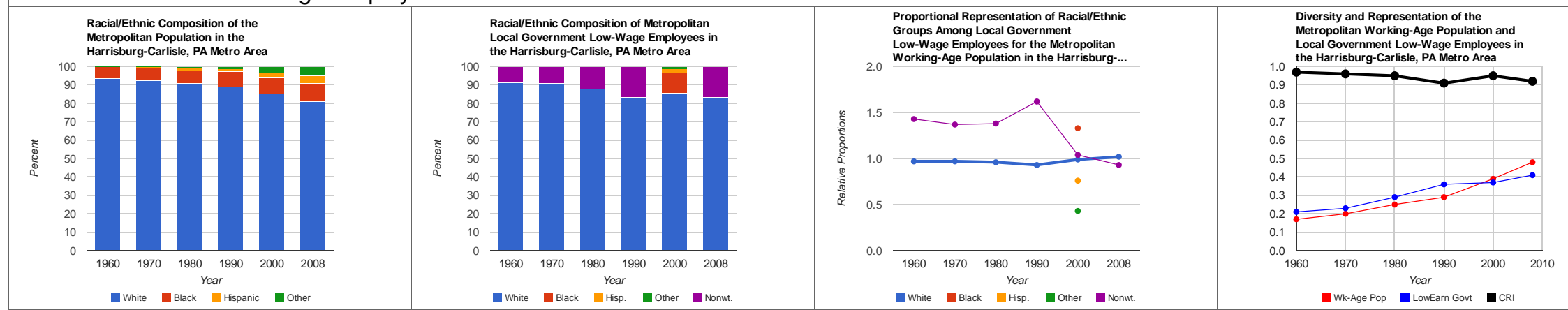

Local Government Low-Wage Employees in the Central City
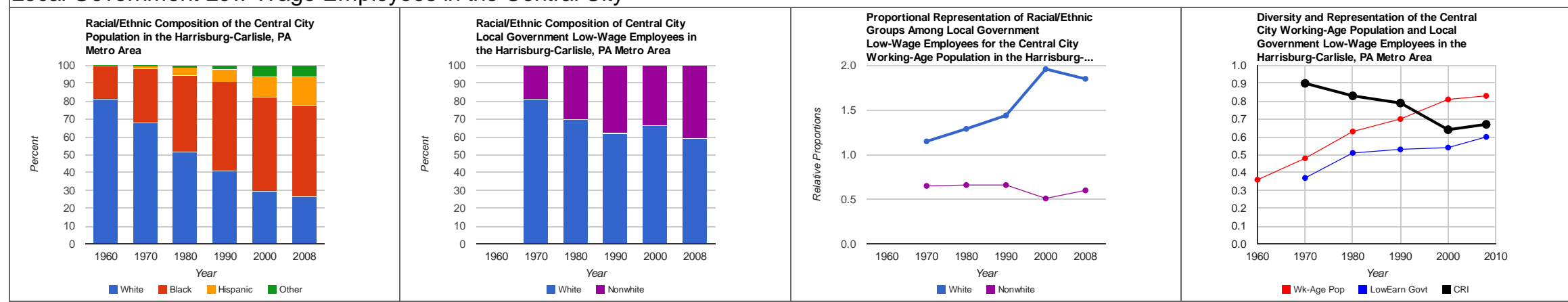


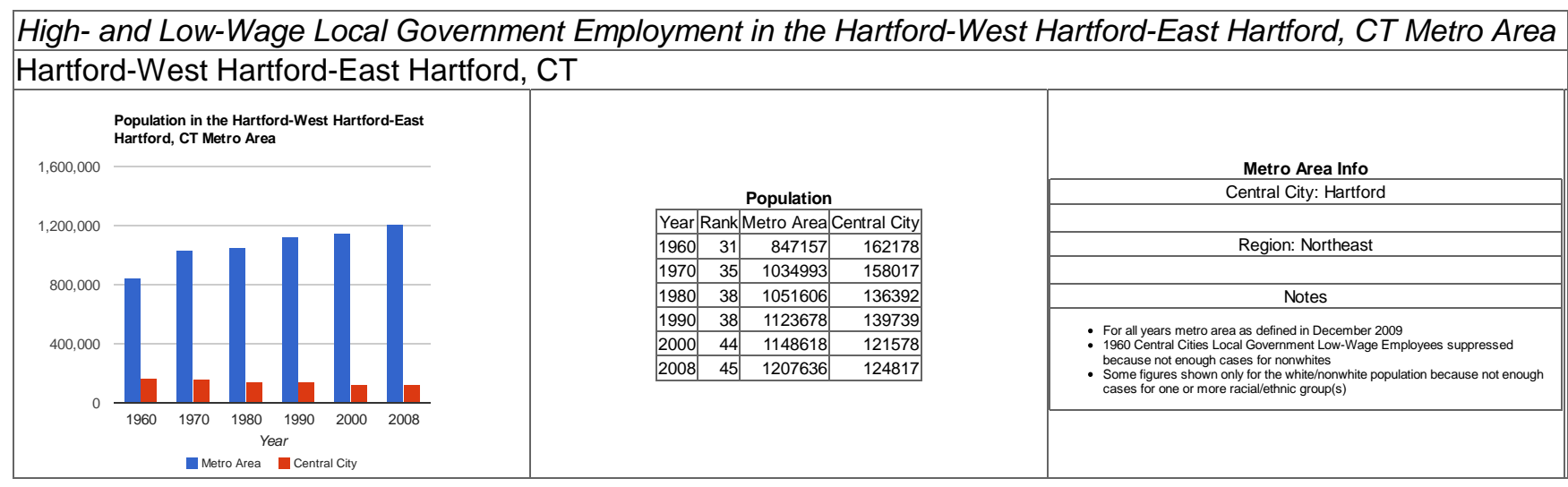


High- and Low-Wage Local Government Employment in the Hartford-West Hartford-East Hartford, CT Metro Area Local Government High-Wage Employees in the Metro Area
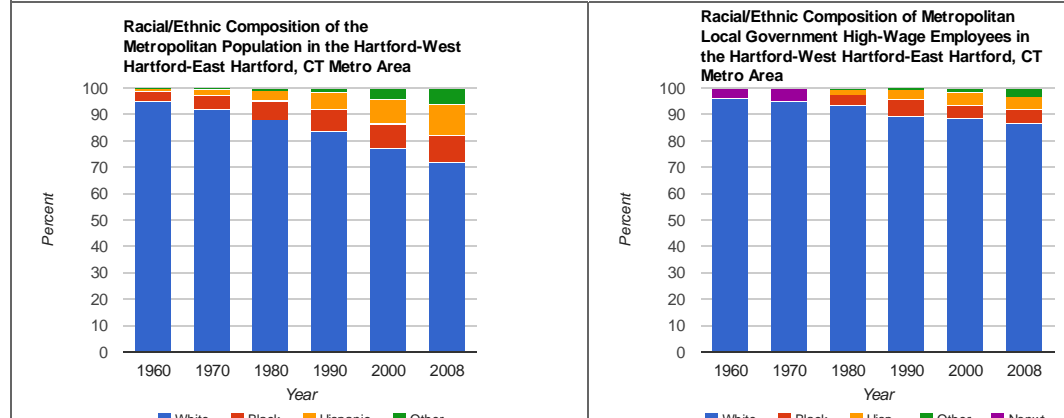

Local Government High-Wage Employees in the Central City
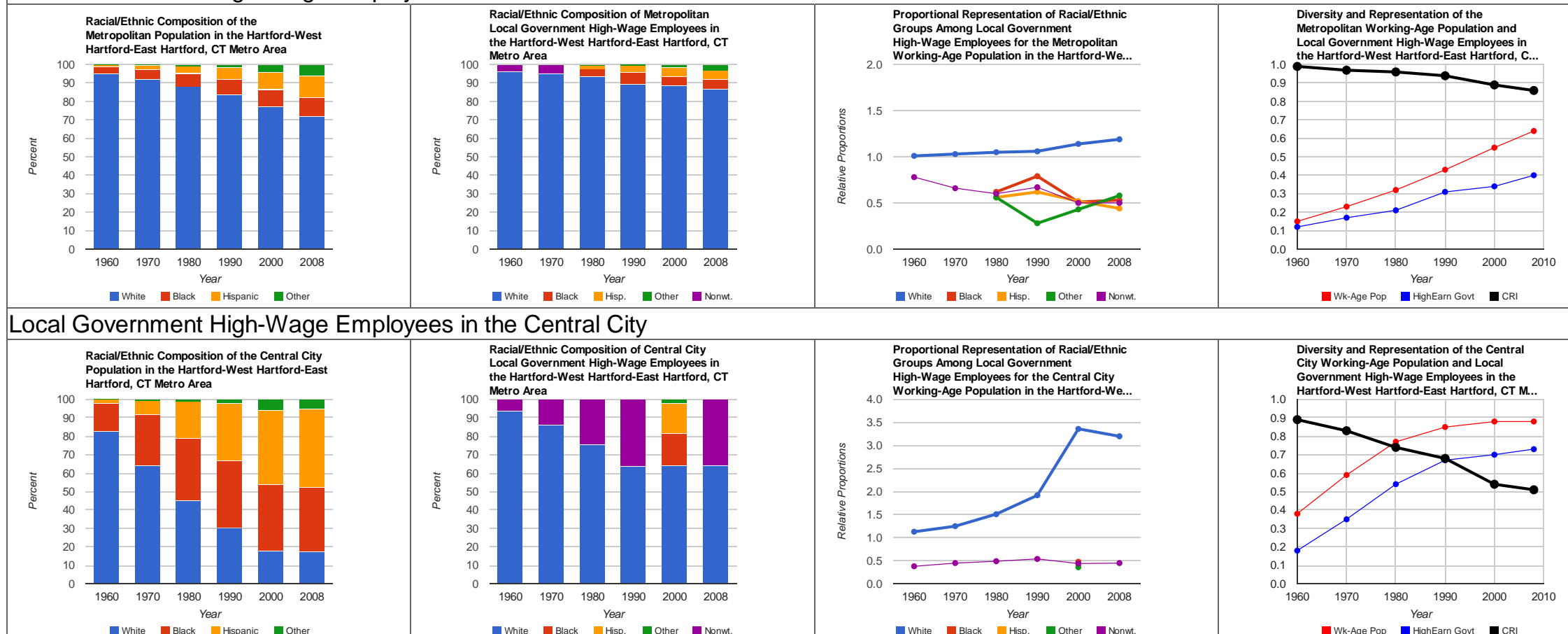

-Wk-Age Pop M HighEarn Govt MCRI

White Black Year

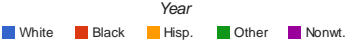

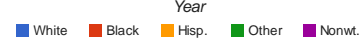

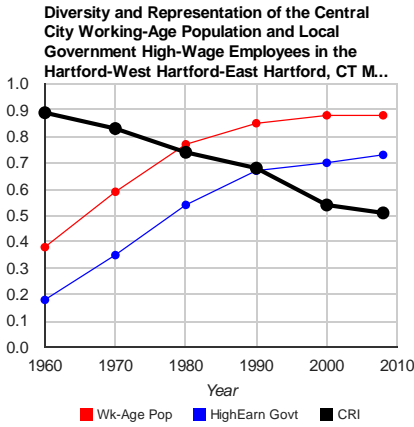


High- and Low-Wage Local Government Employment in the Hartford-West Hartford-East Hartford, CT Metro Area Local Government Low-Wage Employees in the Metro Area
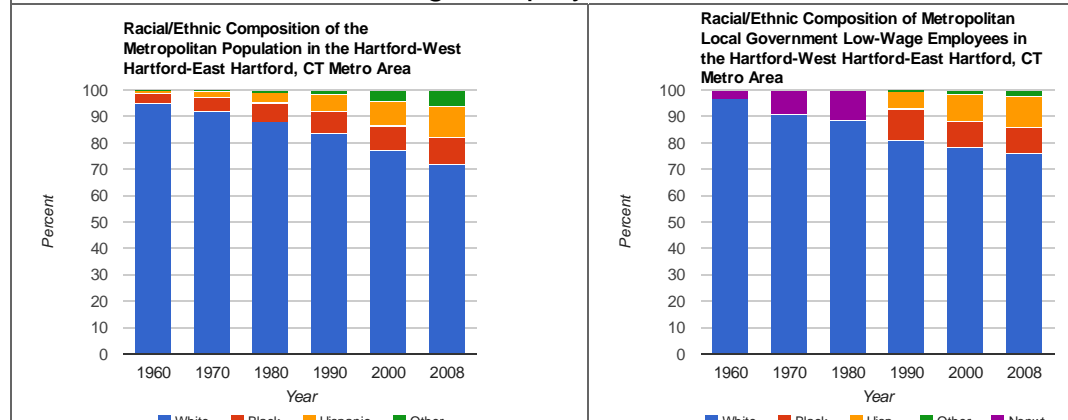

Local Government Low-Wage Employees in the Central City

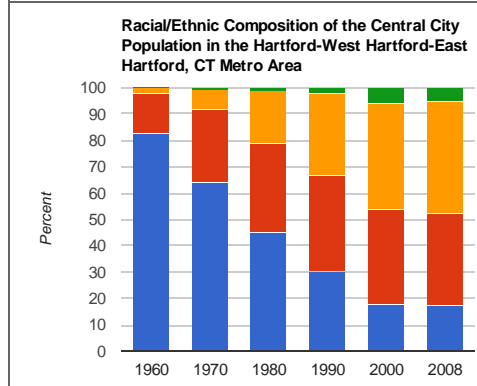

White Wlack Mear
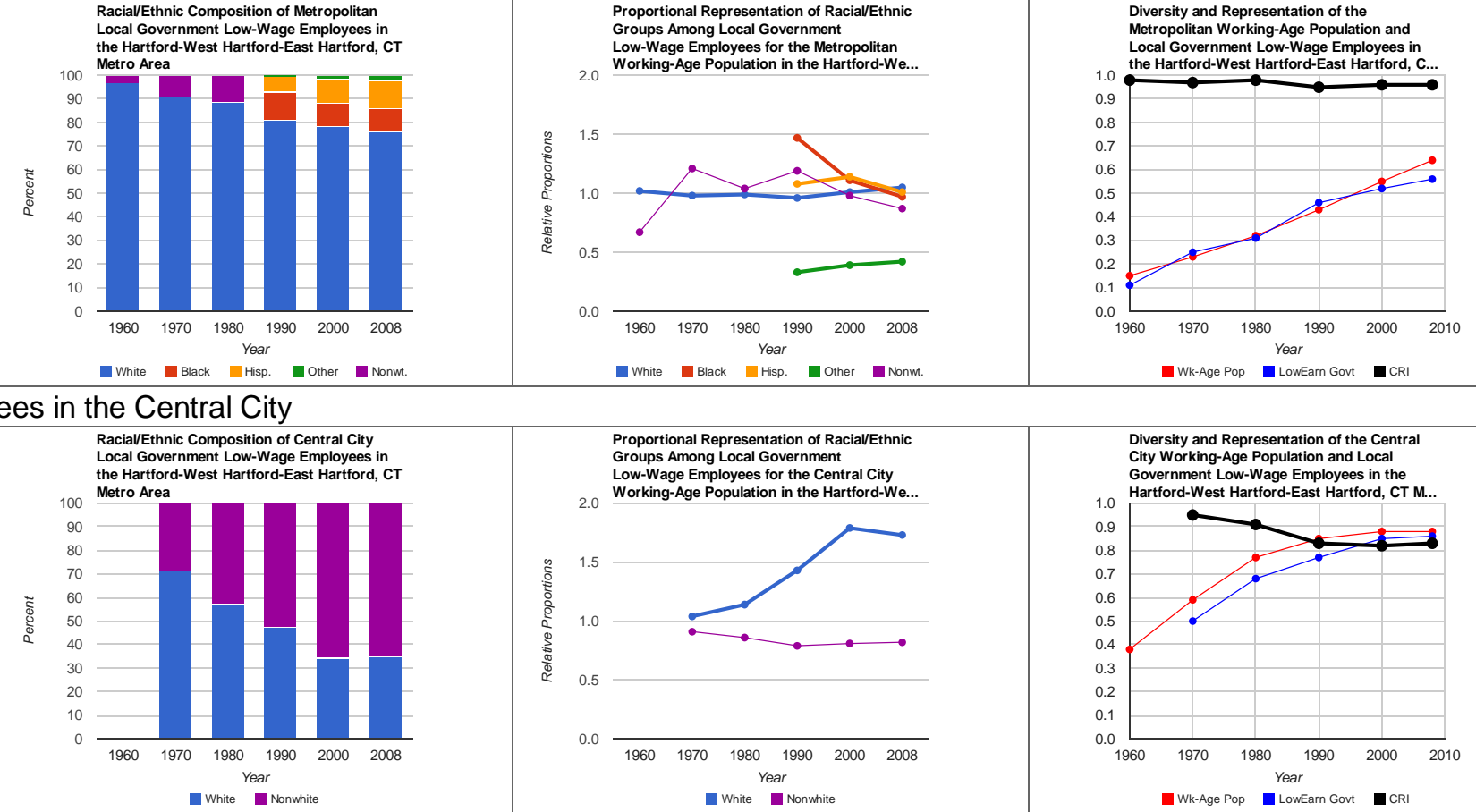

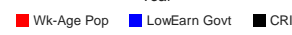

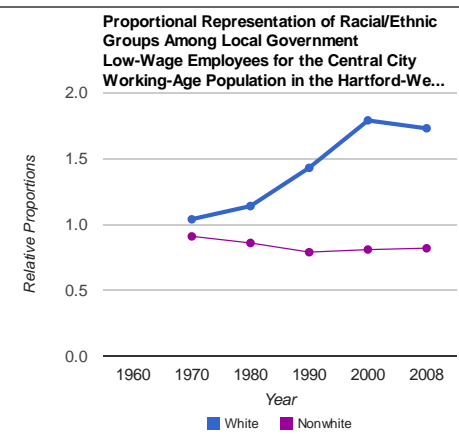

Proportional Representation of Raciall/Ethnic

2.0 Working-Age Population in the Hartford-We...

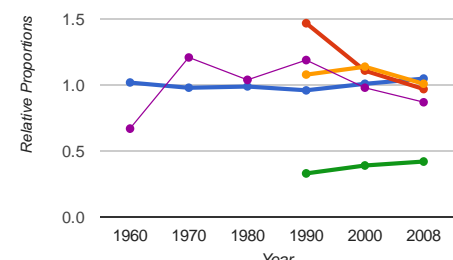

$\begin{array}{cccccc}1960 & 1970 & 1980 & 1990 & 2000 & 2008 \\ \text { Year } & & & \end{array}$

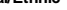
Low-Wage Employees for the Central City
Working-Age Population in the Hartford-We...

White Year 


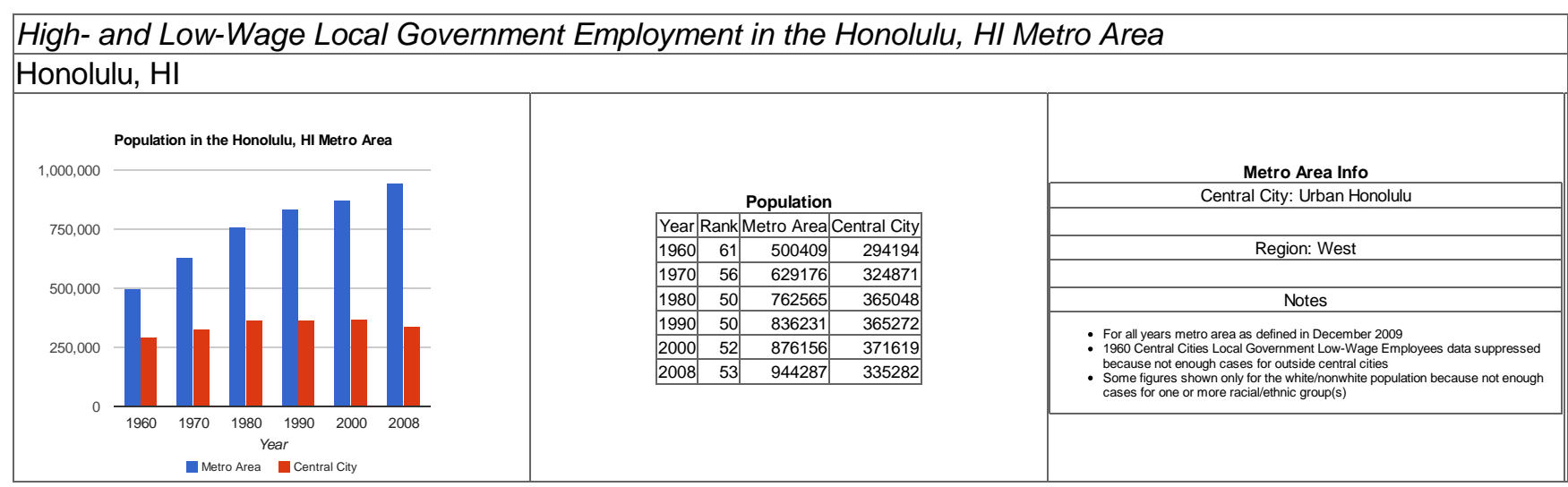


High- and Low-Wage Local Government Employment in the Honolulu, HI Metro Area

Local Government High-Wage Employees in the Metro Area
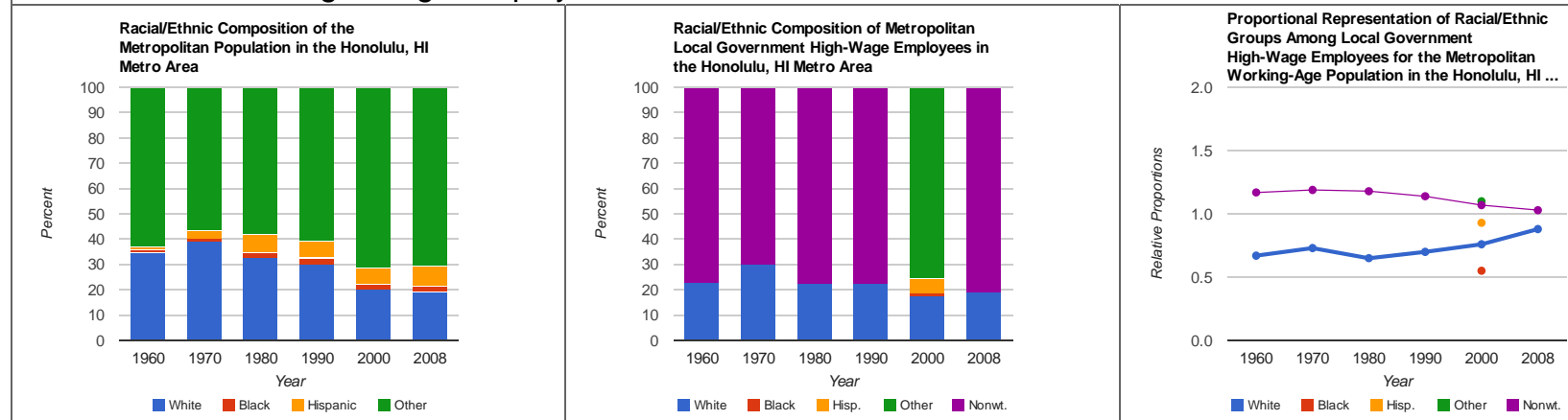
Diversity and Representation of the
Metropolitan Working-Age Population and
Local Government High-Wage Employees in the Honolulu, HI Metro Area White 1 Black M Hisp

Local Government High-Wage Employees in the Central City

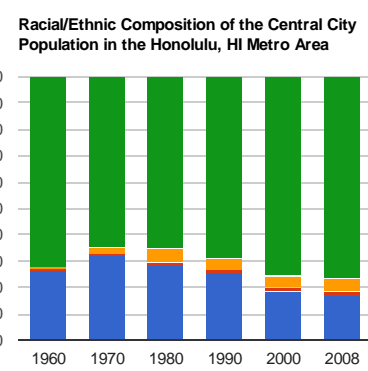

White Black Year

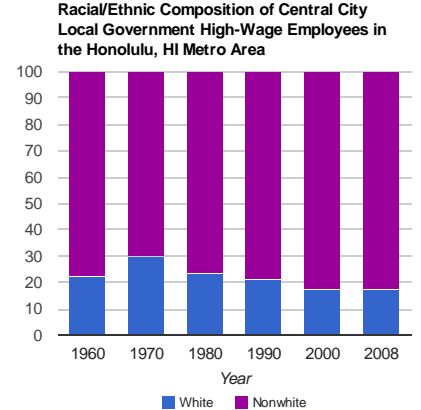

White ${ }^{-10}$ Nonwhite
Proportional Representation of Raciall/Ethnic Groups Among Local Government High-- -
Working-Age Population in the Honolulu, HI..

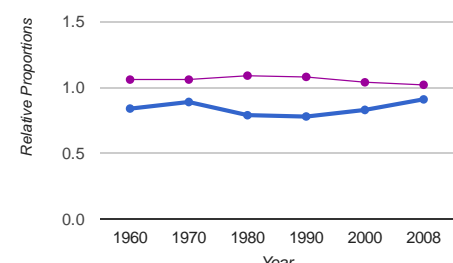

White $\quad$ Year

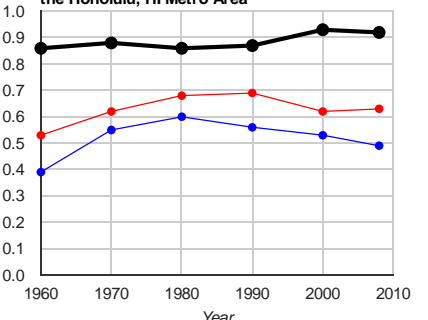

Wh-Age Pop HighEarn Govt

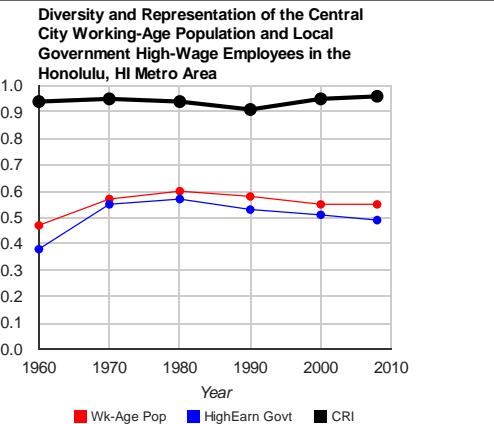


High- and Low-Wage Local Government Employment in the Honolulu, HI Metro Area

Local Government Low-Wage Employees in the Metro Area
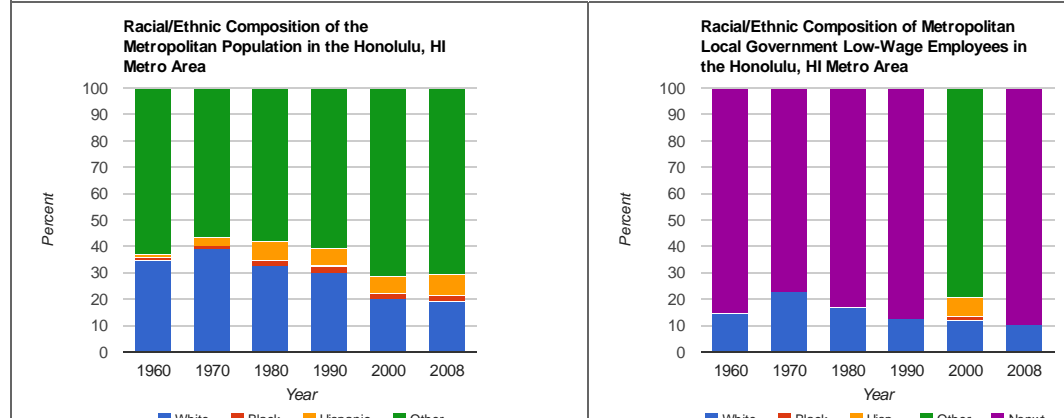

Proportional Representation of Raciall:thnic

Groups Among Local Government

Working-Age Population in the Honolulu, HI..

White Black Hear Ho. Other Nonwt.

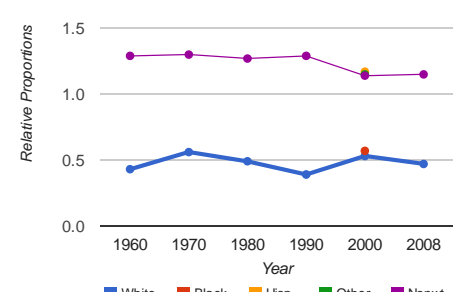
Diversity and Representation of the
Metropolitan Working-Age Population and
Local Government Low-Wage Employees in the Honolulu, HI Metro Area

overnment Low-Wage Employees in the Central City

Lacial/Ethnic Composition of the Central city
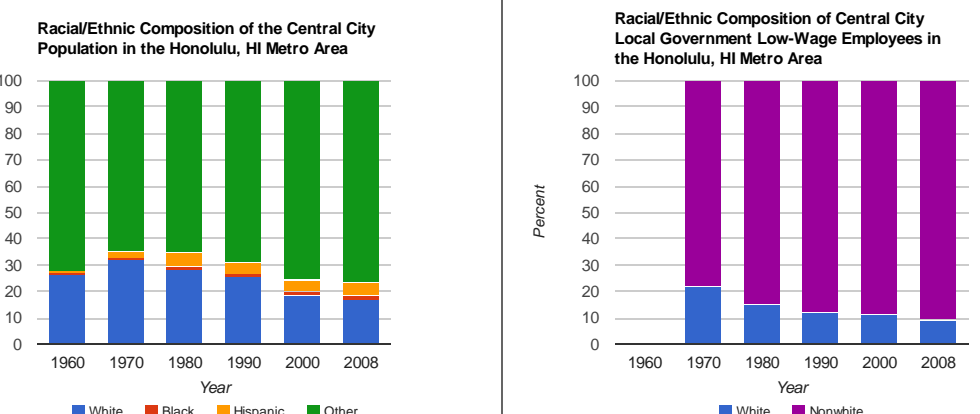

Proportional Representation of Racial/thn Groups Among Local Government Working-Age Population in the Honolulu, HI.

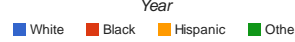
- White $\stackrel{\text { Year }}{\text { Nonwhite }}$

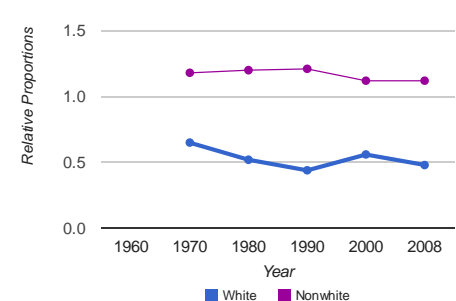

White Nonuthite

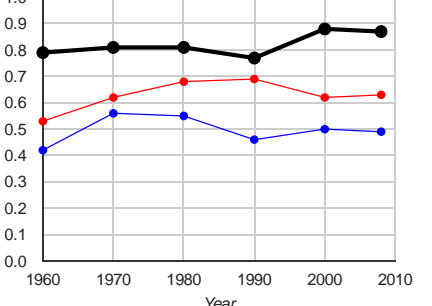

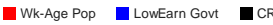
City Working-Age Population and Local
Government Low-Wage Employes in the

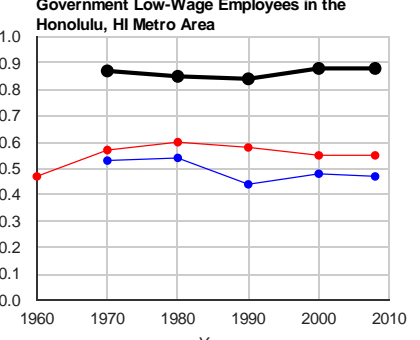

- Wh-Age Pop IL LowEarn Govt MCR 


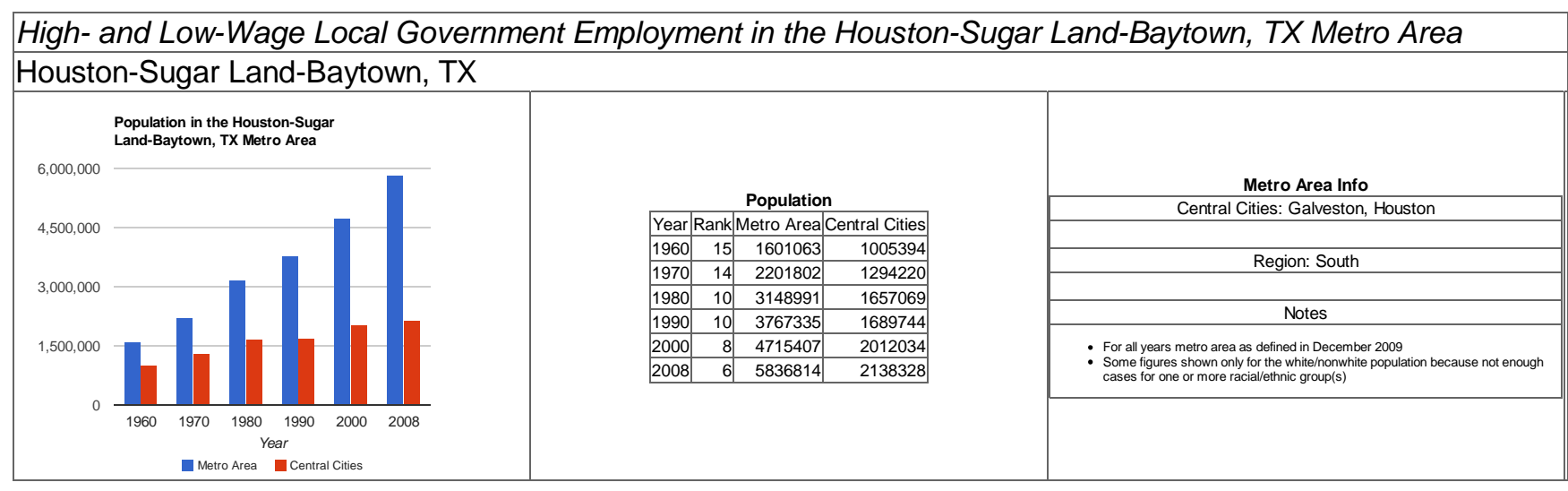


High- and Low-Wage Local Government Employment in the Houston-Sugar Land-Baytown, TX Metro Area Local Government High-Wage Employees in the Metro Area
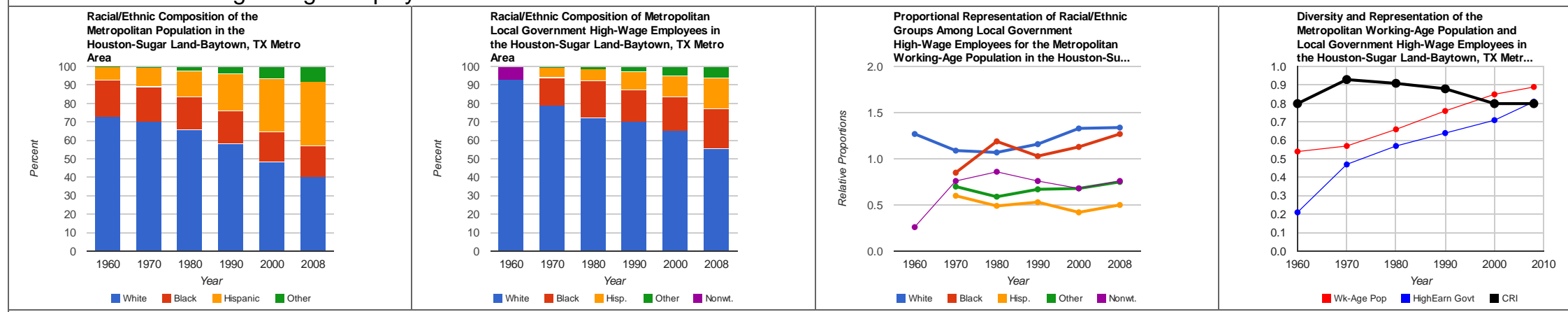

Local Government High-Wage Employees in the Central Cities
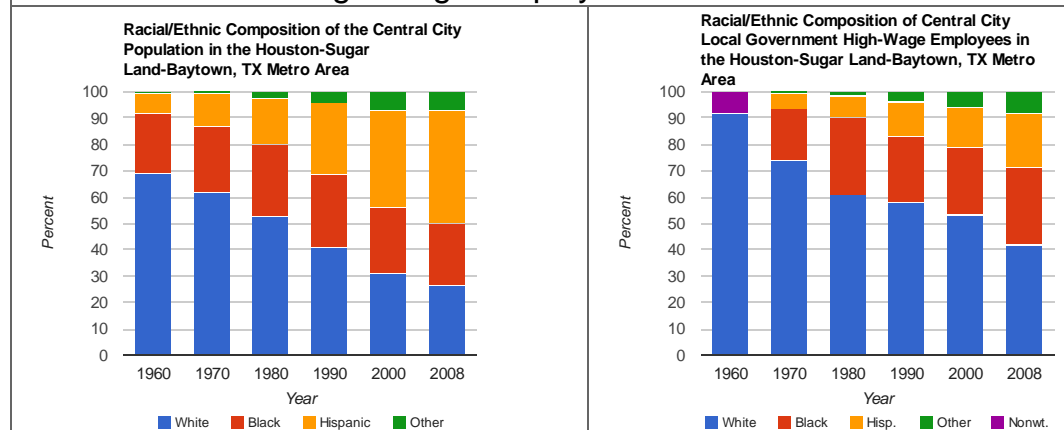

Proportional Representation of RaciallEthnic Groups Among Local Government
High-Wage Employes for the Central City
W.0 Working-Age Population in the Houston-Su...

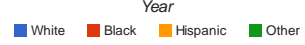

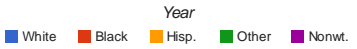

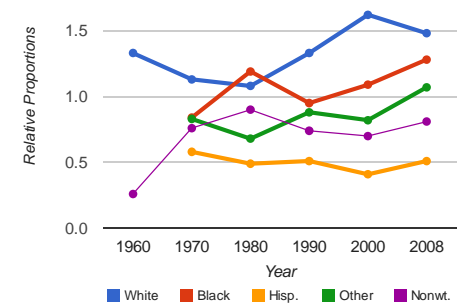
Diversity and Representation of the Central
City Working-Age Population and Local
Government High-Wage Employees in the

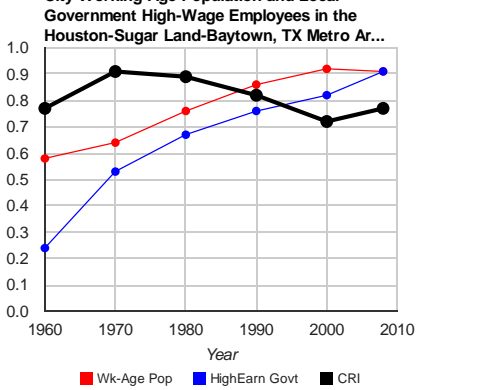


High- and Low-Wage Local Government Employment in the Houston-Sugar Land-Baytown, TX Metro Area Local Government Low-Wage Employees in the Metro Area
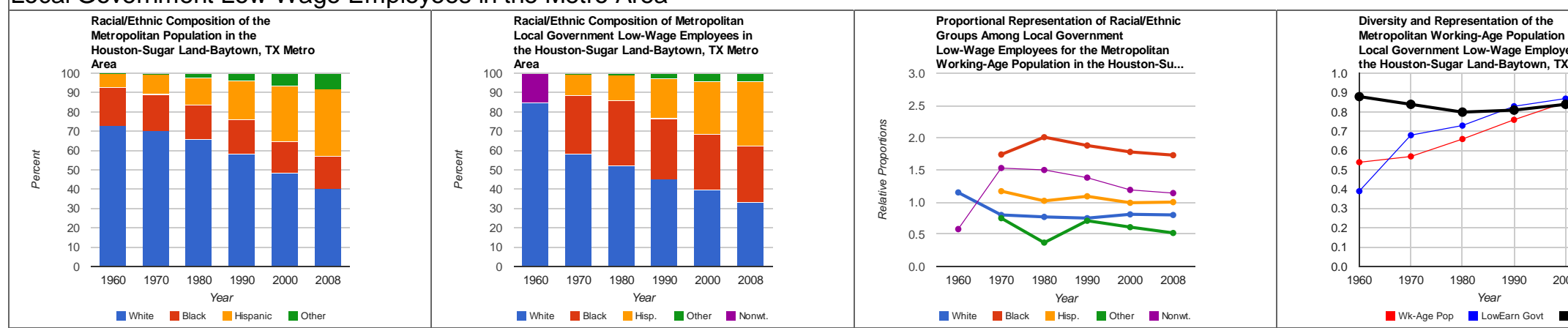

Diversity and Representation of the
Metropolitan Working-Age Population and

the Houston-Sugar Land-Baytown, TX Metr.

White Black Hispanic $\quad$ Oother

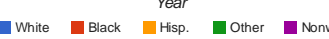

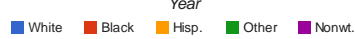

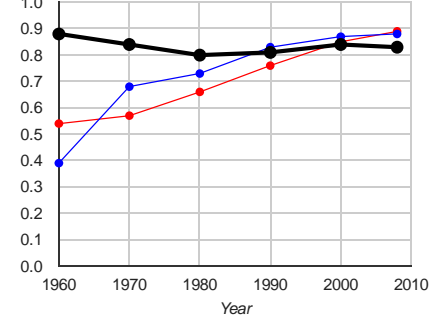

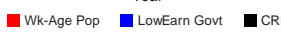

Local Government Low-Wage Employees in the Central Cities

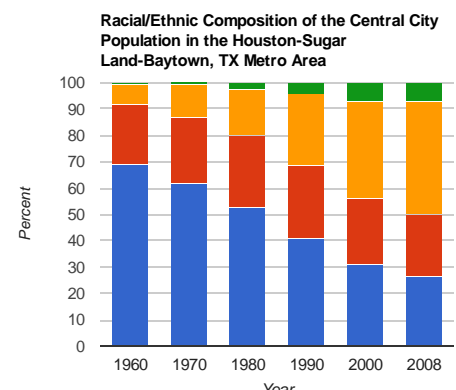

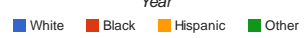

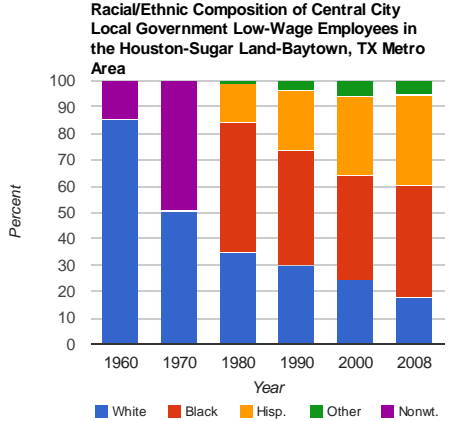

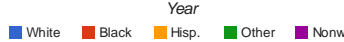

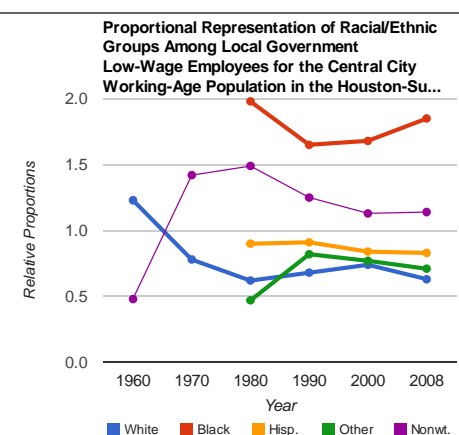

White Black Year
Diversity and Representation of the Central
City Working-Age Population and Local Government Low-Wage Employe
Houston-Sugar Land-Baytown, TX Metro Ar.

1.0
0.9

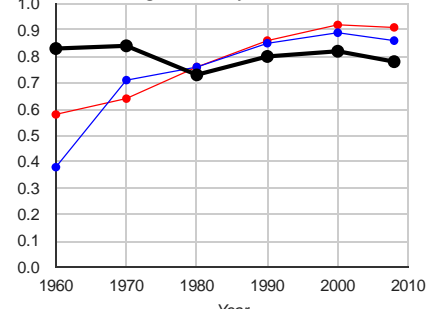

-Wk-Age Pop L LowEarn Govt - CRI 


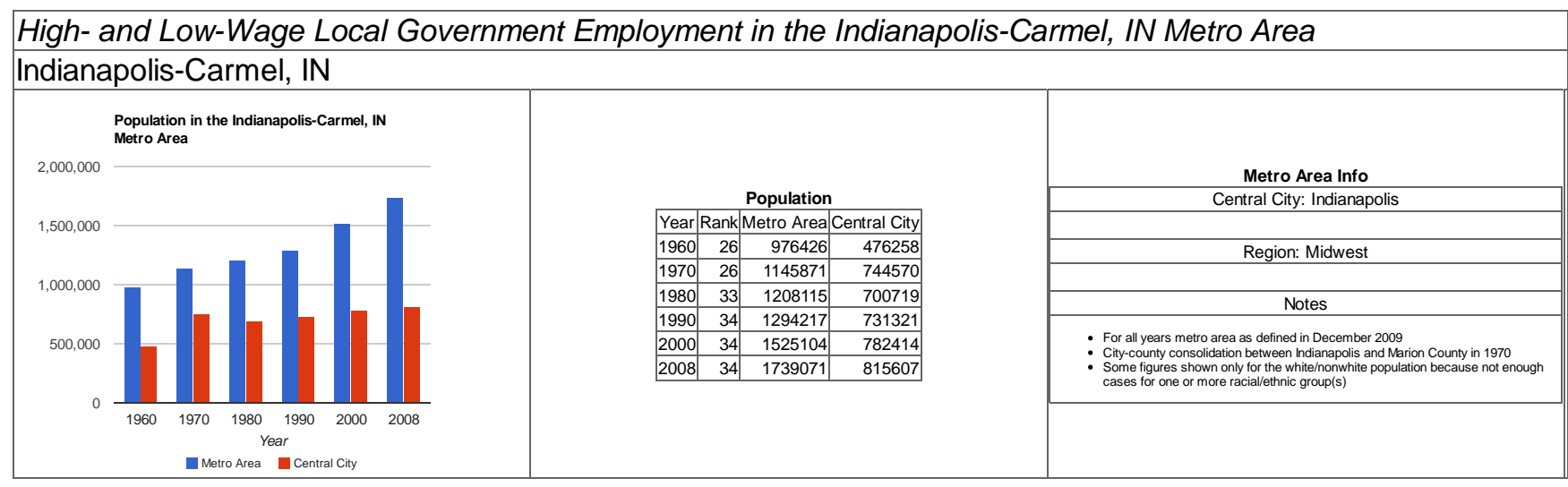


High- and Low-Wage Local Government Employment in the Indianapolis-Carmel, IN Metro Area

Local Government High-Wage Employees in the Metro Area
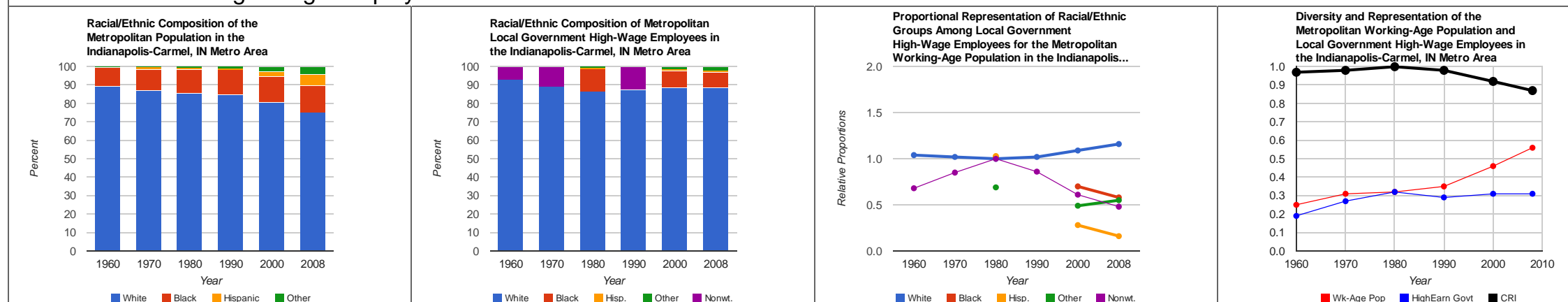

Local Government High-Wage Employees in the Central City
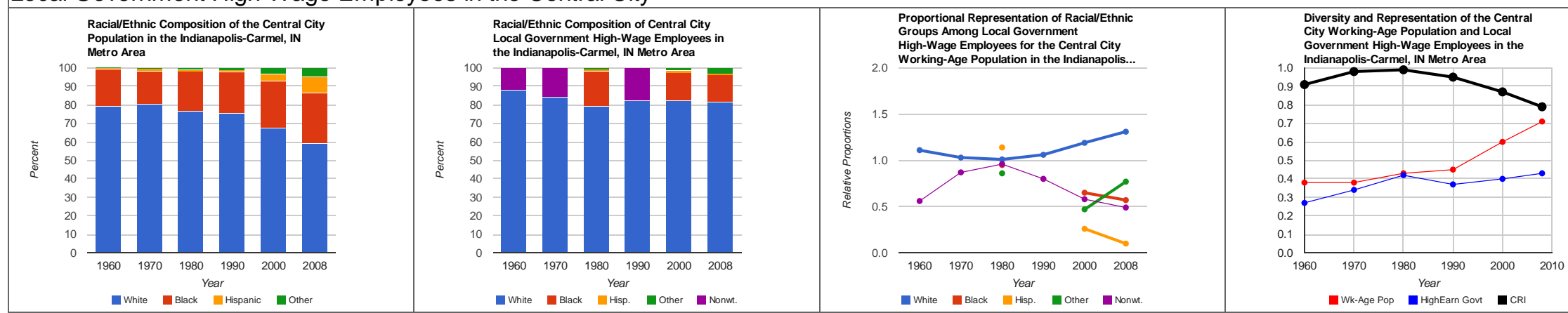
High- and Low-Wage Local Government Employment in the Indianapolis-Carmel, IN Metro Area

Local Government Low-Wage Employees in the Metro Area
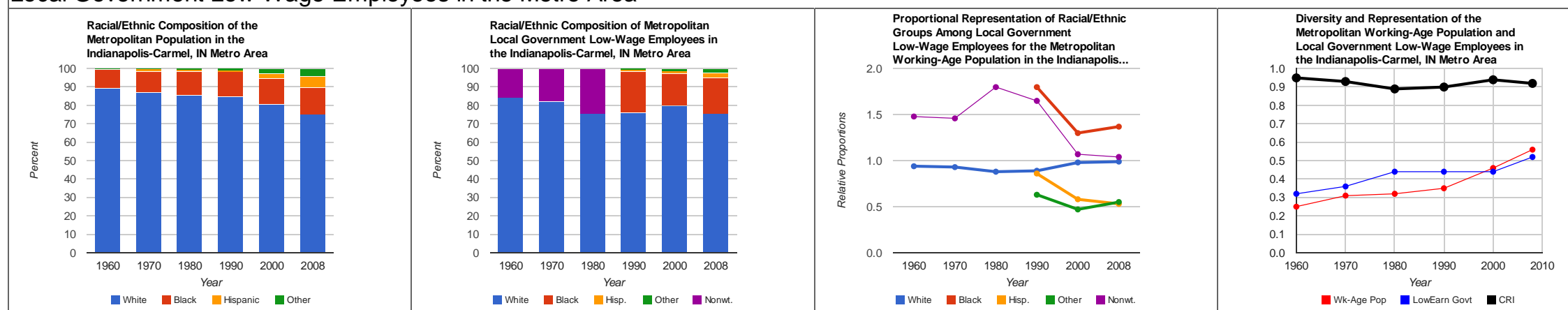

Local Government Low-Wage Employees in the Central City
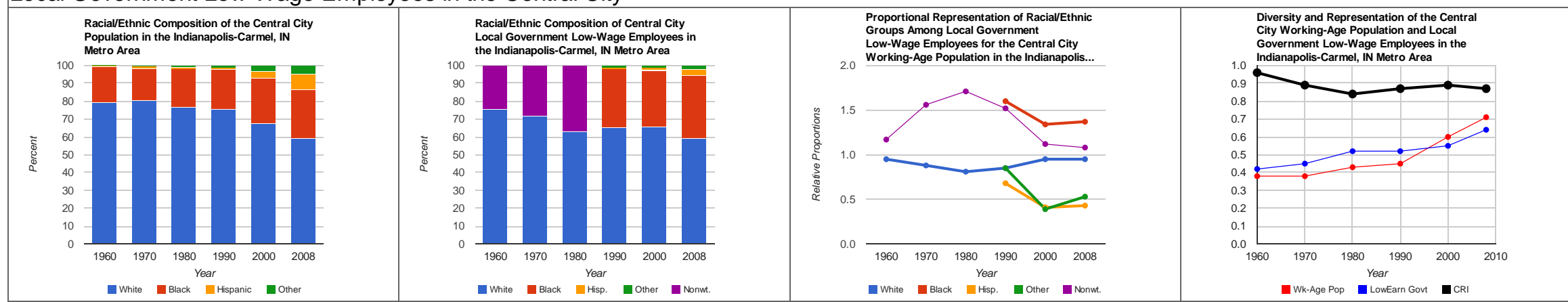


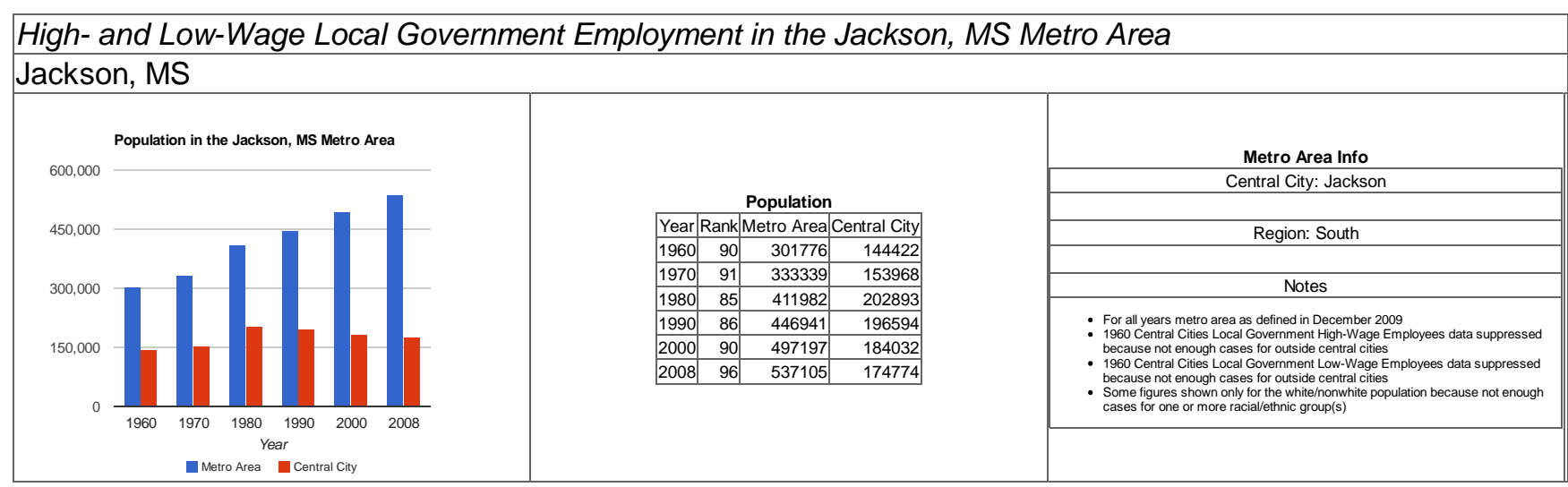


High- and Low-Wage Local Government Employment in the Jackson, MS Metro Area

Local Government High-Wage Employees in the Metro Area
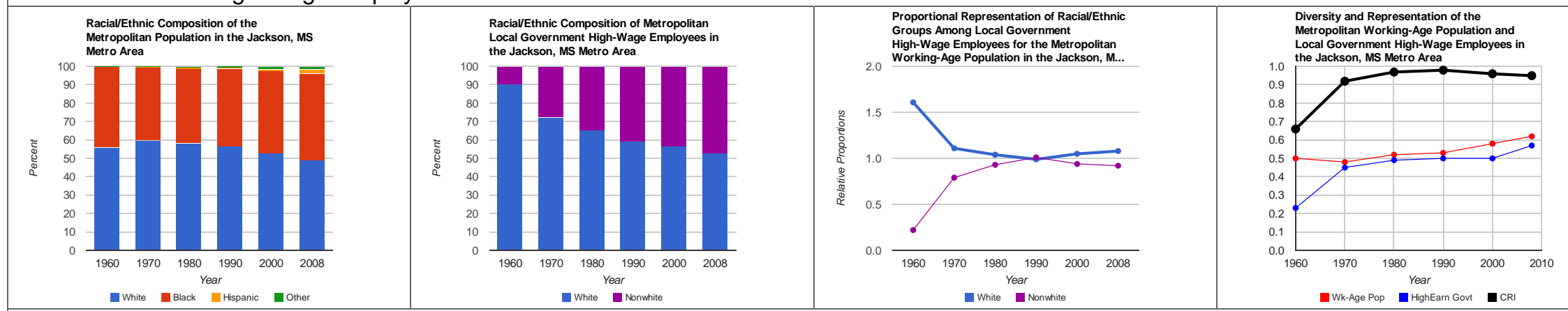

Local Government High-Wage Employees in the Central City
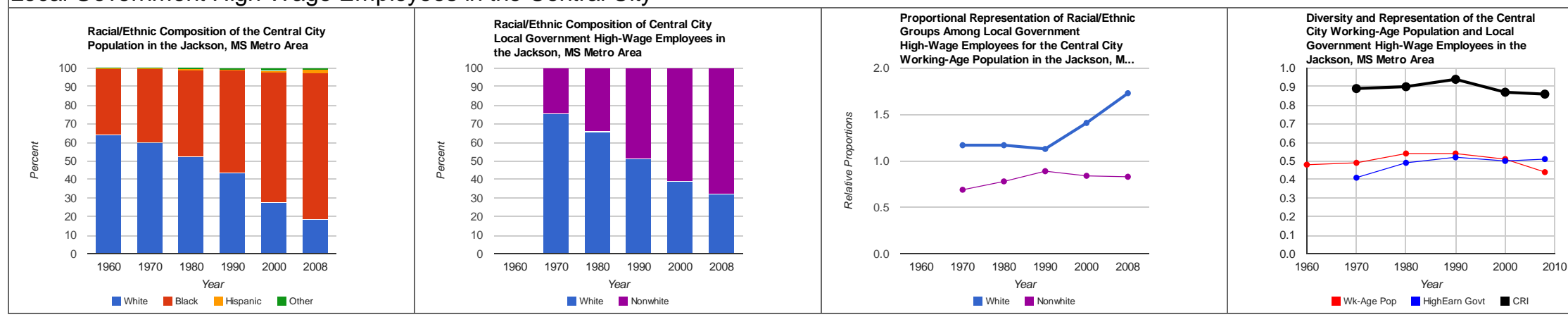
High- and Low-Wage Local Government Employment in the Jackson, MS Metro Area

Local Government Low-Wage Employees in the Metro Area
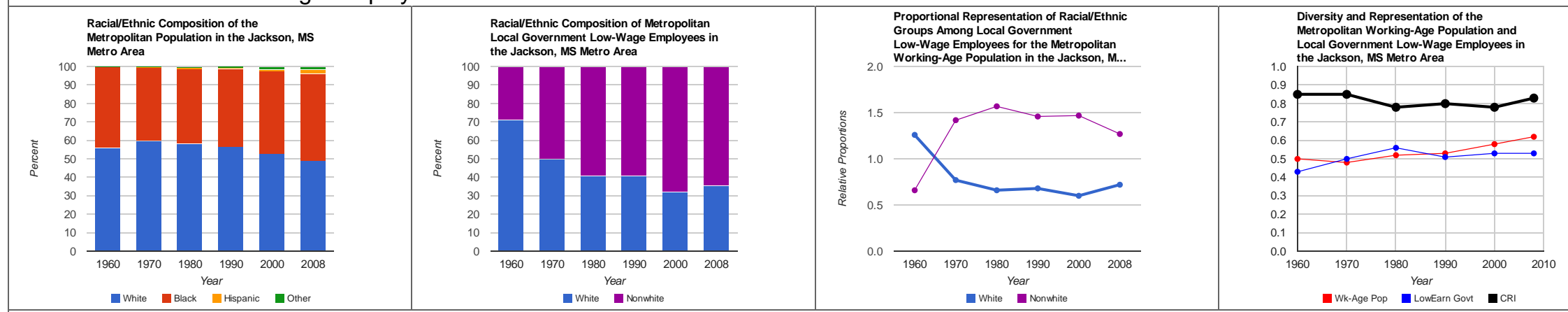

Local Government Low-Wage Employees in the Central City
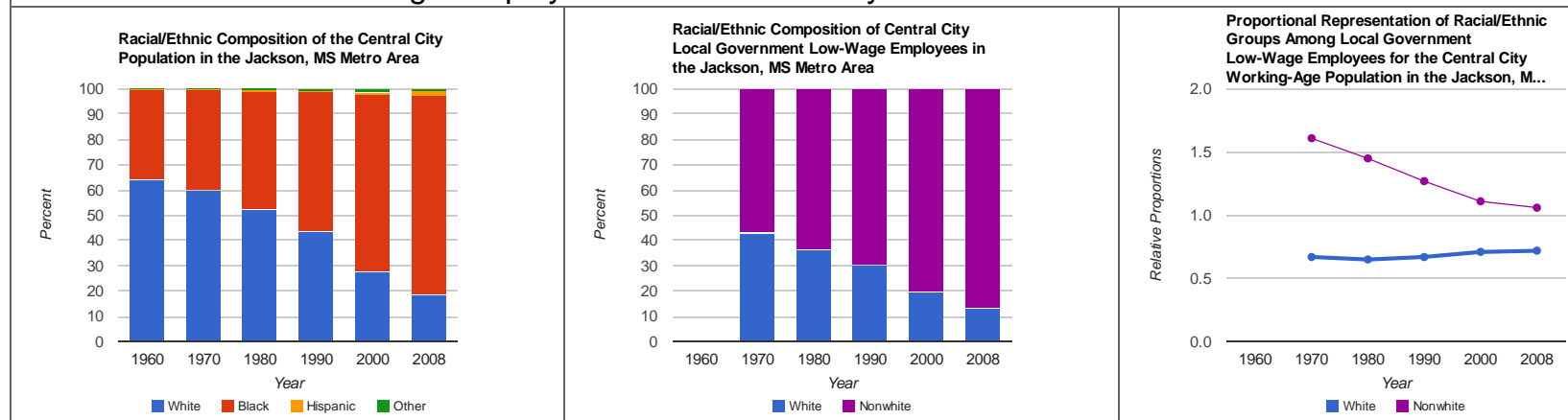

Diversity and Representation of the Central
City Working-Age Population and Lat City Working-Age Population and Local Jackson, MS Metro Area

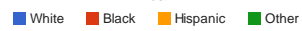
- White $\stackrel{\text { Year }}{\text { Nonwhite }}$

White ${ }_{\text {Nonmhite }}^{\text {Year }}$

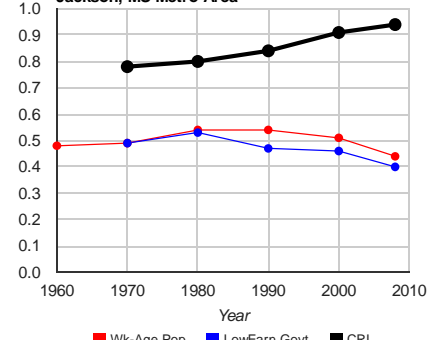

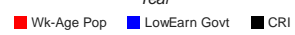




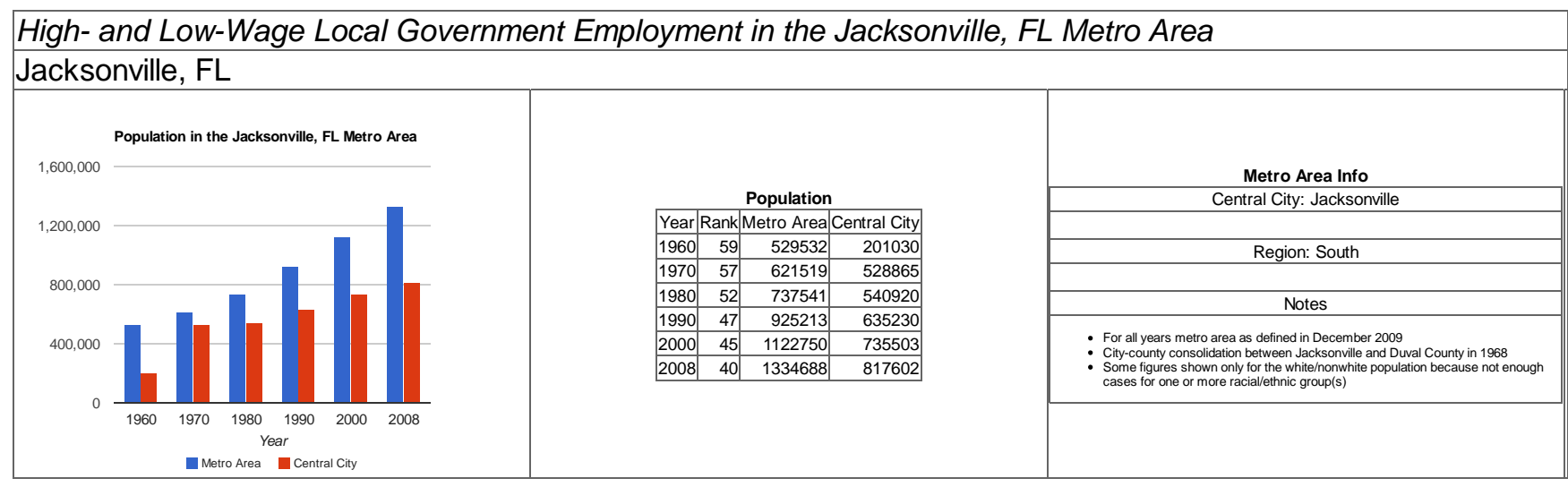


High- and Low-Wage Local Government Employment in the Jacksonville, FL Metro Area

Local Government High-Wage Employees in the Metro Area
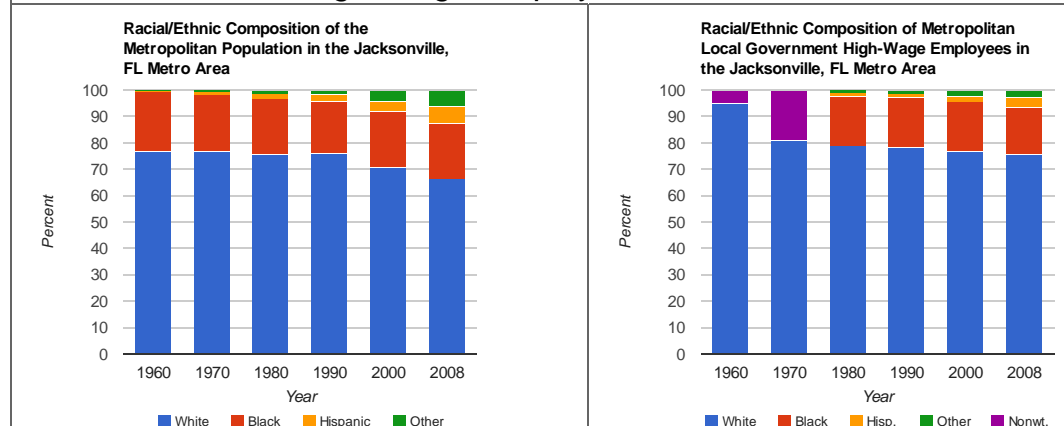

Local Government High-Wage Employees in the Central City
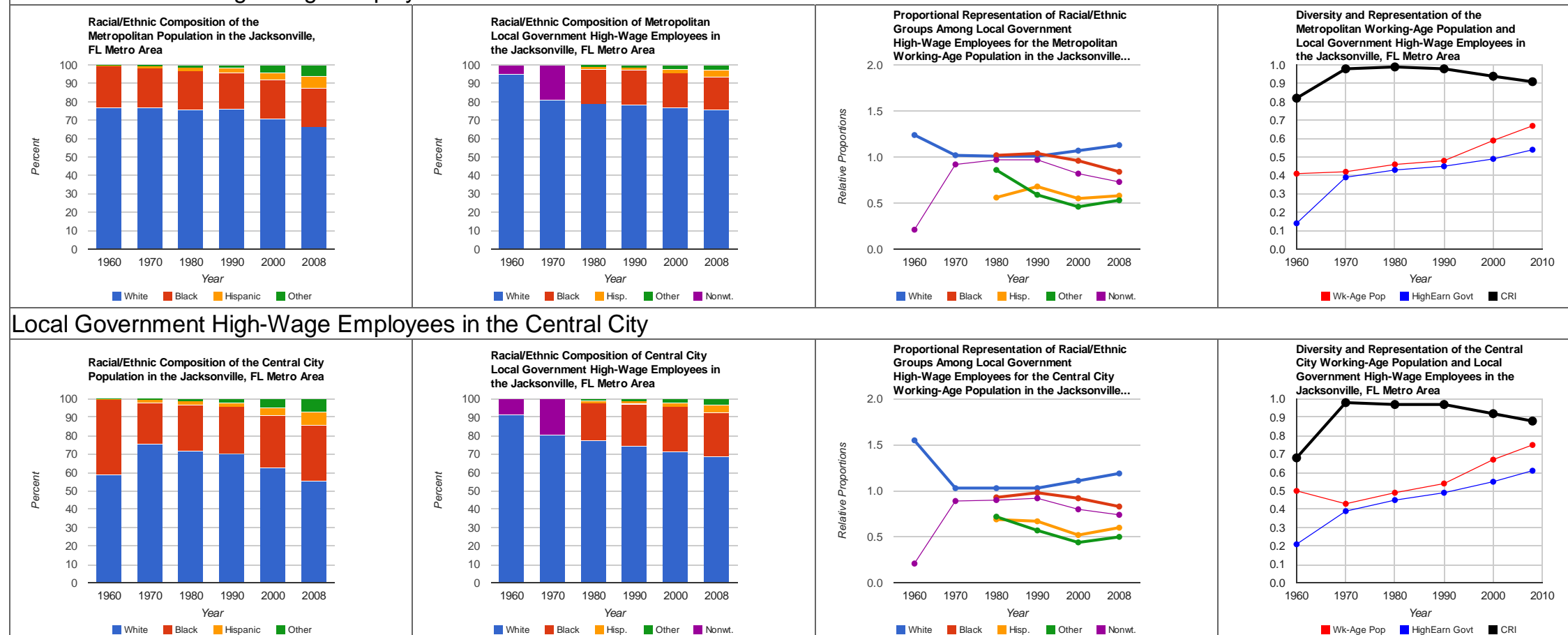

White In Black Inspanic Inother

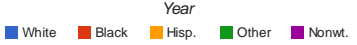

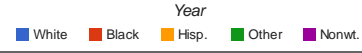

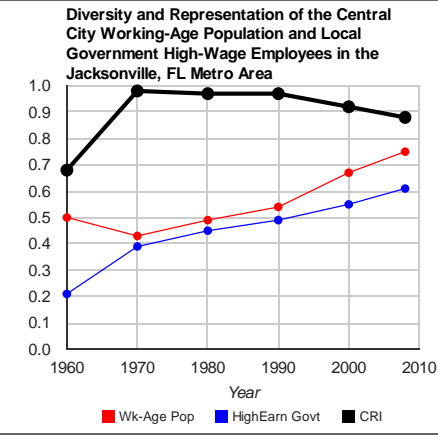


High- and Low-Wage Local Government Employment in the Jacksonville, FL Metro Area

Local Government Low-Wage Employees in the Metro Area
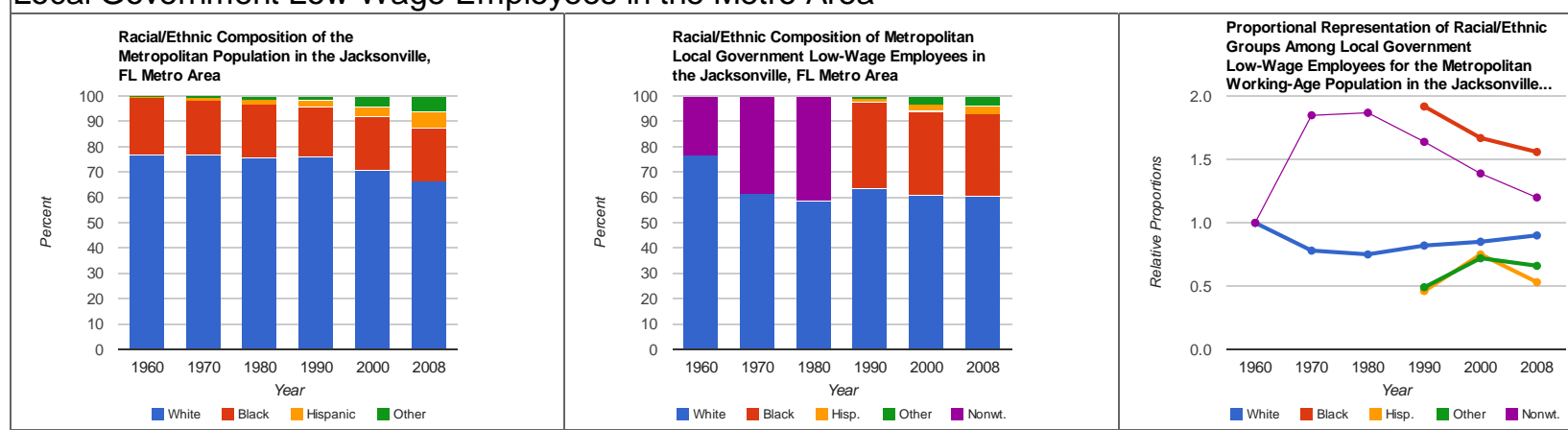

Diversity and Representation of the
Metropolitan Working-Age Population

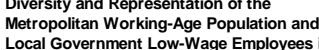

White Black Hispanic motter

- White Black Hisp.

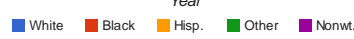

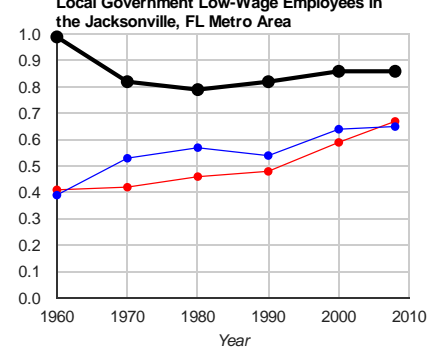

Local Government Low-Wage Employees in the Central City
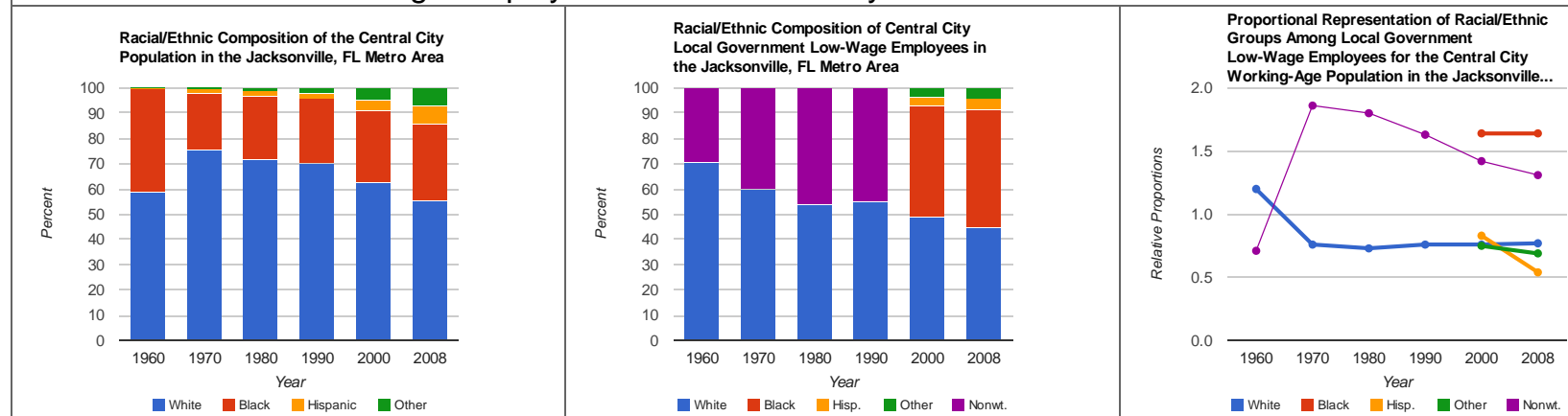

Diversity and Representation of the Central City Working-Age Population and Local

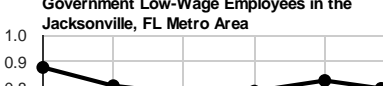

White Black Hispanic @ Other

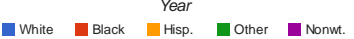

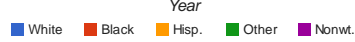

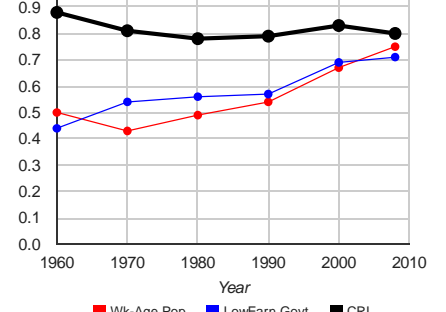

Wh-Age Pop LowEarn Gout 


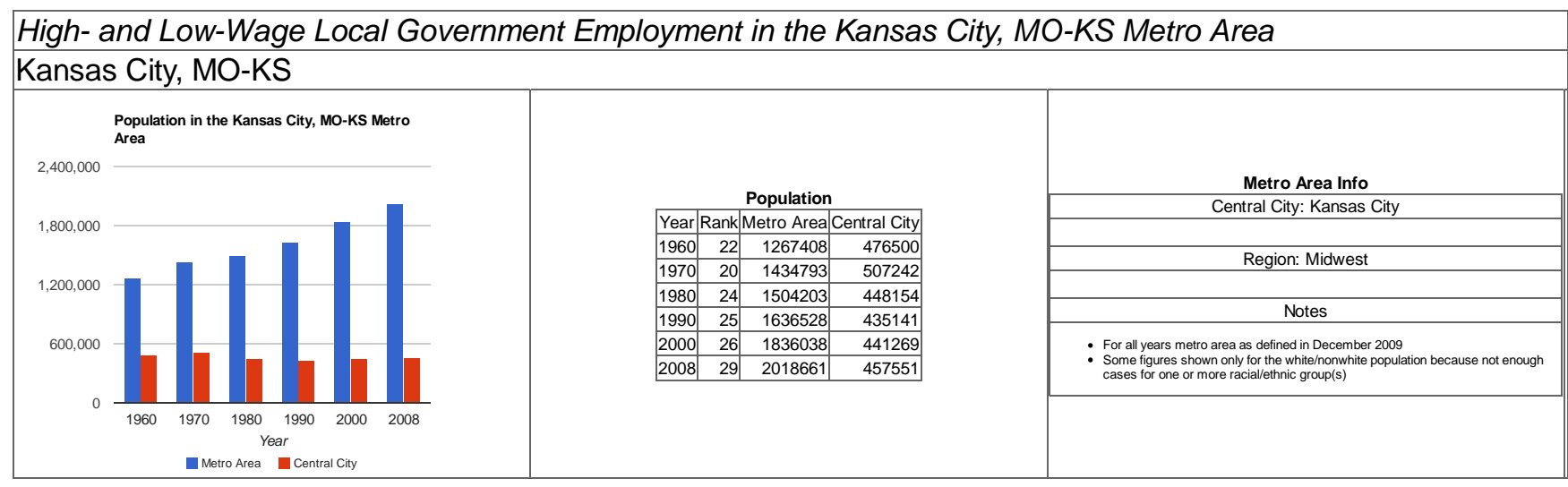


High- and Low-Wage Local Government Employment in the Kansas City, MO-KS Metro Area

Local Government High-Wage Employees in the Metro Area
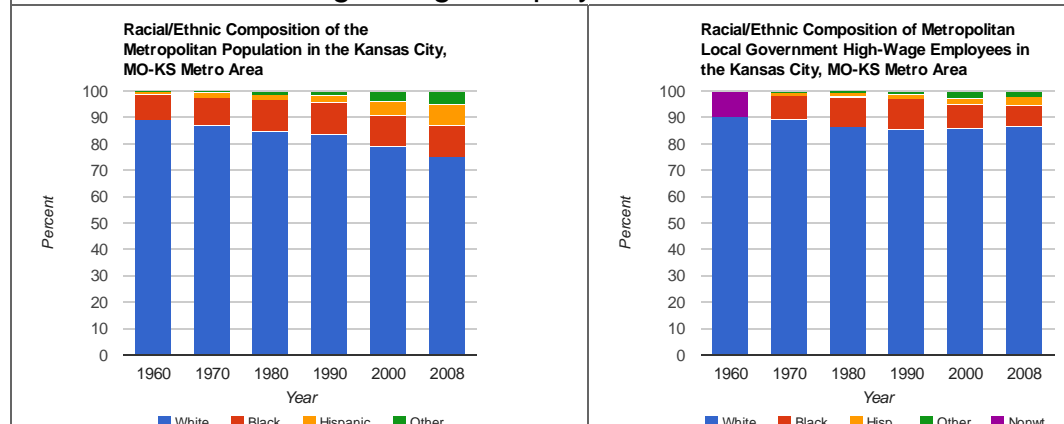

Local Government High-Wage Employees in the Central City
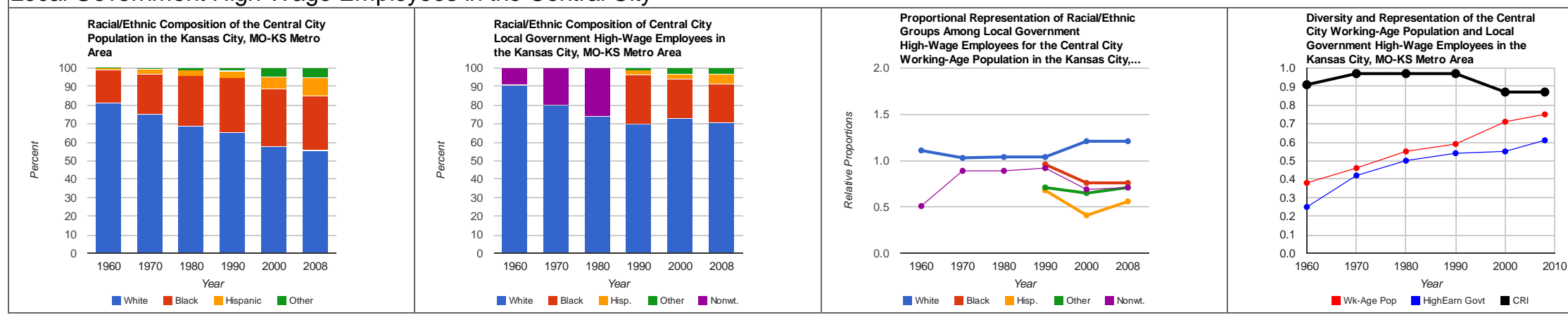
High- and Low-Wage Local Government Employment in the Kansas City, MO-KS Metro Area

Local Government Low-Wage Employees in the Metro Area
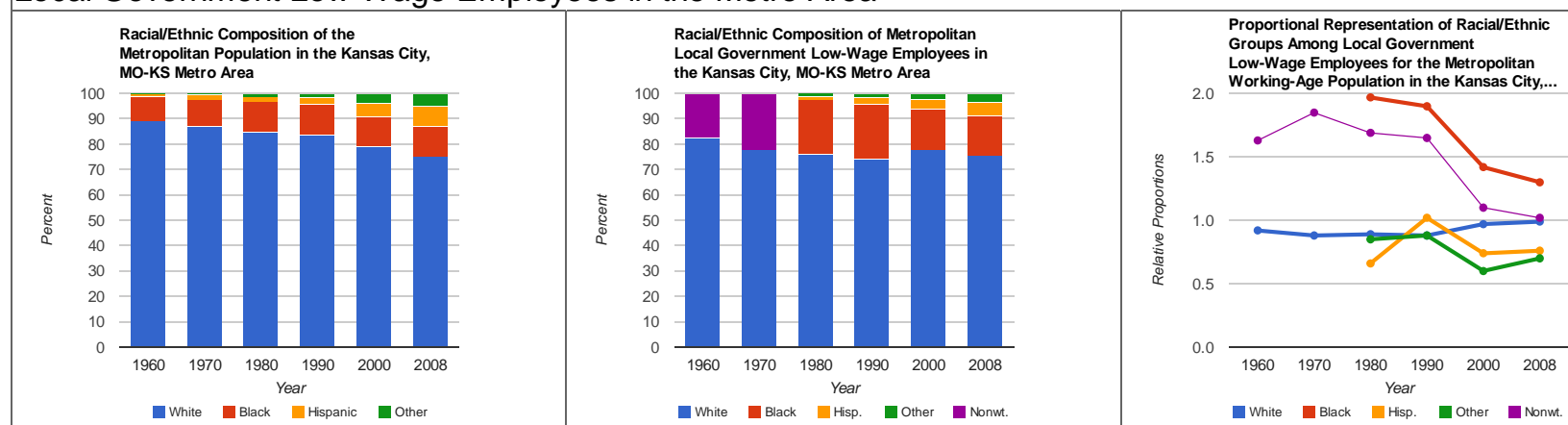
Diversity and Representation of the
Metropolitan Working-Age Population and
Local Government ${ }^{-0 w-W a g e ~ E m p l o y e e s ~ i n ~}$

the Kansas City, MO-Ks Metro Area

White Black Hispanic other

- White Black

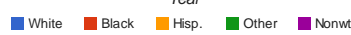

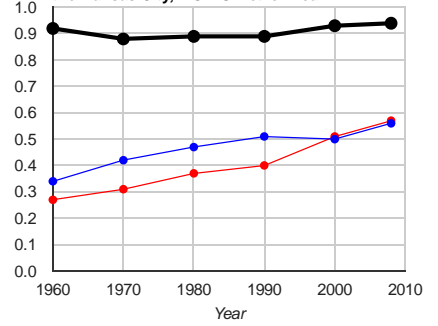

Local Government Low-Wage Employees in the Central City

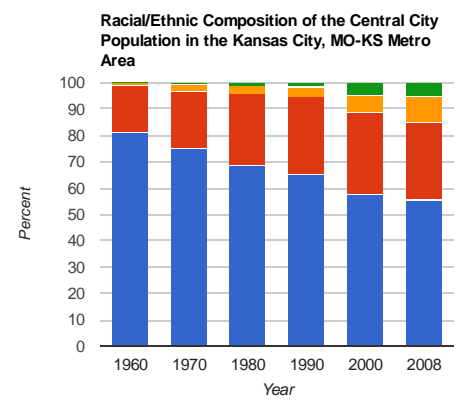

RaciallEthnic Composition of Central city Proportional Representation of Raciall/Ethnic
Groups Among Local Government
Low-Wage Employees for the Central City

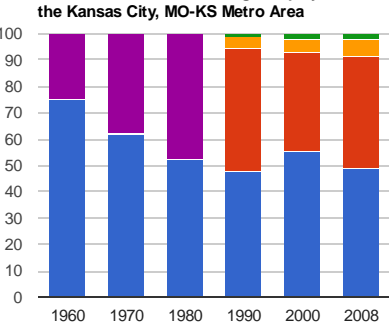

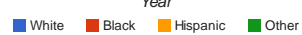

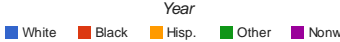

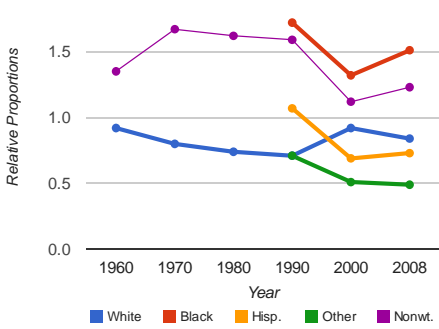
Diversity and Representation of the Central
City Working-Age Population and Local
Government Low-Wage Employees in the Government Low-Wage Employees
Kansas City, MO-KS Metro Area

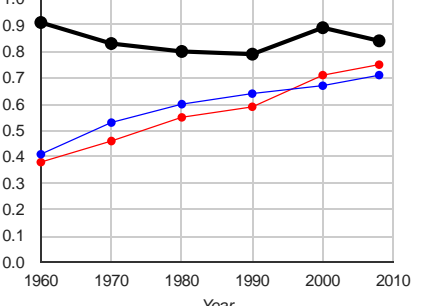

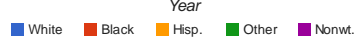

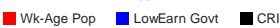




\begin{tabular}{|c|c|c|}
\hline \multicolumn{3}{|l|}{ Knoxville, TN } \\
\hline \multirow{9}{*}{ 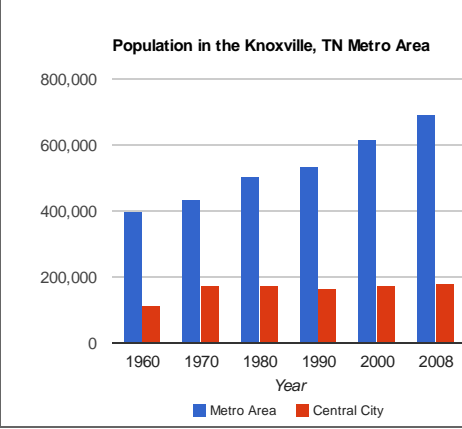 } & \multirow{7}{*}{$\begin{array}{l}\text { Population } \\
\begin{array}{|l|r|r|r|}\text { Year|r|rank } & \text { Retro Area Central City } \\
1960 & 65 & 400317 & 111827 \\
1970 & 70 & 433675 & 174587 \\
1980 & 71 & 505070 & 175030 \\
1990 & 79 & 534917 & 165121 \\
2000 & 76 & 616079 & 173680 \\
2008 & 75 & 692803 & 179085 \\
\end{array}\end{array}$} & $\begin{array}{l}\text { Metro Area Info } \\
\text { Central Citik Knopoxille }\end{array}$ \\
\hline & & Region: South \\
\hline & & Notes \\
\hline & & 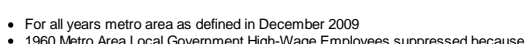 \\
\hline & & 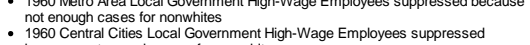 \\
\hline & & 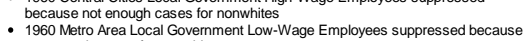 \\
\hline & & 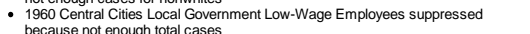 \\
\hline & & 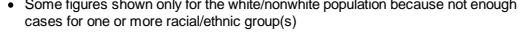 \\
\hline & & \\
\hline
\end{tabular}


High- and Low-Wage Local Government Employment in the Knoxville, TN Metro Area

Local Government High-Wage Employees in the Metro Area
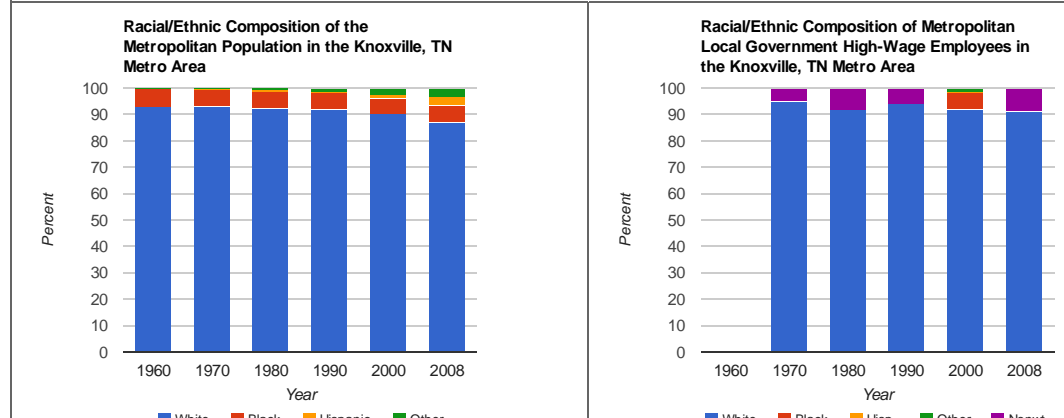

Local Government High-Wage Employees in the Central City

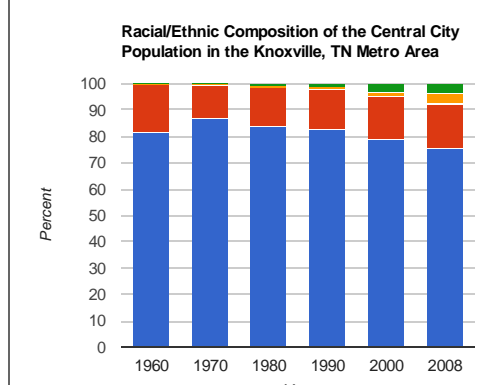

White Black Year

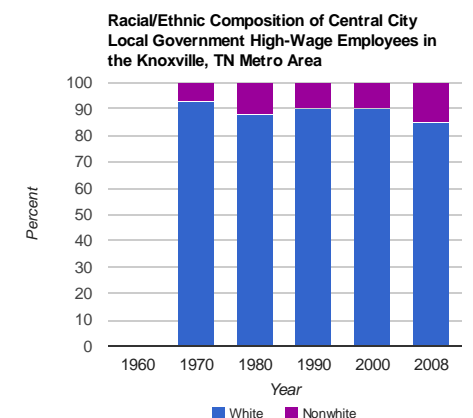

White ${ }_{\text {Nonnwite }}$
Proportional Representation of Raciall/Ethnic Groups Among Local Government Working-Age Population in the Knoxville, T.

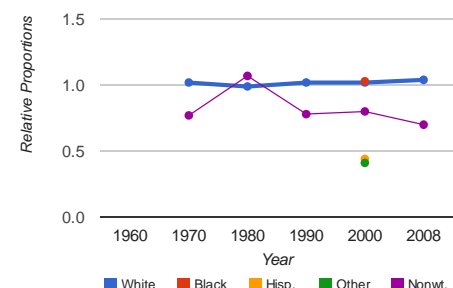

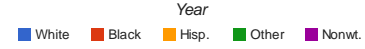
Proportional Representation of Raciall/Ethnic
Groups Among Local Government
High-Wage Employees for the Central City High-Wage Employees for the Central City
Working-Age Population in the Knoxville, $\mathrm{T}$.

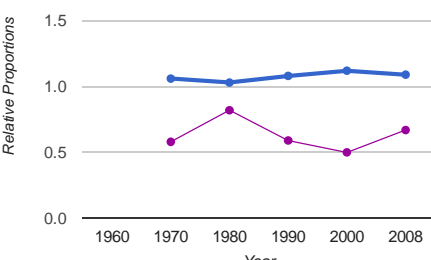

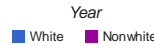
Diversity and Representation of the
Metropolitan Working-Age Population and
Local Government High-Wage Employees in

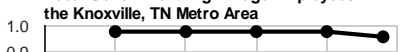

0.9

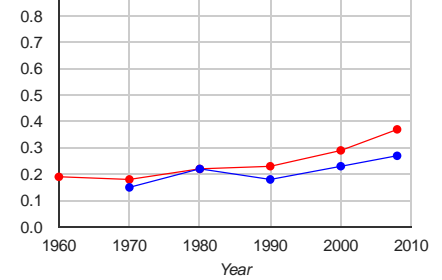

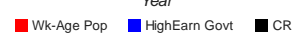

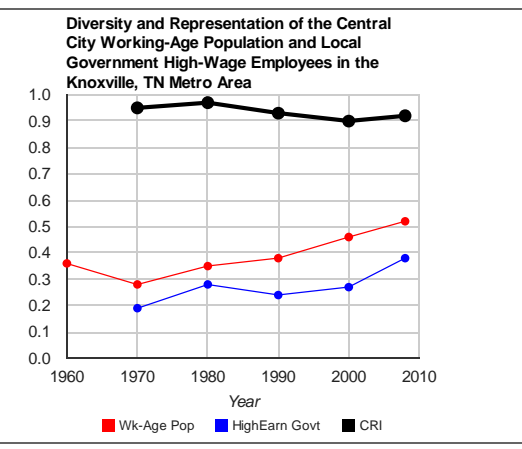


High- and Low-Wage Local Government Employment in the Knoxville, TN Metro Area

Local Government Low-Wage Employees in the Metro Area
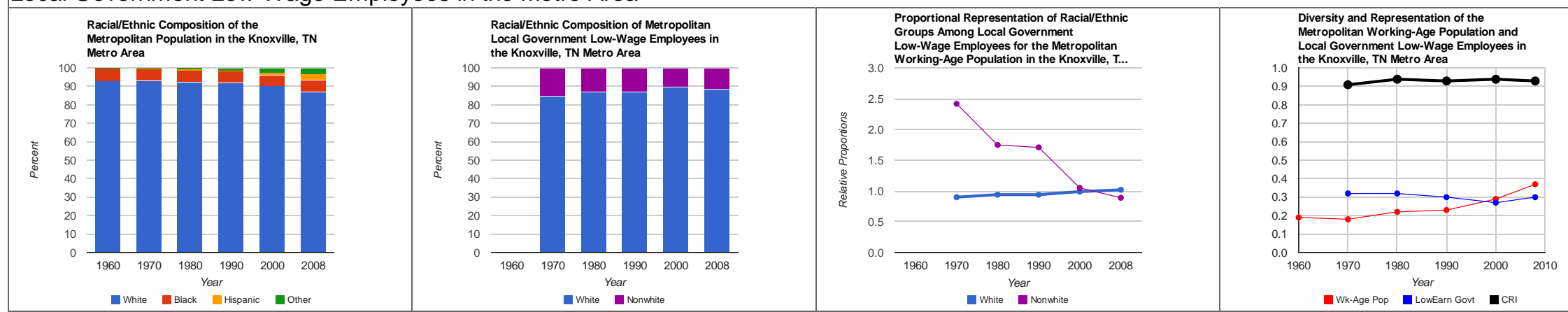

Local Government Low-Wage Employees in the Central City
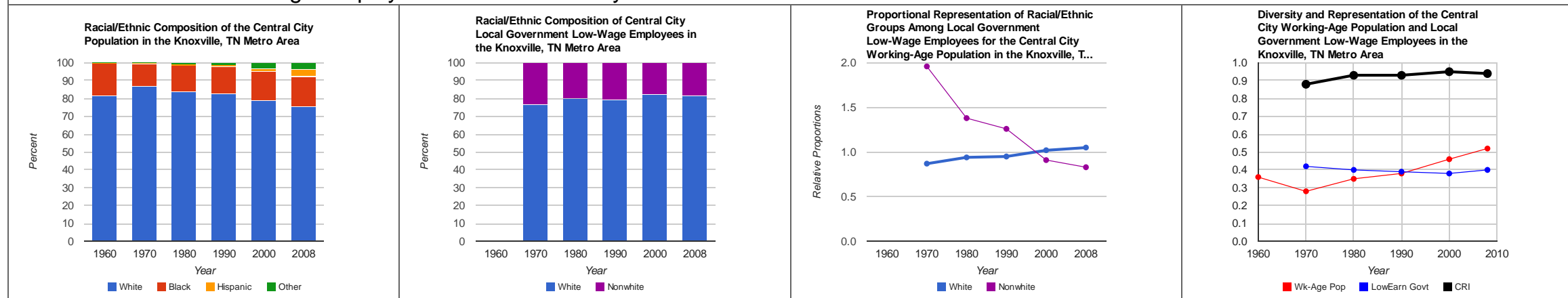


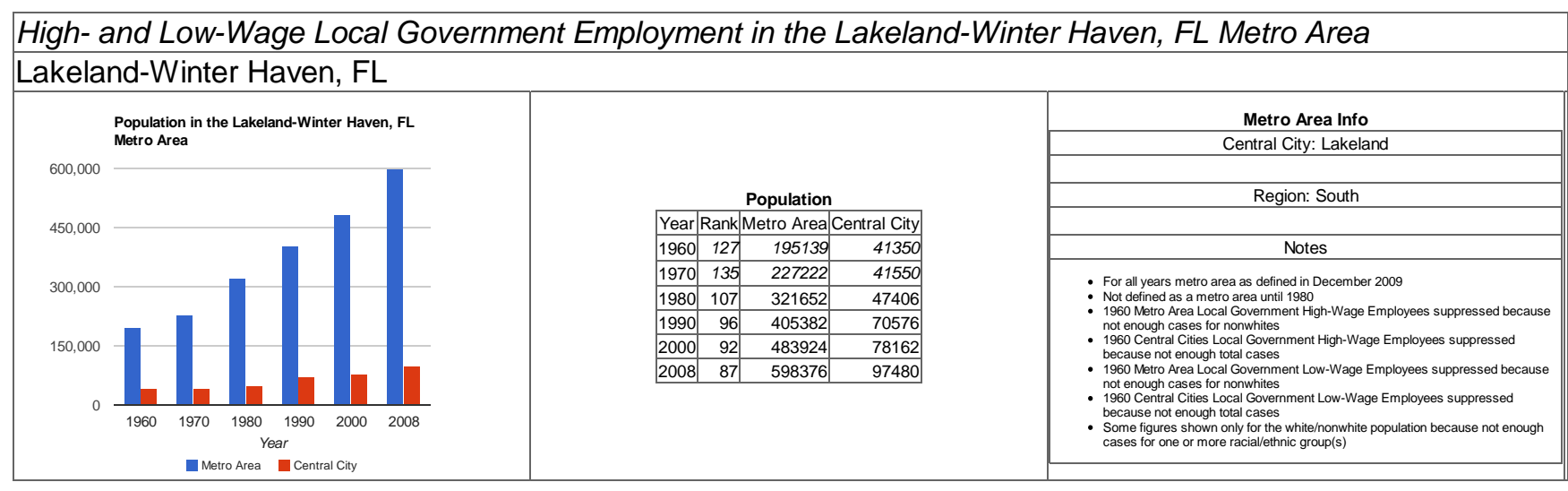


High- and Low-Wage Local Government Employment in the Lakeland-Winter Haven, FL Metro Area

Local Government High-Wage Employees in the Metro Area
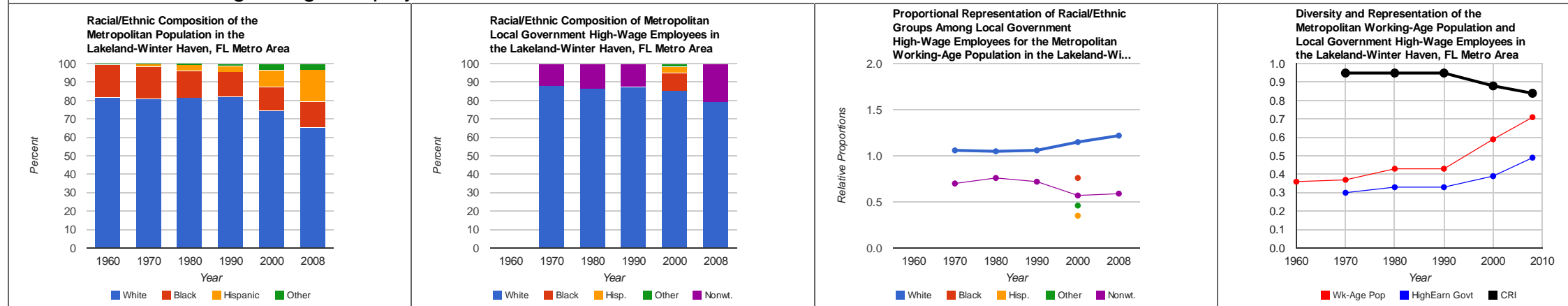

Local Government High-Wage Employees in the Central City

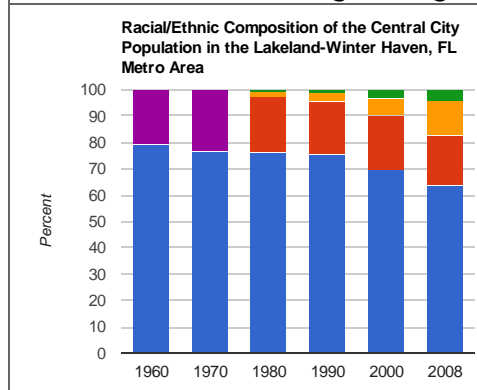

Local Government High-Wage Employees in
the Lakeland-Winter Haven,

100
90

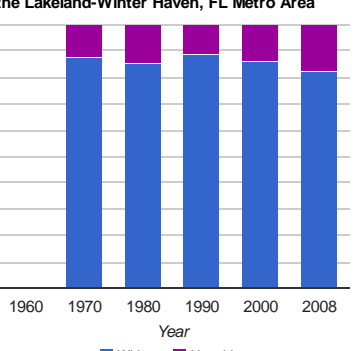
Groups Among Local Government Working-Age Population in the Lakeland-Wi..

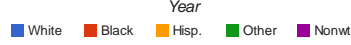
- White $\stackrel{\text { Year }}{\text { Nonwhite }}$

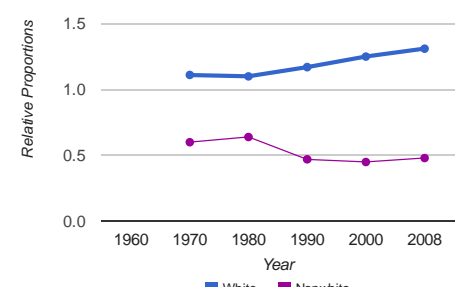
Diversity and Representation of the Central
City Working-Age Population and Local
Government High-Wage Employees in the Government High-Wage Employees in the
1.0 Lakeland-Winter Haven, FL Metro Area White ${ }_{\text {Nonunhit }}$

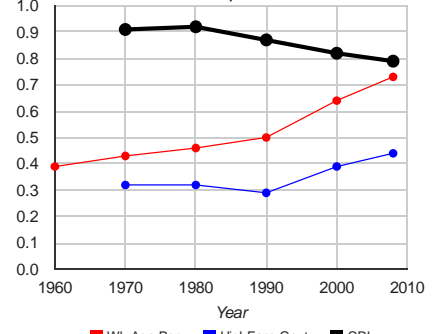

-Wk-Age Pop - MighEarn Govt - CRl 
High- and Low-Wage Local Government Employment in the Lakeland-Winter Haven, FL Metro Area Local Government Low-Wage Employees in the Metro Area
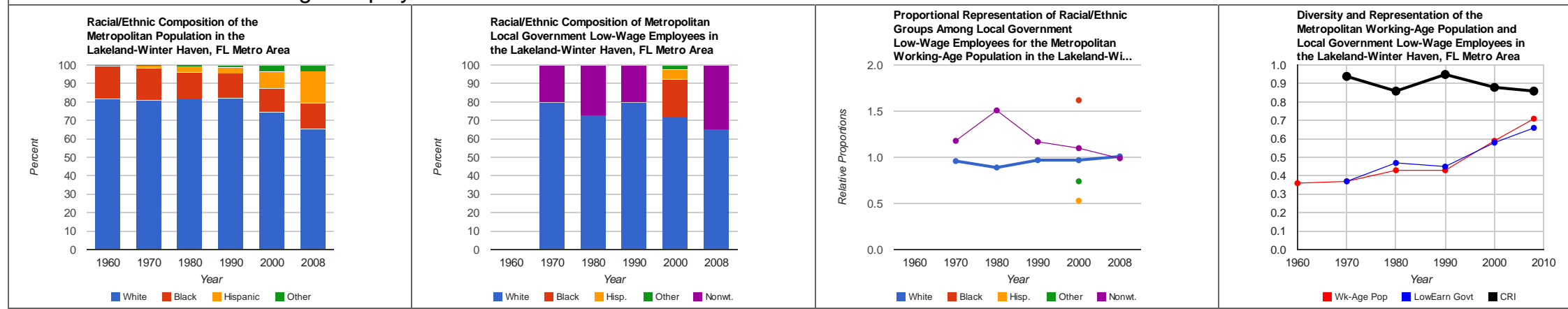

Local Government Low-Wage Employees in the Central City
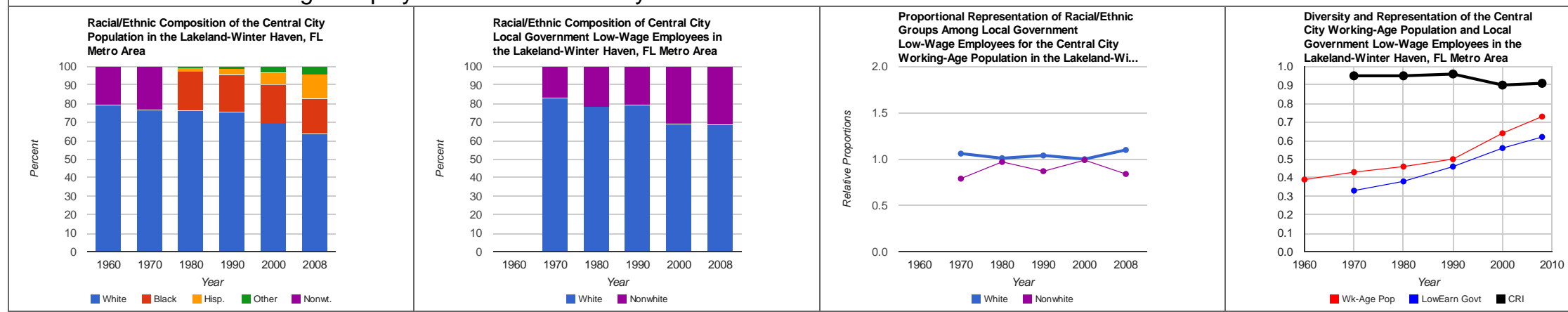
High- and Low-Wage Local Government Employment in the Lancaster, PA Metro Area

Lancaster, PA

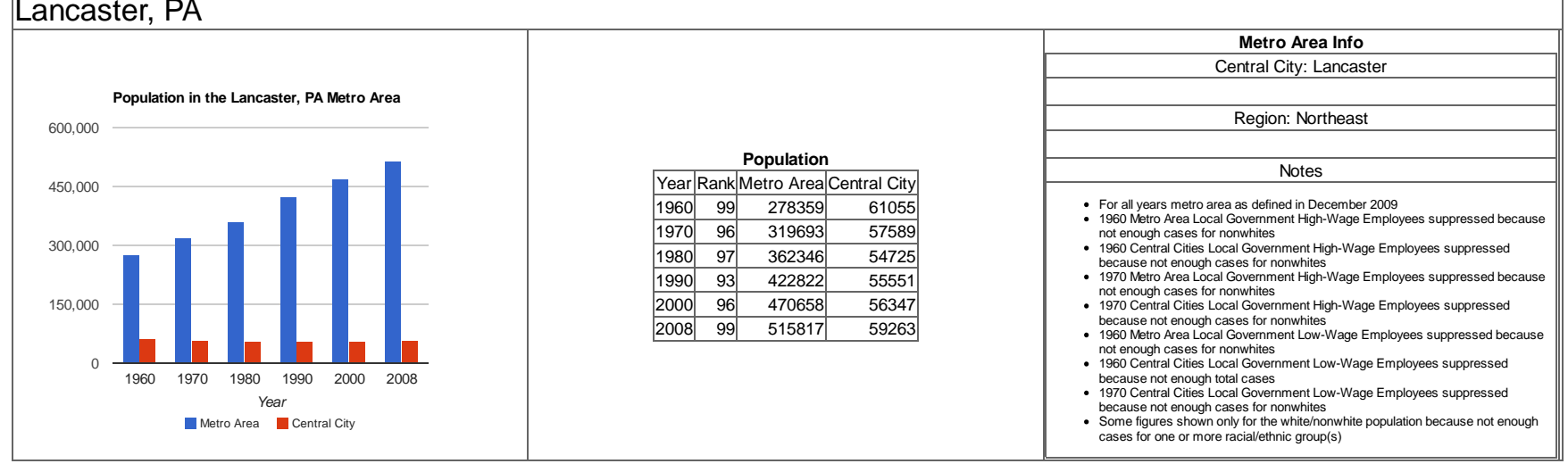


High- and Low-Wage Local Government Employment in the Lancaster, PA Metro Area

Local Government High-Wage Employees in the Metro Area
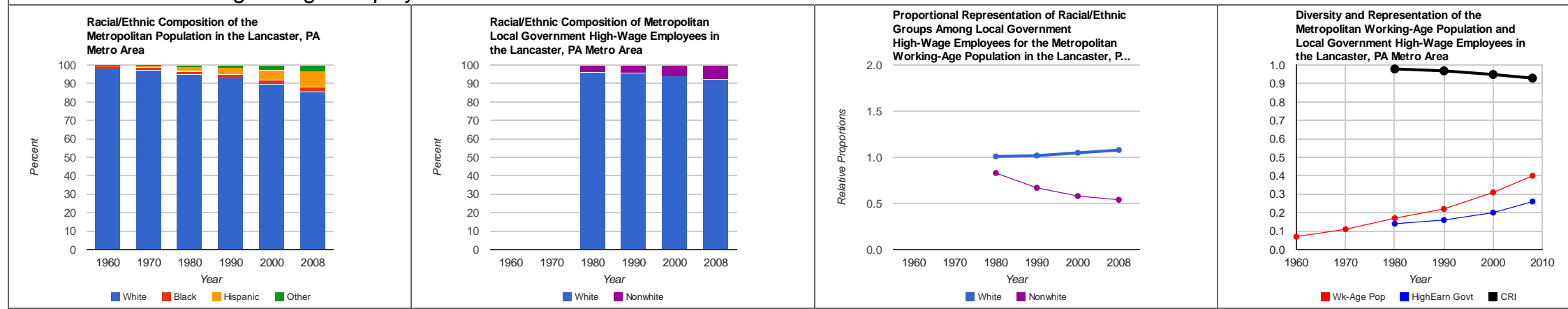

Local Government High-Wage Employees in the Central City
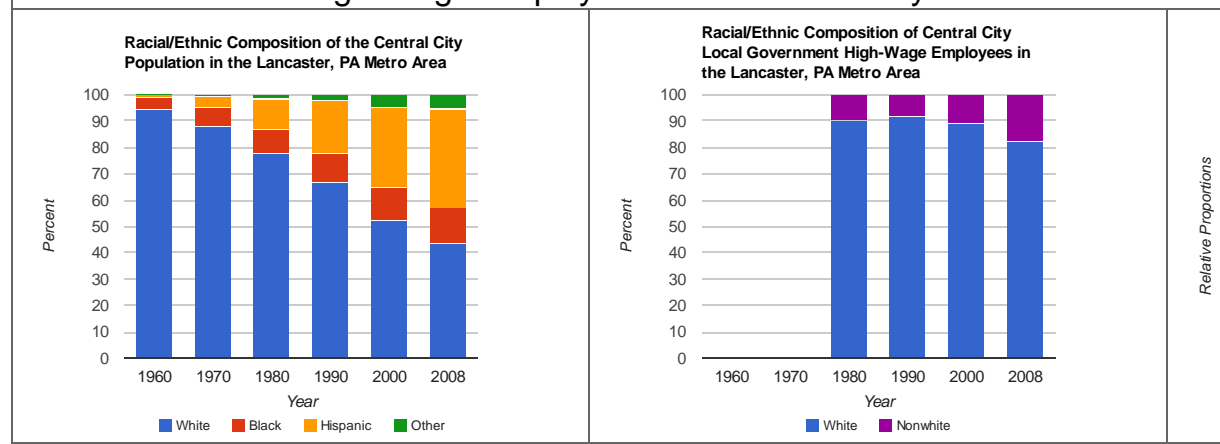
Proportional Representation of Racial/Ethnic
Groups Among Local Government
High-Wage Employees for the Central City High-Wage Employees for the Central City
Working-Age Population in the Lancaster, $\mathrm{P}$... @White 1 Black Year - White Menumhite $^{2}$

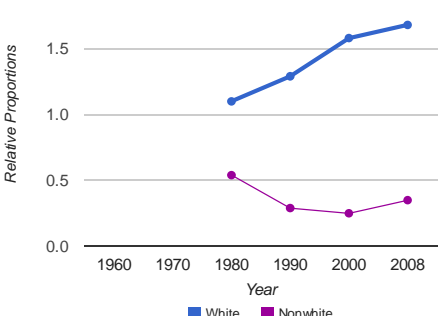
Diversity and Representation of the Central
City Working-Age Population and Local
Government High-Wage Employees in the

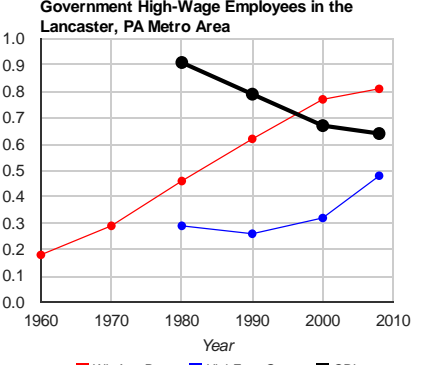

White Year $_{\text {Nonwhite }}$

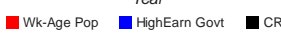


High- and Low-Wage Local Government Employment in the Lancaster, PA Metro Area

Local Government Low-Wage Employees in the Metro Area
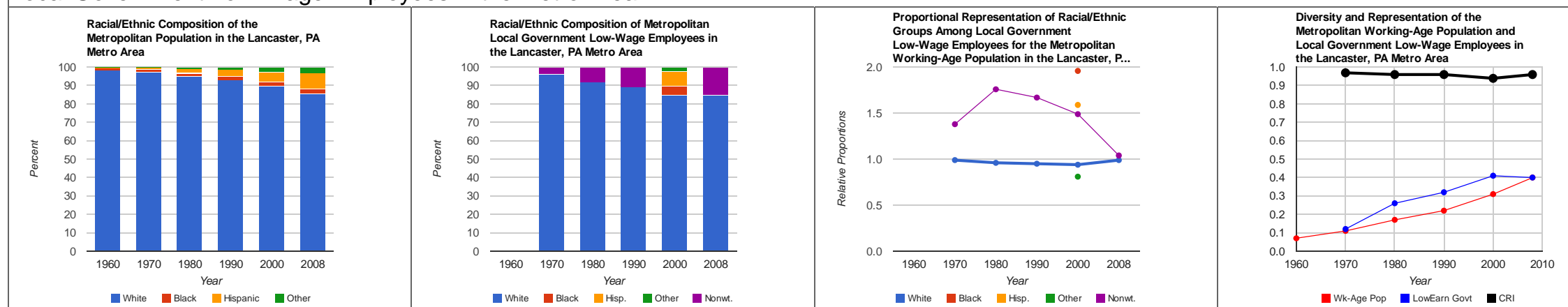

Local Government Low-Wage Employees in the Central City

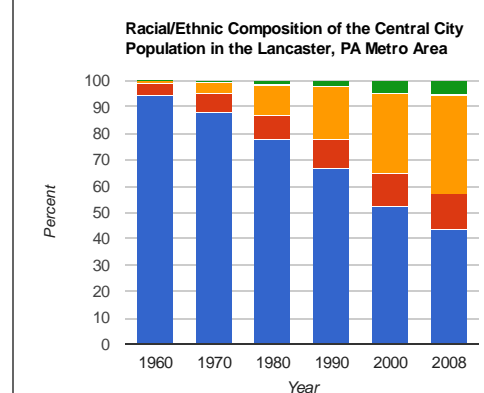

- White I Black Year Hispanic Inother

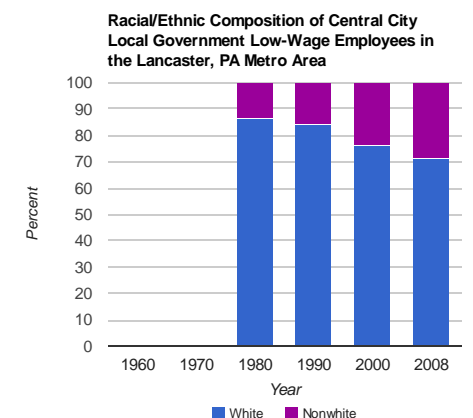

White Year Proportional Representation of Raciall/Ethnic
Groups Among Local Government
Low-Wage Employees for the Central City Low-Wage Employees for the Central City
20 Working-Age Population in the Lancaster, P...

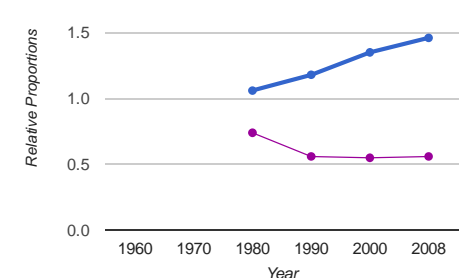

White ${ }_{\text {Nonunite }}$

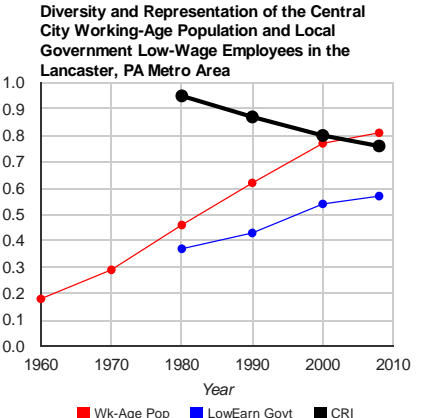

- Wk-Age Pop GLowEarn Govt - 


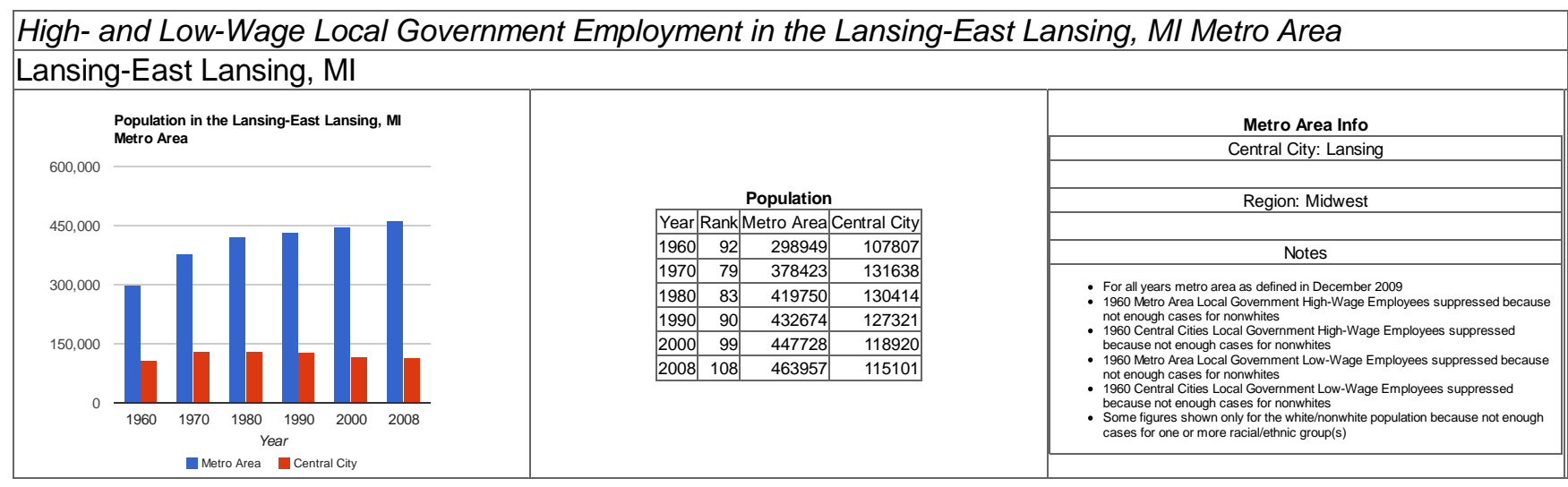


High- and Low-Wage Local Government Employment in the Lansing-East Lansing, MI Metro Area

Local Government High-Wage Employees in the Metro Area
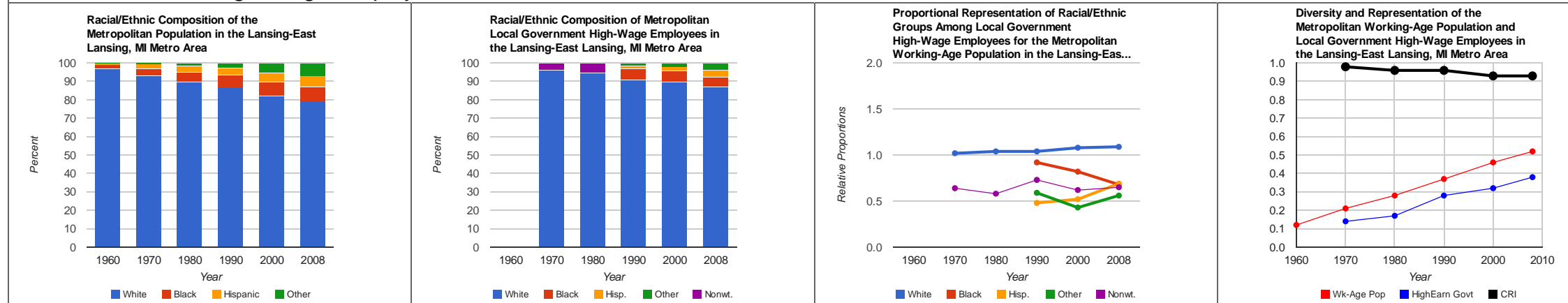

Local Government High-Wage Employees in the Central City
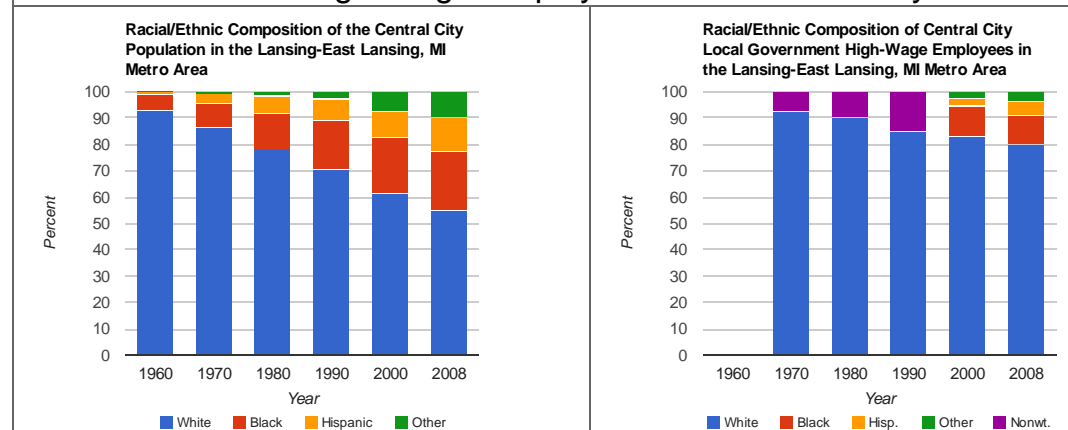
Proportional Representatition of Raciall/Ethnic
Grousp Among Local Government
High-W Agage Employees for the Central City 20 Working-Age Population in the Lansing-Eas.. White Elack Mear Hispanic nother

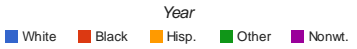
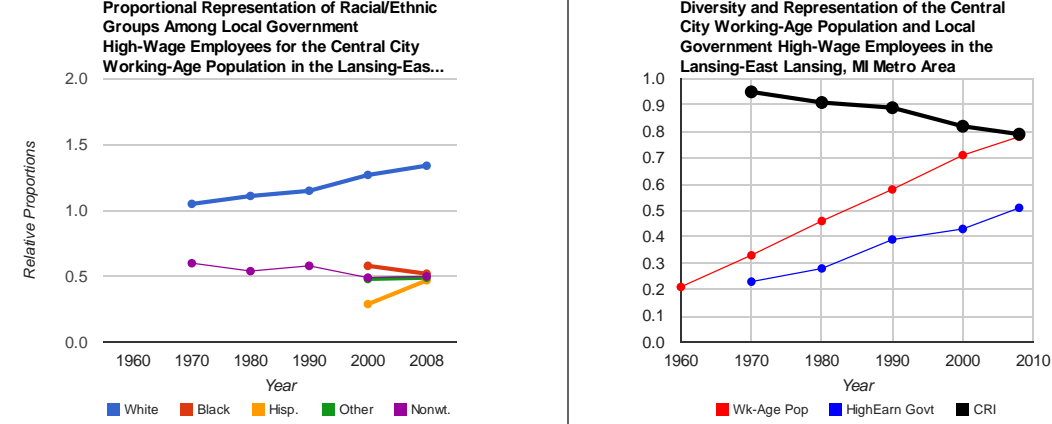
High- and Low-Wage Local Government Employment in the Lansing-East Lansing, MI Metro Area

Local Government Low-Wage Employees in the Metro Area
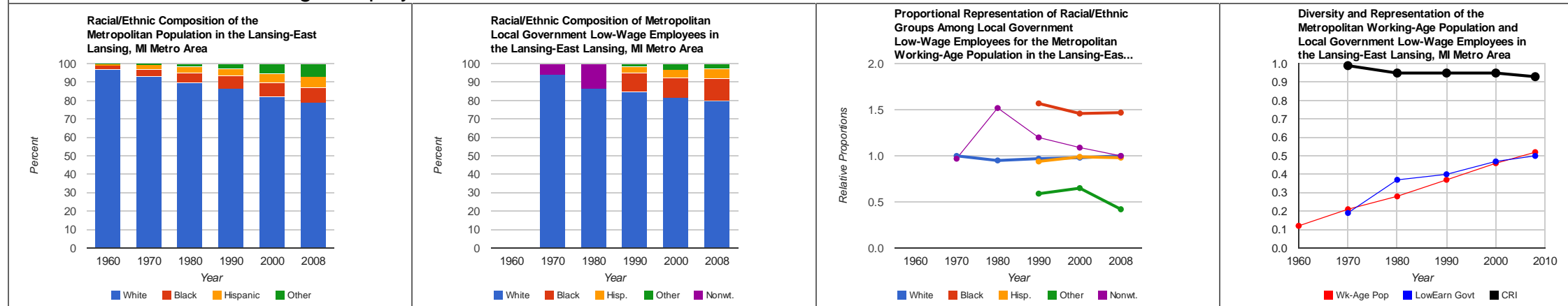

Local Government Low-Wage Employees in the Central City
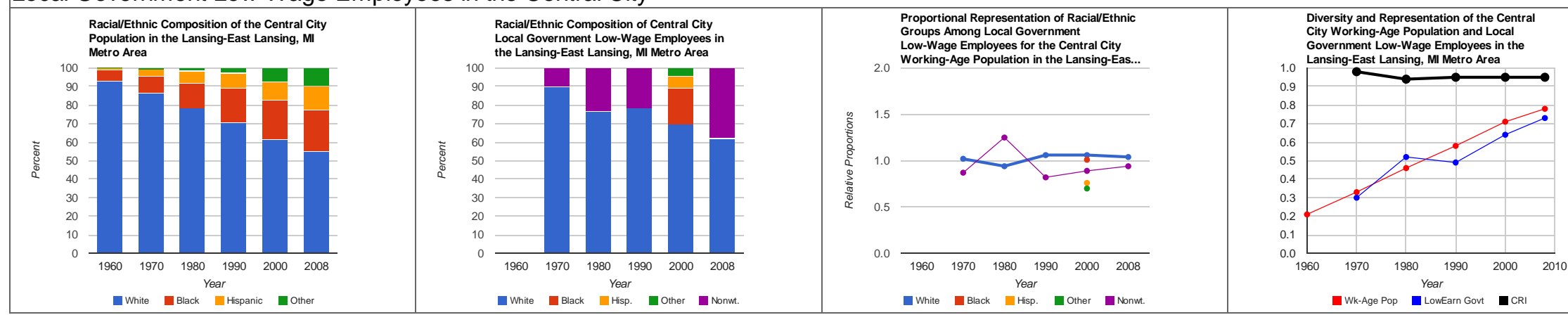


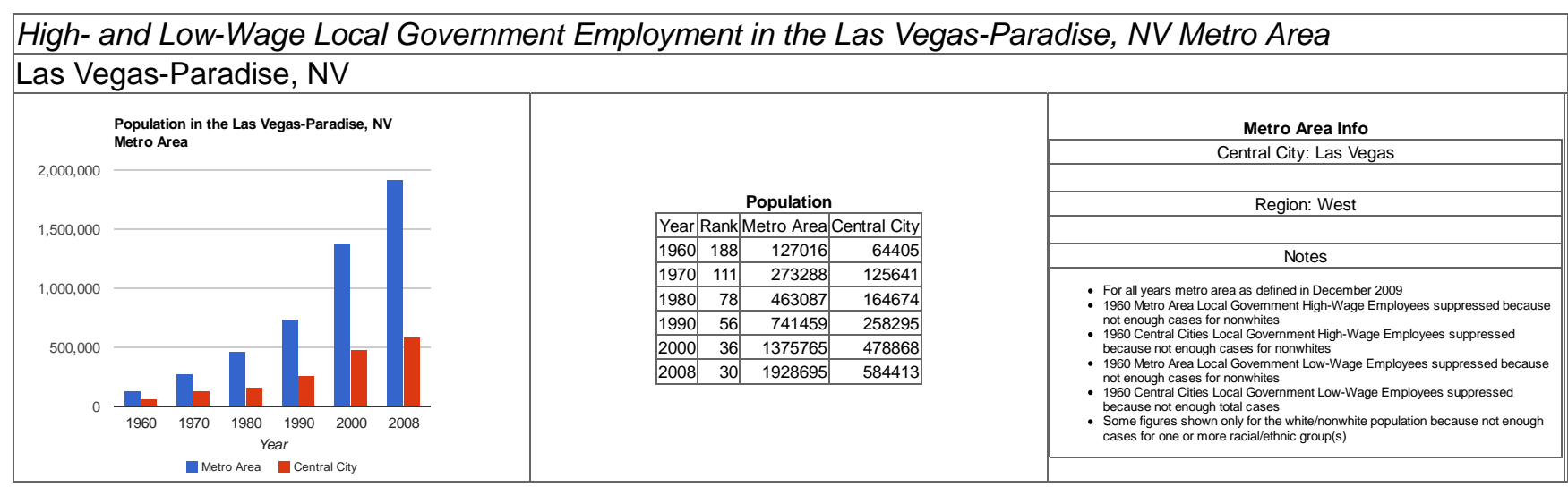


High- and Low-Wage Local Government Employment in the Las Vegas-Paradise, NV Metro Area

Local Government High-Wage Employees in the Metro Area
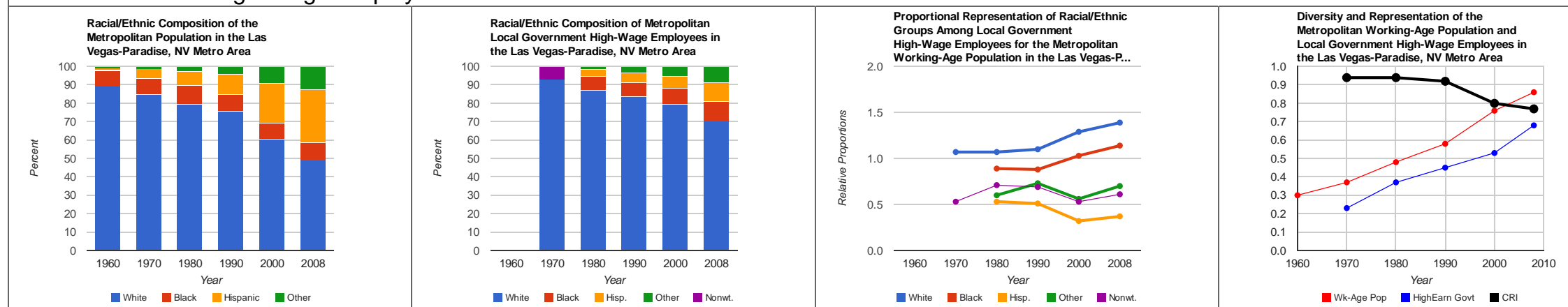

Local Government High-Wage Employees in the Central City
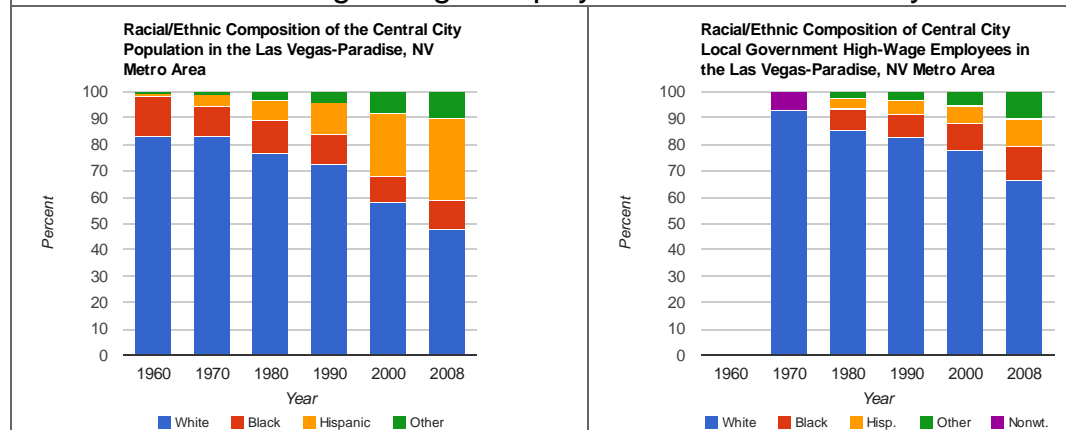
Proportional Representation of Raciall/Ethnic
Groups Among Local Government
High-Wage Employees for the Central City Working-Age Population in the Las Vegas-P...

White Elack YHispanic nother

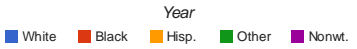

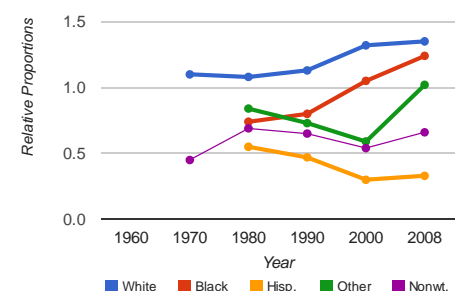
Diversity and Representation of the Central
City Working-Age Population and Local
Government High-Wage Employees in the

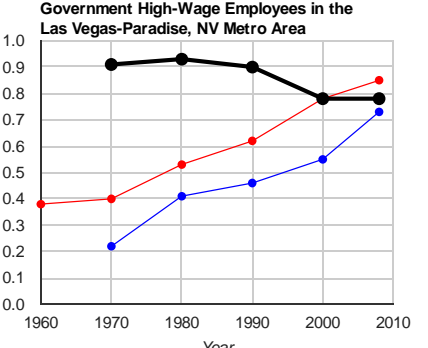

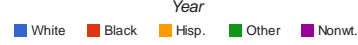

- Wk-Age Pop - Highearn Govt 
High- and Low-Wage Local Government Employment in the Las Vegas-Paradise, NV Metro Area

Local Government Low-Wage Employees in the Metro Area
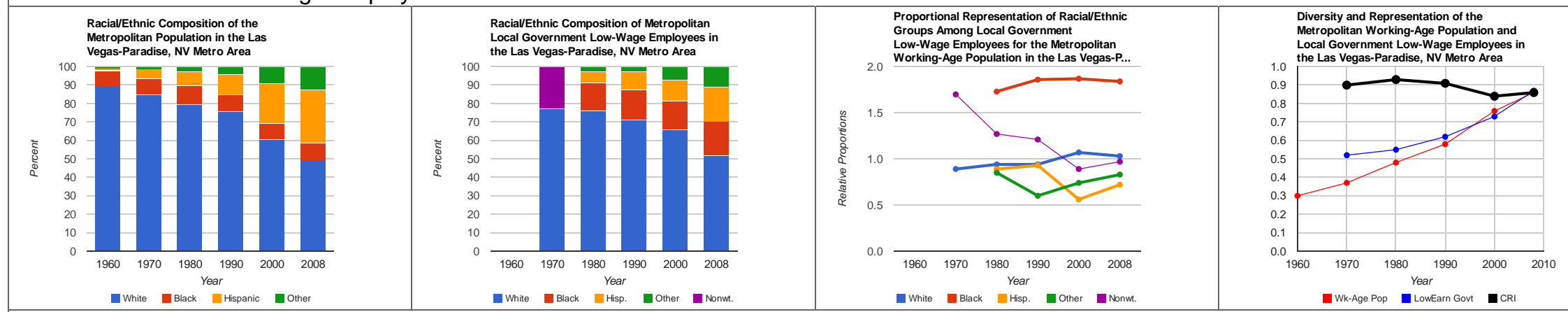

Local Government Low-Wage Employees in the Central City
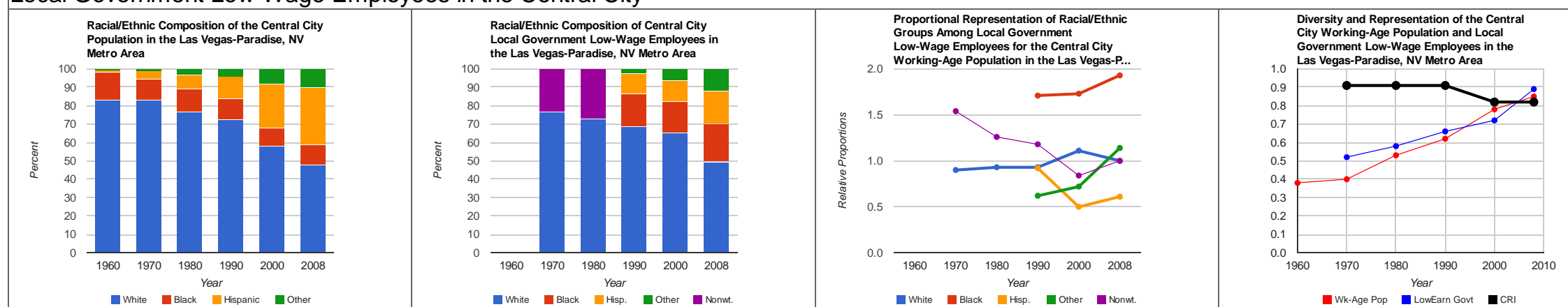


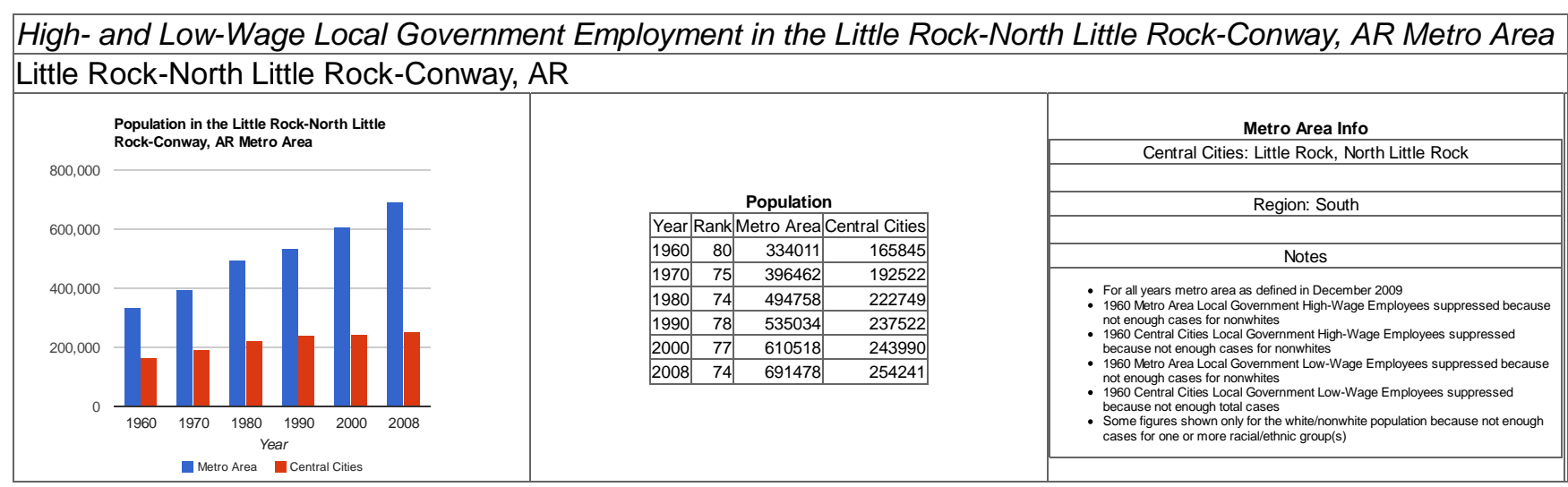


High- and Low-Wage Local Government Employment in the Little Rock-North Little Rock-Conway, AR Metro Area Local Government High-Wage Employees in the Metro Area
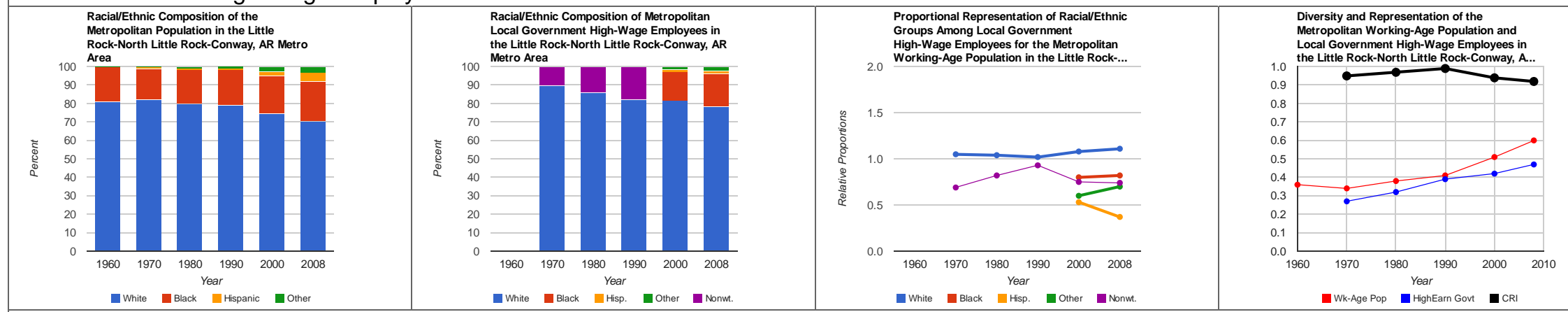

Local Government High-Wage Employees in the Central Cities
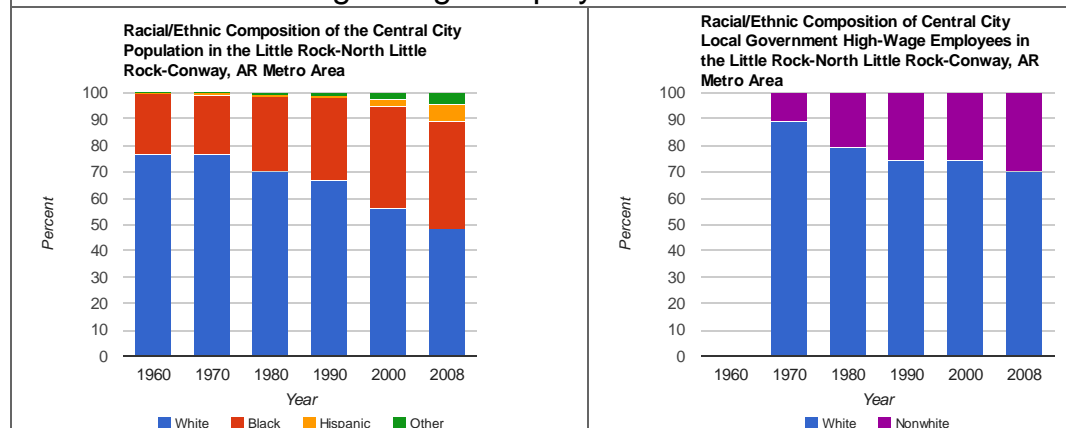
Proportional Representation of Raciall/thnic
Groups Among Local Government
High-Wage Employees for the Central City Working-Age Population in the Little Rock-...

White Elack YHispanic Inother - White $\stackrel{\text { Year }}{\text { Nonwhite }}$

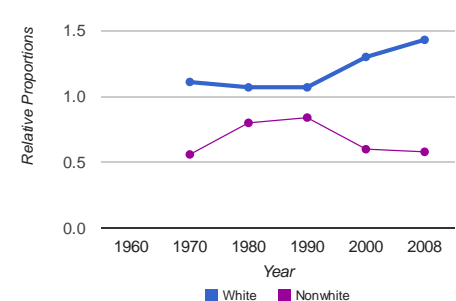

White ${ }_{\text {Nonmite }}^{\text {Year }}$

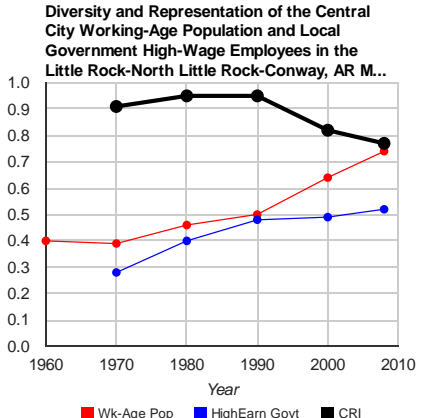

-Wk-Age Pop M HighEarn Govt $\quad$ CR 
High- and Low-Wage Local Government Employment in the Little Rock-North Little Rock-Conway, AR Metro Area Local Government Low-Wage Employees in the Metro Area
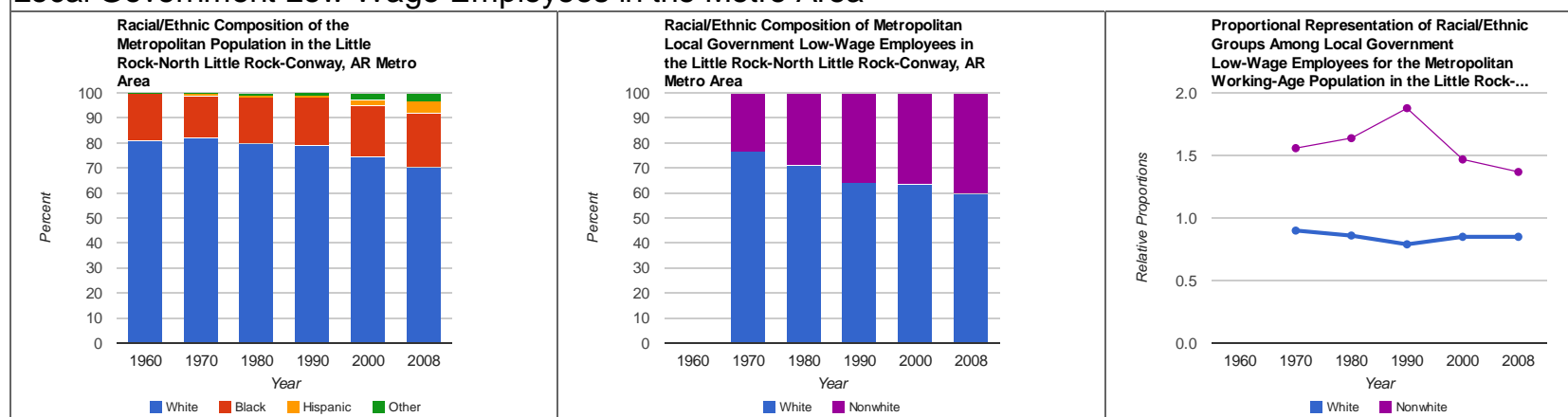

Local Government Low-Wage Employees in the Central Cities
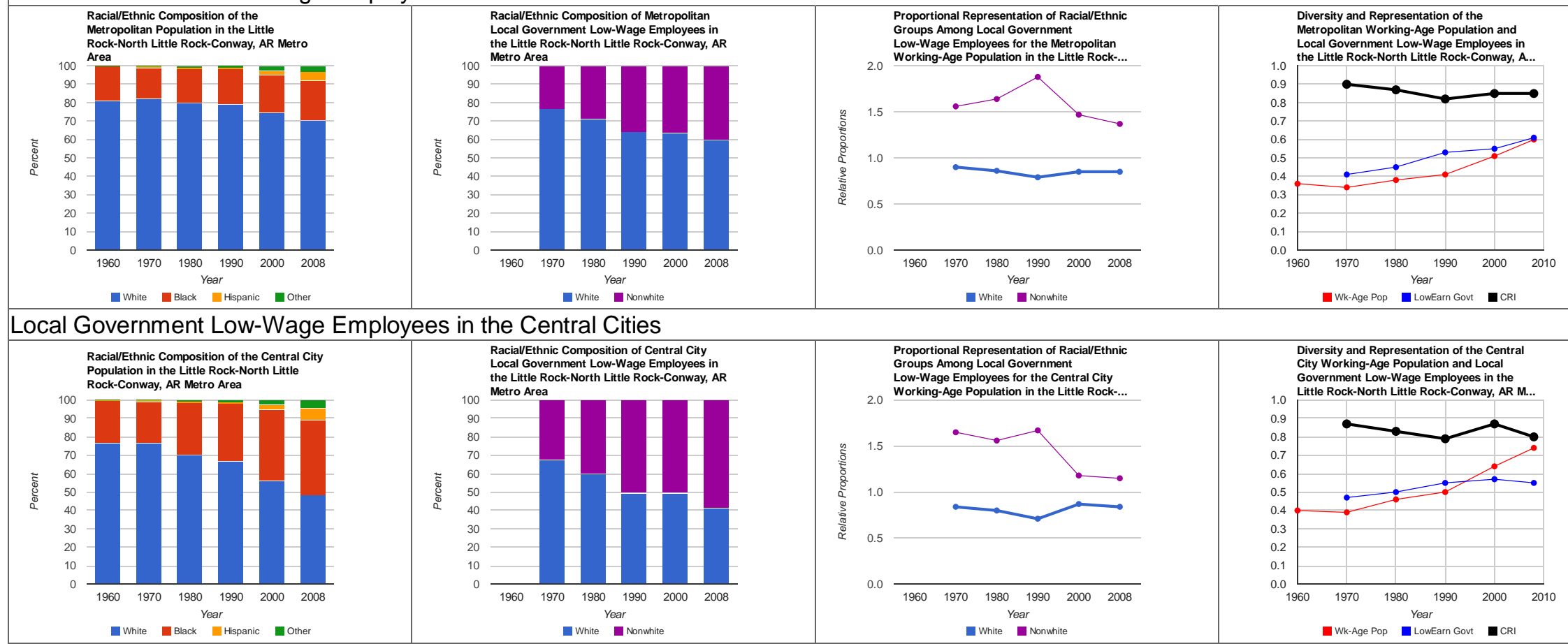

White $\quad$ Black $\quad$ Hispanic $\quad$ Other

- White $\stackrel{\text { Year }}{\text { Nonwhite }}$

White ${ }_{\text {Nonumite }}$

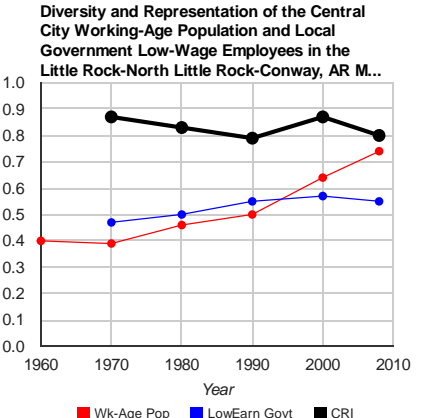

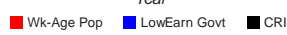




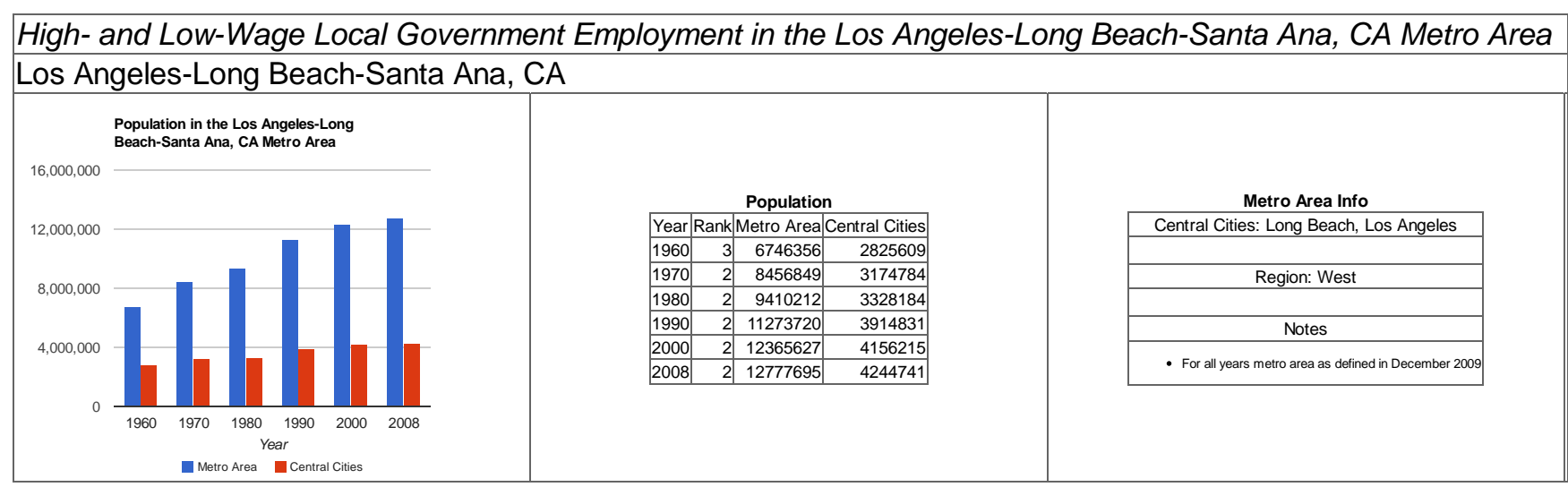


High- and Low-Wage Local Government Employment in the Los Angeles-Long Beach-Santa Ana, CA Metro Area Local Government High-Wage Employees in the Metro Area
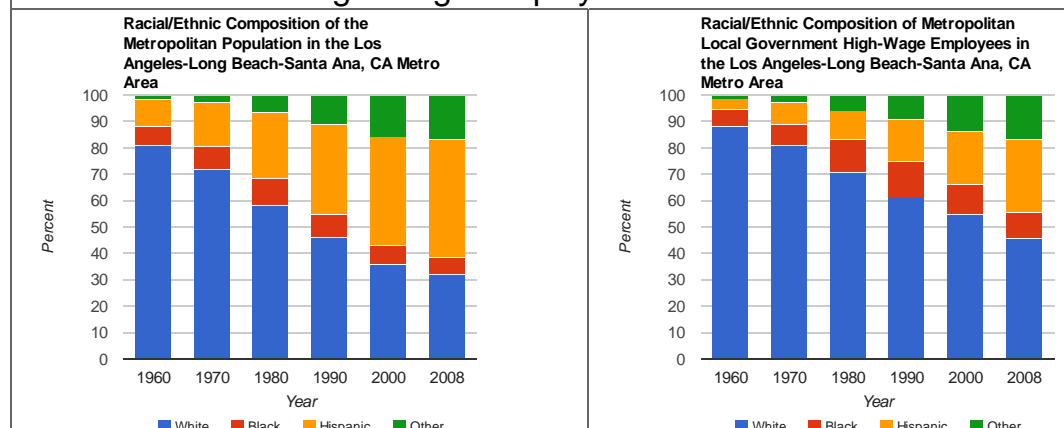

Local Government High-Wage Employees in the Central Cities
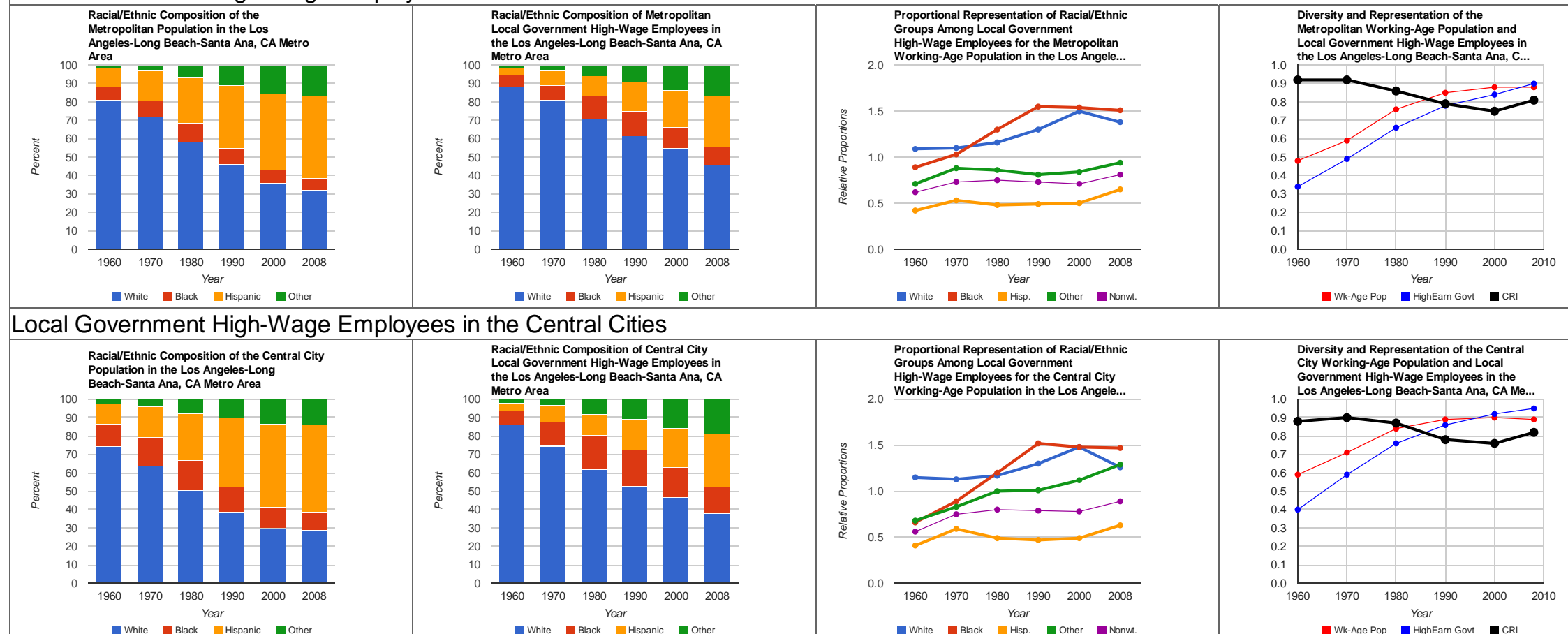

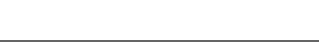

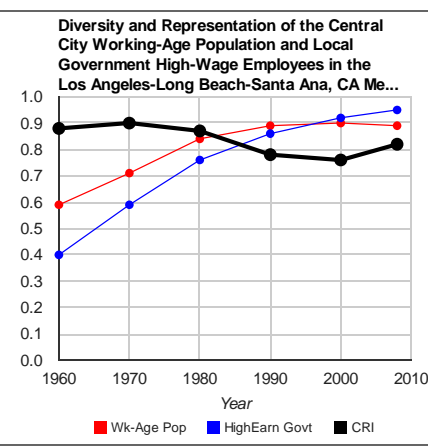


High- and Low-Wage Local Government Employment in the Los Angeles-Long Beach-Santa Ana, CA Metro Area Local Government Low-Wage Employees in the Metro Area
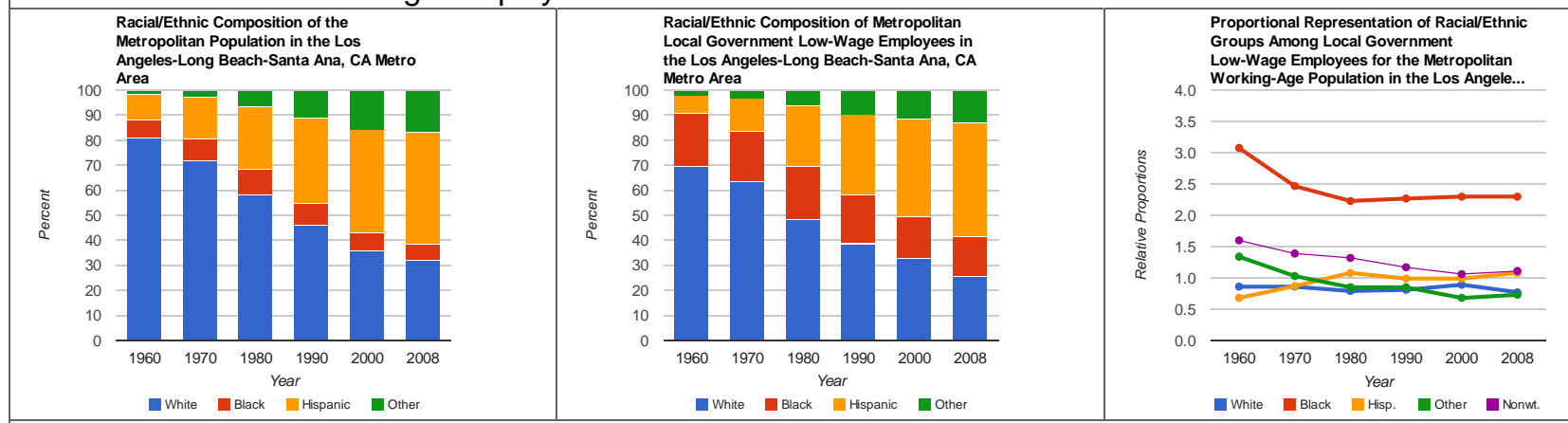
Diversity and Representation of the
Metropolitan Working-Age Population and the Los Angeles-Long Beach-Santa Ana, C..

White Black Hispanic Other

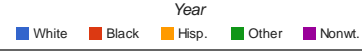

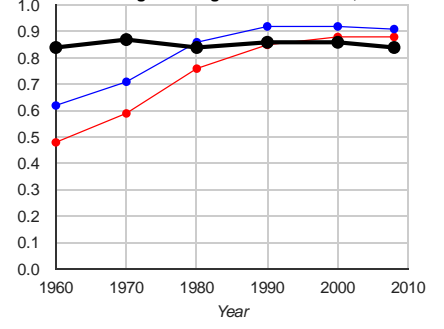

Local Government Low-Wage Employees in the Central Cities
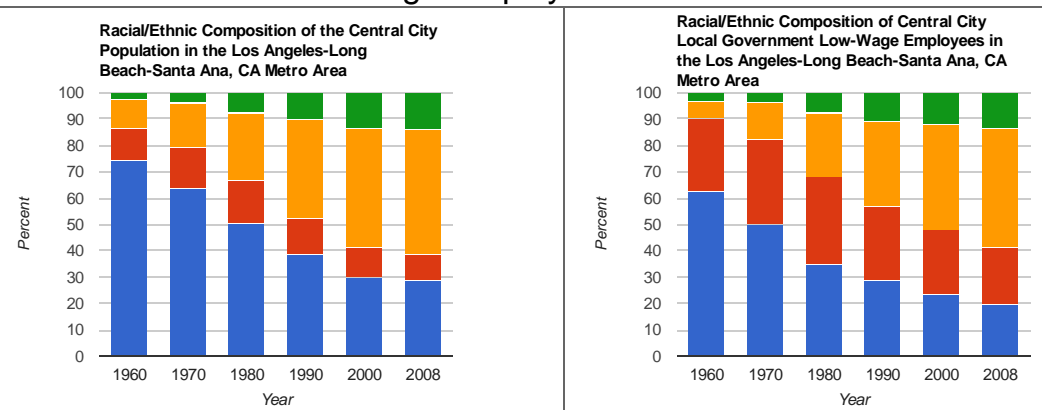
Proportional Representation of Racial/:thnic
Groups Among Local Government
Low-Whage Employees for the Central City Low-Wage Employees tor the Central City
Working-Age Population in the Los Angele.

White Inlack Yur Hispanic Eother White 1 Black $\quad$ Hispanic $\square$ other

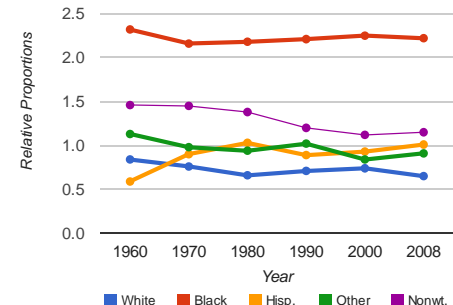
Diversity and Representation of the Central
City Working-Age Population and Local
Government Low-Wage Employees in the Government Low-Wage Employees in the
1.0 Los Angeles-Long Beach-Santa Ana, CA Me... 0.9

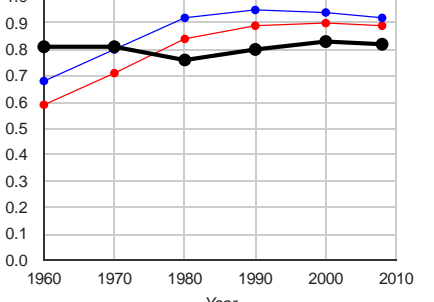

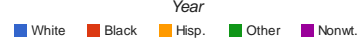




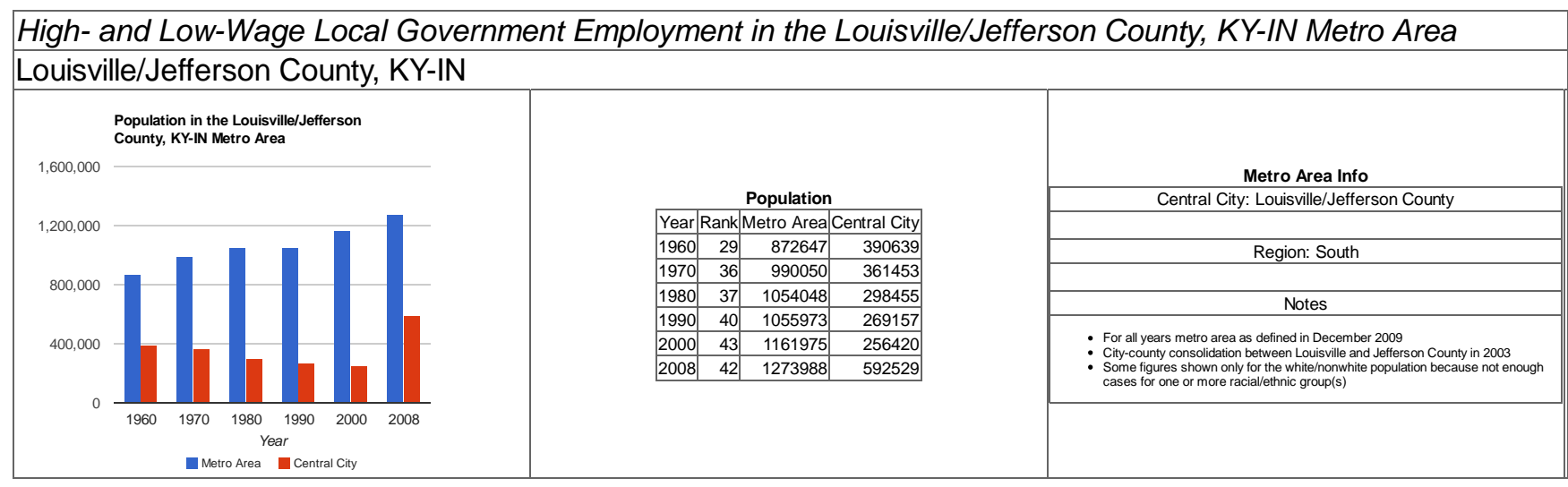


High- and Low-Wage Local Government Employment in the Louisville/Jefferson County, KY-IN Metro Area Local Government High-Wage Employees in the Metro Area
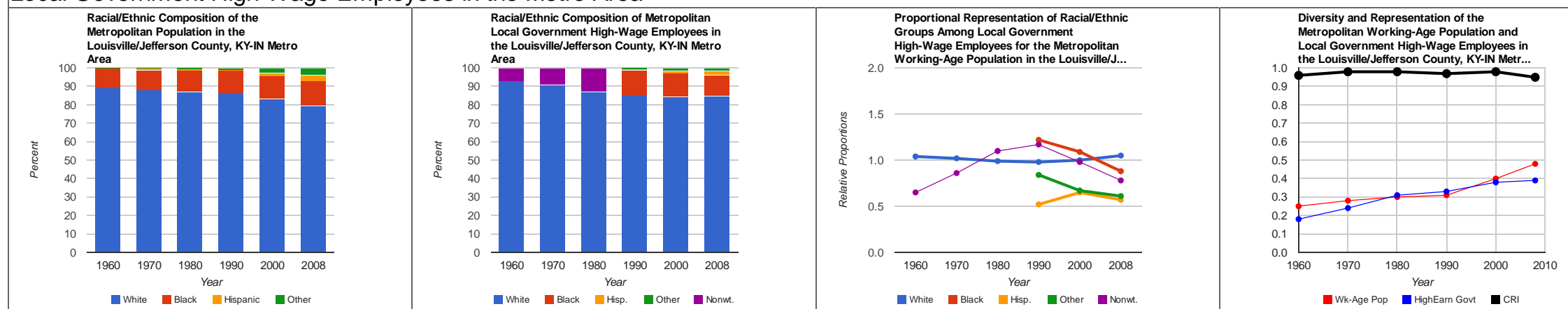

Local Government High-Wage Employees in the Central City
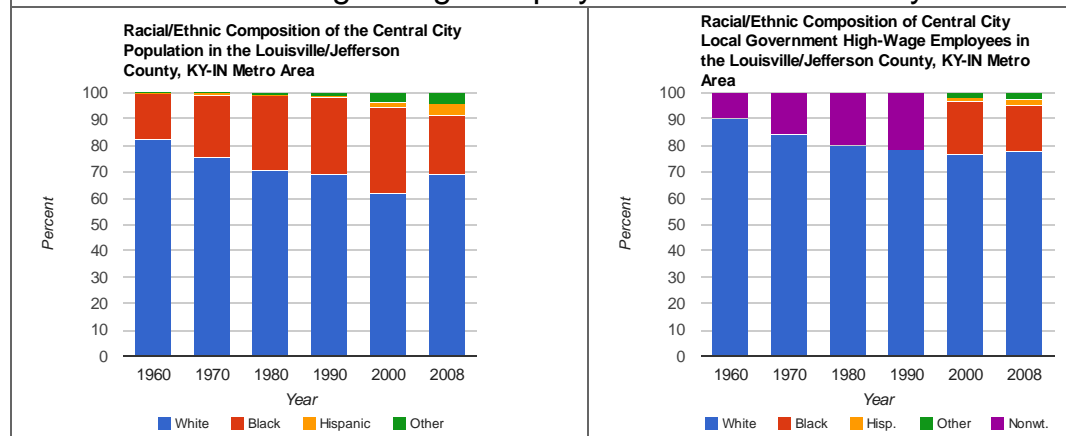
Proportional Representation of Raciall/Ethnic
Groups Among Local Government
High-Wage Employees for the Central City 20 Working-Age Population in the Louisville/J.

White Elack YHispanic Inother

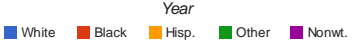

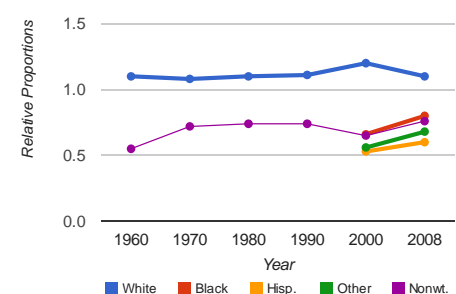
Diversity and Representation of the Central
City Working-Age Population and Local
Government High-Wage Employees in the Government High-Wage Employees in the
Louisville/Jefferson County, KY-IN Metro Ar.

Coputytion in the Louisville/

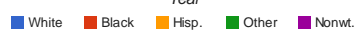

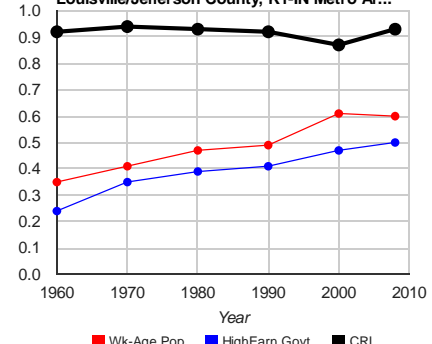

Wh-Age Pop HighEarn Govt 
High- and Low-Wage Local Government Employment in the Louisville/Jefferson County, KY-IN Metro Area Local Government Low-Wage Employees in the Metro Area
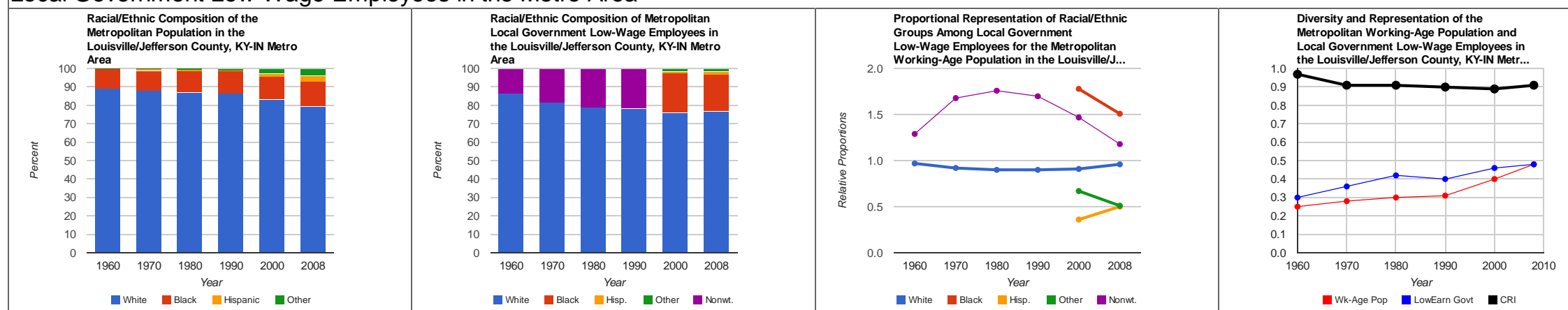

Local Government Low-Wage Employees in the Central City
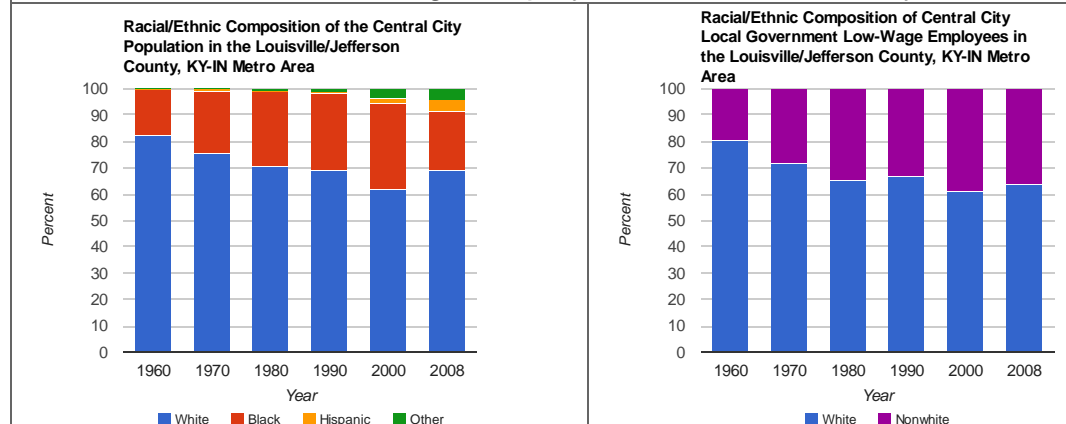
Proportional Representation of Raciall/Ethnic
Groups Among Local Government
Low-Wage Employees for the Central City Working-Age Population in the Louisvillel].

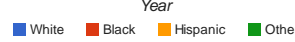
- White $\stackrel{\text { Year }}{\text { Nonwhite }}$
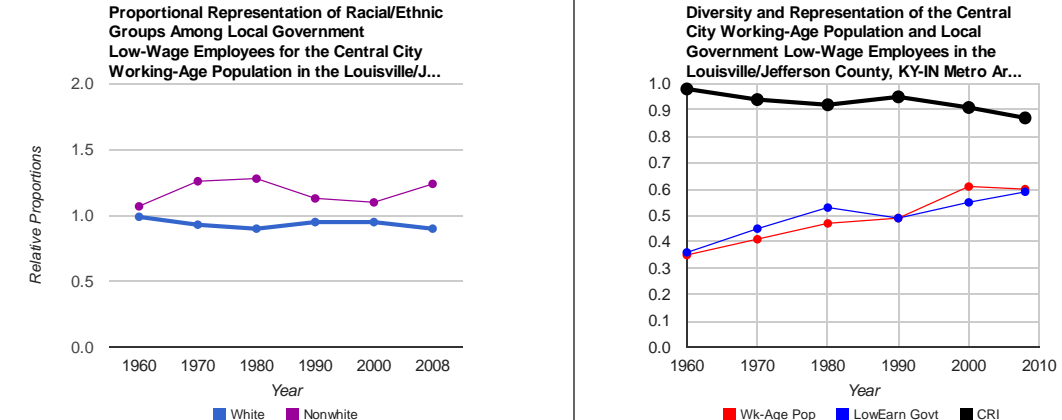

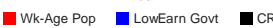




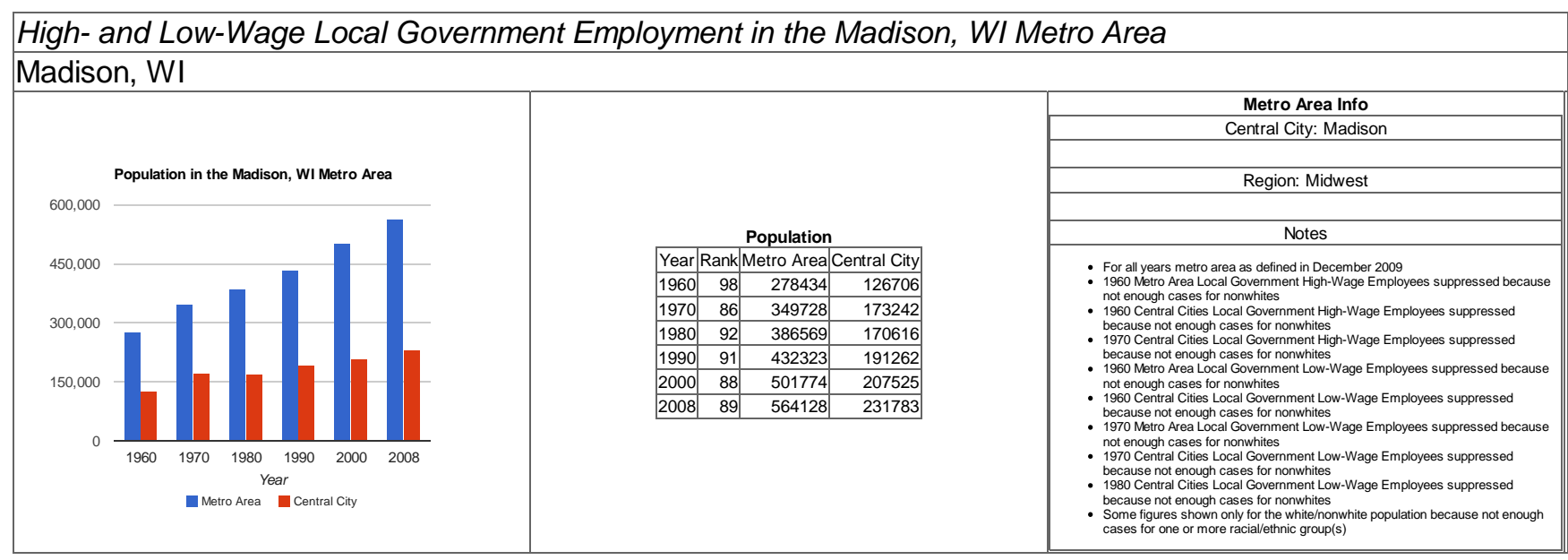


High- and Low-Wage Local Government Employment in the Madison, WI Metro Area

Local Government High-Wage Employees in the Metro Area
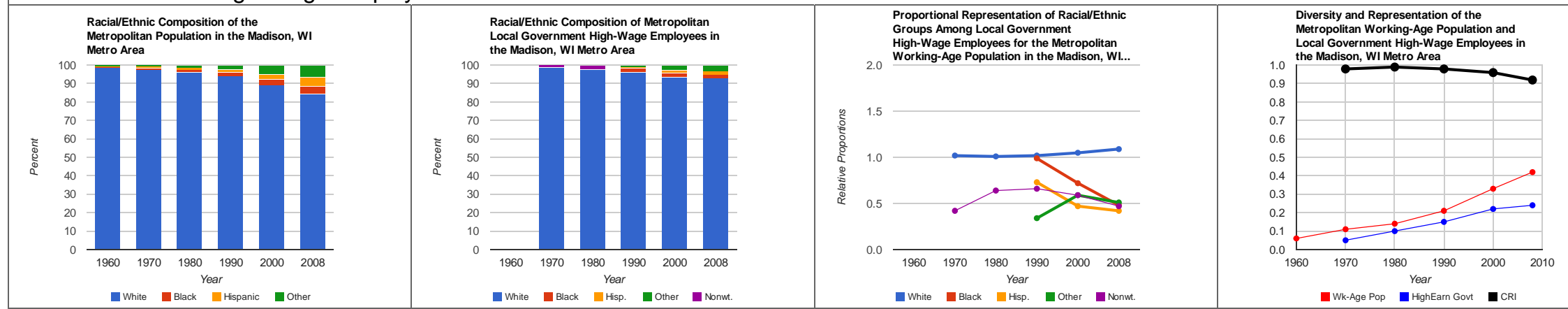

Local Government High-Wage Employees in the Central City
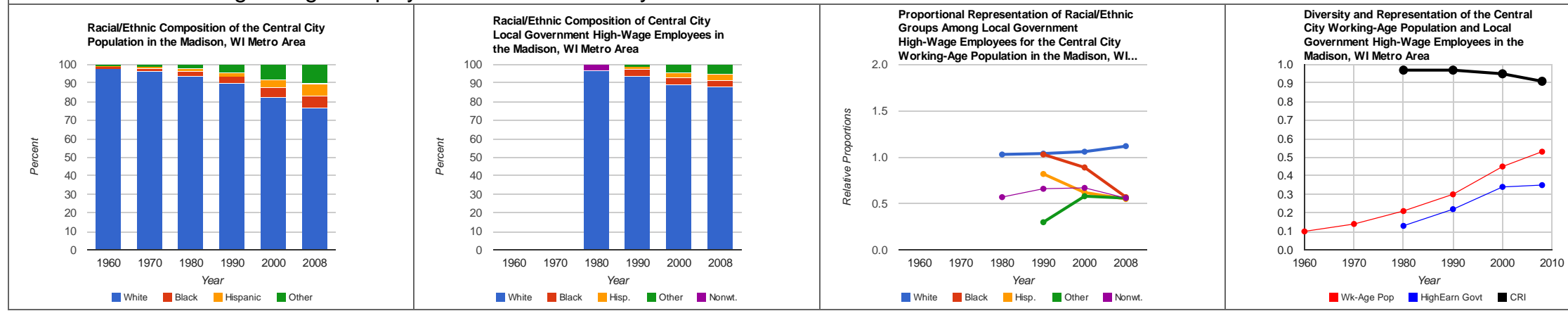
High- and Low-Wage Local Government Employment in the Madison, WI Metro Area

Local Government Low-Wage Employees in the Metro Area
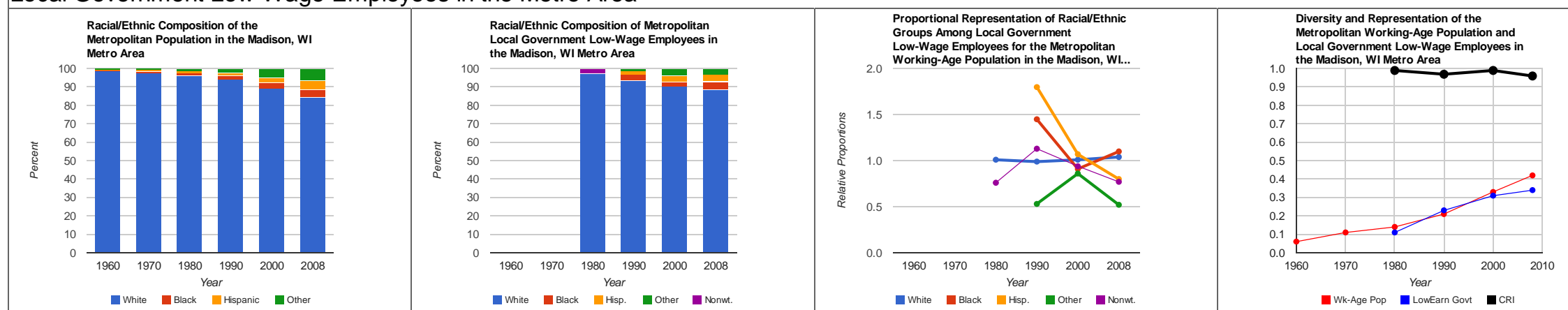

Local Government Low-Wage Employees in the Central City
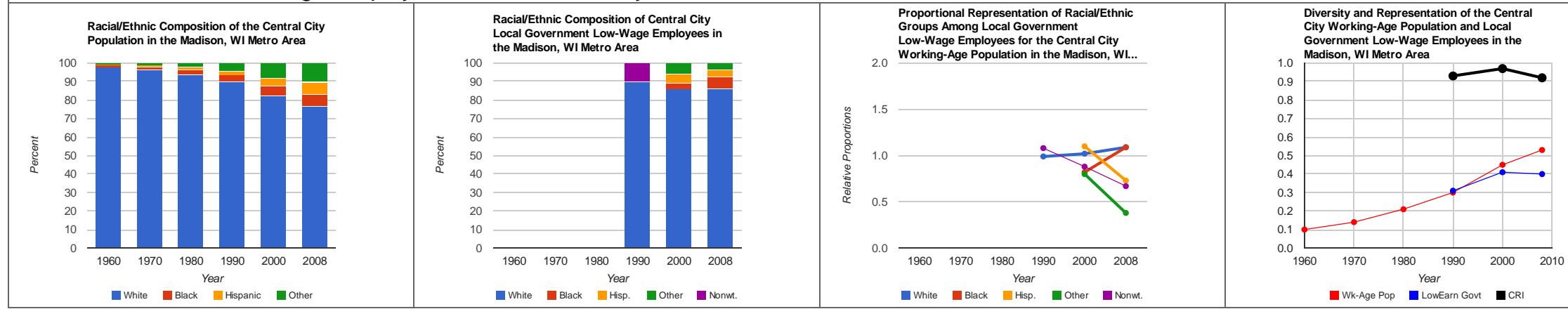


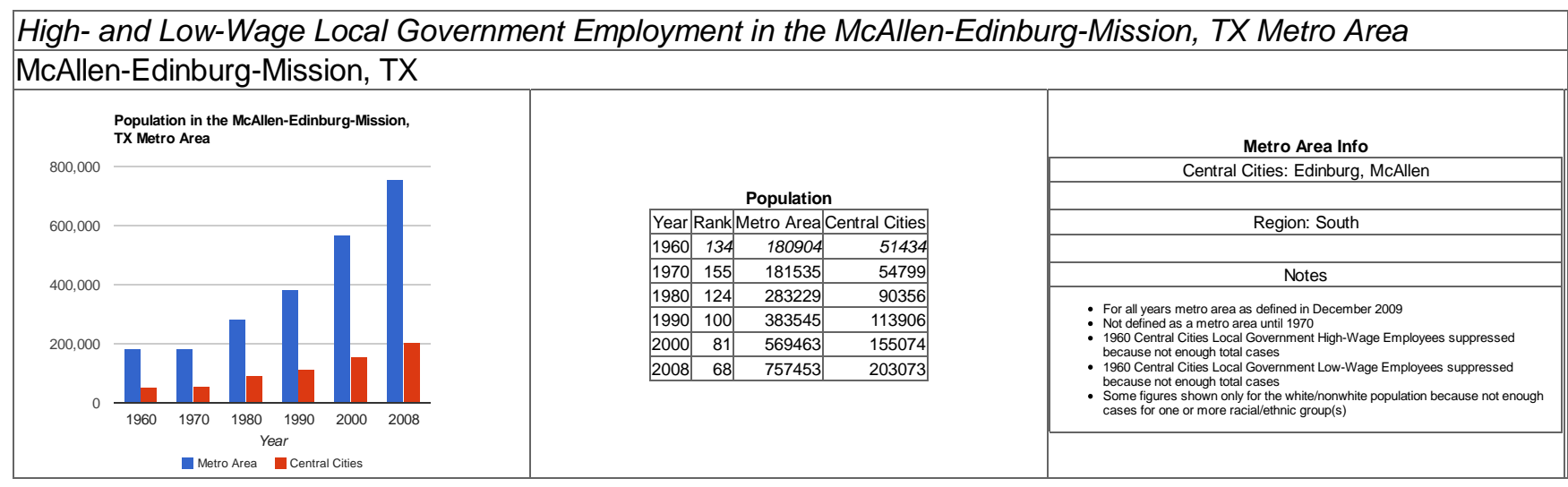


High- and Low-Wage Local Government Employment in the McAllen-Edinburg-Mission, TX Metro Area

Local Government High-Wage Employees in the Metro Area
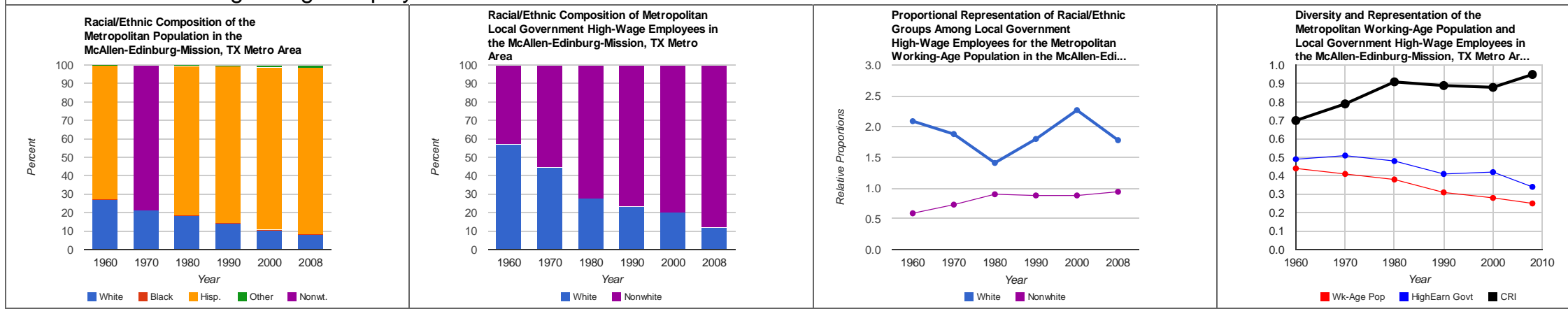

Local Government High-Wage Employees in the Central Cities
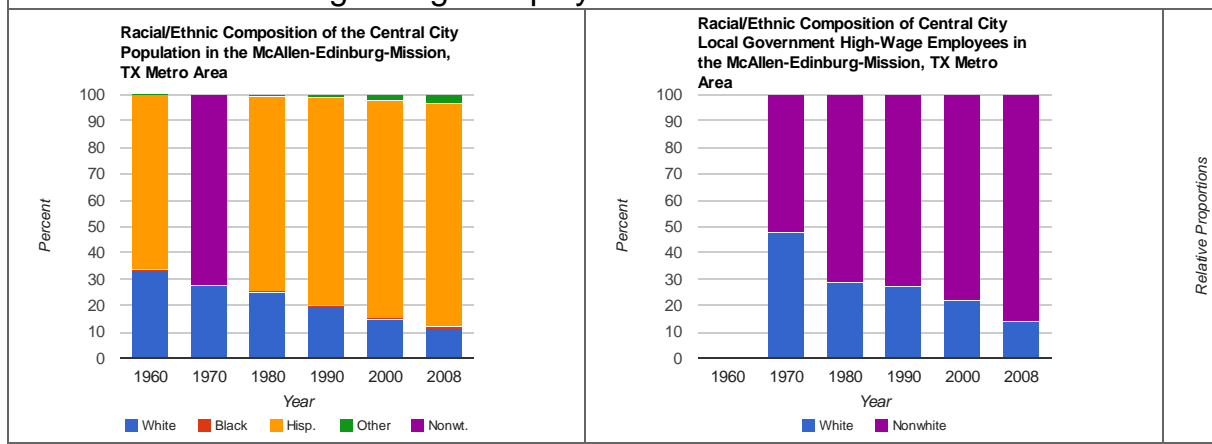
Proportional Representation of Racial/Ethnic
Groups Among Local Government
High-Wage Employees for the Central City High-Wage Employees for the Central City
Working-Age Population in the McAllen-Edi...

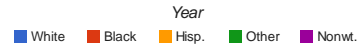
- White $\stackrel{\text { Year }}{\text { Nonwhite }}$

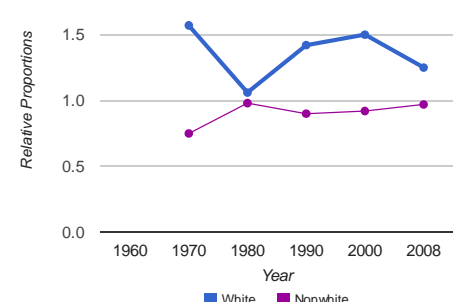
Diversity and Representation of the Central
City Working-Age Population and Local
Government High-Wage Employees in the

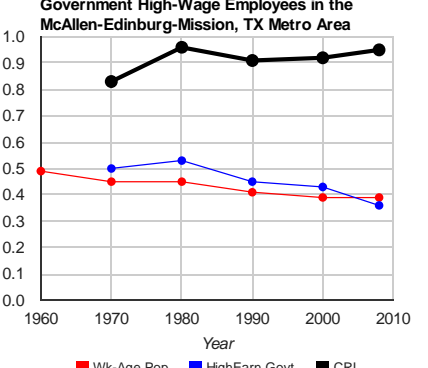

White $\quad$ Nonmhite

-Wk-Age Pop W Highearn Govt - 
High- and Low-Wage Local Government Employment in the McAllen-Edinburg-Mission, TX Metro Area

Local Government Low-Wage Employees in the Metro Area
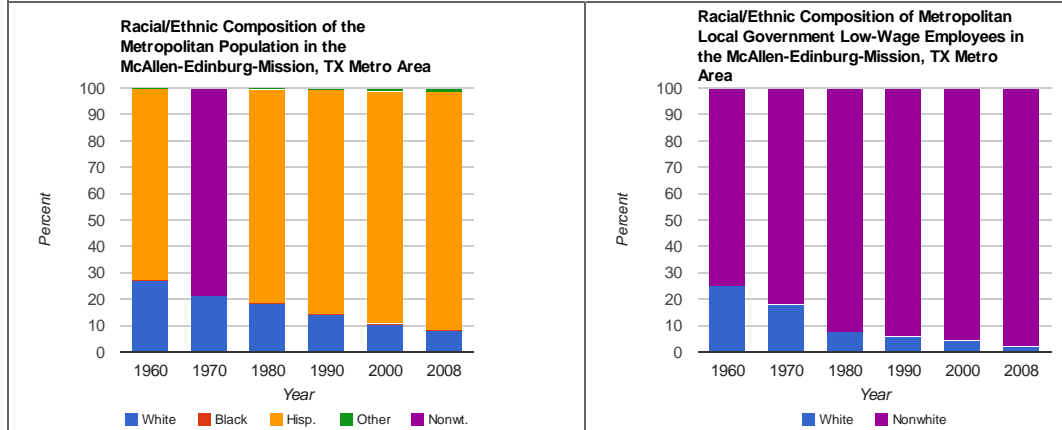

Proportional Representation of Raciall/thnic Groups Among Local Government Working-Age Population in the McAllen-Edi...

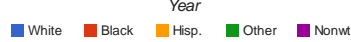

anhite Nonwhite

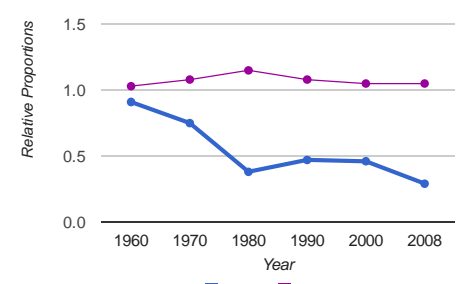
White ${ }_{\text {Nonnhite }}^{\text {Year }}$

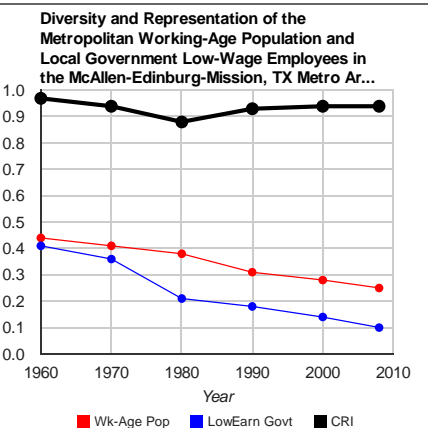

Local Government Low-Wage Employees in the Central Cities
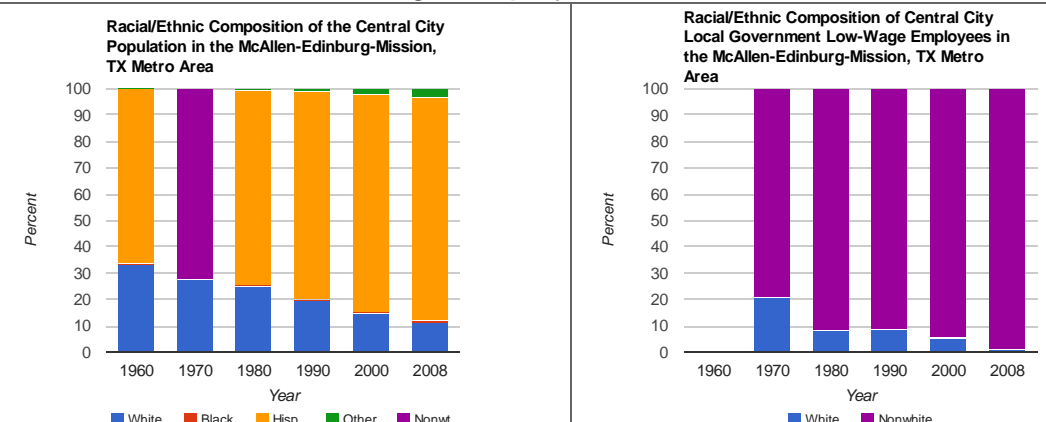
Proportional Representation of Raciall/Ethnic
Groups Among Local Government
Low-Whage Employees for the Central City

(1)

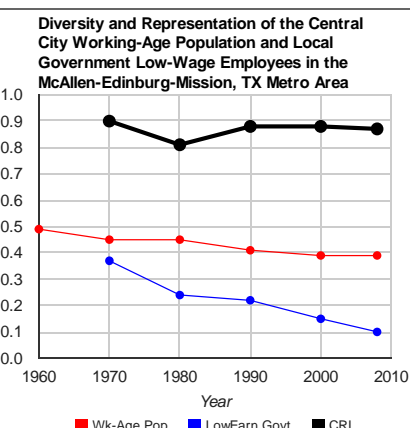

—White $\quad \begin{gathered}\text { Year } \\ \text { Black }\end{gathered}$

- White $\stackrel{\text { Year }}{\text { Nonwhite }}$

Low--Wage Employees for the Central City
2.0 Working-Age Population in the McAllen-Edi...

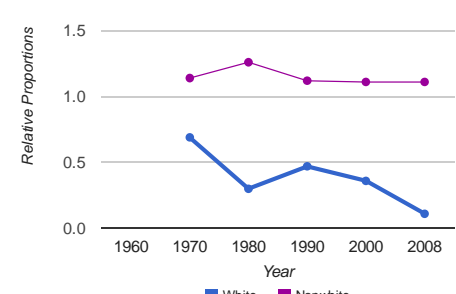

White ${ }_{\text {Nonunhite }}^{\text {Year }}$ 


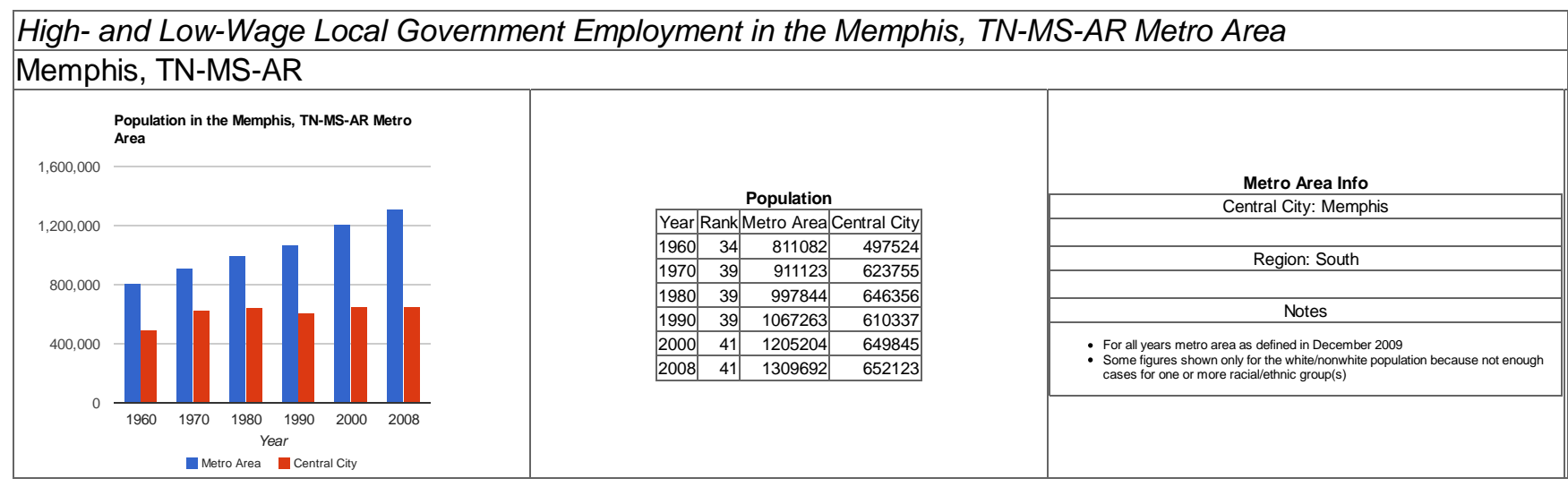


High- and Low-Wage Local Government Employment in the Memphis, TN-MS-AR Metro Area

Local Government High-Wage Employees in the Metro Area
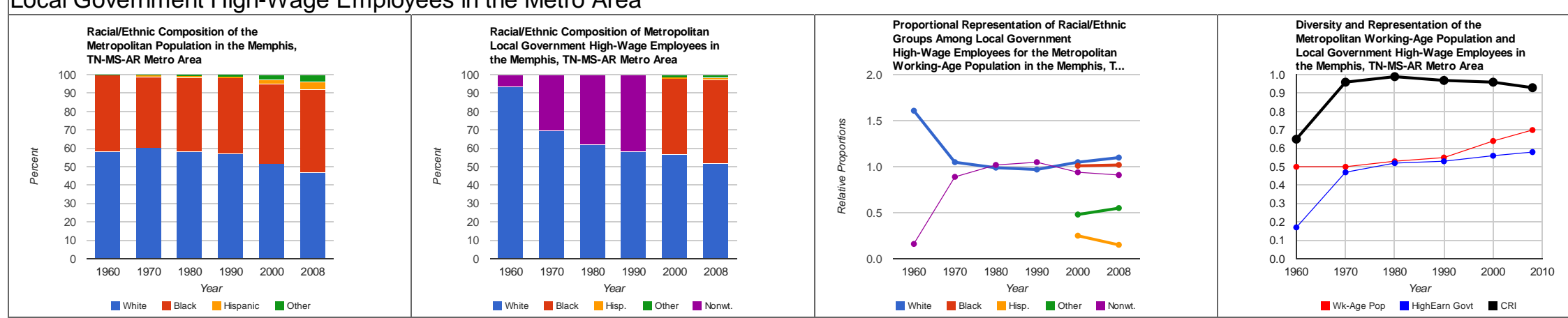

Local Government High-Wage Employees in the Central City
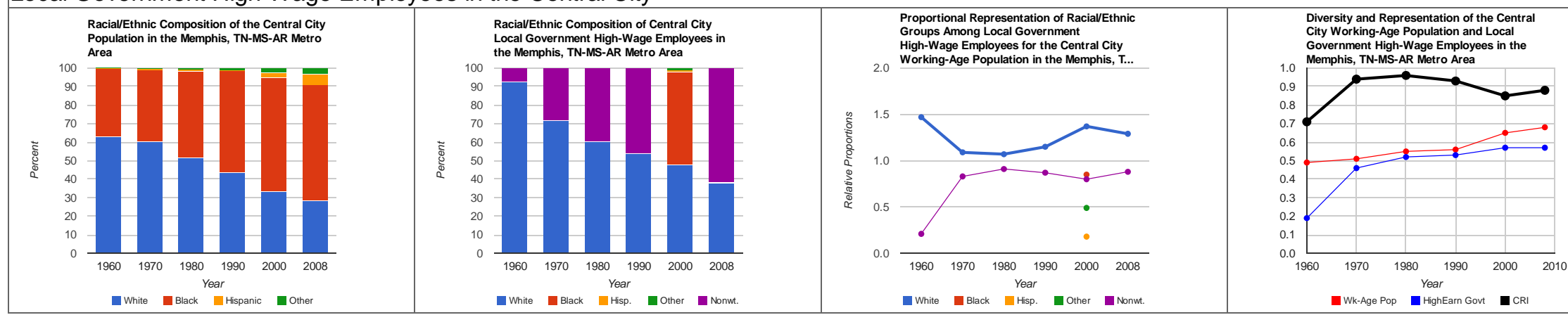
High- and Low-Wage Local Government Employment in the Memphis, TN-MS-AR Metro Area

Local Government Low-Wage Employees in the Metro Area
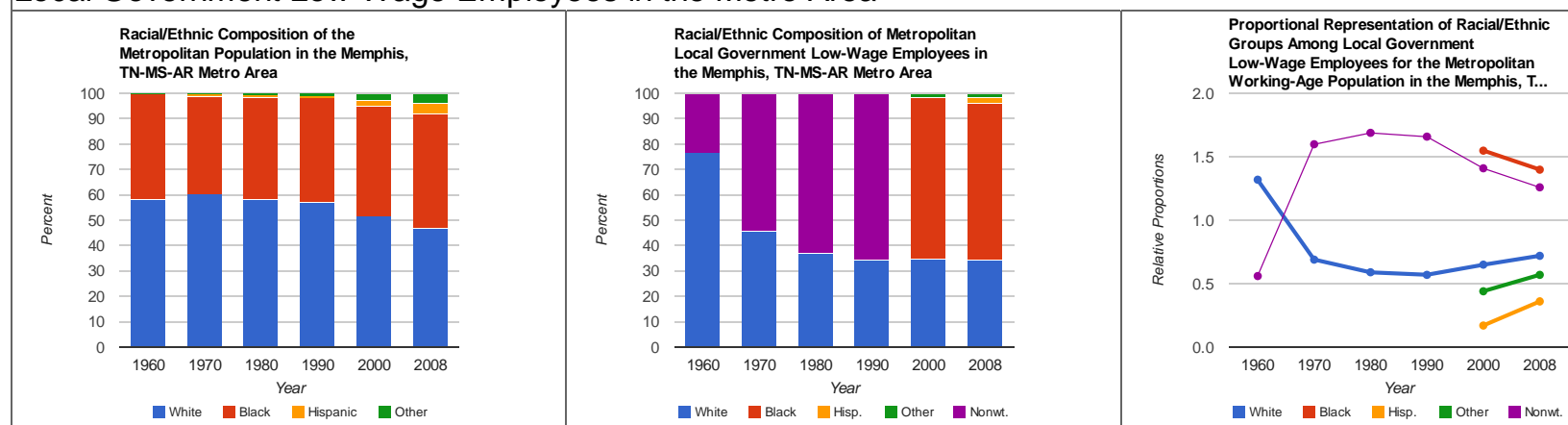
Diversity and Representation of the
Metropolitan Working-Age Population and the Memphis, TN-MS-AR Metro Area

TN-MS-AR Metro Area

White IBlack HHispanic nother White Black Year

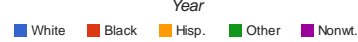

1.0

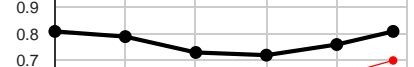

0.6

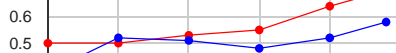

0.4

0.3
0.2

0.1

$\begin{array}{llllll}0.0 & 1960 \quad 1970 & 1980 & 1990 & 2000 & 2010\end{array}$

- Wk-Age Pop - Lowearn Govt - $\mathrm{c}$

Local Government Low-Wage Employees in the Central City

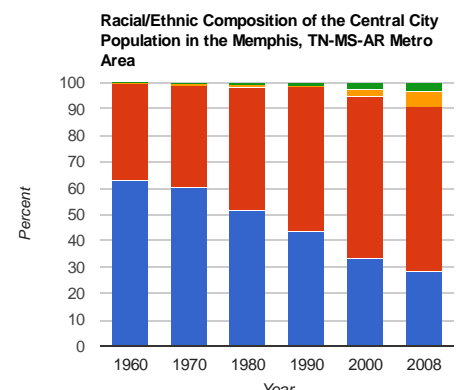

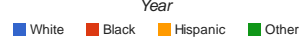

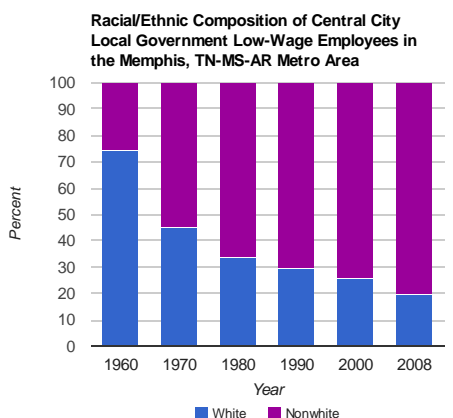

White ${ }_{\text {Nonnwite }}$ Proportional Representation of Raciall/Ethnic
Groups Among Local Government
Low-Wage Employees for the Central City Low-Wage Employees or the Central City
Working-Age Population in the Memphis, T.

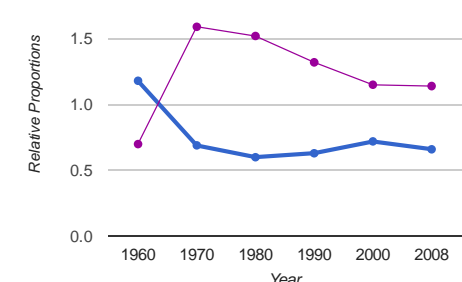

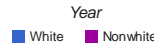

Diversity and Representation of the Central
City Working-Age Population and Local City Working-Age Population and Local Government Low-Wage Employees
Memphis, TN-MS-AR Metro Area

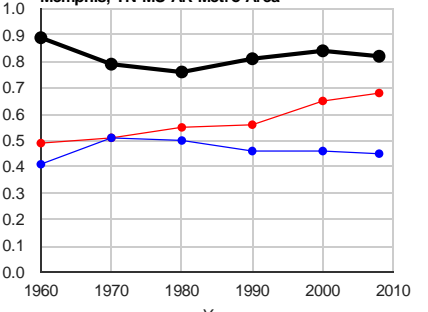

—Wk-Age Pop L LowEearn Govt @ CRI 
High- and Low-Wage Local Government Employment in the Miami-Fort Lauderdale-Pompano Beach, FL Metro Area Miami-Fort Lauderdale-Pompano Beach, FL

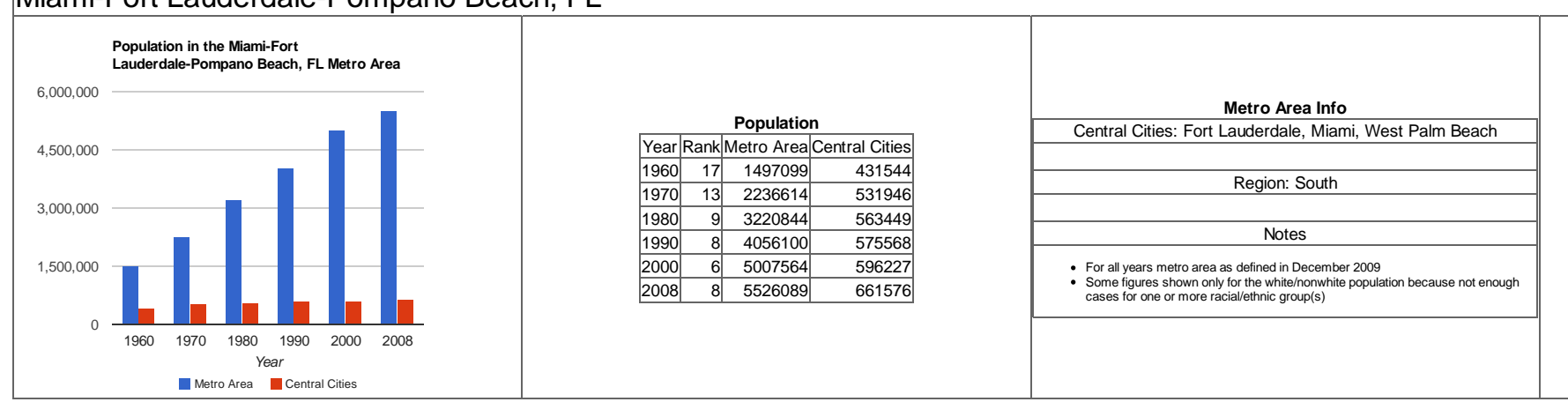


High- and Low-Wage Local Government Employment in the Miami-Fort Lauderdale-Pompano Beach, FL Metro Area Local Government High-Wage Employees in the Metro Area
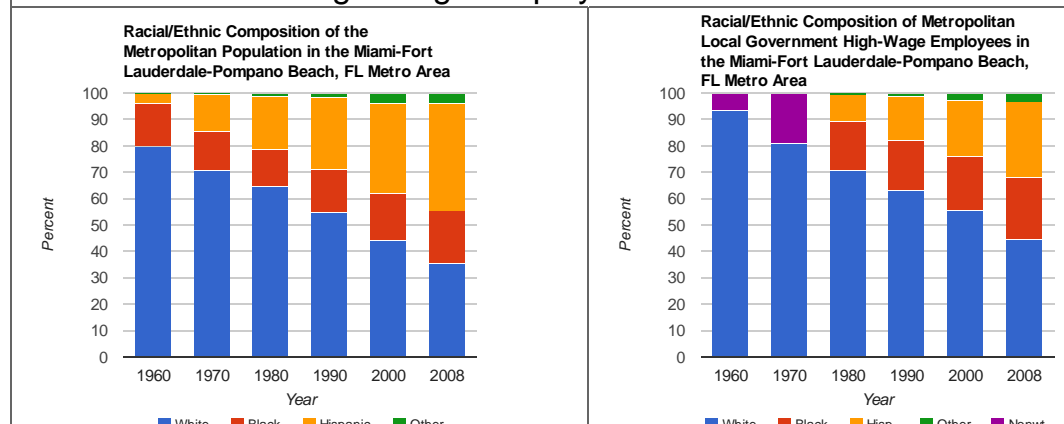

Local Government High-Wage Employees in the Central Cities
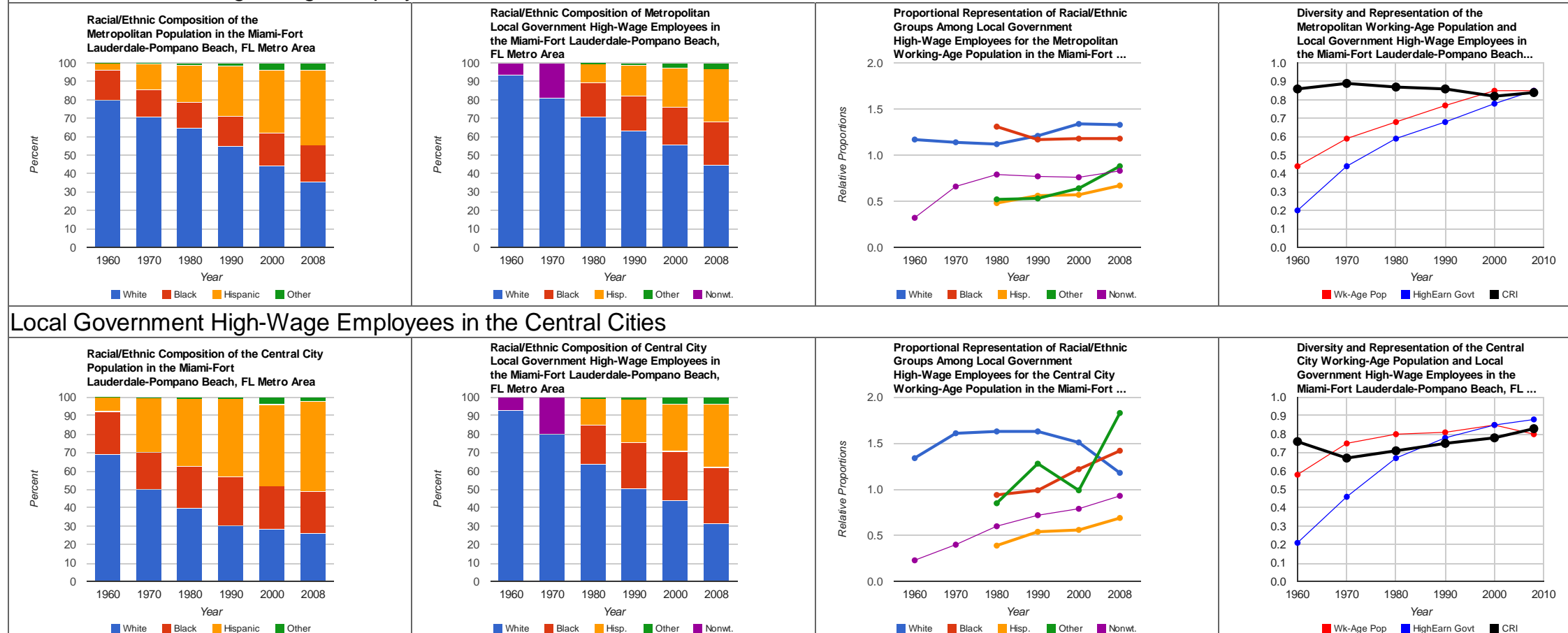

White In Black Hispanic Inother

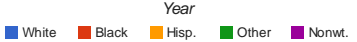

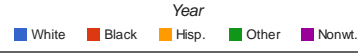

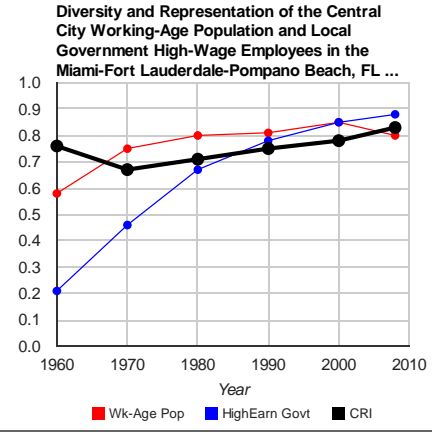


High- and Low-Wage Local Government Employment in the Miami-Fort Lauderdale-Pompano Beach, FL Metro Area Local Government Low-Wage Employees in the Metro Area
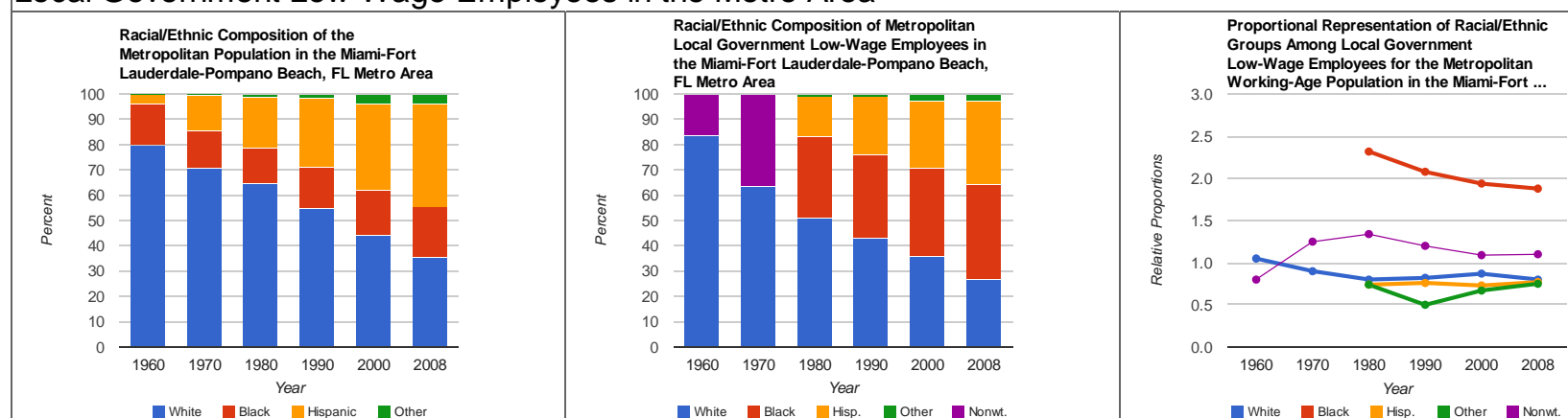

Local Government Low-Wage Employees in the Central Cities
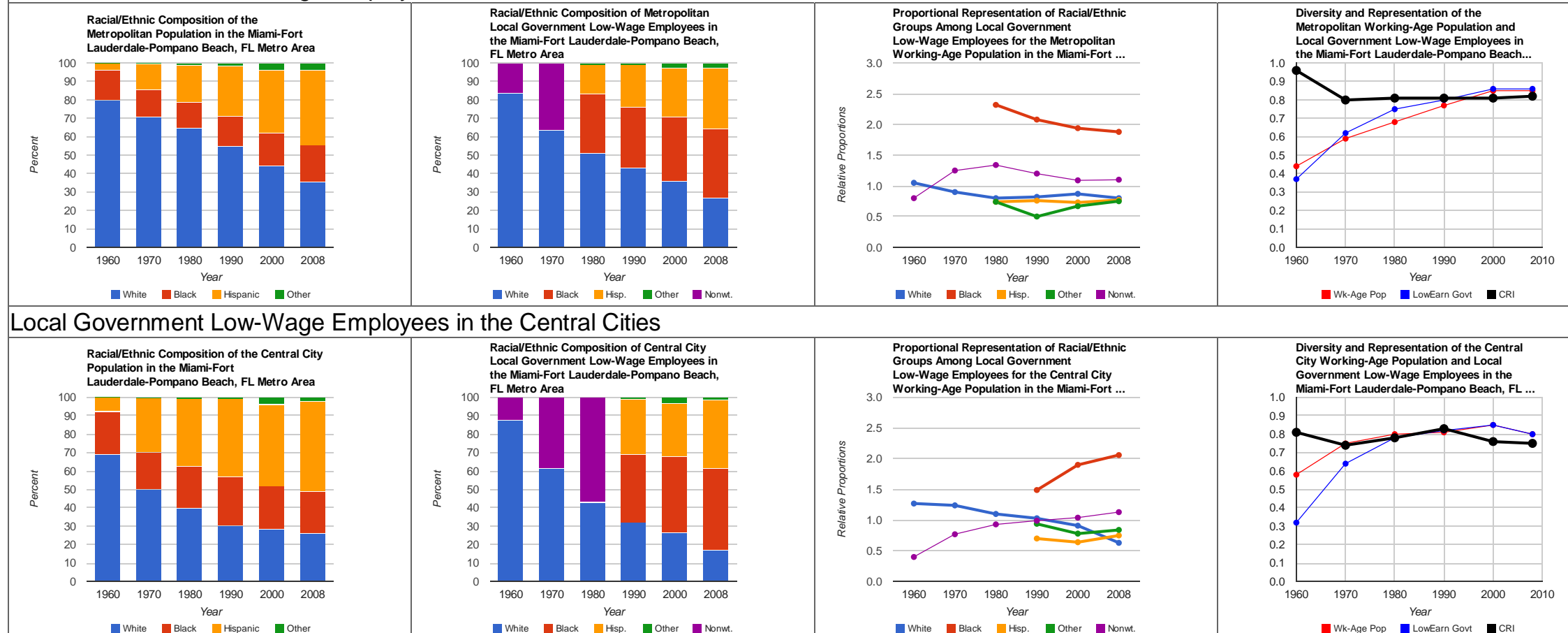

White Black Hispanic Mother

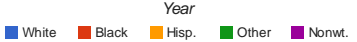

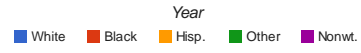

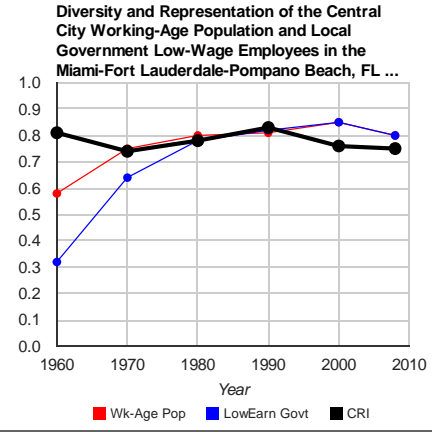


High-and Low-Wage Local Government Employment in the Milwaukee-Waukesha-West Allis, WI Metro Area Milwaukee-Waukesha-West Allis, WI

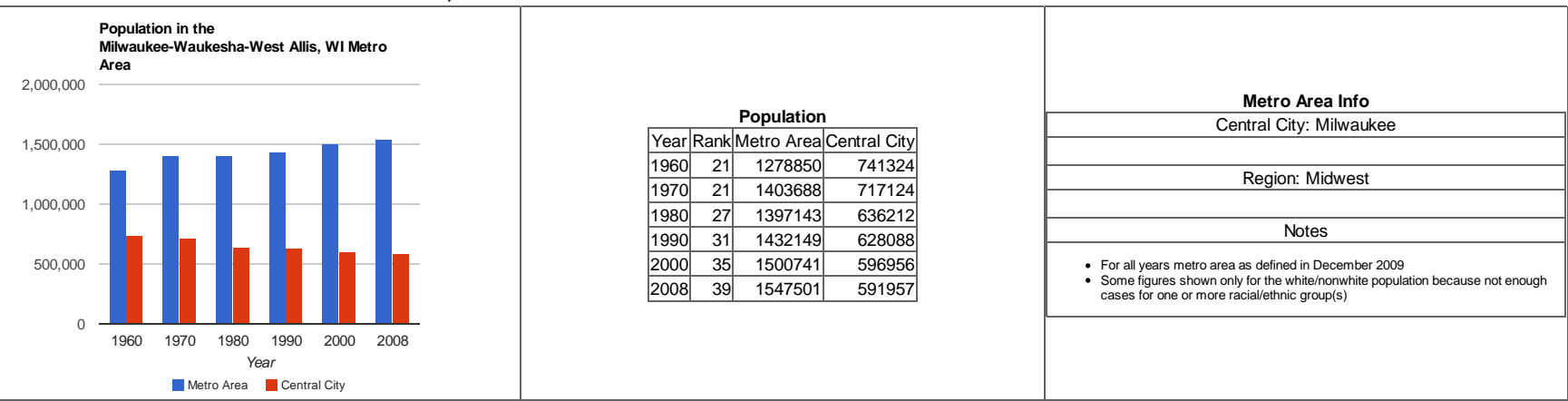


High- and Low-Wage Local Government Employment in the Milwaukee-Waukesha-West Allis, WI Metro Area Local Government High-Wage Employees in the Metro Area
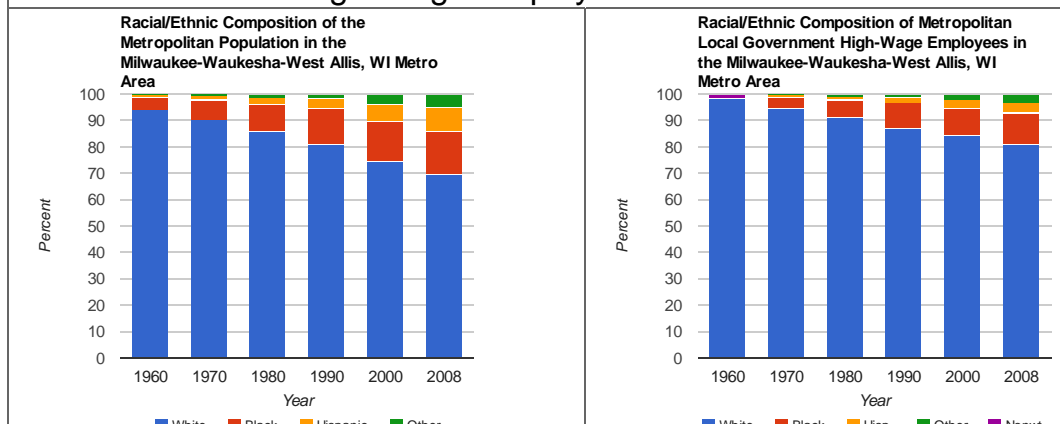

Local Government High-Wage Employees in the Central City
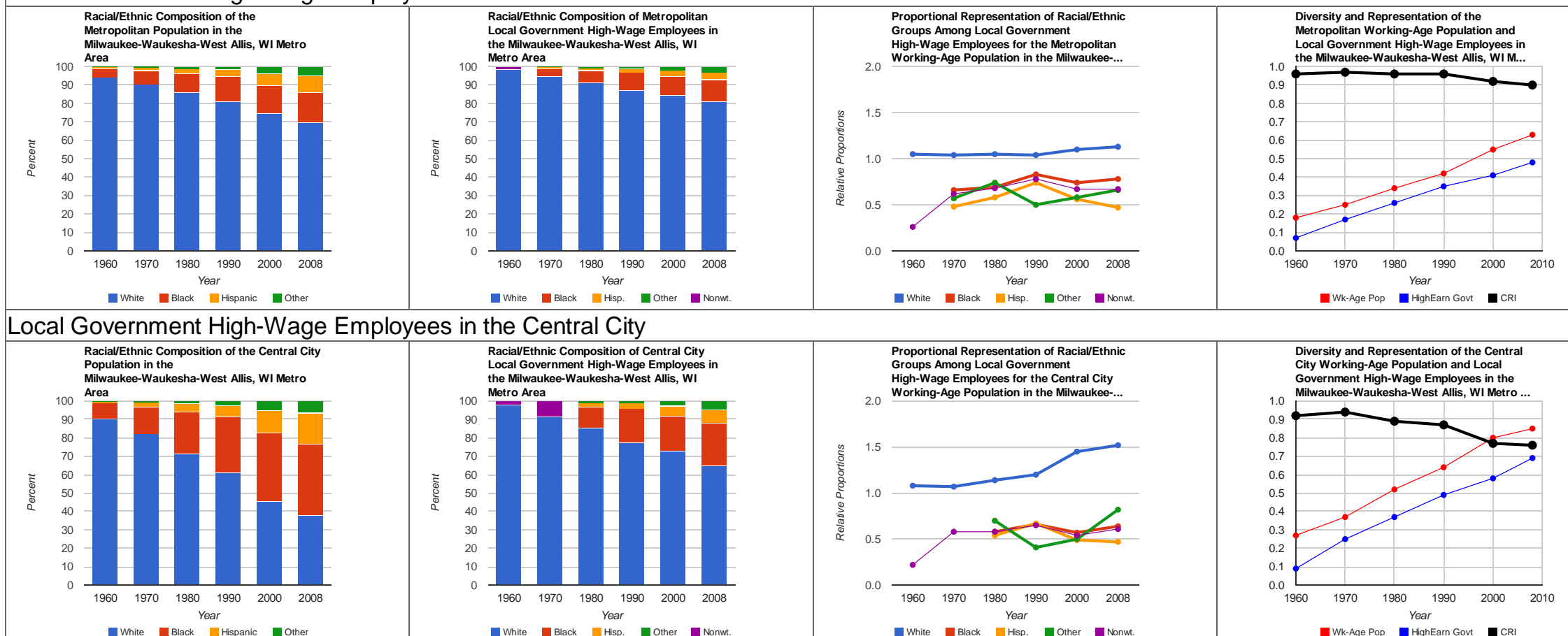

White In Black Hispanic Inother

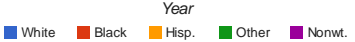

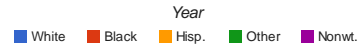

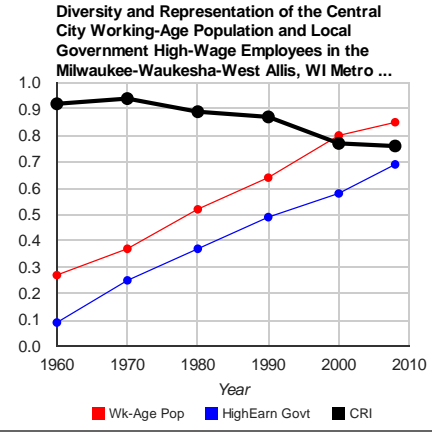


High- and Low-Wage Local Government Employment in the Milwaukee-Waukesha-West Allis, WI Metro Area Local Government Low-Wage Employees in the Metro Area
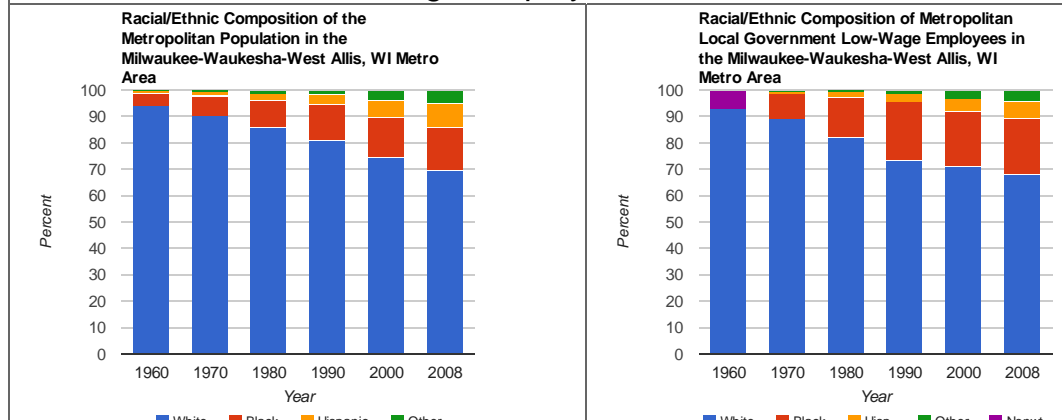

Local Government Low-Wage Employees in the Central City
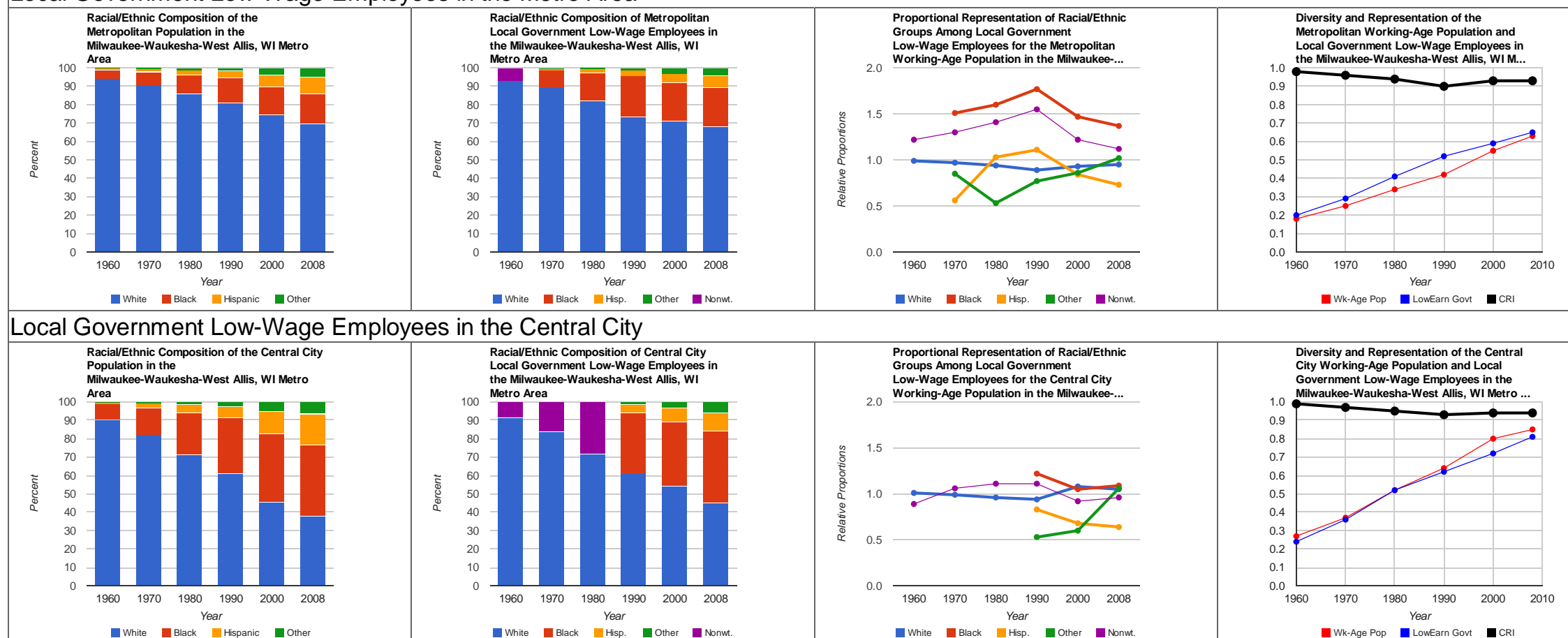

White In Black Hispanic Inother

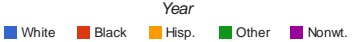

Proportional Representation of RaciallEthnic
Groups Among Local Government Groups Among Local Government
Low-Wage Employees for the Central 20 Working-Age Population in the Milwaukee-.

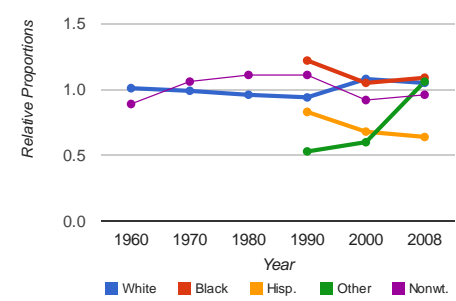

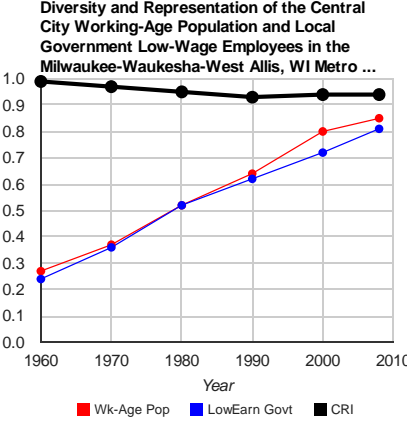




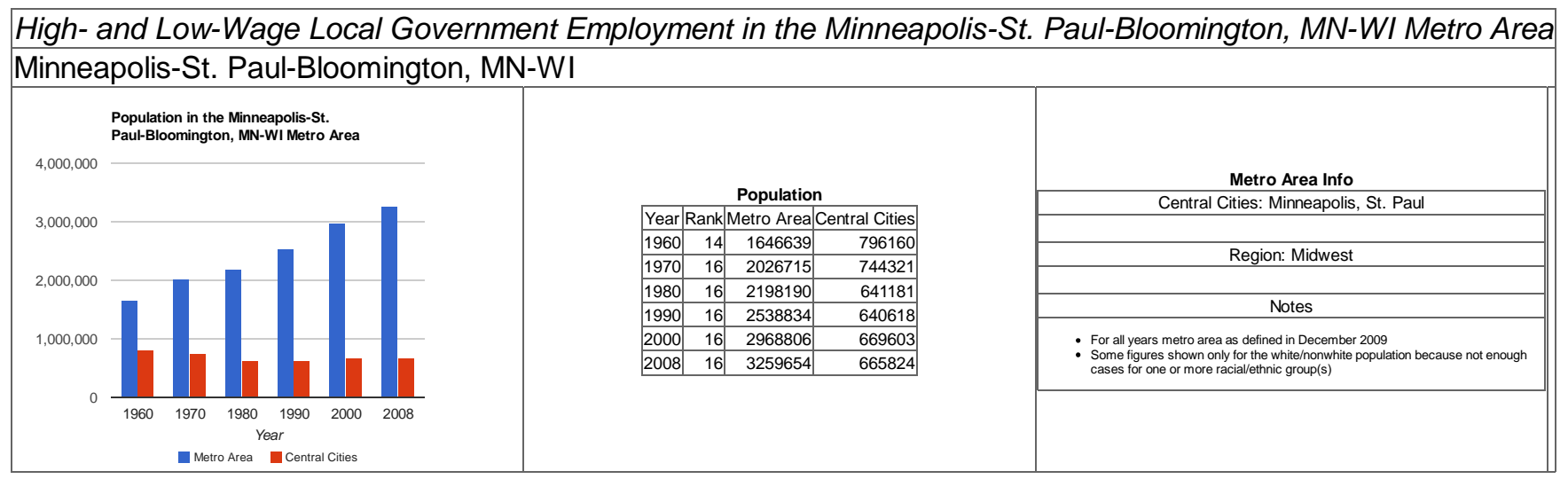


High- and Low-Wage Local Government Employment in the Minneapolis-St. Paul-Bloomington, MN-WI Metro Area Local Government High-Wage Employees in the Metro Area
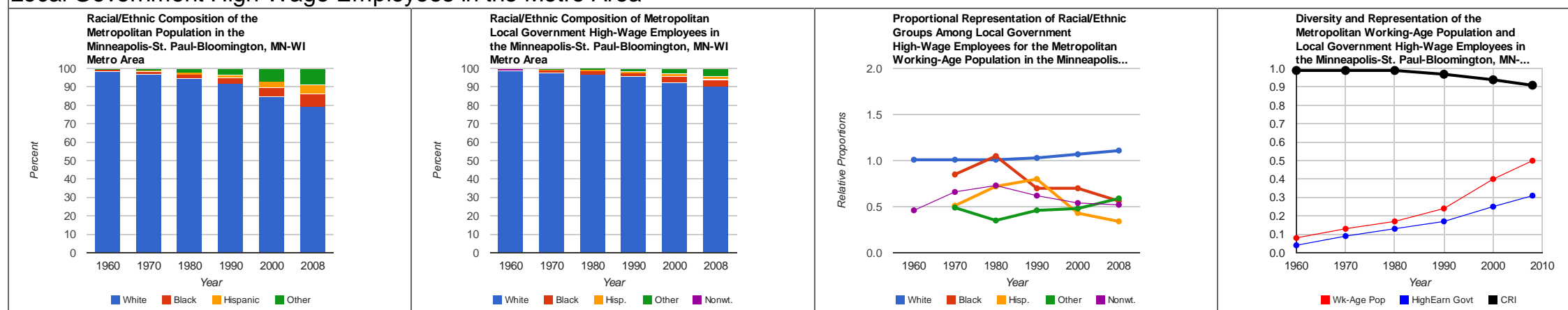

Local Government High-Wage Employees in the Central Cities
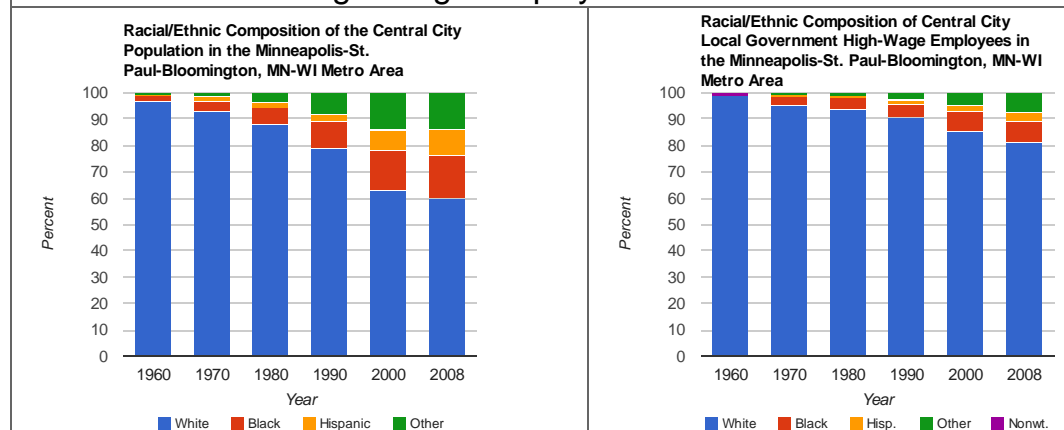
Proportional Representation of Raciall/thnic
Groups Among Local Government
High-Wage Employees for the Central City 20 Working-Age Population in the Minneapolis... White Ilack Hear Hispanic nother

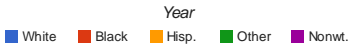
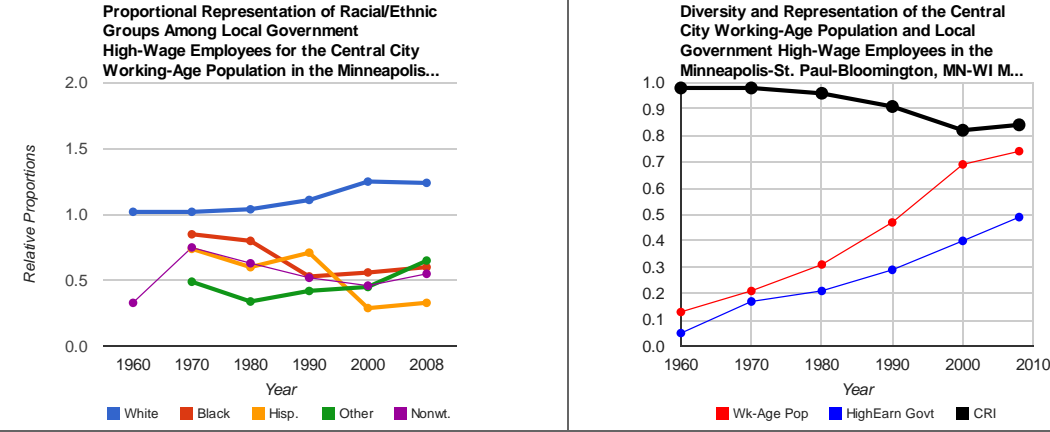
High- and Low-Wage Local Government Employment in the Minneapolis-St. Paul-Bloomington, MN-WI Metro Area Local Government Low-Wage Employees in the Metro Area
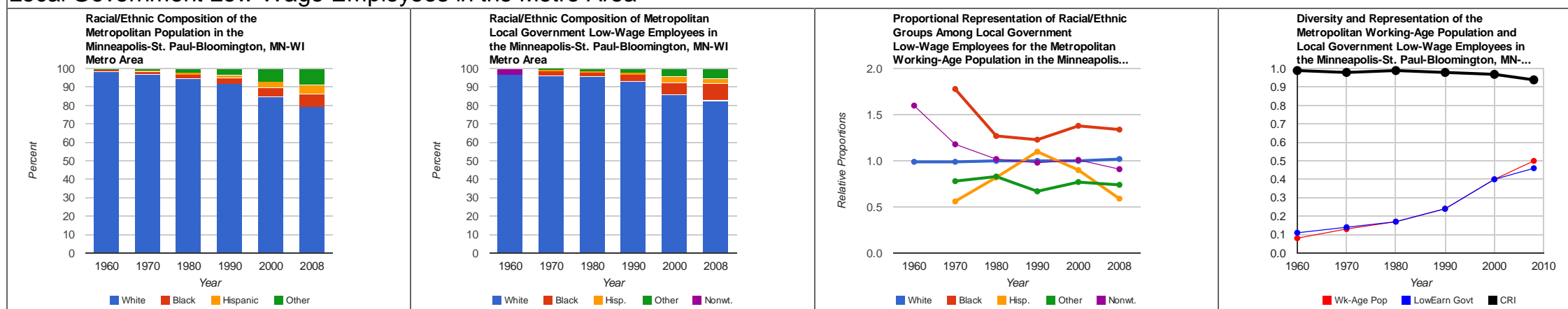

Local Government Low-Wage Employees in the Central Cities
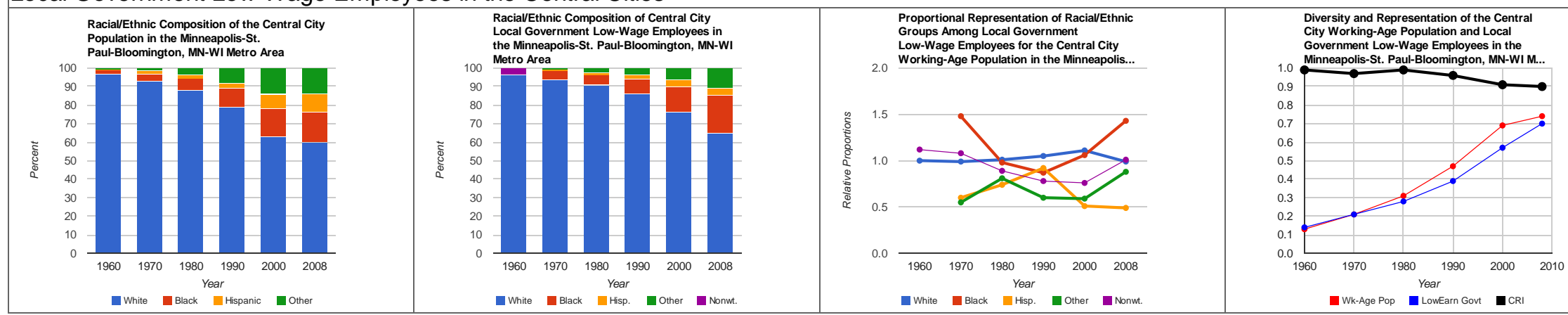
High- and Low-Wage Local Government Employment in the Modesto, CA Metro Area

Modesto, CA

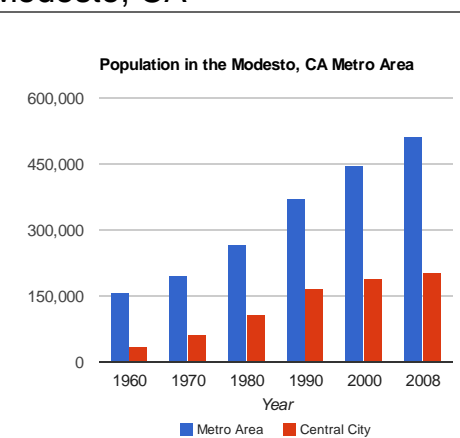

Population

\begin{tabular}{|l|l|l|}
\hline Year & Rank Metro Area|Central City \\
\hline
\end{tabular}

\begin{tabular}{|l|l|l|r|}
\hline 1960 & 154 & 157294 & 36585 \\
\hline 1970 & 147 & 192506 & 61712 \\
\hline
\end{tabular}

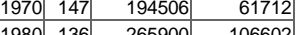

\begin{tabular}{|l|l|l|r|}
\hline 1980 & 136 & 265900 & 106602 \\
\hline 1990 & 103 & 370522 & 164730 \\
\hline
\end{tabular}

\begin{tabular}{|l|l|l|l|}
\hline 2000 & 100 & 446997 & 189460 \\
\hline 2008 & 100 & 512469 & 201886 \\
\hline
\end{tabular}

Metro Area Info

Metro Area Info
Central City: Modesto

\begin{tabular}{|c|}
\hline $\begin{array}{l}\text { Metro Area Info } \\
\text { Central City: Modesto }\end{array}$ \\
\hline Region: West \\
\hline Notes \\
\hline 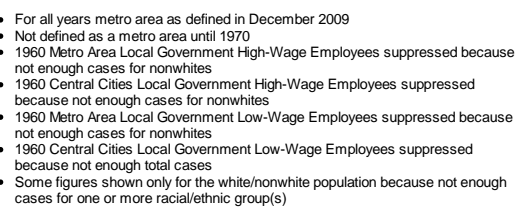 \\
\hline
\end{tabular}


High- and Low-Wage Local Government Employment in the Modesto, CA Metro Area

Local Government High-Wage Employees in the Metro Area
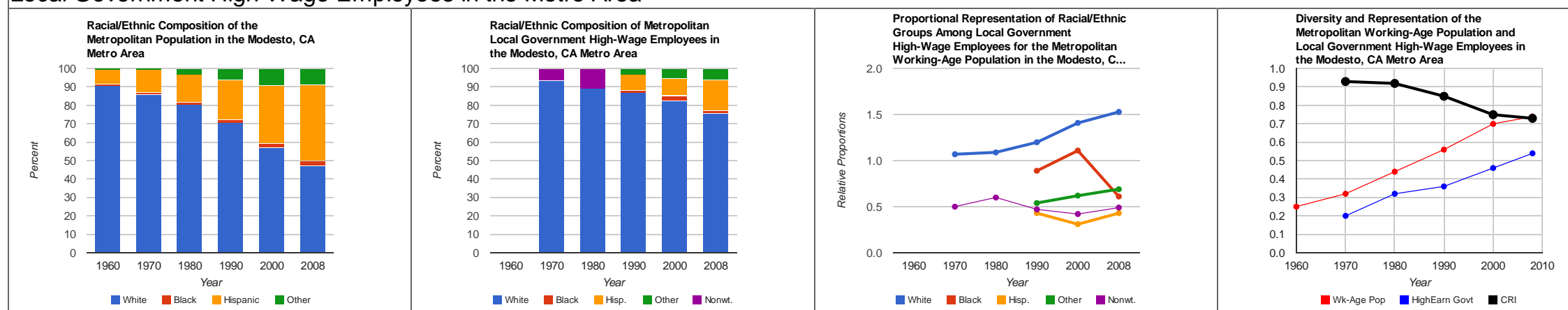

Local Government High-Wage Employees in the Central City
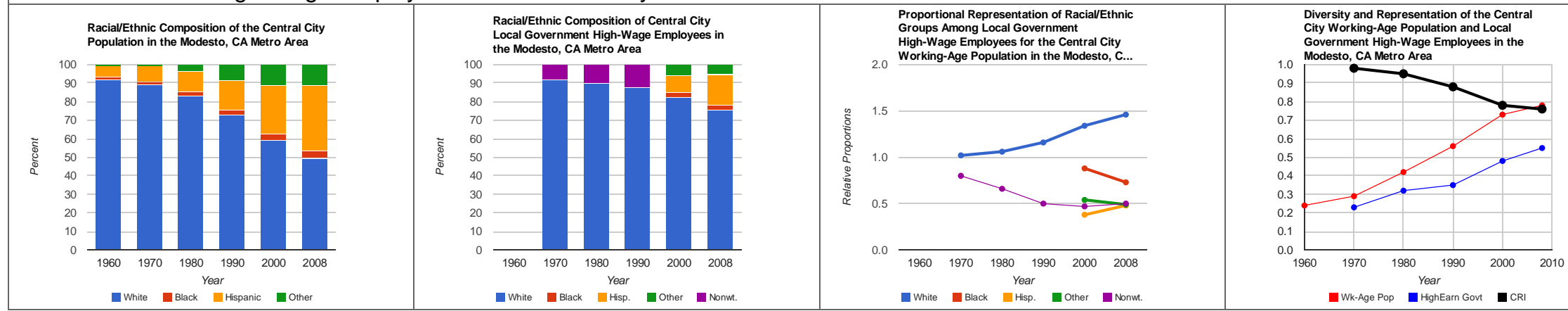
High- and Low-Wage Local Government Employment in the Modesto, CA Metro Area

Local Government Low-Wage Employees in the Metro Area
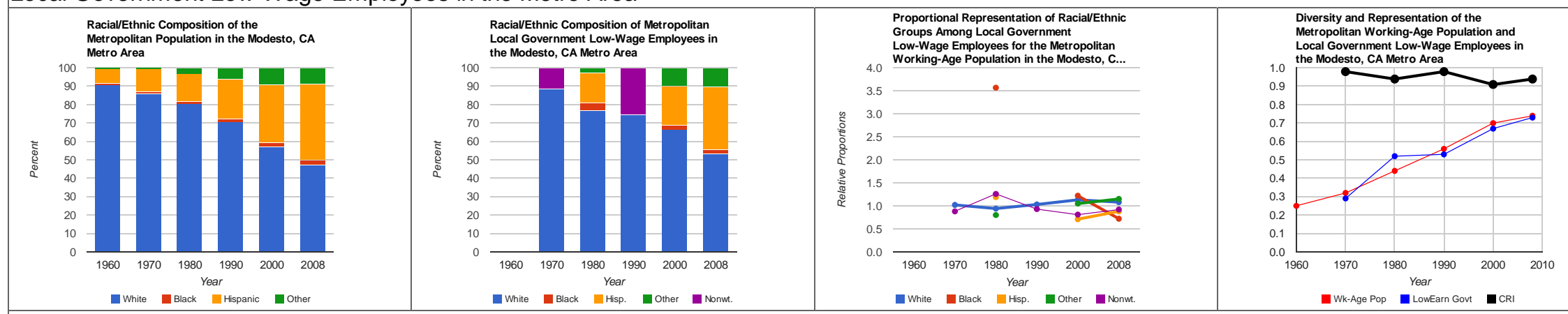

Local Government Low-Wage Employees in the Central City
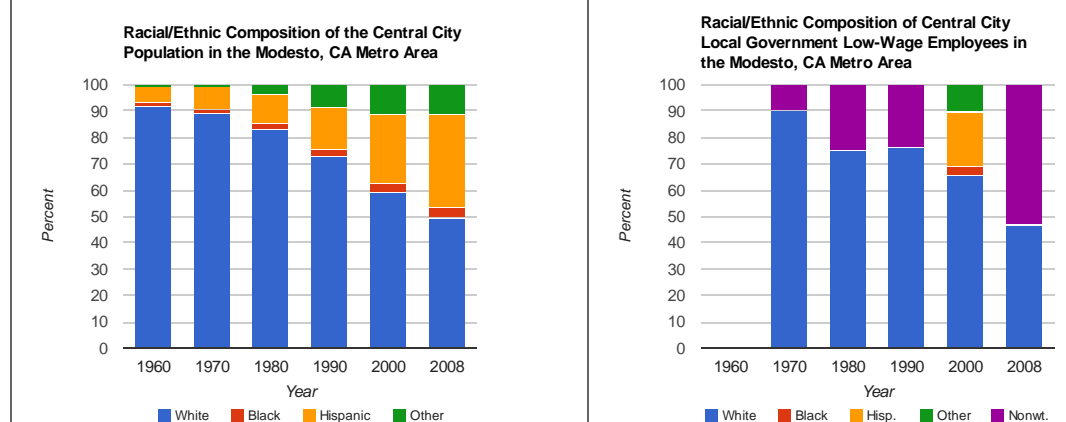
Proportional Representation of Raciall/Ethnic
Groups Among Local Government
Low-Wage Employees for the Central City Working-Age Population in the Modesto, $\mathrm{C...}$

White Inlack Hear Hispanic nother

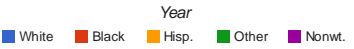
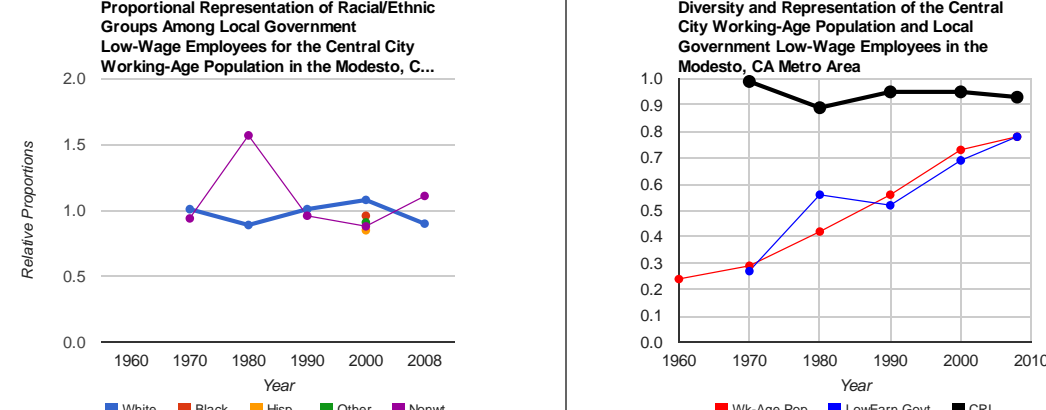

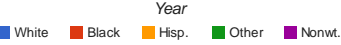

W. Whage Pop Lowearn Gout - 


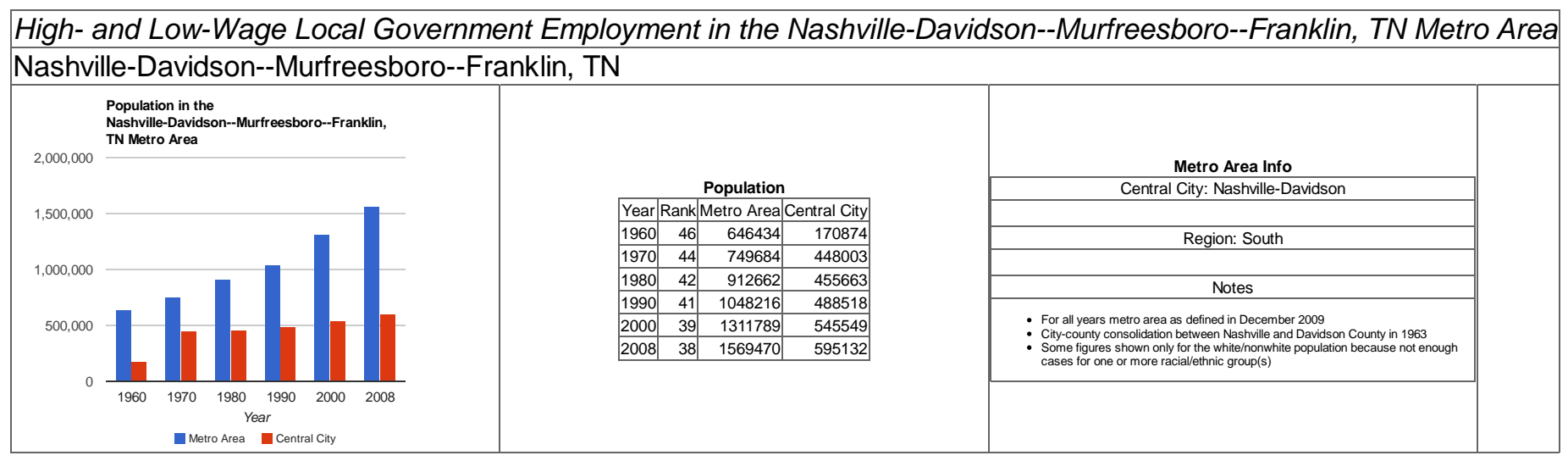


High- and Low-Wage Local Government Employment in the Nashville-Davidson--Murfreesboro--Franklin, TN Metro Area Local Government High-Wage Employees in the Metro Area
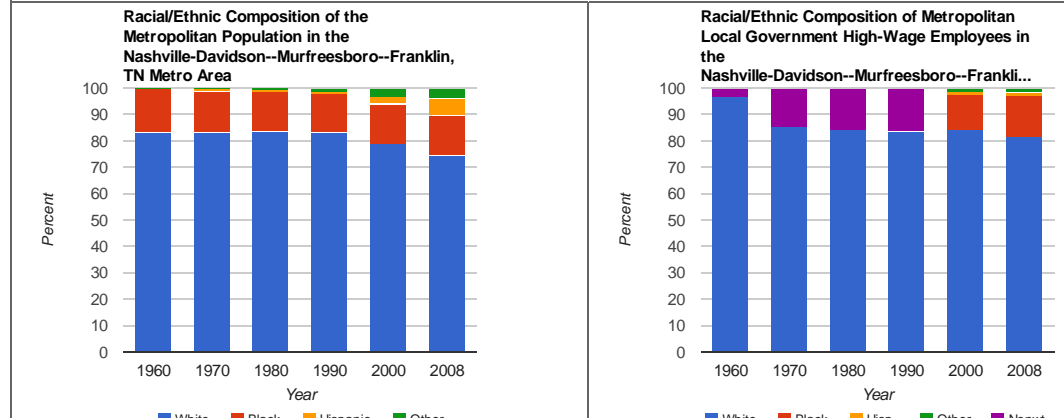

Local Government High-Wage Employees in the Central City
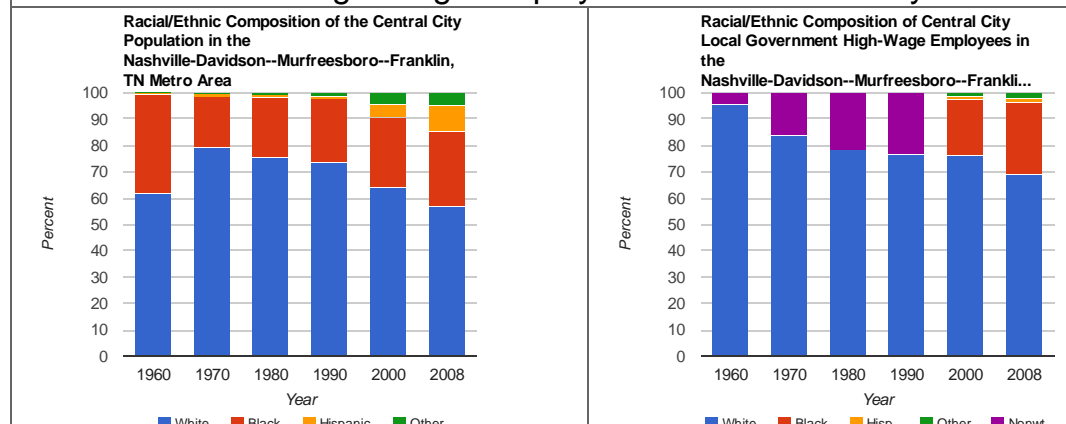
Groups Among Local Government
High-Wage Employees for the Central city High--Sage Employeses for the Central City
Working-Age Population in the Nashville-Da... White 1 Black Year

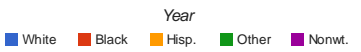

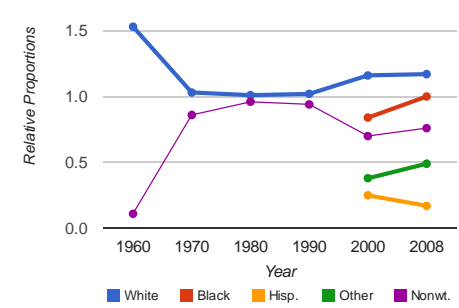

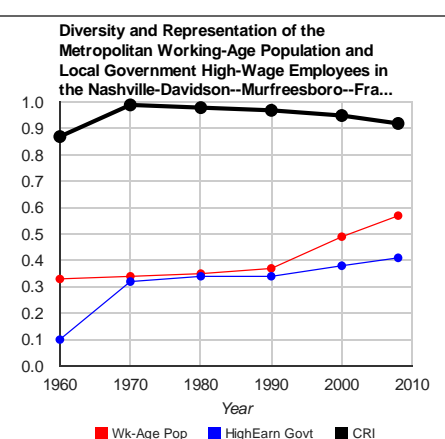

-Wk-Age Pop M Highearn Govt - CRP

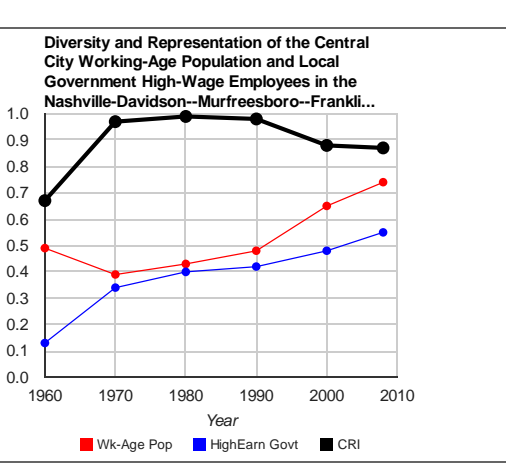


High- and Low-Wage Local Government Employment in the Nashville-Davidson--Murfreesboro--Franklin, TN Metro Area Local Government Low-Wage Employees in the Metro Area
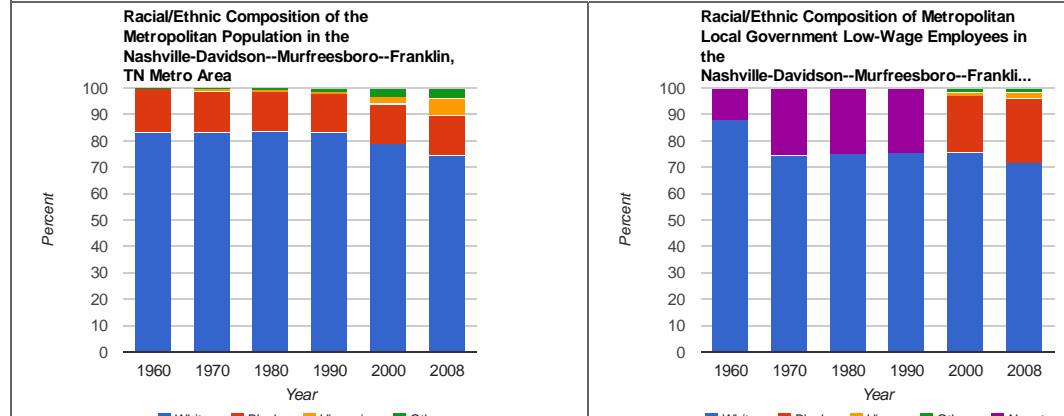

Local Government Low-Wage Employees in the Central City
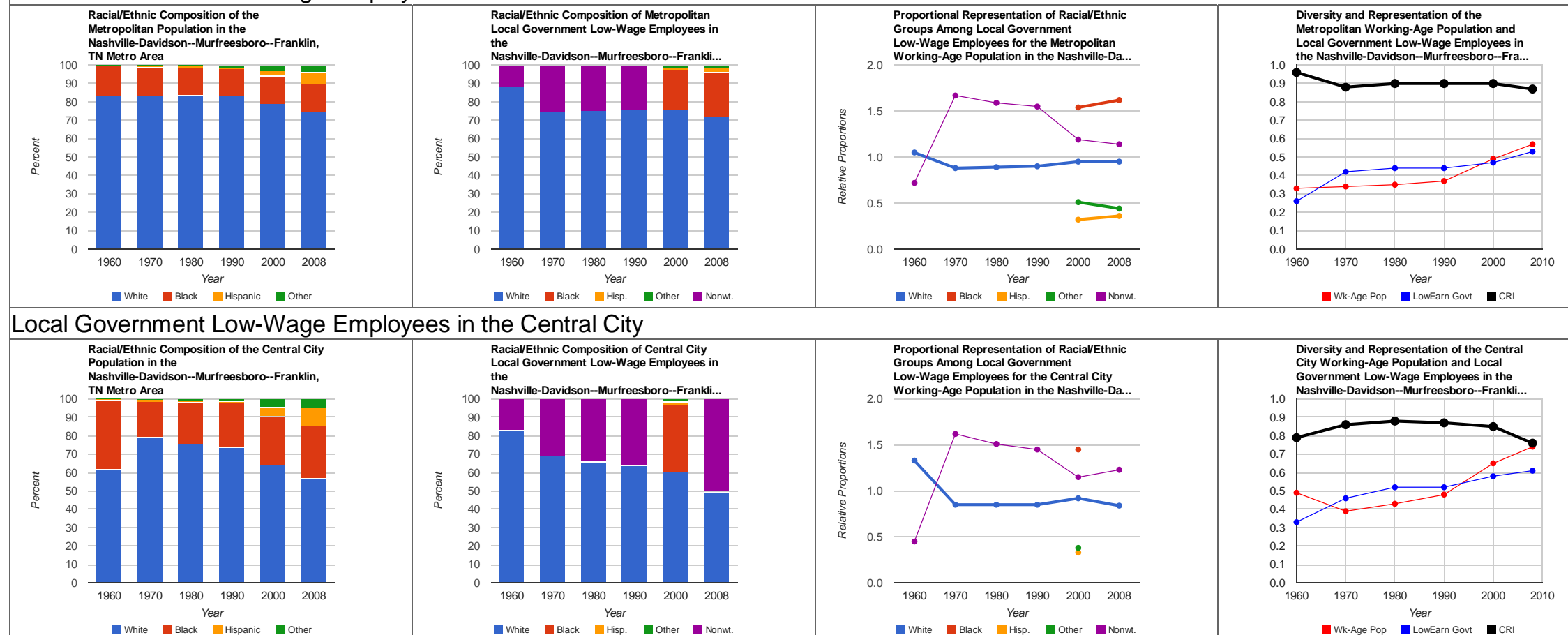

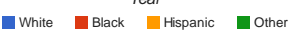

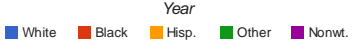

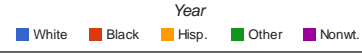

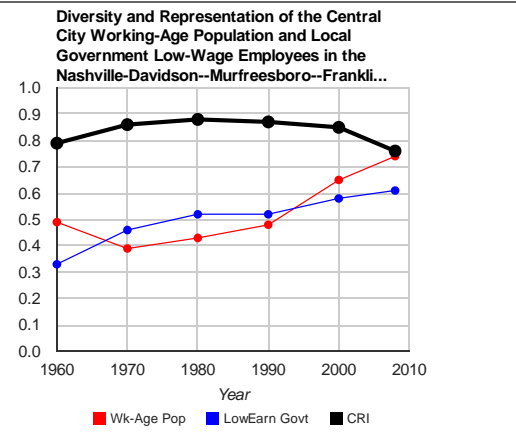




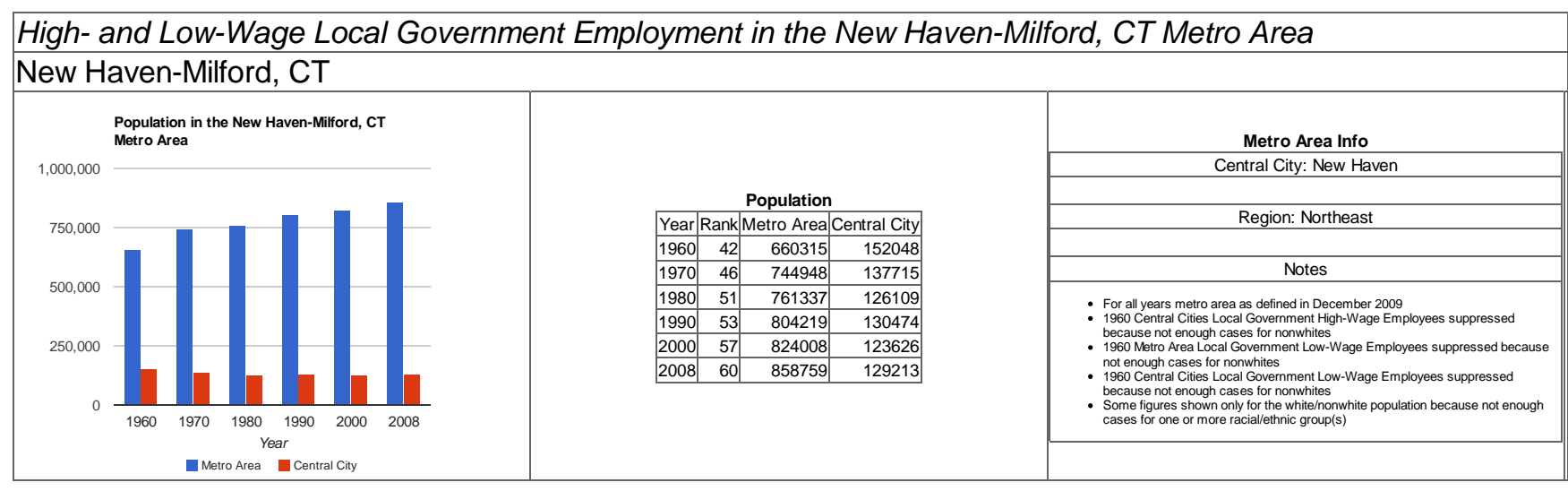


High- and Low-Wage Local Government Employment in the New Haven-Milford, CT Metro Area Local Government High-Wage Employees in the Metro Area
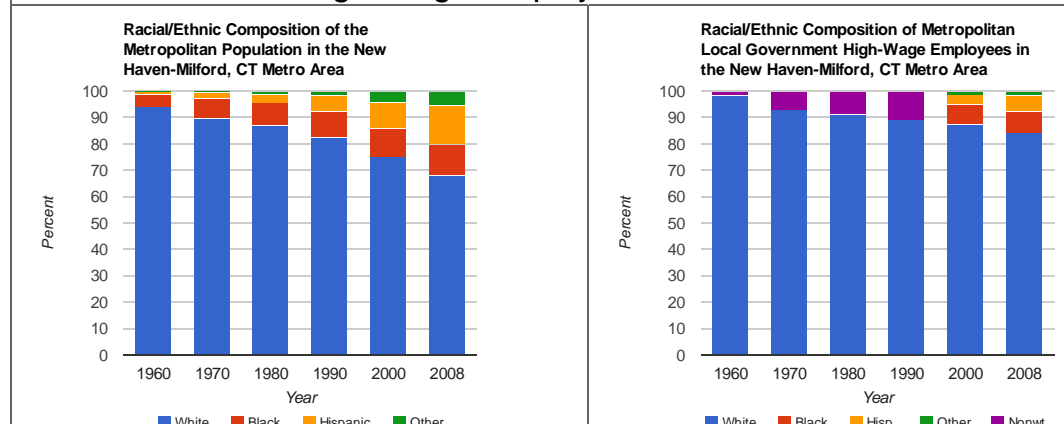

Local Government High-Wage Employees in the Central City

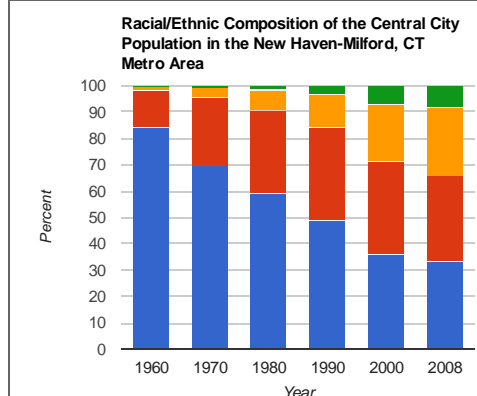

White Inlack Year Hispanic Eother

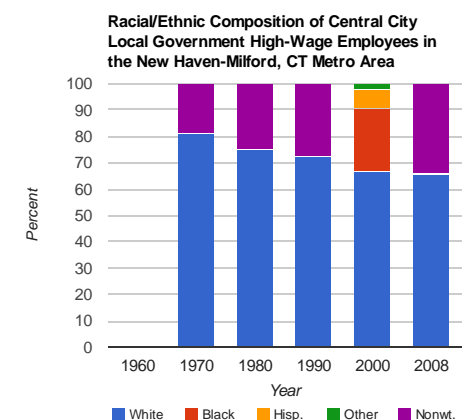

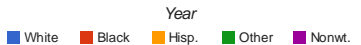

Proportional Representation of Raciall/Ethnic Groups Among Local Government
High-Wage Employees for the Metropolitan Working-Age Population in the New Haven-...

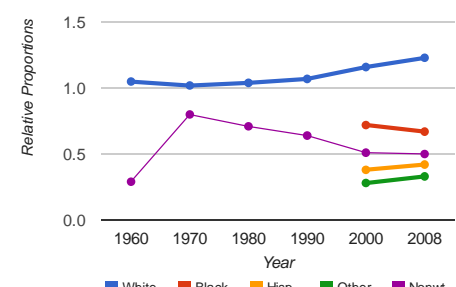

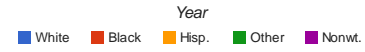

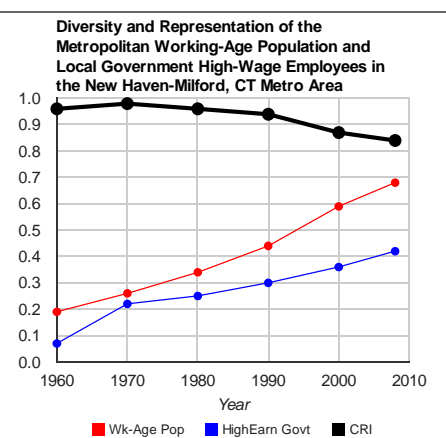

—Wk-Age Pop M HighEarn Govt M CR
Proportional Representation of Raciall/Ethnic Groups Among Local Government
High-Wage Employees for the Central City High-Wage Employees for the Central City
2.0 Working-Age Population in the New Haven-...

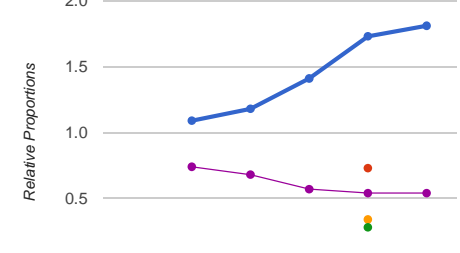

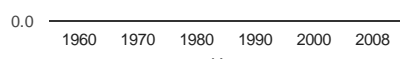

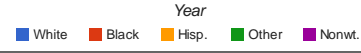

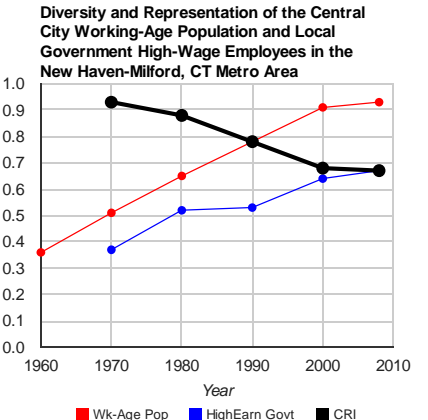

-Wk-Age Pop - Highearn Govt - CR 
High- and Low-Wage Local Government Employment in the New Haven-Milford, CT Metro Area Local Government Low-Wage Employees in the Metro Area
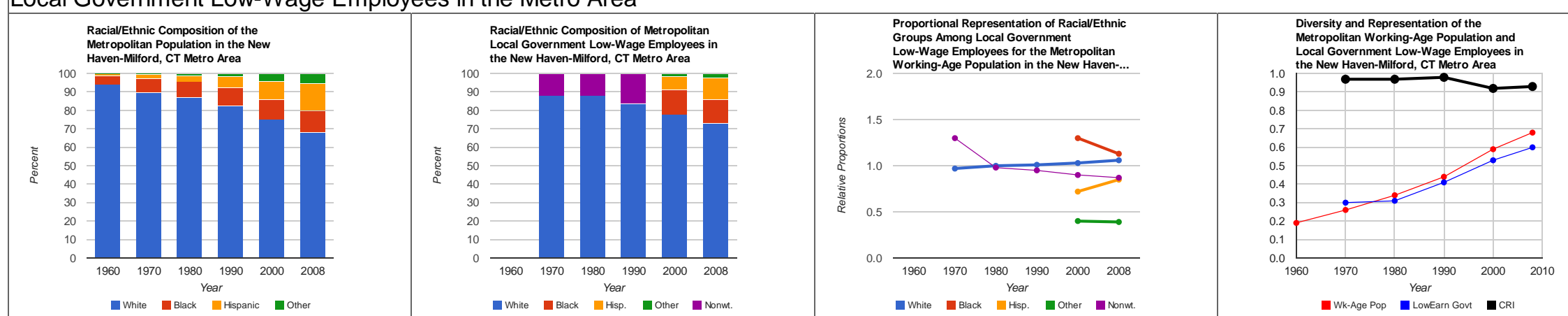

Local Government Low-Wage Employees in the Central City
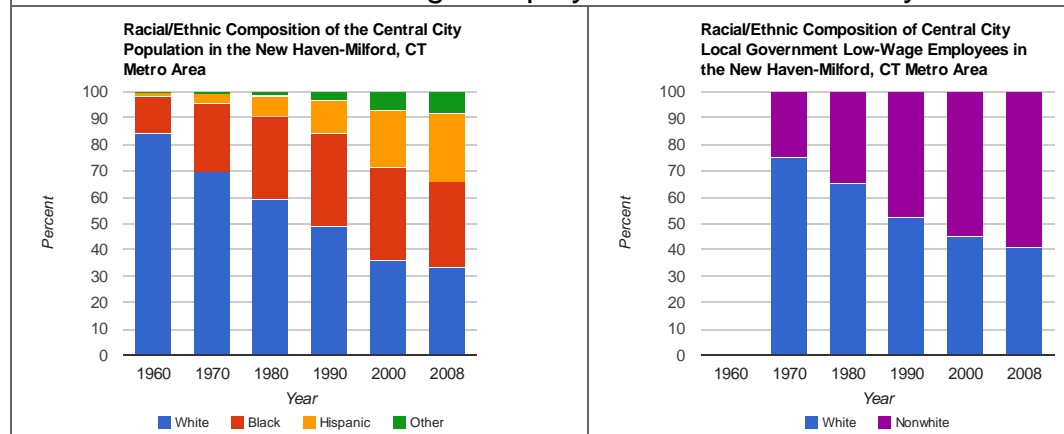

Proportional Representation of Raciall/Ethnic
Groups Among Local Government
Low-Wage Employees for the Central City

20 Working-Age Population in the New Haven-...

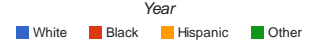

- White $\stackrel{\text { Year }}{\text { Nonwhite }}$
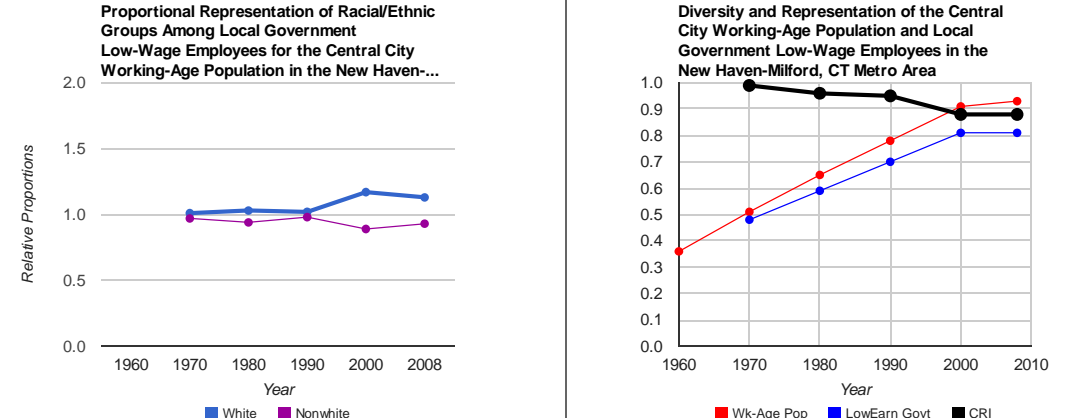

- Wk-Age Pop LowEarn Gout MCRI 


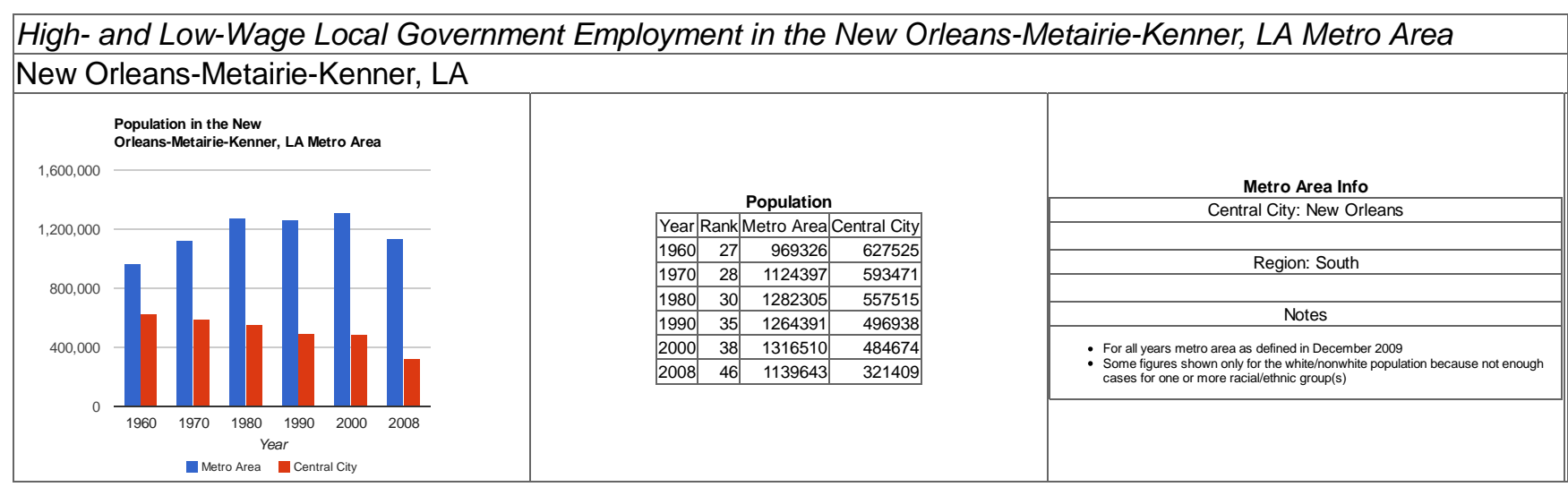


High- and Low-Wage Local Government Employment in the New Orleans-Metairie-Kenner, LA Metro Area Local Government High-Wage Employees in the Metro Area
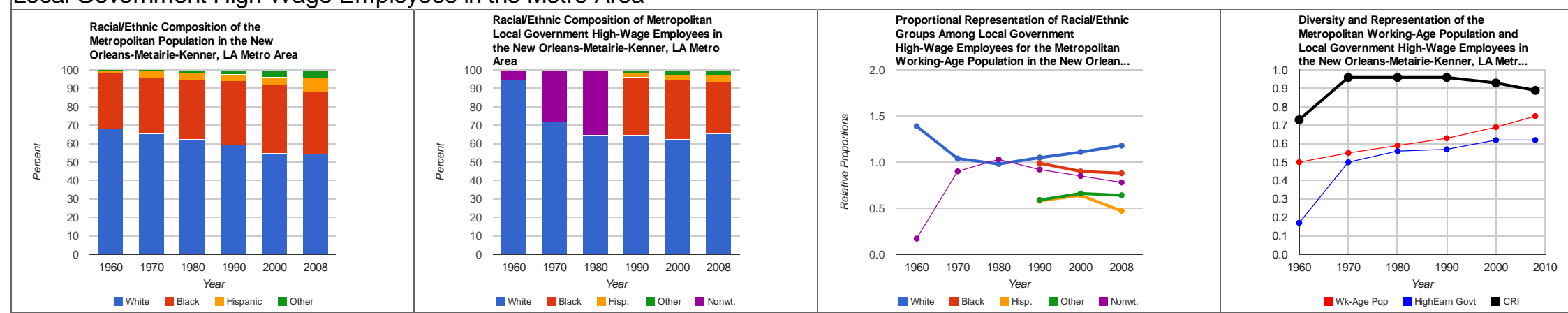

Local Government High-Wage Employees in the Central City
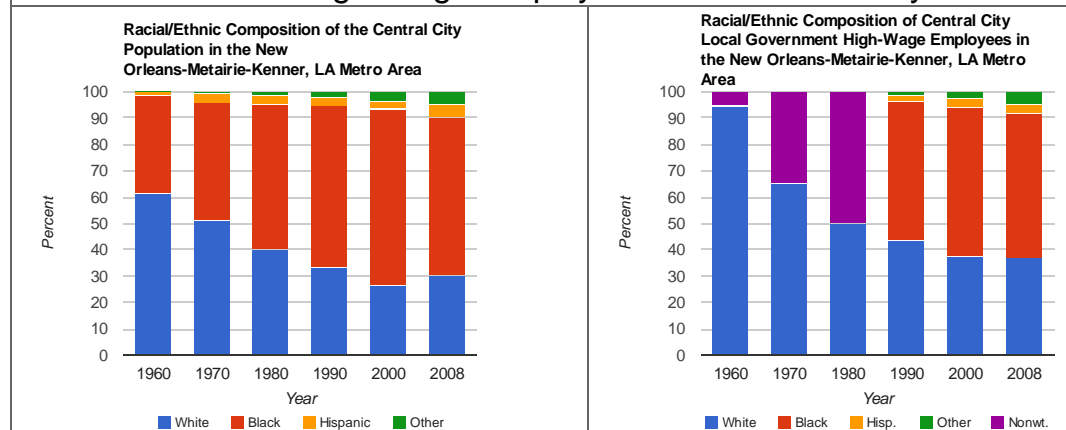
Proportional Representation of Raciall/Ethnic
Groups Among Local Government
High-Wage Employees for the Central City Groups Among Local Government
High-Wage Employes for the Central City
Working-Age Population in the New Orlean...

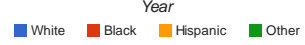

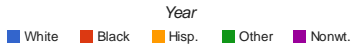
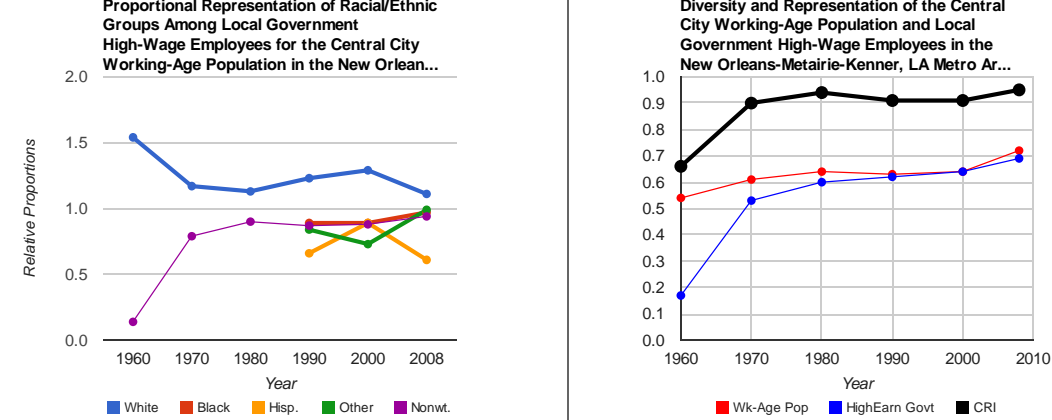
High- and Low-Wage Local Government Employment in the New Orleans-Metairie-Kenner, LA Metro Area Local Government Low-Wage Employees in the Metro Area
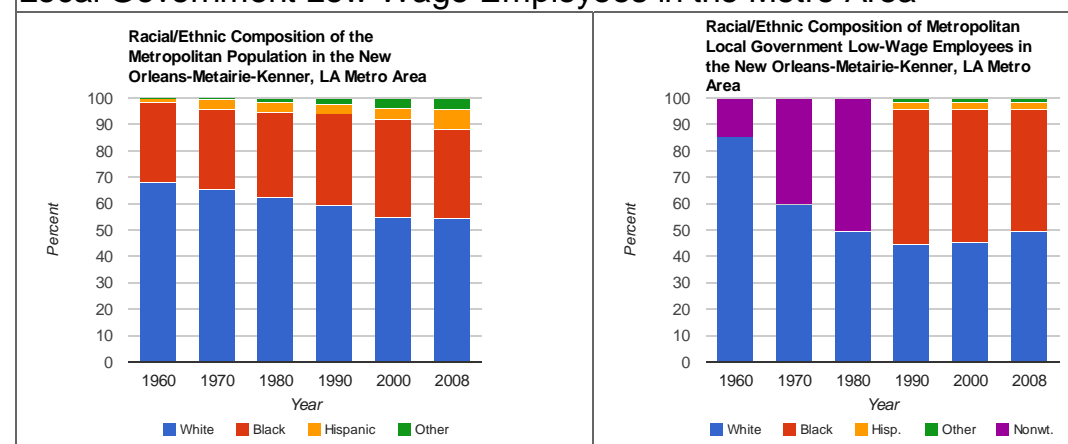

Local Government Low-Wage Employees in the Central City
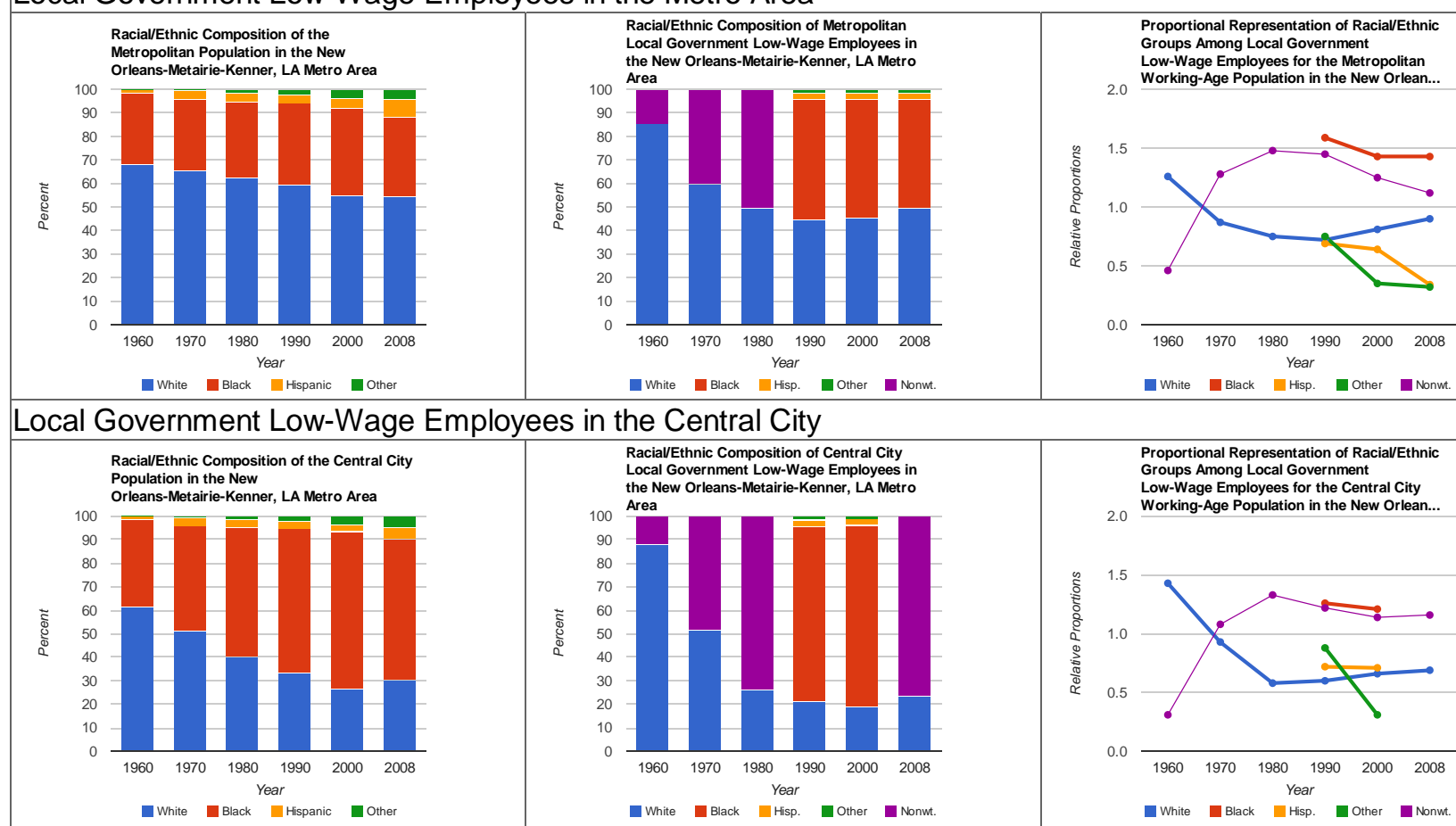

Diversity and Representation of the
Metropolitan Working-Age Population and
Local Government Low-Wage Employees in

the New Orleans-Metairie-Kenner, LA Metr...

Year

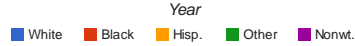

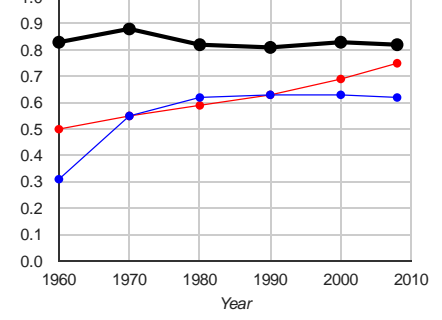

-Wk-Age Pop W Lowearn Govt MCR Proportional Representation of Raciall/Ethnic
Groups Among Local Government
Low-Wage Employees for the Central City Working-Age Population in the New Orlean...

White Ilack Hear Hispanic nother

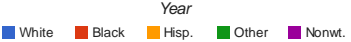

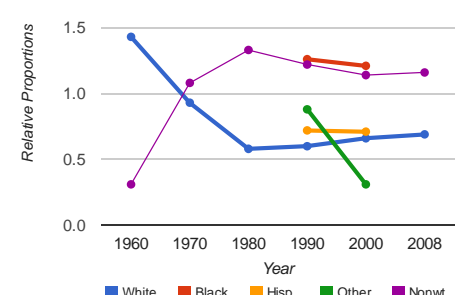
Diversity and Representation of the Central
City Working-Age Population and Local
Government Low-Wage Employees in the Government Low-Wage Employees in the
New Orleans-Metairie-Kenner, LA Metro Ar...

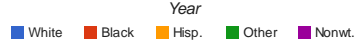

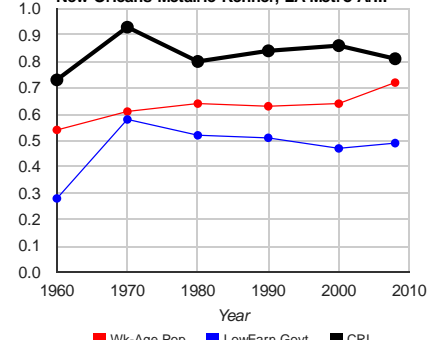

-Wk-Age Pop LowEarn Gout $\quad$ CRl 


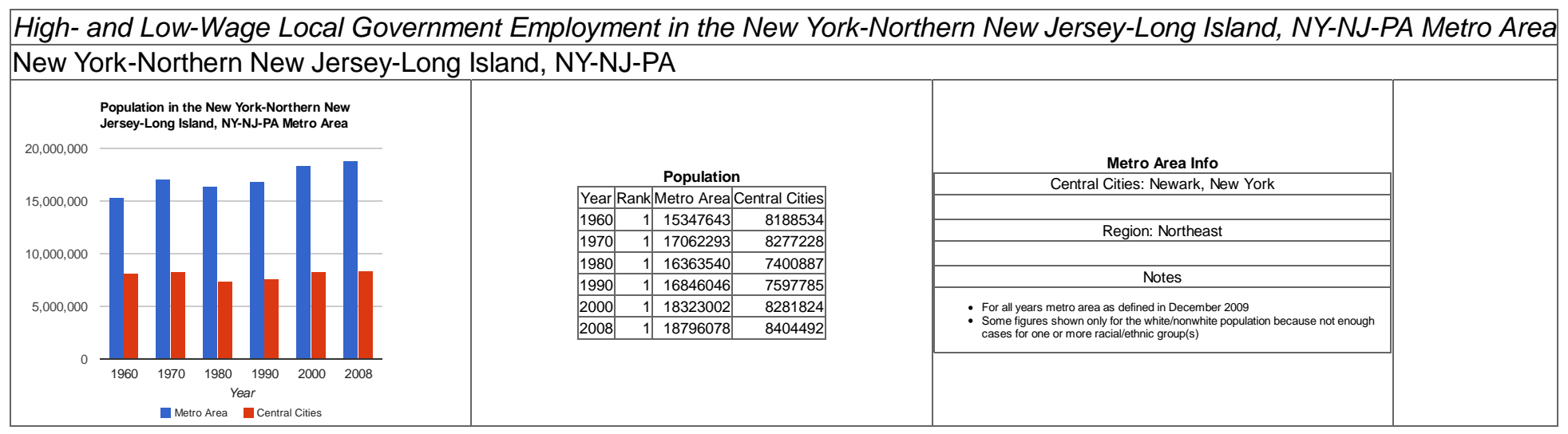


High- and Low-Wage Local Government Employment in the New York-Northern New Jersey-Long Island, NY-NJ-PA Metro Area Local Government High-Wage Employees in the Metro Area
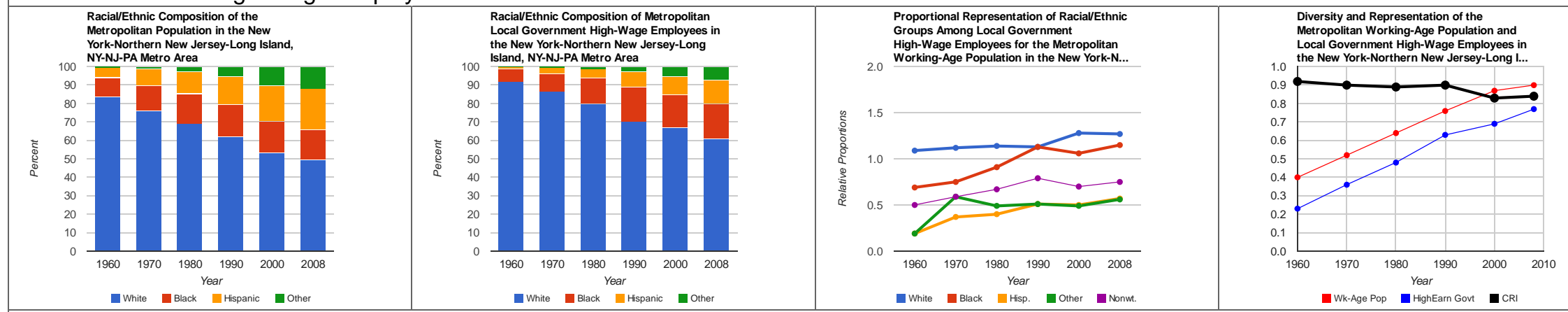

Local Government High-Wage Employees in the Central Cities
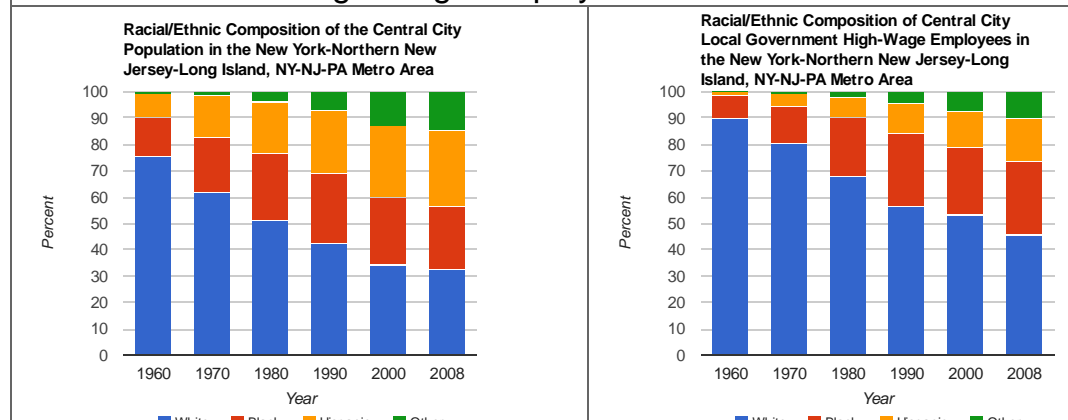
Proportional Representation of Raciall/Ethnic
Groups Among Local Government
High-Wage Employees for the Central City Groups Among Local Government
High-Wage Employes for the Central City
Working-Age Population in the New York-N... @White 1 Black Year White Black Hispanic Wother

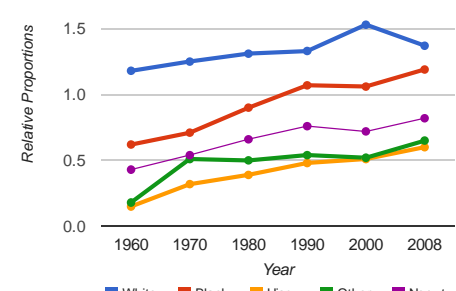
Diversity and Representation of the Central
City Working-Age Population and Local
Government High-Wage Employees in the

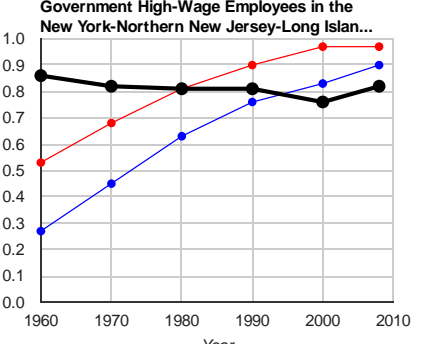

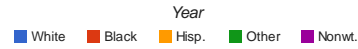

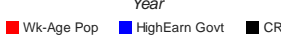


High- and Low-Wage Local Government Employment in the New York-Northern New Jersey-Long Island, NY-NJ-PA Metro Area Local Government Low-Wage Employees in the Metro Area
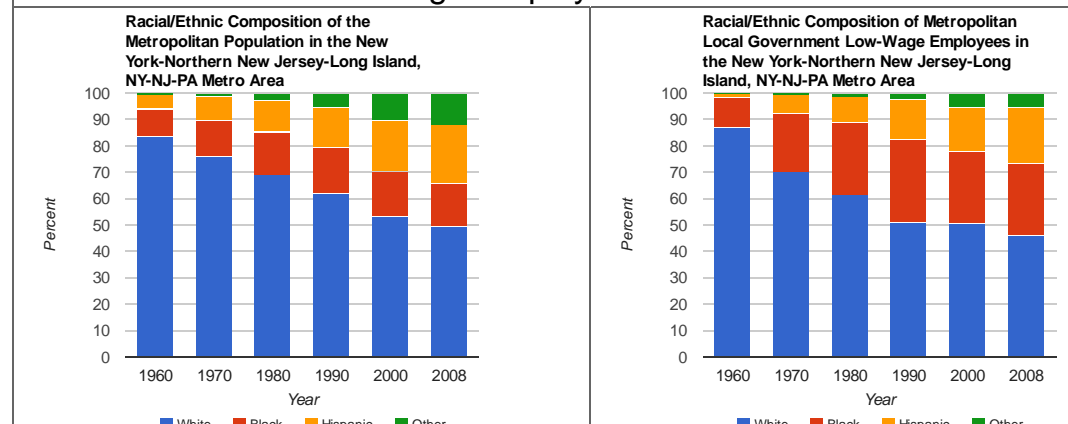

White Black Hispanic other

Local Government Low-Wage Employees in the Central Cities
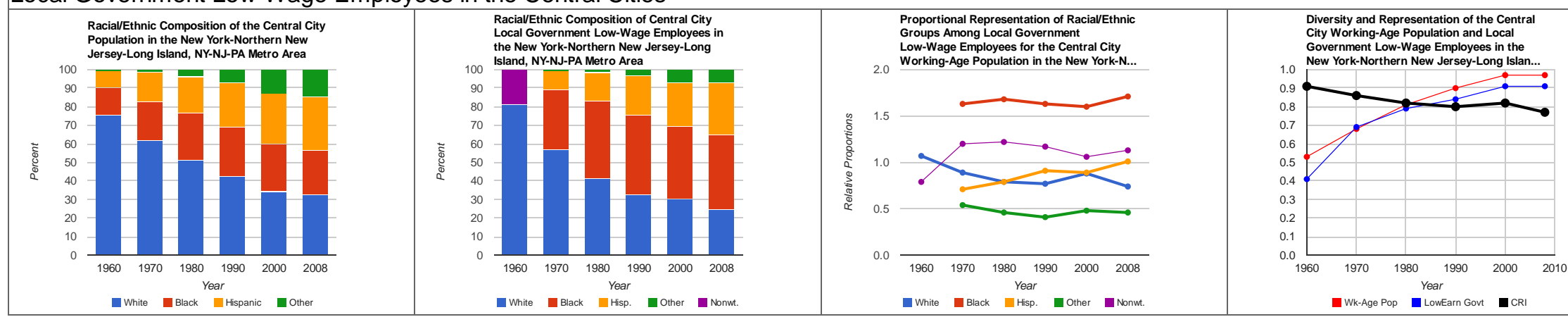


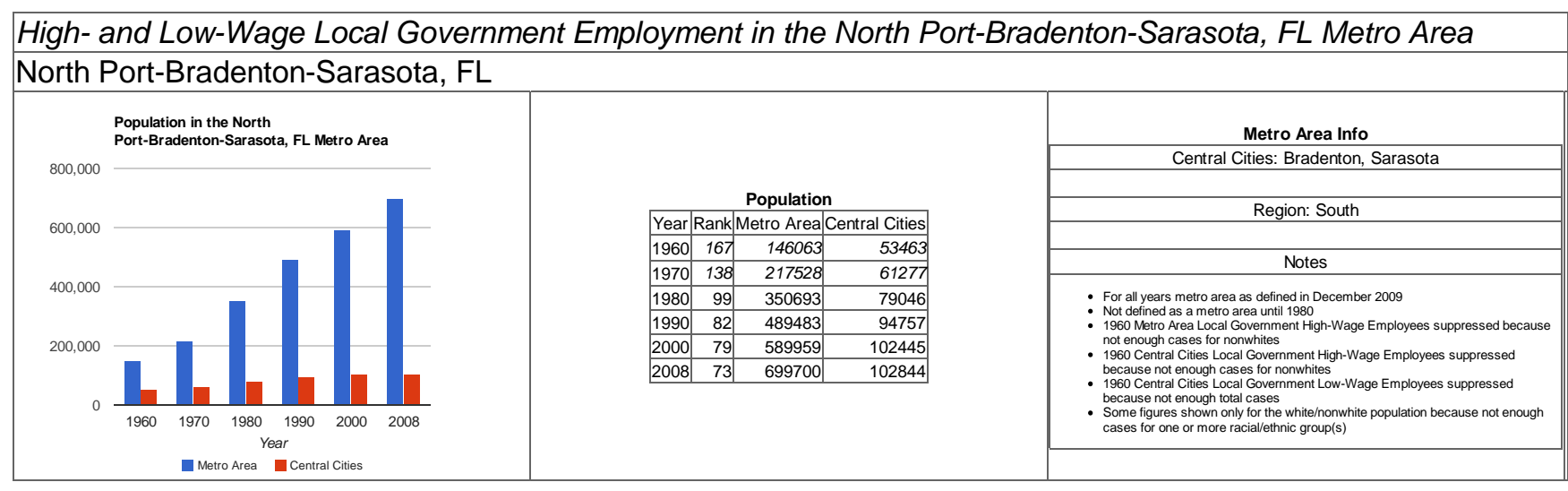


High- and Low-Wage Local Government Employment in the North Port-Bradenton-Sarasota, FL Metro Area Local Government High-Wage Employees in the Metro Area
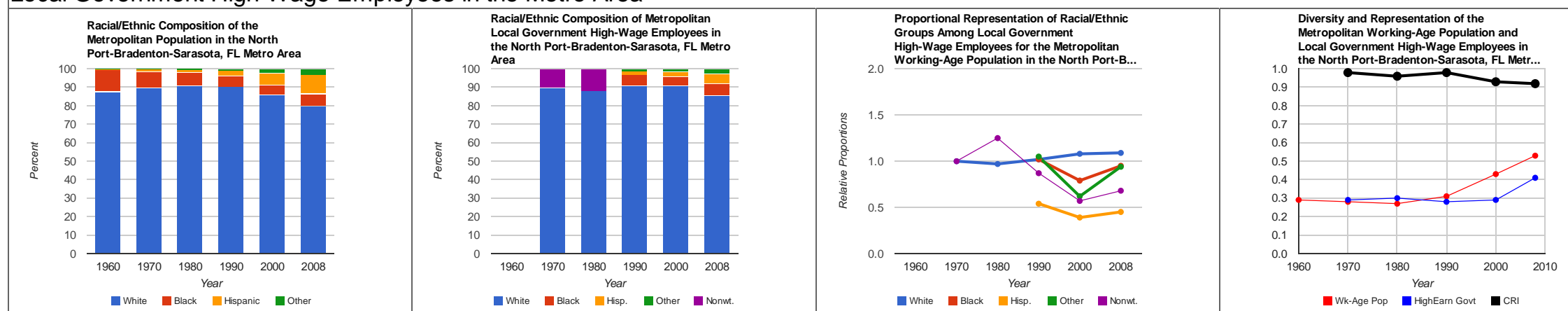

Local Government High-Wage Employees in the Central Cities
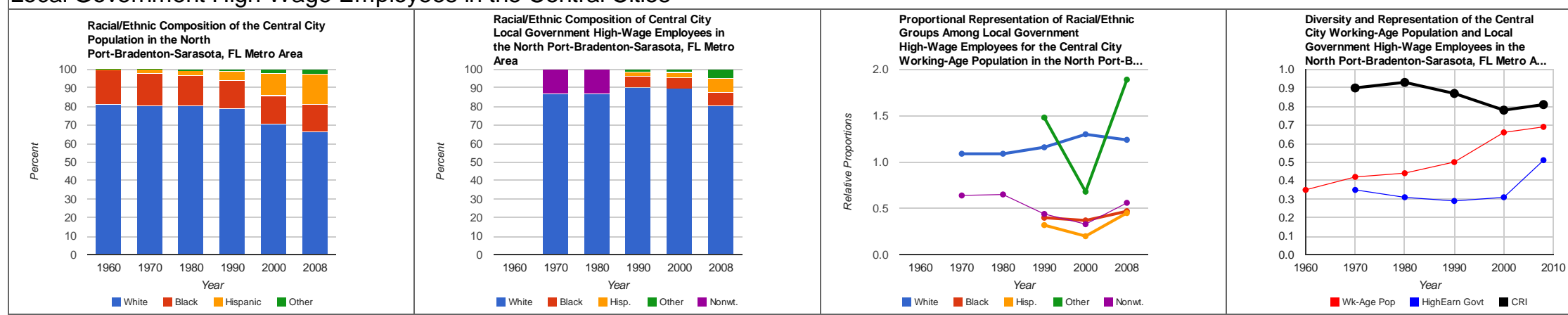
High- and Low-Wage Local Government Employment in the North Port-Bradenton-Sarasota, FL Metro Area Local Government Low-Wage Employees in the Metro Area
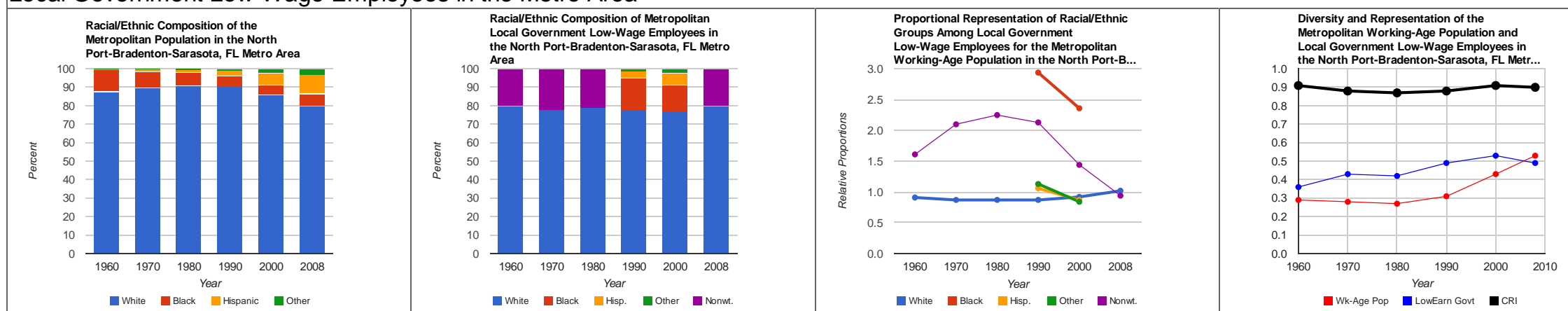

Local Government Low-Wage Employees in the Central Cities
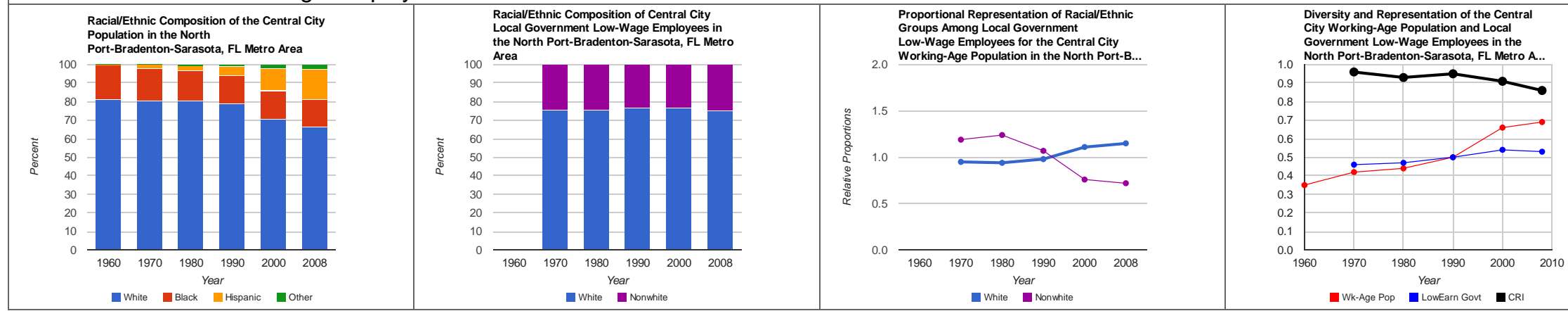


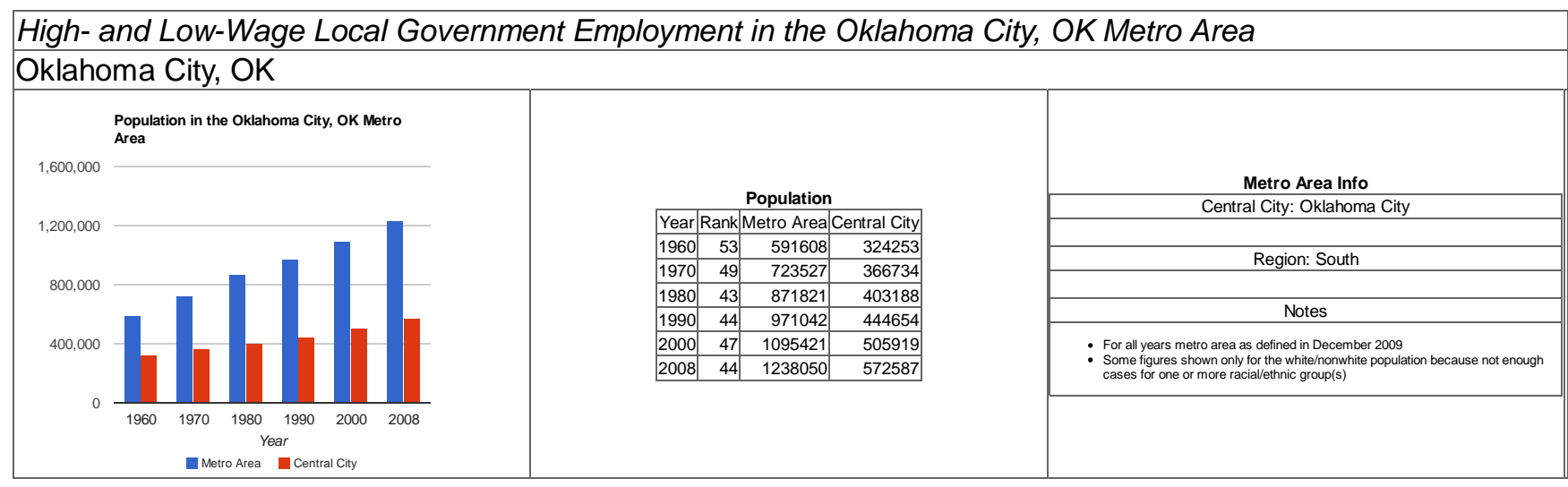


High- and Low-Wage Local Government Employment in the Oklahoma City, OK Metro Area

Local Government High-Wage Employees in the Metro Area
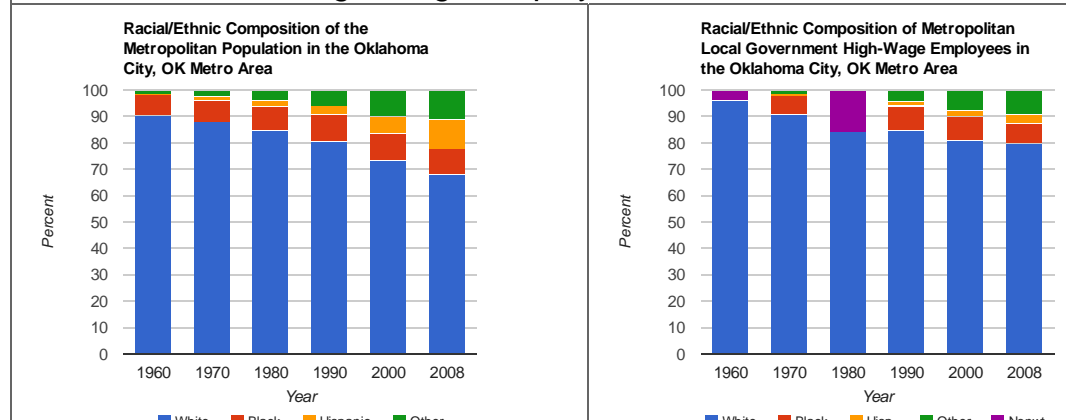

Local Government High-Wage Employees in the Central City
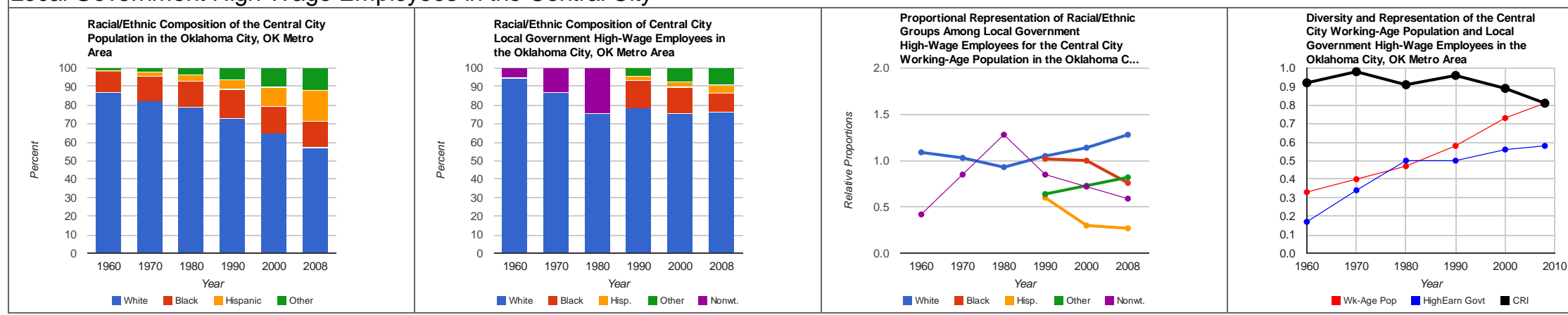
High- and Low-Wage Local Government Employment in the Oklahoma City, OK Metro Area

Local Government Low-Wage Employees in the Metro Area
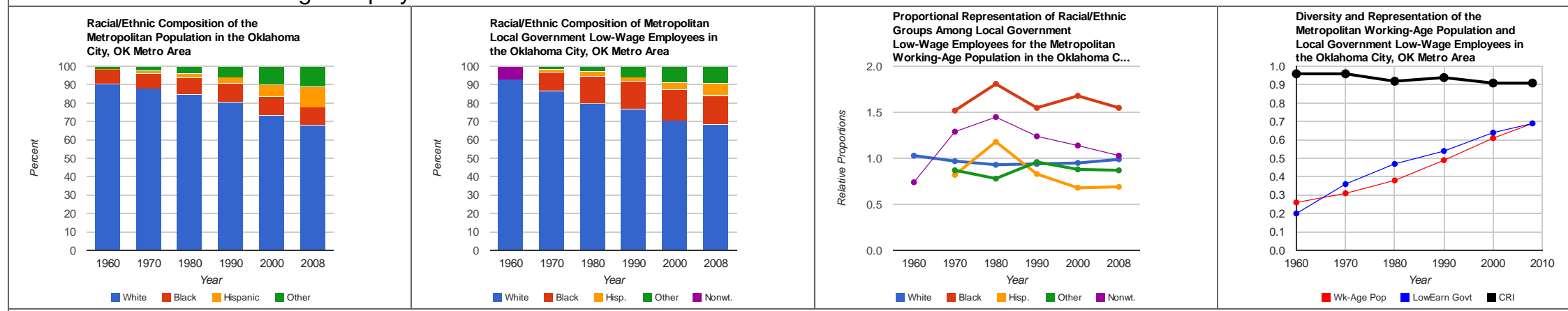

Local Government Low-Wage Employees in the Central City
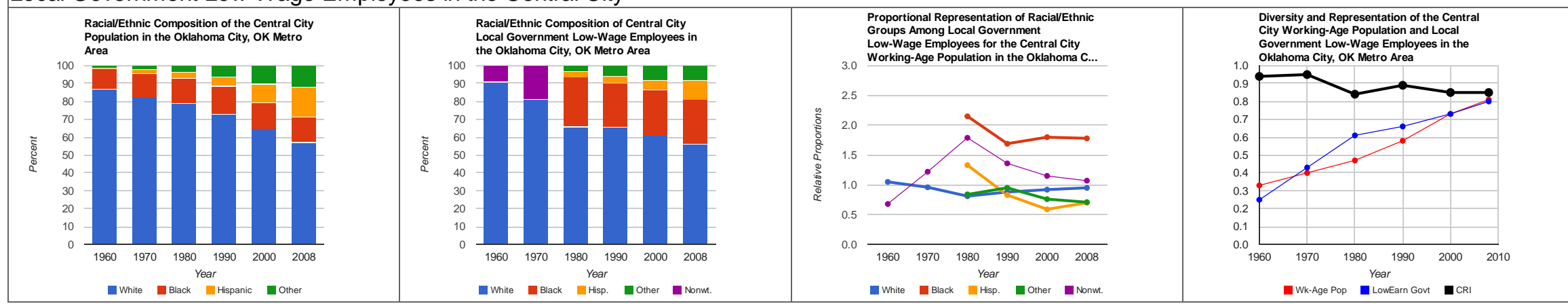


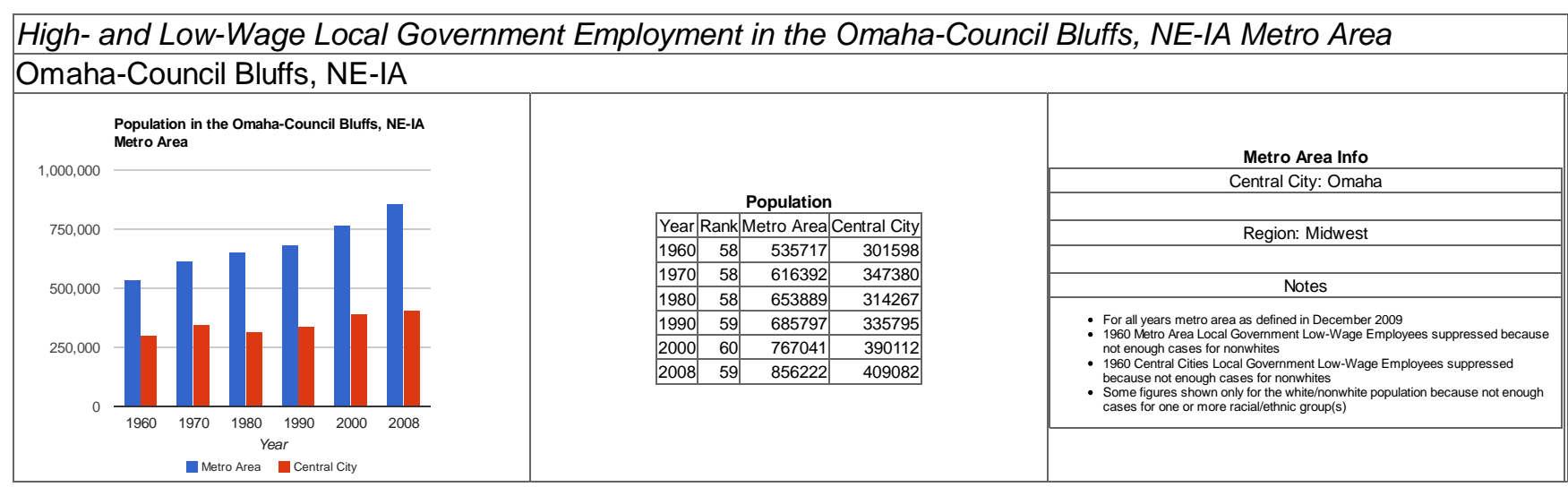


High- and Low-Wage Local Government Employment in the Omaha-Council Bluffs, NE-IA Metro Area Local Government High-Wage Employees in the Metro Area
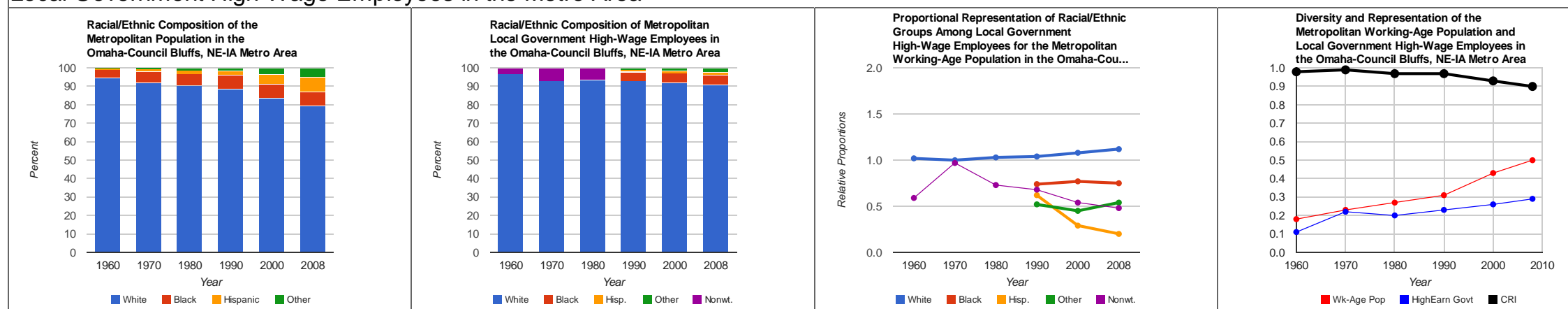

Local Government High-Wage Employees in the Central City
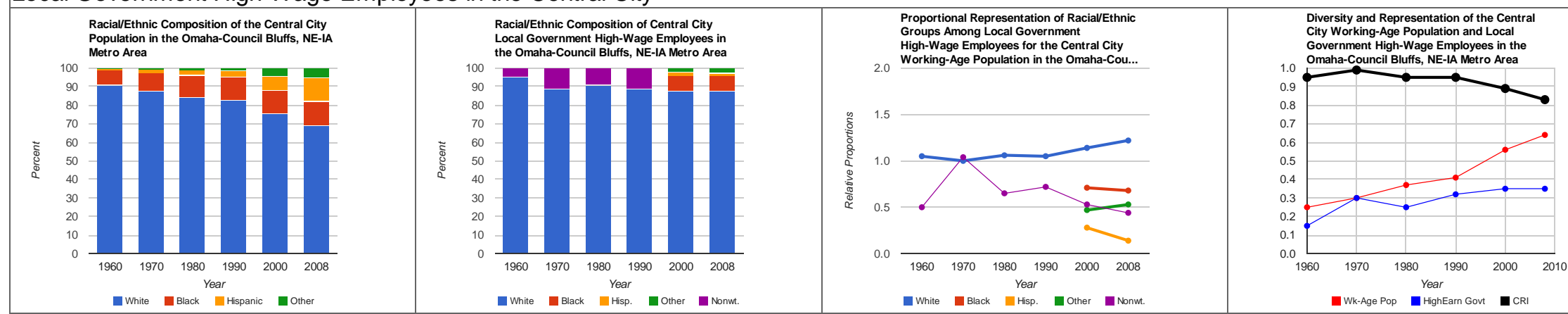
High- and Low-Wage Local Government Employment in the Omaha-Council Bluffs, NE-IA Metro Area Local Government Low-Wage Employees in the Metro Area
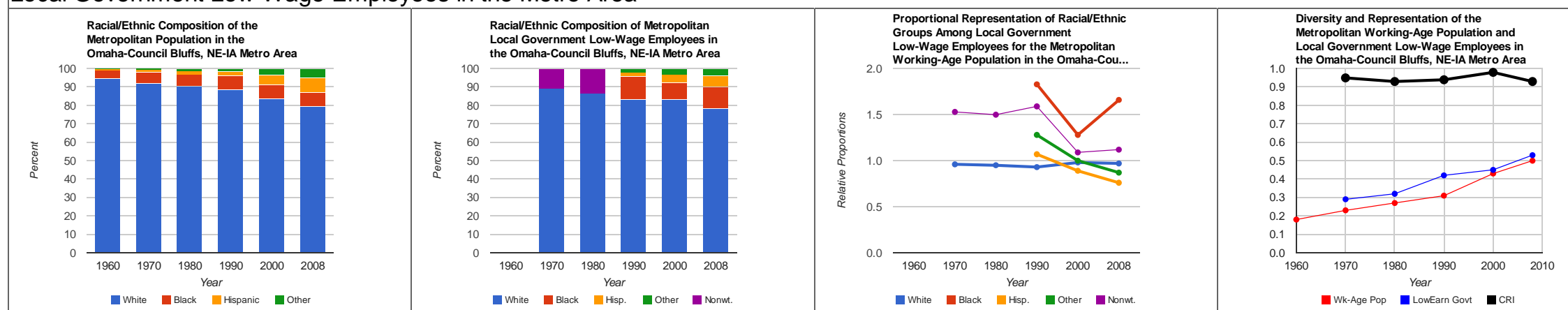

Local Government Low-Wage Employees in the Central City
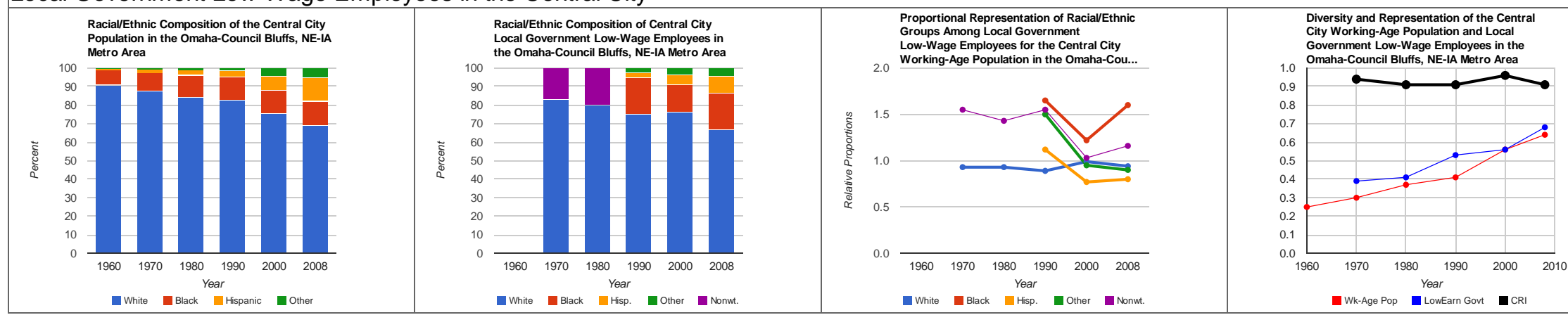


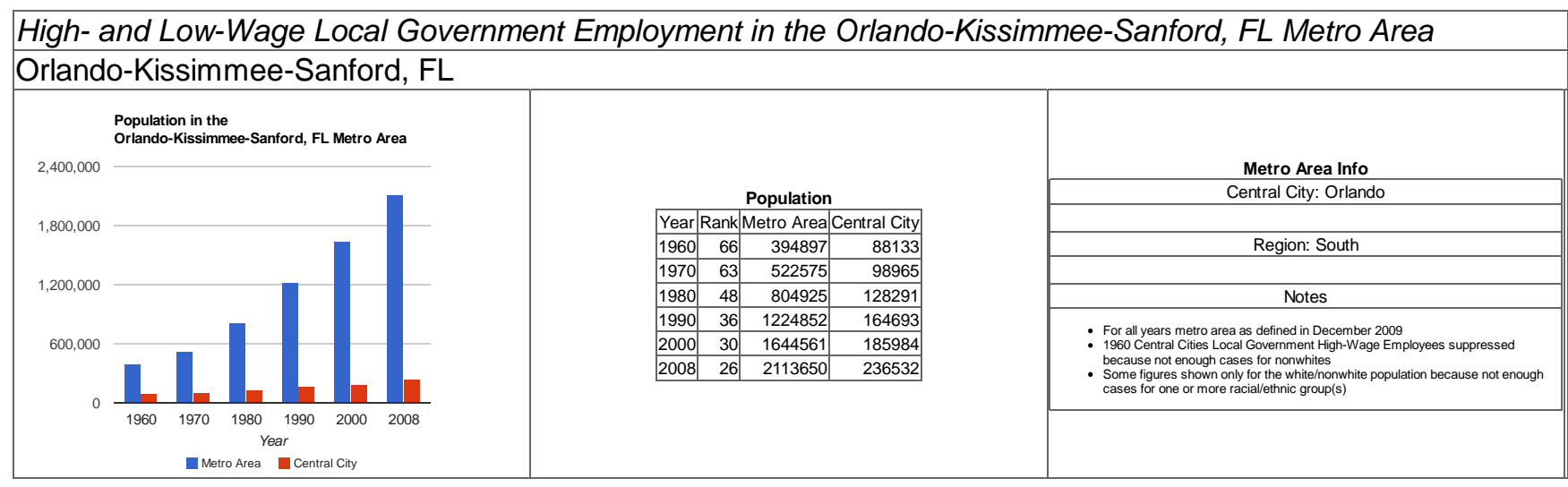


High- and Low-Wage Local Government Employment in the Orlando-Kissimmee-Sanford, FL Metro Area Local Government High-Wage Employees in the Metro Area
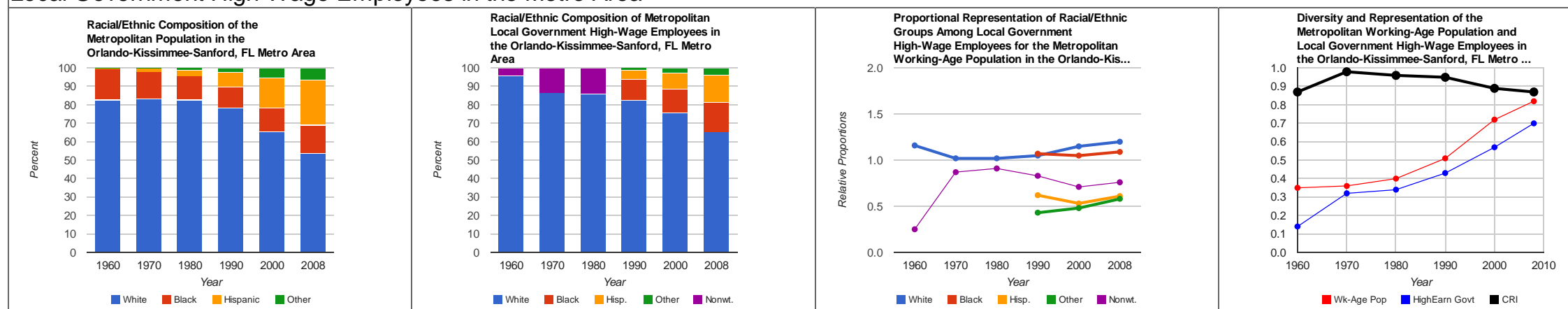

Local Government High-Wage Employees in the Central City
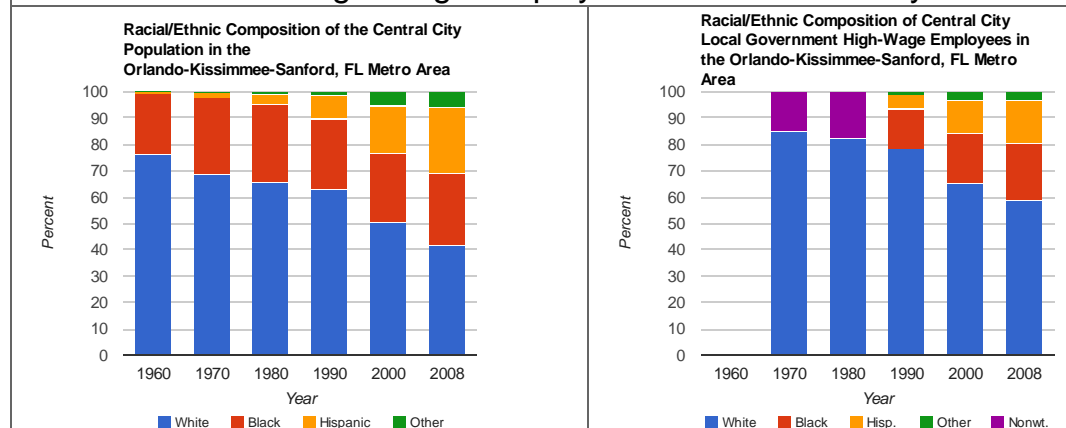
Proportional Representation of Raciall/Ethnic
Groups Among Local Government
High-Wage Employees for the Central City 20 Working-Age Population in the Orlando-Kis...

White Ulack Hear Hispanic nother

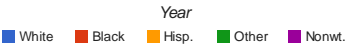

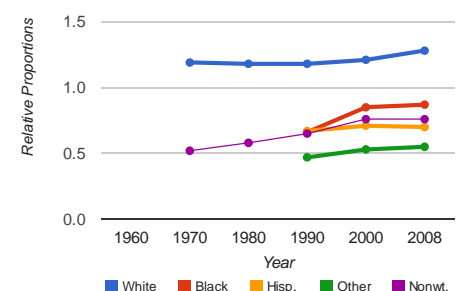
Diversity and Representation of the Central
City Working-Age Population and Local
Government High-Wage Employees in the

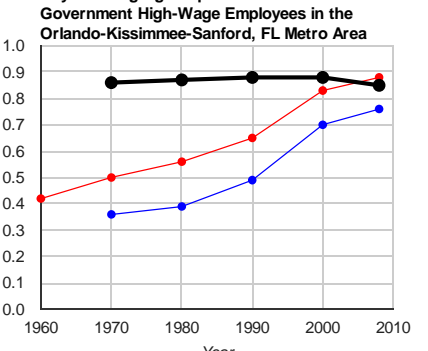

White $\square$ Black $\begin{gathered}\text { Year } \\ \text { Hisp. }\end{gathered}$

Wk-Age Pop - Mighearn Govt 
High- and Low-Wage Local Government Employment in the Orlando-Kissimmee-Sanford, FL Metro Area Local Government Low-Wage Employees in the Metro Area
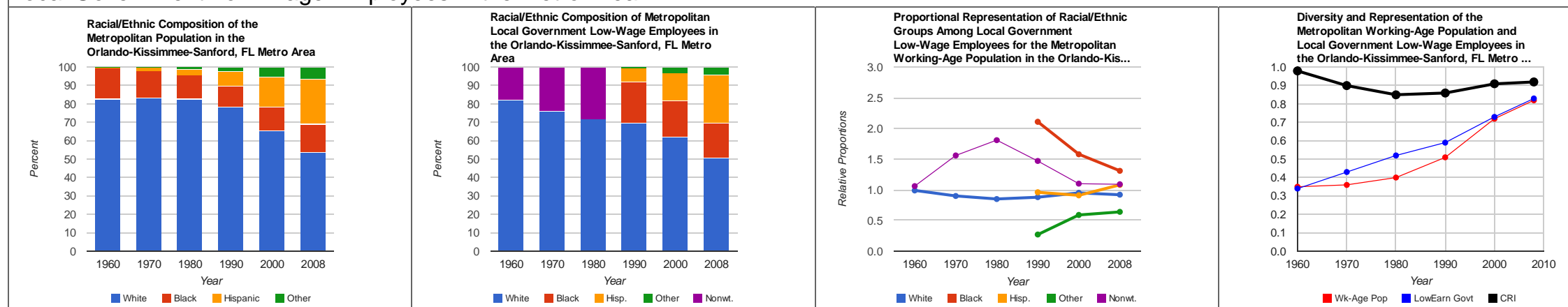

Local Government Low-Wage Employees in the Central City
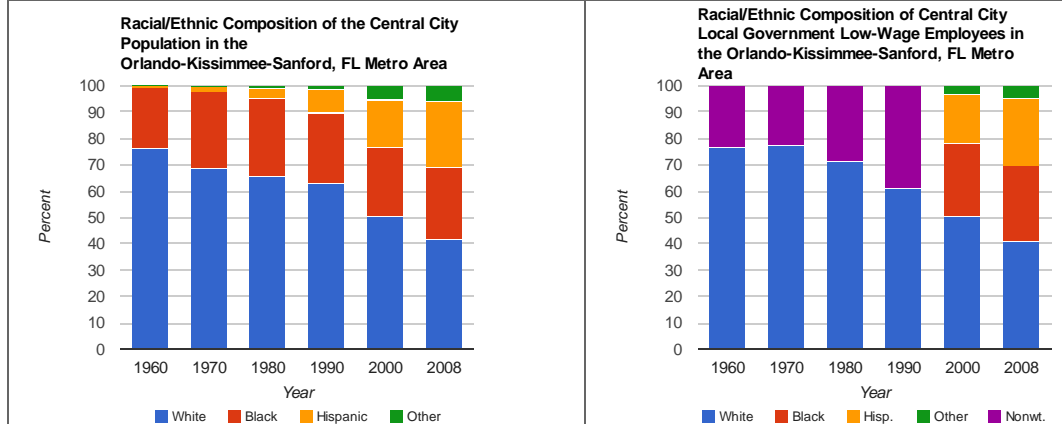
Proportional Representation of Raciall/Ethnic
Groups Among Local Government
Low-Wage Employees for the Central City 20 Working-Age Population in the Orlando-Kis...

White Ulack Hear Hispanic nother

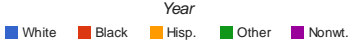
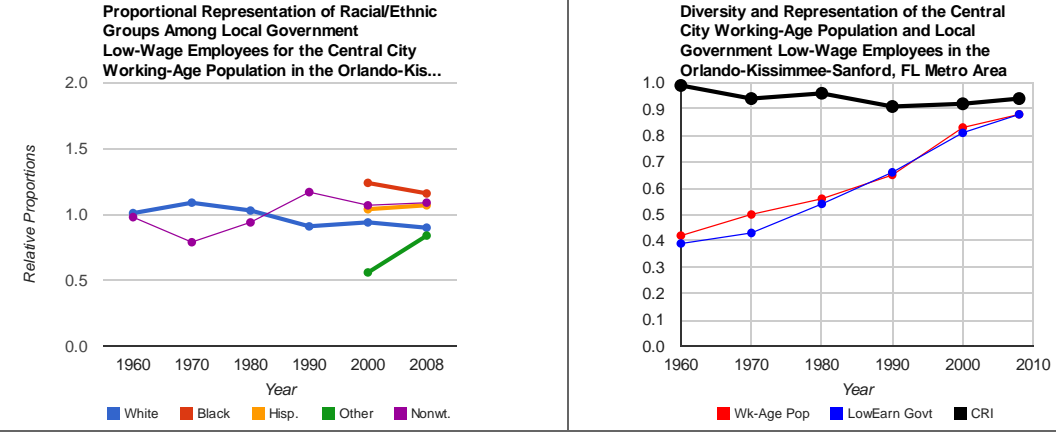


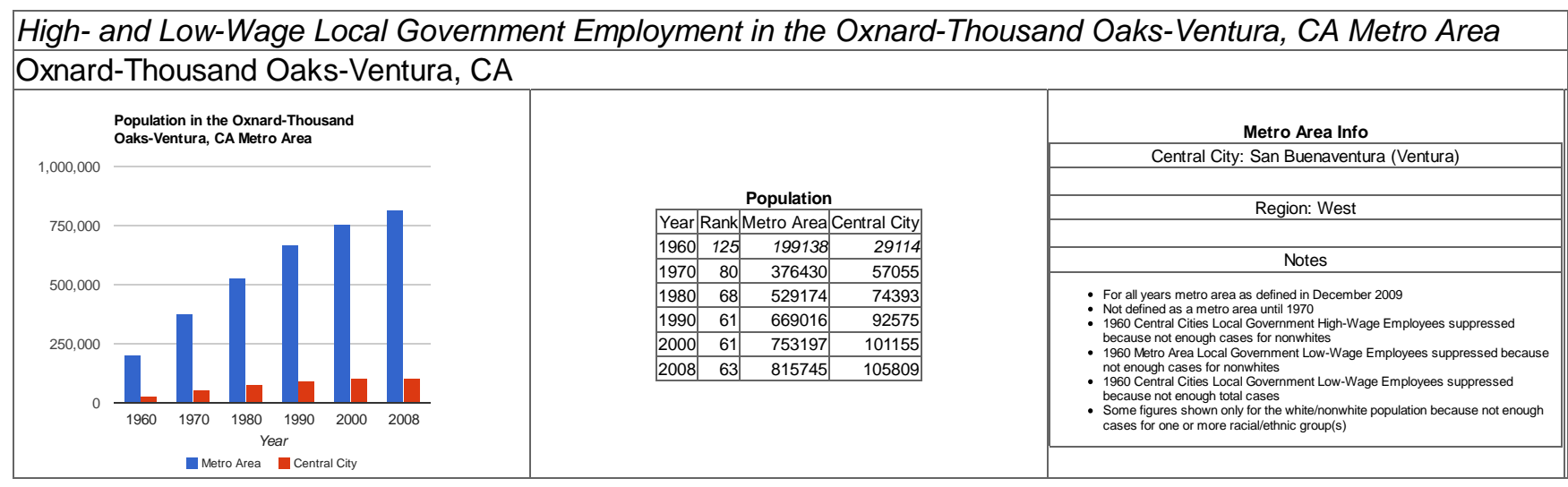


High- and Low-Wage Local Government Employment in the Oxnard-Thousand Oaks-Ventura, CA Metro Area Local Government High-Wage Employees in the Metro Area
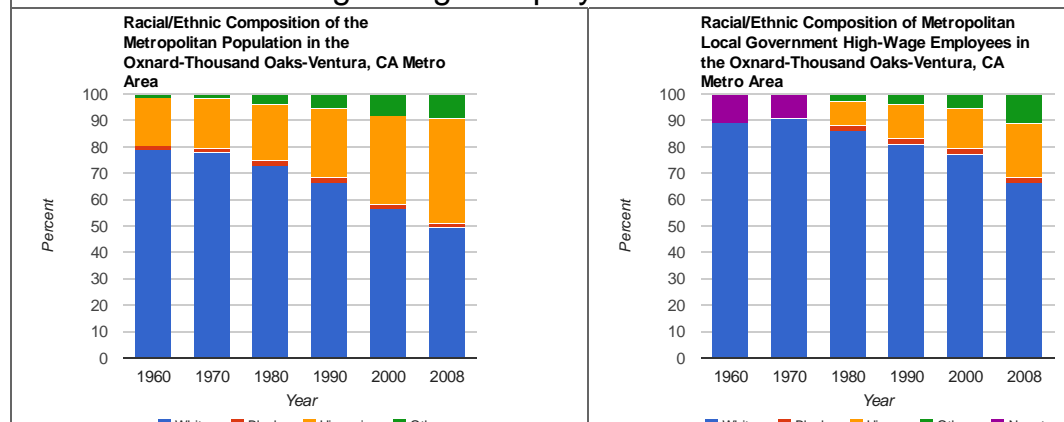

White 1 Black Year

Local Government High-Wage Employees in the Central City

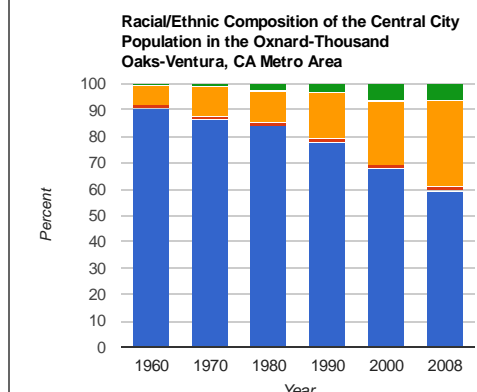

White Ulack Hear Hispanic nother

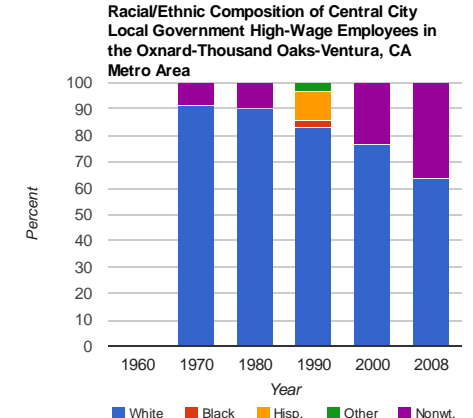

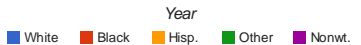

Proportional Representation of Raciall/Ethnic High-Wage Employees for the Metropolitn

20 Working-Age Population in the Oxnard-Tho...

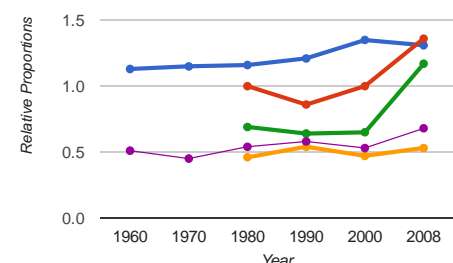

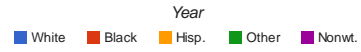

Diversity and Representation of the
Metropolitan Working-Age Poputhen

Metropolitan Working-Age Population and

the Oxnard-Thousand Oaks-Ventura, CA M...

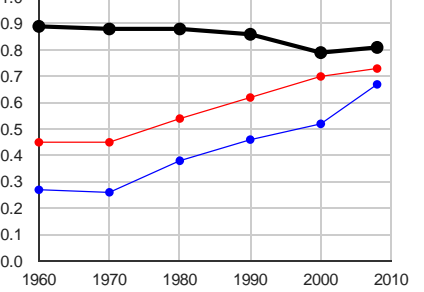

$1960 \quad 1970 \quad 1980 \quad 1990 \quad 2000 \quad 2010$

-Wk-Age Pop n Highearn Govt -
Proportional Representation of Raciall/Ethnic
Groups Among Local Government Groups Among Local Government
High-Wage Employees for the Working-Age Population in the Oxnard-Tho...

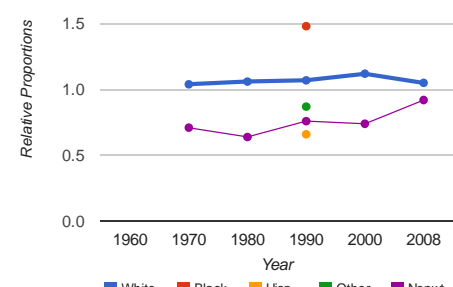

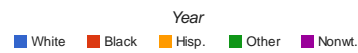

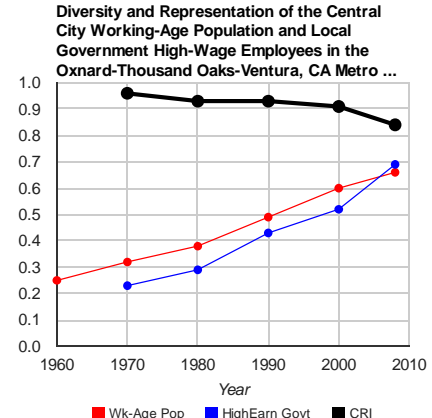

-Wk-Age Pop WighEarn Govt 
High- and Low-Wage Local Government Employment in the Oxnard-Thousand Oaks-Ventura, CA Metro Area Local Government Low-Wage Employees in the Metro Area
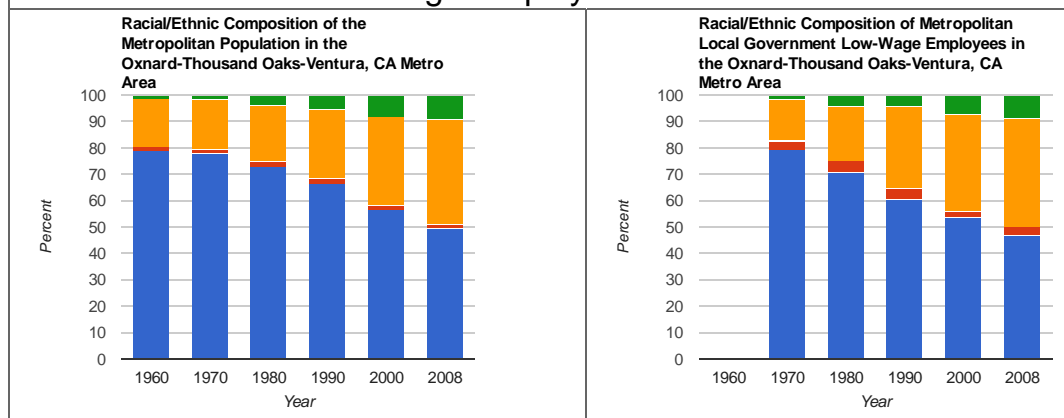

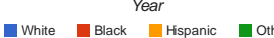

Local Government Low-Wage Employees in the Central City

RaciallEthnic Composition of the Central City

Population in the Oxnard-Thousan
Oaks-Ventura, $C A$ Metro

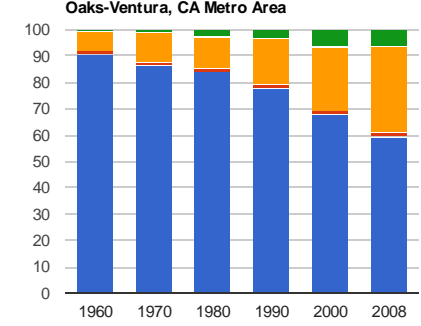

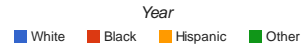

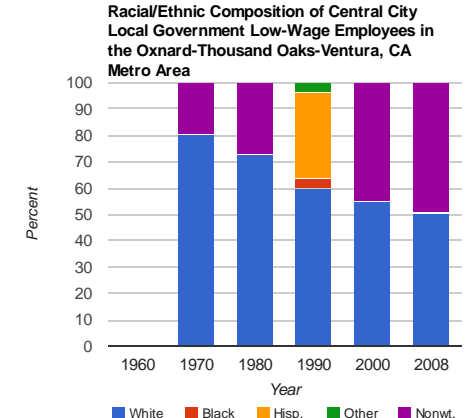

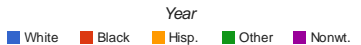

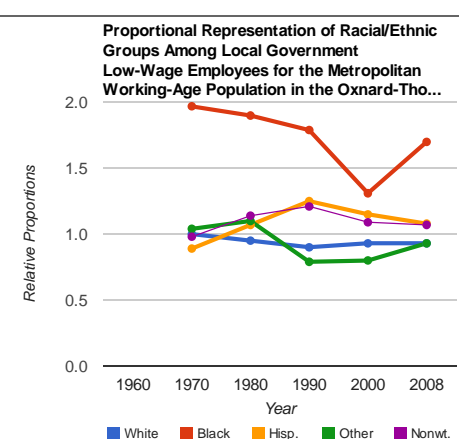

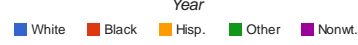

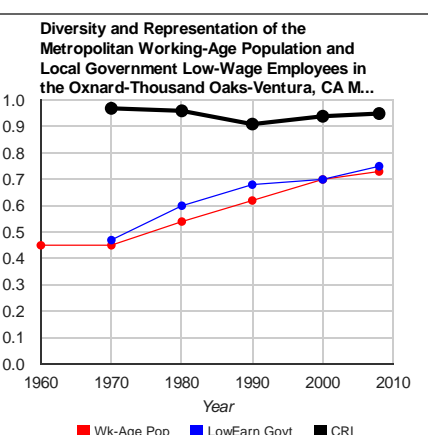

- Wk-Age Pop LowEarn Govt -
Proportional Representation of Raciall/thnic
Groups Among Local Government Groups Among Local Government Low-Wage- Employest for the Central City
Working-Age Population in the Oxnard-Tho...

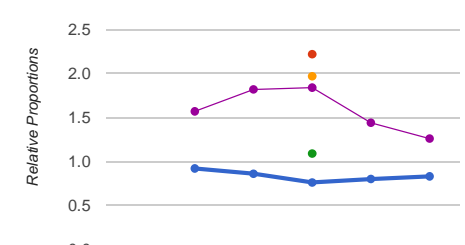

0.0 \begin{tabular}{llllll}
\hline 1960 & 1970 & 1980 & 1990 & 2000 & 2008
\end{tabular}

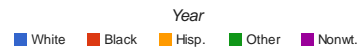

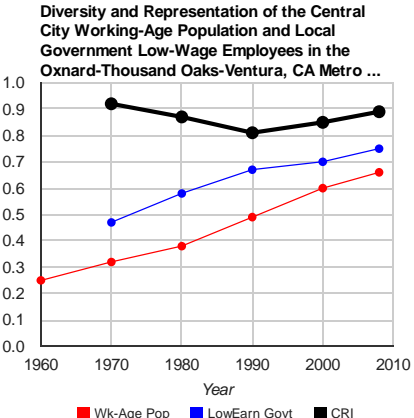

-Wk-Age Pop $\quad$ LowEarn Govt 
High- and Low-Wage Local Government Employment in the Palm Bay-Melbourne-Titusville, FL Metro Area Palm Bay-Melbourne-Titusville, FL

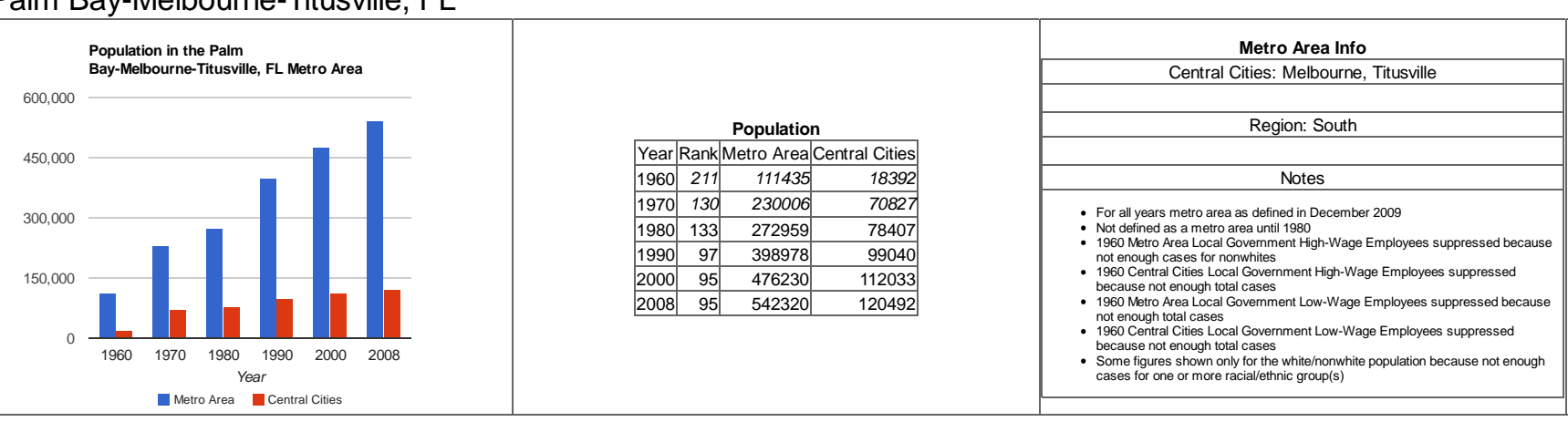


High- and Low-Wage Local Government Employment in the Palm Bay-Melbourne-Titusville, FL Metro Area Local Government High-Wage Employees in the Metro Area
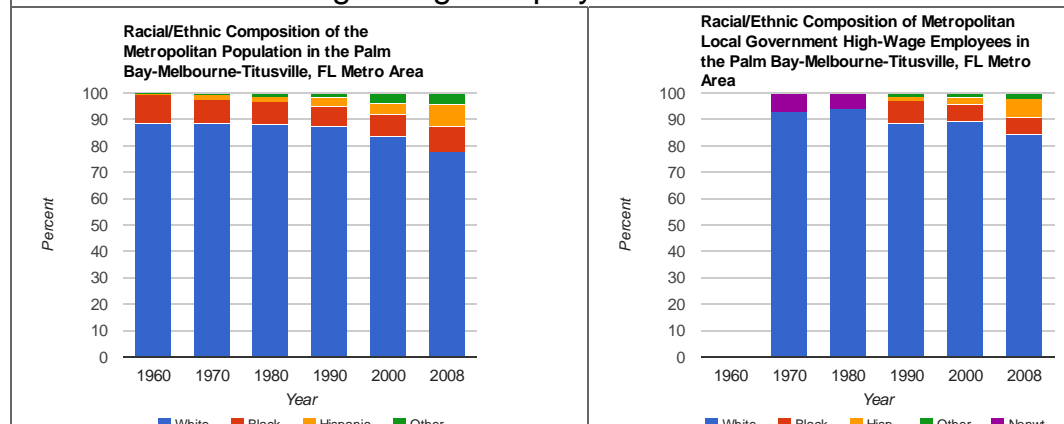

Local Government High-Wage Employees in the Central Cities
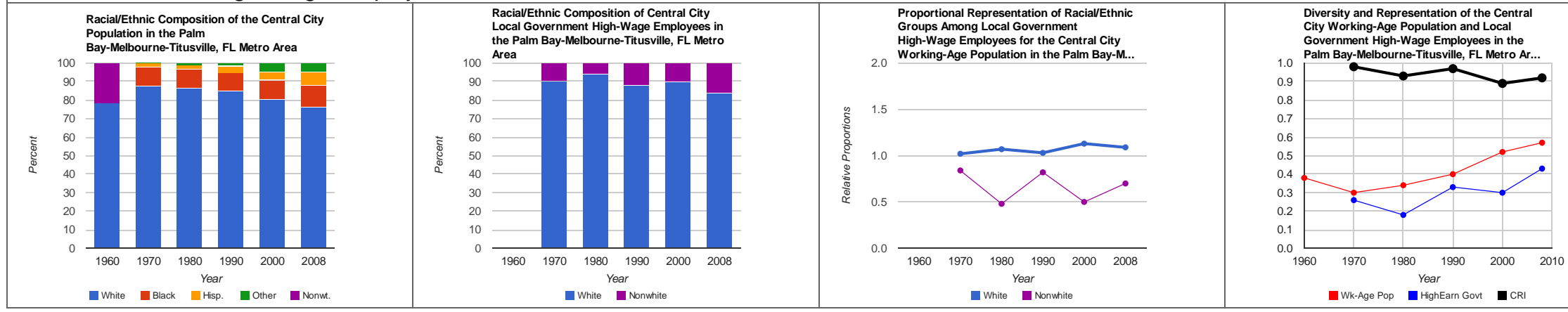

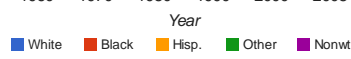

- White $\stackrel{\text { Year }}{\text { Nonwhite }}$

-Wk-Age Pop - HighEarn Govt -

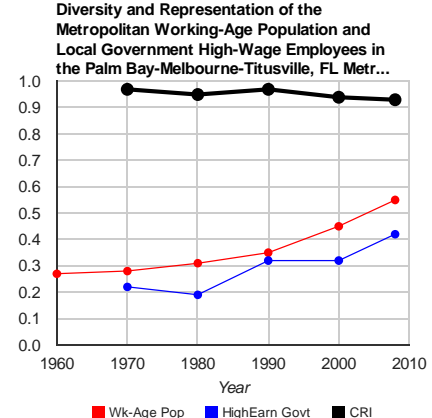

Wk-Age Pop HighEarn Gout -

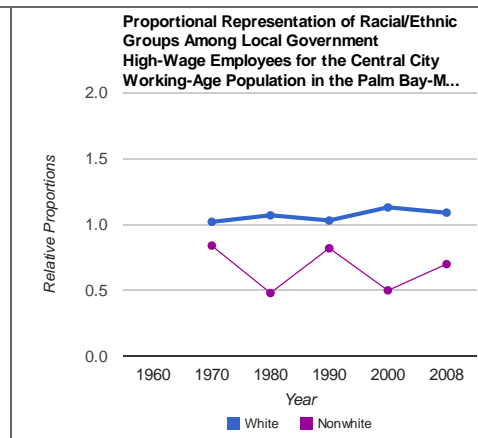

White Nonwhite

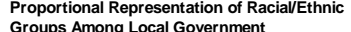
High-Wage Employees for the Metropolitan
Working-Age Population in the Palm Bay-M

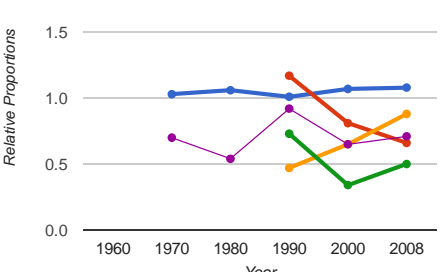

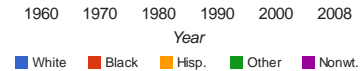

Proportional Representation of Racial/Ethnic High-Wage Employees for the Central City
Working-Age Population in the Palm Bay-M 
High- and Low-Wage Local Government Employment in the Palm Bay-Melbourne-Titusville, FL Metro Area Local Government Low-Wage Employees in the Metro Area
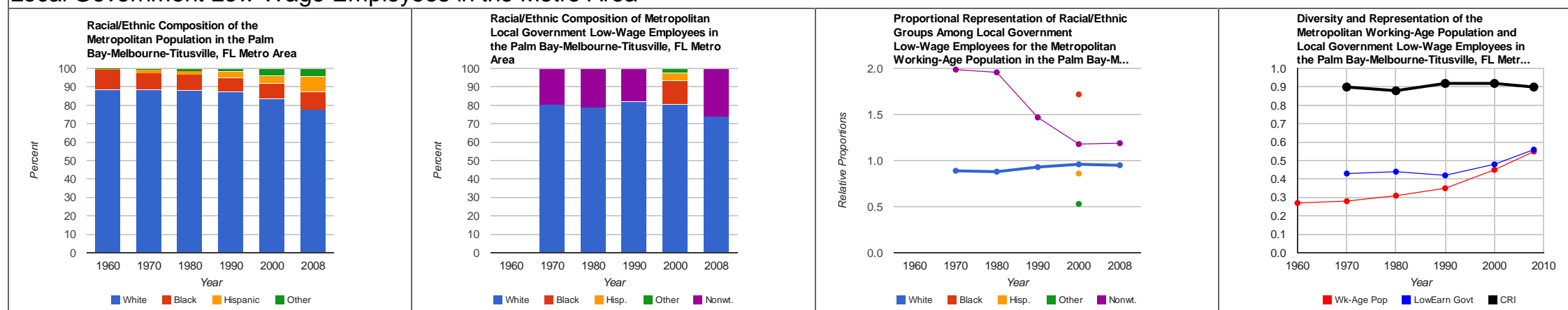

Local Government Low-Wage Employees in the Central Cities
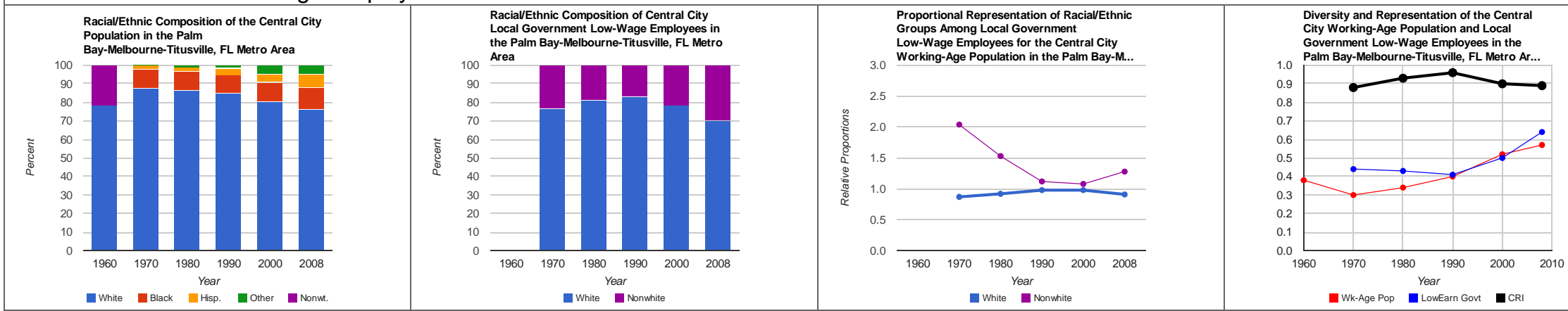


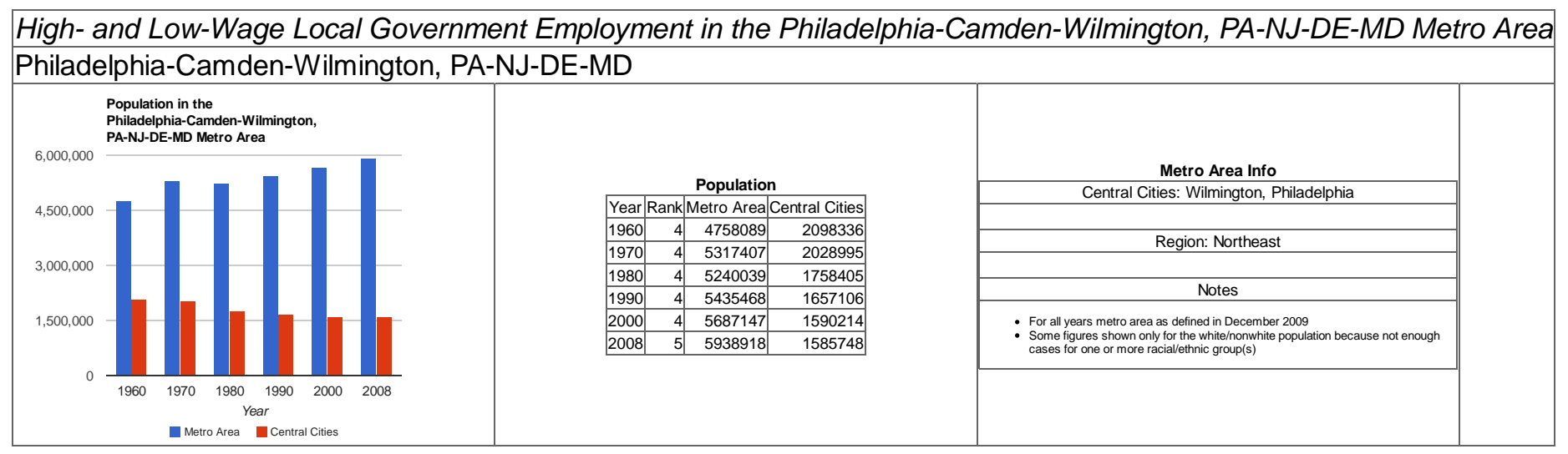


High- and Low-Wage Local Government Employment in the Philadelphia-Camden-Wilmington, PA-NJ-DE-MD Metro Area Local Government High-Wage Employees in the Metro Area
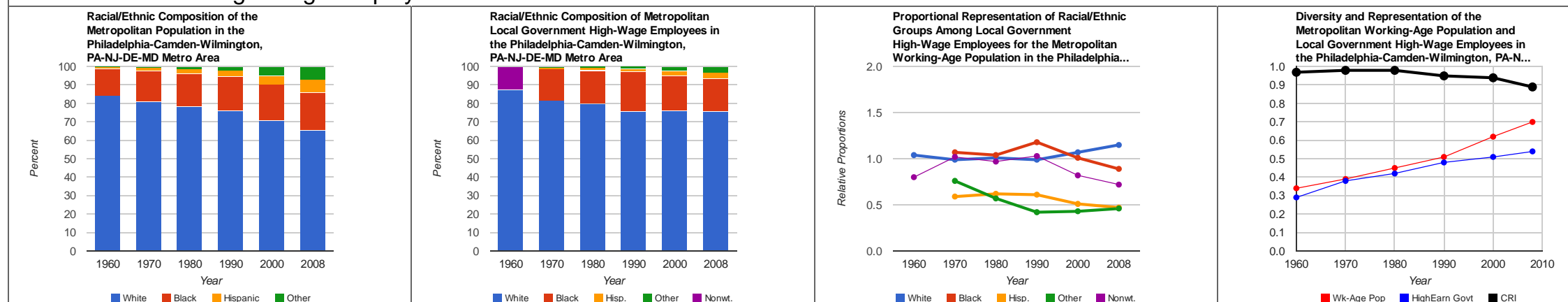

Local Government High-Wage Employees in the Central Cities
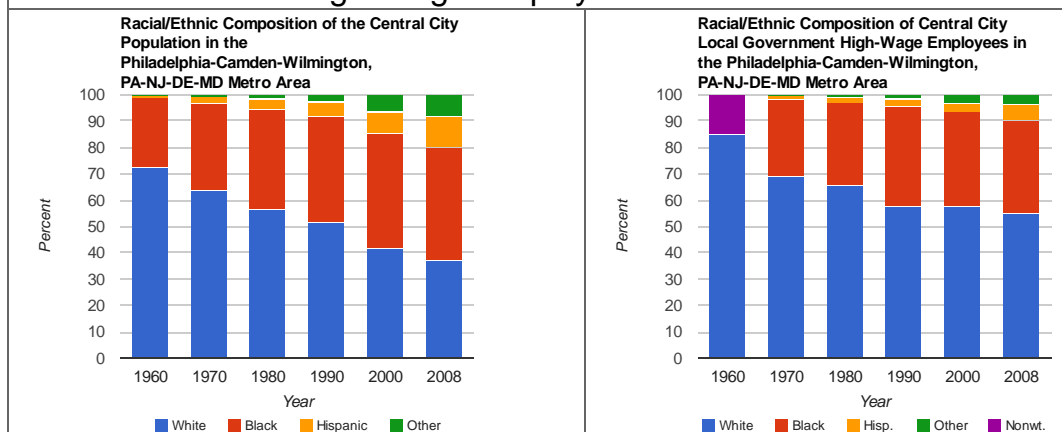
Proportional Representation of Raciall/Ethnic
Groups Among Local Government
High-Wage Employees for the Central City Working-Age Population in the Philadelphia... White Elack YHispanic Inother

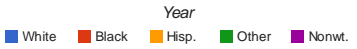
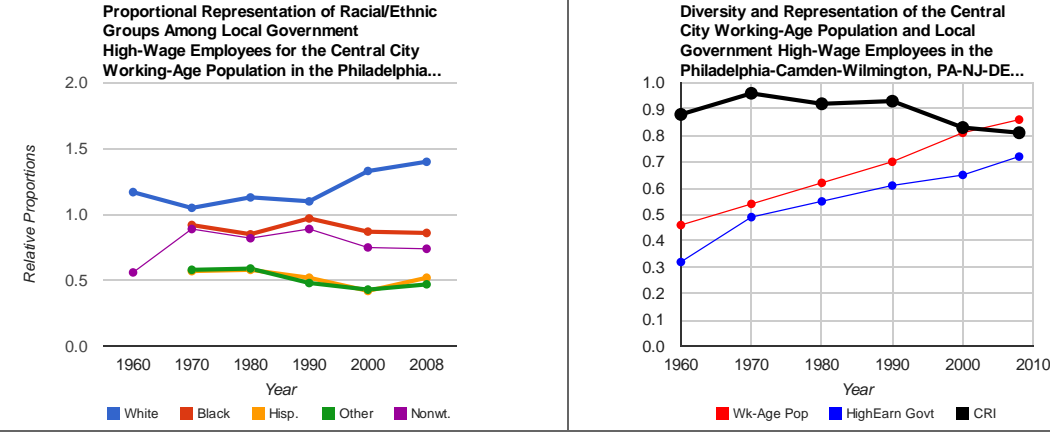
High- and Low-Wage Local Government Employment in the Philadelphia-Camden-Wilmington, PA-NJ-DE-MD Metro Area Local Government Low-Wage Employees in the Metro Area
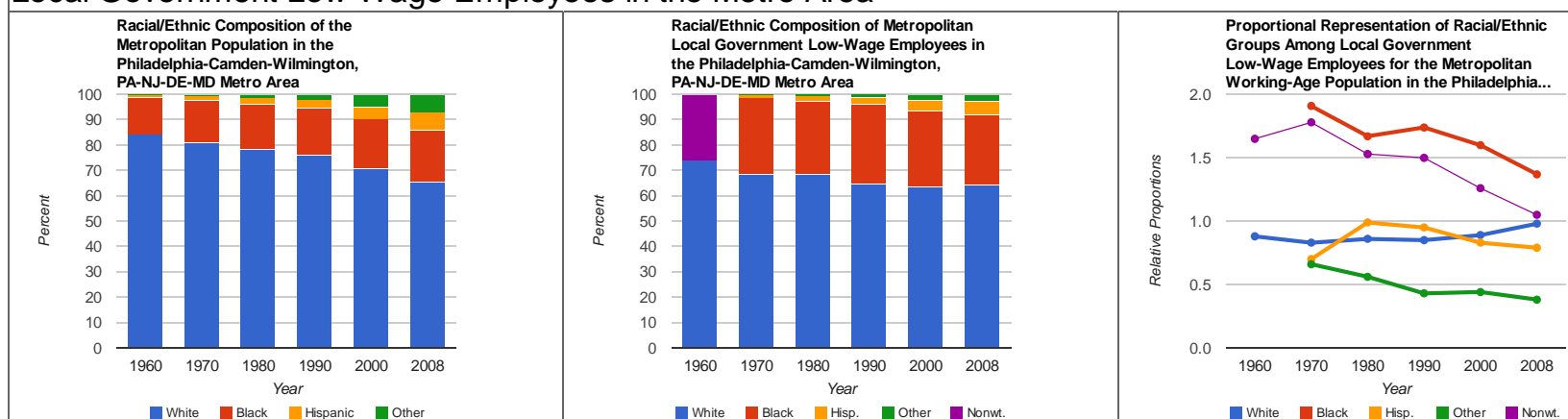

Diversity and Representation of the
Metropolitan Working-Age Pop Metropolitan Working-Age Population an

White Black Hispanic other

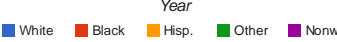

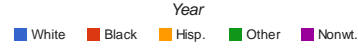

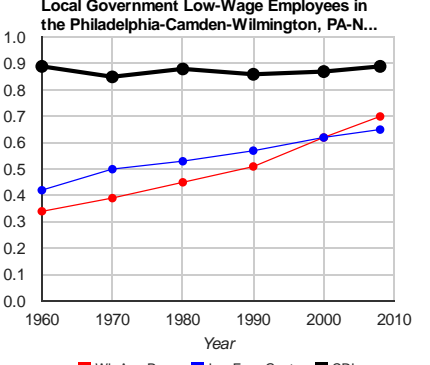

Local Government Low-Wage Employees in the Central Cities
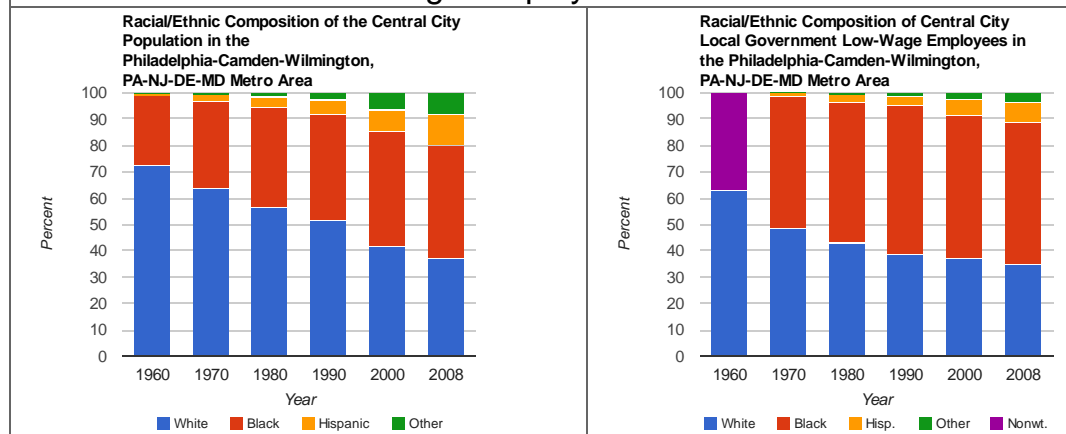

Groportional Representation of Racial/Ethnic Groups Among Local Government
Low-Wage Employees for the Central city Working-Age Population in the Philadelphia...

White Ulack Hear Hispanic nother

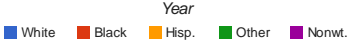

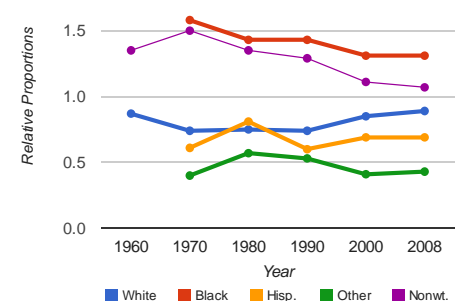
Diversity and Representation of the Central
City Working-Age Population and Local
Government Low-Wage Employees in the Government Low-Wage Employees in the
Philadelephia-Camden-Wilmington, PA-NJ-DE..

PA-NJ-DE-MD Metro Ar

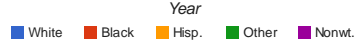

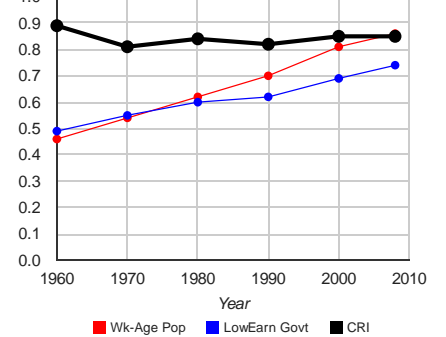




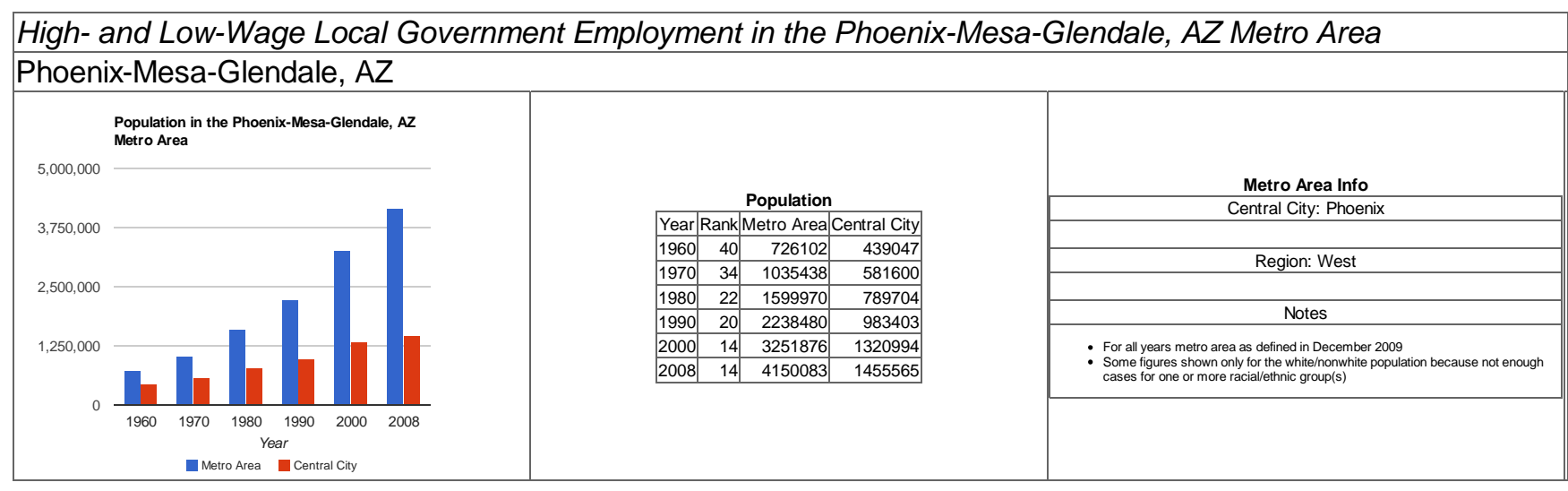


High- and Low-Wage Local Government Employment in the Phoenix-Mesa-Glendale, AZ Metro Area

Local Government High-Wage Employees in the Metro Area
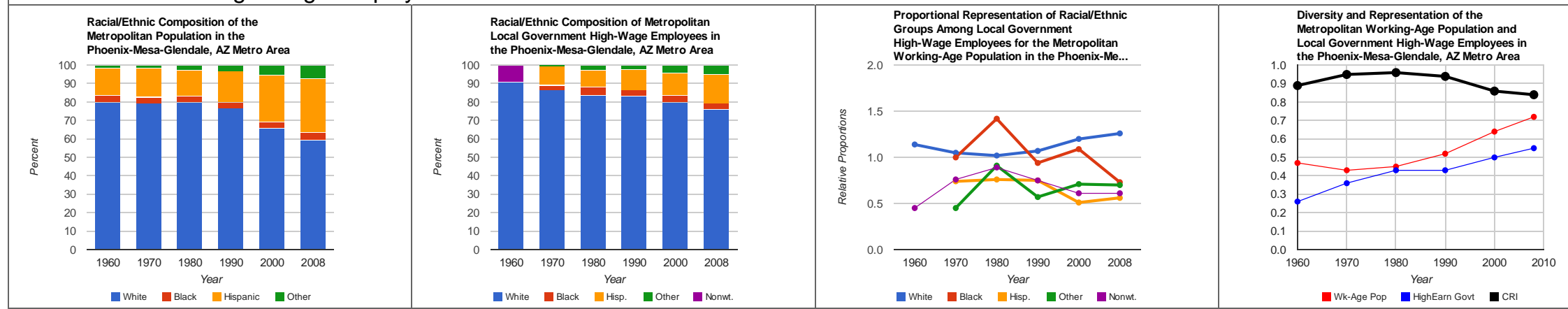

Local Government High-Wage Employees in the Central City
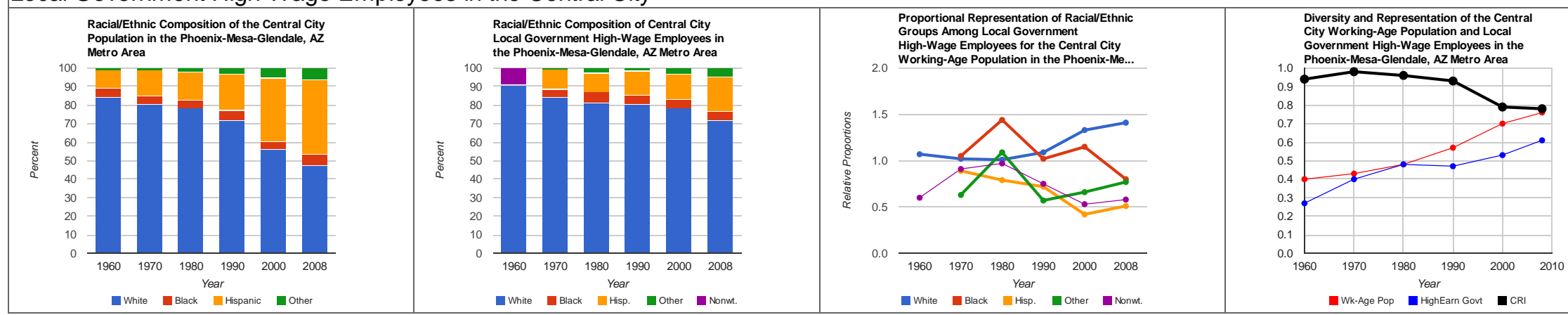
High- and Low-Wage Local Government Employment in the Phoenix-Mesa-Glendale, AZ Metro Area

Local Government Low-Wage Employees in the Metro Area
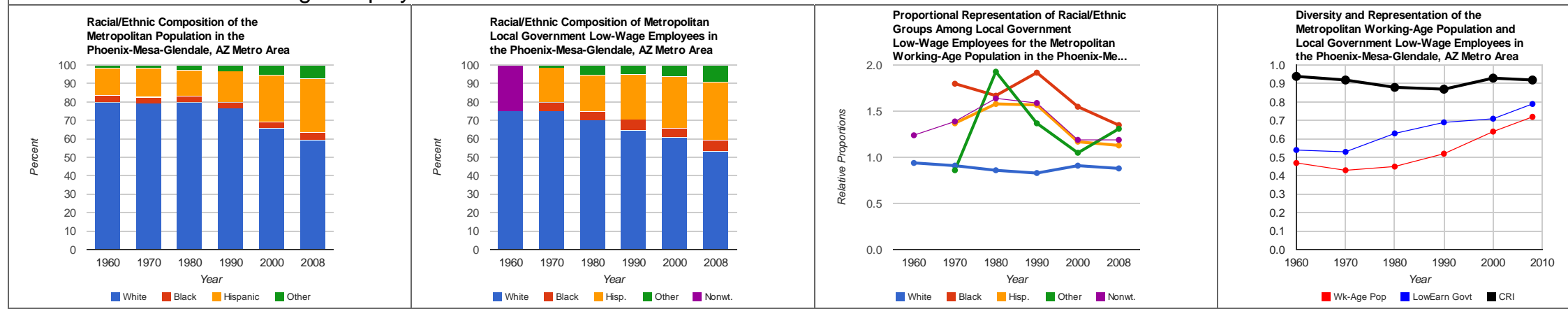

Local Government Low-Wage Employees in the Central City
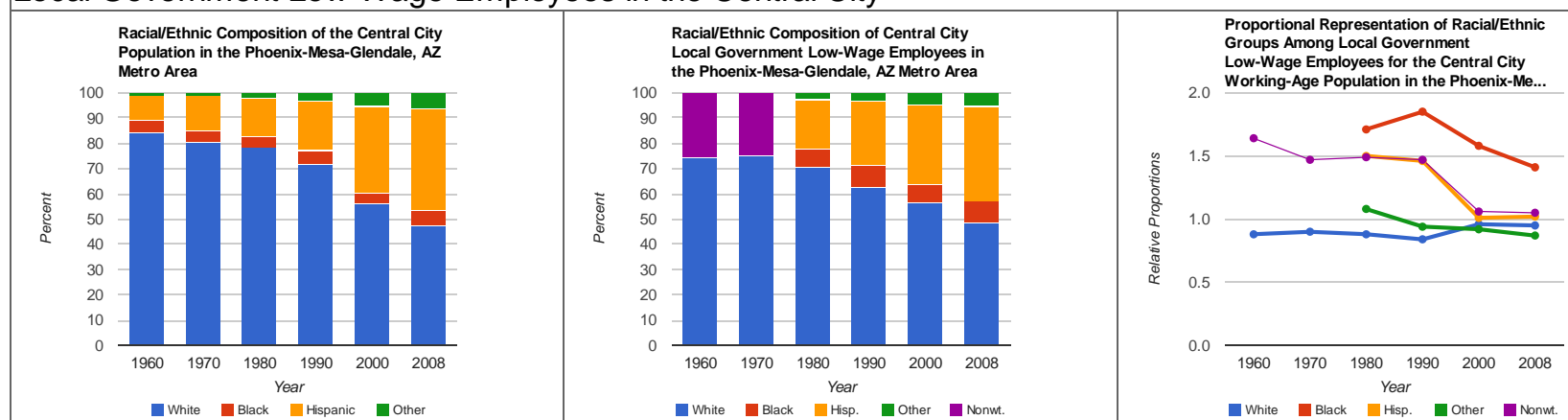
Diversity and Representation of the Central
City Working-Age Population and Local
Government Low-Wage Employees in the Government Low-Lage Employees in the
Phoenix-Mesa--ilendale, AZ Metro Area

Meptratain Area

@White 1 Black Year

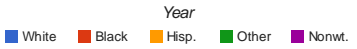

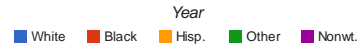

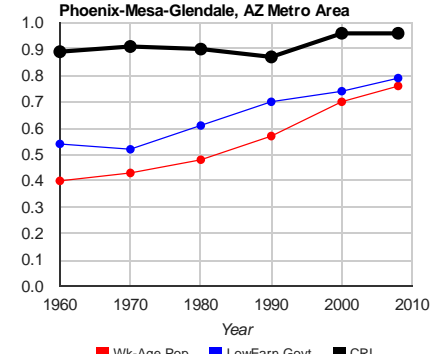

- Wk-Age Pop D LowEarn Govt $\quad$ CRI 
High- and Low-Wage Local Government Employment in the Pittsburgh, PA Metro Area

Pittsburgh, PA

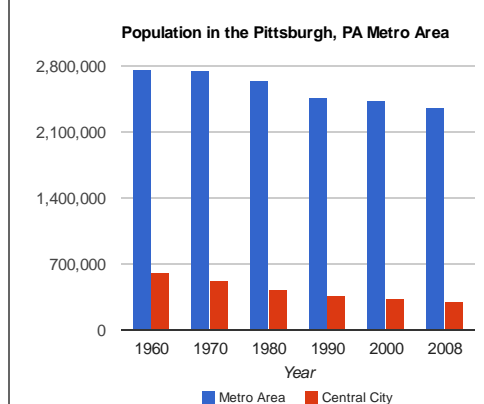

Population

Year Rank Metro Area Central City

\begin{tabular}{|l|l|l|r|}
\hline 1960 & 7 & 2769804 & 604332 \\
\hline 1970 & 9 & 275944 & 520167 \\
\hline
\end{tabular}

\begin{tabular}{r|rrrr|r|}
1970 & 9 & 2759443 & 520167 \\
\hline 1980 & 12 & 2648991 & 423038 \\
\hline
\end{tabular}

\begin{tabular}{|l|l|l|r|}
\hline 1980 & 12 & 2648991 & 423938 \\
\hline 1990 & 18 & 2468289 & 369879 \\
\hline
\end{tabular}

\begin{tabular}{|l|l|l|r|}
\hline 2000 & 20 & 2431087 & 334563 \\
\hline
\end{tabular}

\begin{tabular}{|l|l|l|r|}
\hline 2000 & 20 & 2431087 & 334563 \\
\hline 2008 & 22 & 2357769 & 307532 \\
\hline
\end{tabular}

Metro Area Info

Central City: Pittsburgh

Metro Area $\quad$ Central City 
High- and Low-Wage Local Government Employment in the Pittsburgh, PA Metro Area

Local Government High-Wage Employees in the Metro Area
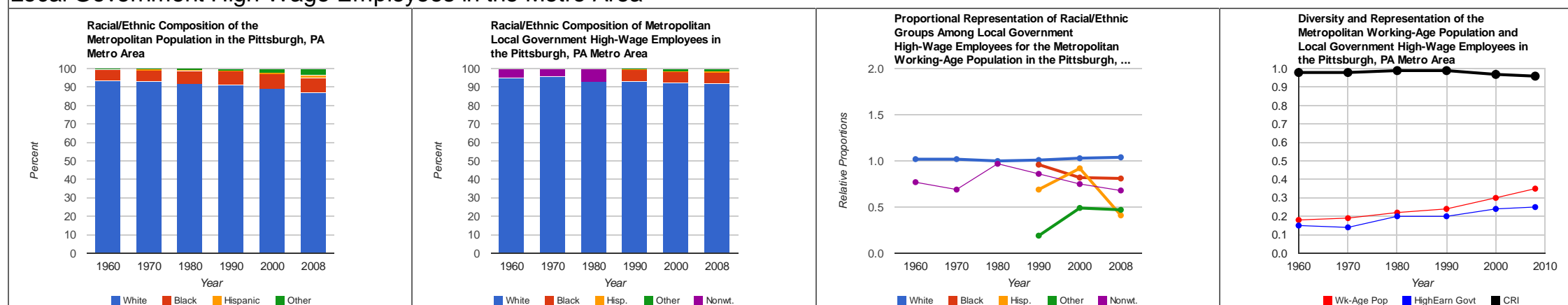

Local Government High-Wage Employees in the Central City
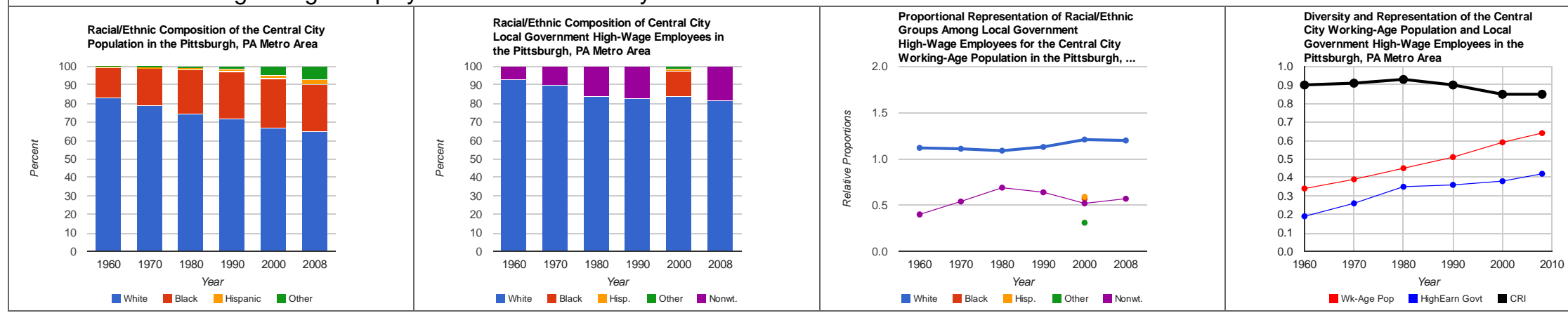
High- and Low-Wage Local Government Employment in the Pittsburgh, PA Metro Area

Local Government Low-Wage Employees in the Metro Area
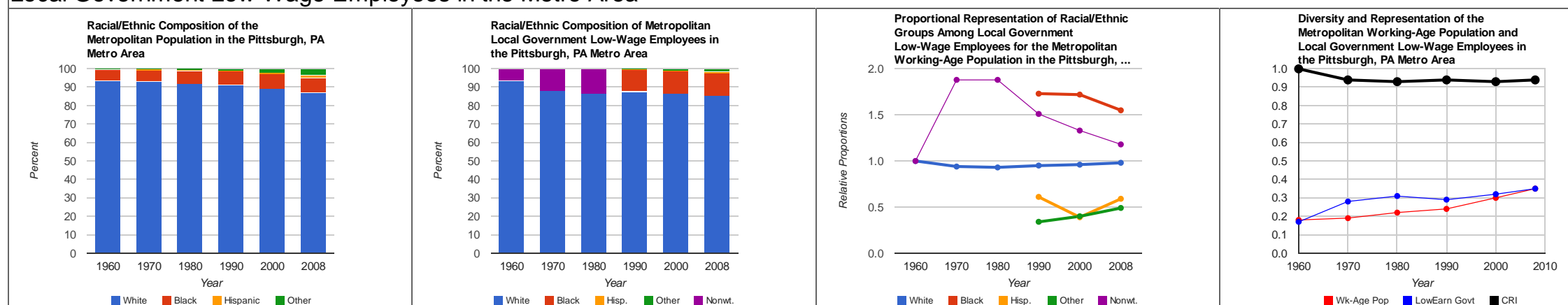

Local Government Low-Wage Employees in the Central City

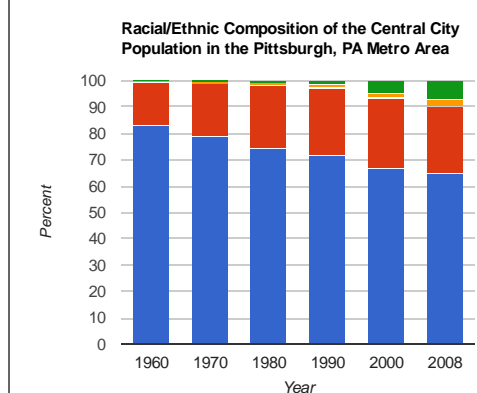

- White I Black Year Hispanic Inother

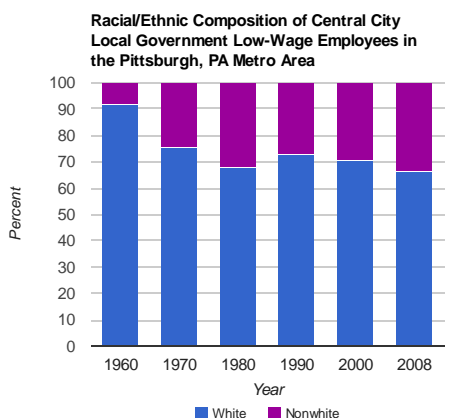

White Year Proportional Representation of Raciall/Ethnic
Groups Among Local Government
Low-Wage Employees for the Central City Low-Wage Employees for the Central City
Working-Age Population in the Pittsburgh, ...

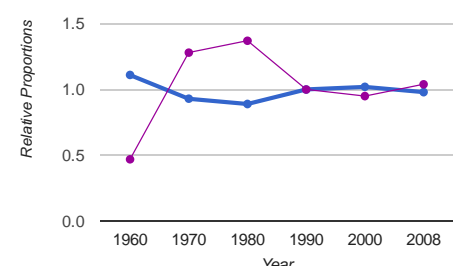

White ${ }_{\text {Nonunite }}$

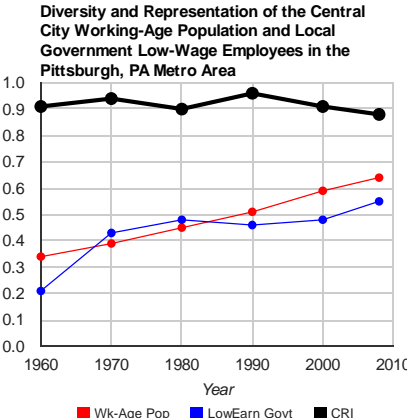

- Wk-Age Pop L LowEarn Govt - CPR 


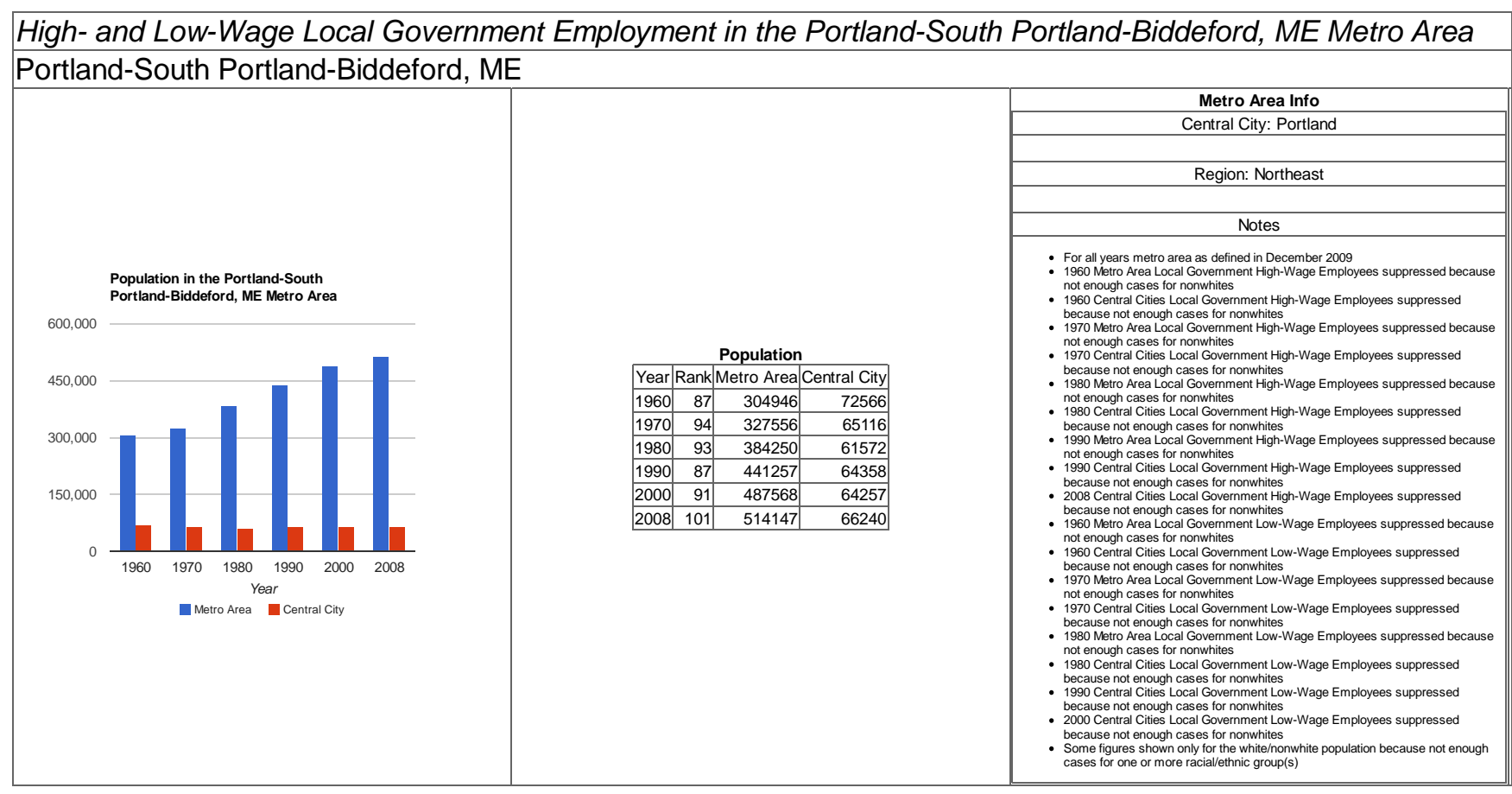


High- and Low-Wage Local Government Employment in the Portland-South Portland-Biddeford, ME Metro Area Local Government High-Wage Employees in the Metro Area
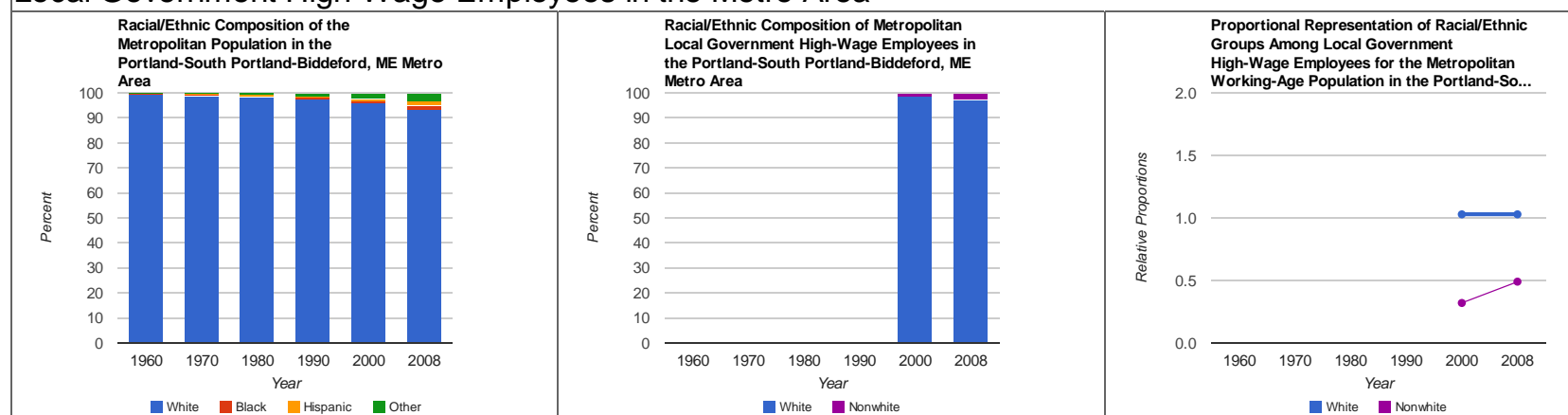

Local Government High-Wage Employees in the Central City
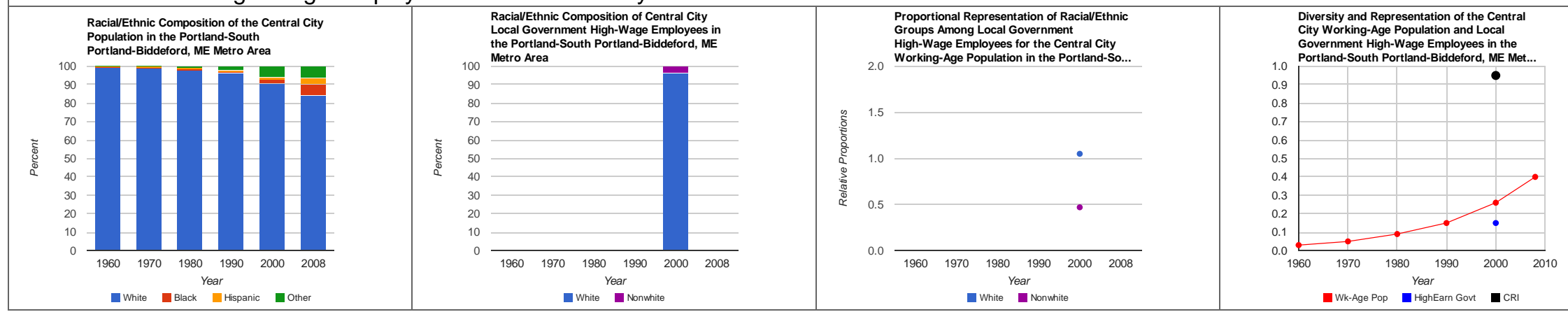
High- and Low-Wage Local Government Employment in the Portland-South Portland-Biddeford, ME Metro Area Local Government Low-Wage Employees in the Metro Area
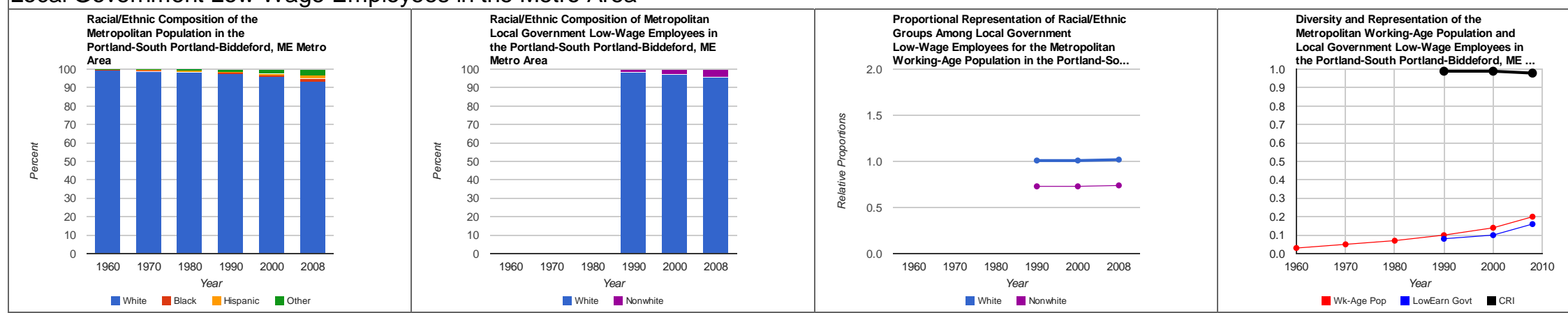

Local Government Low-Wage Employees in the Central City
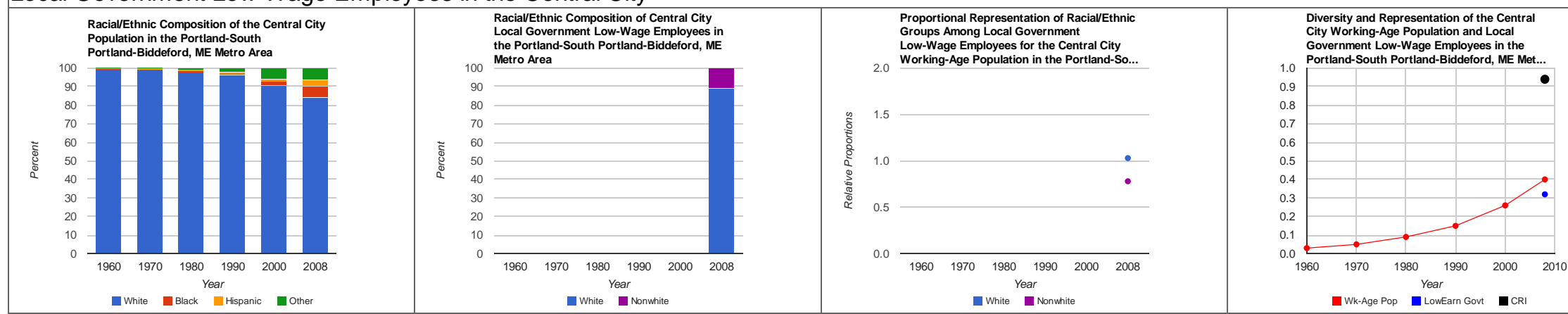


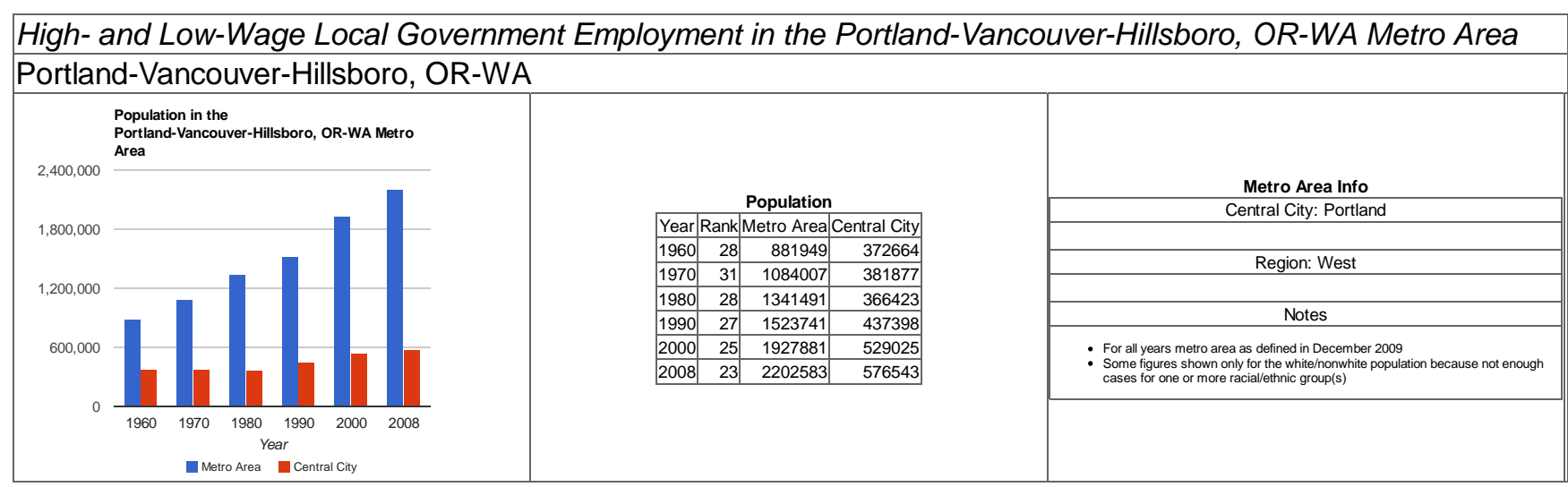


High- and Low-Wage Local Government Employment in the Portland-Vancouver-Hillsboro, OR-WA Metro Area Local Government High-Wage Employees in the Metro Area
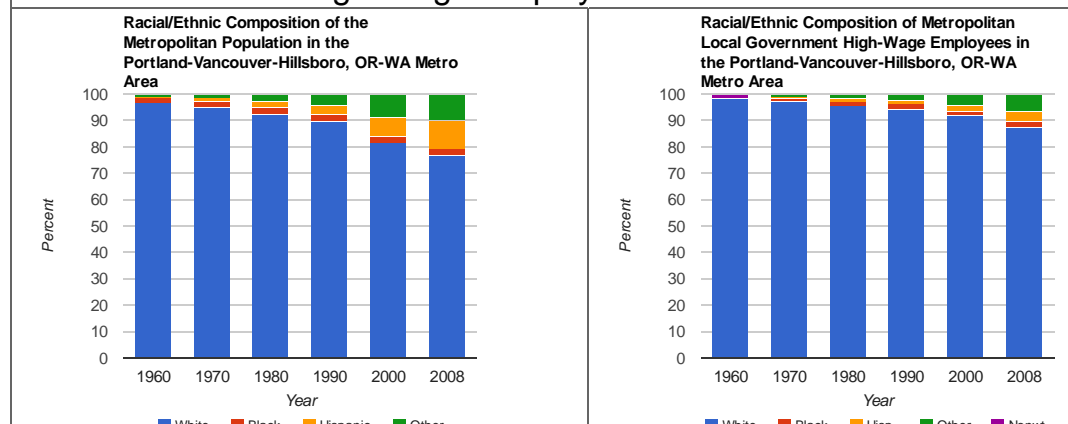

Local Government High-Wage Employees in the Central City
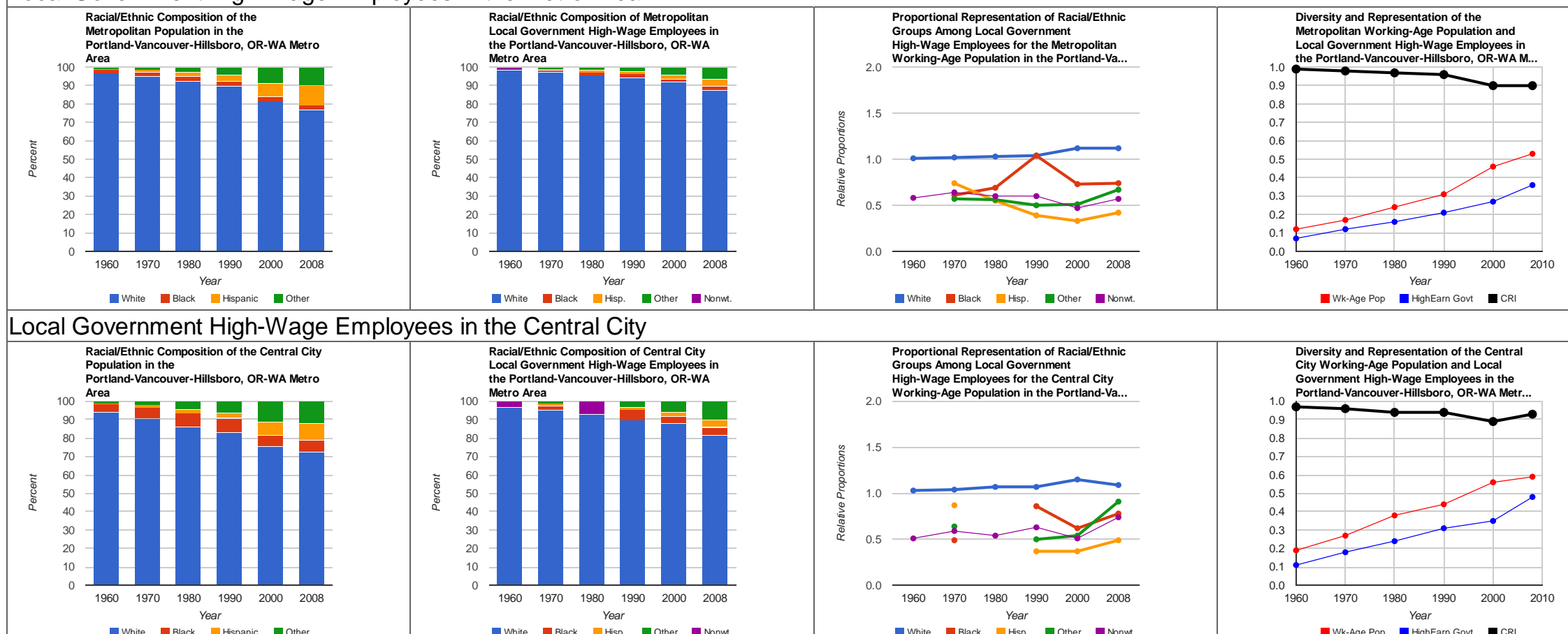

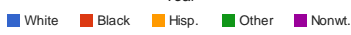

-Wk-Age Pop HighEarn Govt M Cr

White $\square$ Black Hispanic $\quad$ Other

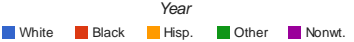

Groups Among Lecentation of Raciallethnic High-Wage Employees for the Central City
Working-Age Population in the Portland-Va
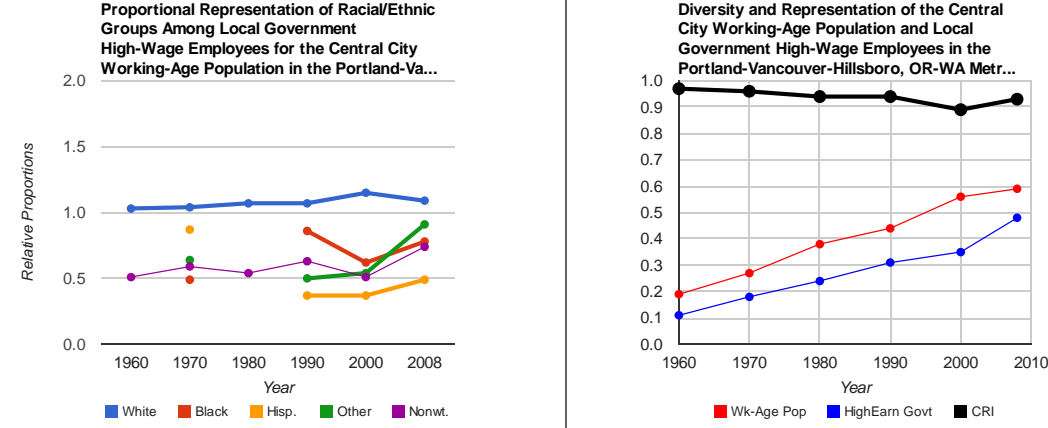
High- and Low-Wage Local Government Employment in the Portland-Vancouver-Hillsboro, OR-WA Metro Area Local Government Low-Wage Employees in the Metro Area
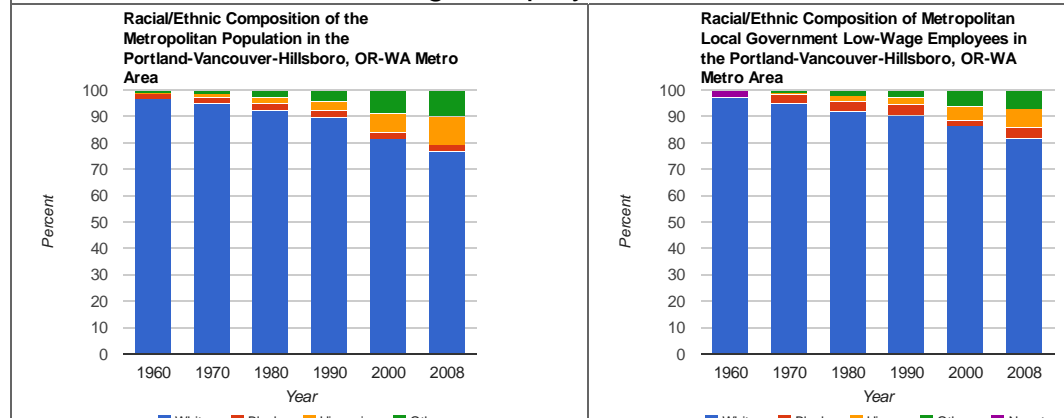

Local Government Low-Wage Employees in the Central City
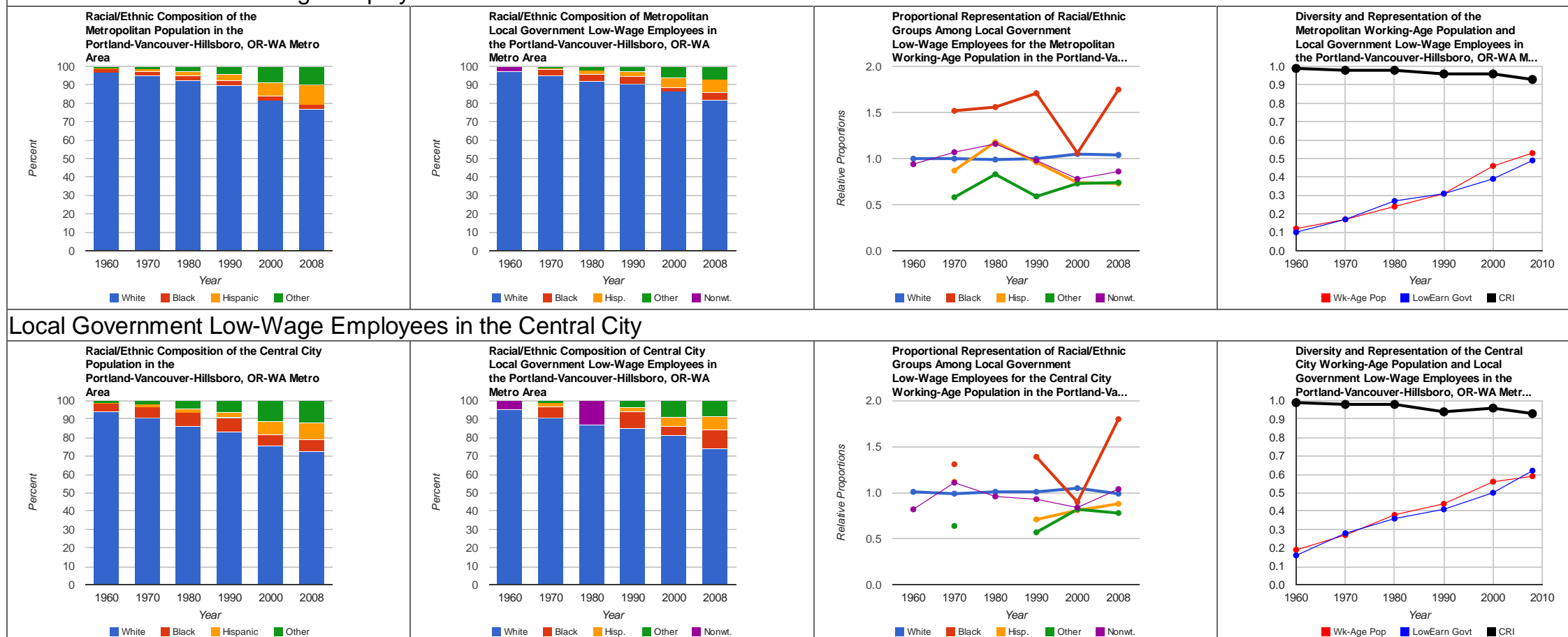

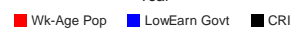

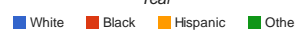

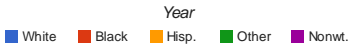

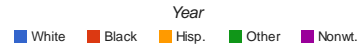

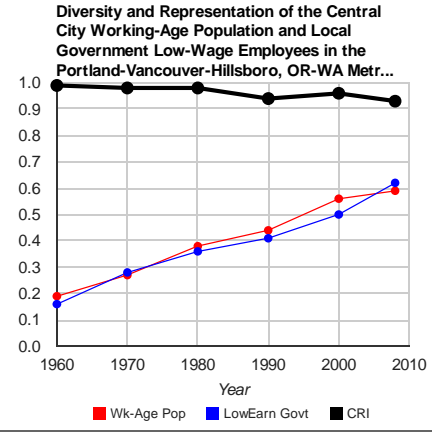




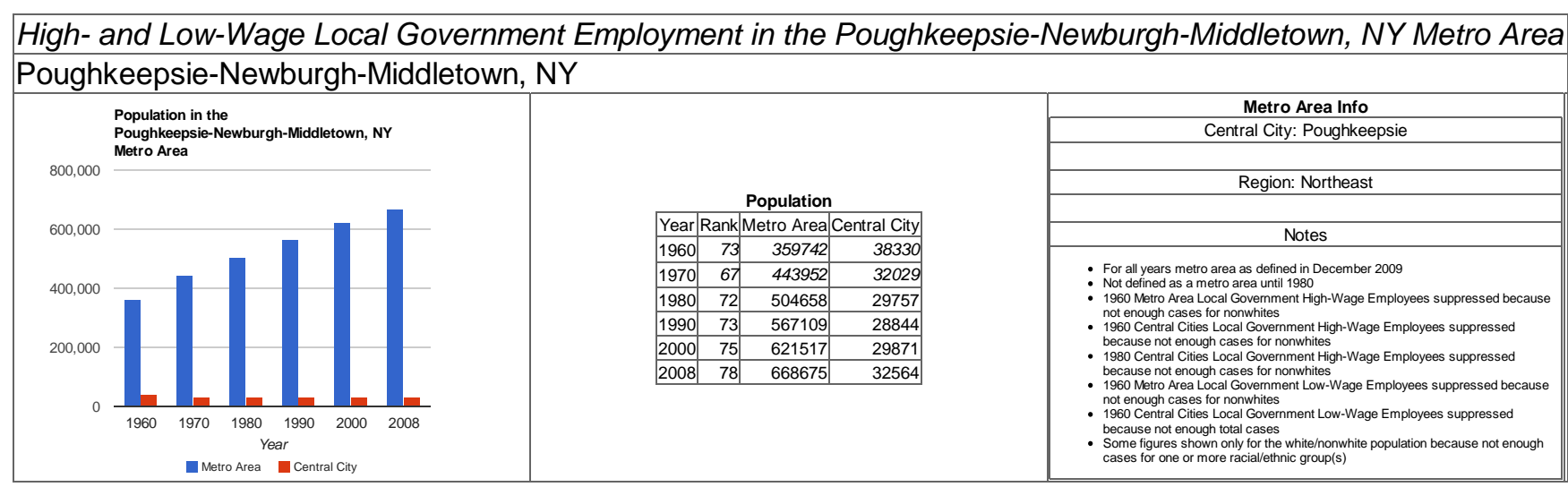


High- and Low-Wage Local Government Employment in the Poughkeepsie-Newburgh-Middletown, NY Metro Area Local Government High-Wage Employees in the Metro Area

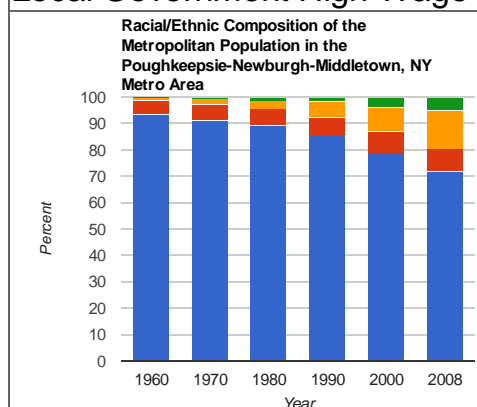

White Black Hispanic nother

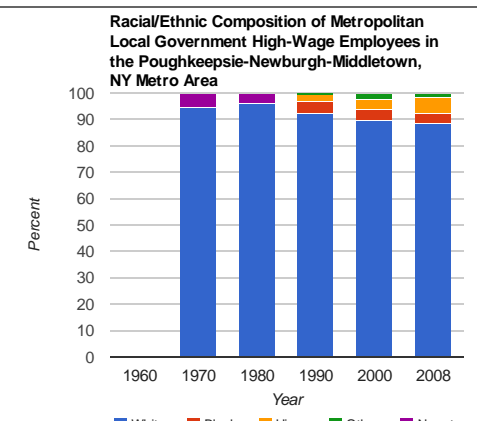

WWhite Black rear

Local Government High-Wage Employees in the Central City

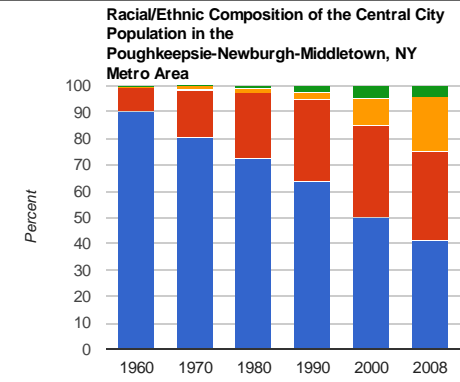

White Black Hear

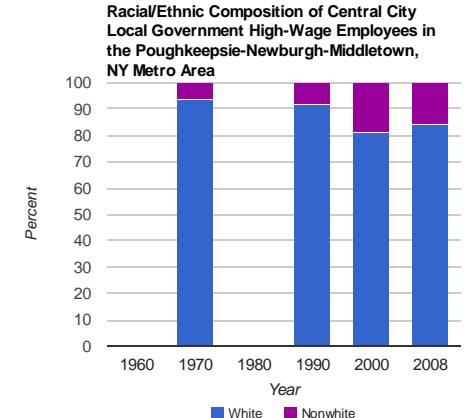

White ${ }_{\text {Nonnwite }}$

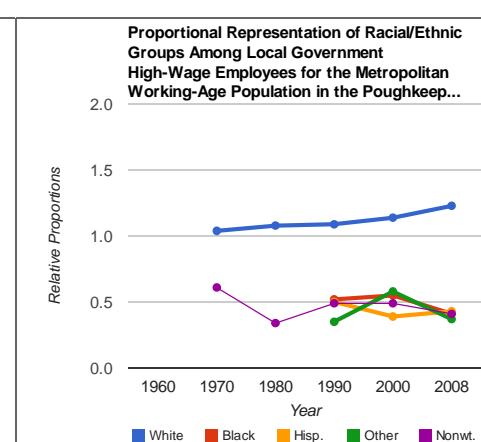

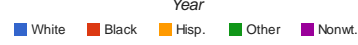

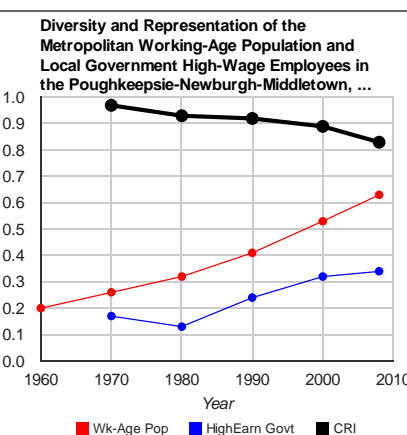

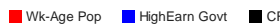

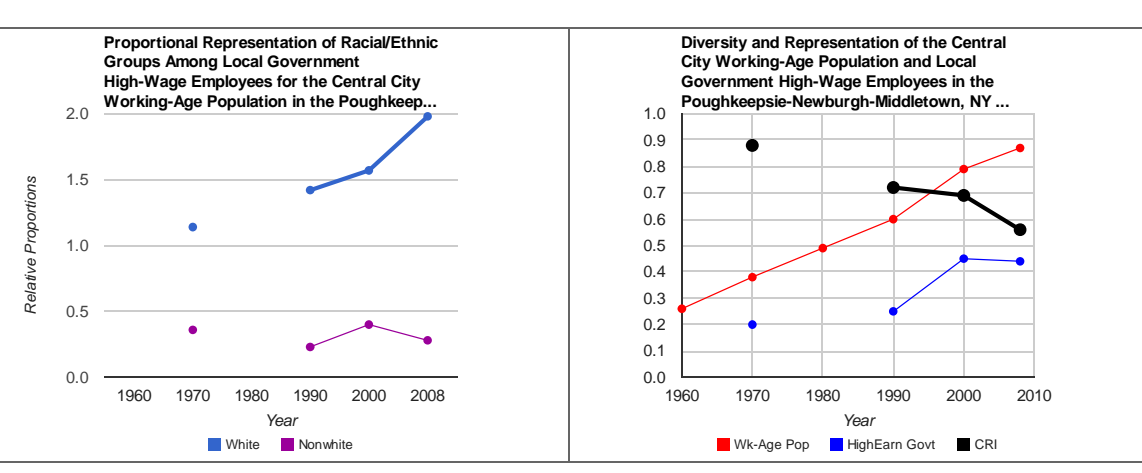


High- and Low-Wage Local Government Employment in the Poughkeepsie-Newburgh-Middletown, NY Metro Area Local Government Low-Wage Employees in the Metro Area

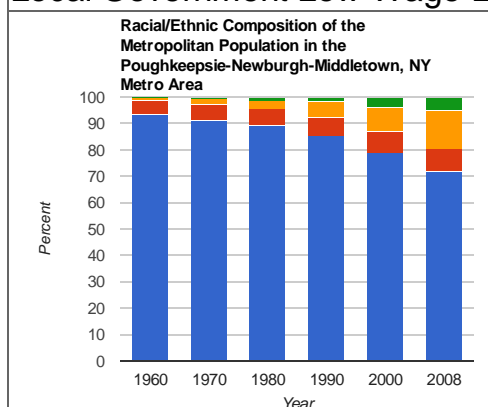

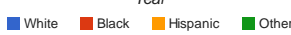

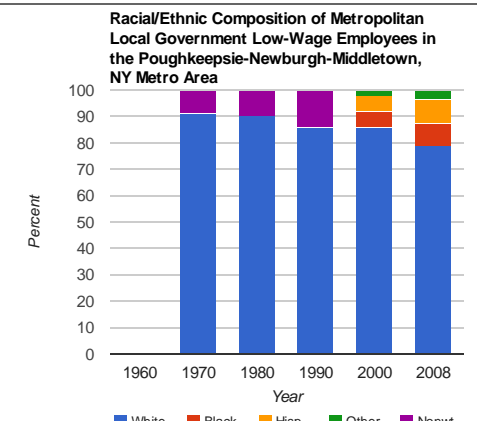

White Year

Local Government Low-Wage Employees in the Central City

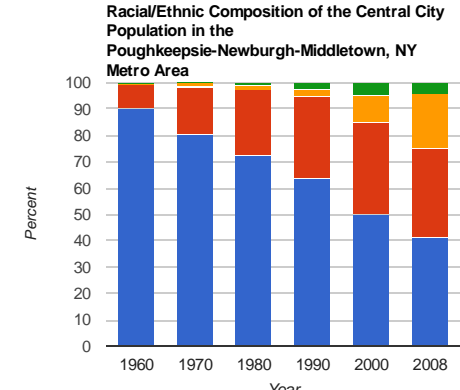

White Black Hear Hispanic

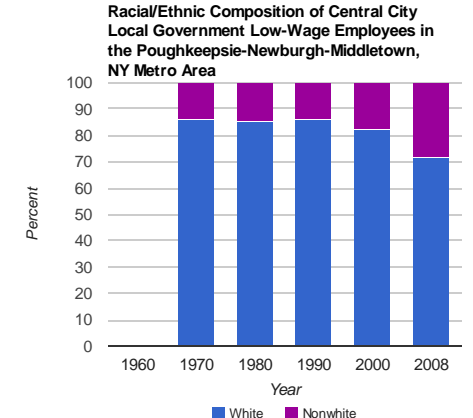

White ${ }_{\text {Nonnwite }}$
Proportional Representation of RaciallEthn

Groups Among Local Government

2.0 Working-Age Population in the Poughkeep..

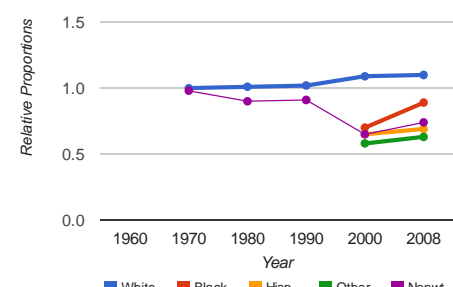

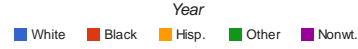

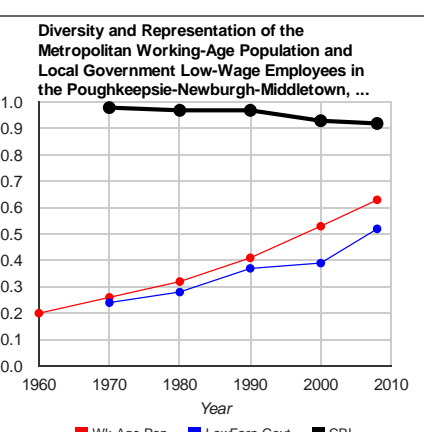

- Wk-Age Pop L LowEarn Govt - CPRI
Proportional Representation of Raciall/Ethnic
Groups Among Local Government Groups Among Local Government
Low-Wage Employees for the Central City Low-Wag- Employees tor the Central City
Working-Age Population in the Poughkeep.

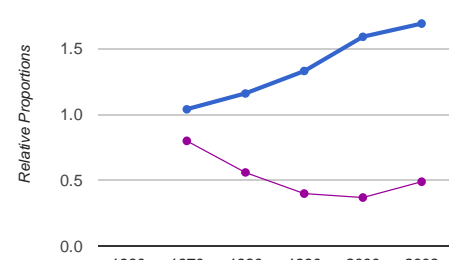

$0 . 0 \longdiv { 1 9 6 0 } \quad 1 9 7 0 \quad 1 9 8 0 \quad 1 9 9 0 \quad 2 0 0 0 \quad 2 0 0 8$ White 1 Nonunhite

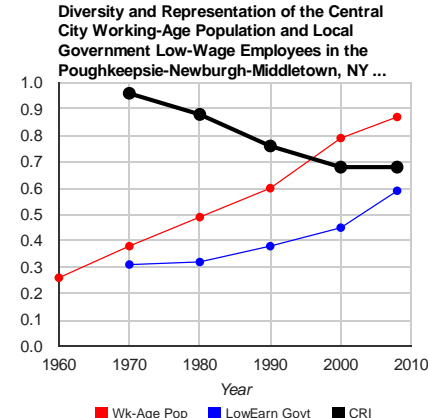

-Wk-Age Pop L LowEarn Govt 


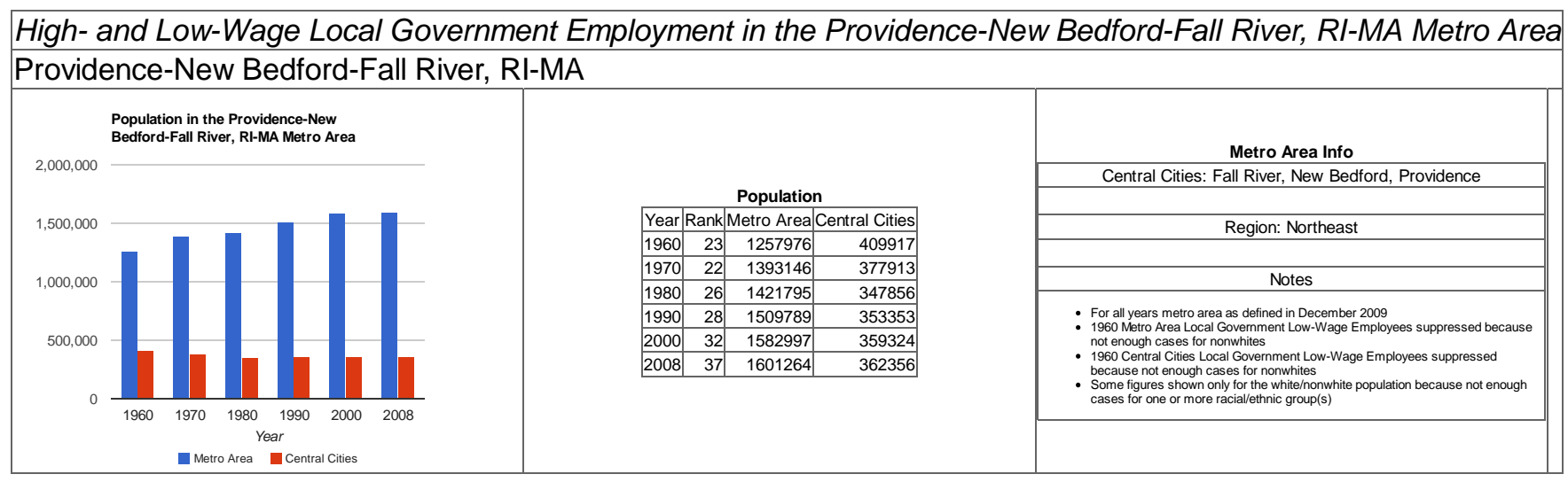


High- and Low-Wage Local Government Employment in the Providence-New Bedford-Fall River, RI-MA Metro Area Local Government High-Wage Employees in the Metro Area
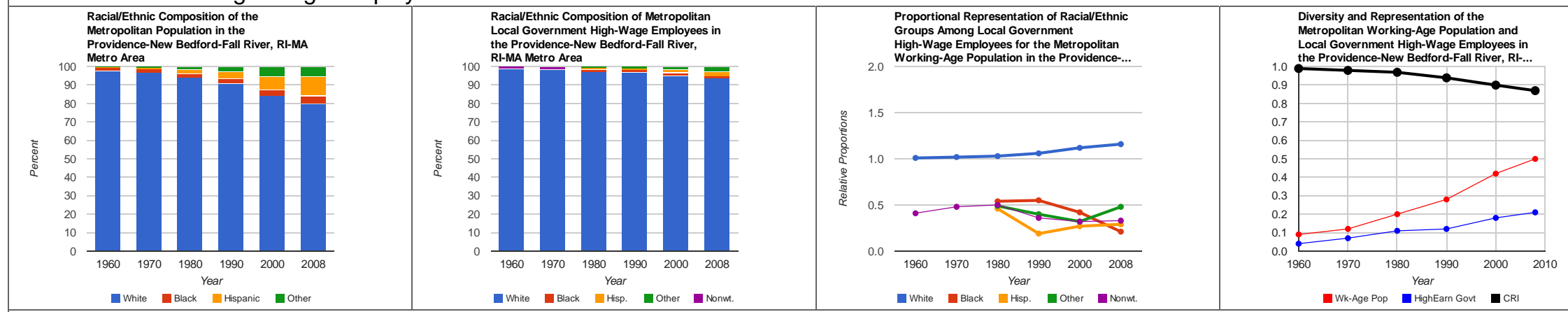

Local Government High-Wage Employees in the Central Cities
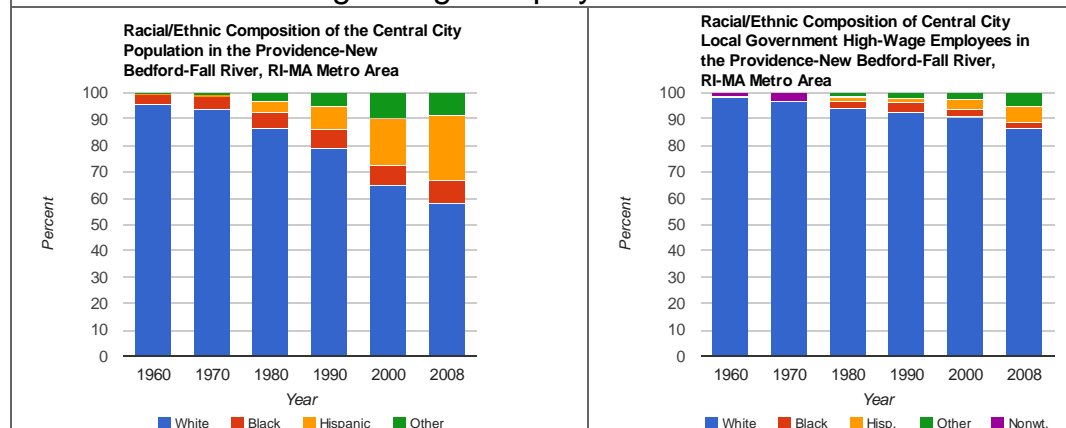

Proportional Representation of RaciallEthnic Groups Among Local Government
High-Wage Employees for the Central 20 Working-Age Population in the Providence-... White Elack YHispanic Inother

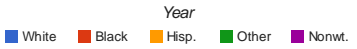
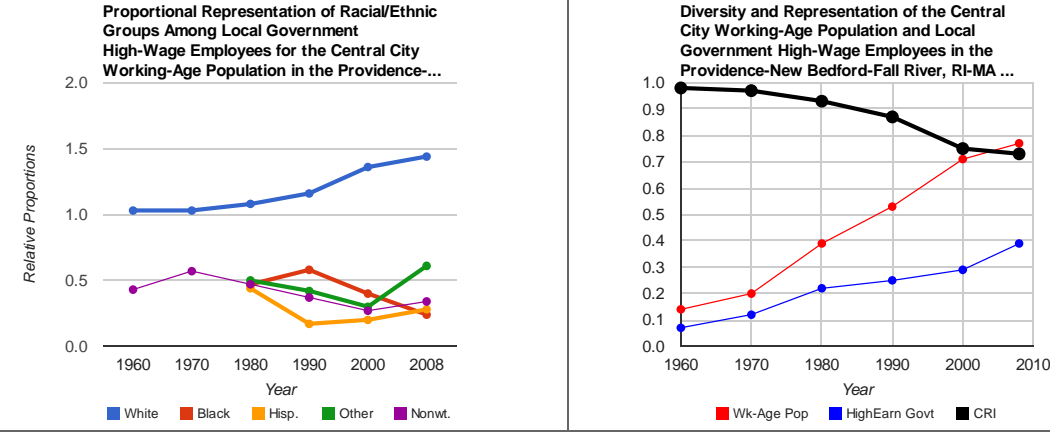
High- and Low-Wage Local Government Employment in the Providence-New Bedford-Fall River, RI-MA Metro Area Local Government Low-Wage Employees in the Metro Area

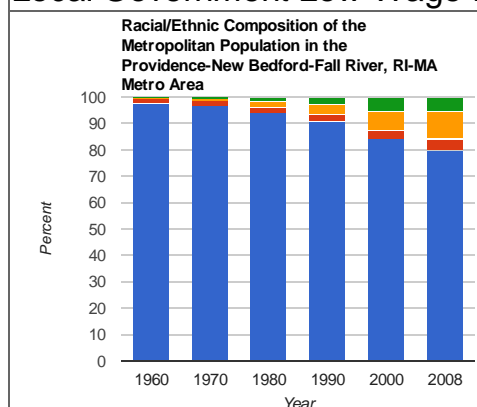

White Black Hispanic nother

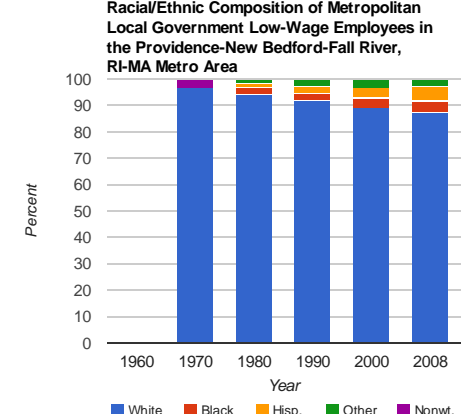

White Black Year

Local Government Low-Wage Employees in the Central Cities

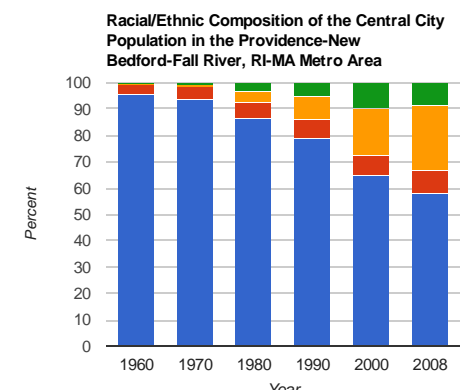

White Black Hispanic Wother

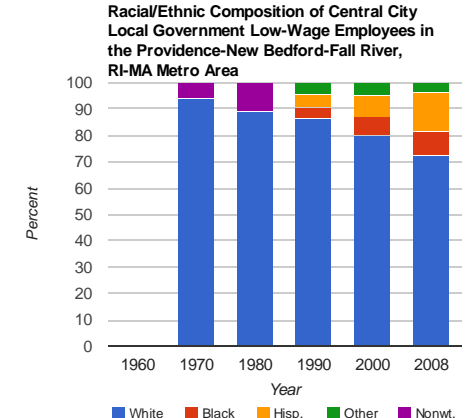

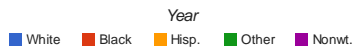

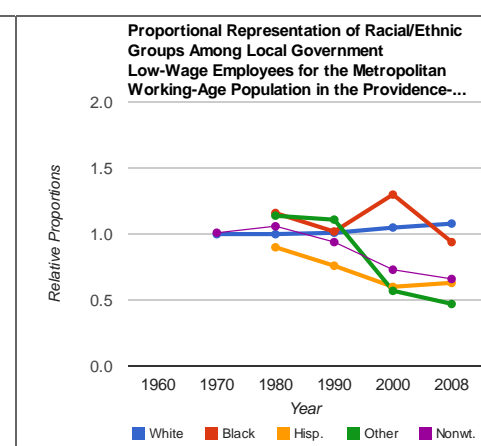

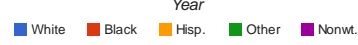

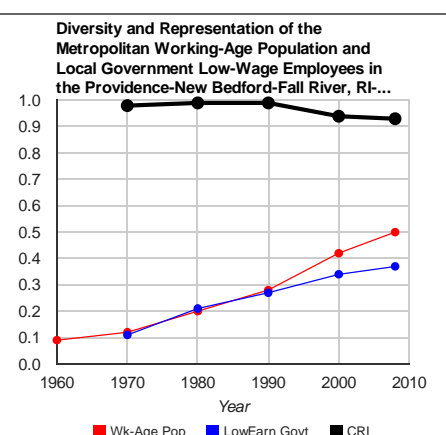

Wh-Age Pop Lowearn Govt MCR
Proportional Representation of RaciallEthnic
Groups Among Local Government Groups Among Local Government
Low-Wage Employees for the Central City 2.0 Working-Age Population in the Providence-...
Wow

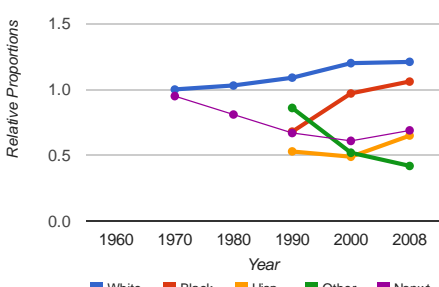

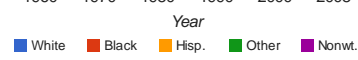

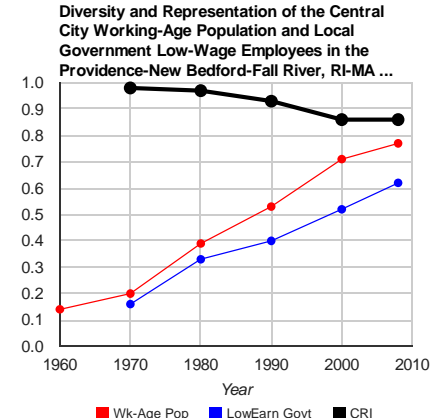

-Wk-Age Pop —L LowEarn Govt - 


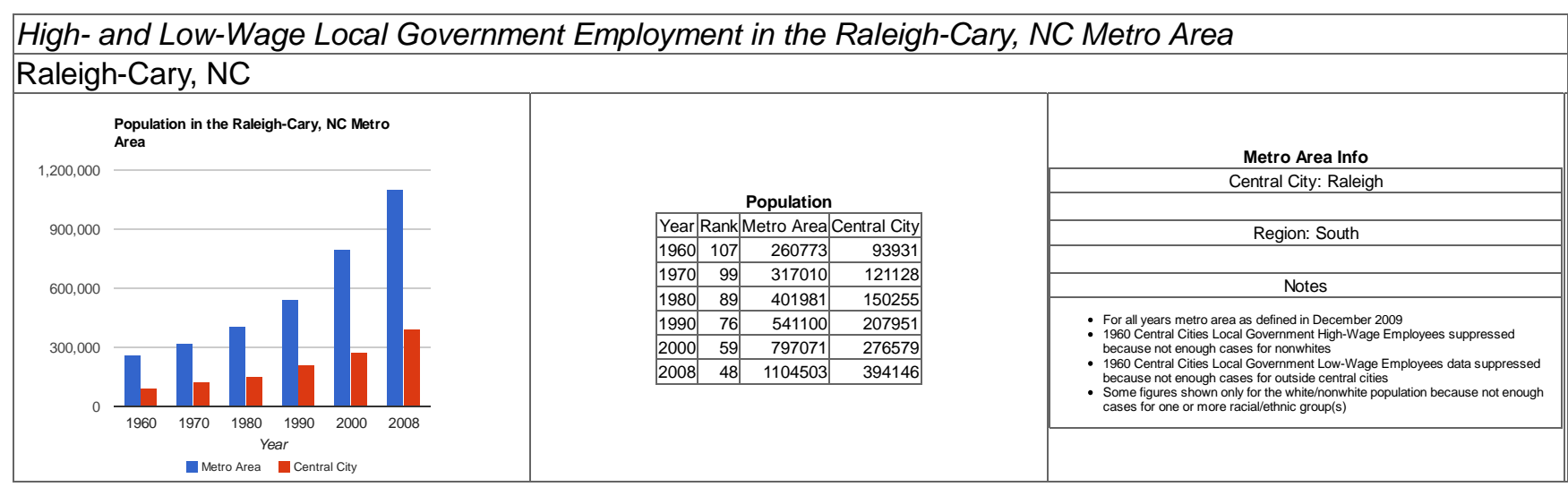


High- and Low-Wage Local Government Employment in the Raleigh-Cary, NC Metro Area

Local Government High-Wage Employees in the Metro Area
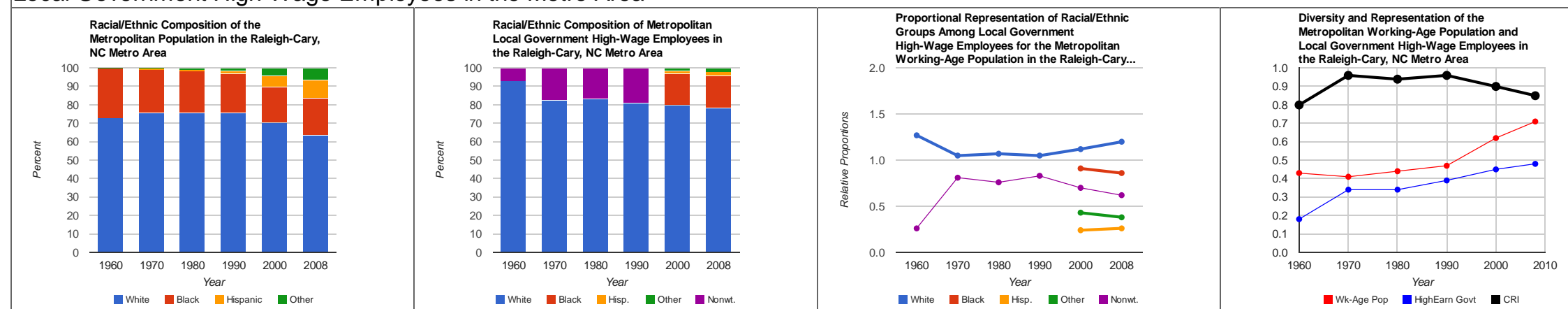

Local Government High-Wage Employees in the Central City
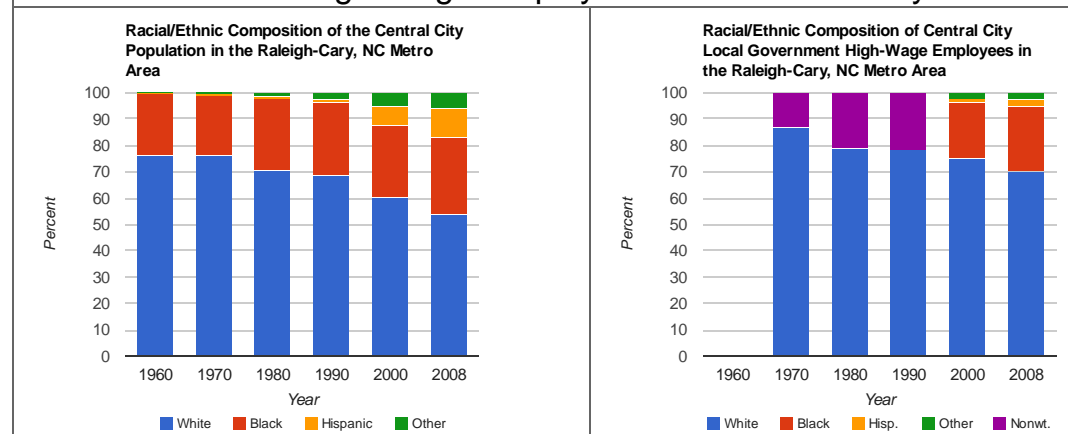
Proportional Representation of Racial//Ethnic
Groups Among Local Government
High-W age Employees for the Central City 20 Working-Age Population in the Raleigh-Cary... White Ilack Hear Hispanic nother

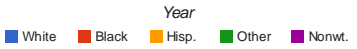
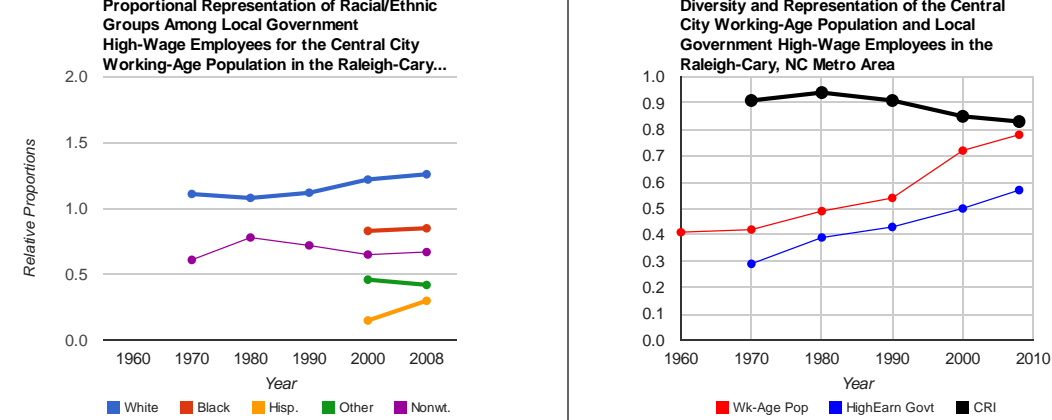
High- and Low-Wage Local Government Employment in the Raleigh-Cary, NC Metro Area

Local Government Low-Wage Employees in the Metro Area
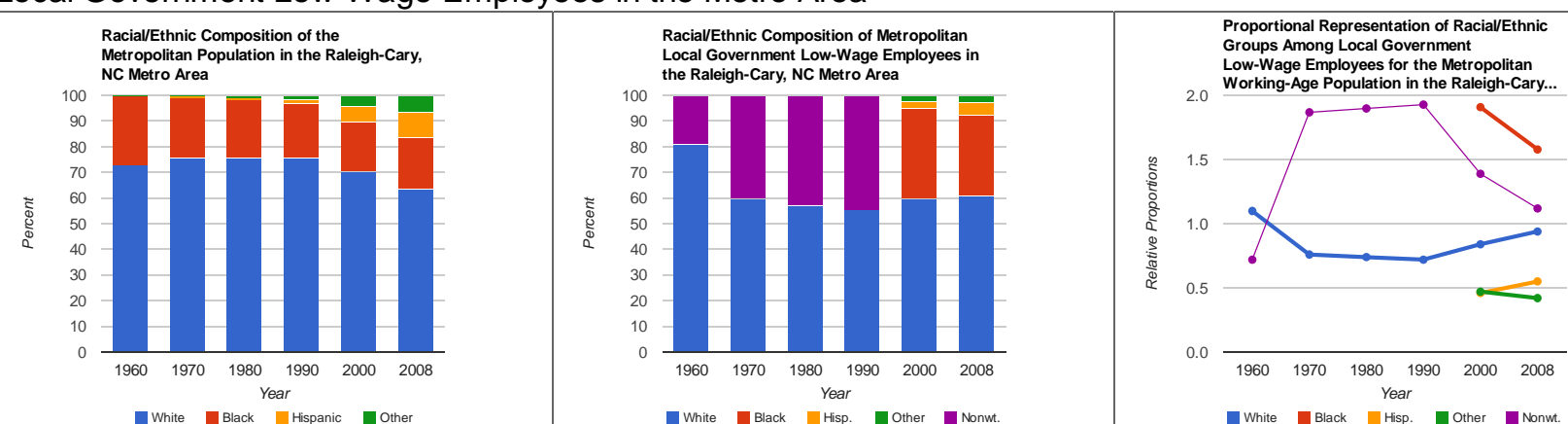
Diversity and Representation of the
Metropolitan Working-Age Population and

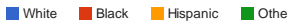

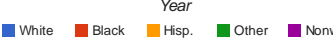

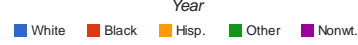

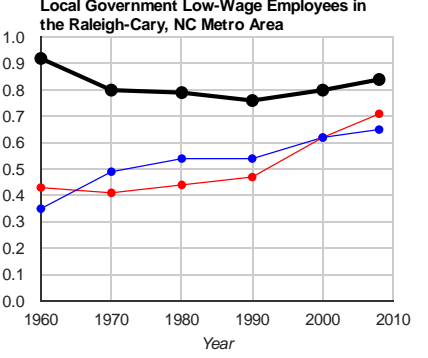

Local Government Low-Wage Employees in the Central City

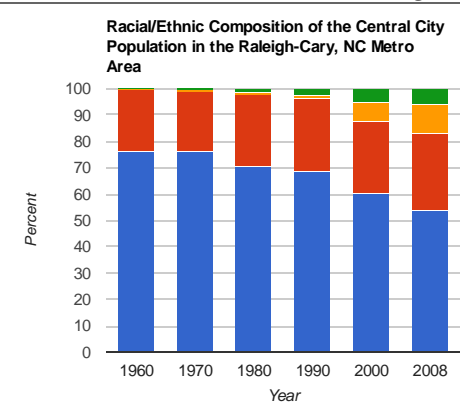

Racial/Ethnic Composition of Central City
Local Govich Proportional Representation of Racial//Ethnic
Groups Among Local Government
Low-Wage Employees for the Central City Working-Age Population in the Raleigh-Cary..

- Wk-Age Pop LowEarn Gout
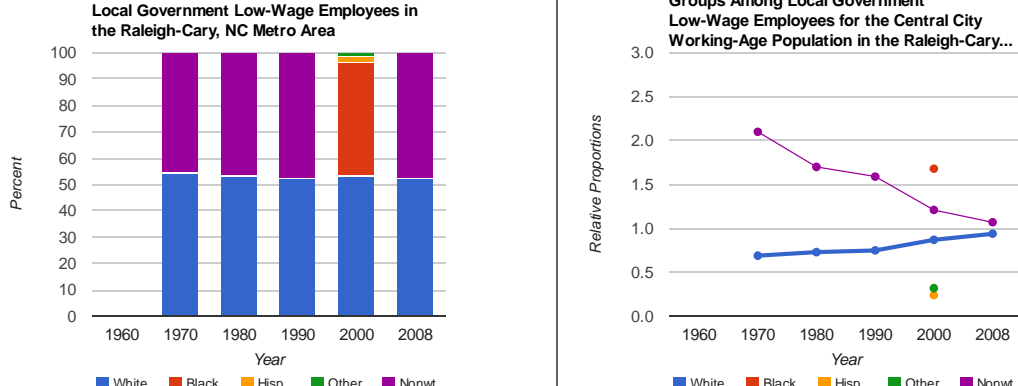

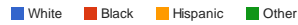

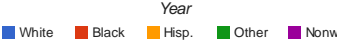

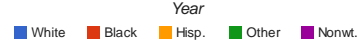

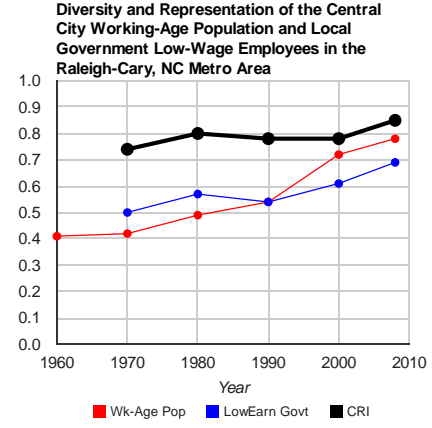




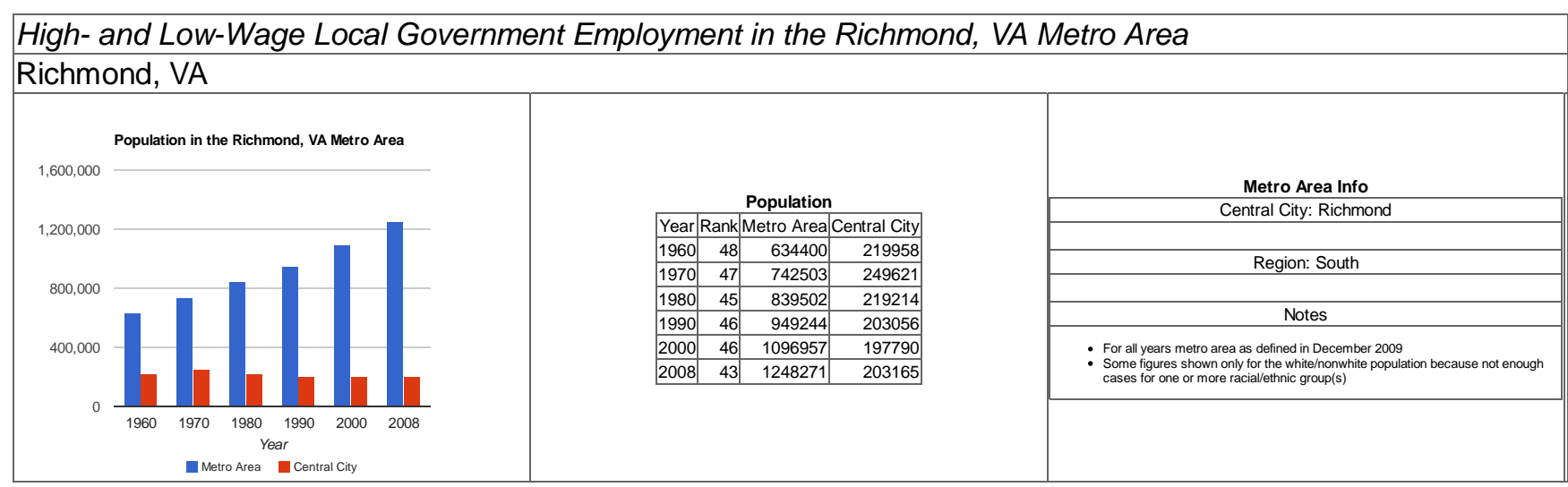


High- and Low-Wage Local Government Employment in the Richmond, VA Metro Area

Local Government High-Wage Employees in the Metro Area
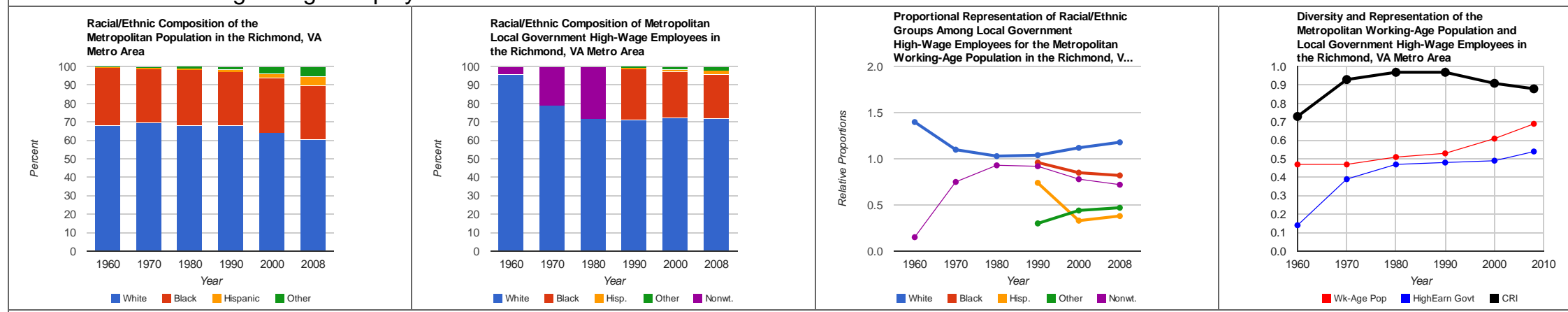

Local Government High-Wage Employees in the Central City
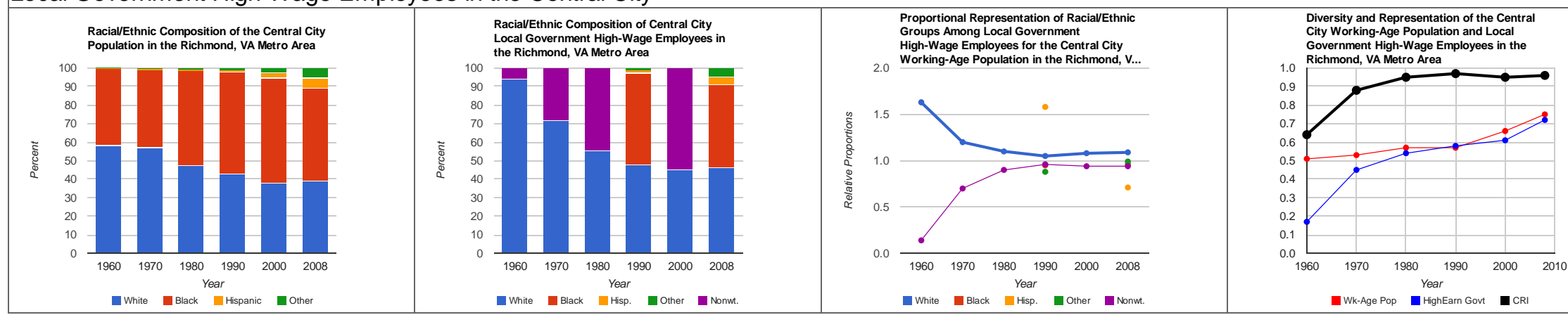
High- and Low-Wage Local Government Employment in the Richmond, VA Metro Area

Local Government Low-Wage Employees in the Metro Area
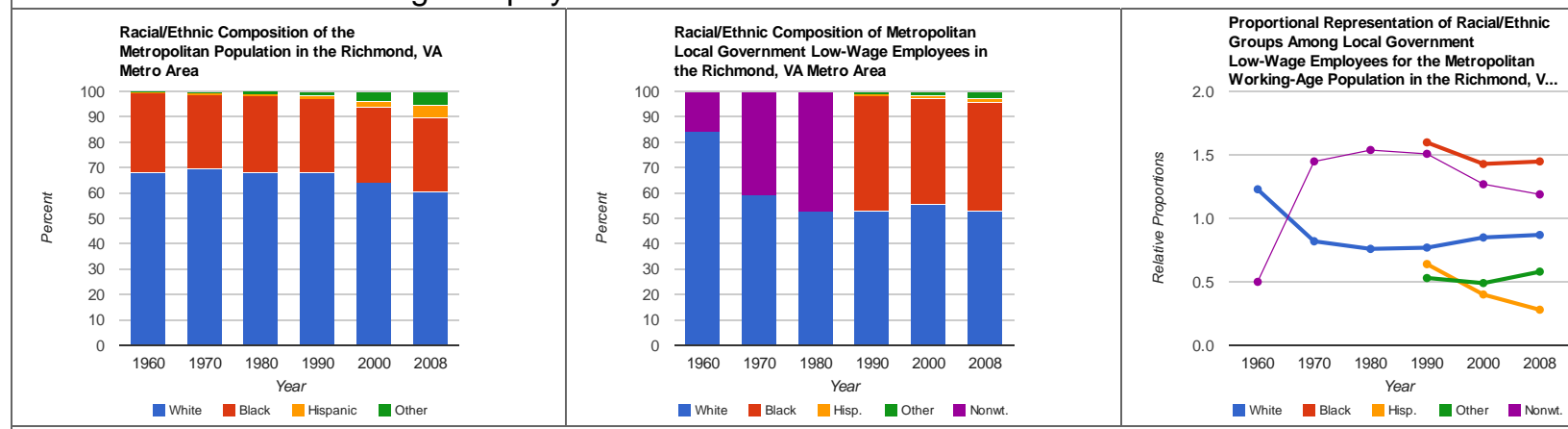

Diversity and Representation of the
Metropolitan Working-Age Population and
Local Government Low-Wage Employees

the Richmond, VA Metro Area

White Black Henspanic

White Black Hisp. Other Monw.

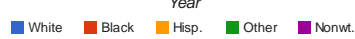

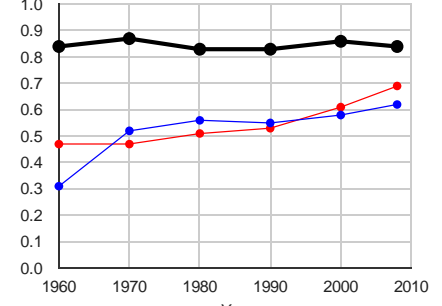

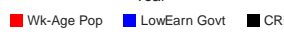

Local Government Low-Wage Employees in the Central City

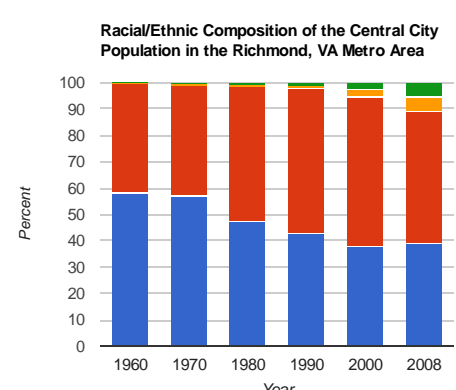

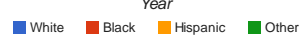

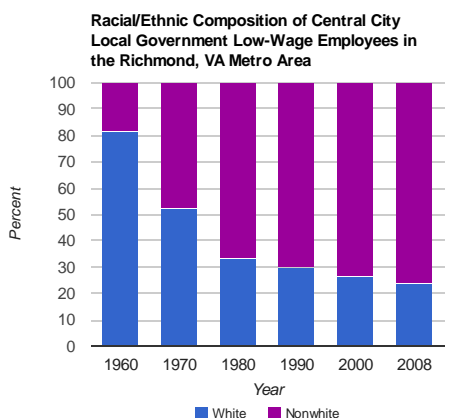

White ${ }^{-10}$ Nonwhite
Proportional Representation of Racial/Ethnic Groups Among Local Government Working-Age Population in the Richmond, $v$...

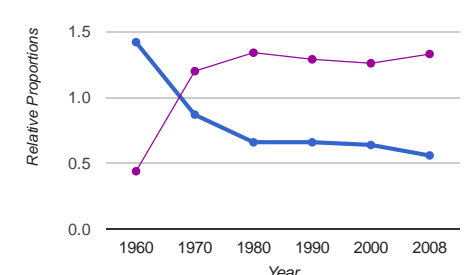

White ${ }_{\text {Nonumite }}$
Diversity and Representation of the Central City Working-Age Population and Local

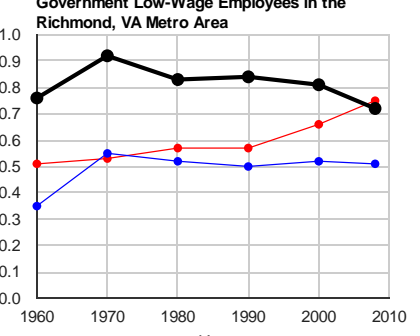

- Wh-Age Pop LowEarn Govt - CRI 


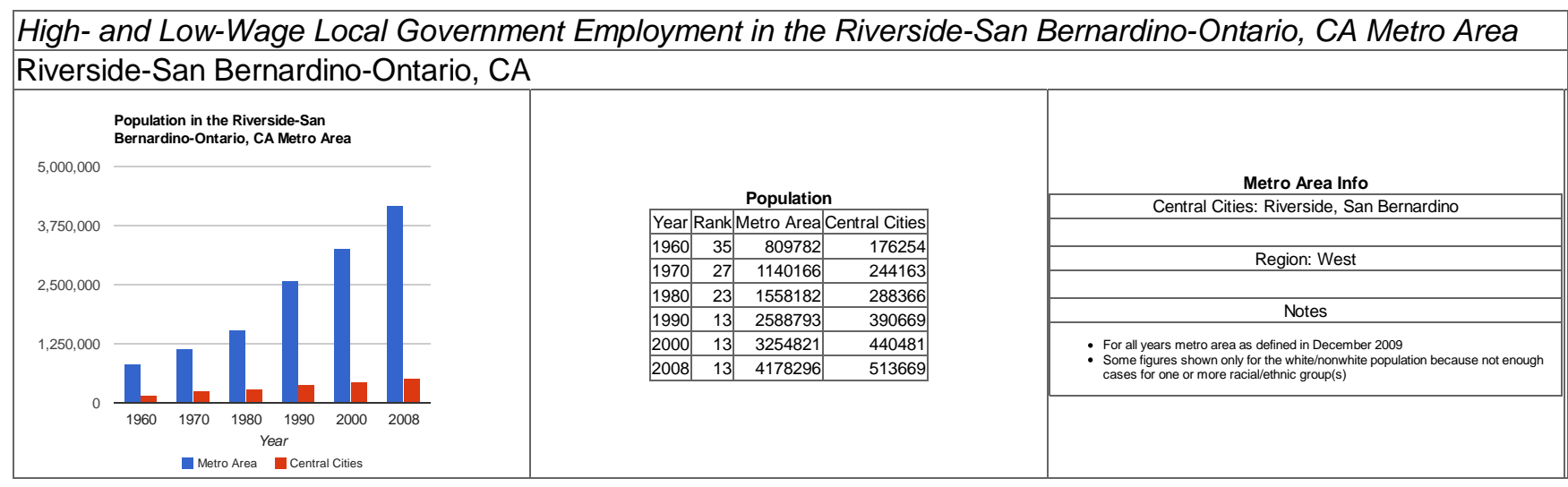


High- and Low-Wage Local Government Employment in the Riverside-San Bernardino-Ontario, CA Metro Area Local Government High-Wage Employees in the Metro Area
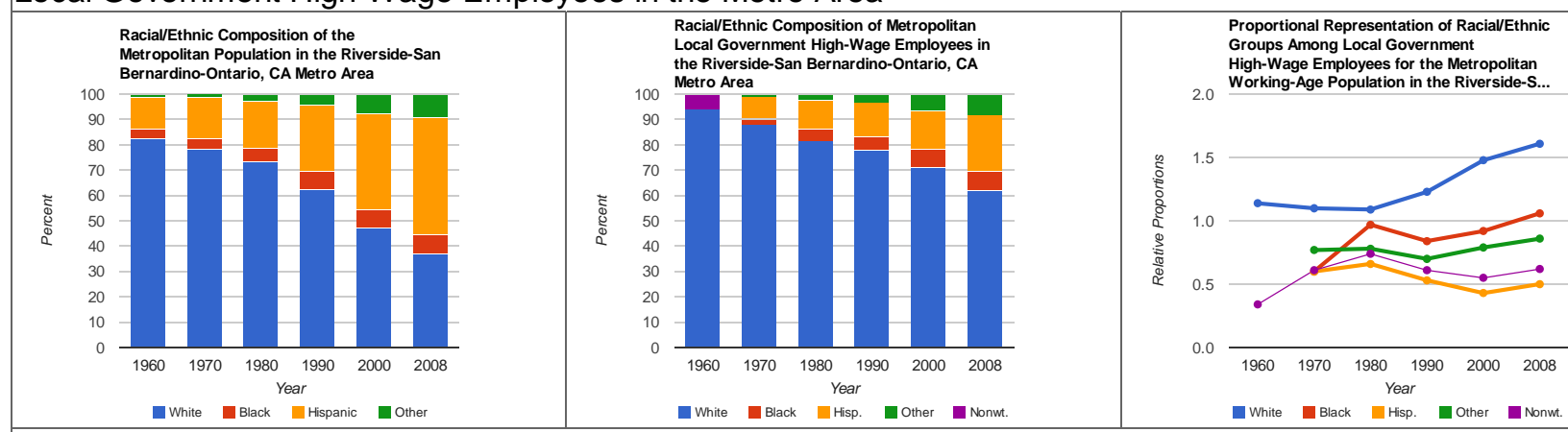
Diversity and Representation of the
Metropolitan Working-Agge Population and the Riverside-San Bernardino-Ontario, CA...

White Black Hispanic Wother

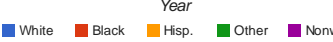

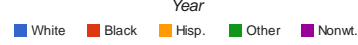

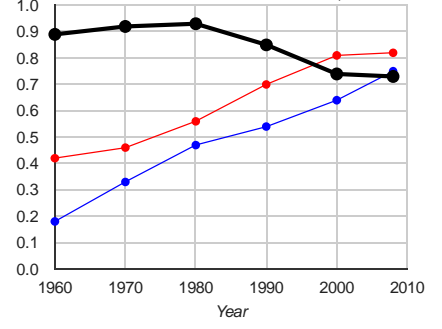

Local Government High-Wage Employees in the Central Cities
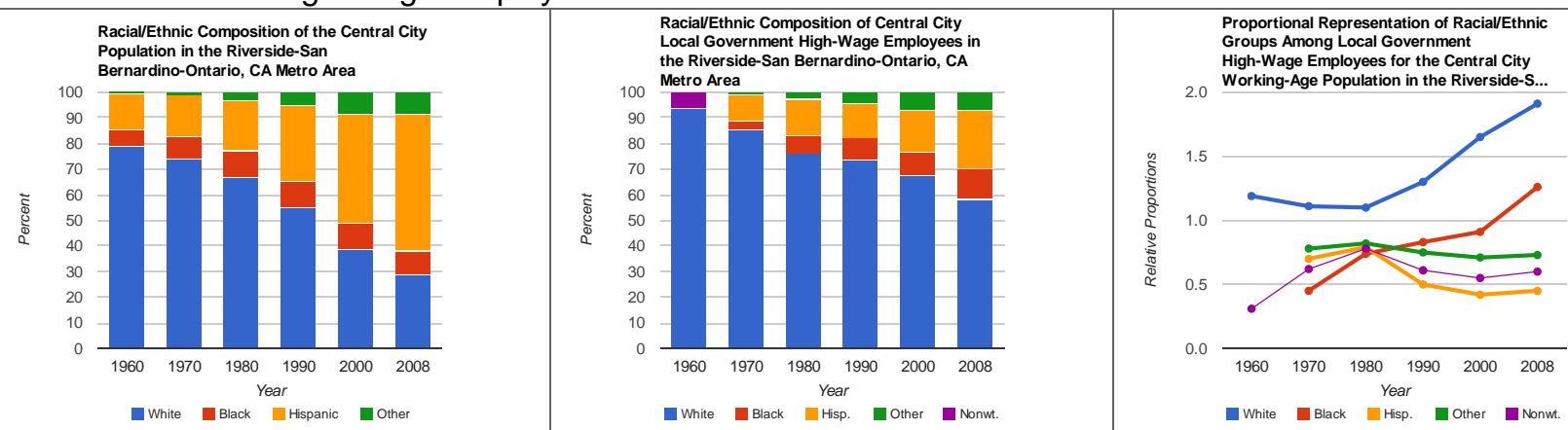
Diversity and Representation of the Central
City Working-Age Population and Local
Government High-Wage Employees in the Government High-Wage Employees in the
Riverside-San Bernardino-ontario, CA Metr..

- White Black Hear Hispanic \#other

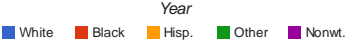

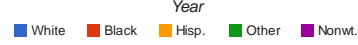

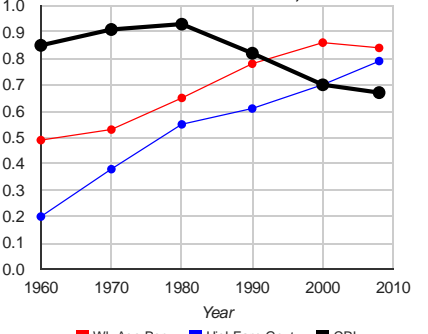

- Wk-Age Pop - Highearn Govt 
High- and Low-Wage Local Government Employment in the Riverside-San Bernardino-Ontario, CA Metro Area Local Government Low-Wage Employees in the Metro Area
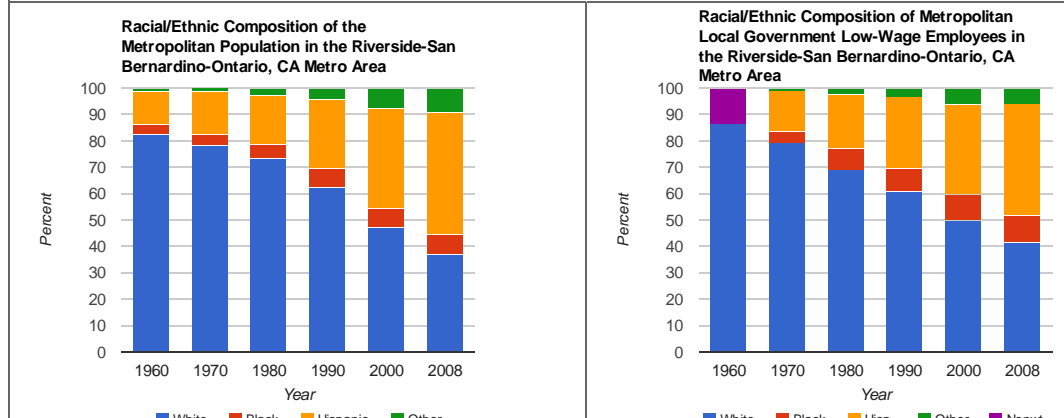

Local Government Low-Wage Employees in the Central Cities
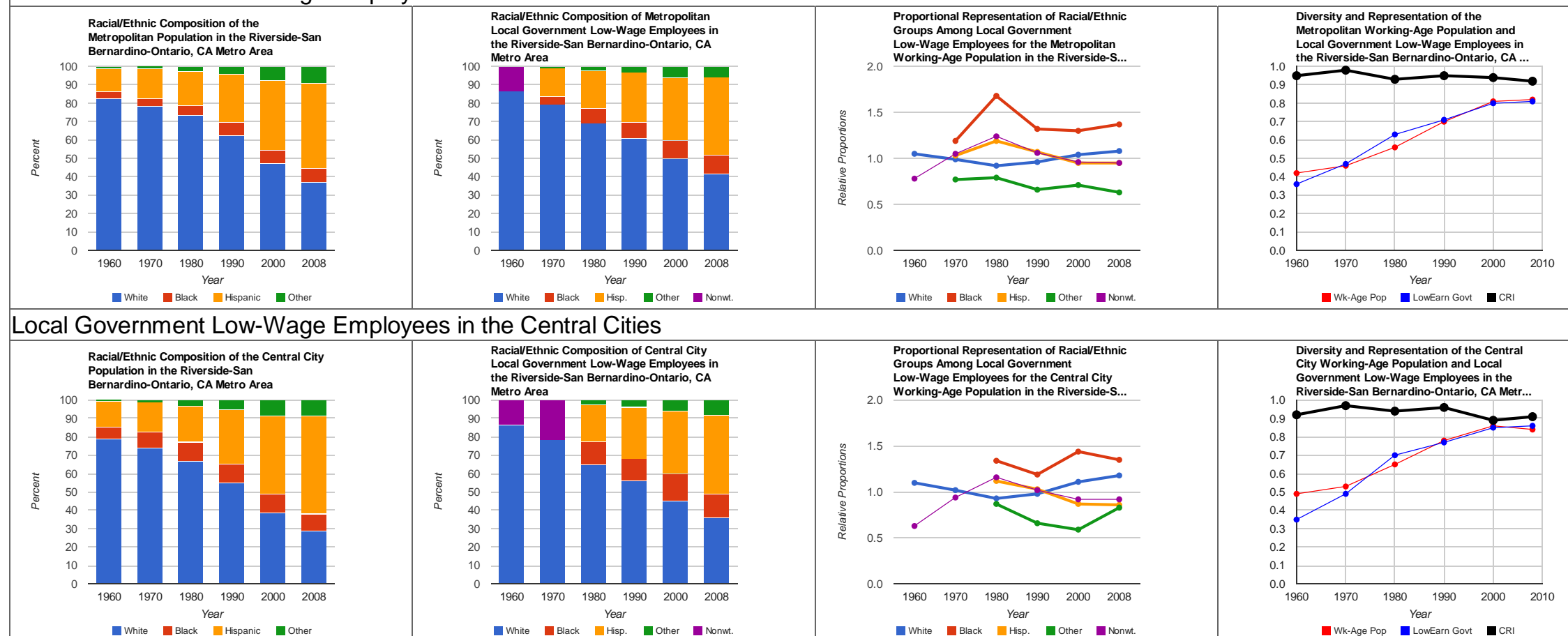

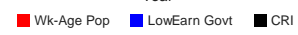

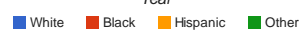

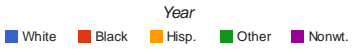

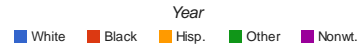

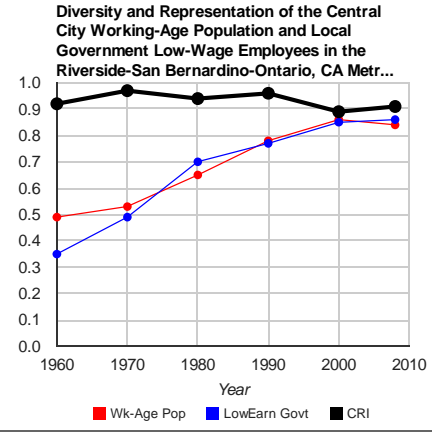


High- and Low-Wage Local Government Employment in the Rochester, NY Metro Area

Rochester, NY

Population in the Rochester, NY Metro Area

$1,200,000$

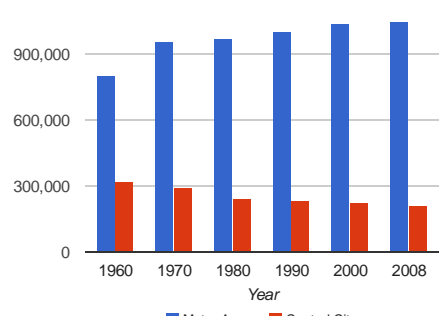

Population

Year Rank Metro Area Central City

\begin{tabular}{|l|l|l|r|}
\hline 1960 & 36 & 800658 & 318611 \\
\hline 1970 & 37 & 961516 & 26233 \\
\hline
\end{tabular}

\begin{tabular}{|l|l|l|l|l|}
1970 & 37 & 961516 & 296233 \\
\hline 1980 & 40 & 971230 & 241741 \\
\hline
\end{tabular}

\begin{tabular}{r|r|r|r|r|}
1980 & 40 & 971230 & 241741 \\
\hline 1990 & 43 & 1002410 & 231636 \\
\hline
\end{tabular}

\begin{tabular}{|l|r|r|r|}
12000 & 49 & 1037831 & 219700 \\
\hline
\end{tabular}

\begin{tabular}{|l|l|l|l|}
\hline 2000 & 49 & 1037831 & 219766 \\
\hline 2008 & 51 & 1051879 & 211457 \\
\hline
\end{tabular}

Metro Area Info

Central City: Rochester

- Metro Area $\quad$ Central City

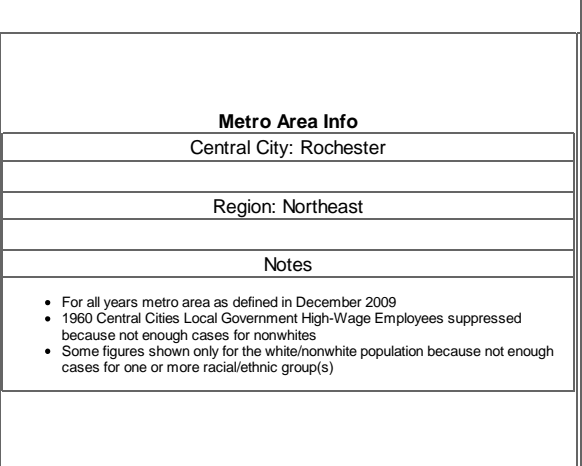


High- and Low-Wage Local Government Employment in the Rochester, NY Metro Area

Local Government High-Wage Employees in the Metro Area
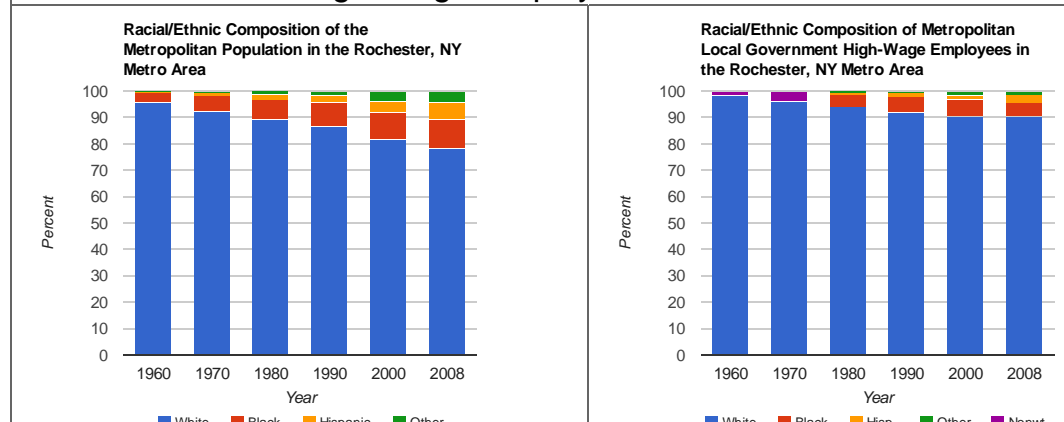

Local Government High-Wage Employees in the Central City

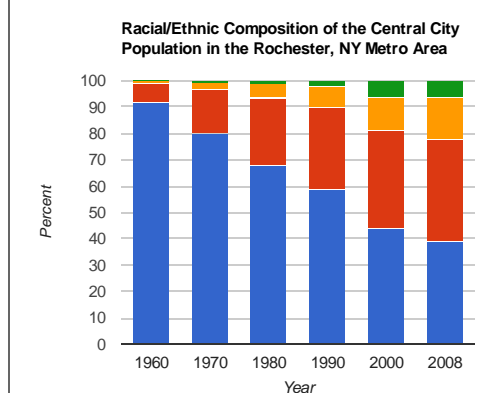

White Elack YHispanic Mother

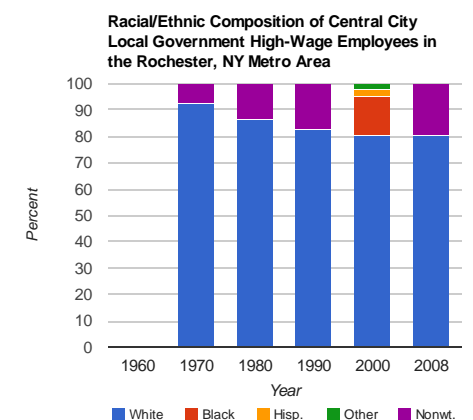

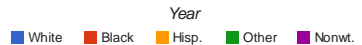

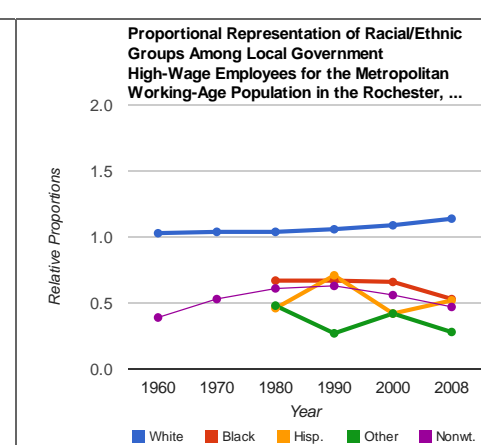

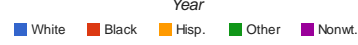

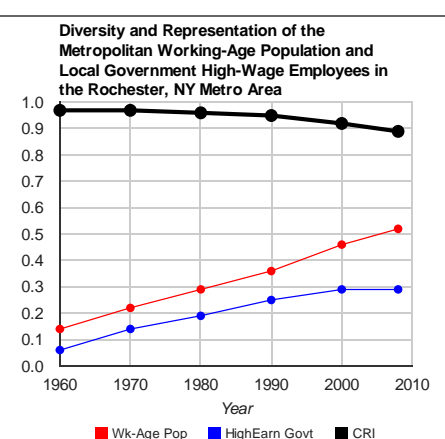

Wk-Age Pop MHighEarn Govt - CP
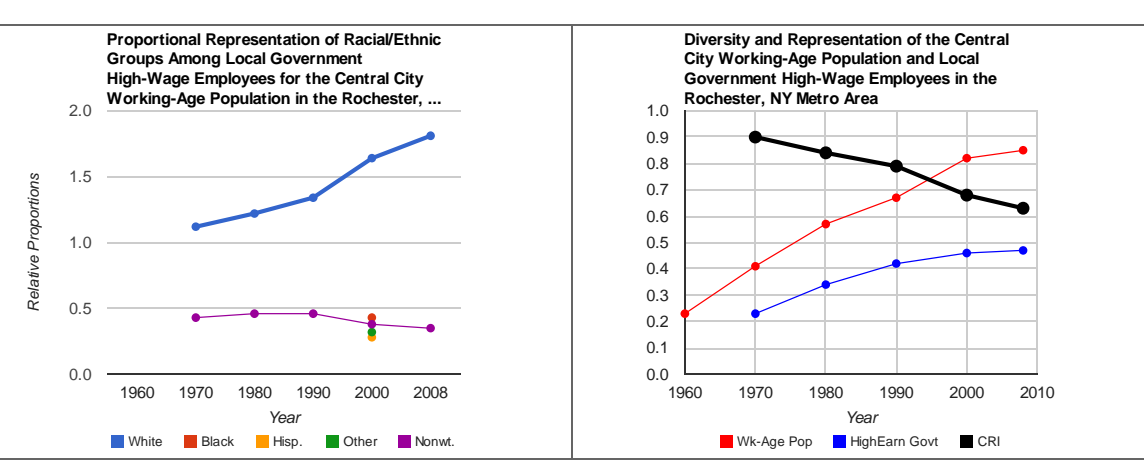
High- and Low-Wage Local Government Employment in the Rochester, NY Metro Area

Local Government Low-Wage Employees in the Metro Area
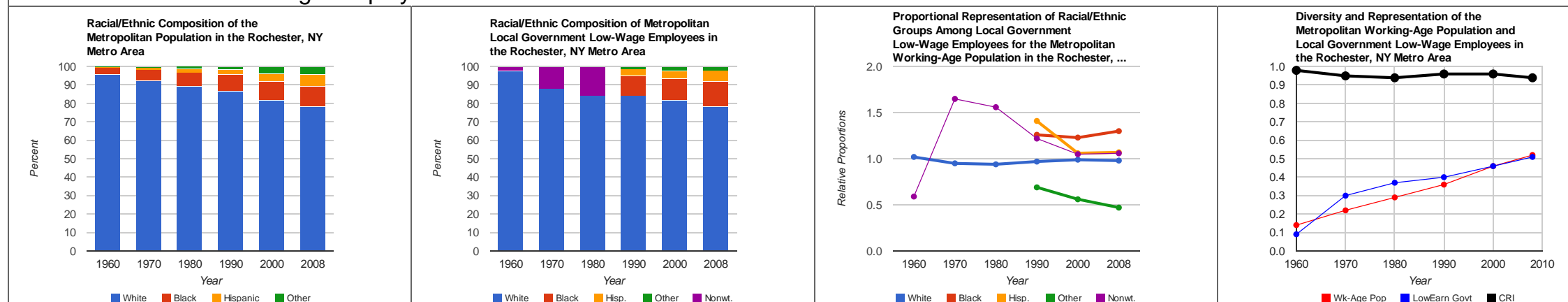

Local Government Low-Wage Employees in the Central City
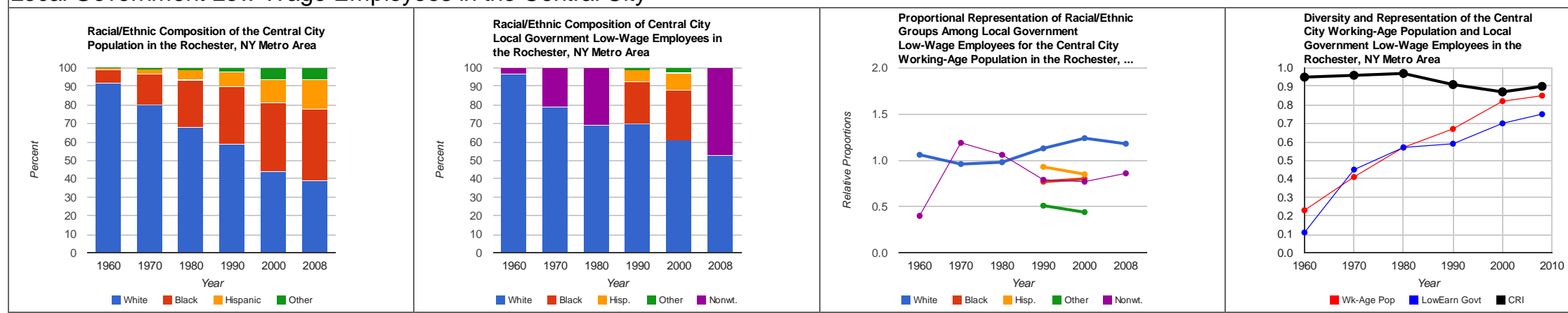
High- and Low-Wage Local Government Employment in the Sacramento--Arden-Arcade--Roseville, CA Metro Area Sacramento--Arden-Arcade--Roseville, CA

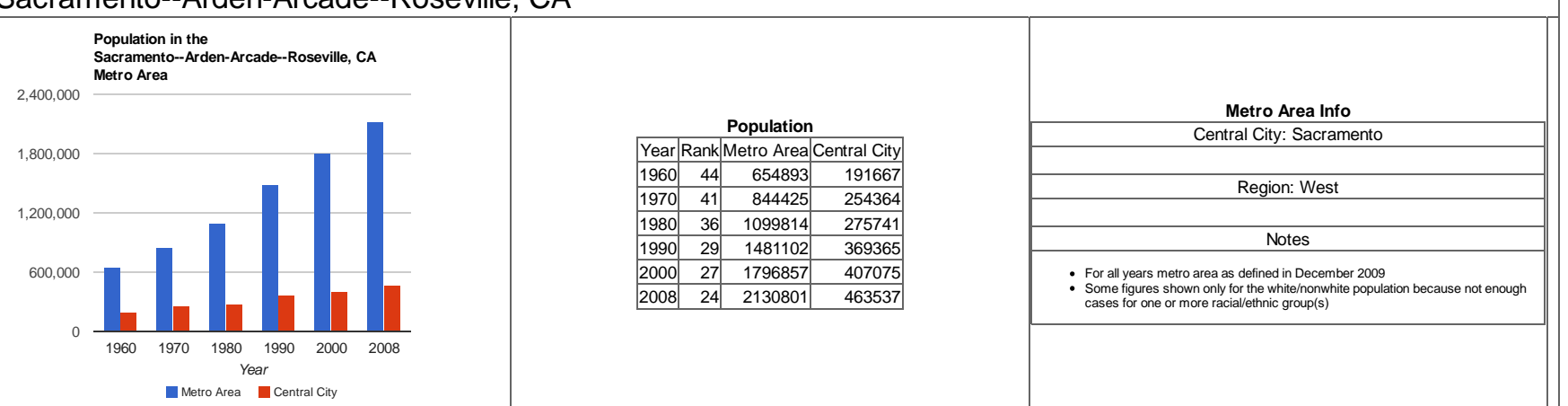


High- and Low-Wage Local Government Employment in the Sacramento--Arden-Arcade--Roseville, CA Metro Area Local Government High-Wage Employees in the Metro Area
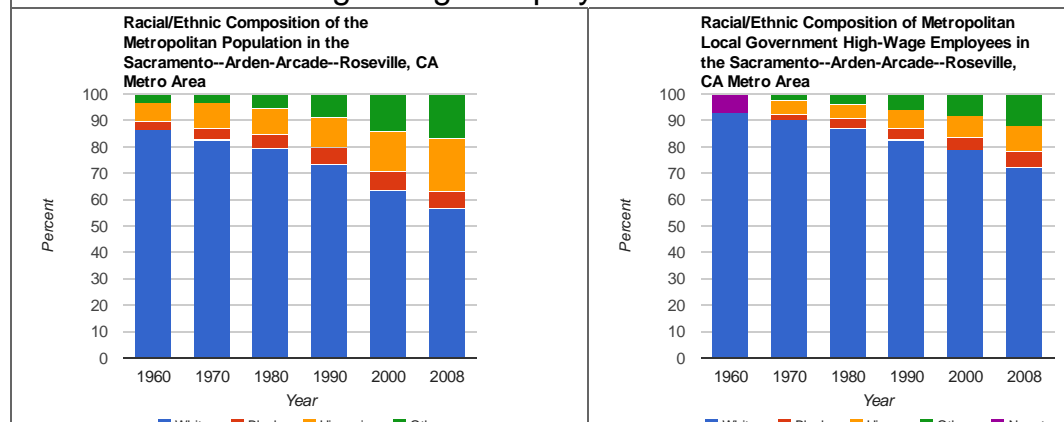

Local Government High-Wage Employees in the Central City
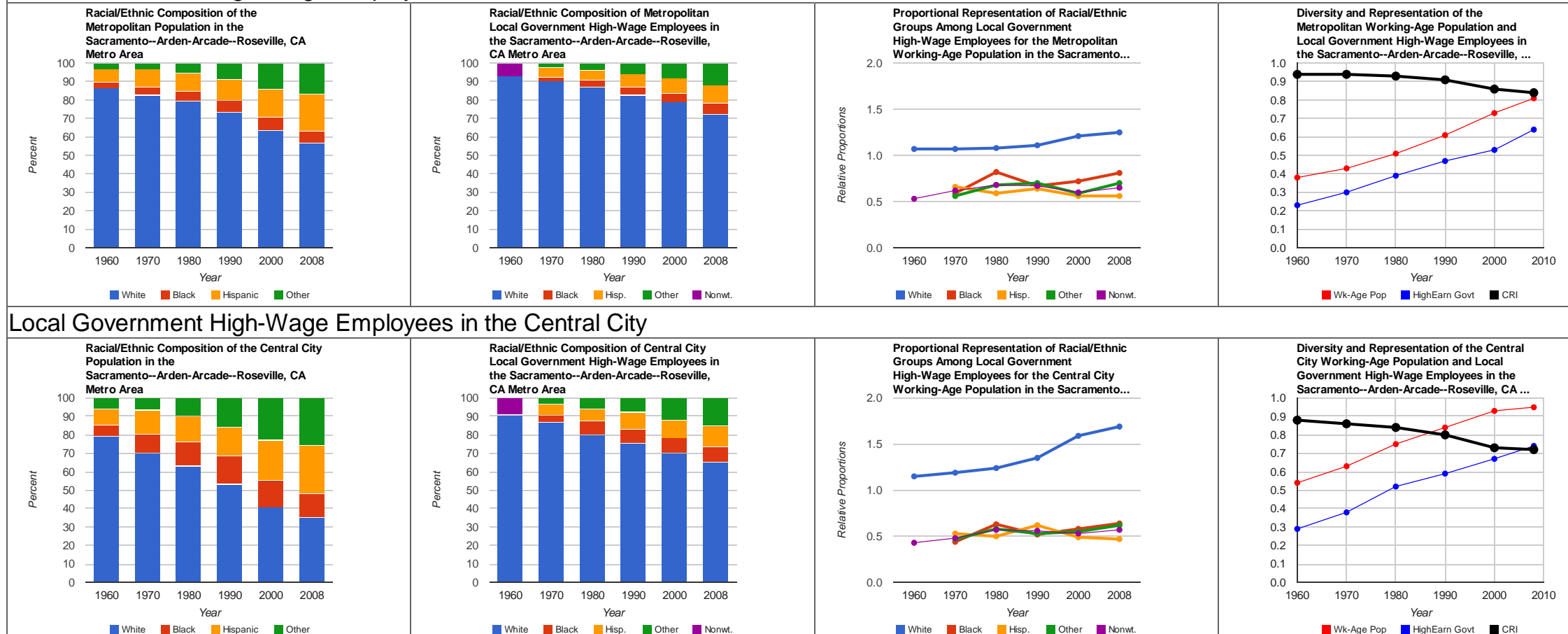

White In Black Hispanic Inother

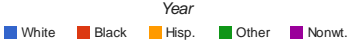

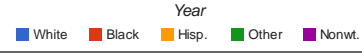

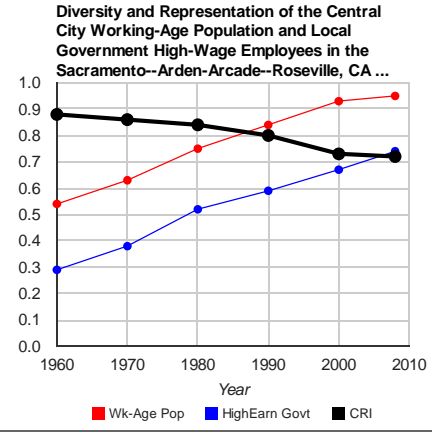


High- and Low-Wage Local Government Employment in the Sacramento--Arden-Arcade--Roseville, CA Metro Area Local Government Low-Wage Employees in the Metro Area

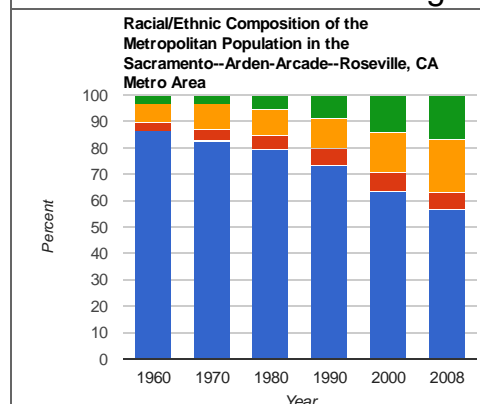

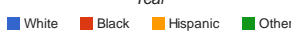

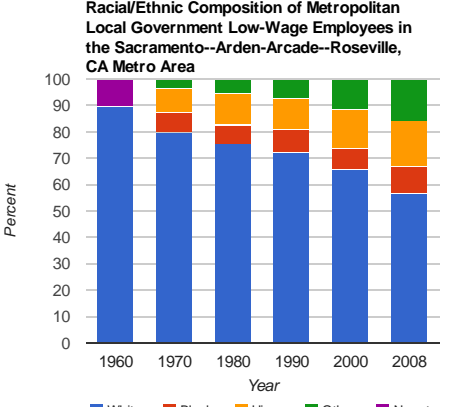

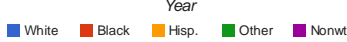

Local Government Low-Wage Employees in the Central City

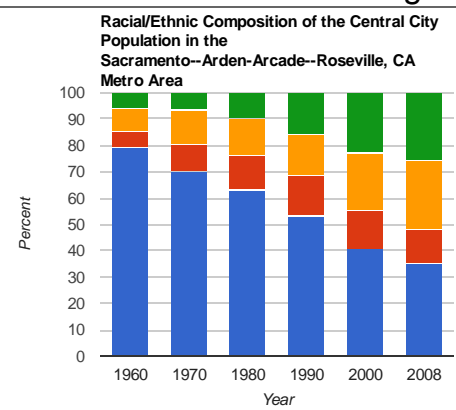

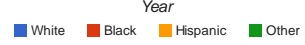

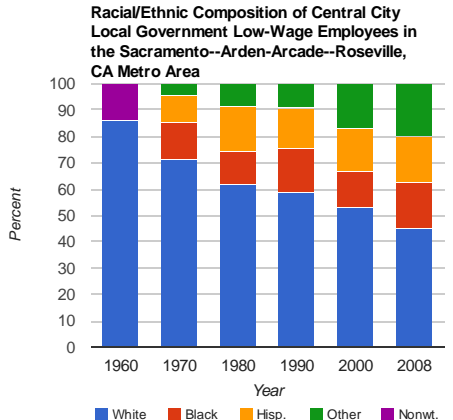
Groups Among Local Government
Low-Wage Emplaternic Low-Wage Employees for the Central City
2.0 Working-Age Population in the Sacramento...
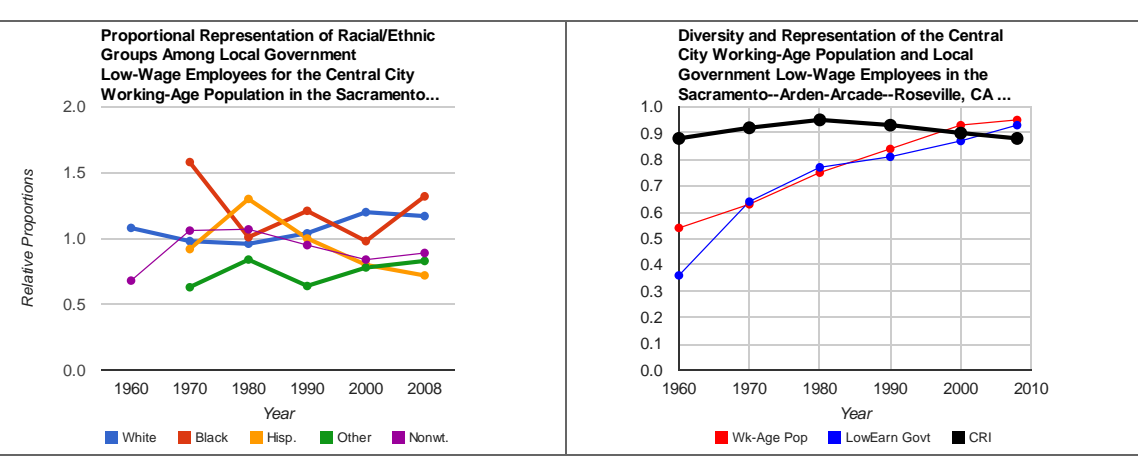

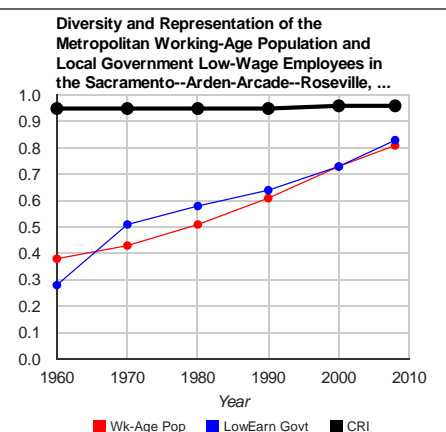

- Wk-Age Pop L LowEarn Govt - CPRI 


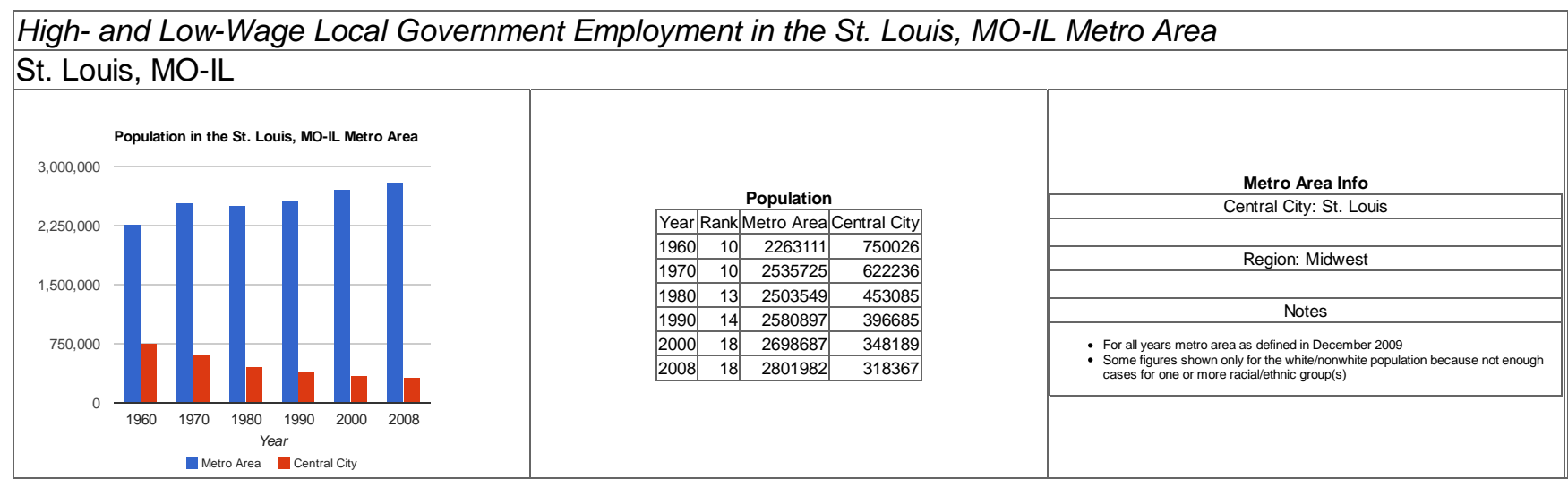


High- and Low-Wage Local Government Employment in the St. Louis, MO-IL Metro Area

Local Government High-Wage Employees in the Metro Area
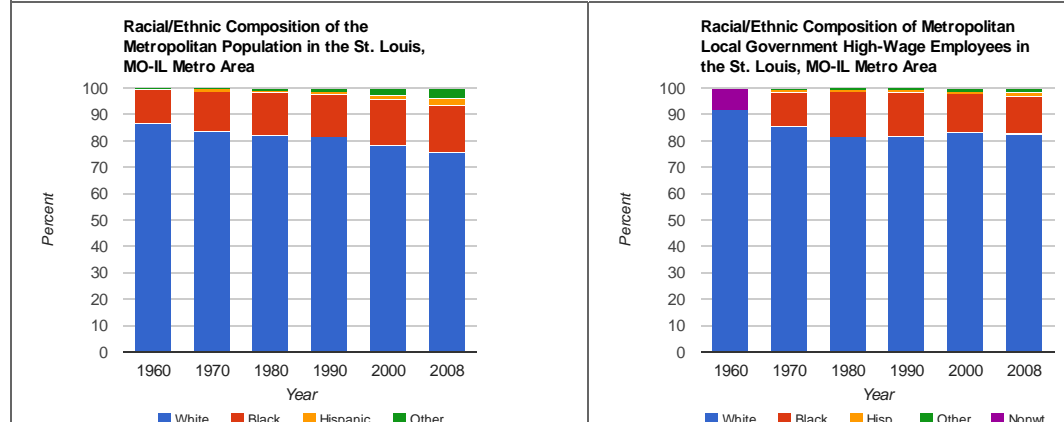

Local Government High-Wage Employees in the Central City
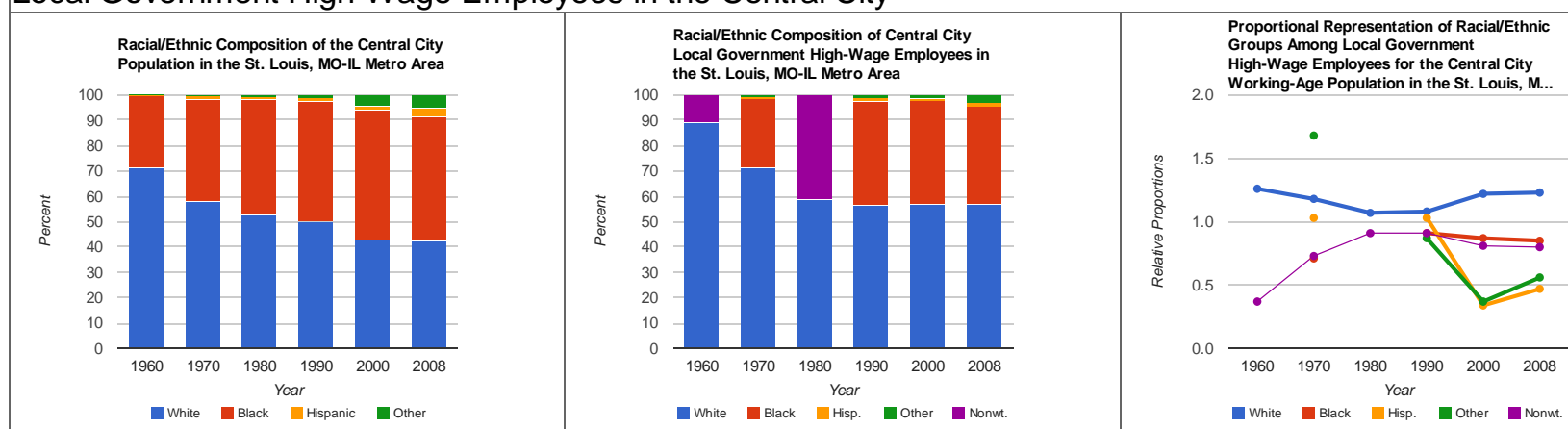
Diversity and Representation of the Central
City Working-Agg Population and Local
Government High-Wage Employees in the $S$ Proportional Representation of Racial/Ethnic
Groups Among Local Government High-Wage Employees for the Metropolitan
Working-Age Population in the St. Louis, M...

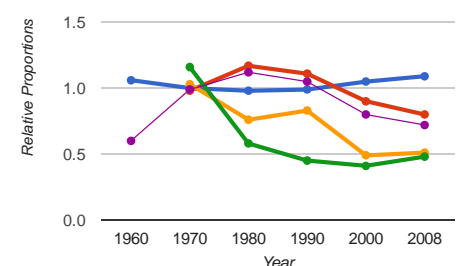

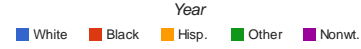

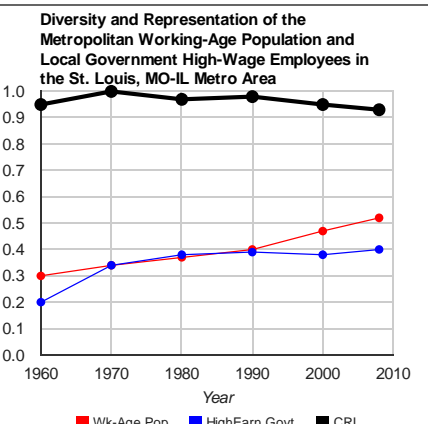

-Wk-Age Pop Highearn Govt CRI

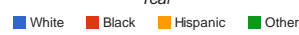

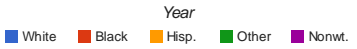
White In Black Yrear

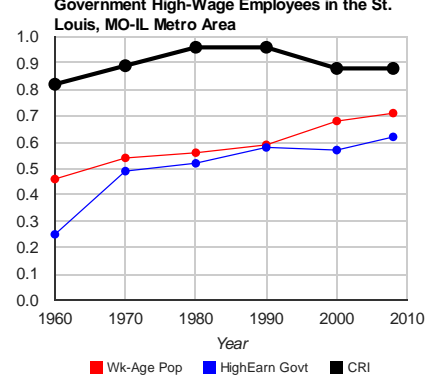


High- and Low-Wage Local Government Employment in the St. Louis, MO-IL Metro Area

Local Government Low-Wage Employees in the Metro Area
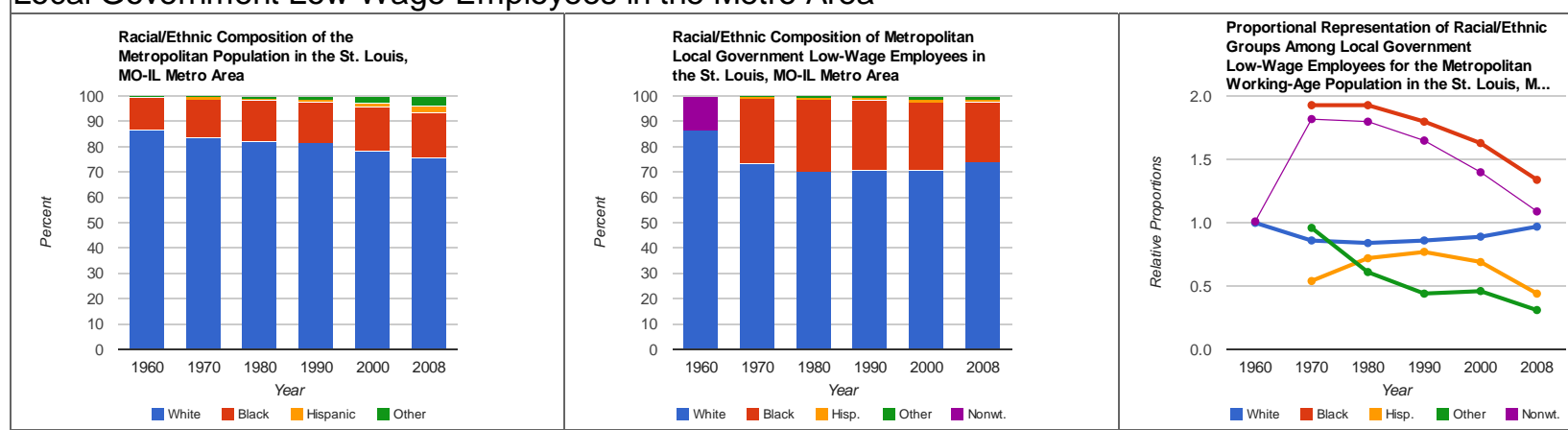

Diversity and Representation of the
Metropolitan Working-Age Population and

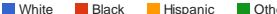

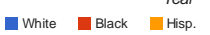

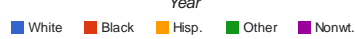

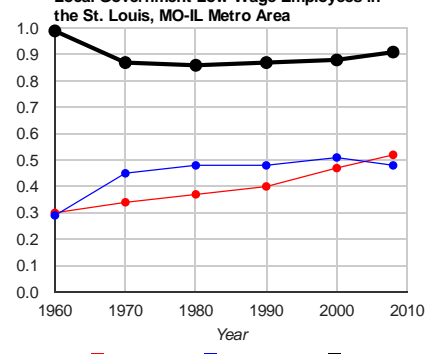

Local Government Low-Wage Employees in the Central City
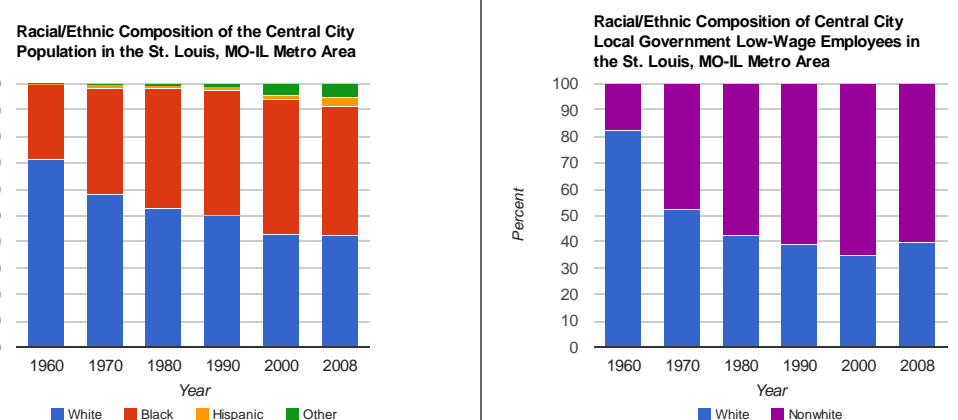
Proportional Representation of Racial//thnic
Groups Among Local Government
Low-Wage Employees for the Central City 20 Working-Age Population in the St. Louis, M...

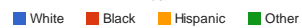

- White $\stackrel{\text { Year }}{\text { Nonwhite }}$

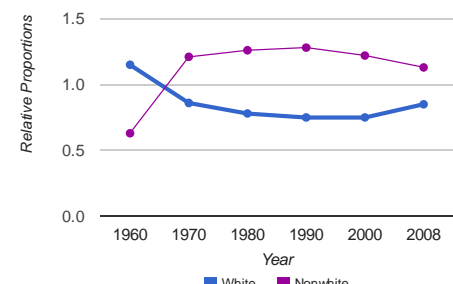
Diversity and Representation of the Central
City Working-Age Population and Local
Government Low-Wage Employees in the St.

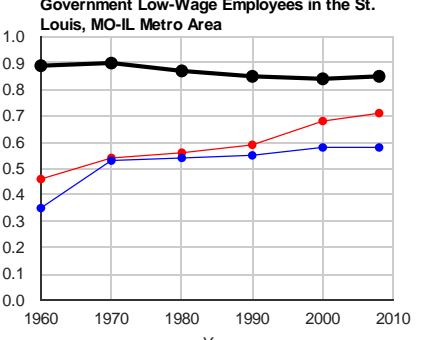

White Year

-Wk-Age Pop L LowEarn Gout 
High- and Low-Wage Local Government Employment in the Salt Lake City, UT Metro Area

Salt Lake City, UT

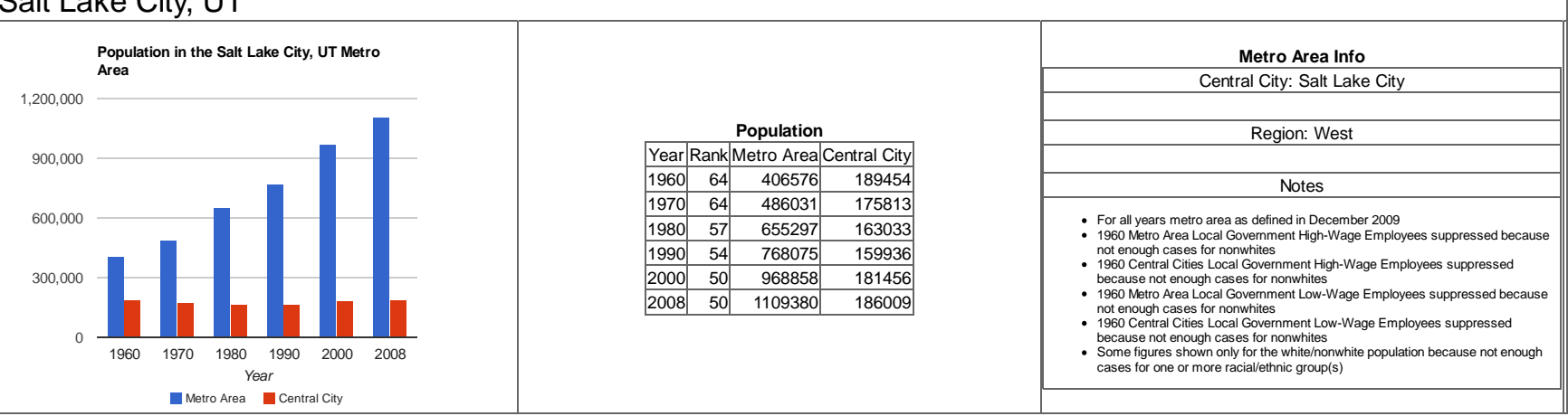


High- and Low-Wage Local Government Employment in the Salt Lake City, UT Metro Area

Local Government High-Wage Employees in the Metro Area
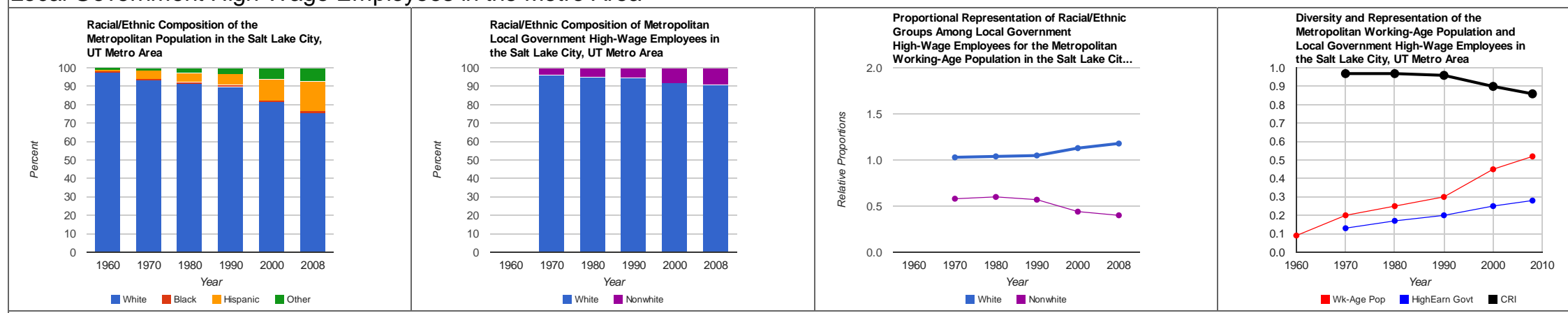

Local Government High-Wage Employees in the Central City
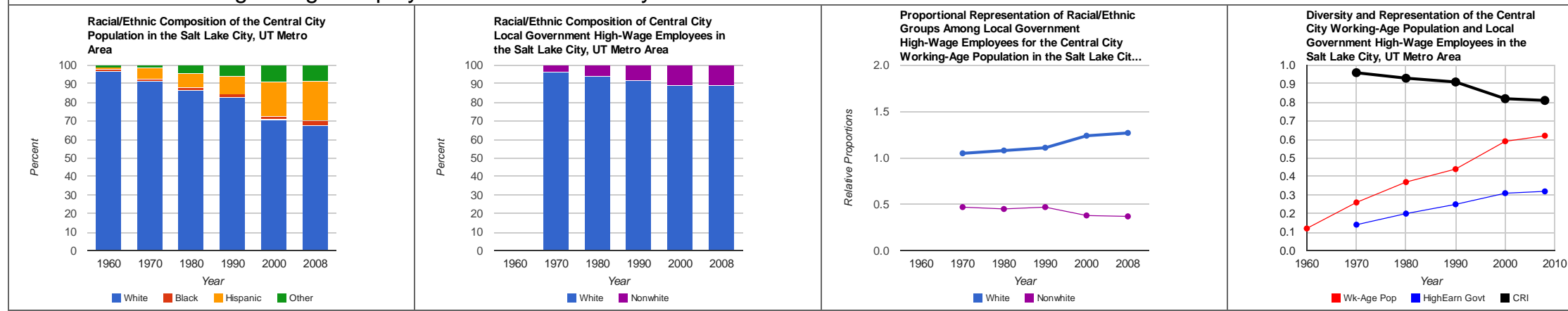
High- and Low-Wage Local Government Employment in the Salt Lake City, UT Metro Area

Local Government Low-Wage Employees in the Metro Area
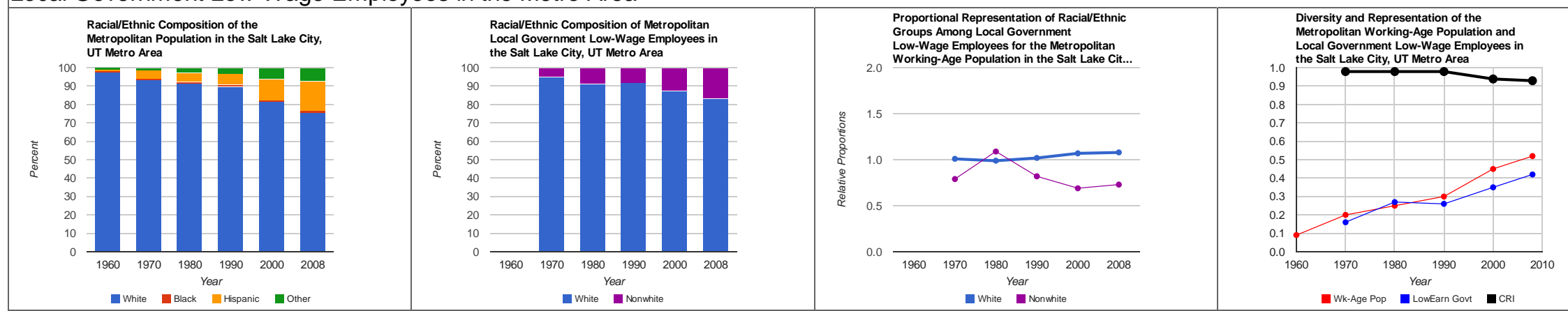

Local Government Low-Wage Employees in the Central City
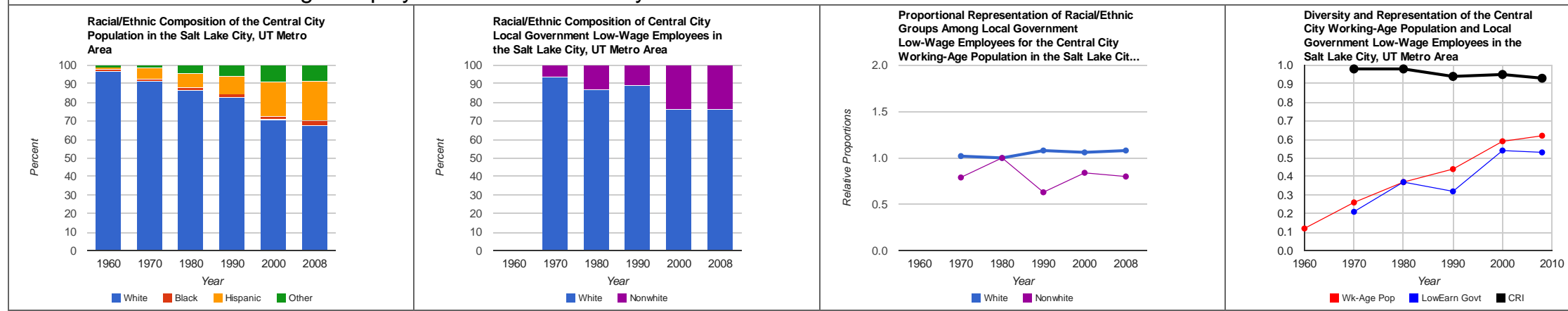


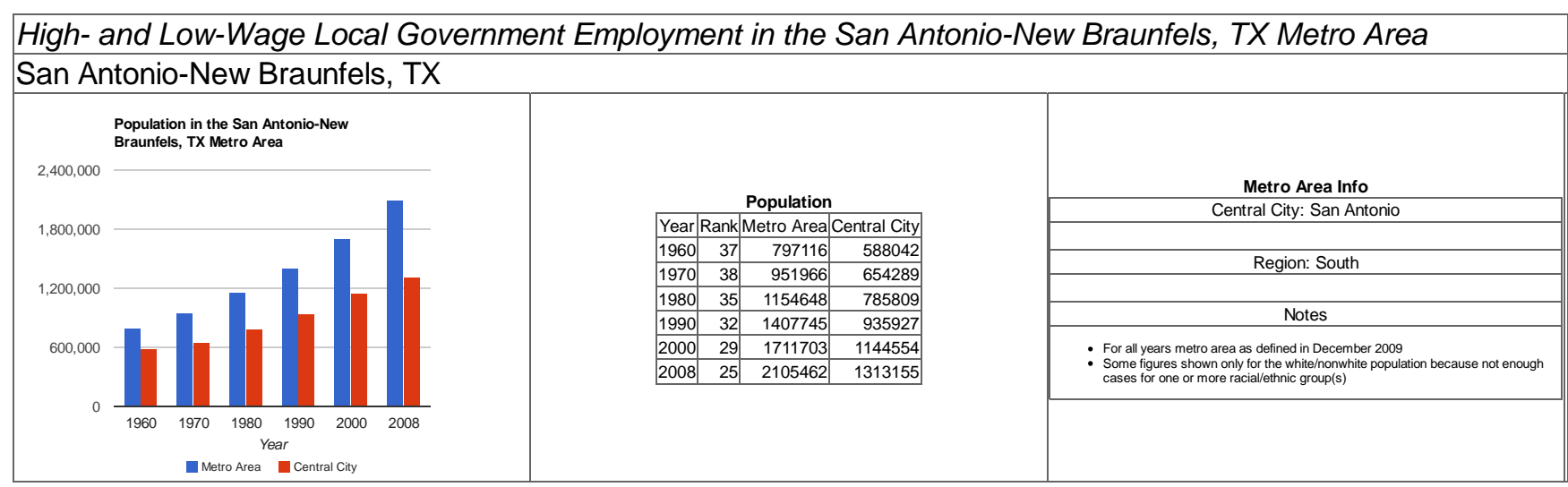


High- and Low-Wage Local Government Employment in the San Antonio-New Braunfels, TX Metro Area Local Government High-Wage Employees in the Metro Area
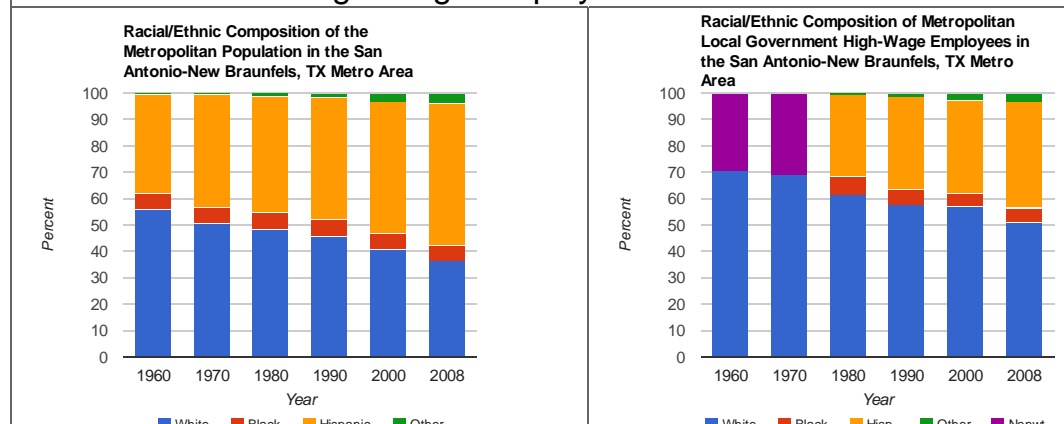

Local Government High-Wage Employees in the Central City
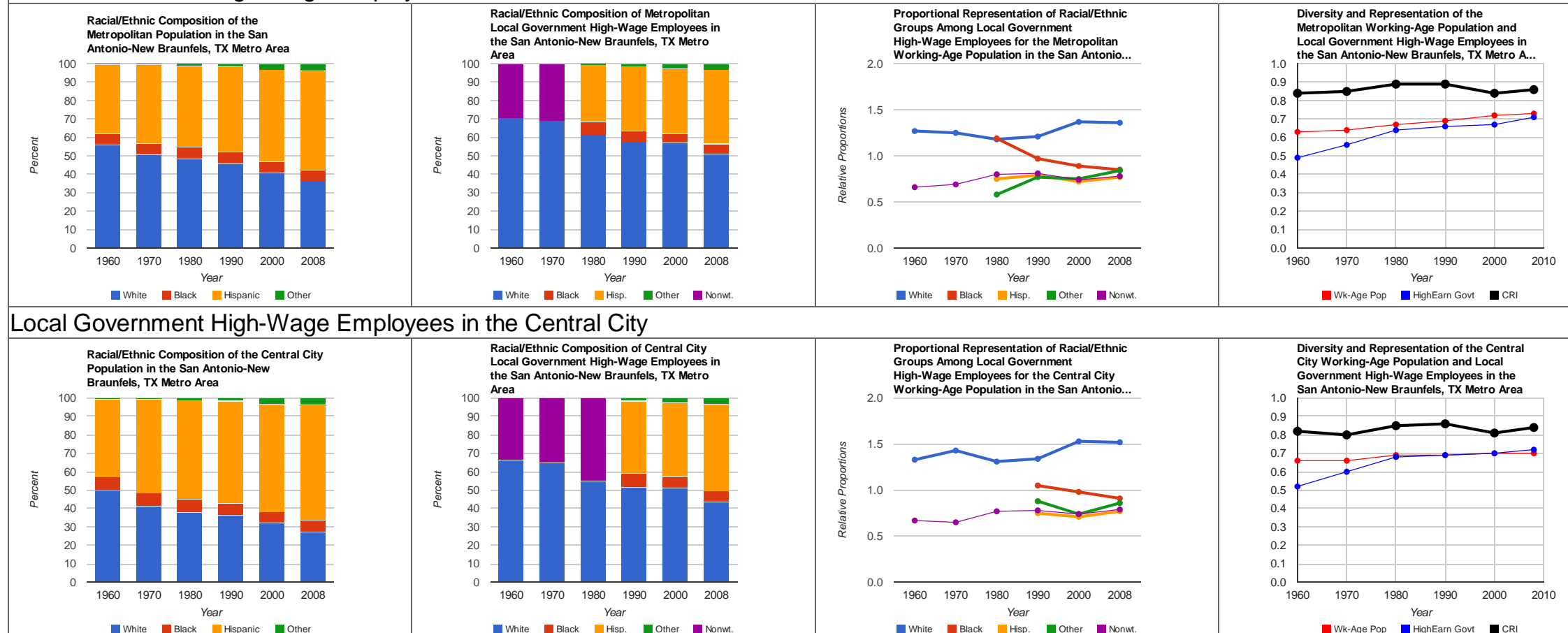

Proportional Representation of Racial/Ethnic
Groups Among Local Government High--wage Employees for the Metropolitan
Working-Age Population in the San Antonio...

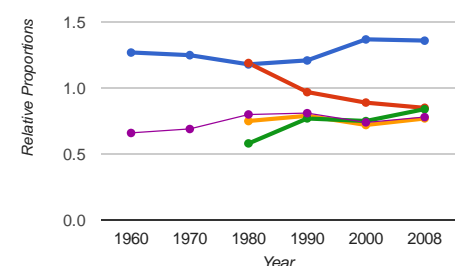

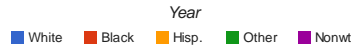

-Wk-Age Pop M Highearn Govt - CPR

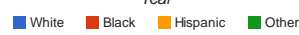

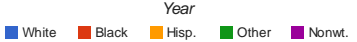

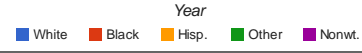

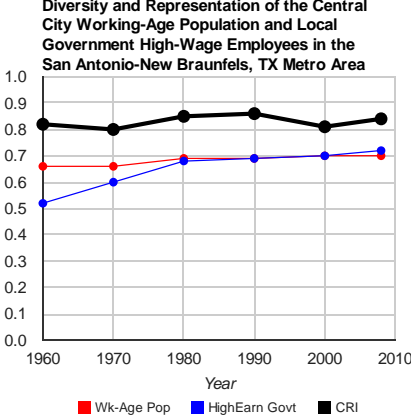


High- and Low-Wage Local Government Employment in the San Antonio-New Braunfels, TX Metro Area Local Government Low-Wage Employees in the Metro Area
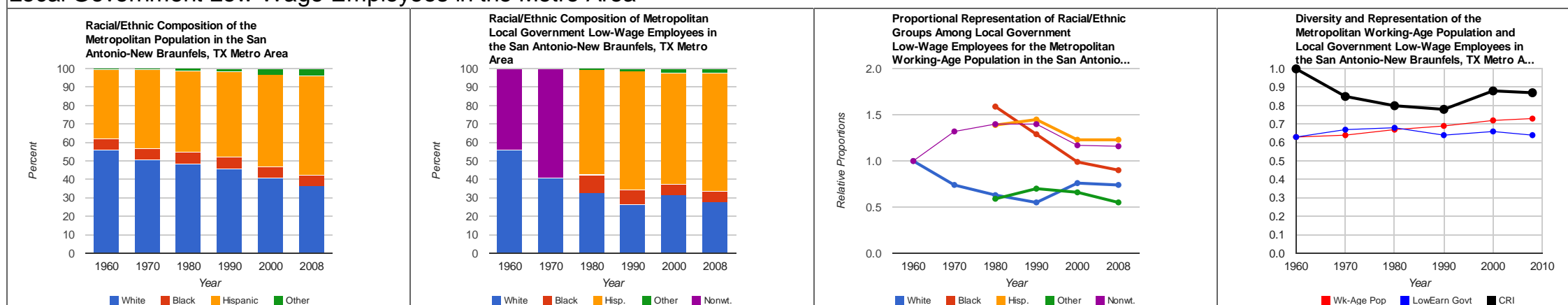

Local Government Low-Wage Employees in the Central City
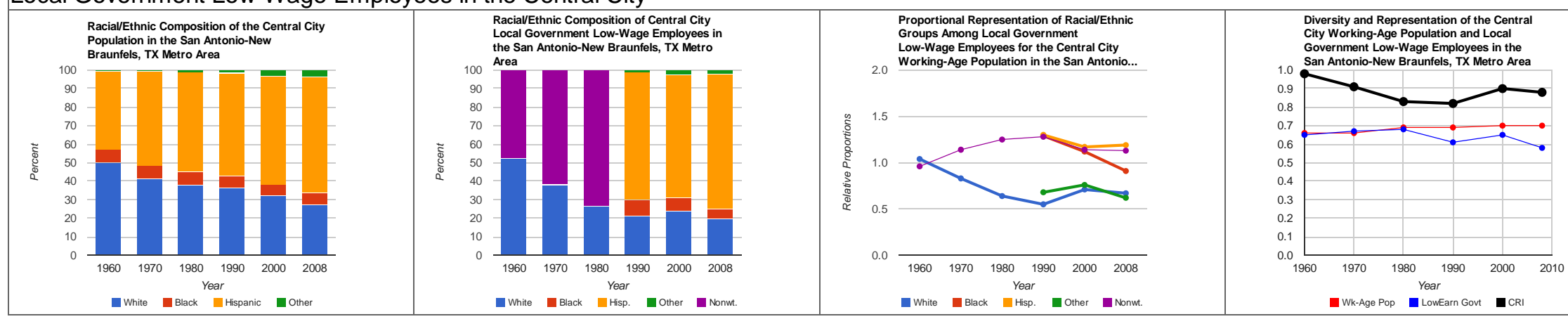


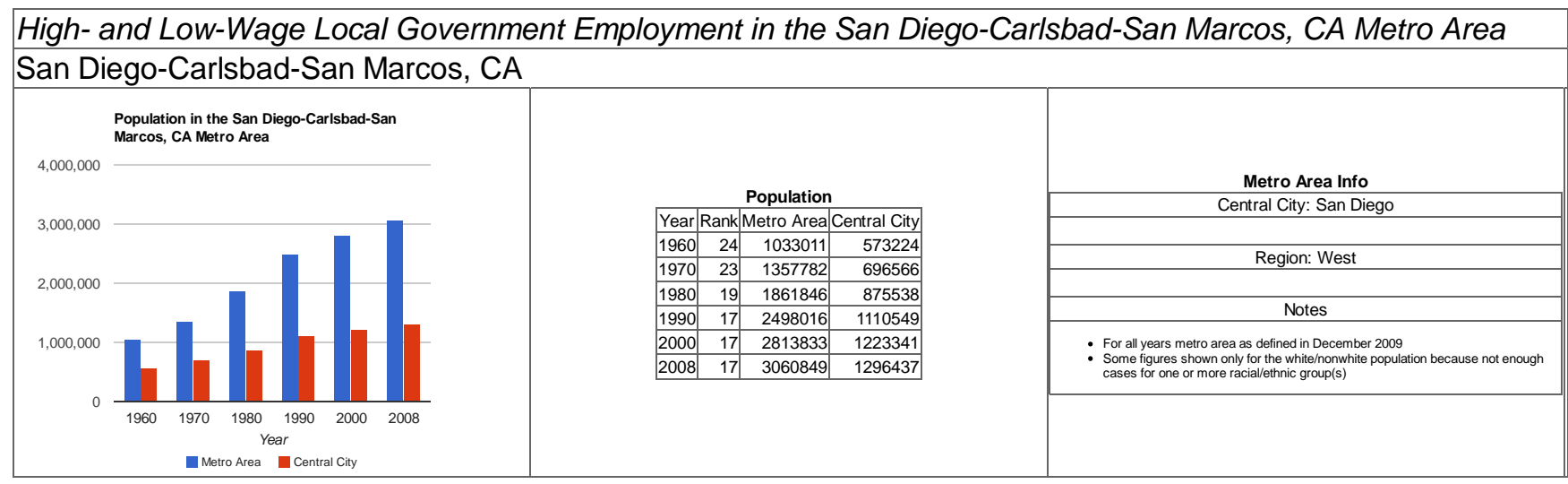


High- and Low-Wage Local Government Employment in the San Diego-Carlsbad-San Marcos, CA Metro Area Local Government High-Wage Employees in the Metro Area
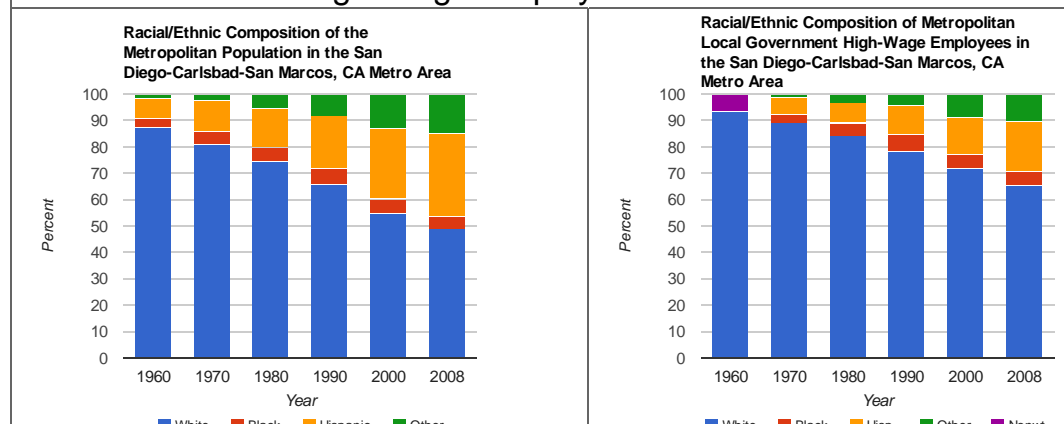

Local Government High-Wage Employees in the Central City
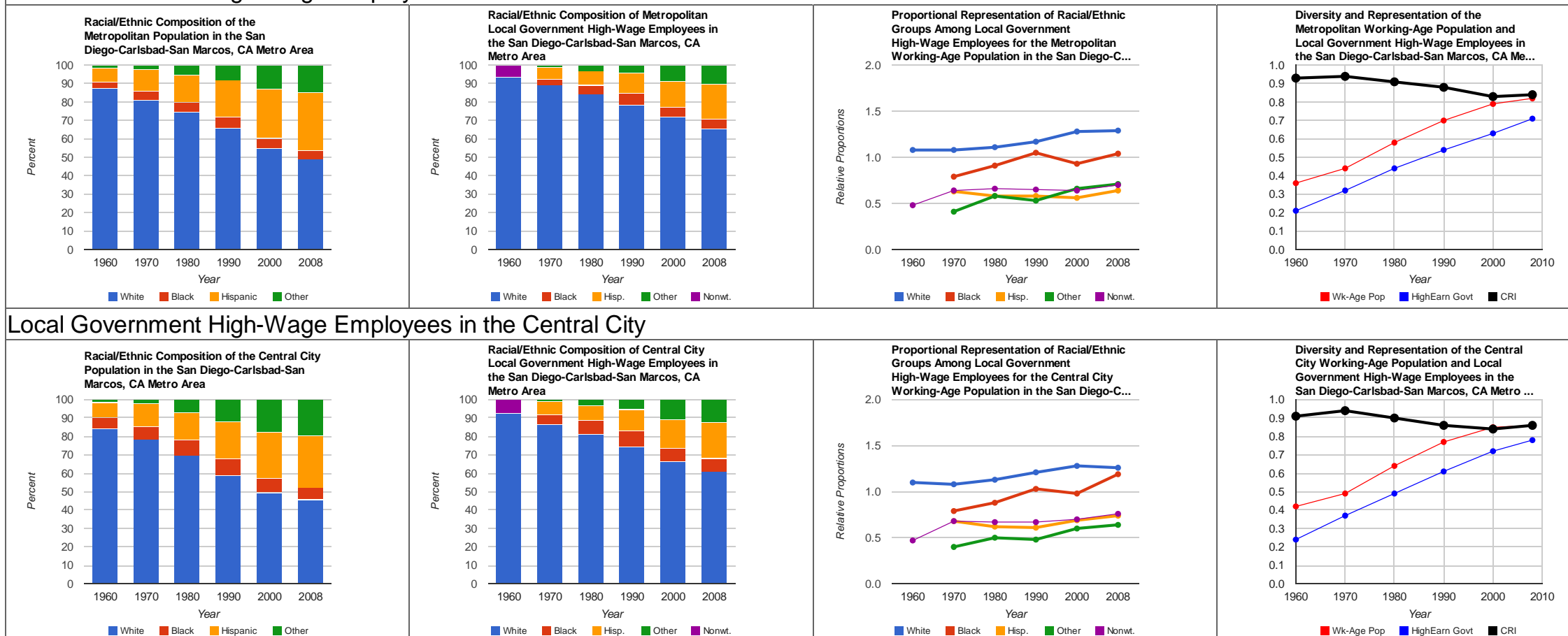

White Black Hispanic $\quad$ Oother

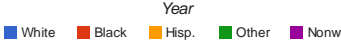

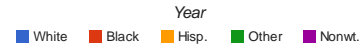

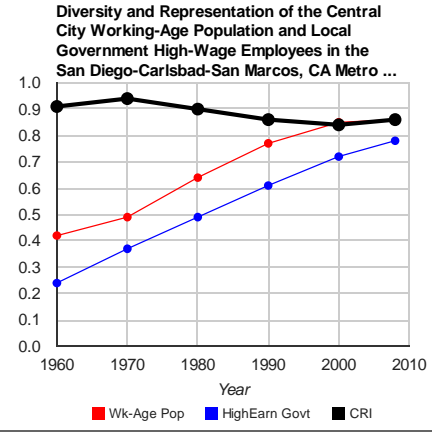


High- and Low-Wage Local Government Employment in the San Diego-Carlsbad-San Marcos, CA Metro Area Local Government Low-Wage Employees in the Metro Area
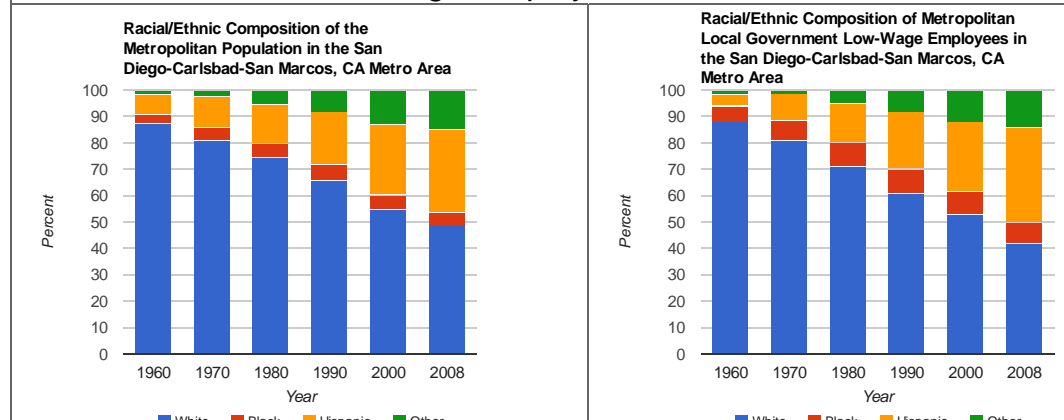

White Black Year

Local Government Low-Wage Employees in the Central City

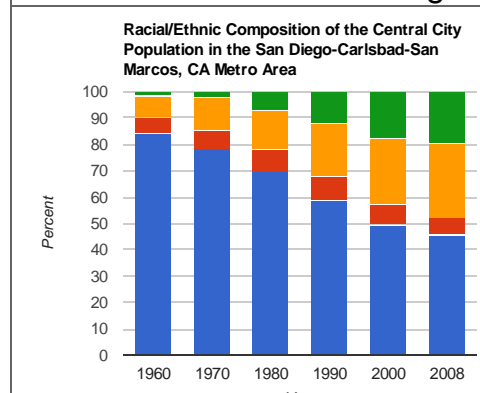

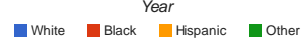

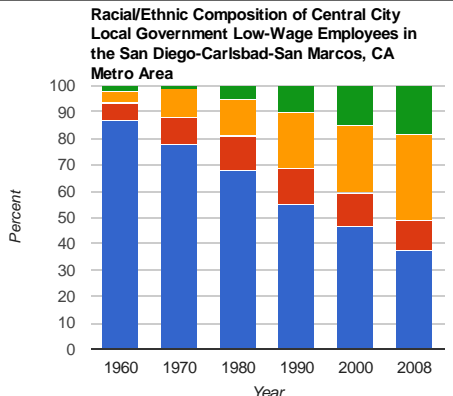

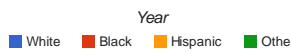
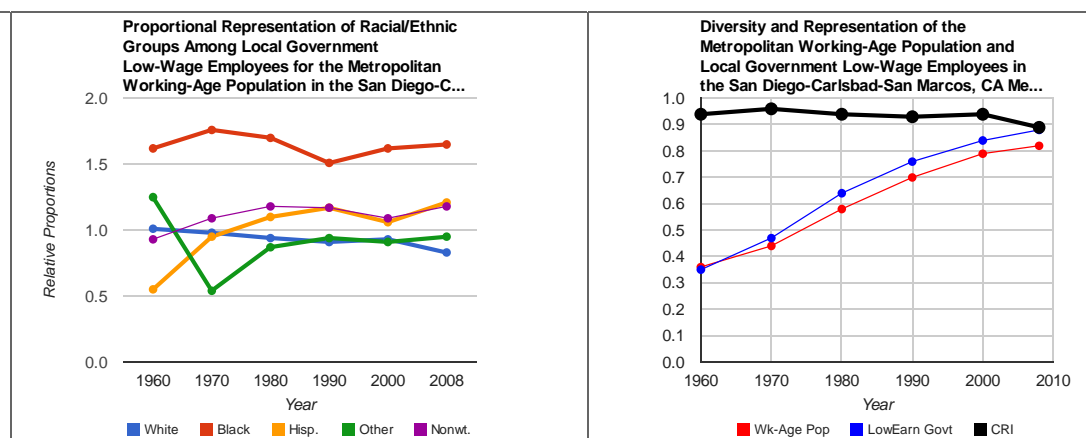

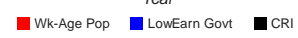

Proportional Representation of Raciall/thnic Low-Wage Employees for the Central City
Working-Age Population in the San Diego-c...

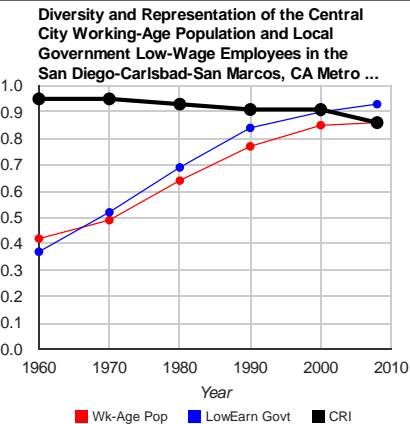
$\begin{array}{cccccc}1960 & 1970 & 1980 & 1990 & 2000 & 2008 \\ \text { Year }\end{array}$

-Wk-Age Pop —Lowearn Govt - 


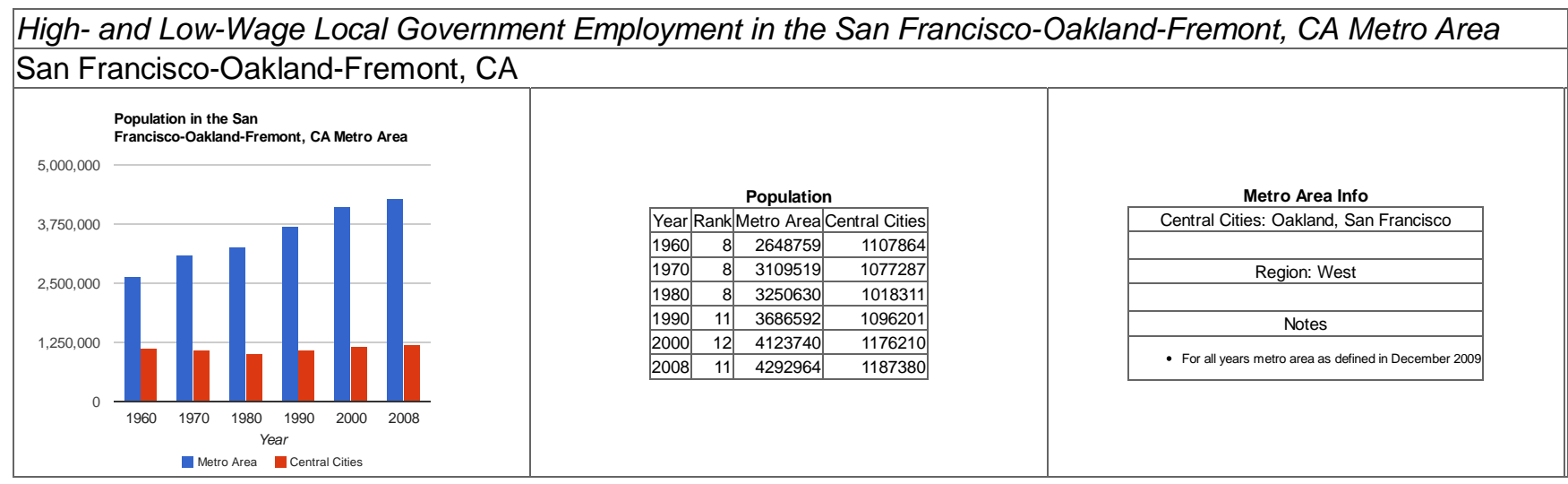


High- and Low-Wage Local Government Employment in the San Francisco-Oakland-Fremont, CA Metro Area Local Government High-Wage Employees in the Metro Area
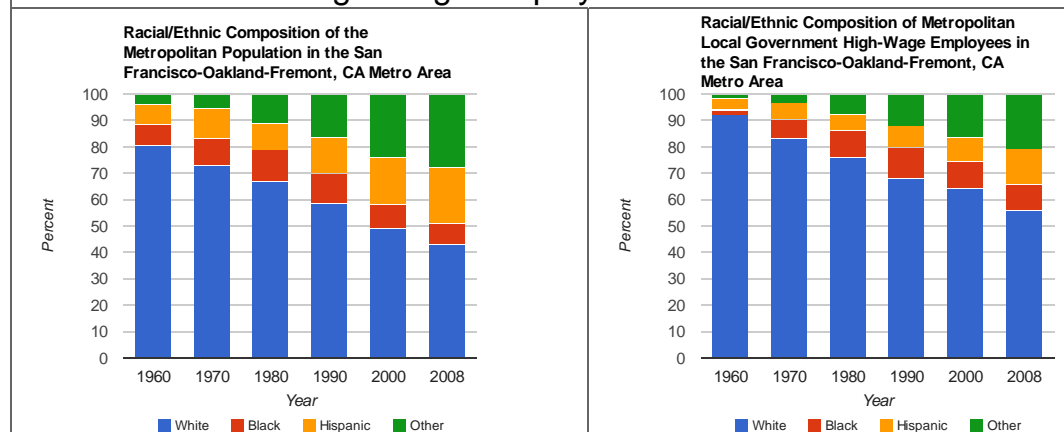

Local Government High-Wage Employees in the Central Cities
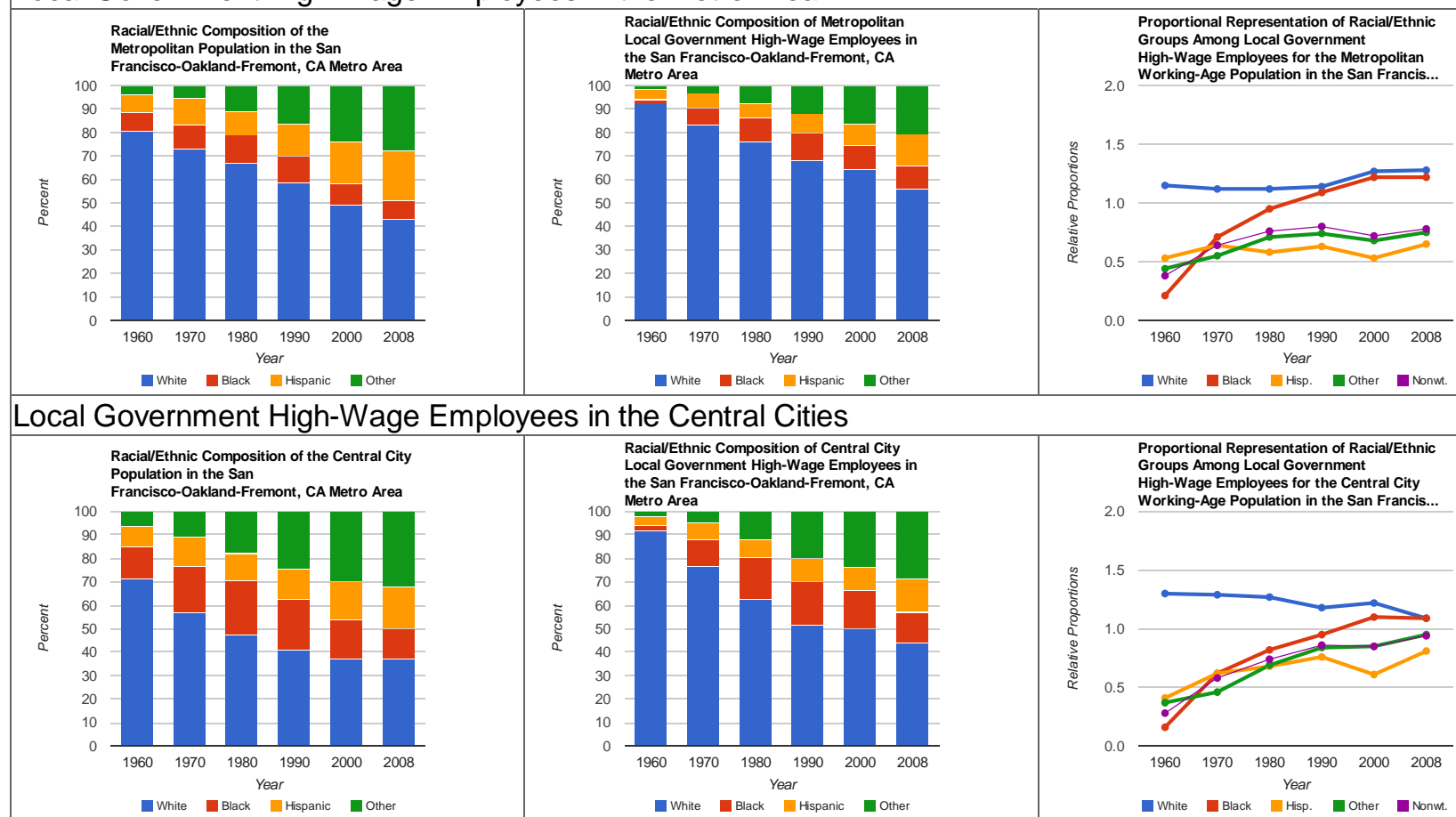

Diversity and Representation of the
Metropolitan Working-Age Poputation Metropolitan Working-Age Population and the San Francisco-Oakland-Fremont, CA Me..

cisco-Oakland-Fremont, CA Metro

.

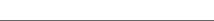

Proportional Representation of Racial//Ethnic
Groups Among Local Government Groups Among Local Government
High-Wage Employees for the Central City
Working-Age Population in the San Francis. @White 1 Black Year

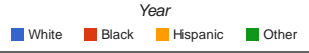

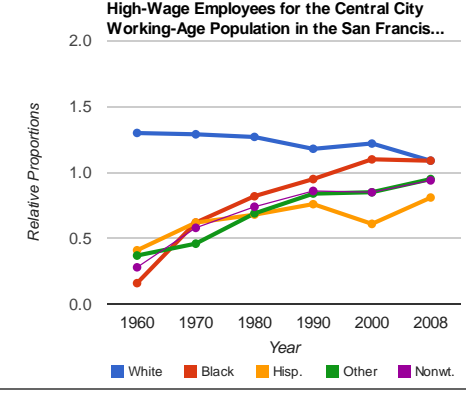
Diversity and Representation of the Central
City Working-Age Population and Local
Government High-Wage Employees in the Government High-Wage Employees in the
San Francisco-Oakland-Fremont, CA Metro

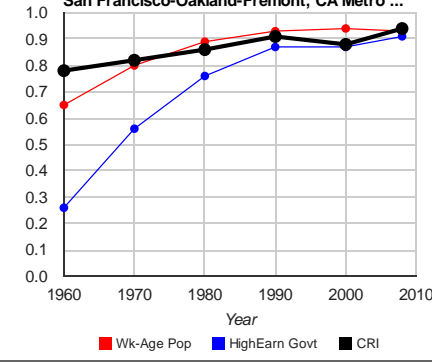


High- and Low-Wage Local Government Employment in the San Francisco-Oakland-Fremont, CA Metro Area Local Government Low-Wage Employees in the Metro Area
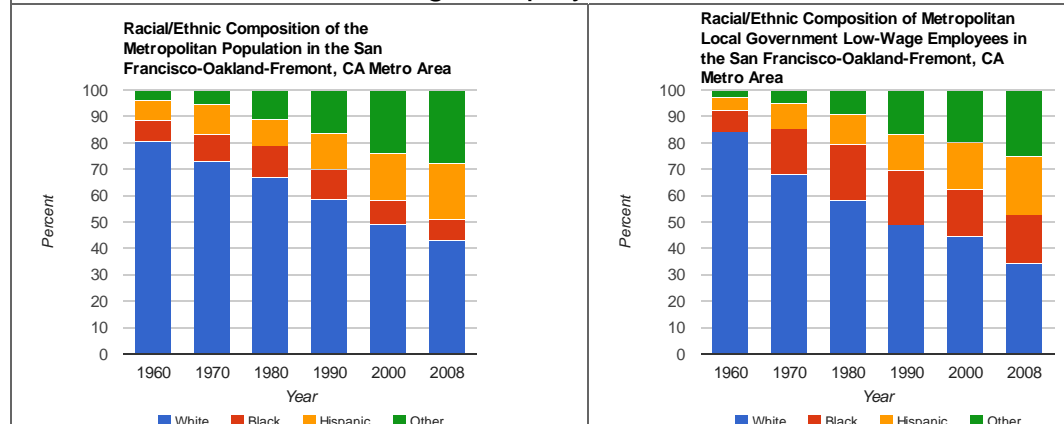

Local Government Low-Wage Employees in the Central Cities
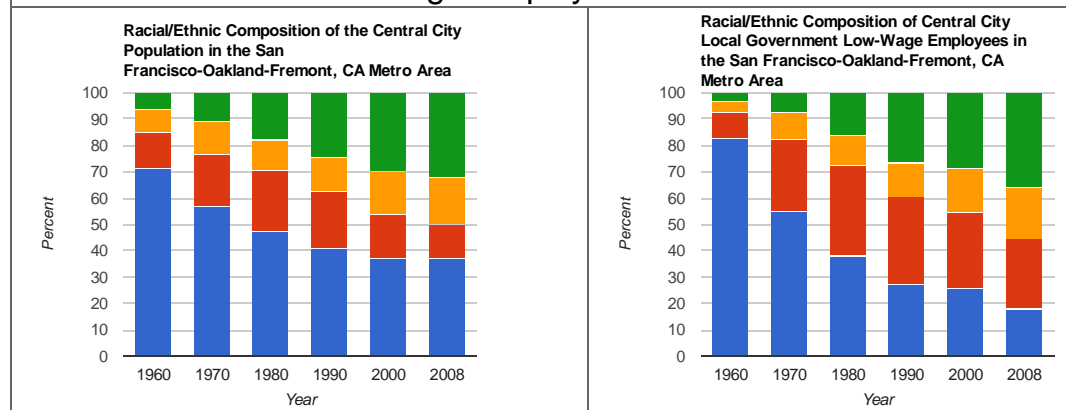

White Black Hispanic Wother
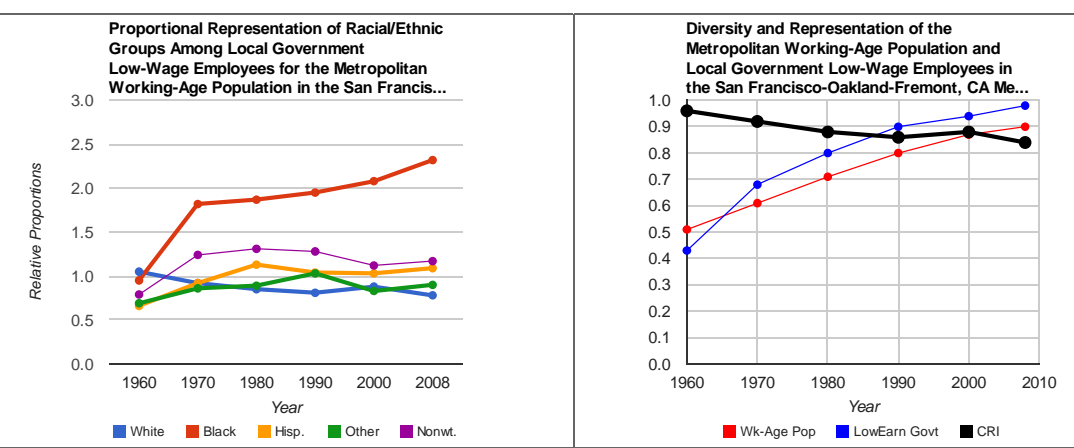

-Wk-Age Pop L Lowearn Gout - $\quad$ CRI

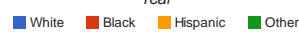

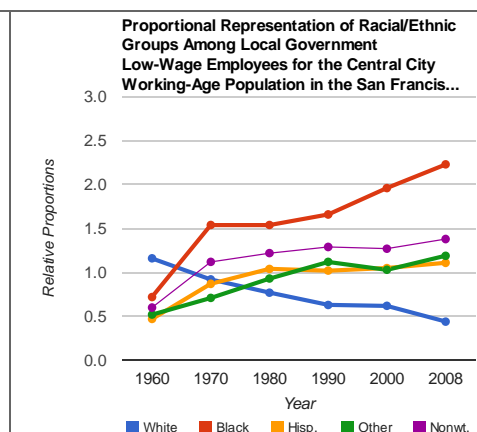

Diversity and Representation of the Central
City Working-Age Population and Local

Government Low-Wage Employees in the
San Francisco-Oakland-Fremont, CA Metro...

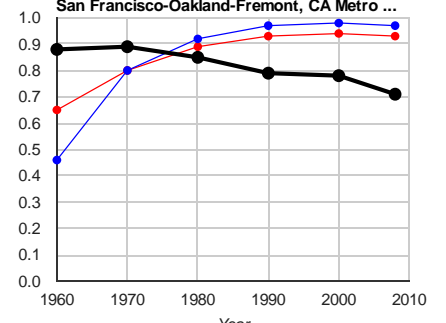

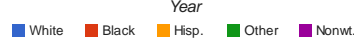

-Wk-Age Pop —Lowearn Govt - 


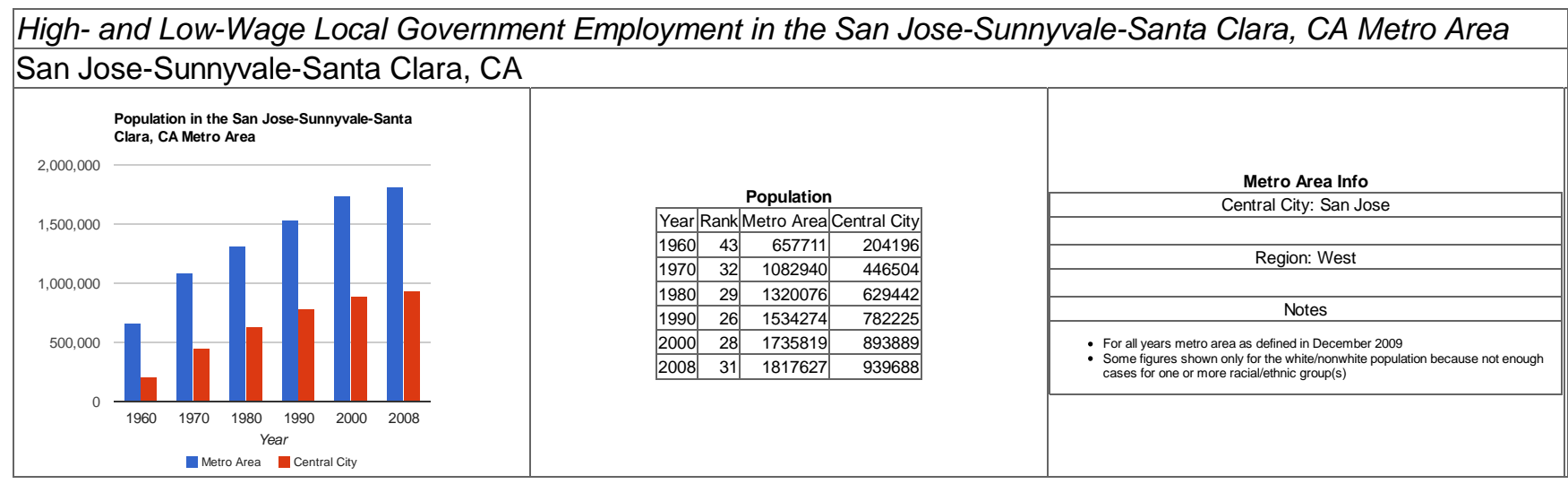


High- and Low-Wage Local Government Employment in the San Jose-Sunnyvale-Santa Clara, CA Metro Area Local Government High-Wage Employees in the Metro Area
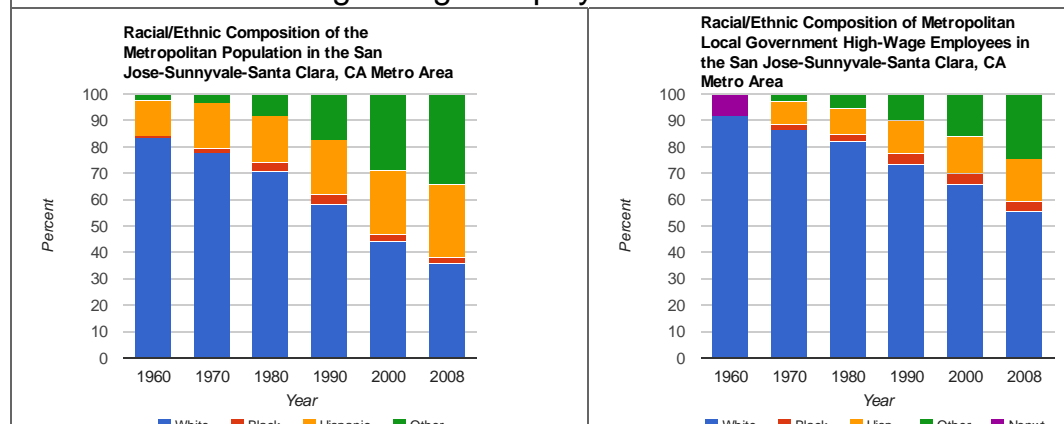

Local Government High-Wage Employees in the Central City
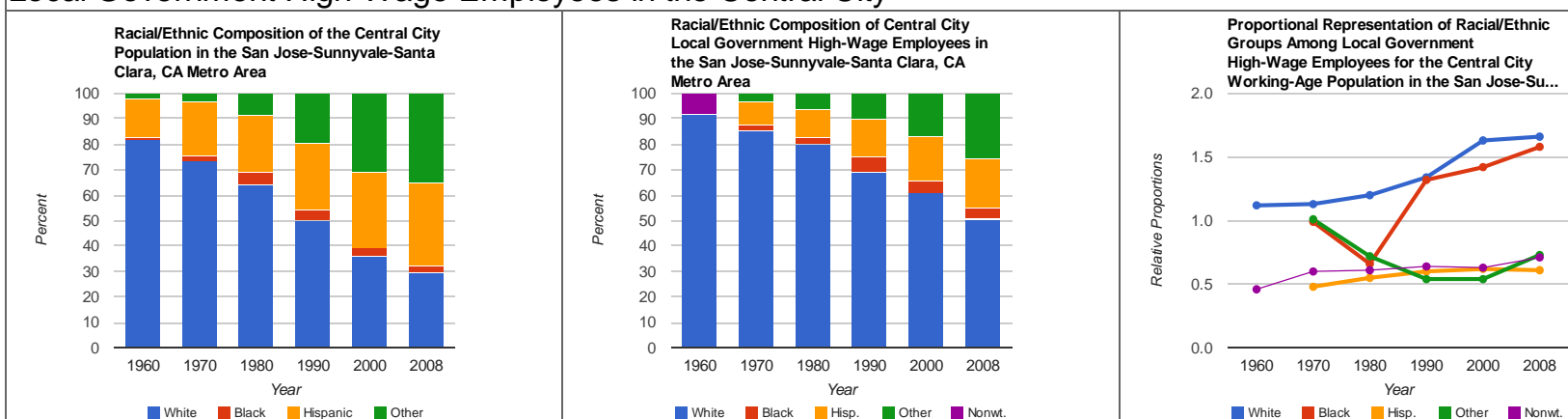
Diversity and Representation of the Central
City Working-Age Population and Local
Government High-Wage Employees in the Proportional Representation of Racial/Ethnic
Groups Among Local Government
High-Wage Employees for the Metropolitan 20 Working-Age Population in the San Jose-Su..

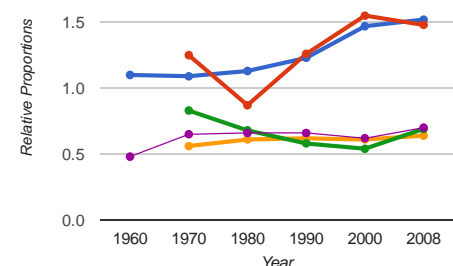
Local Government High-Wage Employees in
the San Jose-Sunnyvale-Santa Clara, CA Me..

vale-Santa Clara, CA Metro Ar

White MBack Mear Hispanic Wother

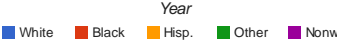

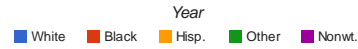

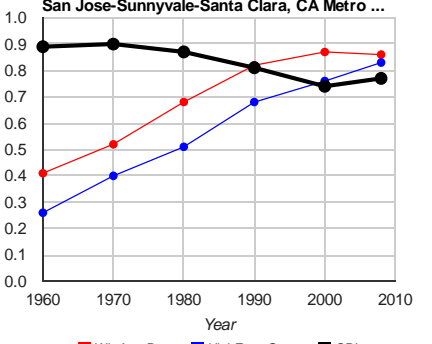

-Wk-Age Pop - HighEarn Govt - 
High- and Low-Wage Local Government Employment in the San Jose-Sunnyvale-Santa Clara, CA Metro Area Local Government Low-Wage Employees in the Metro Area
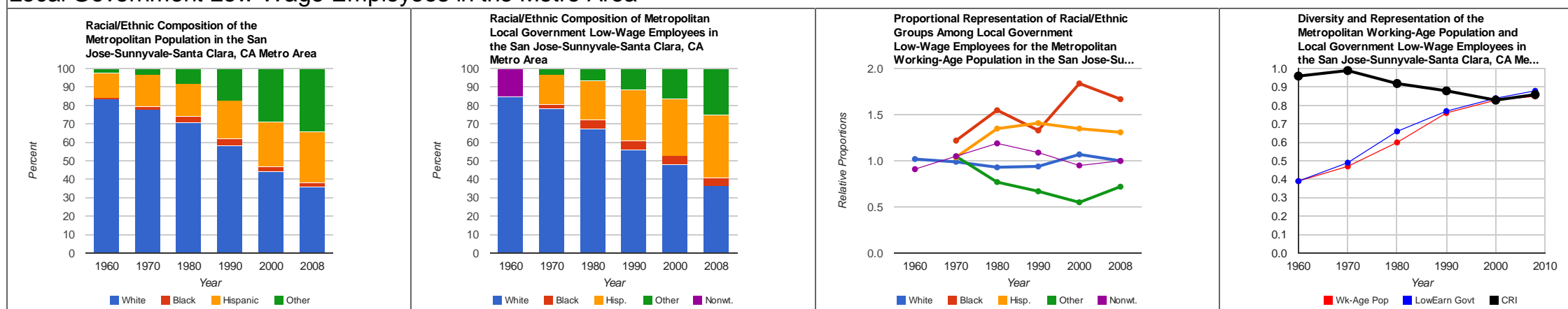

Local Government Low-Wage Employees in the Central City
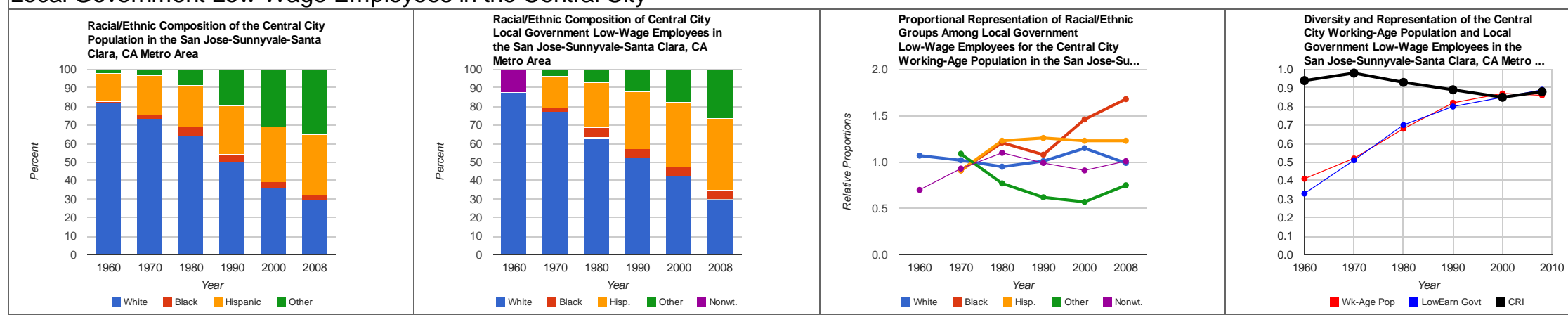
High- and Low-Wage Local Government Employment in the Santa Rosa-Petaluma, CA Metro Area

Santa Rosa-Petaluma, CA

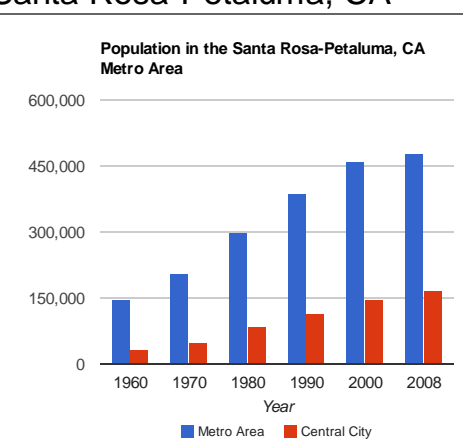

Population

Year Rank Metro Area Central City

\begin{tabular}{|l|l|l|r|}
\hline 1960 & 165 & 147375 & 31027 \\
\hline 1970 & 143 & 20485 & 49873 \\
\hline
\end{tabular}

\begin{tabular}{|l|l|l|l|}
1970 & 143 & 204885 & 49873 \\
\hline 1980 & 115 & 299081 & 83320 \\
\hline
\end{tabular}

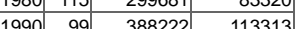

\begin{tabular}{|c|c|c|c|}
1900 & 98 & 4582214 & 113313 \\
\hline
\end{tabular}

\begin{tabular}{|r|r|r|r|}
\hline 2008 & 104 & 478551 & 164976 \\
\hline
\end{tabular}

Metro Area Info

Central City: Santa Rosa

Metro Area Central City

\begin{tabular}{|c|}
\hline $\begin{array}{c}\text { Metro Area Info } \\
\text { Central City: Santa Rosa }\end{array}$ \\
\hline Region: West \\
\hline Notes \\
\hline 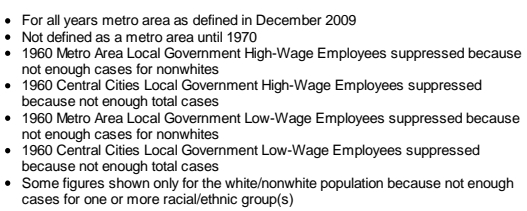 \\
\hline
\end{tabular}


High- and Low-Wage Local Government Employment in the Santa Rosa-Petaluma, CA Metro Area Local Government High-Wage Employees in the Metro Area
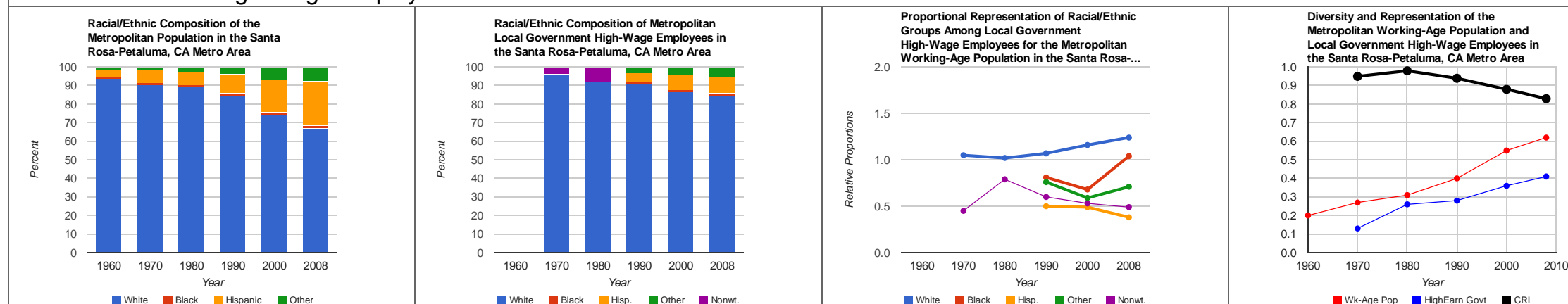

Local Government High-Wage Employees in the Central City
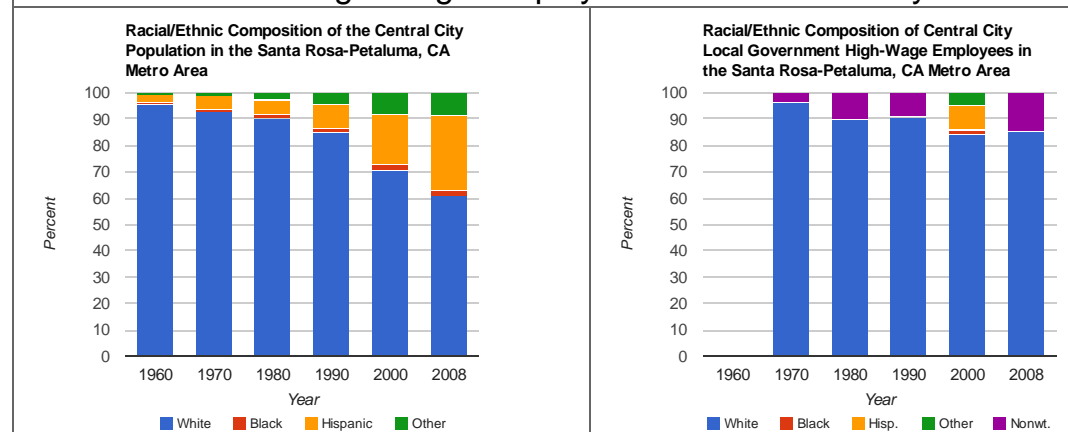
Proportional Representation of Raciall/Ethnic
Groups Among Local Government
High-Wage Employees for the Central City 20 Working-Age Population in the Santa Rosa-... White Elack YHispanic nother

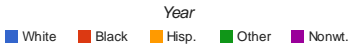
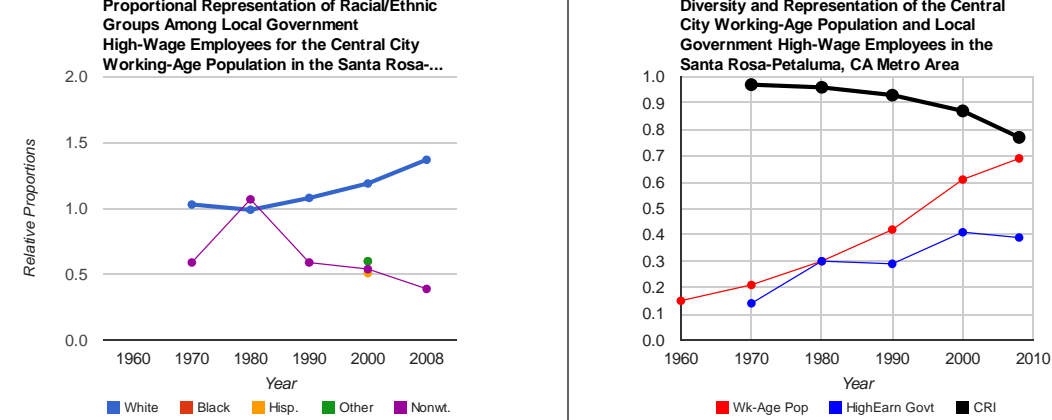
High- and Low-Wage Local Government Employment in the Santa Rosa-Petaluma, CA Metro Area Local Government Low-Wage Employees in the Metro Area
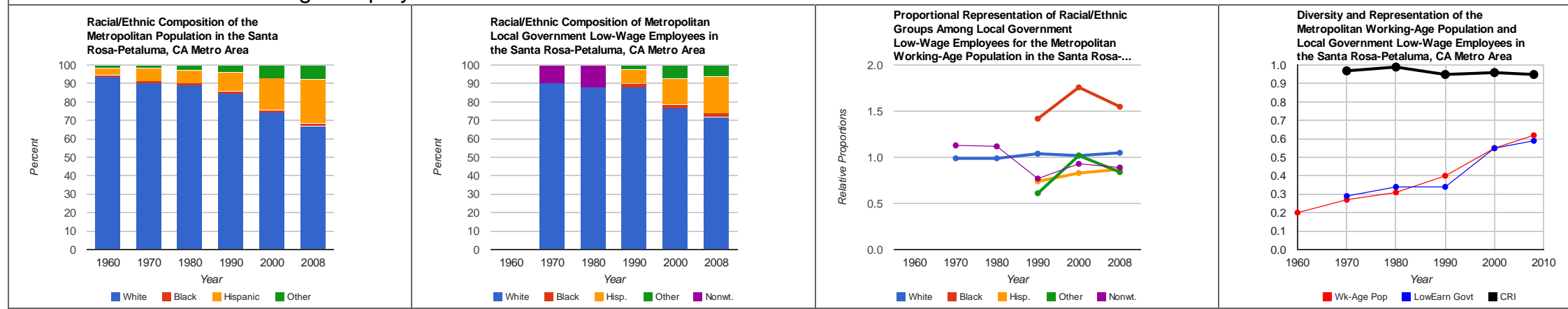

Local Government Low-Wage Employees in the Central City
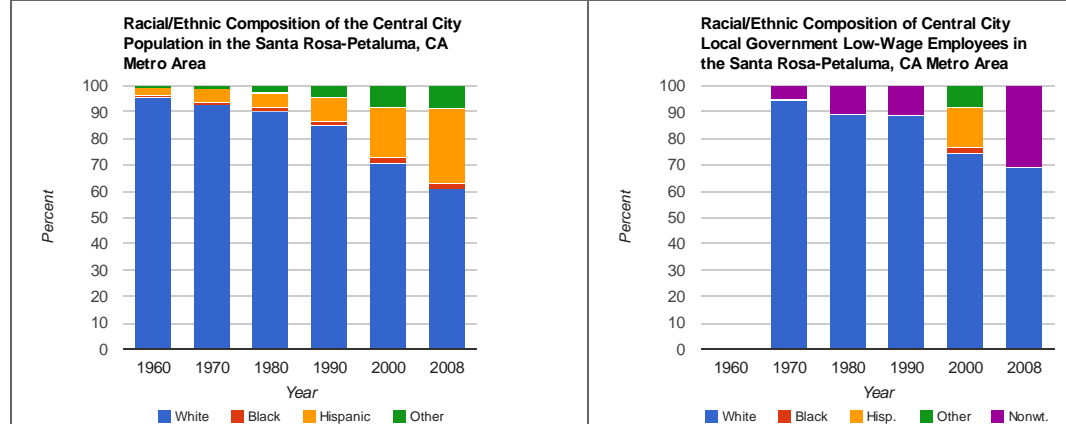

Proportional Representation of Raciall/Ethnic
Groups Among Local Government
Low-Wage Employees for the Central City

Low-Wage Employees tor the Central City
Working-Age Population in the Santa Rosa....

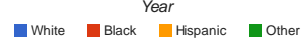

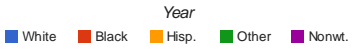
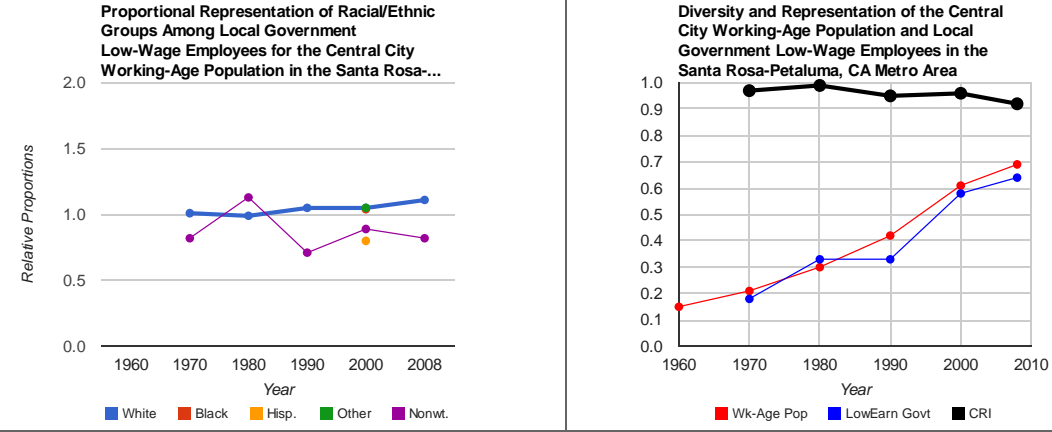
High- and Low-Wage Local Government Employment in the Scranton--Wilkes-Barre, PA Metro Area Scranton--Wilkes-Barre, PA

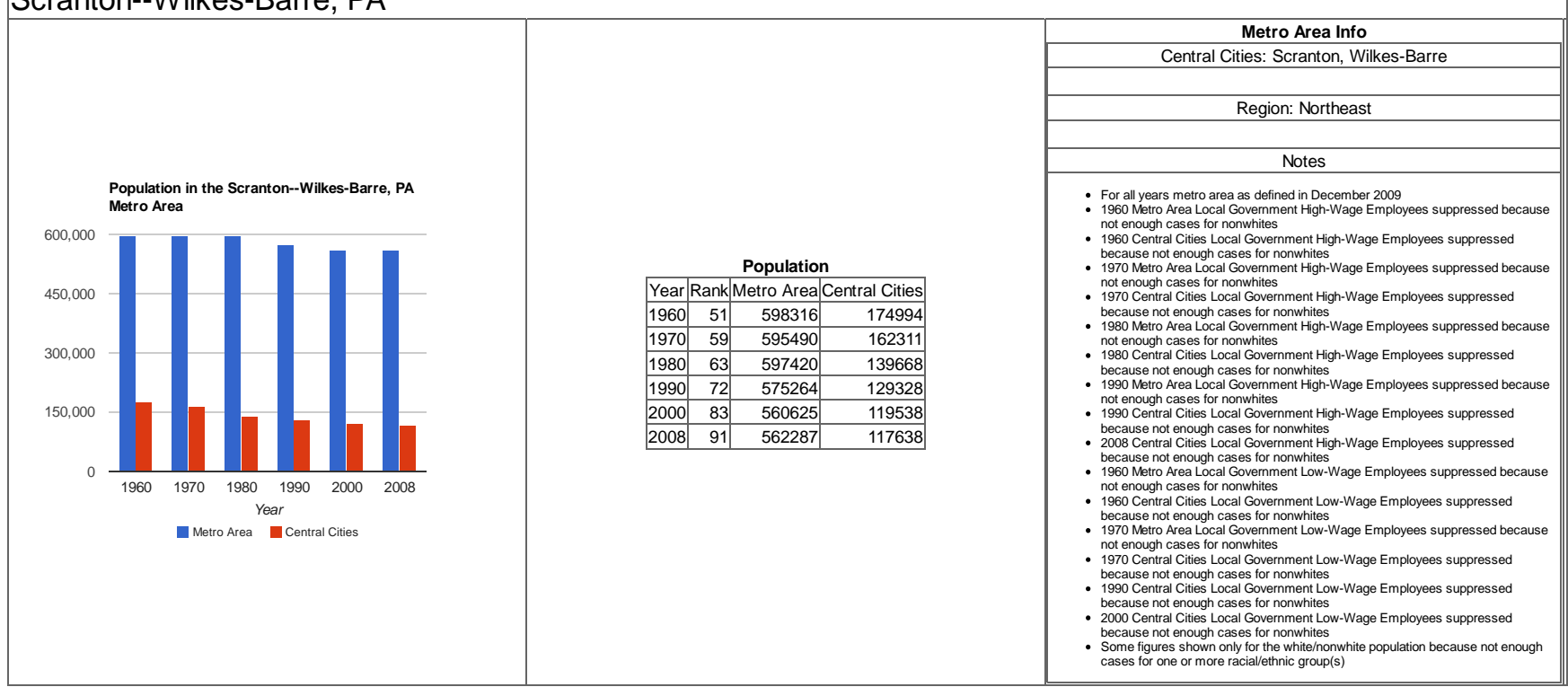


High- and Low-Wage Local Government Employment in the Scranton--Wilkes-Barre, PA Metro Area Local Government High-Wage Employees in the Metro Area
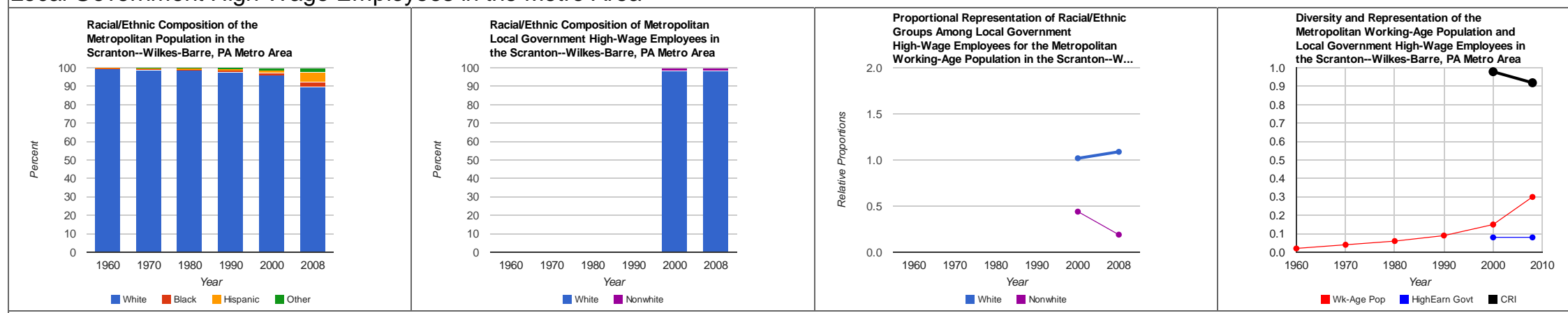

Local Government High-Wage Employees in the Central Cities
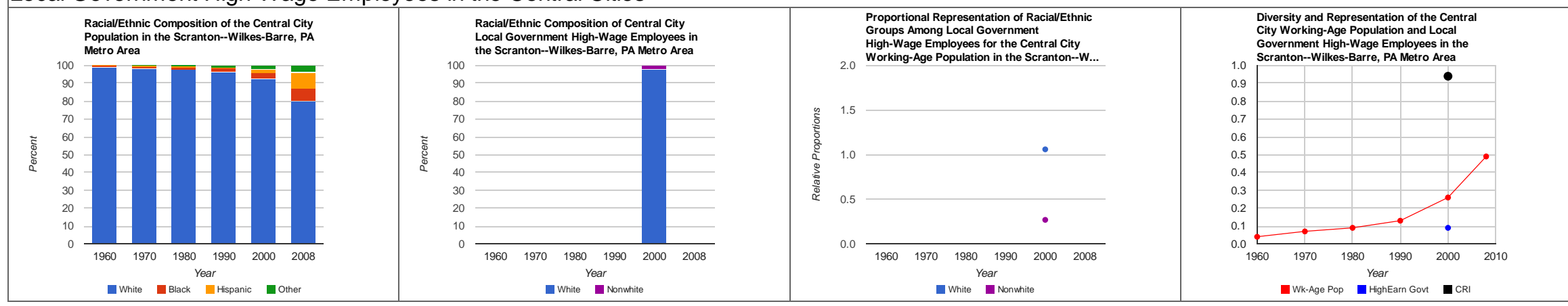
High- and Low-Wage Local Government Employment in the Scranton--Wilkes-Barre, PA Metro Area

Local Government Low-Wage Employees in the Metro Area
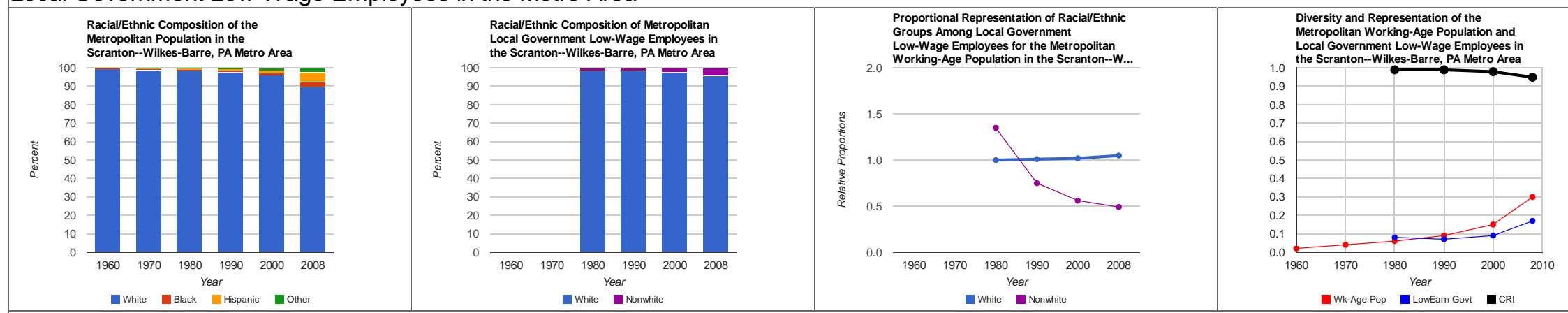

Local Government Low-Wage Employees in the Central Cities
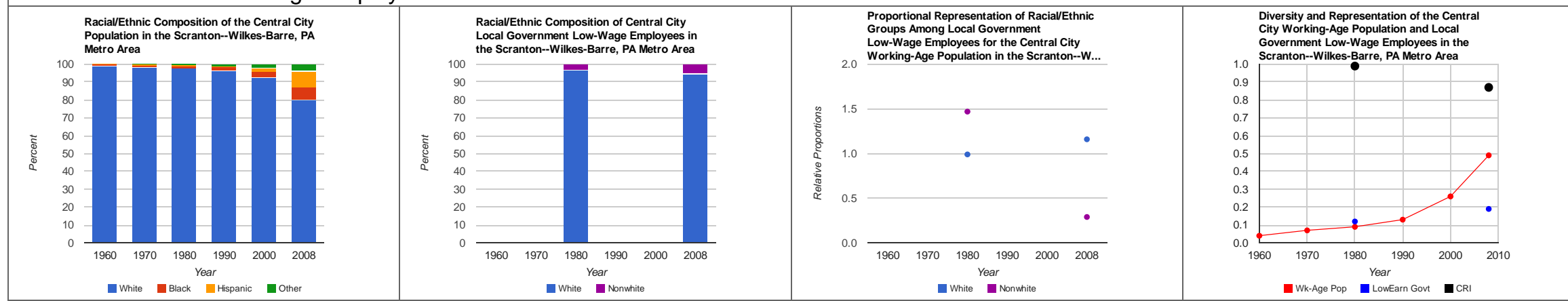


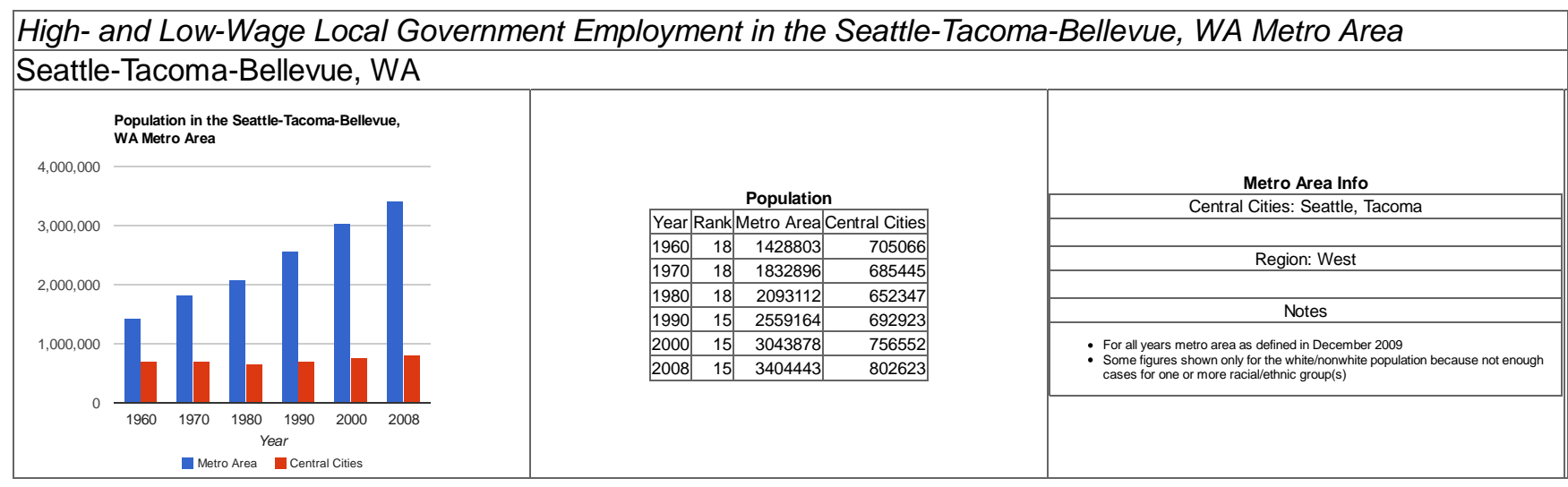


High- and Low-Wage Local Government Employment in the Seattle-Tacoma-Bellevue, WA Metro Area Local Government High-Wage Employees in the Metro Area
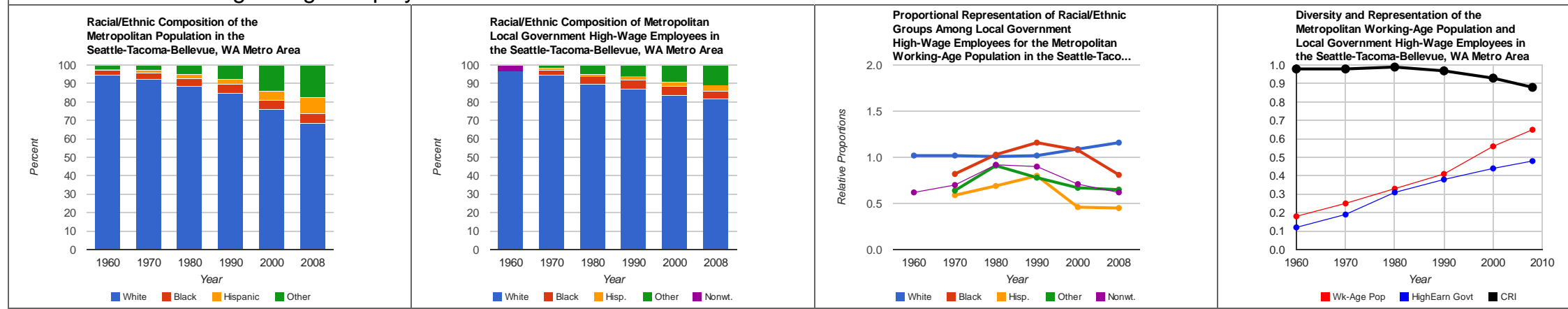

Local Government High-Wage Employees in the Central Cities
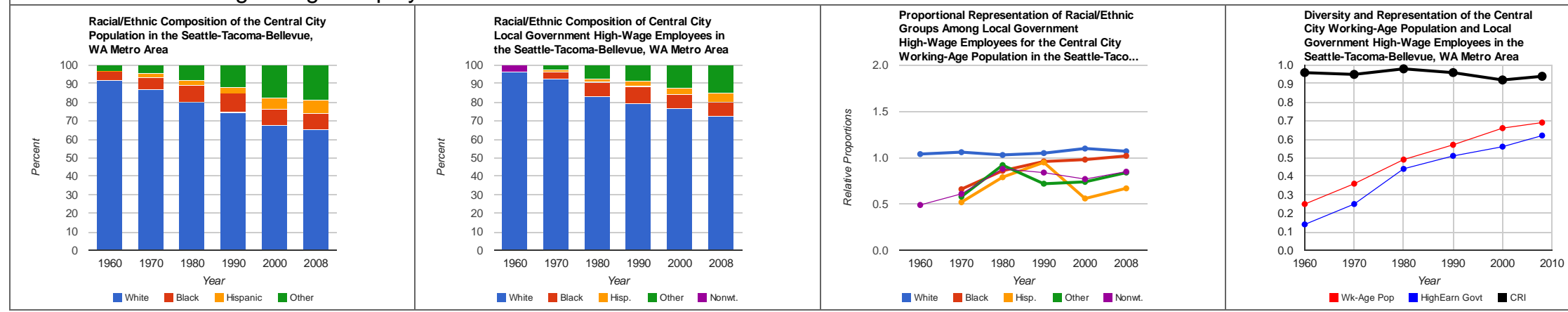
High- and Low-Wage Local Government Employment in the Seattle-Tacoma-Bellevue, WA Metro Area Local Government Low-Wage Employees in the Metro Area
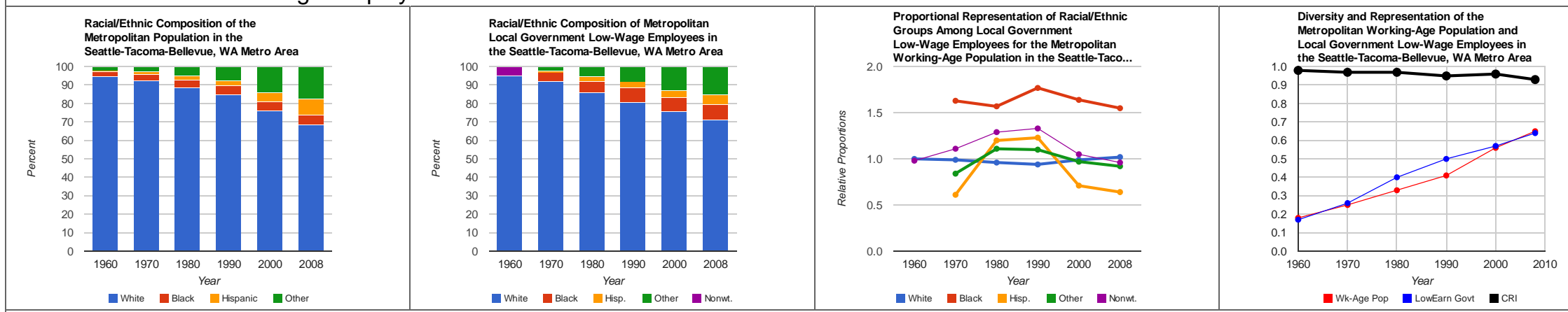

Local Government Low-Wage Employees in the Central Cities
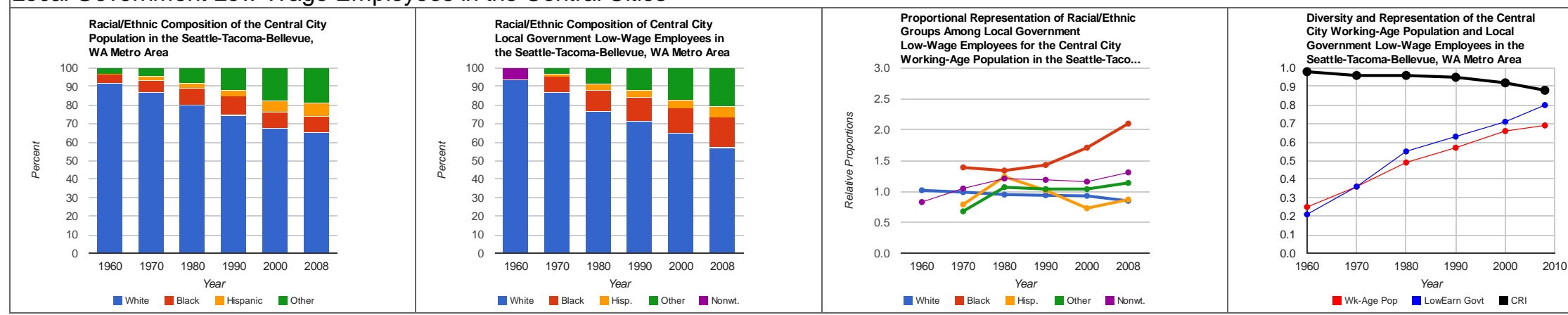
High- and Low-Wage Local Government Employment in the Springfield, MA Metro Area

Springfield, MA

Population in the Springrield, MA Metro Area

800,000

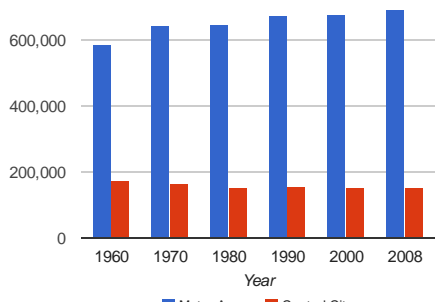

Population

Year Rank Metro Area Central City

\begin{tabular}{|l|l|l|l|}
\hline 1960 & 54 & 587446 & 174463 \\
\hline 1970 & 53 & 642241 & 15380 \\
\hline
\end{tabular}

\begin{tabular}{|l|l|l|l|}
1970 & 53 & 642241 & 163886 \\
\hline 1980 & 60 & 646148 & 152319 \\
\hline
\end{tabular}

\begin{tabular}{|l|l|l|l|}
\hline 1980 & 60 & 646148 & 152319 \\
\hline 1990 & 60 & 672970 & 156983 \\
\hline
\end{tabular}

$000000014 \quad 152082$

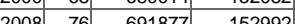

Metro Area Info

Central City: Springfield

nMetro Area $n$ Central City

\begin{tabular}{|c|}
\hline Metro Area Info \\
\hline Central City: Springfield \\
\hline Region: Northeast \\
\hline Notes \\
\hline 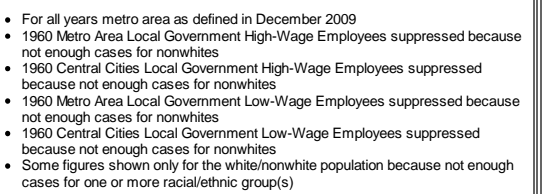 \\
\hline
\end{tabular}


High- and Low-Wage Local Government Employment in the Springfield, MA Metro Area

Local Government High-Wage Employees in the Metro Area
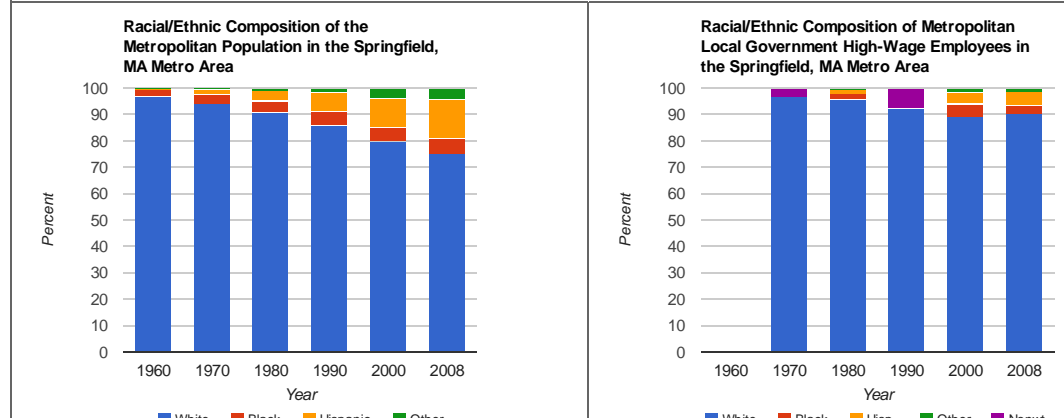

Local Government High-Wage Employees in the Central City

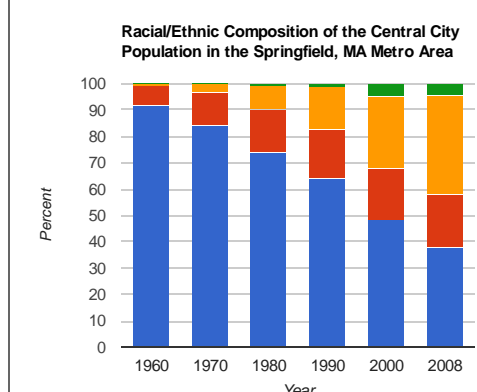

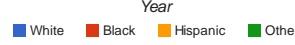

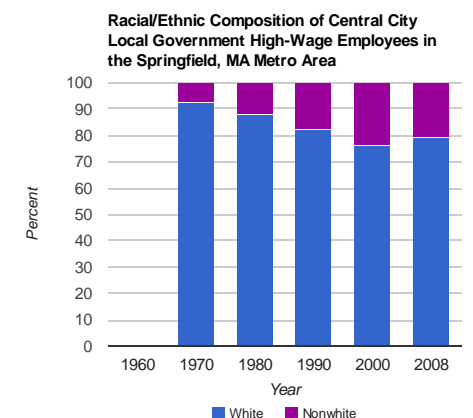

- White $\stackrel{\text { Year }}{\text { Nonwhite }}$
Proportional Representation of Racial/Ethnic Groups Among Local Government Working-Age Population in the Springfield, ...

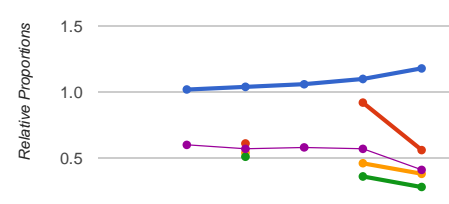

0.0 \begin{tabular}{llllll}
\hline 1960 & 1970 & 1980 & 1990 & 2000 & 2008
\end{tabular}

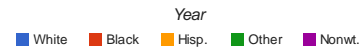

Proportional Representation of Racial/Ethnic Groups Among Local Government
High-Wage Employees for the Central High-Wage Employees for the Central City
Working-Age Population in the Springfield,

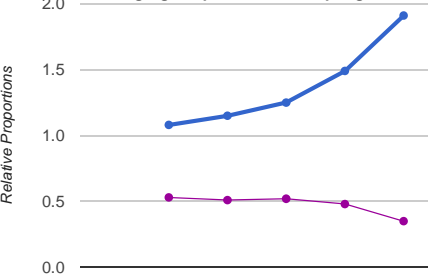

$0 . 0 \longdiv { 1 9 6 0 } \quad 1 9 7 0 \quad 1 9 8 0 \quad 1 9 9 0 \quad 2 0 0 0 \quad 2 0 0 8$ - White ${ }_{\text {Nonwhite }}^{\text {Year }}$ Diversity and Representation of the
Metropolitan Working-Age Population and
Local Government High-Wage Employees in the Springfield, MA Metro Area

\begin{tabular}{l|l}
1.0 \\
0.9
\end{tabular}

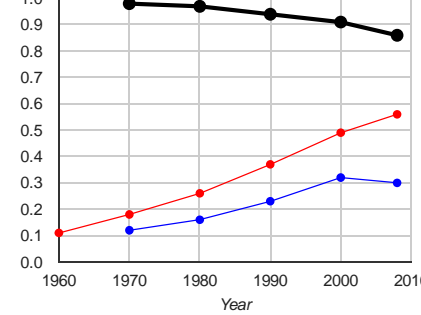

-Wk-Age Pop MHighEarn Govt

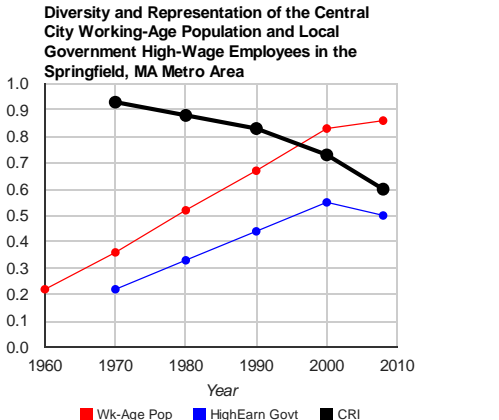

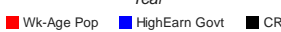


High- and Low-Wage Local Government Employment in the Springfield, MA Metro Area

Local Government Low-Wage Employees in the Metro Area
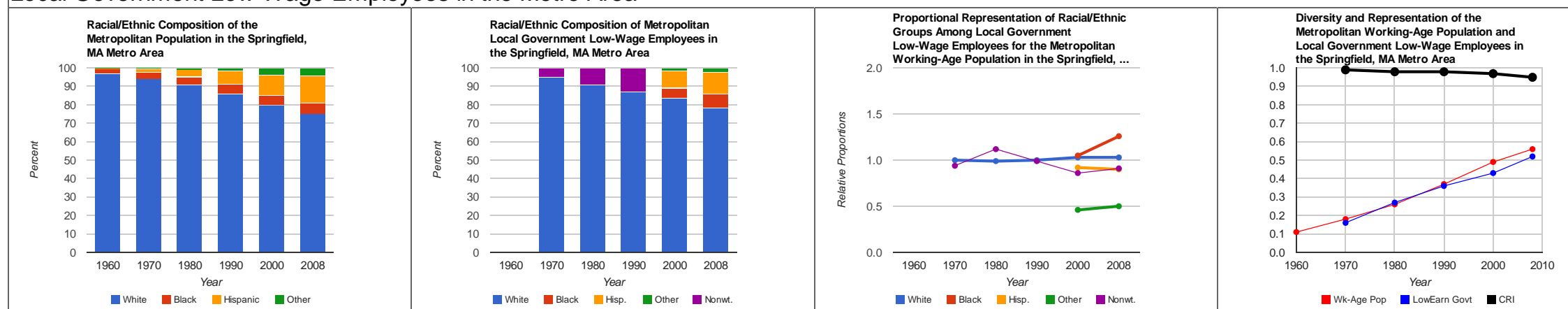

Local Government Low-Wage Employees in the Central City
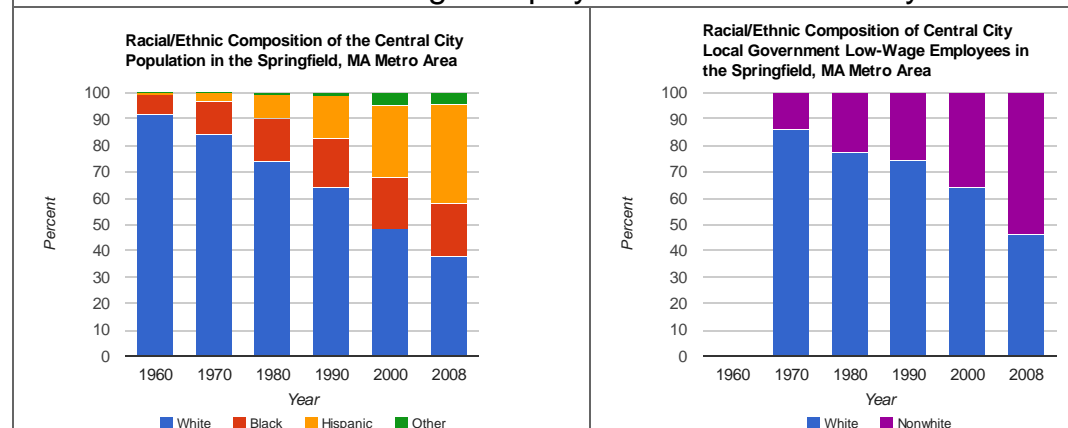
Proportional Representation of RaciallEthnic
Groups Among Local Government
Low-Whage Working-Age Population in the Springfield, ,...

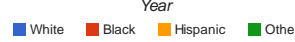
- White $\stackrel{\text { Year }}{\text { Nonwhite }}$

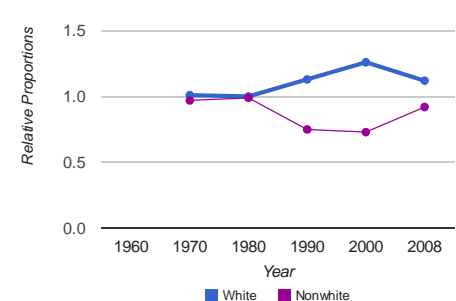

White $\quad$ Year

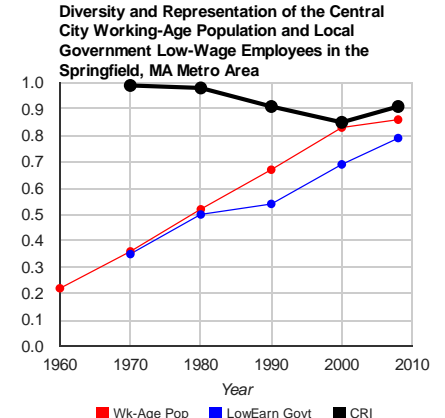

-Wk-Age Pop GLowEarn Govt - $\mathrm{CRl}$ 


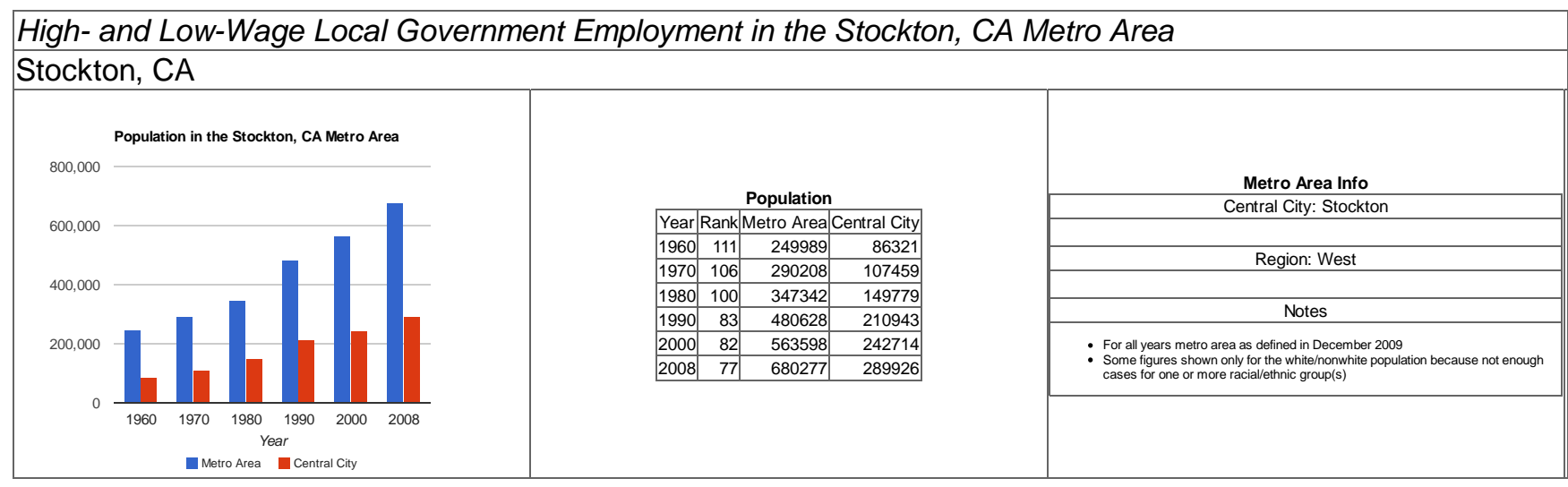


High- and Low-Wage Local Government Employment in the Stockton, CA Metro Area

Local Government High-Wage Employees in the Metro Area
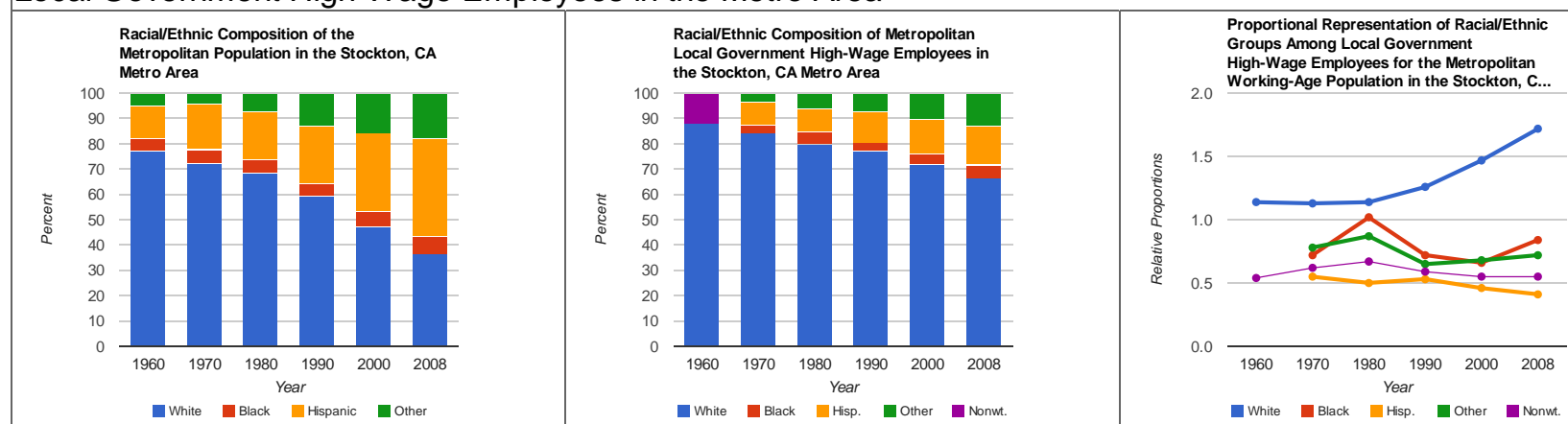

Diversity and Representation of the
Metropolitan Working-Age Population Metropolitan Working-Age Population and
Local Government High-Wage Employees in the Stockton, CA Metro Area White 1 Black MHisp.

Local Government High-Wage Employees in the Central City RaciallEthnic Composition of the Central City
Population in the Stockton, CA Metro Area

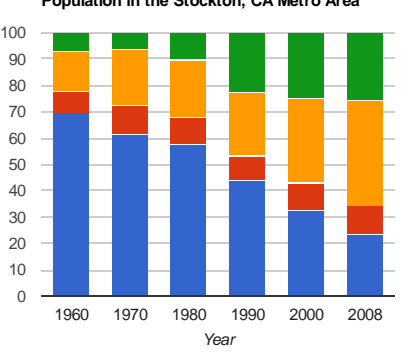

Raciallethnic Composition of Central City
Local Government

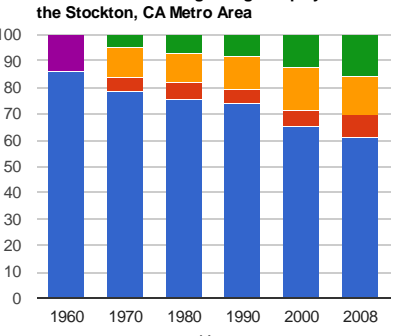

WWite MBlack Hear Hispanic Mother

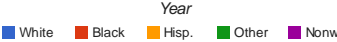

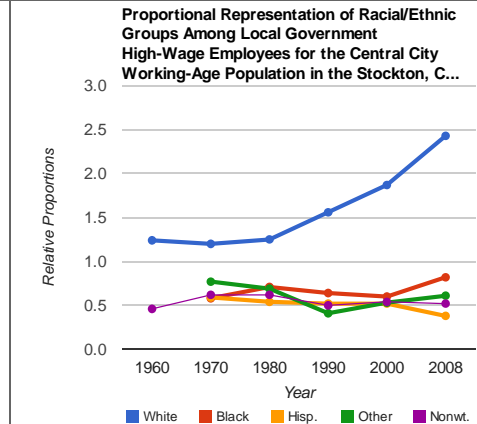

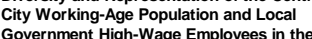
10 Stockton, CA Metro Area

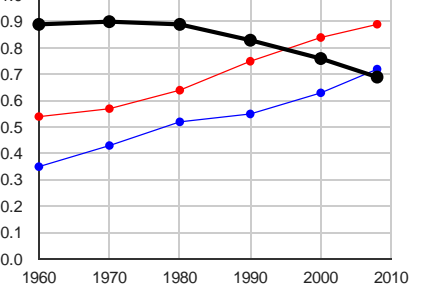

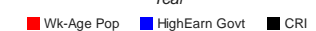

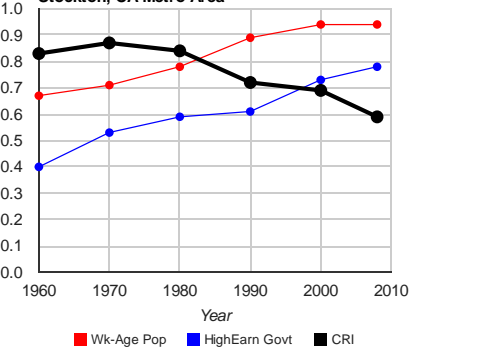


High- and Low-Wage Local Government Employment in the Stockton, CA Metro Area

Local Government Low-Wage Employees in the Metro Area
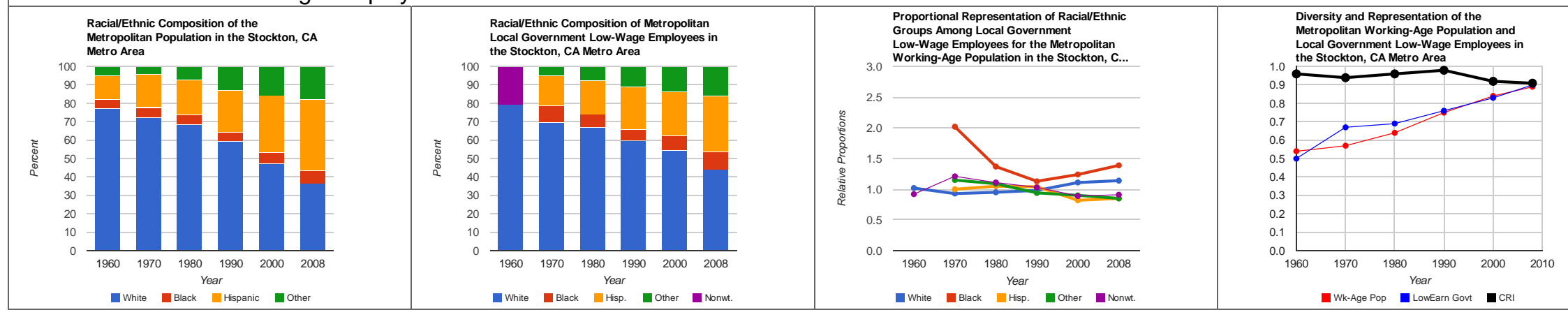

Local Government Low-Wage Employees in the Central City
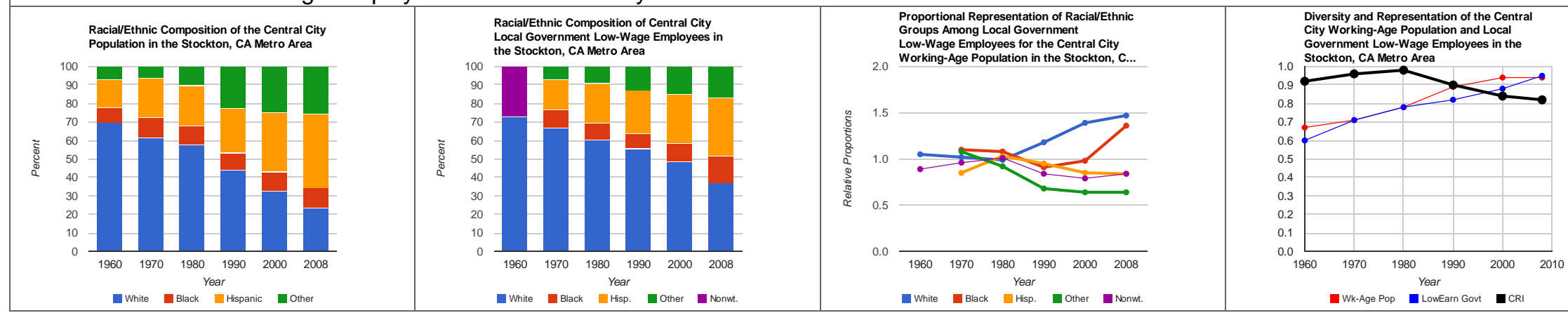
High- and Low-Wage Local Government Employment in the Syracuse, NY Metro Area

Syracuse, NY

Population in the Syracuse, NY Metro Area

800,000

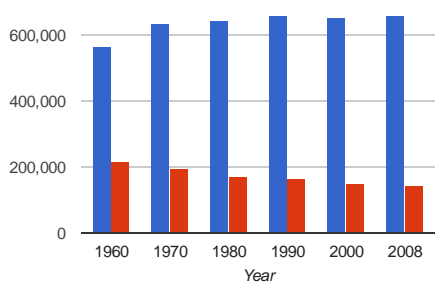

Population

Year $/$ Rank/Metro ArealCentral City

\begin{tabular}{|l|l|l|l|}
\hline 1960 & 56 & 563781 & 216038 \\
\hline 1970 & 55 & 635507 & 167270 \\
\hline
\end{tabular}

\begin{tabular}{|l|l|l|l|l|}
1970 & 55 & 636507 & 197270 \\
\hline 1980 & 61 & 642971 & 170105 \\
\hline
\end{tabular}

\begin{tabular}{|l|lll|l|}
\hline 1980 & 61 & 642971 & 170105 \\
\hline 1990 & 64 & 659864 & 163860 \\
\hline
\end{tabular}

\begin{tabular}{|l|l|l|l|}
2000 & 72 & 650154 & 147326
\end{tabular}

2008 - $80 \quad-060283 \quad 144883$

Metro Area Info

Central City: Syracuse

nMetro Area $n$ Central City

\begin{tabular}{|c|}
\hline Metro Area Info \\
\hline Central City: Syracuse \\
\hline Region: Northeast \\
\hline Notes \\
\hline 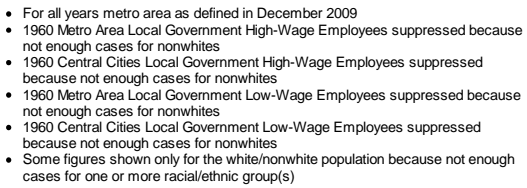 \\
\hline
\end{tabular}


High- and Low-Wage Local Government Employment in the Syracuse, NY Metro Area

Local Government High-Wage Employees in the Metro Area
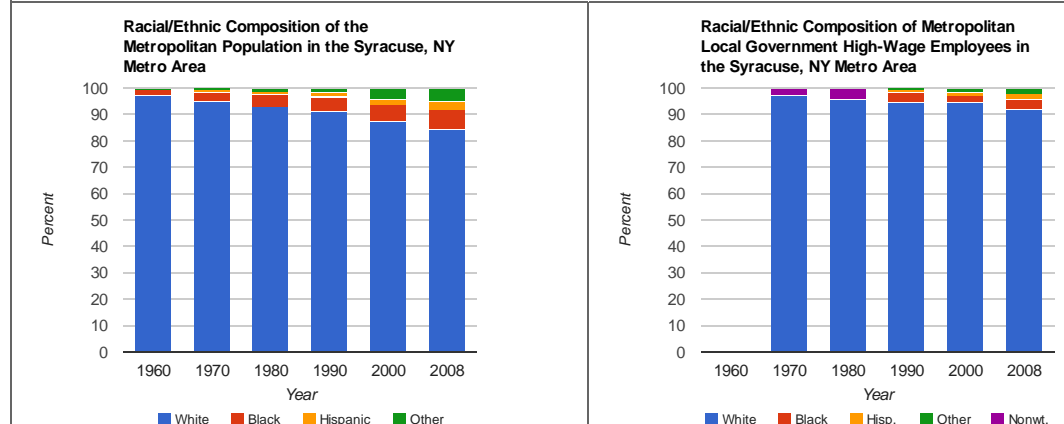

Local Government High-Wage Employees in the Central City

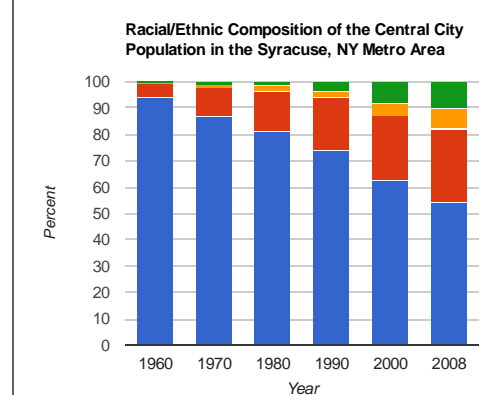

White Inlack Hear Hispanic nother

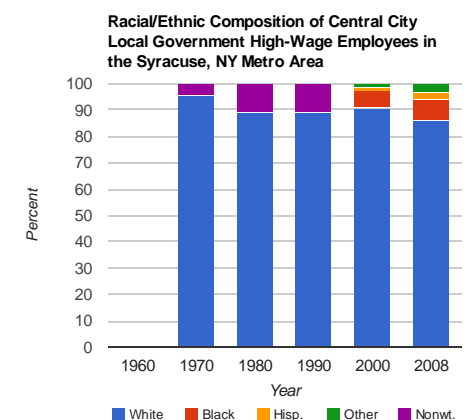

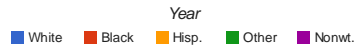

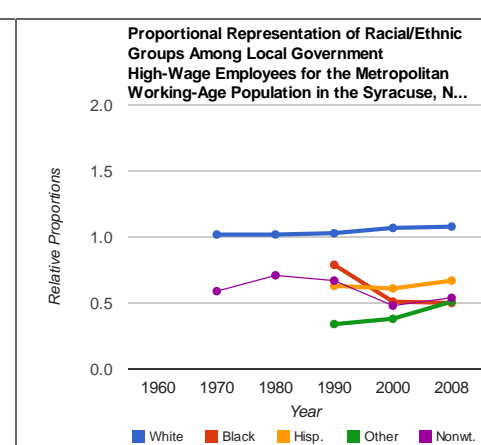

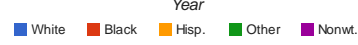

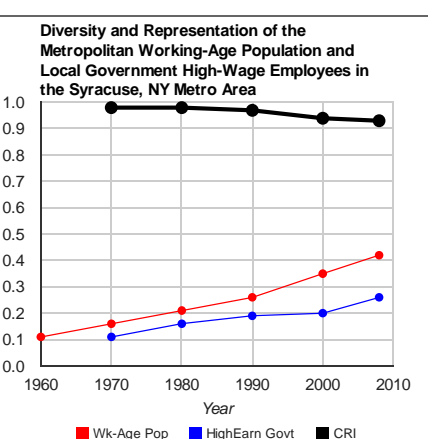

Wk-Age Pop MHighEarn Govt - CR
Proportional Representation of RaciallEthnic Groups Among Local Government
High-Wage High-Wage Employes for the Central City
Working-Age Population in the Syracuse, N...

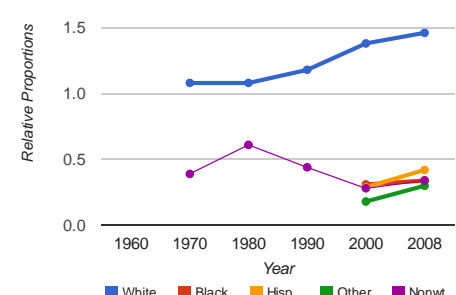

Diversity and Representation of the Central City Working-Age Population and Local
Government High-Wage Employees in the

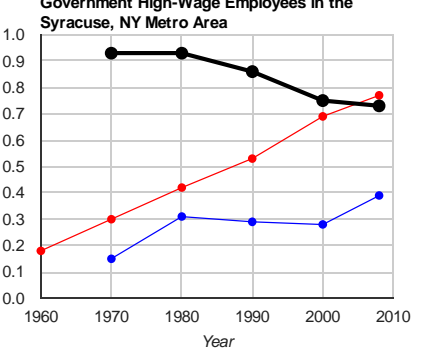

—Wk-Age Pop - Year 
High- and Low-Wage Local Government Employment in the Syracuse, NY Metro Area

Local Government Low-Wage Employees in the Metro Area
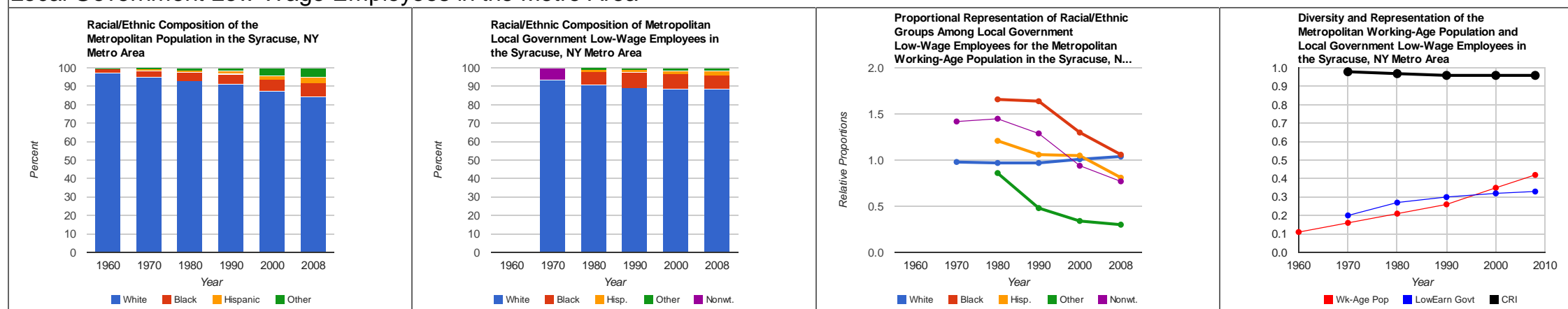

Local Government Low-Wage Employees in the Central City
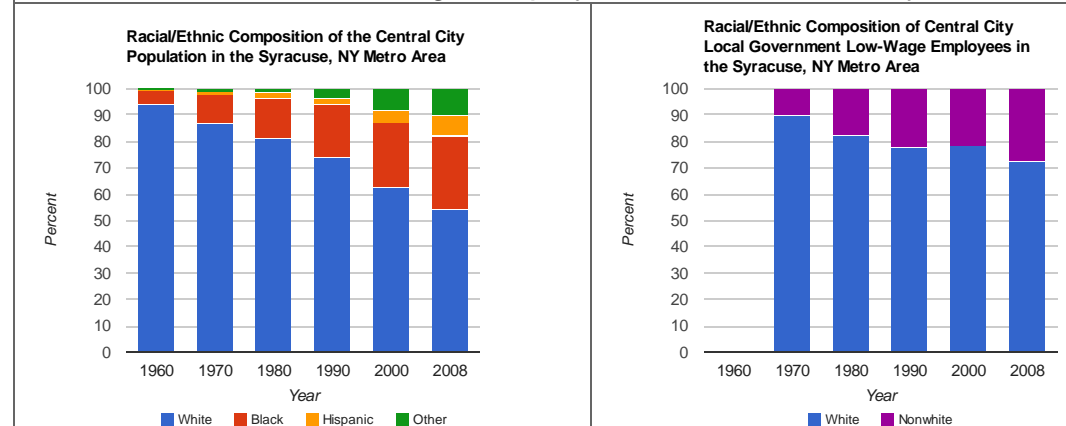
Proportional Representation of RaciallEthn
Groups Among Local Government
Low-Wage Employees for the Central City Working-Age Population in the Syracuse, N...

- White Inlack Year Hispanic Inother - White $\stackrel{\text { Year }}{\text { Nonwhite }}$

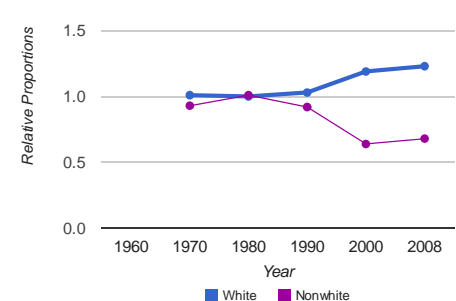

White $\quad$ Year

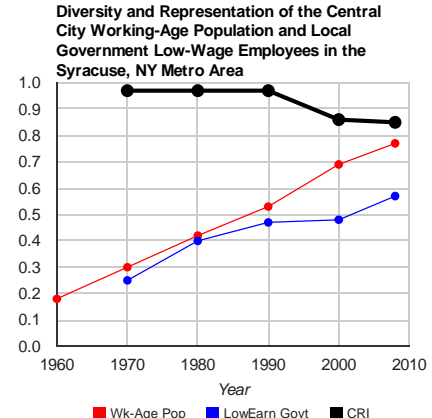

- Wk-Age Pop L LowEarn Govt 


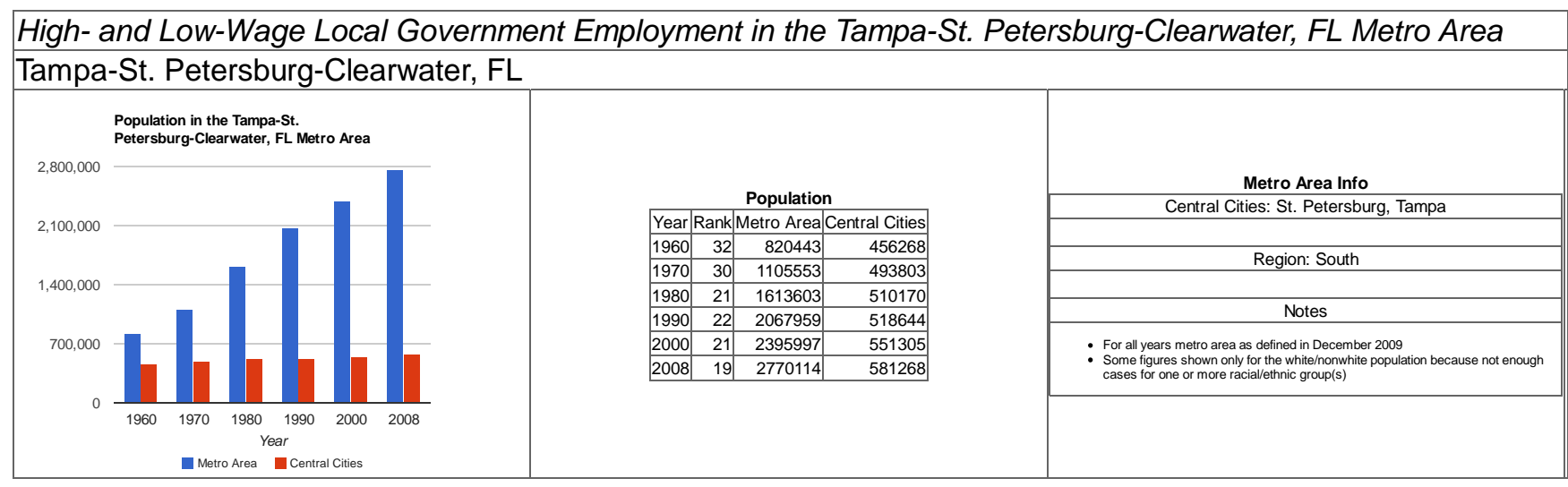


High- and Low-Wage Local Government Employment in the Tampa-St. Petersburg-Clearwater, FL Metro Area Local Government High-Wage Employees in the Metro Area
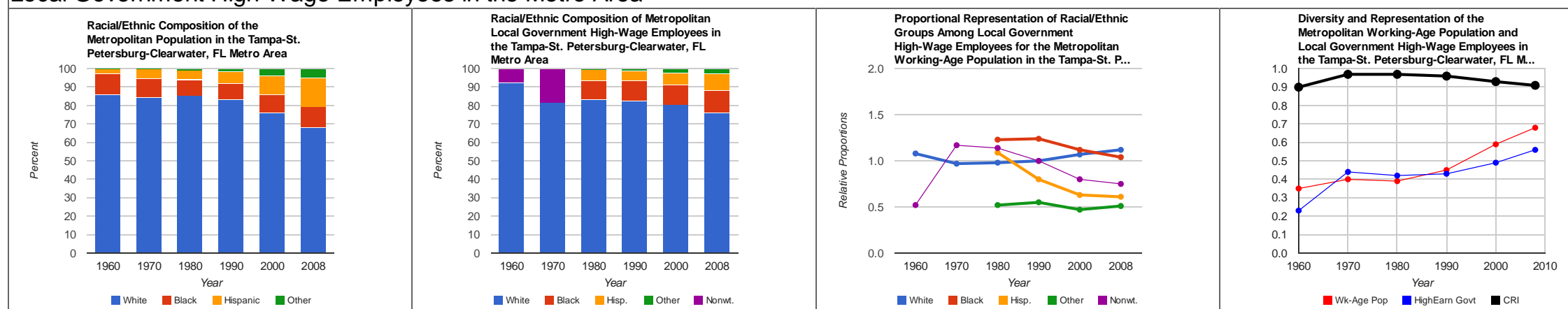

Local Government High-Wage Employees in the Central Cities
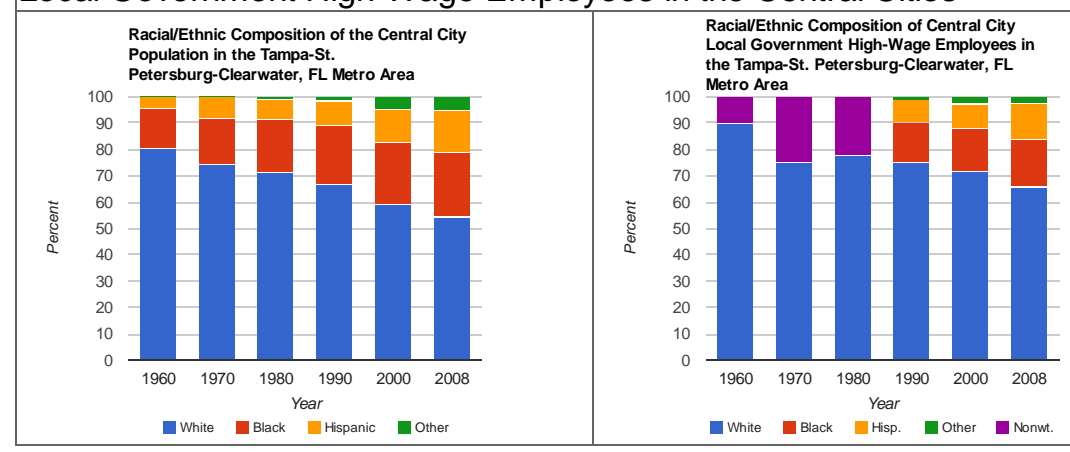
Proportional Representation of Raciall/thnic
Groups Among Local Government
High-Wage Employees for the Central City 20 Working-Age Population in the Tampa-St. P... White 1 Black Year

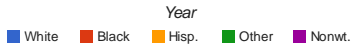

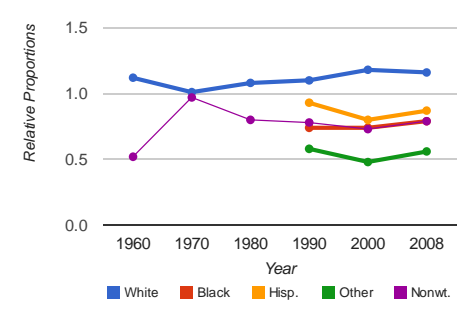
Diversity and Representation of the Central
City Working-Age Population and Local
Government ligh-Wage Employees in the Government High-Wage Employees in the
Tampa-St. Petersburg-Clearwater, FL Metr...

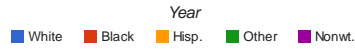

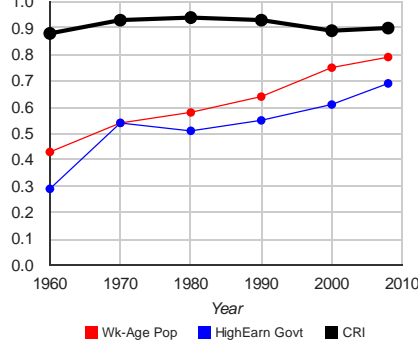


High- and Low-Wage Local Government Employment in the Tampa-St. Petersburg-Clearwater, FL Metro Area Local Government Low-Wage Employees in the Metro Area
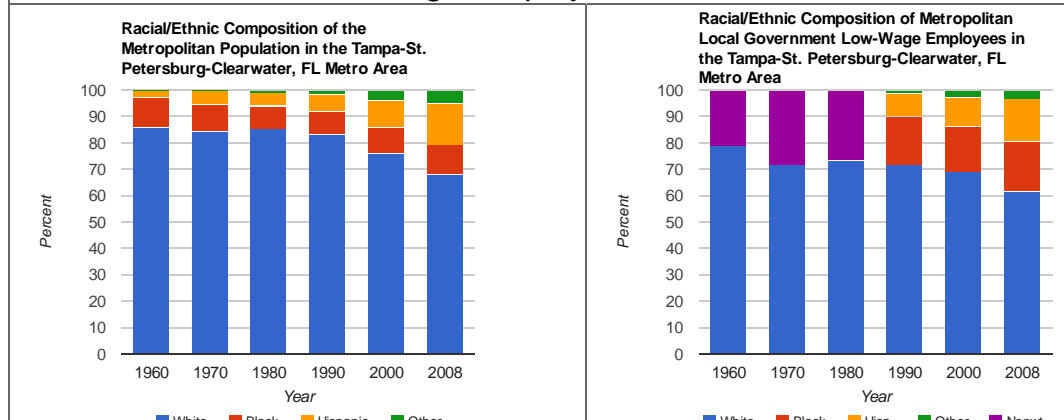

Local Government Low-Wage Employees in the Central Cities
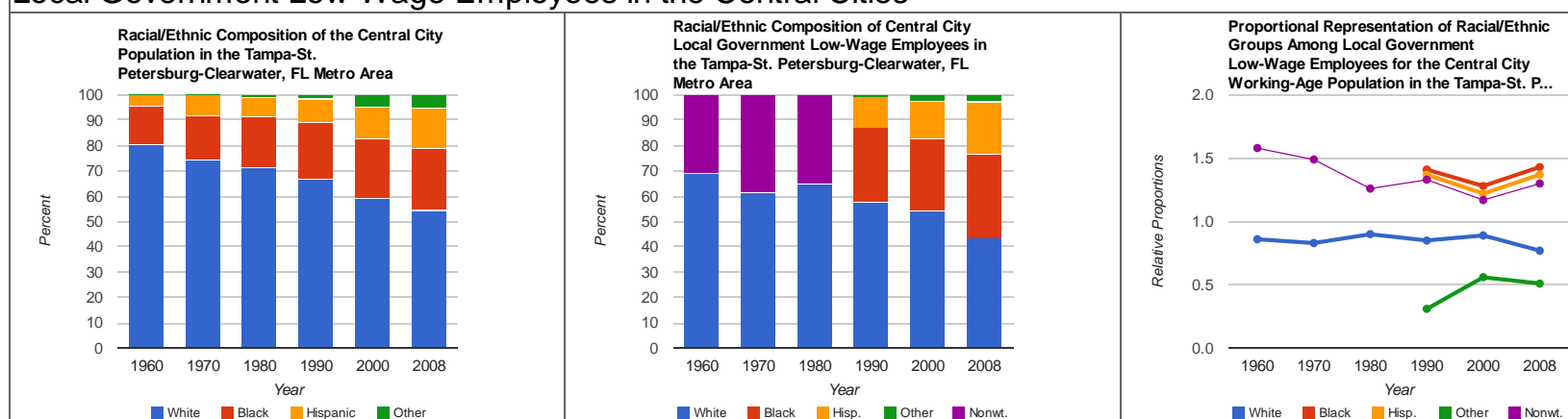
Proportional Representation of Raciall/Ethnic
Groups Among Local Government
Low-Wage Employees for the Metropolitan Working-Age Population in the Tampa-St. P...

White $\square$ Black $\quad$ Hispanic $\quad$ Other

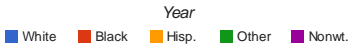

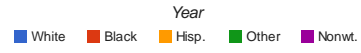
Diversity and Representation of the Central
City Working-Age Population and Local
Government Low-Wage Employees in the

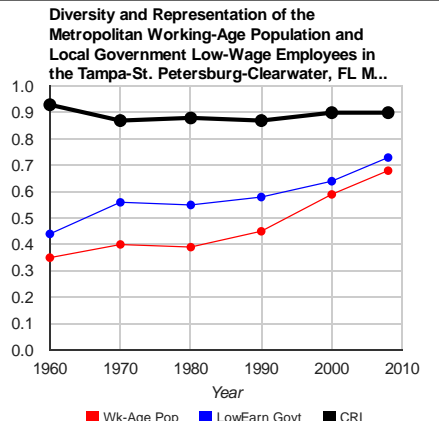

-Wk-Age Pop LowEarn Gout - CPI

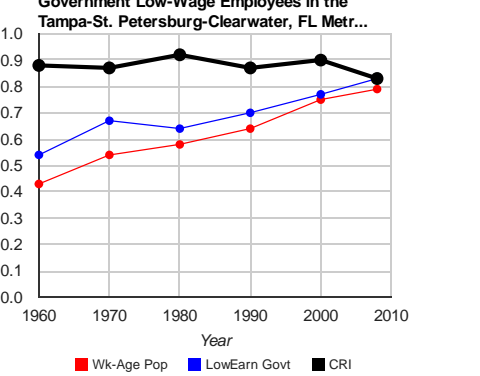


High- and Low-Wage Local Government Employment in the Toledo, OH Metro Area

Toledo, $\mathrm{OH}$

Population in the Toledo, OH Metro Area

800,000

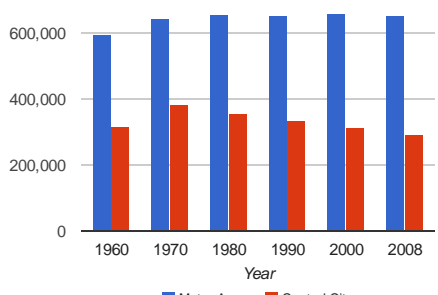

Population

Year Rank Metro Area Central City

\begin{tabular}{|l|l|l|l|}
\hline 1960 & 52 & 594151 & 318003 \\
\hline 1970 & 52 & 641262 & 38015 \\
\hline
\end{tabular}

\begin{tabular}{|l|l|l|l|l|l|}
1970 & 52 & 644262 & 384015 \\
\hline 1980 & 56 & 65690 & 354635 \\
\hline
\end{tabular}

\begin{tabular}{|l|l|l|l|l|}
\hline 1980 & 56 & 656940 & 354635 \\
\hline 1990 & 66 & 654157 & 332943 \\
\hline
\end{tabular}

$2000 \quad 71 \quad 059180 \quad 313587$

\begin{tabular}{|l|l|l|l|}
\hline 2000 & 71 & 659188 & 313587 \\
\hline 2008 & 81 & 652484 & 289628 \\
\hline
\end{tabular}

Metro Area Info

Central City: Toledo

Region: Midwest

nMetro Area $n$ Central City 
High- and Low-Wage Local Government Employment in the Toledo, OH Metro Area

Local Government High-Wage Employees in the Metro Area
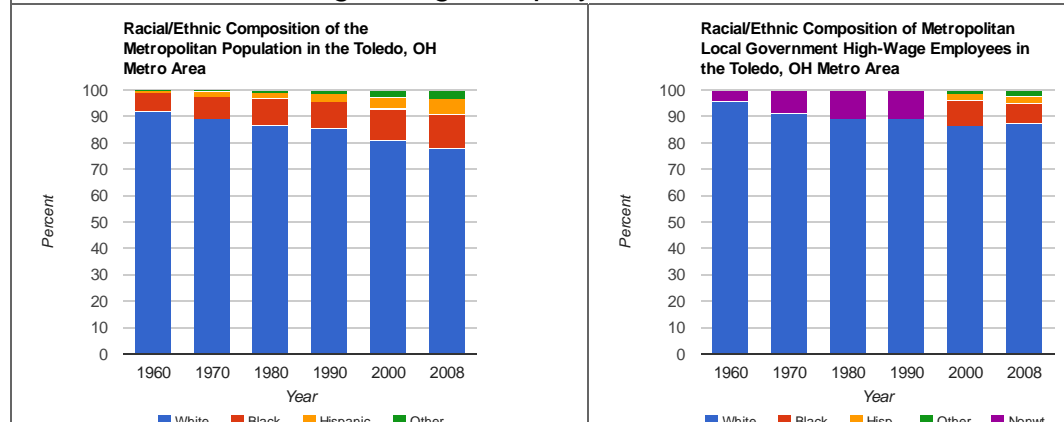

Local Government High-Wage Employees in the Central City
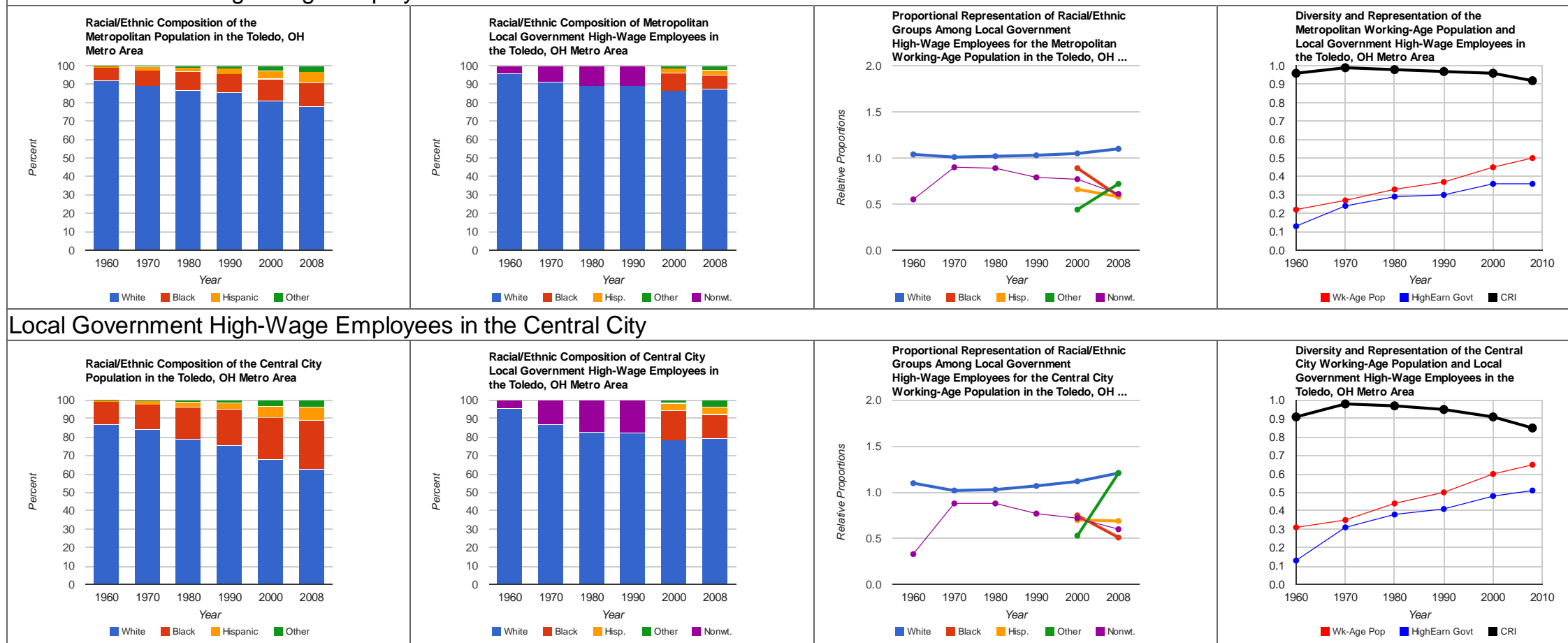

White In Black Inspanic Inother

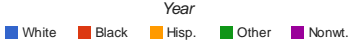

White In Black Yrear

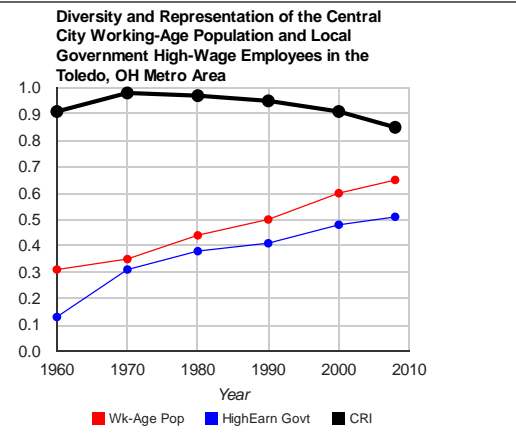


High- and Low-Wage Local Government Employment in the Toledo, OH Metro Area

Local Government Low-Wage Employees in the Metro Area
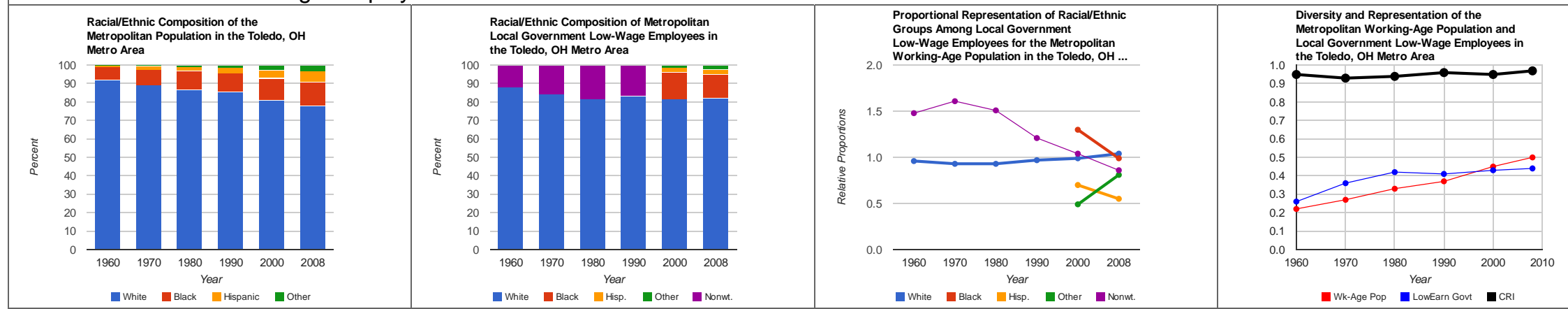

Local Government Low-Wage Employees in the Central City
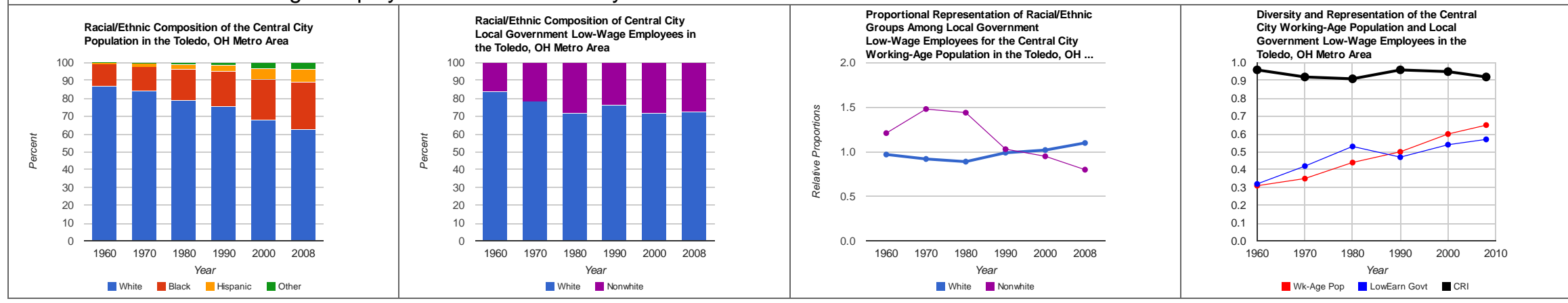


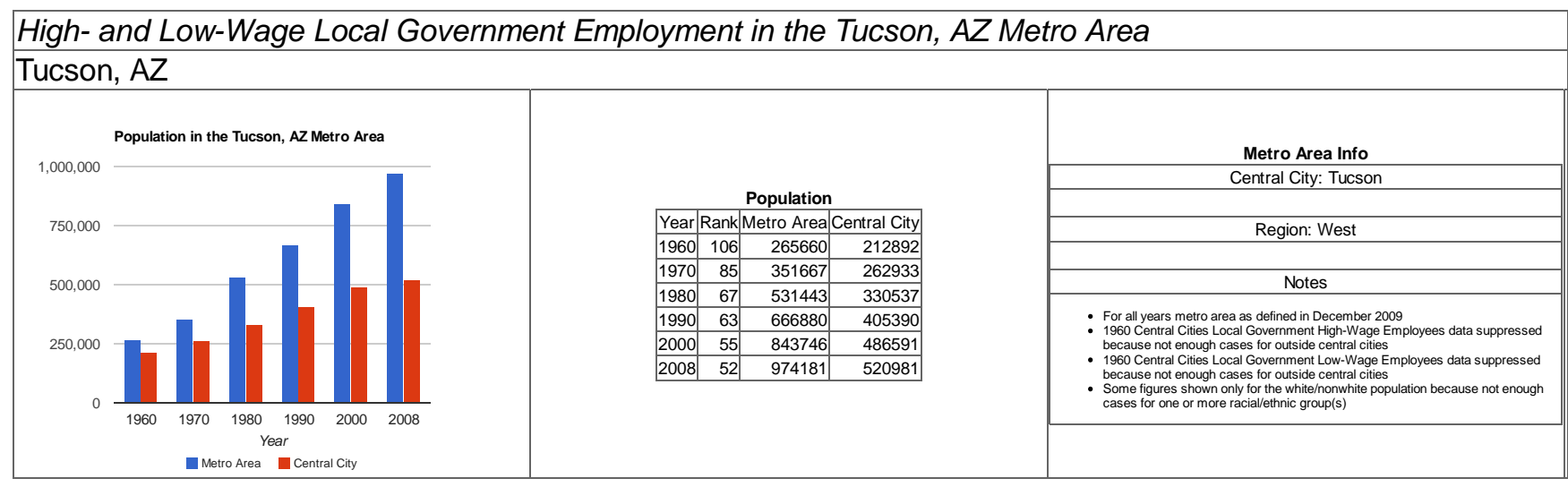


High- and Low-Wage Local Government Employment in the Tucson, AZ Metro Area

Local Government High-Wage Employees in the Metro Area
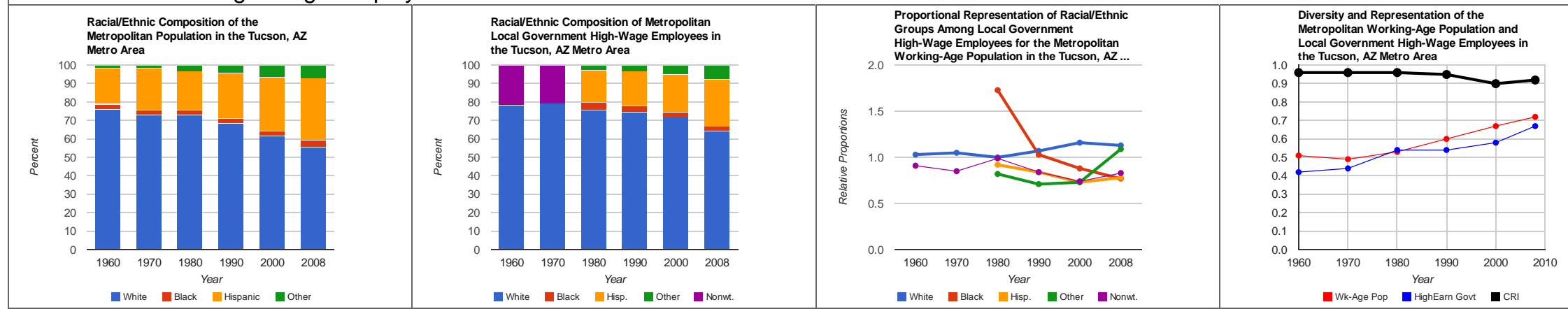

Local Government High-Wage Employees in the Central City
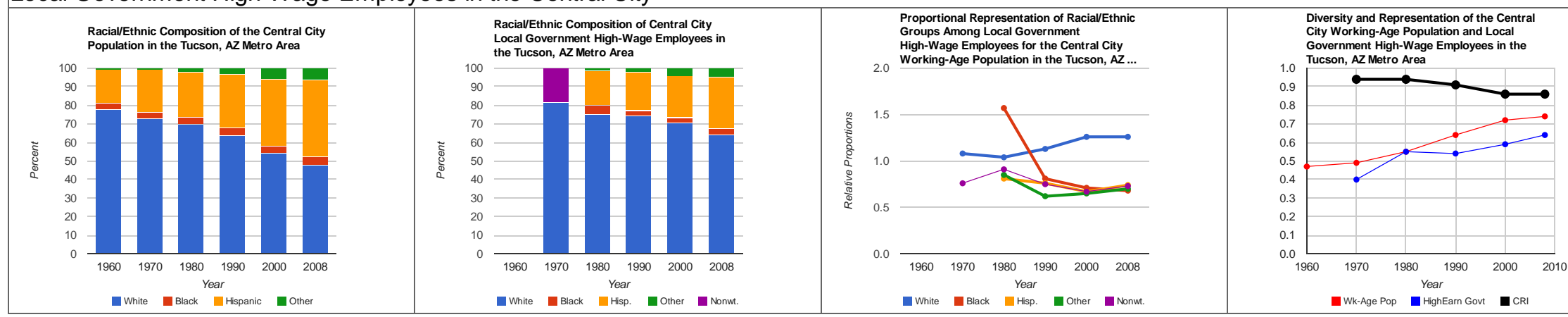
High- and Low-Wage Local Government Employment in the Tucson, AZ Metro Area

Local Government Low-Wage Employees in the Metro Area
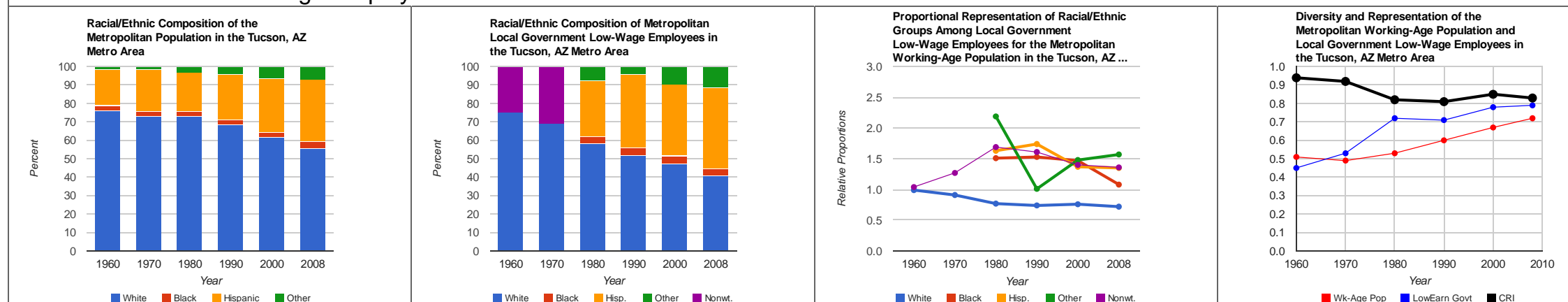

Local Government Low-Wage Employees in the Central City
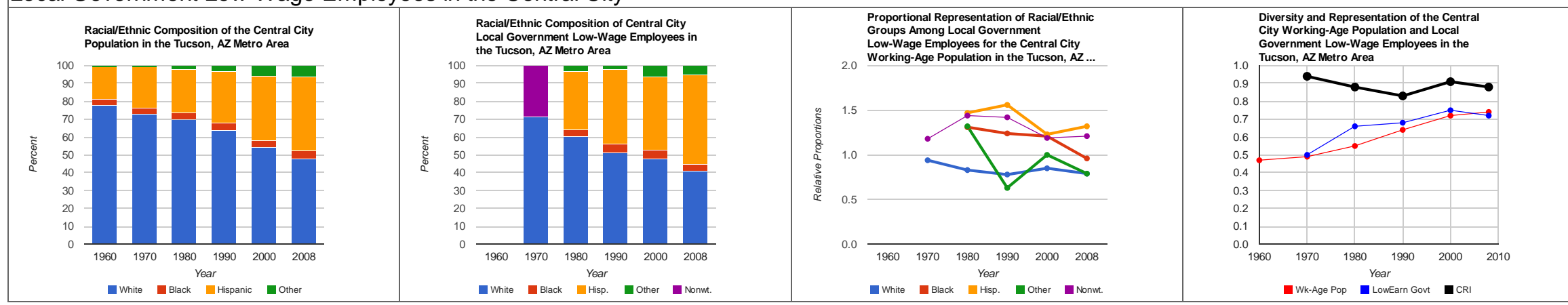


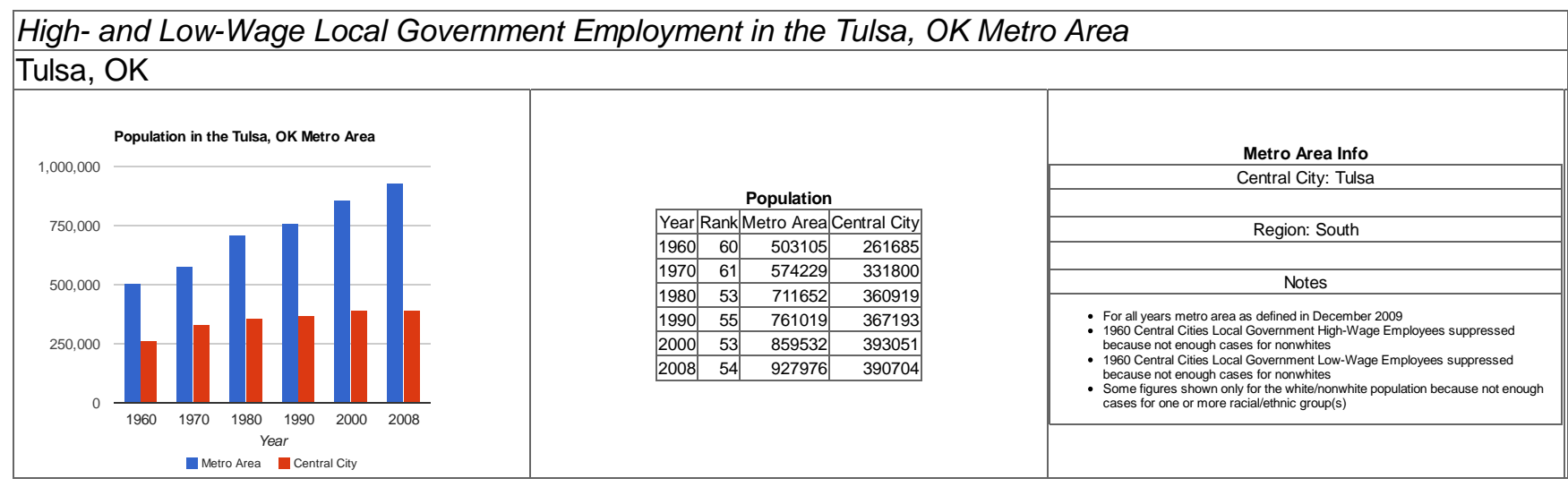


High- and Low-Wage Local Government Employment in the Tulsa, OK Metro Area

Local Government High-Wage Employees in the Metro Area
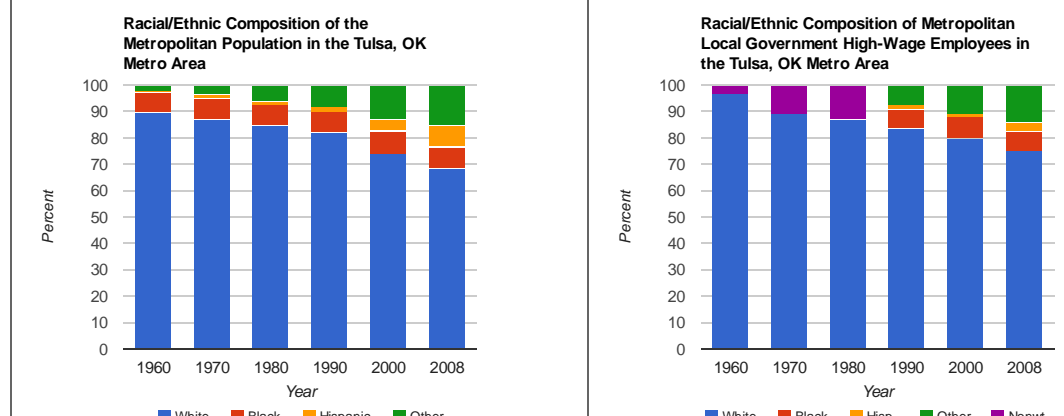

Local Government High-Wage Employees in the Central City
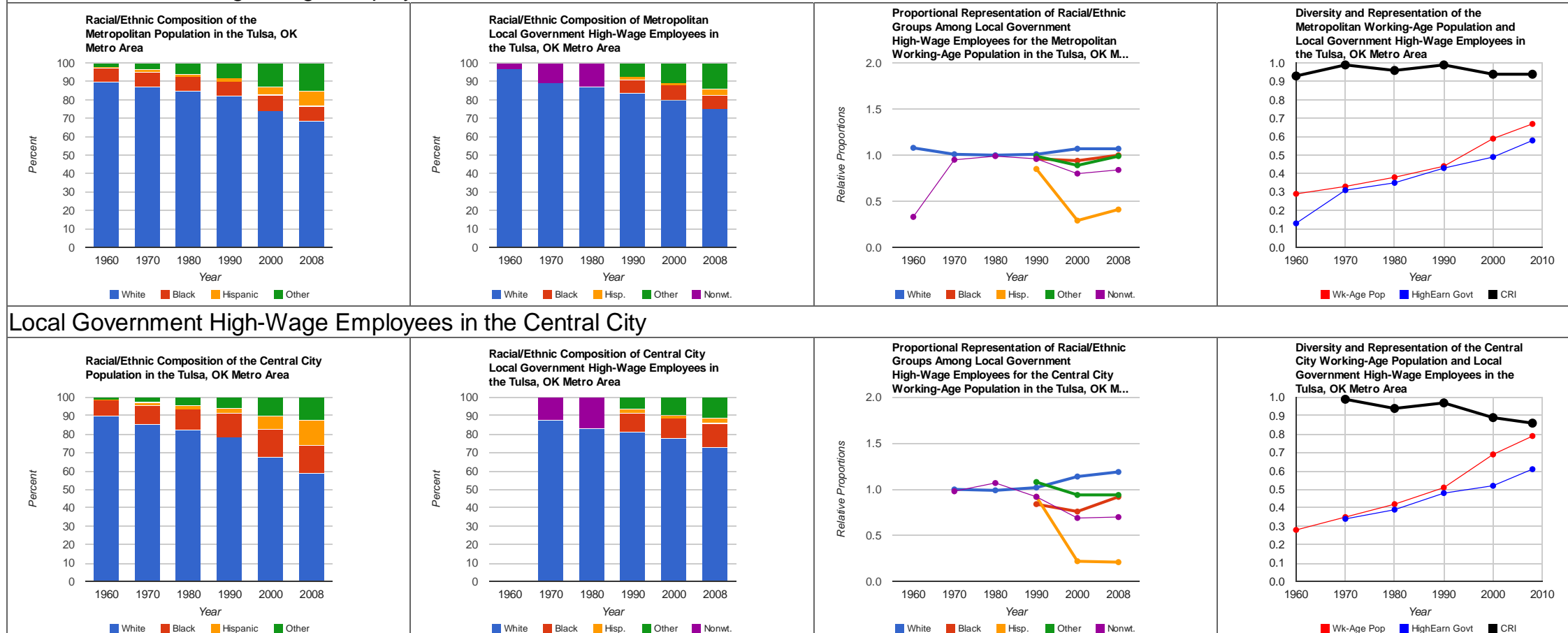

White Elack Hispanic Wother

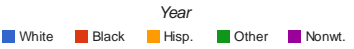

- White Black Year

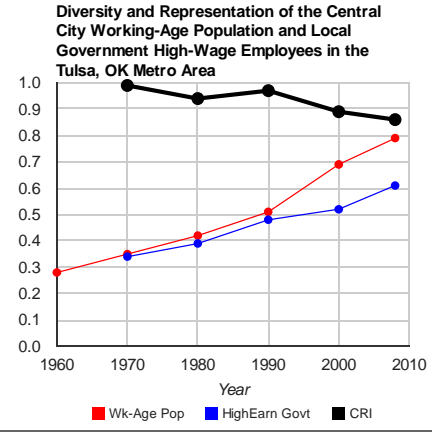


High- and Low-Wage Local Government Employment in the Tulsa, OK Metro Area

Local Government Low-Wage Employees in the Metro Area
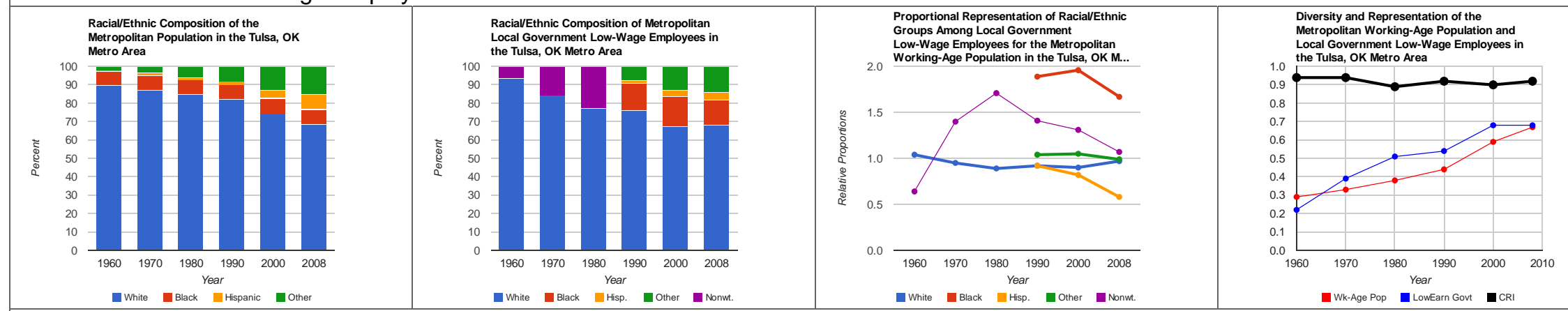

Local Government Low-Wage Employees in the Central City
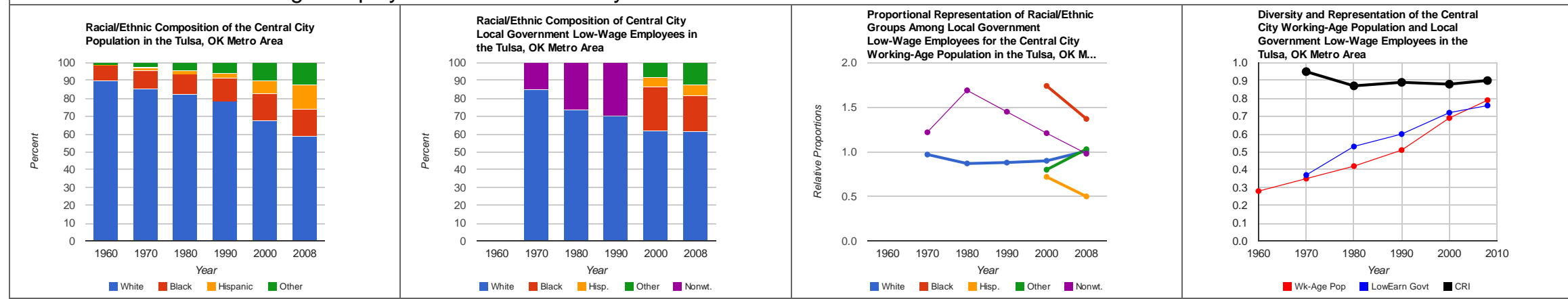


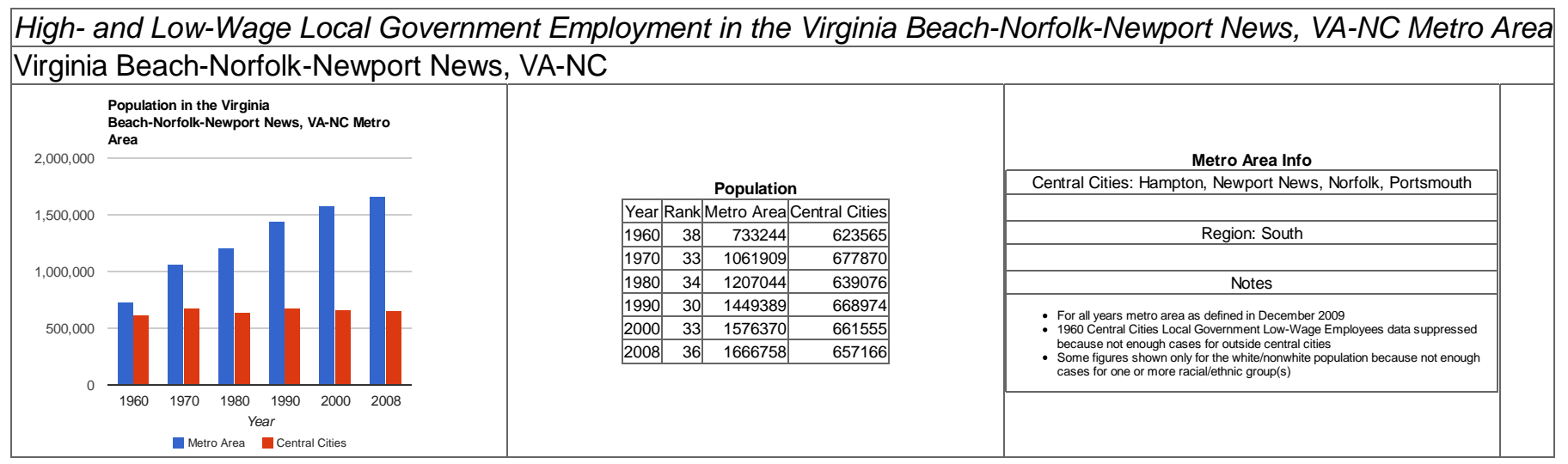


High- and Low-Wage Local Government Employment in the Virginia Beach-Norfolk-Newport News, VA-NC Metro Area Local Government High-Wage Employees in the Metro Area
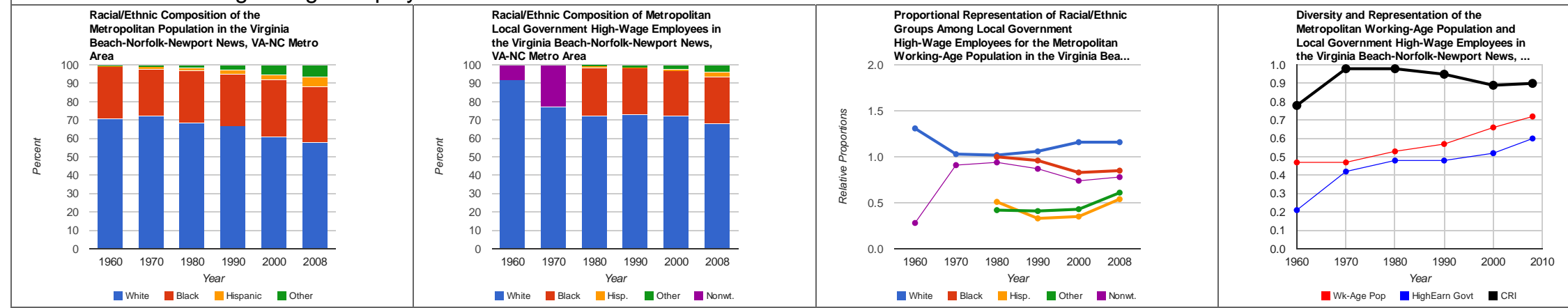

Local Government High-Wage Employees in the Central Cities
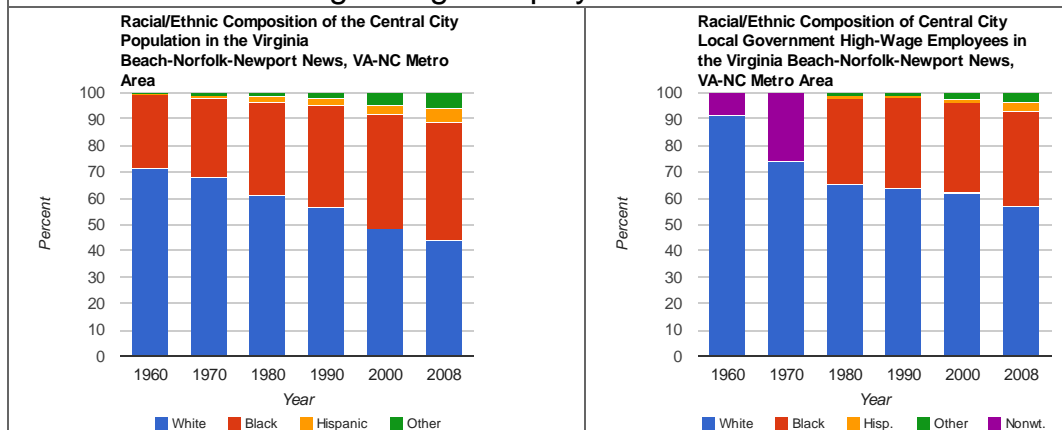
Proportional Representation of Raciall/thnic
Groups Among Local Government
High-Wage Employees for the Central City 2.0 Working-Age Population in the Virginia Bea... White Ulack Hear Hispanic nother

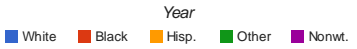
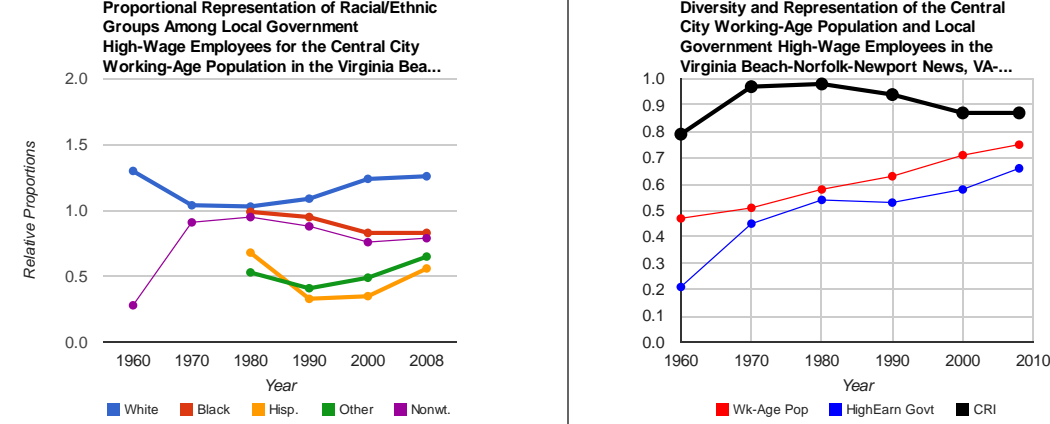
High- and Low-Wage Local Government Employment in the Virginia Beach-Norfolk-Newport News, VA-NC Metro Area Local Government Low-Wage Employees in the Metro Area
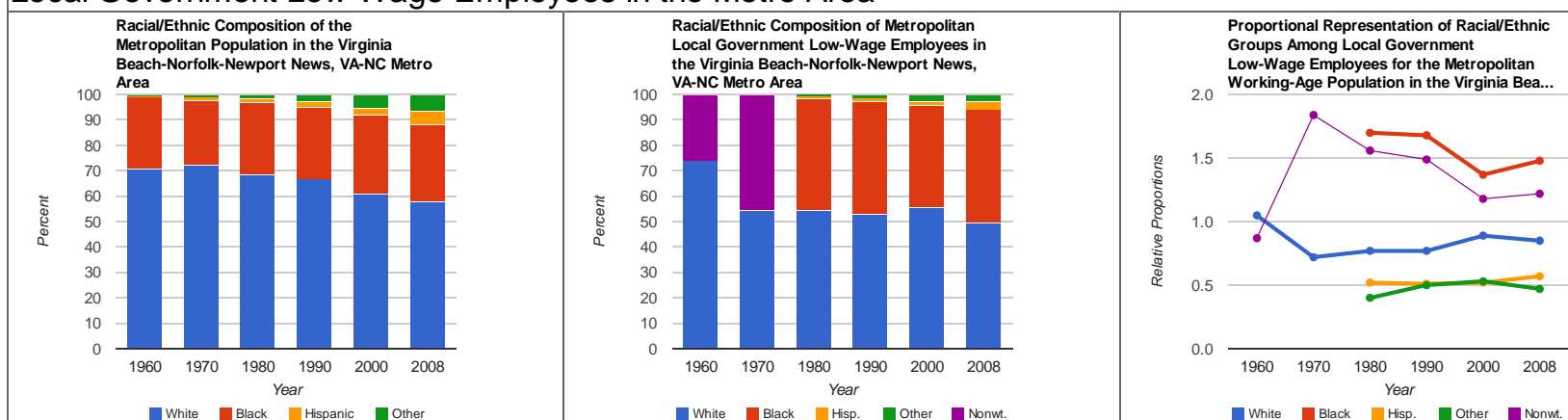

Diversity and Representation of the
Metropolitan Working-Age Population and

White Black Hispanic other

White M Black Year

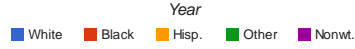

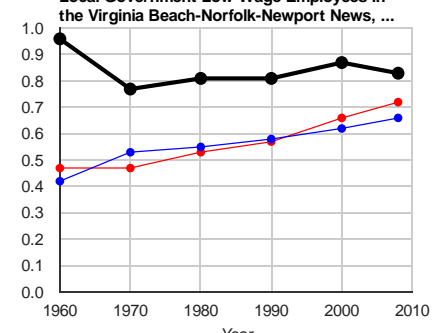

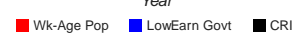

Local Government Low-Wage Employees in the Central Cities

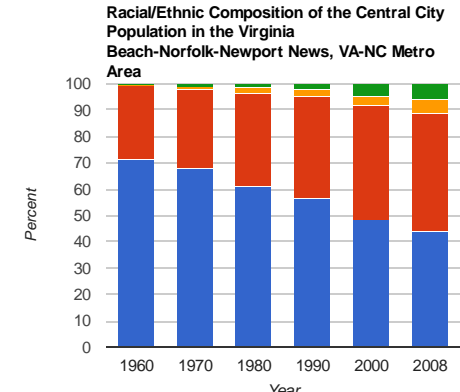

White Ilack Hear Hispanic nother

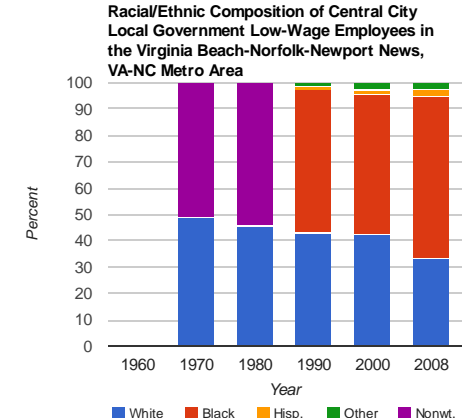

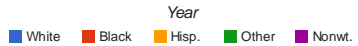

Proportional Representation of Racial/Ethnic
Groups Among Local Low-Wage Employees for the Central City
Working-Age Population in the Virginia Ba

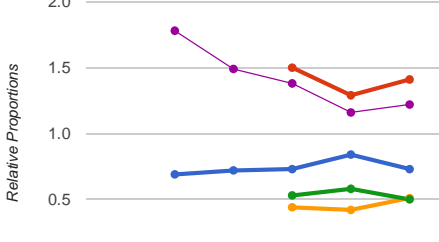

0.0 \begin{tabular}{llllll}
\hline 1960 & 1970 & 1980 & 1990 & 2000 & 2008
\end{tabular}

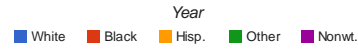

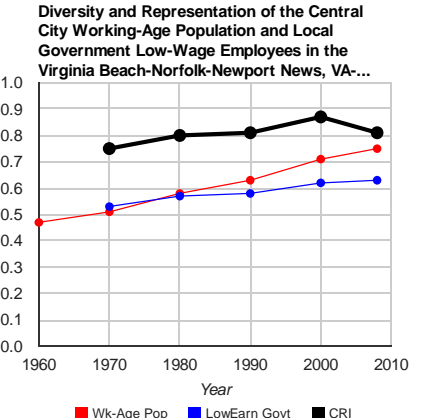

-Wk-Age Pop L LowEarn Govt 


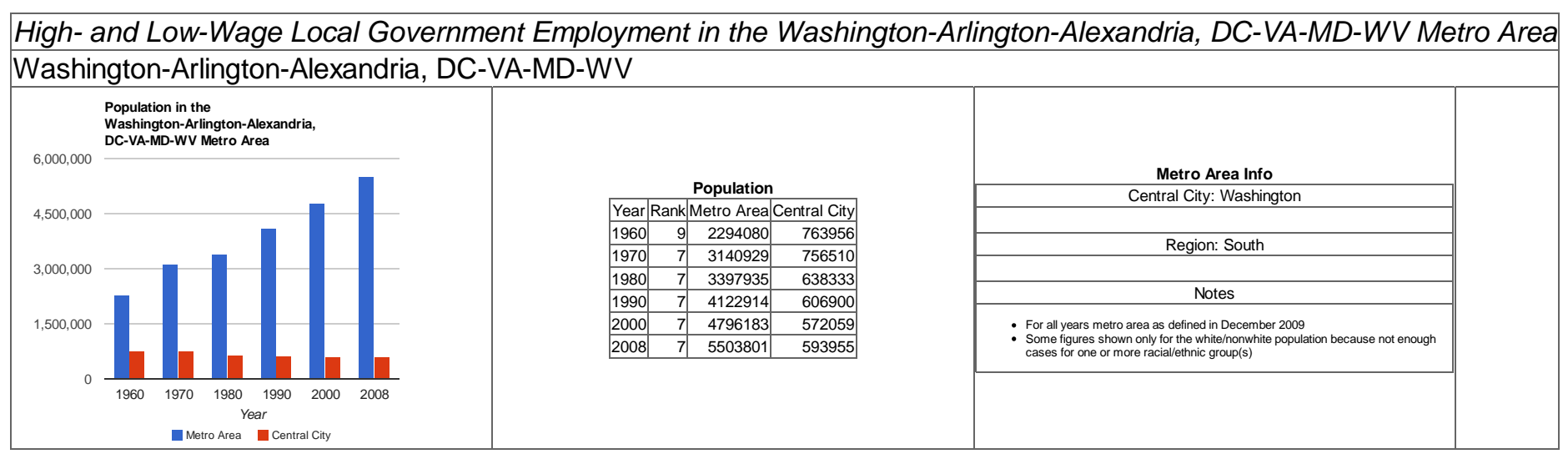


High- and Low-Wage Local Government Employment in the Washington-Arlington-Alexandria, DC-VA-MD-WV Metro Area Local Government High-Wage Employees in the Metro Area
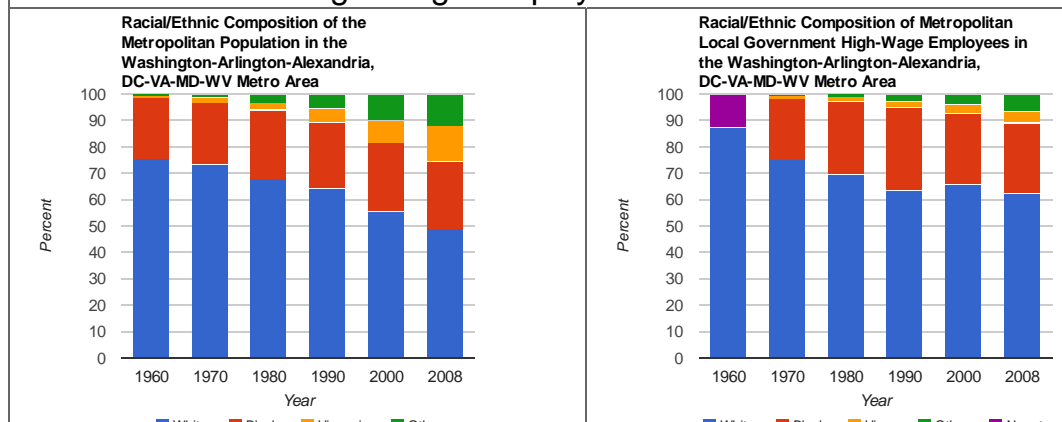

Local Government High-Wage Employees in the Central City
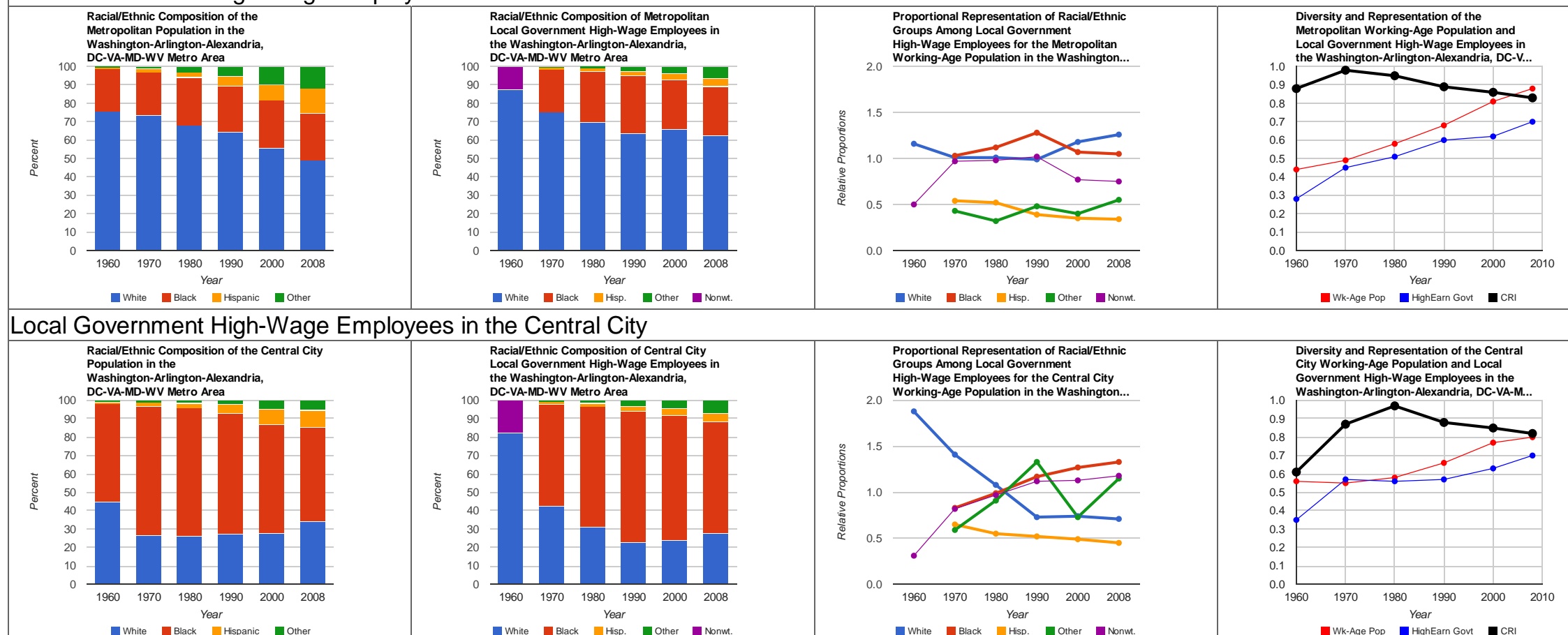

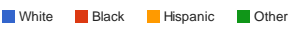

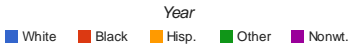

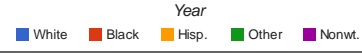

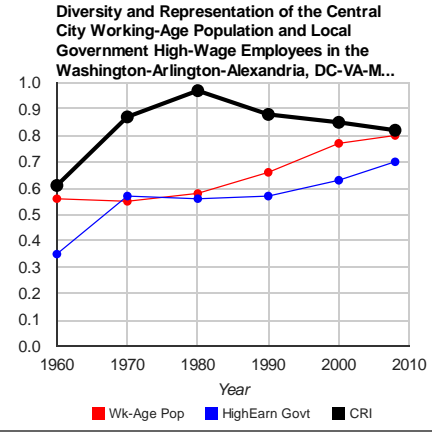


High- and Low-Wage Local Government Employment in the Washington-Arlington-Alexandria, DC-VA-MD-WV Metro Area Local Government Low-Wage Employees in the Metro Area
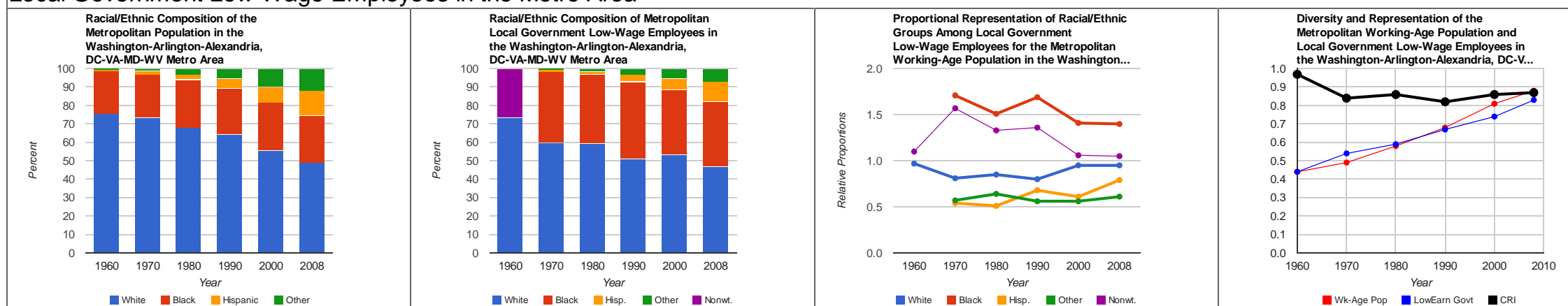

Local Government Low-Wage Employees in the Central City
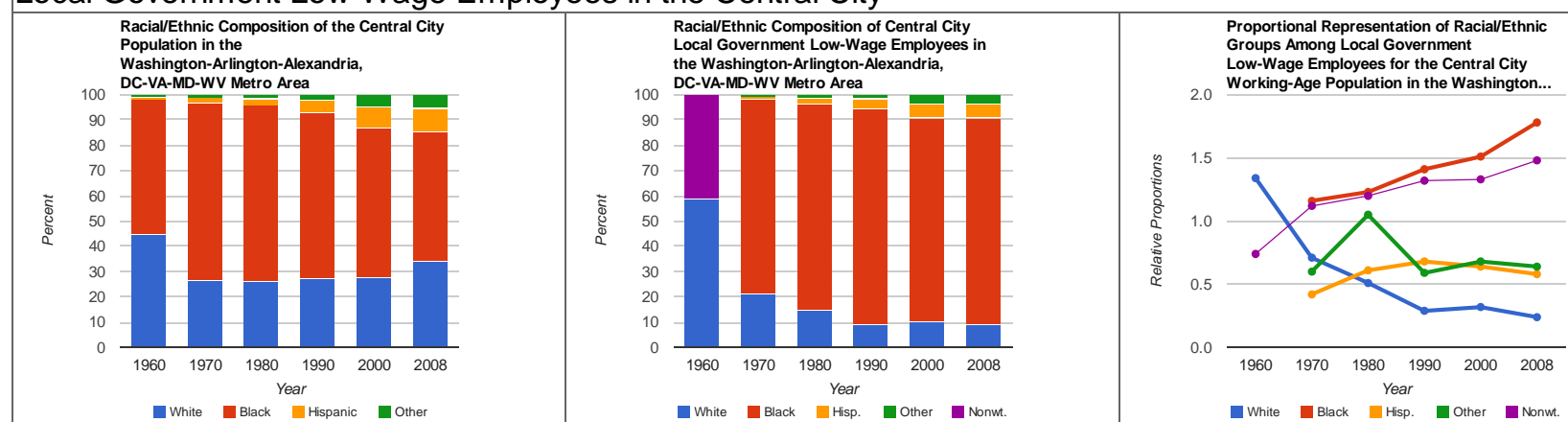

Diversity and Representation of the Central
City Working-Age Population and Lat City Working-Age Population and Local Government Low-Wage Employeses in the
Washington-Arlington-Alexandria, DC-VA-M. @White 1 Black Year

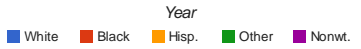

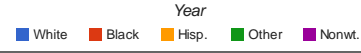

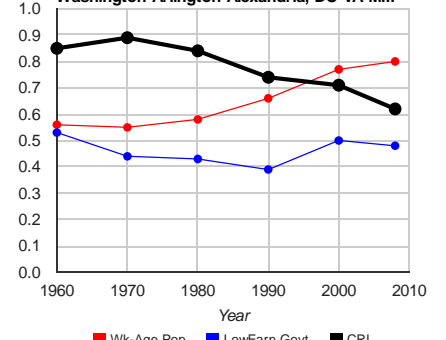

- Wk-Age Pop LowEarn Govt M CRI 


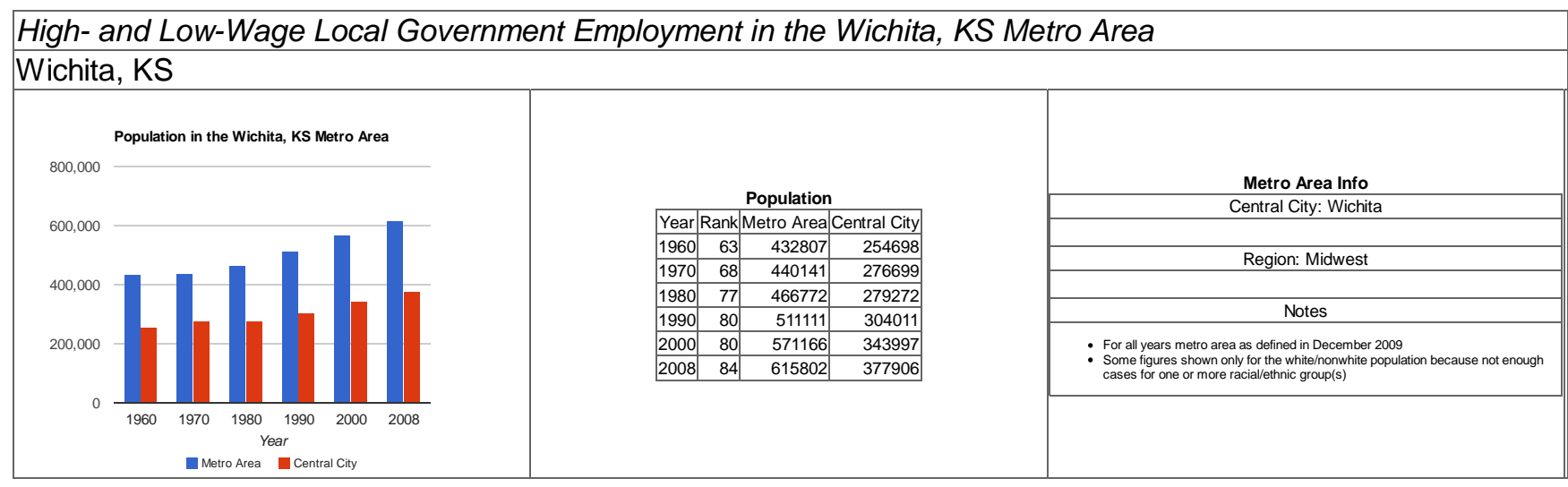


High- and Low-Wage Local Government Employment in the Wichita, KS Metro Area

Local Government High-Wage Employees in the Metro Area
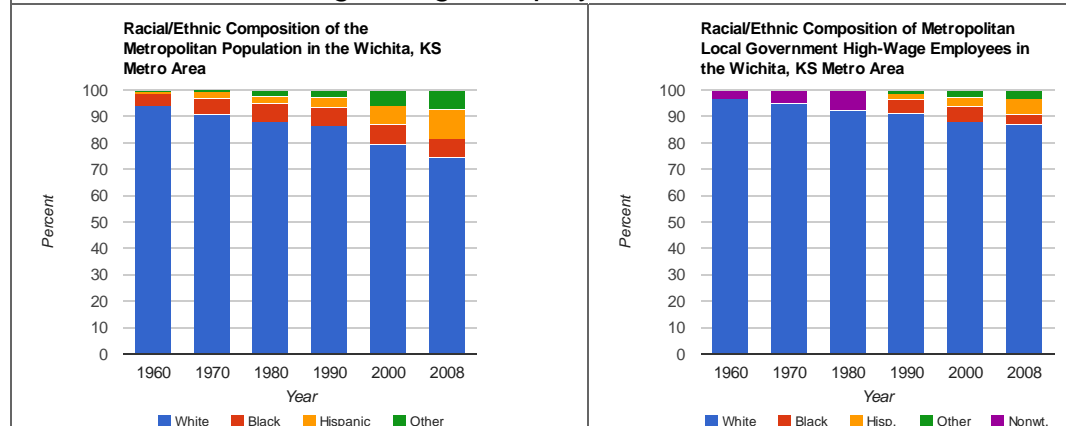

Local Government High-Wage Employees in the Central City
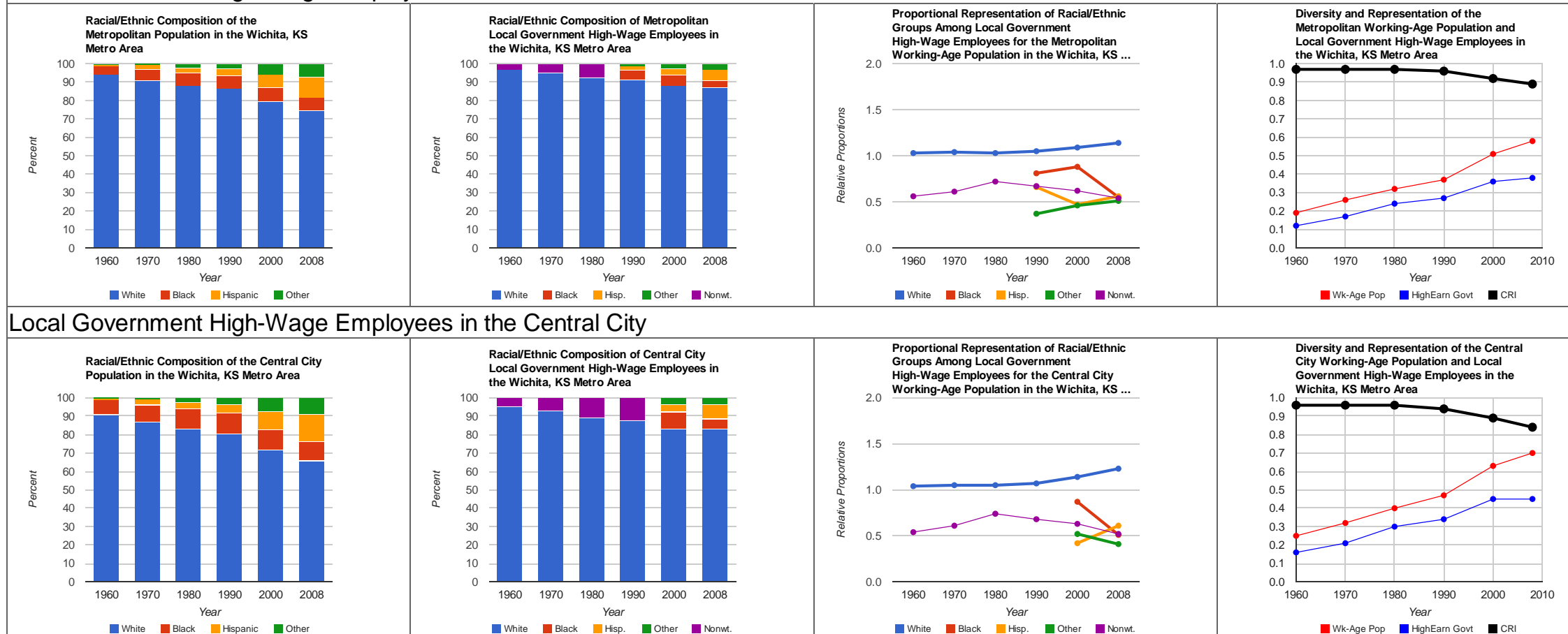

White In Black Inspanic Inother

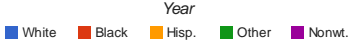

White In Black Yrear

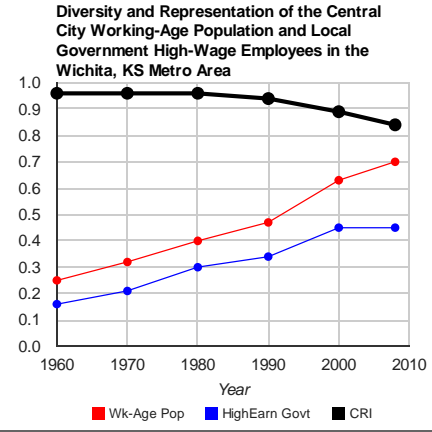


High- and Low-Wage Local Government Employment in the Wichita, KS Metro Area

Local Government Low-Wage Employees in the Metro Area
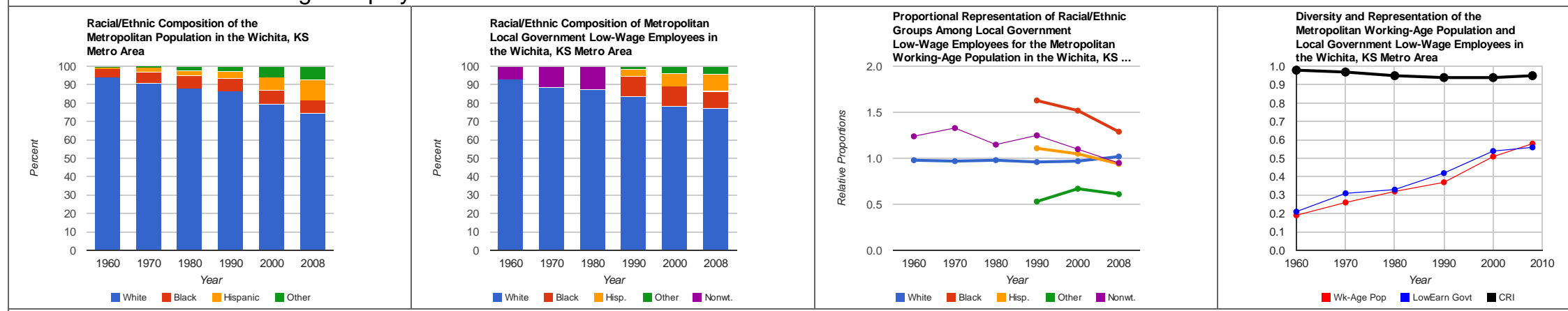

Local Government Low-Wage Employees in the Central City
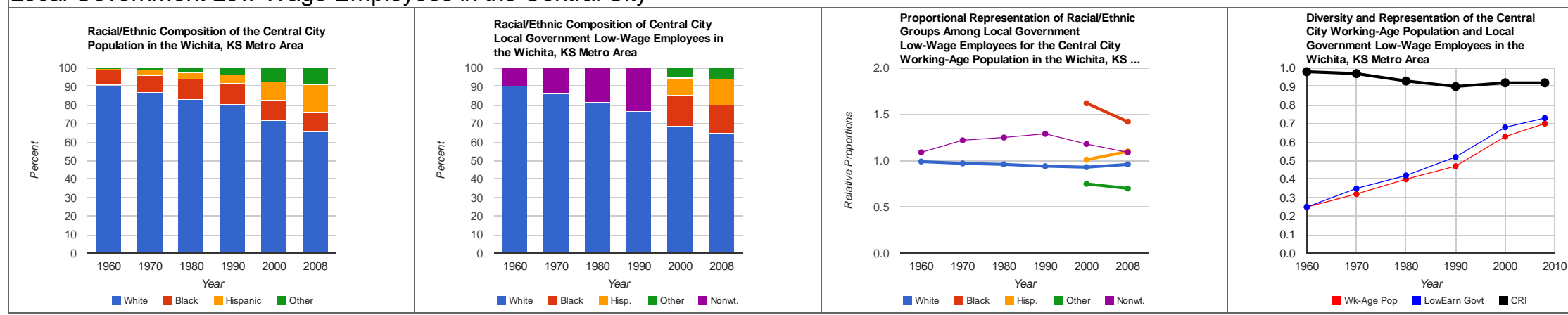
High- and Low-Wage Local Government Employment in the Worcester, MA Metro Area

Worcester, MA

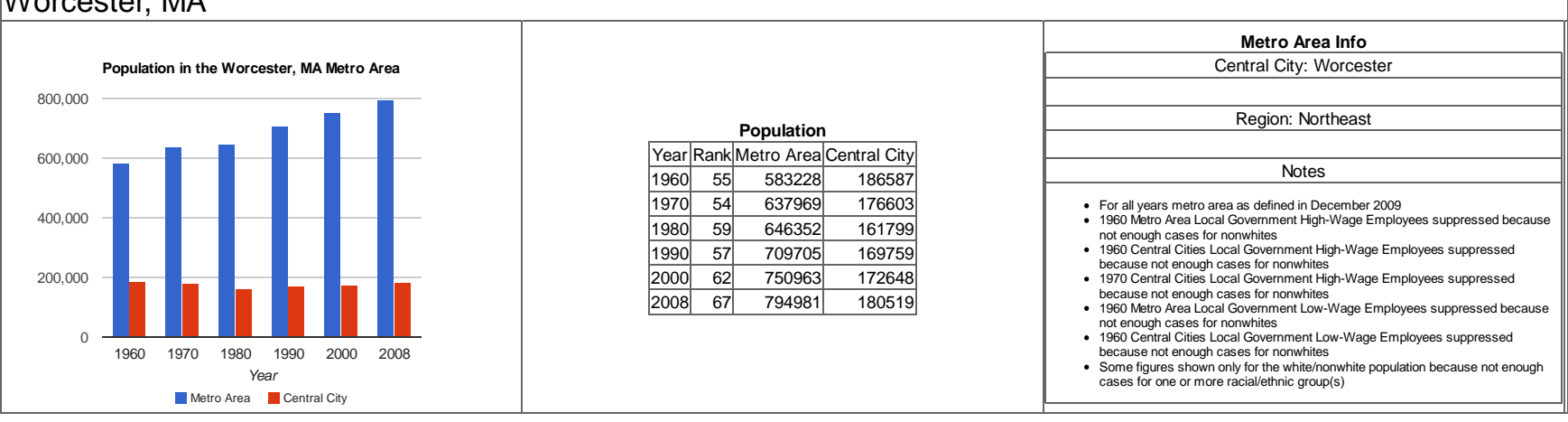


High- and Low-Wage Local Government Employment in the Worcester, MA Metro Area

Local Government High-Wage Employees in the Metro Area
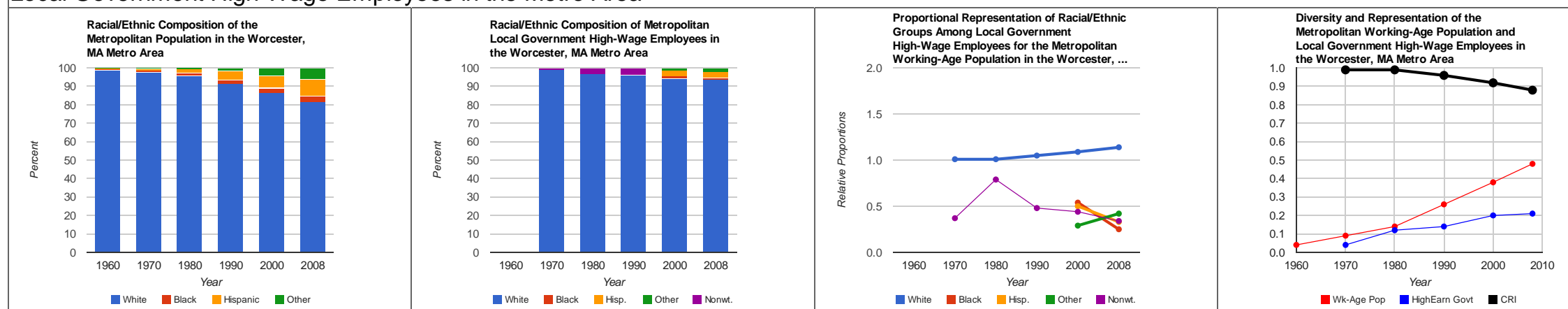

Local Government High-Wage Employees in the Central City
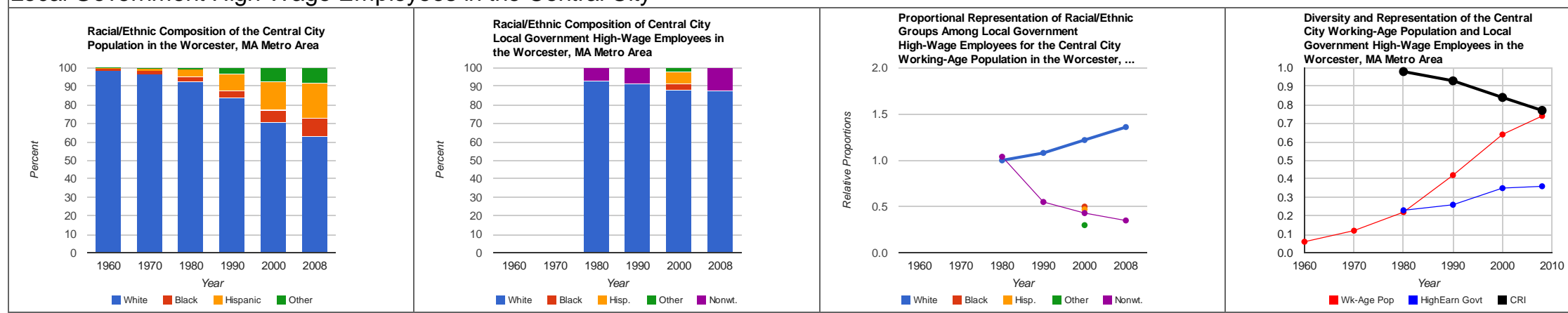
High- and Low-Wage Local Government Employment in the Worcester, MA Metro Area

Local Government Low-Wage Employees in the Metro Area
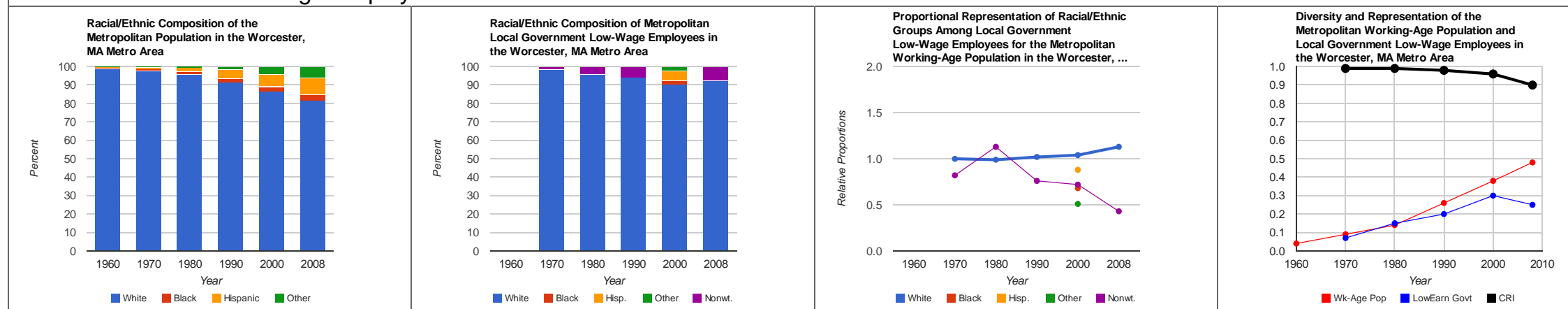

Local Government Low-Wage Employees in the Central City
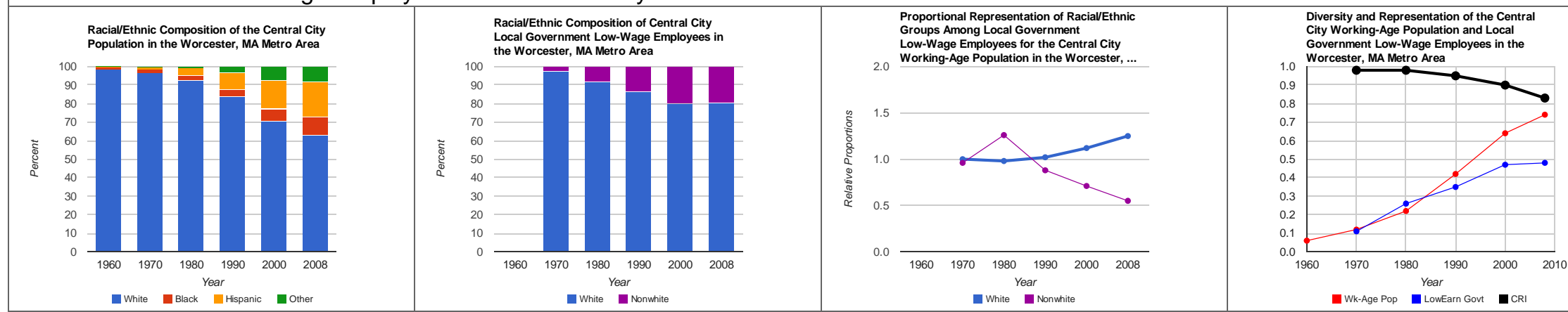


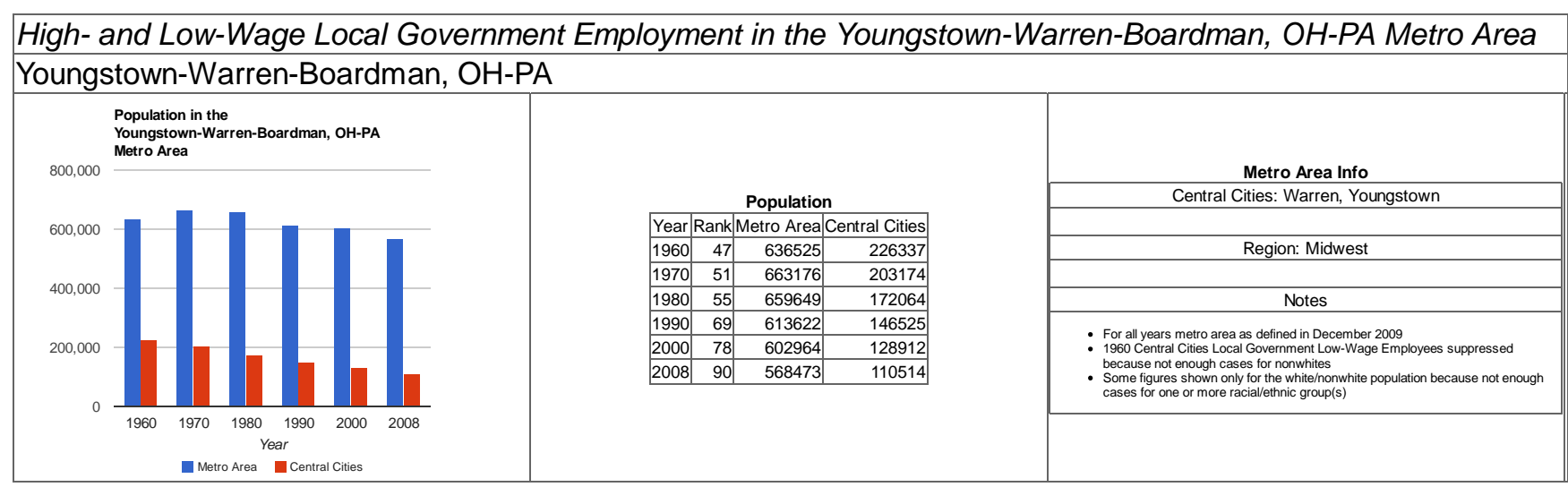


High- and Low-Wage Local Government Employment in the Youngstown-Warren-Boardman, OH-PA Metro Area Local Government High-Wage Employees in the Metro Area
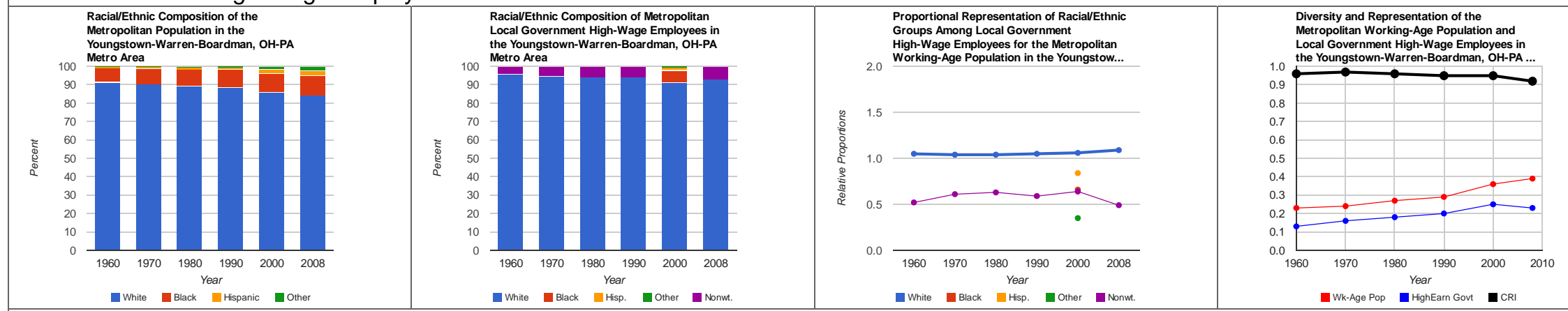

Local Government High-Wage Employees in the Central Cities
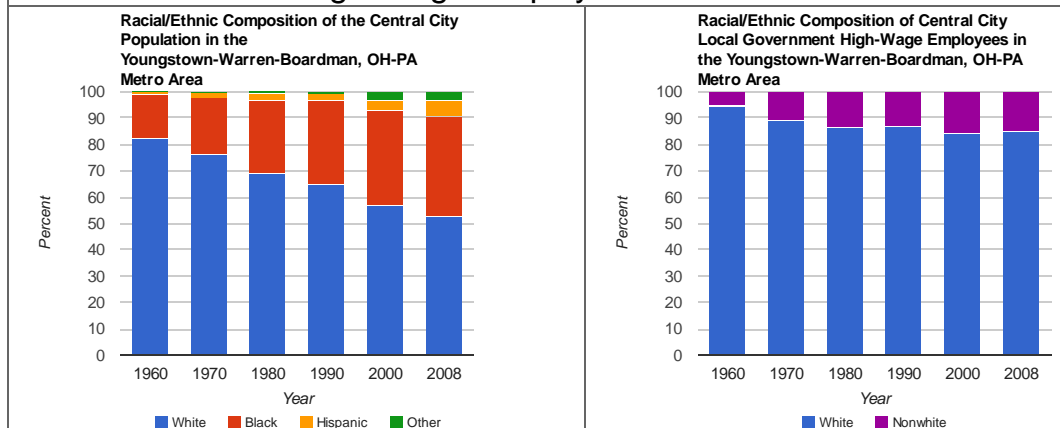
Proportional Representation of Raciall/thnic
Groups Among Local Government
High-Wage Employees for the Central City Working-Age Population in the Youngstow...

White Ulack Mispanic nother - White $\stackrel{\text { Year }}{\text { Nonwhite }}$

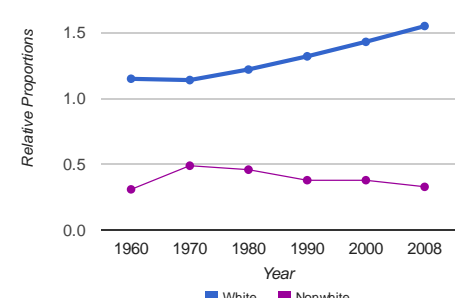
Diversity and Representation of the Central
City Working-Age Population and Local
Government High-Waage Employees in the Government Aigh-Wage Employees in the
Youngstown-Warren-Boardman, OH-PA Met.. - White ${ }_{\text {Nonwhite }}$

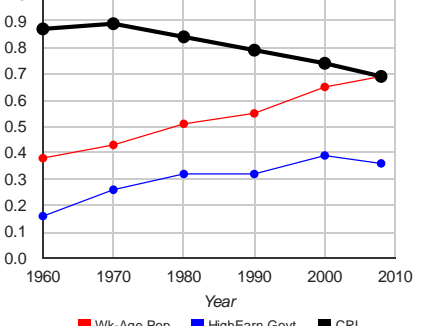

-Wk-Age Pop - Highearn Govt 
High- and Low-Wage Local Government Employment in the Youngstown-Warren-Boardman, OH-PA Metro Area Local Government Low-Wage Employees in the Metro Area
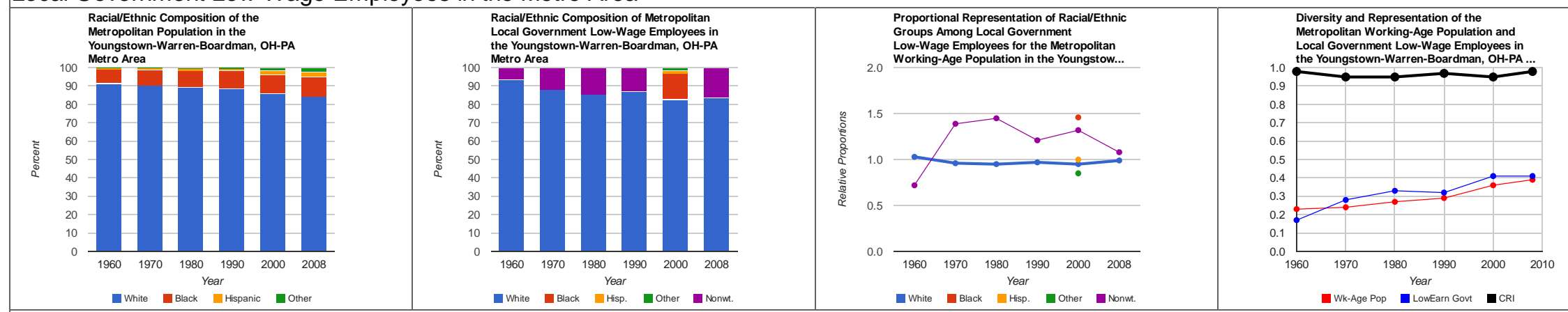

Local Government Low-Wage Employees in the Central Cities
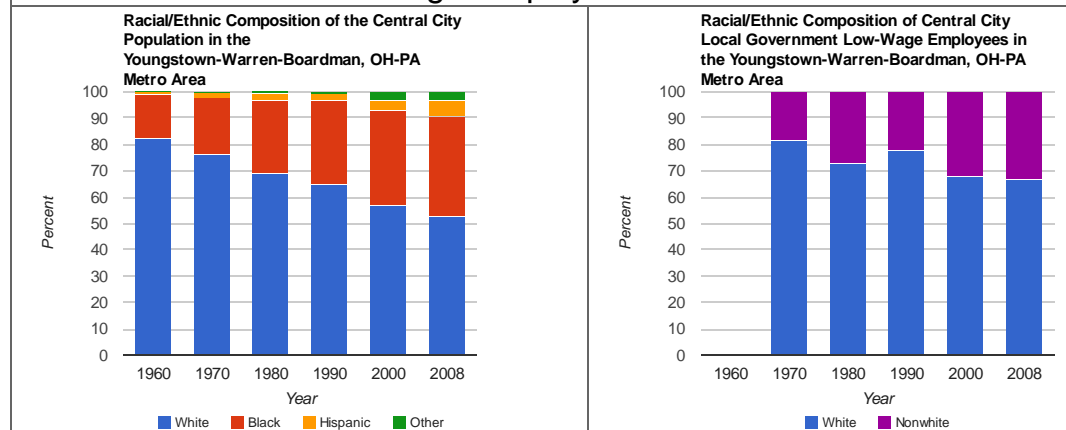
Proportional Representation of Raciall/thnic
Groups Among Local Government
Low-Wage Employees for the Central City Working-Age Population in the Youngstow..

White Inlack Year Hispanic Eother - White $\stackrel{\text { Year }}{\text { Nonwhite }}$
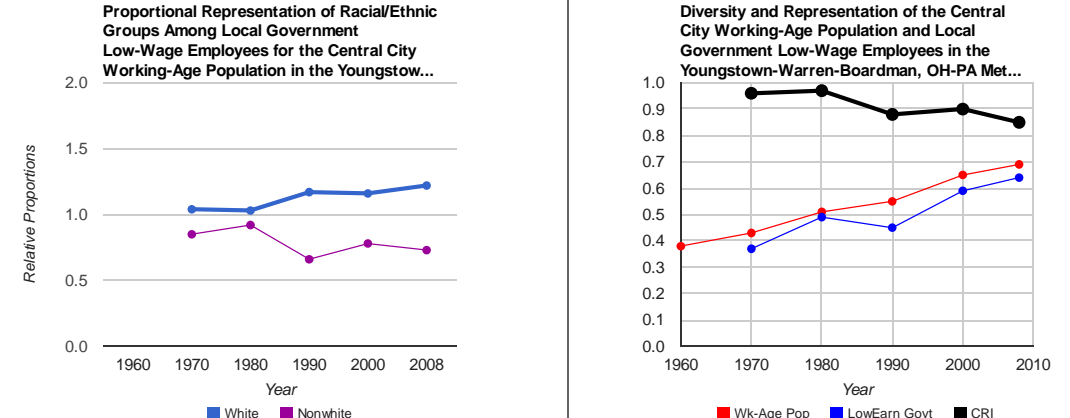

- Wk-Age Pop L LowEarn Gout MCRL 